\title{
Materials Reliability Program Resistance to Primary Water Stress Corrosion Cracking of Alloys 690, 52, and 152 in Pressurized Water Reactors (MRP-111)
}

\author{
1009801
}

This report describes research sponsored by EPRI and the U.S. Department of Energy (Award No. DE-FC07-00NE22796). 



\title{
Materials Reliability Program Resistance to Primary Water Stress Corrosion Cracking of Alloys 690, 52, and 152 in Pressurized Water Reactors (MRP-111)
}

\author{
1009801 \\ Technical Update, March 2004 \\ EPRI Project Manager \\ J. Hickling \\ C. King \\ Cosponsor \\ U.S. Department of Energy \\ Washington, DC
}




\section{DISCLAIMER OF WARRANTIES AND LIMITATION OF LIABILITIES}

THIS DOCUMENT WAS PREPARED BY THE ORGANIZATION(S) NAMED BELOW AS AN ACCOUNT OF WORK SPONSORED OR COSPONSORED BY THE ELECTRIC POWER RESEARCH INSTITUTE, INC. (EPRI). NEITHER EPRI, ANY MEMBER OF EPRI, ANY COSPONSOR, THE ORGANIZATION(S) BELOW, NOR ANY PERSON ACTING ON BEHALF OF ANY OF THEM:

(A) MAKES ANY WARRANTY OR REPRESENTATION WHATSOEVER, EXPRESS OR IMPLIED, (I) WITH RESPECT TO THE USE OF ANY INFORMATION, APPARATUS, METHOD, PROCESS, OR SIMILAR ITEM DISCLOSED IN THIS DOCUMENT, INCLUDING MERCHANTABILTTY AND FITNESS FOR A PARTICULAR PURPOSE, OR (II) THAT SUCH USE DOES NOT INFRINGE ON OR INTERFERE WITH PRIVATELY OWNED RIGHTS, INCLUDING ANY PARTY'S INTELLECTUAL PROPERTY, OR (III) THAT THIS DOCUMENT IS SUITABLE TO ANY PARTICULAR USER'S CIRCUMSTANCE; OR

(B) ASSUMES RESPONSIBILITY FOR ANY DAMAGES OR OTHER LIABILITY WHATSOEVER (INCLUDING ANY CONSEQUENTIAL DAMAGES, EVEN IF EPRI OR ANY EPRI REPRESENTATIVE HAS BEEN ADVISED OF THE POSSIBILITY OF SUCH DAMAGES) RESULTING FROM YOUR SELECTION OR USE OF THIS DOCUMENT OR ANY INFORMATION, APPARATUS, METHOD, PROCESS, OR SIMILAR ITEM DISCLOSED IN THIS DOCUMENT.

ORGANIZATION(S) THAT PREPARED THIS DOCUMENT

Framatome ANP

This is an EPRI Technical Update report. A Technical Update report is intended as an informal report of continuing research, a meeting, or a topical study. It is not a final EPRI technical report.

\section{ORDERING INFORMATION}

Requests for copies of this report should be directed to EPRI Orders and Conferences, 1355 Willow Way, Suite 278, Concord, CA 94520 . Toll-free number: 800.313 .3774 , press 2, or internally x5379; voice: 925.609 .9169 ; fax: 925.609 .1310$.

Electric Power Research Institute and EPRI are registered service marks of the Electric Power Research Institute, Inc. EPRI. ELECTRIFY THE WORLD is a service mark of the Electric Power Research Institute, Inc.

Copyright (C) 2004 Electric Power Research Institute, Inc. All rights reserved. 


\section{CITATIONS}

This report was prepared by Framatome ANP

Principal Investigators

H. Xu and S. Fyfitch, Framatome ANP, Inc.

3315 Old Forest Road

P.O. Box 10935

Lynchburg, VA 24506-0935

P. Scott

Framatome ANP, SAS

Tour AREVA

92084 Paris La Défense, France

M. Foucault

Framatome ANP, SAS

Porte Magenta - BP 181

71205 Le Creusot Cedex, France

R. Kilian and M. Winters,

Framatome ANP, GmbH

Freyeslebenstr. $1-91058$

TGM - P.O. Box 3220 - 91050

Erlangen, Germany

This report describes research sponsored by EPRI and the U.S. Department of Energy (Award No. DE-FC07-00NE22796. Task FY02-3-207).

The report is a corporate document that should be cited in the literature in the following manner:

Materials Reliability Program (MRP), Resistance to Primary Water Stress Corrosion Cracking of Alloys 690, 52, and 152 in Pressurized Water Reactors (MRP-111), EPRI, Palo Alto, CA, U.S. Department of Energy, Washington, DC: 2004. 1009801. 



\section{REPORT SUMMARY}

Wrought Alloy 600 and its weld metals (Alloy 182 and Alloy 82) were originally used in pressurized water reactors (PWRs) due to the material's inherent resistance to general corrosion in a number of aggressive environments and because of a coefficient of thermal expansion that is very close to that of low alloy and carbon steel. Over the last thirty years, stress corrosion cracking in PWR primary water (PWSCC) has been observed in numerous Alloy 600 component items and associated welds, sometimes after relatively long incubation times. The occurrence of PWSCC has been responsible for significant downtime and replacement power costs.

Component repairs and replacements have generally utilized wrought Alloy 690 material and its compatible weld metals (Alloy 152 and Alloy 52), which have been shown to be highly resistant to PWSCC in laboratory experiments and have been free from cracking in operating reactors over periods already up to nearly 15 years. The challenge is to attempt to quantify the longevity of these materials with respect to aging degradation by corrosion in order to provide a sound technical basis for the development of future inspection requirements for repaired or replaced component items.

\section{Approach}

This document first reviews numerous laboratory tests, conducted over the last two decades, that were performed with wrought Alloy 690 and Alloy 52 or 152 weld materials under various test conditions pertinent to corrosion resistance in PWR environments. The main focus of the present review is on PWSCC, but secondary-side conditions are also briefly considered. Wherever possible, the existing laboratory test data have been evaluated to estimate the improvement factor of Alloy 690 relative to Alloy 600. In addition, Alloy 690 service experience in PWRs has been reviewed to augment the laboratory findings. The project team also worked to identify gaps in the existing database and suitable strategies to rectify these, as well as to provide a technical justification basis for future inspection requirements for these materials.

\section{Results \& Findings}

It is concluded that wrought Alloy 690 and its weld metals (Alloys 52 and 152) are acceptable and highly corrosion-resistant replacement materials for Alloy 600 and its weld metals in PWRs, although limited, further testing is needed to examine some specific knowledge gaps that have been identified. Average improvement factors of at least 26 relative to Alloy 600MA material and 13 relative to Alloy 600TT material can be derived, but these numbers are clearly conservative, due to an absence of PWSCC in most Alloy 690 specimens within the test duration. 
No stress corrosion degradation of the Alloy 690 materials has been observed in any replacement application to date. Service experience ranges from approximately10 to 14 years, depending upon the type of component considered.

The PWSCC inspection regimes developed in recent years for thick-walled components made of Alloys 600,182 , and 82 would be unnecessarily stringent if applied in exactly the same way to comparable component locations involving Alloy 690 and its weld metals. A separate inspection program, commensurate with the magnitude of improvement in PWSCC resistance already demonstrated, should be developed.

\section{Applications, Values \& Use}

This report should be of interest to utility engineers and scientists concerned with all aspects of Alloy 600 cracking in PWR primary water, and especially to those involved in developing inspection regimes, making decisions on component replacement and dealing with plant aging issues. It will be of direct value in obtaining regulatory acceptance for the solutions adopted by the industry to deal with increasing incidences of PWSCC in thick-walled components of existing plants.

As part of an ongoing, comprehensive program involving utilities, reactor vendors and engineering/research organizations, this report will also help to ensure that corrosion degradation of nickel-base alloys does not limit service life and that full benefit can be obtained from improved designs for both replacement components and new reactors.

\section{EPRI Perspective}

The challenge facing the project team was first to gain access to a large amount of both published and unpublished data, and then to analyze and integrate the findings from very diverse experimental programs carried out over many years in a coherent way. EPRI was in a unique position to facilitate this exercise and benefited, in particular, from extensive previous experience gained in connection with related studies of steam generator tube degradation (see, e.g., TR 1003589 published in July, 2003). Together with consideration of field experience, this has resulted in a comprehensive status document addressing the issue of what factor of improvement can be expected when replacing PWSCC susceptible Alloy 600 materials in thick-walled components with Alloy 690 and its weld metals.

Some specific knowledge gaps were identified during the present review and will enable scant resources to be focused appropriately on future testing of Alloy 690 materials and monitoring of their service behavior. It is anticipated that this report will be updated and further refined as additional laboratory results and field inspection data become available.

\section{Keywords}

Alloy 600, Alloy 690, Alloy 52, Alloy 152, PWSCC, Material Degradation, Predictive Maintenance. 


\section{ABSTRACT}

Over the last thirty years, stress corrosion cracking in PWR primary water (PWSCC) has been observed in numerous Alloy 600 component items and associated welds, sometimes after relatively long incubation times. Repairs and replacements have generally utilized wrought Alloy 690 material and its compatible weld metals (Alloy 152 and Alloy 52), which have been shown to be very highly resistant to PWSCC in laboratory experiments and have been free from cracking in operating reactors over periods already up to nearly 15 years. It is nevertheless prudent for the PWR industry to attempt to quantify the longevity of these materials with respect to aging degradation by corrosion in order to provide a sound technical basis for the development of future inspection requirements for repaired or replaced component items.

This document first reviews numerous laboratory tests, conducted over the last two decades, that were performed with wrought Alloy 690 and Alloy 52 or Alloy 152 weld materials under various test conditions pertinent to corrosion resistance in PWR environments. The main focus of the present review is on PWSCC, but secondary-side conditions are also briefly considered. Test media relevant to the primary circuit included high temperature de-aerated/hydrogenated water (with and without additions of zinc or some impurities), simulated primary water and hydrogenated steam (sometimes doped with contaminants).

The vast majority of the Alloy 690 specimens did not develop cracking after exposure time as long as 100,000 hours, whereas most of the Alloy 600 specimens in both MA and TT conditions developed PWSCC in the same studies, often after relatively brief periods. Occasional instances of shallow intergranular cracking in Alloy 690 material were more consistent with mechanical microfissuring than PWSCC, although the latter may be possible to a small extent in conjunction with abnormal heat treatments and unusual alloy microstructures or compositions. No PWSCC of the Alloy 152/52 weld metals has been identified to date, but investigations are limited and the resistance of the weld heat affected zone in the base metal does not appear to have been separately studied. Focused testing of Alloy 690 material and its weld metals should be carried out to fill in some specific knowledge gaps that have been identified in the present review.

Wherever possible, the existing laboratory test data have been evaluated to estimate the improvement factor of Alloy 690 relative to Alloy 600. Average improvement factors of at least 26 relative to Alloy $600 \mathrm{MA}$ material and 13 relative to Alloy $600 \mathrm{TT}$ material can be derived, but these numbers are clearly conservative, due to an absence of PWSCC in most Alloy 690 specimens within the test duration.

In addition, Alloy 690 service experience in PWRs has been reviewed to augment the laboratory findings. Based on both laboratory and field data, it is concluded that Alloy 690 and its weld metals Alloys 52 and 152 are very unlikely that PWSCC would develop during extended PWR 
plant lifetimes (60+ years). Hence, the PWSCC inspection regimes developed in recent years for thick-walled component items made of Alloys 600,182 , and 82 would be unnecessarily stringent if applied in exactly the same way to comparable component item locations involving Alloy 690 and its weld metals. A separate inspection program, commensurate with the magnitude of

improvement in PWSCC resistance already demonstrated, should be developed. It is anticipated that this could be further refined as additional laboratory results and field inspection data become available. 


\section{CONTENTS}

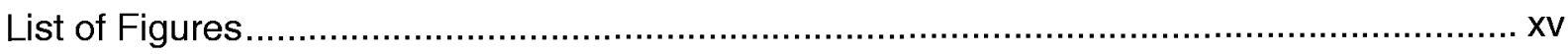

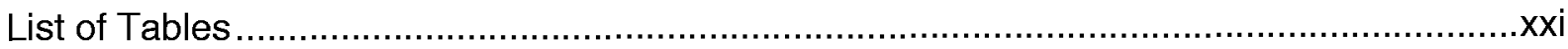

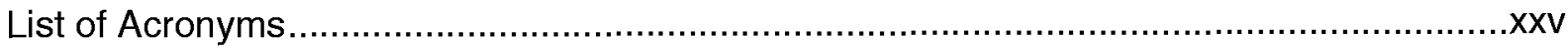

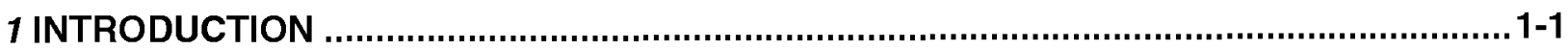

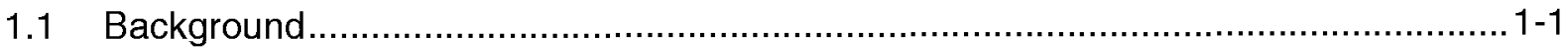

1.2 Causes of Alloy 600 PWSCC.........................................................................

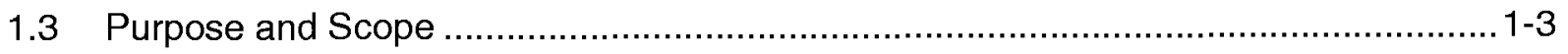

2 ALLOY 690 PROPERTIES AND METALLURGY .................................................... $2-1$

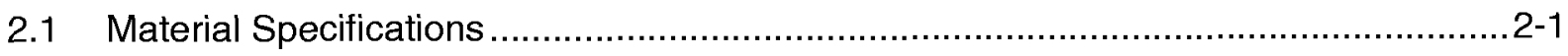

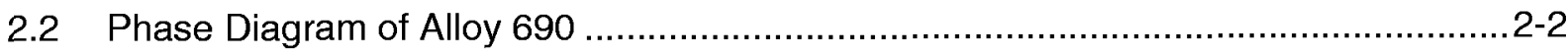

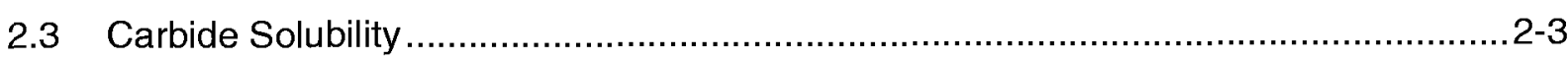

2.4 Intergranular Carbide Precipitation and Sensitization.........................................2-4

2.5 Effect of Elevated Temperature Exposure ..................................................... $2-5$

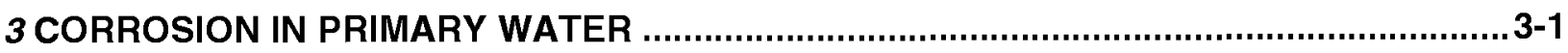

3.1 General Corrosion Tests in Primary Water .................................................... $3-1$

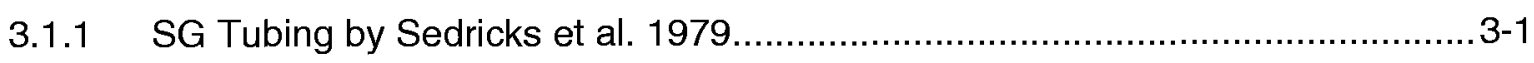

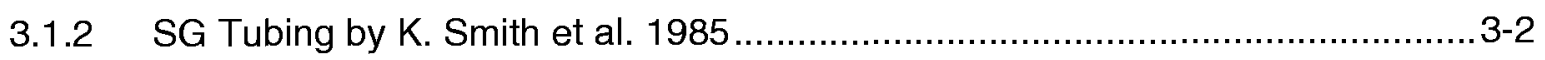

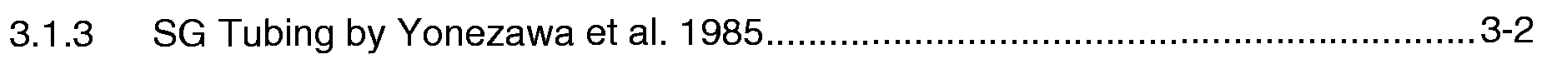

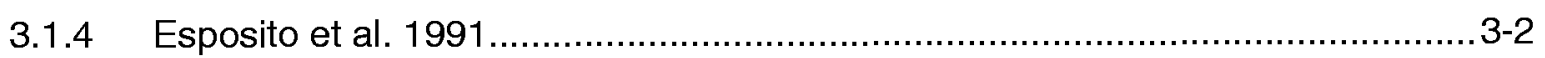

3.2 Stress Corrosion Cracking Tests in Primary Water Relevant Conditions ...................3-3

3.2.1 Deaerated Water Testing ..................................................................

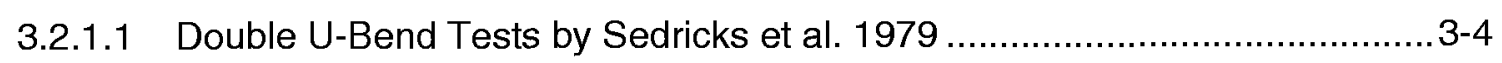

3.2.1.2 C-Ring Test by A. Smith et al. 1989-1991 ......................................... $3-5$

3.2.1.3 RUB by Norring et al. 1987-1991 .................................................... $3-5$

3.2.1.4 CERT Tests of Alloy 690 and Alloy 600 by Angeliu et al. 1991 ................... 3-7 
3.2.2 Deaerated Water With Li/B Testing ..................................................... $3-8$

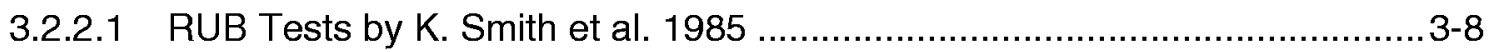

3.2.2.2 RUB and Constant Load Test by Yonezawa et al. 1985............................. 3-9

3.2.2.3 U-Bend Test of Alloy 690 by Nakayama et al. 1987 .................................. 3-9

3.2.2.4 CERT Test of Psaila-Dombrowski et al. 1995-1997 ..................................3-10

3.2.2.5 RUB Test and Constant Load Test by Ogawa et al. 1997 ..........................3-11

3.2.2.6 RUB Tests by Angell et al. 1999 ........................................................ $3-12$

3.2.2.7 Studies by CEA and EdF ................................................................ $3-12$

3.2.2.7.1 CEA Technical Report RT-SCCME 618 Rev. A ${ }^{[45]}-2002 \ldots \ldots \ldots \ldots \ldots . . . . . .3-13$

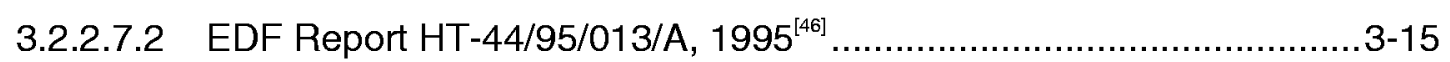

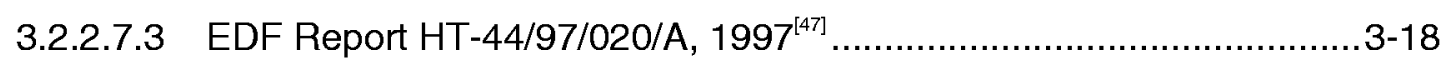

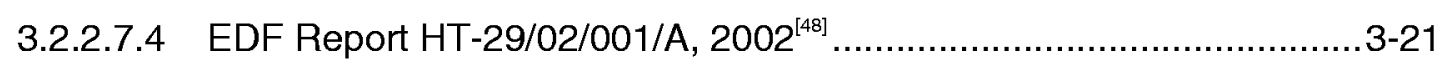

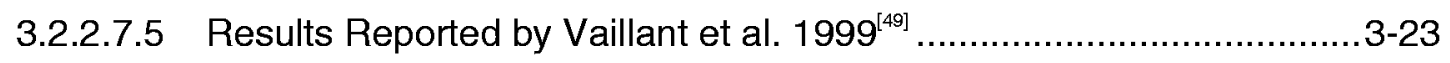

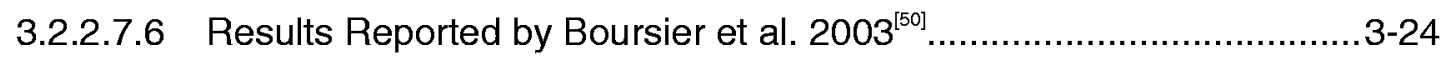

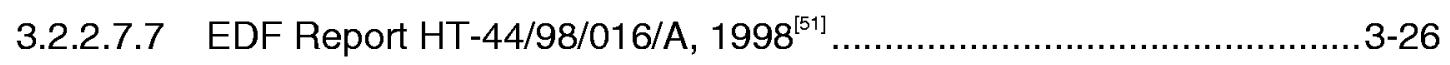

3.2.2.8 SG Tube Mock-Up Test in Hydrogenated Water by Framatome ANP,

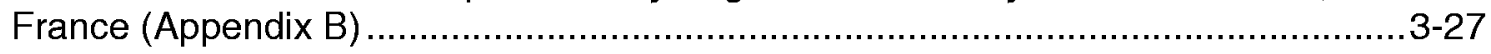

3.2.3 Hydrogenated Steam Testing ............................................................. $3-30$

3.2.3.1 RUB Test in Hydrogenated Steam by Sui et al. 1997 ..............................3-30

3.2.3.2 RUB Test in Hydrogenated Steam by Framatome ANP, Germany

(Appendix A)

3.2.4 Doped Steam Testing ........................................................................ 33

3.2.4.1 Four-Point Bend Tests of Alloys 52M, 182, and 600 in Doped

Hydrogenated Steam by Jacko et al. 2003 ........................................................... $3-33$

3.3 Low Temperature Crack Propagation (LTCP) …..............................................35

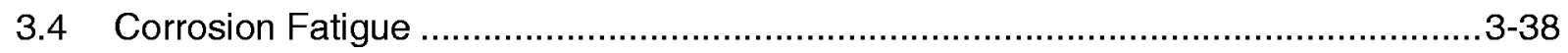

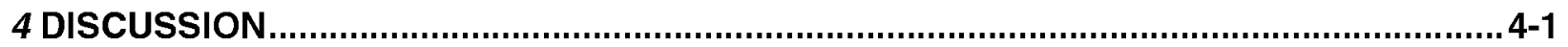

4.1 Alloy 690/152/52 Test Results ................................................................... $4-1$

4.1.1 Single U-Bend Test in Saturated Hydrogen Water with B/Li .......................... 4-1

4.1.2 CERT Tests in Hydrogenated Water with or without B/Li ............................. 4-2

4.1.3 RUB Test in Hydrogenated Steam ........................................................... 4-3

4.2 Weibull and Weibayes Analyses of the Test Results............................................. $4-4$

4.3 Improvement Factor by Weibull Analysis ........................................................... 4-6

4.4 Improvement Factor with Minimum Alloy 600 Crack Time...................................... 4-8

4.5 Alloy 690/152/52 Material Operating Experience in PWRs.......................................4-8 
5.1 Summary of Laboratory and Field Data …………............................................... $5-1$

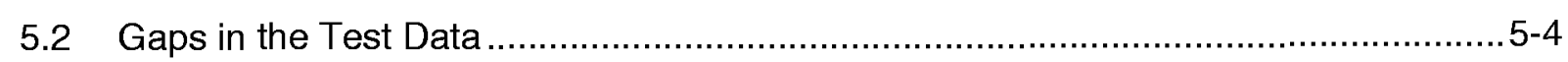

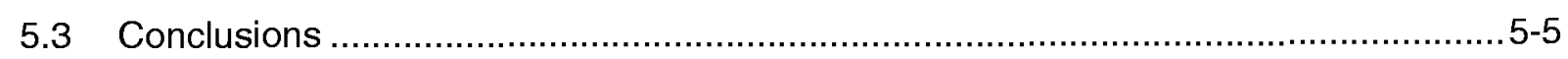

\section{A EFFECTS OF SURFACE DEFECTS ON THE PWSCC BEHAVIOR OF 690TT AND} 600MA - A FRAMATOME ANP (GERMANY) REPORT .............................................. A-1

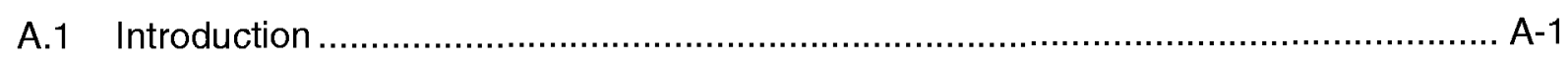

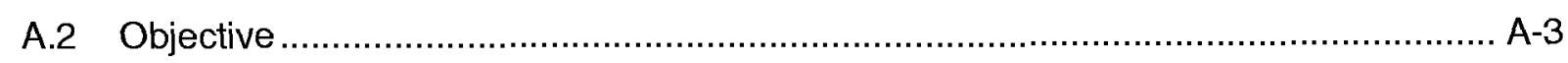

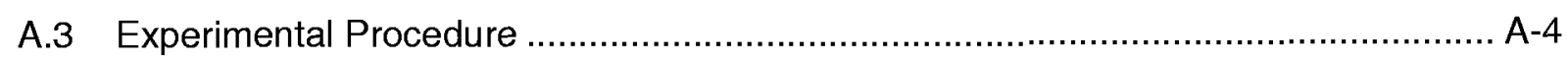

A.3.1 Test Materials................................................................................. A-4

A.3.1.1 Alloy 600MA - Mill Annealed............................................................. A-4

A.3.1.2 Alloy 690TT - Thermally Treated ................................................... A-4

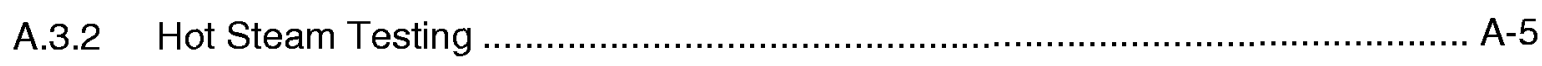

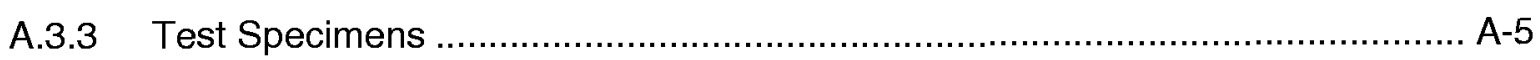

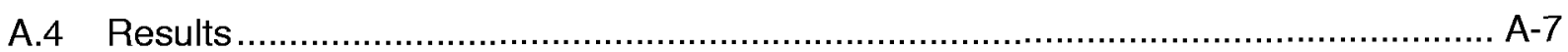

A.4.1 Visual Inspection of RUB Specimens................................................... A-7

A.4.2 Metallography/Microhardness Measurements ............................................. A-9

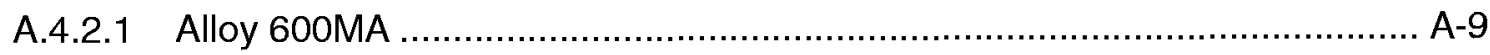

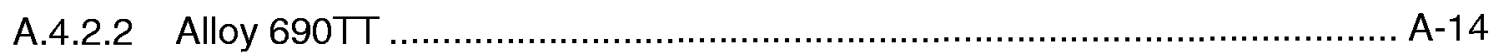

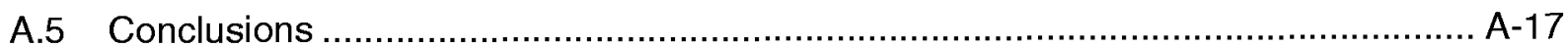

A.5.1 Improvement Factor ............................................................................

A.5.2 Quantification of Experimental Data/Margin of Improvement......................... A-17

A.5.3 Comparability of Experimental Data to In-Service Conditions ........................ A-18

B TESTS ON MOCK-UPS REPRESENTATIVE OF ROLLING ZONES OF STEAM GENERATOR TUBES IN HIGH TEMPERATURE, HYDROGENATED, PURE WATER AT $360^{\circ} \mathrm{C}$ - A FRAMATOME ANP (FRANCE) REPORT …............................................ B-1

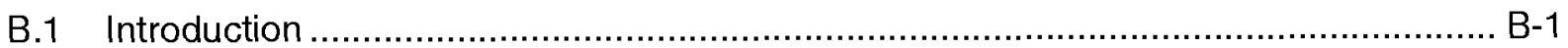

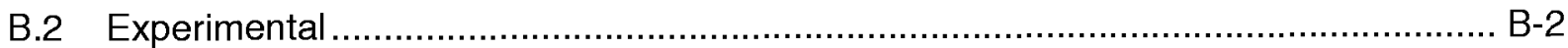

B.2.1 Materials.......................................................................................... B-2

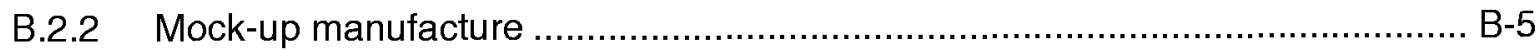

B.2.3 Test procedure ................................................................................ B-7

B.2.4 Monitoring the mock-up's during exposure tests........................................ B-8

B.3 Alloy 690 TT Mock-Up Results ................................................................... B-9

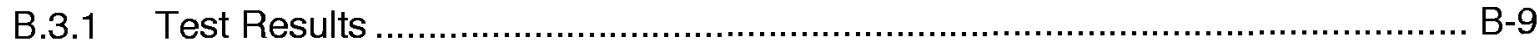




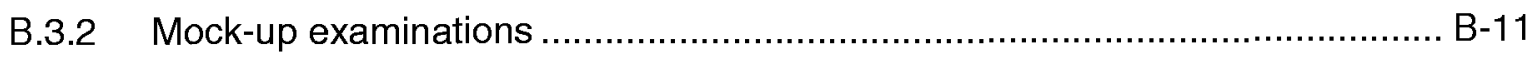

B.3.2.1 Examination of mock-up 506 after 60,000 hours exposure ..................... B-11

B.3.2.2 Examination of mock-ups 502 and 508 after 100,000 hours exposure ..... B-22

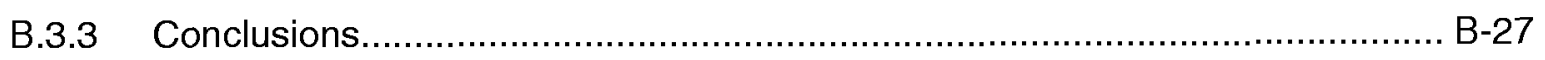

B.4 Alloy 600 TT Mock-Up Results ............................................................. B-28

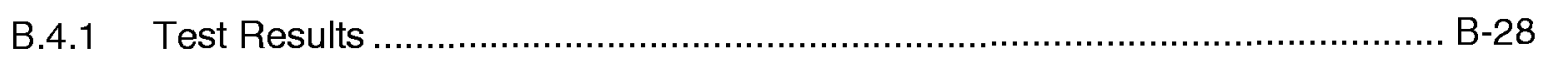

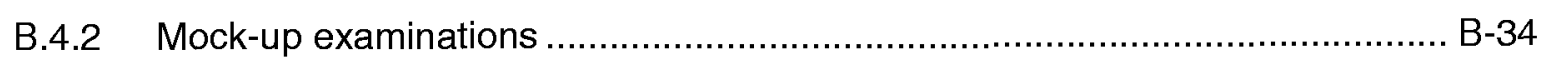

B.4.3 Analysis of results ......................................................................... $\mathrm{B}-39$

B.4.3.1 Tube / tubesheet gap and heat treatment influence ............................ B-39

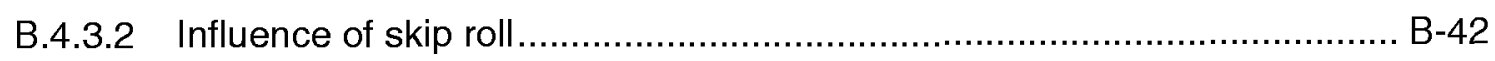

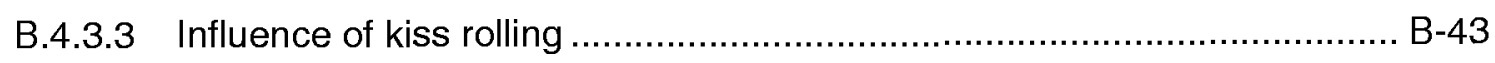

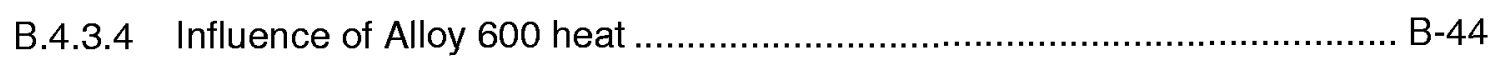

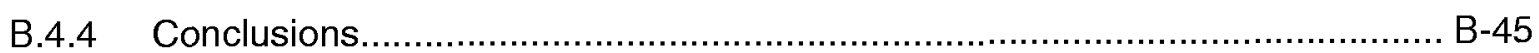

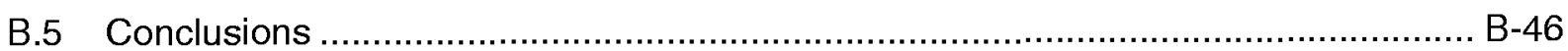

C ALLOY 690 CORROSION IN SECONDARY WATER ............................................... C-1

C.1 AVT Water Environment .................................................................... C

C.2 Deaerated Caustic Solution With or Without Contamination............................... C-2

C.2.1 Sedricks et al................................................................................... $\mathrm{C}-2$

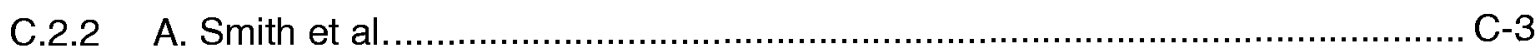

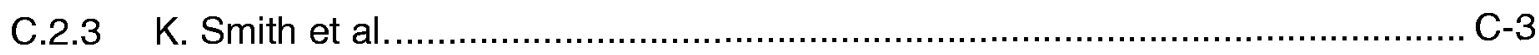

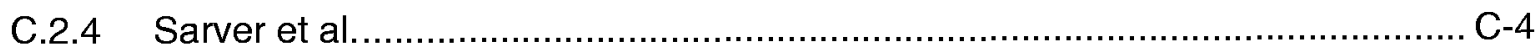

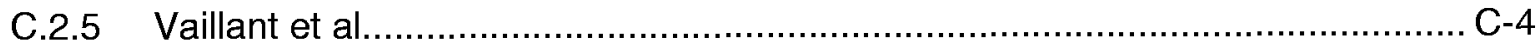

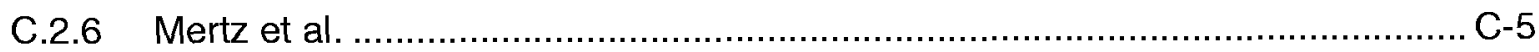

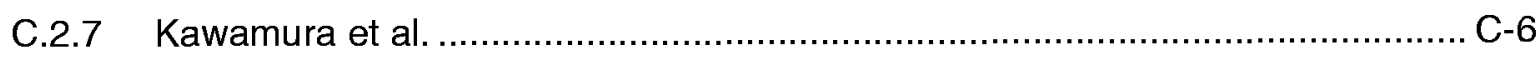

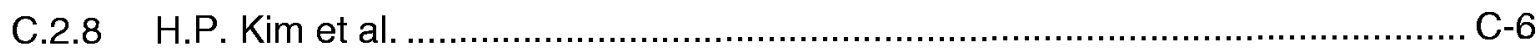

C.3 Lead Contaminated Secondary Water ......................................................... C-7

C.3.1 Castano-Marin et al - Acidic, Caustic, AVT Water + Lead.............................. C-7

C.3.2 Vaillant et al. - Deaerated Caustic Water + Lead ....................................... C-7

C.3.3 Helie - Non-deaerated Acidic Water + Lead ............................................ C-7

C.4 Chloride and Sulfate Containing Secondary Water.......................................... C-8

C.4.1 Berge et al. - Acidic Chloride Containing Solutions .................................... C-8

C.4.2 Cullen et al. - Acidic Sulfate and Chloride Containing Solutions ...................... C-8

C.4.3 Bouvier et al. - Neutral to Slightly Caustic Sulfate Solutions ............................ C-9

C.4.4 Bouvier et al. - Neutral Sulfate Solution + Copper ................................... C-9 


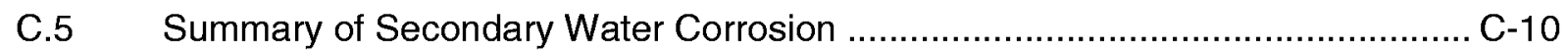

D REFERENCES ............................................................................................. D 



\section{List of Figures}

Figure 2-1 The Ni-Cr-Fe phase diagram showing the location of the $\gamma / \gamma+\alpha$ ' solvus at elevated temperatures from 816 to $1260^{\circ} \mathrm{C}\left(1500\right.$ to $\left.2300^{\circ} \mathrm{F}\right)$. The locations of Alloy 690 and Alloy 600 composition are marked on the diagram. ${ }^{[9]}$

Figure 2-2 Carbon solubility diagram for Alloy 690 and Alloy 600, after Ref. 16.

Figure 2-3 Precipitation of chromium carbides in Alloy 690 and Alloy 600, which were solution annealed at $1100^{\circ} \mathrm{C}\left(2012^{\circ} \mathrm{F}\right)$.

Figure 2-4 High-temperature tensile properties of annealed Alloy 690. Data a composite of cold worked and hot worked products in the annealed condition. ${ }^{[6]}$

Figure 2-5 Time-Temperature-Sensitization diagram by Modified Huey Test, Alloy 690 Heat NX4459HG $(0.06 \% \mathrm{C})$, after Ref. 16.

Figure 2-6 Time-Temperature-Sensitization diagram by Modified Huey Test, Alloy 690 Heat NX9217H $(0.01 \% \mathrm{C})$, after Ref. 16.

Figure 2-7 Time-Temperature-Sensitization diagram by Modified Huey Test, Alloy 690

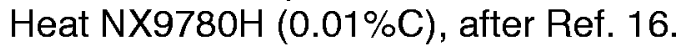

Figure 3-1 Comparison of material lost to stream in $316^{\circ} \mathrm{F}\left(600^{\circ} \mathrm{F}\right)$ deaerated water flowing at a velocity of $18 \mathrm{ft} / \mathrm{sec}(5.5 \mathrm{~m} / \mathrm{sec})$. After Ref. 9.

Figure 3-2 Comparison of general corrosion and material release to stream in simulated high temperature PWR primary water. After Ref. 11.

Figure 3-3 Cumulative number of RUB specimens cracked as function of test time by $\mathrm{K}$. Smith. None of the Alloy 690 TT and MA cracked. The number of RUB specimens for each series is $10 .{ }^{[11]}$

Figure 3-4 Testing of RUB Specimens in simulated primary water at $680^{\circ} \mathrm{F}\left(360^{\circ} \mathrm{C}\right)$. The stress was measured by X-ray diffraction. After Ref. 17.

Figure 3-5 Constant load test (CLT) in simulated primary water at $680^{\circ} \mathrm{F}\left(360^{\circ} \mathrm{C}\right)$. The stress level was measured by X-ray diffraction. After Ref. 17.

Figure 3-6 Schematic of weld mock-up block indicating the location and orientation of CERT specimens. ${ }^{[42]}$

Figure 3-7 CERT specimen design. ${ }^{[42]}$

Figure 3-8 Above, Alloy 82/Alloy 152 CERT specimen surface after testing in water showed several cracks in Alloy 82. Below, SEM micrograph of the final fracture surface showed a ductile dimpled fracture surface in Alloy 152 and a brittle intergranular crack surface in Alloy $82 .{ }^{[42]}$

Figure 3-9 Alloy 152 CERT specimen surface after testing in water. No cracks were seen. ${ }^{[42]}$

Figure 3-10 PWSCC crack growth rate (CGR) in CERT tests at $360^{\circ} \mathrm{C}\left(680^{\circ} \mathrm{F}\right)$ versus the grain boundary (creep) viscosity. After Figure 1 of Ref. 50.

Figure 3-11 PWSCC crack depth in CERT test of Alloy 690 Exp 1 material at $360^{\circ} \mathrm{C}$ $\left(680^{\circ} \mathrm{F}\right)$. After Figure 4 of Ref. 50.

Figure 3-12 Fields of cracking for CERTs and constant load tests as a function of time and strain rate (Experimental alloy 690 in the as-received condition, hydrogenated PWR primary water at $\left.360^{\circ} \mathrm{C}\right) .{ }^{[50]}$ 
Figure 3-13 Cracks observed in Alloy 690 RUB specimen 5R (from Heat B) after 13,824 hours exposure in hydrogenated steam at $380^{\circ} \mathrm{C}\left(716^{\circ} \mathrm{F}\right) .^{[52]}$

Figure 3-14 Short crack on the RUB specimen I.D. surface produced by flattening at room temperature. The RUB specimen was from Alloy 690 Heat $A$ (the heat did not develop intergranular cracking) and had been exposed to hydrogenated steam at $380^{\circ} \mathrm{C}\left(716^{\circ} \mathrm{F}\right)$ for 13,824 hours. ${ }^{[52]}$

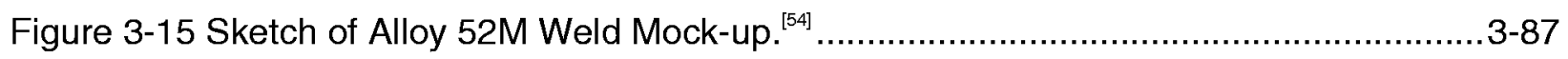

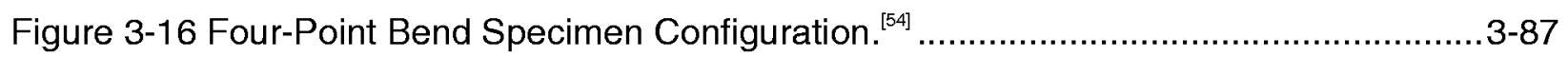

Figure 3-17 SG Tube Mock-Up [App. B] …........................................................... $3-88$

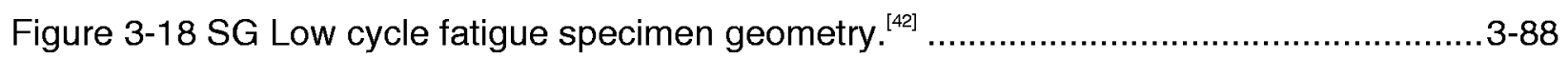

Figure 3-19 Plot of S/N fatigue properties of Alloy 690 and Alloys 52, 152, and 82 weld

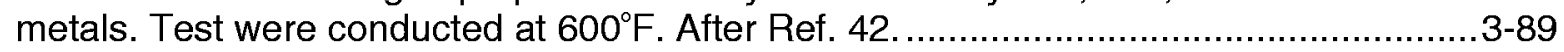

Figure 3-20 Plot of fatigue crack growth properties of Alloys 52 and 82 weld metals. After

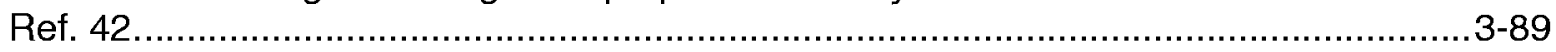

Figure 4-1 Vickers hardness number as a function of cold reduction \%. Alloy 690 has a higher work-hardening rate than Alloy 600. After Ref. 6.

Figure 4-2 Weibull plot of Alloy 600 RUB results in primary water at $680^{\circ} \mathrm{F}$ reported by $\mathrm{K}$. Smith et al. (shown in Figure 3-3). The test data in the beginning-fuel-cycle and the end-fuel-cycle water have been combined. The Alloy 690 (three heats) Weibayes line assumes $\beta=5.0$.

Figure 4-3 Weibull plot of different heats of Alloy 600 RUB results in deaerated water at $689^{\circ} \mathrm{F}$ reported by Norring et al. The Alloy 690 (many heats) Weibayes line assumes $\beta=5.0$.

Figure 4-4 Weibull plot of different EPRI special production heats of Alloy 600 RUB results in deaerated water at $689^{\circ} \mathrm{F}$ reported by Norring et al. The Alloy 690 (many heats) Weibayes line assumes $\beta=5.0$.

Figure 4-5 Weibull comparison between 7/8" dia. and 3/4" dia. Alloy 600 RUB results in deaerated water at $689^{\circ} \mathrm{F}$ reported by Norring et al. The Alloy 690 (many heats) Weibayes line assumes $\beta=5.0$.

Figure 4-6 Weibull plots of Alloy 600MA (one heat) during constant load test (CLT) at $85.3 \mathrm{ksi}, 644^{\circ} \mathrm{F}$ reported by Ogawa et al. (a) Results in the optimum ( $\mathrm{pH}=7.1$ ) and reference $\mathrm{pH}(\mathrm{pH}=7.3)$ primary water chemistry. (b) Results in the candidate (2.0 ppm Li) and reference primary water chemistry $(3.5 \mathrm{ppm} \mathrm{Li})$. The Alloy 600MA CLT specimens showed similar cracking behavior in the four variations of primary water chemistry.

Figure 4-7 Weibull plots of Alloy 600MA (one heat) CLT results at $85.3 \mathrm{ksi}, 644^{\circ} \mathrm{F}$ in primary water reported by Ogawa et al. No failure was observed in all Alloy 600MA\&TT CLT specimens tested at $608^{\circ} \mathrm{F}$ and in the Alloy 690TT (one heat) CLT specimens tested at $680^{\circ} \mathrm{F}$. The Weibayes lines for the Alloy $690 \mathrm{TT}$ and Alloy 600MA\&TT assume $\beta=5.0$.

Figure 4-8 Weibull plot of Alloy 600MA (one heat) RUB results at $608{ }^{\circ} \mathrm{F}$ in primary water reported by Ogawa et al. The RUB specimens were prestrained to different levels. The Weibayes line for the $0 \%$ prestrain (no failure) assumes $\beta=5.0$. 
Figure 4-9 Weibull plot of Alloy 600TT (one heat) RUB results at $608{ }^{\circ} \mathrm{F}$ in primary water reported by Ogawa et al. The RUB specimens were prestrained to different levels. The Weibayes line for the $0 \%, 5 \%$, and $15 \%$ prestrain (no failure) assume $\beta=5.0 \ldots \ldots .4-26$

Figure 4-10 Comparison of the 20\% prestrained RUB from Alloy 600MA\&TT (tested at $608^{\circ} \mathrm{F}$ ) and from Alloy $690 \mathrm{TT}$ (tested at $680^{\circ} \mathrm{F}$ ) in primary water reported by Ogawa et al. The Alloy 690TT Weibayes line for the assume $\beta=5.0$.

Figure 4-11 Weibull plot of RUB results at $680^{\circ} \mathrm{F}$ in primary water reported by Vaillant et al. The Alloy 600 RUB specimens were from four different heats in the MA and TT conditions. The Alloy 690 RUB specimens, from four different heats in the $T T$ and MA conditions, experienced no failure after up to 54,000 hours of exposure. The Alloy 690 Weibayes line assumes $\beta=5.0$.

Figure 4-12 Weibull plot of SG mockups tested in deaerated water at $680^{\circ} \mathrm{F}$ by Framatome ANP, France. Alloy 690TT SG mockups experienced no failure after 100,000 hours of exposure. The Alloy 690 Weibayes line assumes $\beta=5.0$.

Figure 4-13 Weibull $\theta$ and $\beta$ for Alloy 600 listed in Table 4-2.

Figure 4-14 Improvement factors listed in Table 4-3 and Table 4-4 per Eq. 4-8.

Figure 4-15 Boat Sample Removed from North Anna Unit 2, CRDM Nozzle \#51 in 2002.

Above, a sketch of the boat removal location with respect to the Alloy 52 weld overlay repair made in 2001 . Below, a sketch of the wetted surface (plan view) with the weld materials determined by EDS analysis. ${ }^{[72]}$

Figure A-1 Schematic diagram showing the influence of nickel content on the cracking behavior of different alloys when stressed slightly above yield strength in $350^{\circ} \mathrm{C}$ water (demineralized or $1000 \mathrm{ppm} \mathrm{Cl-} \mathrm{);} \mathrm{according} \mathrm{to} \mathrm{Coriou} \mathrm{[75]}$

Figure A-2 Schematic The PWSCC system and the necessary conditions for cracking to occur.

Figure A-3 Bending device used for RUB manufacturing .

Figure A-4 Typical RUB specimen manufactured by bending a split SG tube...................... A-6

Figure A-5 View of total number of test specimens .................................................... A-6

Figure A-6 Top view of scored RUB specimen showing the nature and orientation of grooves

Figure A-7 Typical printout obtained during surface profilometry. The groove depth of this particular sample is approximately $280 \mu \mathrm{m}$, which corresponds to $26 \%$ of the nominal wall thickness.

Figure A-8 Typical appearance of cracking observed in the scored Alloy 600MA specimens as indicated by the red arrows

Figure A-9 Typical appearance of cracking observed in the non-scored Alloy 600MA specimens as indicated by the red arrows.

Figure A-10 Typical view of scored Alloy 600MA metallographic specimen exhibiting numerous cracks, some of which had developed into through-wall defects.

Figure A-11 Typical view of non-scored Alloy 600MA metallographic specimen exhibiting numerous cracks, some of which had developed into through-wall defects.

Figure A-12 General microstructure found in Alloy 600MA specimens displaying a typical austenitic appearance. The grain size according ASTM E 112 was determined to be 8.5 . 
Figure A-13 Close up of Figure A-12 showing intragranular carbides and semicontinuous to discontinuous grain boundary carbide precipitates as a result of custom mill annealing at temperatures between $850^{\circ} \mathrm{C}$ and $900^{\circ} \mathrm{C}$

Figure A-14 Typical view of PWSCC found in the scored Alloy 600MA material; cracking initiated on the highly cold worked external specimen surface (formerly the internal SG tube surface); the crack propagation occurred in an intergranular manner.

Figure A-15 Typical view of PWSCC found in the non-scored Alloy 600MA specimens also displaying an intergranular crack progression mode.

Figure A-16 Close-up of typical crack tip found in Alloy 600MA; the crack progression clearly occurred in an intergranular manner.

Figure A-17 Typical view of scored Alloy 690TT metallographic specimen exhibiting no PWSCC.

Figure A-18 Typical view of non-scored Alloy 690TT metallographic specimen exhibiting no PWSCC.

Figure A-19 General microstructure of Alloy 690TT displaying some intragranular carbides and a semi-continuous to continuous network of grain boundary carbide precipitates as a result of the thermal treatment. The grain size for this material ranged between 5 and 7 .

Figure A-20 Non-scored Alloy 690TT specimen showing no PWSCC.............................. A-16

Figure A-21 Scored Alloy 690TT specimen showing no PWSCC.................................... A-16

Figure B-1 Structure of the Alloy 690 TT WE 094 tube at mid thickness................................ B-4

Figure B-2 Structure of the Alloy 690 TT WE 094 tube at the inner surface.......................... B-4

Figure B-3 Hardness across the Alloy 690 TT WE 094 tube wall thickness. ......................... B-5

Figure B-4 Sketch of a standard mock-up (dimensions in $\mathrm{mm}$ ). ........................................ B-6

Figure B-5 Schematic representation of the mock-ups for long-term exposure tests. ............. B-7

Figure B-6 Liquid penetrant test on mock-up 506. View of the two half tubes after splitting the mock-up longitudinally (the right hand half is flattened, the other is not

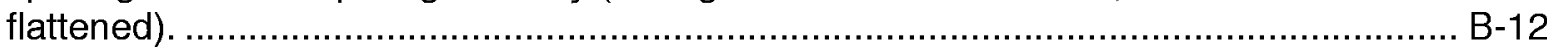

Figure B-7 Macrograph of the non-flattened half tube at the limit of the rolling zone 506B... B-14

Figure B-8 SEM view of the inner surface of the non-flattened half tube at the limit of the rolling zone 506B.

Figure B-9 SEM view of the inner surface of the non flattened half tube at the rolling zone limit $506 \mathrm{H}$.

Figure B-10 Limit of the kiss rolling zone of the flattened half tube 506B (Maximum length of the microcracks: $1.5 \mathrm{~mm}$ ).

Figure B-11 Limit of the rolling zone of the flattened half tube 506B (Maximum length of the microcracks: $0.5 \mathrm{~mm}$ ).

Figure B-12 SEM view of a etched circumferential cross section at the limit of rolling zone 506B.

Figure B-13 SEM view of a etched circumferential cross section of the limit of rolling zone 506B. Detailed view.

Figure B-14 SEM view of a circumferential cross section of the tube outside the rolling zone (unetched surface).

Xviii 
Figure B-15 SEM view of a circumferential cross section of the tube remote from the rolling zone. Detailed view.

Figure B-16 Reference tube of heat WE094. SEM view of an etched cross section after IGA susceptibility test.

Figure B-17 SEM view of an etched cross section of unstrained tube from mockup 506 after IGA susceptibility test.

Figure B-18 Liquid penetrant test on mock-up \#502. View of the two half tubes, (one is flattened, the other is not flattened).

Figure B-19 SEM view of the inner surface of the tube in an unrolled zone. (Non flattened half tube).

Figure B-20 SEM view of the inner surface of the tube in an unrolled zone. (Flattened half tube).

Figure B-21 Mock-up \#508B. SEM view of the inner surface of the non-flattened half tube at the limit of the rolling zone.

Figure B-22 Mock-up \#508B. SEM view of the inner surface of the flattened half tube at the limit of the rolling zone.

Figure B-23 Mock-up \#508B. SEM view of the non etched circumferential cross section through the rolling limit zone.

Figure B-24 Mock-up \#508B. SEM view of the etched circumferential cross section at the limit of the rolling zone

Figure B-25 Profilometry of mock-up $21 \mathrm{H}$ determined by an eddy current technique.

Figure B-26 Profilometry of mock-up.

Figure B-27 Profilometry of mock-up 17-H showing the location of the cracks detected by the $\mathrm{EC}$ technique.

Figure B-28 Detection and location of cracks on mock-up $17 \mathrm{H}$ found at the limit of the kiss roll by an EC technique.

Figure B-29 Liquid dye penetrant test on mock-up $17 \mathrm{H}$. View of the two half tubes after test showing the detected cracks.

Figure B-30 Macrograph of two cracks after flattening the half tubes of mock-up $17 \mathrm{H}$.

Figure B-31 Metallographic cross section of cracks in mock-up $17 \mathrm{H}$.

Figure C-1 Intergranular attack (IGA) in Alloy 690TT C-ring (specimen E3) after 1,200 hours in deaerated $50 \% \mathrm{NaOH}$ at $340^{\circ} \mathrm{C}\left(644^{\circ} \mathrm{F}\right)$. Magnification $500 \mathrm{X}^{[32]}$

Figure C-2 Crack growth rate of Alloy 690TT and Alloy 600MA\&TT from C-Ring specimens in deaerated $10 \% \mathrm{NaOH}$ solution. $(\mathrm{x} \%)$ indicate the loading stress to $\mathrm{x} \%$ of the yield strength. After Ref. 11 .

Figure C-3 Caustic SCC crack depth of Alloy 690 SG tubing thermally heat treated to produce different intergranular carbide morphology. The results indicate that there is little additional improvement in caustic SCC resistance from a continuous intergranular carbide coverage in thermally heat treated Alloy 690. After Ref. 93.

Figure C-4 Caustic SCC crack growth rate as a function of stress intensity factor by DCB tests in deaerated caustic solution. After Ref. 94.

Figure C-5 TGSCC in Alloy 690TT after 500 hours in $10 \% \mathrm{NaOH}+0.1 \mathrm{M} \mathrm{PbO}$ at $350^{\circ} \mathrm{C}$ $\left(662^{\circ} \mathrm{F}\right) \cdot{ }^{[96]}$ 



\section{List of Tables}

Table 1-1 First Reported Occurrence of Alloy 600 PWSCC for Various PWR Component Items

Table 2-1 ASME Specifications of Alloys 690/600, 152/182, and 52/82 ..............................2-6

Table 2-2 ASME Chemical Composition Requirement (wt\%) ${ }^{[23-28]}$........................................ 2-6

Table 2-3 ASME Room Temperature Properties ........................................................... 2-7

Table 2-4 ASME Elevated Temperature Properties for Alloy 690 and Alloy $600{ }^{[30]}$.................2-7

Table 2-5 Effect of Thermal Aging on Room Temperature Properties of an Annealed

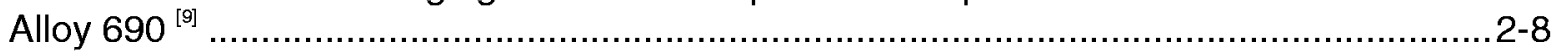

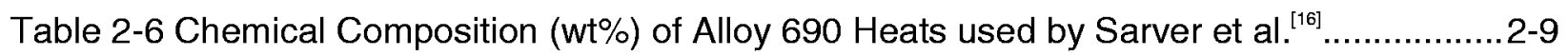

Table 2-7 Effect of heat treatment on Alloy 690 carbide precipitation, after Ref. 16..............2-10

Table 3-1 High Velocity Loop Test Conditions by Sedricks et al. ${ }^{[9]}$..................................... 3-40

Table 3-2 Chemical Composition of Alloy 690 Heats (wt\%) Used by Sedricks et al. ${ }^{[0]}$.............3-40

Table 3-3 Chemical Composition (wt\%) of Alloy 690 Heats Used by K. Smith et al. ${ }^{[1]}$...........3-41

Table 3-4 Chemical Composition (wt\%), Heat Treatment of Specimens Used by

Yonezawa et al. ${ }^{[17]}$

Table 3-5 Test Condition for General Corrosion and RUB Specimens by Yonezawa et al. [17]

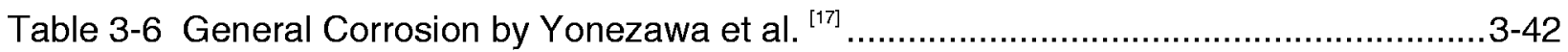

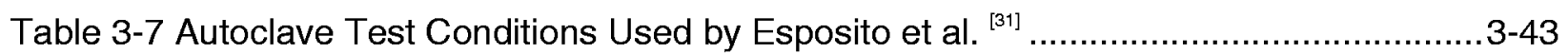

Table 3-8 General Corrosion Rate in Primary Water by Esposito ${ }^{[31]}$.......................................3-43

Table 3-9 General Corrosion Data in PWR Primary Water by Esposito et al. ${ }^{[31]}$.....................3-44

Table 3-10 Double U-Bend Test Conditions Used by Sedricks ${ }^{[0]}$....................................... 3-45

Table 3-11 Double U-Bend (creviced) Test Results Under Test 1a Condition in Table

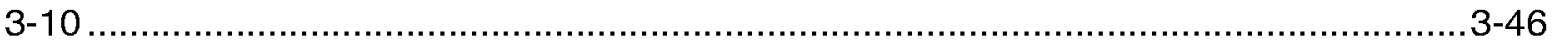

Table 3-12 Double U-Bend (creviced) Test Results Under Test 3 Condition in Table 3-10.....3-47

Table 3-13 Double U-Bend (Creviced) Test Results Under Test 1b Condition in Table

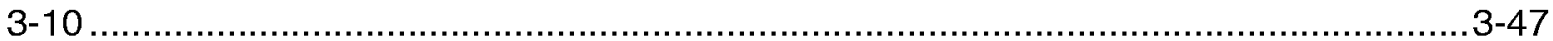

Table 3-14 SG Tubing Reverse U-Bend Test Conditions Use by K. Smith et al. ${ }^{[11]}$................3-48

Table 3-15 Chemical Composition (wt\%) of Alloy 690 Heats Used by A. Smith et al. ${ }^{[32]}$.........3-48

Table 3-16 Chemical Composition (wt\%) of Alloys 600 and 690 Use by Norring et al. ${ }^{[35,36}$ 37]

Table 3-17 Grain Boundary Chemical and Precipitates Evaluation ${ }^{[37]}$..................................3-49

Table 3-18 SG Tubing Reverse U-Bend Test Conditions Use by Norring et al. ....................3-50

Table 3-19 Alloy 690 Reverse U-Bend Test Results by Norring et al. ${ }^{[36,37]}$........................... 3-50

Table 3-20 Alloy 600 Reverse U-Bend Test Results by Norring et al. ${ }^{[36]}$................................3-51

Table 3-21 Alloy 600 Crack Initiation Time from Reverse U-Bend Test by Norring ${ }^{[35]}$..............3-52

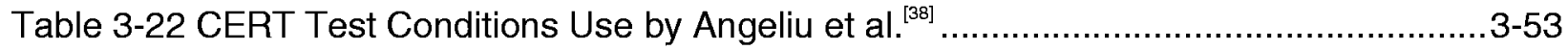

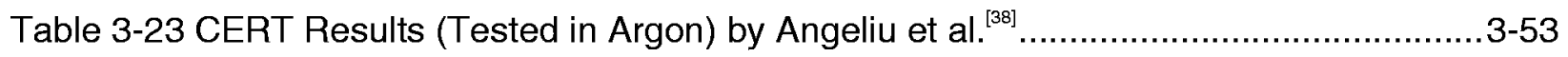


Table 3-24 CERT Results (Tested in Deaerated Water) by Angeliu et al. ${ }^{[38]}$ $3-54$

Table 3-25 Oxide Film on Coupons Exposed to $680^{\circ} \mathrm{F}$ Deaerated Water for $\sim 100$ hours [38]

Table 3-26 Chemical Composition of Alloys 600 and 690 SG Tubing Used by Nakayama et al. ${ }^{[40]}$

Table 3-27 Heat Treatment of Alloys 600 and 690 SG Tubing Used by Nakayama et al. [40]

Table 3-28 Single U-Bend Test Results in Hydrogen Saturated Water by Nakayama et al. ${ }^{[40]}$

Table 3-29 Test Conditions Use by Psaila-Dombrowski et al..$^{[41,42]}$ 3-56

Table 3-30 CERT Test Results by Psaila-Dombrowski et al. ${ }^{[41,42]}$ 3-56

Table 3-31 Alloy 690 and Alloy 690 SG Tubing Used by Ogawa et al. ${ }^{[43]}$ 3-57

Table 3-32 RUB and Constant Load Specimens Used by Ogawa et al. ${ }^{[43]}$ 3-57

Table 3-33 RUB and Constant Load Test Results by Ogawa et al. ${ }^{[43 .}$ 3-58

Table 3-34 Alloy 690 and Alloy 690 SG Tubing Used by Sui et al. ${ }^{[52]}$ 3-60

Table 3-35 RUB Test Results in Hydrogen/Steam at $716^{\circ} \mathrm{F}$ by Sui et al. ${ }^{[52,53]}$ 3-61

Table 3-36 Alloy 690 and Alloy 690 SG Tubing Used by Angell et al. ${ }^{[4]}$ 3-62

Table 3-37 RUB Test Conditions and Results $\left(662^{\circ} \mathrm{F}\right)$ by Angell et al. ${ }^{[4]}$ 3-62

Table 3-38 Origin and thermal treatments of Alloy 690 materials tested by the CEA ${ }^{[45]} \ldots \ldots \ldots . . . . .33$ Table 3-39 Chemical Compositions of Alloy 690 Materials Tested by the CEA ${ }^{[45]} \ldots \ldots \ldots \ldots \ldots . . . . . . .3-64$ Table 3-40 Origins and heat treatments of Alloy 690 SG tube materials tested by EdF ${ }^{[4]}$.......3-65 Table 3-41 Origins and Heat Treatments of Alloy 690 CRDM Nozzles Tested by EdF ${ }^{[46]}$........3-66 Table 3-42 Chemical compositions of Alloy 690 materials tested by EdF ${ }^{[46]}$..........................3-67

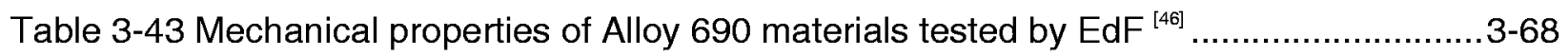

Table 3-44 Alloy 690 and Alloy 690 SG Used by Vaillant et al. ${ }^{[49]}$....................................3-69

Table 3-45 RUB and CERT Test Conditions by Vaillant et al. ${ }^{[49]}$......................................... 3-70

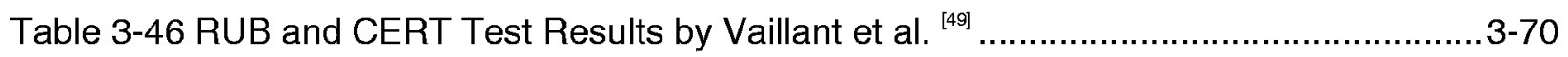

Table 3-47 SG Tubes Used by Boursier et al. ${ }^{[50]}$............................................................. 31

Table 3-48 CERT and Constant Load Test Conditions by Boursier et al. ${ }^{[50]}$.......................... 3-71

Table 3-49 Alloy 690 CERT Test Results by Boursier et al. ${ }^{[50]}$............................................. 3-72

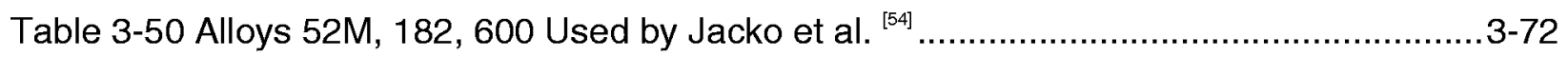

Table 3-51 Calculated Stress in the Four-Point Bend Specimens Used by Jacko et al. ${ }^{[54]} \ldots . . .3-73$

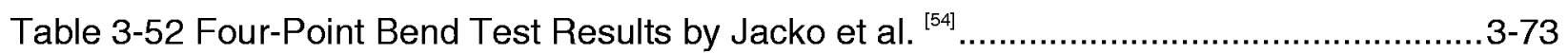

Table 3-53 Alloys 690TT and 600MA Used by Framatome ANP, Germany [App. A] .............3-74

Table 3-54 RUB Test Results by Framatome ANP, Germany [App. A] ................................3-74

Table 3-55 Alloys 690TT and 600MA\&TT Used by Framatome ANP, France [App. B]...........3-75

Table 3-56 Chemical analysis of the aqueous environment in the mock-ups after the 6th

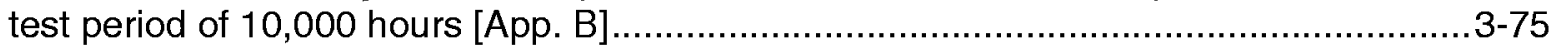

Table 3-57 Results for all mock-ups fabricated from Alloy 600 heat WD281 [App. B] .............3-76

Table 3-58 Results for all mock-ups fabricated from Alloy 600 heat NX3335 [App. B] ............3-77

xxii 
Table 3-59 Chemical Composition of Alloys 600, 690, 82, and 52 Tested by Brown and Mills ${ }^{[56,57]}$

Table 3-60 Low Cycle Fatigue Test Results by Psaila-Dombrowski et al. ${ }^{[42]}$........................ 3-78

Table 3-61 Fatigue Crack Growth Rate Test Results by Psaila-Dombrowski et al. ${ }^{[42]}$.............3-78

Table 4-1 Summary of Surface IG Cracking in Alloy 690 and Alloy 52 Specimens ................4-12

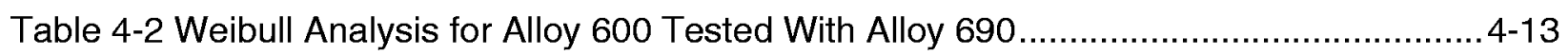

Table 4-3 Summary of Alloy 690 Primary Water Stress Corrosion Test Data .......................4-15

Table 4-4 Summary of Alloy 690 Hydrogenated and Doped Hydrogenated Steam Stress

Corrosion Test Data ........................................................................................ 4-16

Table 4-5 List of Operating Steam Generators Manufactured with Alloy 690 Tubing ${ }^{[68]}$..........4-17

Table 4-6 List of Alloy 690/152/52 Reactor Coolant System (Excluding Steam Generators) Original Equipment or Replacement Component Items and Welds. 4-18

Table A-1 Chemical composition of Alloy 600MA and Alloy 690TT ...................................... A-4

Table A-2 Mechanical properties and SG tube dimensions of Alloy 600MA and Alloy

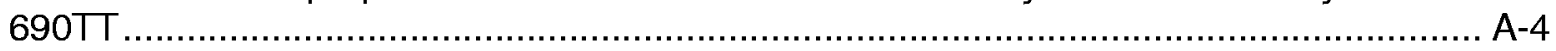

Table A-3 Results of hot steam test with RUB specimens........................................... A-8

Table B-1 Chemical composition of the tested materials ................................................. B-3

Table B-2 Mechanical properties of the tested materials ................................................ B-3

Table B-3 Characteristics of the Alloy 690 TT mock-ups................................................... B-9

Table B-4 Chemical analysis of the aqueous environment in the mock-ups after the $1^{\text {st }}$

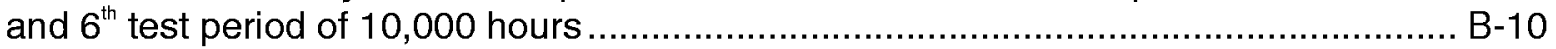

Table B-5 Mass loss results after the IGA susceptibility test following ASTM A 262

Practice $\mathrm{C}$ on Alloy $690 \mathrm{TT}$ tubes .................................................................... B-20

Table B-6 Characteristics of mock-ups \#502 and \#508 ................................................ B-22

Table B-7 Characteristics of the tested mock-ups ...................................................... B-29

Table B-8 Chemical analyses of the water environment from several mock-ups after a

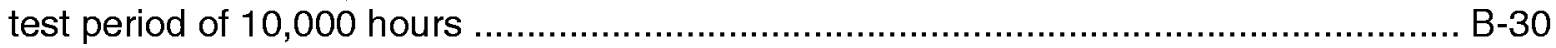

Table B-9 Results for all mock-ups fabricated from Alloy 600 heat WD281 ........................ B-32

Table B-10 Results for all mock-ups fabricated from Alloy 600 heat NX3335 ..................... B-34

Table B-11 Main results obtained by NDT and optical metallographic examination .............. B-37

Table B-12 Results of statistical analysis of the influence of tube/tubesheet gap and heat treatment of Alloy 600 tubes on failure time .......................................................... B-39

Table B-13 Influence of the heat treatment for mock-ups with a large tube / tubesheet gap.

Table B-14 Influence of the heat treatment for mock-ups with the nominal specification tube/tubesheet gap.

Table B-15 Data used to examine the influence of skip roll .......................................... B-42

Table B-16 Analysis of the influence of kiss rolling ......................................................

Table B-17 Influence of Alloy 600 heat .............................................................................. B-44

Table C-1 Alloy 690 Heats Tested in AVT Water by Miglin et al. ${ }^{[88]}$...................................... C-11

Table C-2 Alloys 600 and 690 Corrosion Test in AVT Water by Miglin et al ${ }^{[8]} \ldots \ldots \ldots \ldots \ldots \ldots . . . . . . . .11$ 
Table C-3 Summary of Alloy 690 SCC Results in Deaerated 50\% NaOH Solution ${ }^{[89]}$..... C-12

Table C-4 IGA in Alloy 690TT C-Rings in Deaerated Caustic Solutions at $644^{\circ} \mathrm{F}$ by A. Smith et al. ${ }^{[32]}$

Table C-5 $\mathrm{K}_{\mathrm{scc}}$ of Alloys 600 and 690 in Deaerated $\mathrm{NaOH}$ Solution by K. Smith et al. ${ }^{[11]}$ C-13

Table C-6 Alloys 600 and $690 \mathrm{C}$-Rings in Deaerated $10 \% \mathrm{NaOH}$ at $315^{\circ} \mathrm{C}$ by $\mathrm{K}$. Smith et al. ${ }^{[11]}$

Table C-7 Alloys 690 and 600 Tested in Deaerated 10\% and 30\% $\mathrm{NaOH}$ Solutions by Sarver et al. ${ }^{[91]}$

Table C-8 Results of C-Ring Specimens in Deaerated NaOH Solution by Sarver et al. ${ }^{[91]}$ C-15

Table C-9 Alloys 690 and 600 SG Used by Vaillant et al. ${ }^{[92]}$

Table C-10 IGSCC in $350^{\circ} \mathrm{C}$ Deaerated $\mathrm{NaOH}$ Solution Used by Vaillant et al. ${ }^{[2]}$

Table C-11 Properties of Alloy 690 in the As-Received Condition ${ }^{[93]}$ C-18

Table C-12 Alloy 690 SG Tubing Heat Treatments Used by Mertz et al. ${ }^{[93]}$ C-18

Table C-13 Alloy 690 Plate Heat Treatments Used by Mertz et al. ${ }^{[93]}$

Table C-14 Properties of Alloys 600 and 690 Used by Kawamura et al. ${ }^{[94]}$..... C-19

Table C-15 Properties of Alloys 600 and 690 Used by Kim et al. ${ }^{[95]}$ C-20

Table C-16 Chemical Composition of Alloys 600 and 690 Used by Castano-Marin et al. [96]

Table C-17 Mechanical Properties of Alloys 600 and 690 Used by Castano-Marin et al. [96]

Table C-18 C-Ring Test Condition and Results by Castano-Marin et al. ${ }^{[96]}$

Table C-19 Properties of Alloys 600 and 690 Used by Helie ${ }^{[97]}$

Table C-20 Summary of Alloys 600 and 690 in Chloride Solutions at Low Temperatures [98]

Table C-21 Summary of Alloy 690 in Chloride Solutions at High Temperatures ${ }^{\text {[98] }}$ $\mathrm{C}-23$

Table C-22 Materials Tested in Boiling $\mathrm{MgCl}_{2}$ by Berge et al. ${ }^{[98]}$

Table C-23 RUB Test Results in Boiling $\mathrm{MgCl}_{2}$ by Berge et al. ${ }^{[98]}$

Table C-24 Chemical Composition of Alloys 600 and 690 Used by Cullen et al. ${ }^{[99,100]}$...... $\mathrm{C}-24$ Table C-25 Autoclave Solutions Used for C-Ring Tests by Cullen et al. ${ }^{[100]}$ $\mathrm{C}-24$ Table C-26 Properties of Alloys 600 and 690 Used by Bouvier et al. ${ }^{[101]}$ 


\section{List of Acronyms}

ALARA - As low as reasonably achievable

APFIM - Atom probe field ion microscope (microscopy)

ATEM - Analytical transmission electron microscope (microscopy)

ASME - American Society of Mechanical Engineers

ASTM - American Society for Testing and Materials

AWS - American Welding Society

AVT - All Volatile Treatment

CEA - Commisariat à IÉnergie Atomique (the French Atomic Energy Commission)

$\mathrm{CL}-$ Constant Load

CLT - Constant load test

CEDM - Control element drive mechanism

CERT - Constant extension rate test, also known as slow strain rate test (SSRT)

CRDM - Control rod drive mechanism

DCB -- Double cantilever beam specimen

EdF - Electricité de France (the French national electric utility)

EFPH - Effective full power hours

EFPY - Effective full power years

EPRI - Electric Power Research Institute

GTA - Gas tungsten arc (welding)

HAZ - Heat-affected zone

ID - Inside diameter

IG - Intergranular 
IGA - Intergranular attack

IGSCC - Intergranular stress corrosion cracking

LTCP - Low temperature crack propagation

MA - Mill annealed

OD - Outside diameter

OTSG - Once-through steam generator

ppm - Parts per million

$\mathrm{ppb}-$ Parts per billion

PWR - Pressurized water reactor

PWSCC - Primary water stress corrosion cracking

RUB - Reverse U-Bend stress corrosion cracking specimens made from split half steam generator tubing, hence also known as split tube U-Bend specimens

$\mathrm{SCC}-$ Stress corrosion cracking

SEM - Scanning electron microscope (or microscopy)

SG - Steam generator

SSRT - Slow strain rate test, also known as constant extension rate test (CERT)

STEM - Scanning transmission electron microscope (or microscopy)

TEM - Transmission electron microscope (or microscopy)

TGSCC - transgranular stress corrosion cracking

TT - Thermal treatment

XPS - X-ray photoelectron spectroscopy 


\subsection{Background}

Wrought Alloy 600 and its weld metals (Alloy 182 and Alloy 82) were originally used in pressurized water reactors (PWRs) due to the material's inherent resistance to general corrosion in a number of aggressive environments and because of a coefficient of thermal expansion that is very close to that of low alloy and carbon steel. Over the last thirty years, primary water stress corrosion cracking (PWSCC) has been observed in Alloy 600 component items and Alloy 82/182 welds such as steam generator tubes and plugs, pressurizer heater sleeves and welds, pressurizer instrument nozzles, reactor vessel closure head nozzles and welds, reactor vessel outlet nozzle welds, and more recently in a lower reactor vessel head instrumentation nozzle and weld. Table 1-1 provides a synopsis of the Alloy 600 PWSCC experience in commercial PWRs. This table identifies the first commercially observed occurrence of PWSCC for each particular component item in a PWR and lists the approximate service life (in calendar years) at the time PWSCC was identified at that particular location. PWSCC was first observed at very highly stressed locations in the hot leg of steam generators in the 1970s. Pressurizer nozzles, which operate at the highest temperature in PWRs, were the next locations to have leakage and failures identified. Currently, PWSCC has been observed on nozzles and welds at nearly all locations where it is utilized throughout the reactor coolant system.

The occurrence of PWSCC has been responsible for significant downtime and replacement power costs at PWRs. Notable examples of equipment failures include extended outages and repairs or replacements at Calvert Cliffs, V.C. Summer, Oconee Nuclear Station, Davis-Besse, and North Anna. Repairs and replacements since the late 1980s have generally utilized wrought Alloy 690 material and its weld metals (Alloy 152 and Alloy 52), which have been shown to be considerably less susceptible, if not immune, to PWSCC for all practical purposes under normal operating conditions. Nevertheless, U.S. NRC Bulletin 2002-02, "Reactor Vessel Head and Vessel Head Penetration Nozzle Inspection Programs," dated August 9, 2002 does not indicate that inspection credit will currently be given for upgraded replacement reactor vessel heads, using Alloy 690 wrought and weld materials, over existing head penetrations using Alloy 600 wrought and weld materials that have $<8$ effective degradation years. ${ }^{1}$

\subsection{Causes of Alloy 600 PWSCC}

Stress corrosion cracking of metals and alloys is caused by the synergistic effects of environment, material condition, and stress. In a PWR primary water environment, intergranular stress corrosion cracking of wrought Alloy 600 material and its weld metals (Alloy 182 and

${ }^{1}$ An effective degradation year (EDY) is a means for assessing the potential for PWSCC cracking at a plant. It accounts for the amount of time a plant has operated and the temperatures at which it has operated. 
Alloy 82) is commonly referred to as PWSCC. The occurrence of stress corrosion cracking of Alloy 600 in high-purity water has been extensively studied since the first reported observation of cracking in laboratory tests by Coriou, et al. ${ }^{[1]}$ in 1959 . The mechanism of this cracking phenomenon is not completely understood, and prediction of crack initiation time has proven to be very difficult due to the uncertainty of numerous contributory variables including metallurgical condition, cold work, and residual stress. Although the crack initiation time can vary tremendously from heat to heat, wrought Alloy 600 material and its weld metals are susceptible to PWSCC when the total stress level is close to or in excess of the yield strength.

PWSCC is a thermally-activated mechanism that can be correlated with a Svante Arrhenius relationship (exponential) and is very temperature dependent. The vast majority of PWSCC of steam generator roll expansion transitions has occurred first on the hot leg side of the tube sheet due the $50-70^{\circ} \mathrm{F}\left(27-38^{\circ} \mathrm{C}\right)$ higher temperatures. However, failures of Alloy 600 material have also been reported in France to have occurred in reactor vessel upper head nozzle material at a temperature of approximately $554^{\circ} \mathrm{F}\left(290^{\circ} \mathrm{C}\right) .{ }^{[2]}$ On at least one other occasion PWSCC has been cited on a component item at a significantly lower water temperature of $423^{\circ} \mathrm{F}\left(217^{\circ} \mathrm{C}\right)$ although the details leading to this conclusion have not been independently verified by the authors of this report. [3]

The susceptibility of Alloy 600 depends on several factors including the chemical composition, metallurgical condition during manufacture of the material, heat treatment during fabrication of the component item, and its operating parameters. ${ }^{[4]}$ The carbon and chromium contents appear to be the most important chemical composition variables. These, in turn, affect the chromium carbide precipitation during thermal-mechanical processing. Microstructural conditions such as grain size and location relative to carbide precipitation also are important variables that determine the susceptibility of a material to PWSCC. Finally, fabrication parameters and heat treatment determine the overall yield strength and degree of cold work. Alloy 600 that has been low temperature mill-annealed, with grain boundaries poorly decorated with carbides, and has relatively high yield strength (due to some degree of remaining cold work) is generally observed to be the most susceptible to PWSCC.

Tensile stresses, resulting from both residual and operating stresses, can be significant for some Alloy 600 component items. A stress close to the material yield strength is generally necessary for PWSCC to occur. Operating stresses arise from mechanical (pressure) and thermal loading, while residual stresses are generated as a result of fabrication, installation, and welding processes. Residual stresses are more difficult to quantify than operating stresses and, in many instances, are of a higher magnitude and usually a major factor leading to premature failure.

In summary, PWSCC requires three key factors to be present simultaneously: an environment that promotes intergranular stress corrosion cracking, susceptible material, and significant, prolonged tensile stress. Eliminating any one of these three factors will mitigate cracking in principle, although in practice it is prudent to attack all of these factors at once, wherever feasible.

Based on the excellent test results and field performances, Alloy 690 has become the replacement material of choice for degraded Alloy 600 component items in PWRs. This 
document provides a systematic evaluation of field and laboratory data on potential corrosion mechanisms, particularly PWSCC, and provides a technical basis or justification for development of future inspection requirements for these materials.

\subsection{Purpose and Scope}

Existing data suggest that the effects of corrosion, particularly PWSCC concerns, are minimal with Alloy 690/52/152 materials. Within the EPRI PWR Materials Reliability Program (MRP), the Mitigation Working Group of the Alloy 600 Issue Task Group (ITG) has initiated this effort to demonstrate and quantify the margin of improvement resulting from use of the replacement materials (Alloys 690/152/52). The scope of this document is to:

1. Evaluate both field and laboratory data on the behavior of Alloys $690 / 152 / 52$ exposed to actual or simulated PWR primary water (including off-chemistry conditions and accelerated testing), taking into account the effects of material condition (e.g., thermal processing history, microstructure, cold work) and mechanical stress levels (applied and residual).

2. Analyze the data by comparison with the known behavior of Alloy 600 and its weld materials so as to generate a technical report describing, as far as currently possible, the margins of improvement in resistance to PWSCC expected from use of the replacement alloys.

3. Identify gaps in the existing database and suitable strategies to rectify these.

4. Provide a technical justification basis for development of future inspection requirements for these materials. 
Table 1-1 First Reported Occurrence of Alloy 600 PWSCC for Various PWR Component Items

\begin{tabular}{|c|c|c|}
\hline Component Item & $\begin{array}{l}\text { Date PWSCC } \\
\text { Initially Observed }\end{array}$ & $\begin{array}{l}\text { Service Life }^{(a)} \\
\text { (Calendar Years) }\end{array}$ \\
\hline Steam Generator Hot Leg Tubes & 1971 & 2 \\
\hline Pressurizer Instrument Nozzles & 1986 & 2 \\
\hline Steam Generator Cold Leg Tubes & 1986 & 18 \\
\hline Pressurizer Heaters and Sleeves & 1987 & 5 \\
\hline Steam Generator Channel Head Drain Pipes & 1988 & 1 \\
\hline Pressurizer Heater Diaphragm Plate Weld & 1989 & 16 \\
\hline Control Rod Drive Mechanism Nozzles & 1991 & 12 \\
\hline Hot Leg Instrument Nozzles & 1991 & 5 \\
\hline Power Operated Relief Valve Safe End & 1993 & 22 \\
\hline Pressurizer Nozzle Welds (Repair) & 1994 & 1 \\
\hline Steam Generator Tubesheet Plate Cladding & 1995 & 13 \\
\hline Cold Leg Piping Instrument Nozzles ${ }^{(b)}$ & 1997 & 13 \\
\hline Hot Leg Nozzle Welds & 2000 & 13 \\
\hline Reactor Vessel Hot Leg Nozzle Buttering/Piping Welds & 2000 & 17 \\
\hline Pressurizer Instrumentation Nozzle Welds & 2000 & 27 \\
\hline Control Rod Drive Mechanism Nozzle/RV Head Welds & 2000 & 27 \\
\hline Surge Line Nozzle Welds ${ }^{(c)}$ & 2002 & 21 \\
\hline $\begin{array}{l}\text { Reactor Vessel Lower Head In-Core Instrumentation } \\
\text { Nozzles/Welds }\end{array}$ & 2003 & 14 \\
\hline
\end{tabular}

(a) This listing identifies the first reported occurrence of identified cracking for each component item. Leakage has occurred in some component items in less than one year of service life and in other component items after nearly 30 years of service.

(b) One plant identified "suspect" visual evidence of boric acid leakage around two nozzles during a visual inspection; nozzles were preventively repaired without investigating whether leakage had in fact occurred.

(c) Crack-like flaw indications have not been confirmed as PWSCC at this time. 


\section{ALLOY 690 PROPERTIES AND METALLURGY}

\subsection{Material Specifications}

Alloy 690 and its predecessor Alloy 600 were first developed by Inco Alloys International under the trade names Inconel Alloy 690 and Inconel Alloy 600. ${ }^{[5,6]}$ Alloys 82 and 182 were first introduced by Inco Alloys International under the trade names Inconel Filler Metal 82 and Inconel Welding Electrode 182 for welding Alloy 600 component items. Alloys 52 and 152 were introduced by Inco Alloys International under the trade names Inconel Filler Metal 52 and Inconel Welding Electrode 152 and are now used for welding Alloy 690 component items. The present owner of the trade name of Inconel is Special Metals Corporation. Currently, all these alloys have been adopted by ASTM (American Society for Testing and Materials), ASME (American Society of Mechanical Engineers), and other international materials societies. Even though these alloys are listed under the UNS (Unified Numbering System) numbers in ASTM or ASME standards (see Table 2-1), these alloys are generically referred to as Alloy 600, Alloy 690 , Alloy 82 , Alloy 182 , Alloy 52 or Alloy 152 in the nuclear power industry.

Table 2-1 provides a summary of the most commonly used product forms in the ASME Boiler and Pressure Vessel Code Section II material specifications for the wrought Alloy 690 materials, and the corresponding weld metals Alloys 52 and 152. Because Alloy 690, Alloy 52, and Alloy 152 were developed for replacing their predecessors Alloy 600, Alloys 82, and Alloy 182 for light water nuclear power reactors, they are listed in the same ASME material specifications. It is noted that modified versions of Alloy $152 / 52$ with improved weldability are currently being developed. For example, the Inconel Filler Metal 52M (also called Alloy 52M), offered by Special Metals Corporation, contains boron and zirconium to minimize the tendency for ductility-dip cracking and added resistance to oxide "floaters" and inclusions. Alloy 52M has been proposed to AWS (American Welding Society) and is listed in AWS A5.14 as ERNiCrFe$7 \Lambda{ }^{[7]}$ Inconel Welding Electrode $152 \mathrm{M}$, a modified Alloy 152 , is also being offered by Special Metals Corporation.

Table 2-2 lists the chemical composition requirements for Alloys 690/600, 152/182, and 52/82. The ASME chemical composition requirements for these alloys remain identical to the original specification developed by the Inco Alloys International. However, stricter requirements on chemical composition, mechanical properties, and heat treatment process are imposed on Alloy 600 or 690 by utilities and vendors for applications in PWRs. For Alloy 690 bars, plates, and heavy section tubing, the carbon content is routinely specified to be in a range between $0.010 \%$ and $0.040 \%$ or narrower, instead of the max. $0.050 \%$ carbon specified in $\triangle$ SME Section II. For Alloy 690 SG tubing, the EPRI Guidelines require the carbon content to be between $0.015 \%$ to $0.025 \%$.[8] The lower limit ensures continuous or semi-continuous intergranular carbide precipitation while the upper limit keeps intragranular carbide precipitation to a minimum upon thermal heat treatment. Alloy 690 has higher yield and tensile strengths than Alloy 600 due to 
the increased $\mathrm{Cr}$ content. Therefore, the lowered carbon level does not affect the allowable stresses for Alloy 690 .

Table 2-3 lists the room temperature properties of Alloys 690/600, 152/182, and 52/82. However, ASME properties for the weld metals are not listed, which may be due to the fact the welds are less homogenous (e.g., dilution or mixing with the base metals) and their properties are anisotropic due to the directional solidification structure in welds. Table 2-4 lists the ASME properties of Alloys 690 and 600 at elevated temperatures. Such properties are used in the design of Alloy 600 and 690 component items for repair or replacement and calculating the operating stress.

\subsection{Phase Diagram of Alloy 690}

The first comprehensive study of Alloy 690 was published by Sedriks et al.$^{[9]}$ of Inco Alloys International, Inc. in 1979. This was the time that Alloy 690 began to be introduced for fabricating steam generator tubing in PWRs. The physical metallurgy and properties of Alloy 690 from this study and other sources are summarized below.

Figure 2-1 shows the Ni-Cr-Fe phase diagram with the location of the $\gamma / \gamma+\alpha^{\prime}$ ' solvus line indicated from 816 to $1260^{\circ} \mathrm{C}\left(1500\right.$ to $\left.2300^{\circ} \mathrm{F}\right)$. The lowest temperature at which the $\gamma / \gamma+\alpha^{\prime}$ solvus has been determined is $816^{\circ} \mathrm{C}\left(1500^{\circ} \mathrm{F}\right)$. The locations of Alloys 690 and 600 compositions are marked on the diagram and are both well within the austenite field $(\gamma)$. The range of melting temperatures is $2450-2510^{\circ} \mathrm{F}^{[6]}\left(1343-1377^{\circ} \mathrm{C}\right)$ for Alloy 690 and 2470 $2575^{\circ} \mathrm{F}^{[5]}\left(1354-1413^{\circ} \mathrm{C}\right)$ for Alloy 600 . The $\alpha^{\prime}$ phase is a chromium-rich phase, which is very similar to the iron-chromium $\sigma$ phase both in morphology and hardness. The $\alpha^{\prime}$ phase can cause embrittlement when precipitated during prolonged high temperature exposure in alloys whose compositions lie in the two-phase $\gamma+\alpha^{\prime}$ field. Precipitation of $\alpha^{\prime}$ phase is a mechanism of aging embrittlement of austenitic stainless steel welds or castings containing small amounts of $\delta$ ferrite and of martensitic precipitation-hardenable stainless steel when exposed to elevated operating temperatures in PWRs. ${ }^{[10]}$ Since Alloys 600 and 690 are both stable austenitic solid solution alloys from room temperature to the melting temperature, precipitation of $\alpha^{\prime}$ phase is not expected nor has ever been found in Alloys 600 and 690.

K. Smith et al. evaluated the possible occurrence of an "ordered" $\mathrm{Ni}_{2} \mathrm{Cr}$ phase in Alloy $690 .{ }^{[11]}$ This concern was raised due to the fact that the $\mathrm{Ni} / \mathrm{Cr}$ (atomic) ratio for an alloy with $70 \% \mathrm{Ni}$ $30 \% \mathrm{Cr} \mathrm{wt} \%$ is about 2.1 to 1 , which is very close to that of $\mathrm{Ni}_{2} \mathrm{Cr}$. The brittle and hard intermetallic $\mathrm{Ni}_{2} \mathrm{Cr}$ phase is stable below $580^{\circ} \mathrm{C}\left(1076^{\circ} \mathrm{F}\right)$ and could have a similar embrittling effect as the iron-chromium $\sigma$ intermetallic phase in austenitic alloys. However, K. Smith's research found that iron has an inhibiting effect on the formation of $\mathrm{Ni}_{2} \mathrm{Cr}$ phase and that the minimum specified iron content in Alloy 690 was high enough to inhibit any $\mathrm{Ni}_{2} \mathrm{Cr}$ formation. Later, Larsson et al. performed extensive testing for the same phenomenon including hardness tests, tensile tests, transmission electron microscopy (TEM), differential scanning calorimetry (DSC), and differential thermal analysis (DTA) on commercially produced Alloy 690TT that had been thermally aged for 3000 hours at 400 and $500^{\circ} \mathrm{C}\left(752\right.$ and $\left.932^{\circ} \mathrm{F}\right)$ and an Alloy 690 corrosion specimen exposed at $365^{\circ} \mathrm{C}\left(689^{\circ} \mathrm{F}\right)$ for 32,961 hours. ${ }^{[12]}$ The study confirmed that no evidence of long range ordering of type $\mathrm{Ni}_{2} \mathrm{Cr}$ was found in the thermally aged Alloy 690 . 
Nevertheless, vendors specify higher minimum iron contents than the ASME Code allowed minimum in order to provide a significant margin against formation of an ordered $\mathrm{Ni}_{2} \mathrm{Cr}$ phase in Alloy 690.

The microstructure of Alloy 690 is similar to Alloy 600 , i.e., an austenitic matrix with the secondary phases being predominantly chromium carbides precipitated both intergranularly and intragranularly. The other minor secondary phases in Alloys 600 and 690 are titanium nitrides, titanium carbides, and carbonitrides. Because the austenitic matrix phase is stable up the melting temperature, both alloys are non-heat treatable via phase changes (such as the austenite to martensite transformation in carbon and low alloy steels) and cannot be hardened through secondary phase precipitation (such as through $\gamma^{\prime}$ precipitation in Alloy X-750 or Alloy 718).

\subsection{Carbide Solubility}

The extent of intragranular and intergranular carbide precipitation depends on the thermal mechanical history and carbon content. Most research efforts on Alloys 690 and 600 have been focused on the grain boundary microstructure, especially due to observations of generally higher PWSCC resistance of Alloy 600 with a microstructure containing continuous intergranular carbides and few intragranular carbides. ${ }^{[13]}$ The intergranular carbide precipitates are found to be both $\mathrm{M}_{7} \mathrm{C}_{3}$ and $\mathrm{M}_{23} \mathrm{C}_{6}$ types in Alloy 600 and mostly globular $\mathrm{M}_{23} \mathrm{C}_{6}$ type in Alloy $690 .{ }^{[14,15]}$

It is generally recognized that the solubility of carbon in Alloy 690 is lower than that in Alloy 600. This is due to the higher $\mathrm{Cr}$ content which lowers the solubility while increasing the propensity for carbide precipitation. The carbon solubility curve of Alloy 690 was investigated by Sarver et al. ${ }^{[16]}$ The Alloy 690 heats used are listed in Table 2-6. The results are shown in Figure 2-2 with the Alloy 690 solubility line drawn to separate the specimens having no visible carbides from the specimens having visible carbides. Figure 2-2 also shows the comparison of carbon solubility curves for Alloy 690 and Alloy 600. The equations fitted to these curves are:

Alloy 690

$$
\begin{aligned}
{ }^{\circ} \mathrm{F} & =2647.5+120 \operatorname{Ln}(\% \mathrm{C}) \\
{ }^{\circ} \mathrm{C} & =1453.1+66.9 \operatorname{Ln}(\% \mathrm{C}) \\
\text { Alloy } 600 & \\
{ }^{\circ} \mathrm{F} & =2640+234.5 \operatorname{Ln}(\% \mathrm{C}) \\
{ }^{\circ} \mathrm{C} & =1449+130.3 \operatorname{Ln}(\% \mathrm{C})
\end{aligned}
$$

It should be noted that thermo-mechanical processing of both of these materials may cause grain boundaries to move by recrystallization after all the available carbon has precipitated as carbides on the old grain boundaries, thus creating a "ghost" grain boundary carbide network. Coring or non-equilibrium solidification of the original ingot can also manifest itself in the form of carbide banding. Solution heat treatments at temperatures above the carbon solubility curves for prolonged periods followed by rapid quenches can minimize the observed effects, but cannot eliminate them. Prohibitively long solution heat treatment would be required to dissolve the carbides and allow the carbon to diffuse away from the original sites in order to prevent the carbon from re-precipitating at the old sites during carbide precipitation heat treatment. 


\subsection{Intergranular Carbide Precipitation and Sensitization}

The time-temperature chromium carbide precipitation curves for Alloy 600 and Alloy 690 determined by Yonezawa et al. are shown in Figure 2-3. ${ }^{[1]}$ The highest precipitation rate (the nose of the C-curves) is at approximately $850-950^{\circ} \mathrm{C}\left(1550-1750^{\circ} \mathrm{F}\right)$. The Alloy 690 and Alloy 600 heats were annealed at $1100^{\circ} \mathrm{C}\left(2012^{\circ} \mathrm{F}\right)$ and contained $0.03 \%$ carbon but the exact chemical composition was not listed. From Figure 2-3, chromium carbides precipitate first at the grain boundaries followed by precipitation inside the grains. In addition, carbide precipitation is faster in Alloy 690 than in Alloy 600 due to the higher chromium content of Alloy 690. For Alloy 600, the precipitation of the grain boundary carbides is complete after a short period of time at $1300^{\circ} \mathrm{F}$ $\left(704^{\circ} \mathrm{C}\right)$. However, an extended $10-15$ hours period is required to fully replenish the Cr-depleted grain boundary with $\mathrm{Cr}$ from the bulk of the grains to avoid a "sensitized" microstructure. ${ }^{[18,19]}$ It was reasoned that since Alloy 690 has a much higher $\mathrm{Cr}$ content, full replenishment of the grain boundaries is not necessary and a 4 to 5 hour thermal treatment should be adequate. ${ }^{\text {[20] }}$

Sedriks et al. ${ }^{[9]}$ found that if the carbon content is kept to $0.02 \%$ or below, Alloy 690 cannot be "sensitized" as defined by the Huey test, i.e., the boiling nitric acid test per ASTM A 262 Practice $\mathrm{C}^{[21]}$. This means the $\mathrm{Cr}$ level near the grain boundary was sufficiently high in Alloy 690 containing $\leq 0.02 \%$ carbon after intergranular carbide precipitation to prevent intergranular attack by boiling nitric acid. In the Huey test, specimens are placed in boiling $65 \%$ wt nitric acid, typically for five 48-hour periods, with a fresh nitric acid solution being used in each period. It should be noted that the Huey test for sensitization is normally used for detecting susceptibility to intergranular attack in austenitic stainless steels, not for high-nickel alloys such as Alloy 690 or Alloy 600. "Sensitization" usually refers to grain boundary chromium depletion in austenitic stainless steels such as Type 304 and Type 316 exposed to $800-1500^{\circ} \mathrm{F}\left(427-816^{\circ} \mathrm{C}\right)$ for a prolonged period of time that varies with carbon content. Precipitation of chromium carbides along the grain boundaries causes the $\mathrm{Cr}$ depletion near the grain boundaries, which are preferentially attacked under certain oxidizing environmental conditions (for example in nitric acid or in the normal oxygenated water chemistry used in Boiling Water Reactors).

For Alloy 600 steam generator tubing, a modified Huey Test $\left(25 \% \mathrm{HNO}_{3}\right.$ with two 24-hour boiling periods) is often used, instead of the $65 \% \mathrm{HNO}_{3}$ with five 48 -hour boiling periods specified in ASTM A 262, Practice C. Due to the higher resistance of Alloy 690 to sensitization, Sarver et al. used $65 \% \mathrm{HNO}_{3}$ for sensitization testing of several heats of Alloy 690 with varying carbon contents and heat treatments. The time-temperature-sensitization diagrams plotted by Sarver et al. are shown in Figure 2-5 to Figure 2-7. ${ }^{[16]}$ Figure 2-5 shows very low corrosion rates for heat NX4459HG $(0.06 \% \mathrm{C})$ with a $1900^{\circ} \mathrm{F}\left(1038^{\circ} \mathrm{C}\right)$ anneal before the sensitization treatment. The corrosion rate was highest $(1.7 \mathrm{mil} / \mathrm{month})$ after a sensitization treatment of $1000^{\circ} \mathrm{F}\left(538^{\circ} \mathrm{C}\right)$ for 100 hours. Figure 2-6 shows the corrosion rates for heat NX9217H $(0.01 \% \mathrm{C})$, which was milled annealed at $1900^{\circ} \mathrm{F}\left(1038^{\circ} \mathrm{C}\right)$ for one hour. The corrosion rate was also low except when sensitized at $1000^{\circ} \mathrm{F}\left(538^{\circ} \mathrm{C}\right)$ for $20-100$ hours. Figure $2-7$ shows the results for heat $\mathrm{NX} 9780 \mathrm{H}$, also containing $0.01 \% \mathrm{C}$, but a slightly higher $\mathrm{Cr}$ content than $\mathrm{NX} 9217 \mathrm{H}(29.20 \% \mathrm{vs} .27 .27 \%)$. Heat $\mathrm{NX} 9780 \mathrm{H}$ also showed a very low corrosion rate even when sensitized at $1000^{\circ} \mathrm{F}\left(538^{\circ} \mathrm{C}\right)$ for 10-20 hours. The highest degree of sensitization for Alloy 690, as defined by the Huey test, is produced by heat treatment at $1000^{\circ} \mathrm{F}$ for 20 to 100 hours. The complete chemical compositions of heats NX4459HG, NX9217H, and NX9780H studied by Sarver et al. are summarized in Table 2-6. It should be noted that for Alloy 600 a sensitized microstructure with continuous 
intergranular carbides and grain boundary Cr depletion is more resistant to PWSCC than the same heat without intergranular carbides and grain boundary $\mathrm{Cr}$ depletion. Similarly, the same "sensitization" heat treatment also enhances PWSCC resistance of Alloy 690.

Sarver et al. also investigated the effect of carbon content, annealing temperature, and one-hour precipitation heat treatments on the carbide morphology. The results are shown in Table 2-7. The annealing temperature and carbon level both affected the temperature at which heavy intergranular carbide precipitation occurred. Depending upon the desired annealing temperature and carbon content, a one-hour heat treatment could be chosen to produce heavy intergranular carbide precipitation. The high carbon $(0.03 \% \mathrm{C})$ material was much more likely to show intragranular carbides than the lower carbon $(0.01 \% \mathrm{C})$ material although intergranular precipitation occurred equally in both materials. Although heavy intergranular carbide precipitation was produced by many heat treatments, no significant intergranular sensitization occurred except with the $0.03 \%$ carbon material annealed at $2100^{\circ} \mathrm{F}\left(1149^{\circ} \mathrm{C}\right)$ and heat treated at 1200 and $1300^{\circ} \mathrm{F}\left(649\right.$ and $\left.704^{\circ} \mathrm{C}\right)$, as shown by the Huey test. Corrosion rates in the Huey tests were 3.3 and $1.7 \mathrm{mil} / \mathrm{month}(1.0$ and $1.5 \mathrm{~mm} /$ year $)$, respectively. For all other heat treatments, rates were less than $1.2 \mathrm{mil} /$ month $(0.4 \mathrm{~mm} /$ year $)$.

\subsection{Effect of Elevated Temperature Exposure}

Figure 2-4 shows the results of short-time tensile tests performed on annealed Alloy 690 at temperature ranging from room temperatures up to $1800^{\circ} \mathrm{F}\left(982^{\circ} \mathrm{C}\right) \cdot{ }^{[6]}$ The curves represent average values for both cold-worked and hot-worked products in the annealed condition. Figure 2-4 shows that annealed Alloy 690 retains more than $90 \%$ of its room temperature tensile properties (yield and tensile strengths and elongation) up to $800^{\circ} \mathrm{F}\left(427^{\circ} \mathrm{C}\right)$. Only at temperatures over $1000^{\circ} \mathrm{F}\left(540^{\circ} \mathrm{C}\right)$ does the tensile strength start to decline substantially. The retention of room temperature tensile properties and the long-term high temperature stability are reflected in the ASME design stress intensity values for Alloy 690 and Alloy 600 (see Table 2-4).

Table 2-5 lists the room temperature tensile results of annealed Alloy 690 after exposure to elevated temperatures for various periods of time. ${ }^{[6]}$ The long-term high temperature stability of Alloy 690 was demonstrated by Charpy impact testing of Alloy 690 after long periods at 566 to $760^{\circ} \mathrm{C}\left(1050\right.$ to $\left.1400^{\circ} \mathrm{F}\right)$. This range of temperatures is similar to that of post weld stress relieving heat treatment (PWHT) temperatures for carbon and low alloy steel vessels or piping in PWRs. Table 2-5 shows the room temperature Charpy impact energy (189 J un-aged) was virtually unchanged after 12,000 hours or 500 days at elevated temperatures. The room temperature Charpy impact energy is found to be a very sensitive indicator of the precipitation of $\alpha^{\prime}$ or $\sigma$ phases for alloys with an austenitic matrix. For example, aging at $400^{\circ} \mathrm{C}\left(752^{\circ} \mathrm{F}\right)$ for 10,000 hours or 417 days reduced the Charpy impact energy from $\sim 220 \mathrm{~J}$ to $50 \mathrm{~J}$ of a CF-8 casting austenitic stainless steel (the equivalent of wrought Type 304 stainless steel) containing $24 \% \delta$ ferrite. $^{[22]}$

Hence, it can be concluded that thermal aging embrittlement is not a concern for Alloy 690 and Alloy 600 component items from exposure to high temperatures during fabrication or repair welding or PWHT heat treatment at $800-1300^{\circ} \mathrm{F}$, or from long-term exposure to PWR operating temperature of up to $650^{\circ} \mathrm{F}\left(343^{\circ} \mathrm{C}\right)$. 
Table 2-1 ASME Specifications of Alloys 690/600, 152/182, and 52/82

\begin{tabular}{|l|l|l|}
\hline Specification & Alloy & Product Form \\
\hline ASME SB-163 ${ }^{[23]}$ & $\begin{array}{l}\text { UNS N06690 (Alloy 690) } \\
\text { UNS N06600 (Alloy 600) }\end{array}$ & Seamless Tubing \\
\hline ASME SB-166 ${ }^{[24]}$ & $\begin{array}{l}\text { UNS N06690 (Alloy 690) } \\
\text { UNS N06600 (Alloy 600) }\end{array}$ & Rod, Bar, Wire \\
\hline ASME SB-167 ${ }^{[25]}$ & $\begin{array}{l}\text { UNS N06690 (Alloy 690) } \\
\text { UNS N06600 (Alloy 600) }\end{array}$ & Seamless Pipe and Tube \\
\hline ASME SB-168 ${ }^{[26]}$ & $\begin{array}{l}\text { UNS N06690 (Alloy 690) } \\
\text { UNS N06600 (Alloy 600) }\end{array}$ & Plate, Sheet, Strip \\
\hline ASME SFA-5.11 ${ }^{[27]}$ & $\begin{array}{l}\text { ENiCrFe-7, UNS W86152 (Alloy 152) } \\
\text { ENiCrFe-3, UNS W86182 (Alloy 182) }\end{array}$ & Coated welding electrode \\
\hline ASME SFA-5.14 ${ }^{[2]}$ & $\begin{array}{l}\text { ERNiCrFe-7, UNS N06052 (Alloy 52) } \\
\text { ERNiCr-3, UNS N06082 (Alloy 82) }\end{array}$ & Bare welding electrode and rod \\
\hline
\end{tabular}

Table 2-2 ASME Chemical Composition Requirement (wt\%) ${ }^{[23-28]}$

\begin{tabular}{|c|c|c|c|c|c|c|c|c|c|c|c|c|c|c|}
\hline Alloy & $\mathrm{Ni}$ & $\mathrm{Cr}$ & $\mathrm{Fe}$ & C & $\mathrm{Mn}$ & $\mathrm{Si}$ & $S$ & $\mathrm{Ti}$ & $\begin{array}{c}\mathrm{Nb}+ \\
\mathrm{Ta}\end{array}$ & $\mathrm{Cu}$ & $\mathbf{P}$ & Al & Mo & Other \\
\hline 690 & $\begin{array}{l}58.0 \\
\min \end{array}$ & $\begin{array}{l}27.0- \\
31.0\end{array}$ & $\begin{array}{l}7.0- \\
11.0\end{array}$ & $\begin{array}{l}0.05 \\
\max \end{array}$ & $\begin{array}{l}0.50 \\
\max \end{array}$ & $\begin{array}{l}0.50 \\
\max \end{array}$ & $\begin{array}{c}0.015 \\
\max \end{array}$ & - & - & $\begin{array}{l}0.50 \\
\max \end{array}$ & - & - & -- & - \\
\hline 600 & $\begin{array}{c}72.0 \\
\min \end{array}$ & $\begin{array}{l}14.0- \\
17.0\end{array}$ & $\begin{array}{l}6.0- \\
10.0\end{array}$ & $\begin{array}{l}0.15 \\
\max \end{array}$ & $\begin{array}{c}1.0 \\
\max \end{array}$ & $\begin{array}{l}0.50 \\
\max \end{array}$ & $\begin{array}{c}0.015 \\
\max \end{array}$ & -- & - & $\begin{array}{l}0.50 \\
\max \end{array}$ & - & -- & -- & -- \\
\hline $152^{(a)}$ & Bal. & $\begin{array}{l}28.0- \\
31.5\end{array}$ & $\begin{array}{l}7.0- \\
12.0\end{array}$ & $\begin{array}{l}0.05 \\
\max \end{array}$ & $\begin{array}{c}5.0 \\
\max \end{array}$ & $\begin{array}{l}0.75 \\
\max \end{array}$ & $\begin{array}{c}0.015 \\
\max \end{array}$ & $\begin{array}{l}0.50 \\
\max \end{array}$ & $\begin{array}{l}1.0- \\
2.5\end{array}$ & $\begin{array}{l}0.50 \\
\max \end{array}$ & $\begin{array}{l}0.03 \\
\max \end{array}$ & $\begin{array}{l}0.50 \\
\max \end{array}$ & $\begin{array}{l}0.50 \\
\max \end{array}$ & $\begin{array}{l}0.50 \\
\max \end{array}$ \\
\hline 182 & $\begin{array}{l}59.0 \\
\min \end{array}$ & $\begin{array}{l}13.0- \\
17.0\end{array}$ & $\begin{array}{l}10.0 \\
\max \end{array}$ & $\begin{array}{l}0.10 \\
\max \end{array}$ & $\begin{array}{l}5.0- \\
9.5\end{array}$ & $\begin{array}{c}1.0 \\
\max \end{array}$ & $\begin{array}{c}0.015 \\
\max \end{array}$ & $\begin{array}{c}1.0 \\
\max \end{array}$ & $\begin{array}{l}1.0- \\
2.5\end{array}$ & $\begin{array}{l}0.50 \\
\max \end{array}$ & $\begin{array}{l}0.03 \\
\max \end{array}$ & -- & -- & $\begin{array}{l}0.50 \\
\max \end{array}$ \\
\hline $52^{(a)}$ & Bal. & $\begin{array}{l}28.0- \\
31.5\end{array}$ & $\begin{array}{l}7.0- \\
11.0\end{array}$ & $\begin{array}{l}0.04 \\
\max \end{array}$ & $\begin{array}{c}1.0 \\
\max \end{array}$ & $\begin{array}{l}0.50 \\
\max \end{array}$ & $\begin{array}{c}0.015 \\
\max \end{array}$ & $\begin{array}{c}1.0 \\
\max \end{array}$ & $\begin{array}{l}0.10 \\
\max \end{array}$ & $\begin{array}{l}0.30 \\
\max \end{array}$ & $\begin{array}{l}0.02 \\
\max \end{array}$ & $\begin{array}{l}1.10 \\
\max \end{array}$ & $\begin{array}{l}0.50 \\
\max \end{array}$ & $\begin{array}{l}0.50 \\
\max \end{array}$ \\
\hline 82 & $\begin{array}{l}67.0 \\
\min \end{array}$ & $\begin{array}{l}18.0- \\
22.0\end{array}$ & $\begin{array}{l}3.0 \\
\max \end{array}$ & $\begin{array}{l}0.10 \\
\max \end{array}$ & $\begin{array}{c}2.5- \\
3.5\end{array}$ & $\begin{array}{l}0.50 \\
\max \end{array}$ & $\begin{array}{c}0.015 \\
\max \end{array}$ & $\begin{array}{l}0.75 \\
\max \end{array}$ & $\begin{array}{l}2.0- \\
3.0\end{array}$ & $\begin{array}{l}0.50 \\
\max \end{array}$ & $\begin{array}{l}0.03 \\
\max \end{array}$ & -- & -- & $\begin{array}{l}0.50 \\
\max \end{array}$ \\
\hline
\end{tabular}

(a) It is noted that modified versions of Alloy $152 / 52$ with improved weldability are currently being developed. 
Table 2-3 ASME Room Temperature Properties

\begin{tabular}{|c|c|c|c|c|c|c|c|}
\hline & & Alloy 690 & Alloy 600 & Alloy 152 & Alloy 182 & Alloy 52 & Alloy 82 \\
\hline \multirow{2}{*}{ Density } & $\mathrm{lb} / \mathrm{in}^{3}$ & $0.293^{(a)}$ & $0.300^{(a)}$ & \multirow{2}{*}{ NA } & \multirow{2}{*}{ NA } & \multirow{2}{*}{ NA } & \multirow{2}{*}{ NA } \\
\hline & $\mathrm{kg} / \mathrm{cm}^{3}$ & $8.11^{\text {(a) }}$ & $8.30^{\text {(a) }}$ & & & & \\
\hline $\begin{array}{l}\text { Poison's } \\
\text { Ratio }\end{array}$ & - & $0.29^{(b)}$ & $0.29^{(b)}$ & NA & NA & NA & NA \\
\hline \multirow{2}{*}{$\begin{array}{l}\text { Min. Tensile } \\
\text { Strength }\end{array}$} & ksi & $85^{[25]}$ & $80^{[25]}$ & $80^{[29]}$ & $80^{[29]}$ & $80^{[29]}$ & $80^{[29]}$ \\
\hline & $\mathrm{MPa}$ & $586^{[25]}$ & $550^{[25]}$ & $552^{[29]}$ & $552^{[29]}$ & $552^{[29]}$ & $552^{[29]}$ \\
\hline \multirow{2}{*}{$\begin{array}{l}\text { Min. Yield } \\
\text { Strength }\end{array}$} & ksi & $30^{[25]}$ & $30^{[25]}$ & NA & NA & NA & NA \\
\hline & $\mathrm{MPa}$ & $205^{[25]}$ & $205^{[25]}$ & NA & NA & NA & NA \\
\hline $\begin{array}{l}\text { Min. } \\
\text { Elongation }\end{array}$ & $\%$ & $35^{[25]}$ & $35^{[25]}$ & $30^{[29]}$ & $30^{[29]}$ & $30^{[29]}$ & $30^{[29]}$ \\
\hline
\end{tabular}

(a) From Table NF-2 of Ref. 30.

(b) From Table NF-1 of Ref. 30.

Table 2-4 ASME Elevated Temperature Properties for Alloy 690 and Alloy $600^{[30]}$

\begin{tabular}{|c|c|c|c|c|c|c|c|c|c|c|}
\hline \multirow{2}{*}{$\begin{array}{c}\text { Temp } \\
{ }^{\circ} \mathrm{F}\end{array}$} & \multicolumn{2}{|c|}{$\begin{array}{l}\text { Young's Modulus } \\
E^{(a)}, \times 10^{6} \mathrm{ksi}\end{array}$} & \multicolumn{2}{|c|}{$\begin{array}{c}\text { Coefficient of } \\
\text { Thermal Expansion } \\
a^{(b)}, \times 10^{-6} \text { in } / \text { in } /{ }^{\circ} \mathrm{F}\end{array}$} & \multicolumn{2}{|c|}{$\begin{array}{l}\text { Design Stress } \\
\text { Intensity }{ }^{(c)} \\
S_{m}, k s i\end{array}$} & \multicolumn{2}{|c|}{$\begin{array}{l}\text { Yield Strength } \\
\qquad S_{y}, k^{(d)}\end{array}$} & \multicolumn{2}{|c|}{$\begin{array}{c}\text { Tensile Strength } \\
\mathrm{S}_{\mathrm{u}}, \mathrm{ksi}\end{array}$} \\
\hline & 690 & 600 & 690 & 600 & 690 & 600 & 690 & 600 & 690 & 600 \\
\hline 70 & 30.3 & 31.0 & 7.7 & 6.8 & 23.3 & 23.3 & 35.0 & 35.0 & 85.0 & 80.0 \\
\hline 100 & $30.1^{(\mathrm{a})}$ & 30.8 & 7.8 & 6.9 & 23.3 & 23.3 & 35.0 & 35.0 & 85.0 & 80.0 \\
\hline 200 & 29.5 & 30.2 & 7.9 & 7.1 & 23.3 & 23.3 & 31.7 & 32.0 & 85.0 & 80.0 \\
\hline 300 & 29.1 & 29.8 & 7.9 & 7.3 & 23.3 & 23.3 & 29.8 & 31.2 & 84.0 & 80.0 \\
\hline 400 & 28.8 & 29.5 & 8.0 & 7.5 & 23.3 & 23.3 & 28.6 & 30.7 & 82.0 & 80.0 \\
\hline 500 & 28.3 & 29.0 & 8.1 & 7.6 & 23.3 & 23.3 & 27.9 & 30.3 & 80.8 & 80.0 \\
\hline 600 & 28.1 & 28.7 & 8.2 & 7.8 & 23.3 & 23.3 & 27.6 & 29.9 & 80.2 & 80.0 \\
\hline 650 & $27.9^{(a)}$ & 28.5 & 8.2 & 7.8 & 23.3 & 23.3 & 27.5 & 29.7 & 80.0 & 80.0 \\
\hline 700 & 27.6 & 28.2 & 8.3 & 7.9 & 23.3 & 23.3 & 27.5 & 29.4 & 79.8 & 80.0 \\
\hline
\end{tabular}

(a) From Table TM-4 of Ref. 30. Values of Young's modulus for $100^{\circ} \mathrm{F}$ and $650^{\circ} \mathrm{F}$ are obtained by linear interpolation.

(b) Mean coefficient of thermal expansion going from $70^{\circ} \mathrm{F}$ to the indicated temperature, from Table TE-4 of Ref .

(c) From Table 2B of Ref. 30. For annealed Alloy 690 and Alloy 600 of SB-163, SB-166, SB-167, and SB-168; some exception exists see Table $2 \mathrm{~B}$ of Ref. 30 for details.

(d) From Table Y-1 of Ref. 30. For annealed Alloy 690 and Alloy 600 of SB-163, SB-166, SB-167, and SB-168; some exception exists see Table Y-1 of Ref. 30 for details. 
Table 2-5 Effect of Thermal Aging on Room Temperature Properties of an Annealed Alloy $690^{[9]}$

\begin{tabular}{|c|c|c|c|c|c|c|c|c|c|}
\hline \multicolumn{2}{|c|}{$\begin{array}{l}\text { Exposure } \\
\text { Temperature }\end{array}$} & \multirow{2}{*}{$\begin{array}{c}\begin{array}{c}\text { Aging } \\
\text { Time }\end{array} \\
\text { hour }\end{array}$} & \multicolumn{2}{|c|}{ Yield Strength } & \multicolumn{2}{|c|}{ Tensile Strength } & \multirow{2}{*}{$\begin{array}{c}\text { Elong. } \\
\%\end{array}$} & \multicolumn{2}{|c|}{$\begin{array}{c}\text { Charpy Impact } \\
\text { Energy }\end{array}$} \\
\hline${ }^{\circ} \mathrm{F}$ & ${ }^{\circ} \mathrm{C}$ & & ksi & $\mathrm{MPa}$ & ksi & $\mathrm{MPa}$ & & $\mathrm{ft}-\mathrm{lb}$. & $J$ \\
\hline N/A & N/A & Not Aged & 41.0 & 283 & 103.5 & 714 & 48 & 140 & 190 \\
\hline \multirow{3}{*}{1050} & \multirow{3}{*}{565} & 1,000 & 48.5 & 334 & 105.0 & 727 & 45 & 115 & 156 \\
\hline & & 4,000 & 47.0 & 324 & 105.5 & 724 & 45 & 126 & 171 \\
\hline & & 12,000 & 45.5 & 314 & 105.5 & 727 & 44 & 121 & 164 \\
\hline \multirow{3}{*}{1100} & \multirow{3}{*}{595} & 1,000 & 62.5 & 431 & 107.0 & 738 & 45 & 144 & 195 \\
\hline & & 4,000 & 46.5 & 321 & 106.0 & 731 & 43 & 125 & 170 \\
\hline & & 13,248 & 45.5 & 314 & 105.5 & 727 & 44 & 125 & 170 \\
\hline \multirow{3}{*}{1200} & \multirow{3}{*}{650} & 1,000 & 46.8 & 323 & 105.5 & 727 & 46 & 146 & 198 \\
\hline & & 4,000 & 48.5 & 334 & 106.0 & 731 & 54 & 132 & 179 \\
\hline & & 12,000 & 46.1 & 318 & 108.5 & 748 & 41 & 127 & 172 \\
\hline \multirow{3}{*}{1400} & \multirow{3}{*}{760} & 1,000 & 50.0 & 345 & 107.0 & 738 & 44 & 158 & 214 \\
\hline & & 4,000 & 44.4 & 306 & 103.5 & 714 & 44 & 148 & 201 \\
\hline & & 12,000 & 46.5 & 321 & 103.5 & 714 & 46 & 136 & 184 \\
\hline
\end{tabular}


Table 2-6 Chemical Composition (wt\%) of Alloy 690 Heats used by Sarver et al. ${ }^{[16]}$

\begin{tabular}{|c|c|c|c|c|c|c|c|c|c|c|c|c|c|}
\hline Heat & $\mathbf{N i}$ & $\mathrm{Cr}$ & $\mathbf{F e}$ & C & Mn & Si & $\mathbf{S}$ & $\mathbf{T i}$ & $\begin{array}{c}\mathrm{Nb}+ \\
\mathrm{Ta}\end{array}$ & $\mathrm{Cu}$ & $\mathbf{P}$ & Al & Mo \\
\hline \multicolumn{14}{|c|}{ Intergranular Carbide Precipitation Study } \\
\hline NX9217H & Bal & 27.27 & 10.22 & 0.01 & 0.15 & 0.10 & 0.003 & 0.25 & & 0.15 & & 0.17 & \\
\hline $\mathrm{NX9780H}$ & Bal & 29.20 & 8.85 & 0.01 & 0.33 & 0.43 & 0.001 & 0.46 & & 0.12 & & 0.26 & \\
\hline NX4459HG & Bal & 28.25 & 8.86 & 0.06 & 0.20 & 0.10 & 0.004 & 0.32 & & 0.04 & & 0.17 & \\
\hline $\mathrm{NX} 4401 \mathrm{H}$ & Bal & 29.25 & 10.22 & 0.01 & 0.21 & 0.25 & 0.001 & 0.28 & & 0.26 & & 0.15 & \\
\hline \multicolumn{14}{|c|}{ Carbon Solubility Study } \\
\hline EXP 1 & Bal & 28.7 & 9.2 & $<0.001$ & 0.02 & 0.001 & 0.001 & & & 0.03 & & & \\
\hline EXP 2 & Bal & 28.8 & 9.8 & 0.01 & 0.06 & 0.06 & 0.003 & & & 0.02 & & & \\
\hline $\mathrm{NX} 4458 \mathrm{H}$ & Bal & 27.9 & 9.8 & 0.016 & 0.19 & 0.10 & 0.002 & & & 0.26 & & & \\
\hline EXP 3 & Bal & 29.9 & 9.6 & 0.02 & 0.03 & 0.05 & 0.003 & & & 0.01 & & & \\
\hline EXP 4 & Bal & 28.7 & 9.3 & 0.02 & 0.02 & 0.001 & 0.001 & & & 0.03 & & & \\
\hline NX05E1H & Bal & 29.9 & 9.5 & 0.021 & 0.21 & 0.39 & 0.001 & & & 0.28 & & & \\
\hline $\mathrm{NX10C1H}$ & Bal & 29.8 & 9.4 & 0.039 & 0.15 & 0.15 & 0.008 & & & 0.30 & & & \\
\hline EXP 5 & Bal & 29.0 & 9.1 & 0.04 & 0.02 & 0.001 & 0.002 & & & 0.02 & & & \\
\hline EXP 6 & Bal & 29.1 & 9.1 & 0.058 & 0.02 & 0.001 & 0.001 & & & 0.02 & & & \\
\hline EXP 7 & Bal & 29.4 & 10.3 & 0.06 & 0.03 & 0.06 & 0.003 & & & 0.03 & & & \\
\hline EXP 8 & Bal & 29.5 & 9.8 & 0.06 & 0.01 & 0.05 & 0.003 & & & 0.02 & & & \\
\hline \multicolumn{14}{|l|}{ Heat Treatment Study } \\
\hline $\mathrm{NX} 4401 \mathrm{H}$ & Bal & 29.25 & 10.22 & 0.01 & 0.21 & 0.25 & 0.001 & 0.28 & & 0.26 & & 0.15 & \\
\hline $\mathrm{NX} 4588 \mathrm{H}$ & $\mathrm{Bal}$ & 29.92 & 9.49 & 0.03 & 0.18 & 0.21 & 0.001 & 0.27 & & 0.24 & & 0.21 & \\
\hline $\mathrm{NX2184H}$ & Bal & 28.82 & 8.98 & 0.01 & 0.18 & 0.24 & 0.001 & 0.26 & & 0.24 & & 0.30 & \\
\hline NX4308 (Alloy 600) & Bal & 15.11 & 7.60 & 0.03 & 0.35 & 0.21 & 0.007 & 0.26 & & 0.29 & & 0.50 & \\
\hline
\end{tabular}


Table 2-7 Effect of heat treatment on Alloy 690 carbide precipitation, after Ref. 16.

\begin{tabular}{|c|c|c|c|c|c|c|c|c|c|}
\hline & \multicolumn{4}{|c|}{$0.01 \% \mathrm{C} \mathrm{NX4401 \textrm {H }}$} & \multicolumn{4}{|c|}{$0.03 \% \mathrm{C}$ NX4588H } \\
\hline & & \multicolumn{4}{|c|}{ Initial Anneal Temp, 20 minutes } & \multicolumn{4}{|c|}{ Initial Anneal Temp, 20 minutes } \\
\hline & & $1800^{\circ} \mathrm{F}$ & $1900^{\circ} \mathrm{F}$ & $2000^{\circ} \mathrm{F}$ & $2100^{\circ} \mathrm{F}$ & $1800^{\circ} \mathrm{F}$ & $1900^{\circ} \mathrm{F}$ & $2000^{\circ} \mathrm{F}$ & $2100^{\circ} \mathrm{F}$ \\
\hline \multirow{4}{*}{ 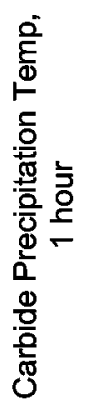 } & $1200^{\circ} \mathrm{F}$ & VL & VL & L & VL & VL & $\mathrm{H}$ & $\underset{\text { Intra }}{\mathbf{H}}$ & $\mathbf{L}$ \\
\hline & $1300^{\circ} \mathrm{F}$ & VL & L & $\underset{\text { Intra }}{\mathrm{H}}$ & $\mathbf{L}$ & $\mathbf{L}$ & $\mathrm{H}$ & $\underset{\text { Intra }}{\mathrm{H}}$ & $\mathbf{L}$ \\
\hline & $1400^{\circ} \mathrm{F}$ & $\mathrm{H}$ & $\mathrm{H}$ & $\mathrm{H}$ & $\mathrm{H}$ & $\underset{\text { Intra }}{\mathrm{L}}$ & $\mathbf{L}$ & $\underset{\text { Intra }}{\mathbf{H}}$ & $\underset{\text { Intra }}{\mathrm{H}}$ \\
\hline & $1500^{\circ} \mathrm{F}$ & VL & $\mathbf{H}$ & $\mathrm{H}$ & $\mathrm{H}$ & $\underset{\text { Intra }}{\text { L }}$ & $\underset{\text { Intra }}{\mathrm{L}}$ & $\underset{\text { Intra }}{\mathbf{H}}$ & $\mathrm{H}$ \\
\hline
\end{tabular}

(a) Heat treatment code:

VL - very light intergranular carbides; $L$ - light intergranular carbides

$\mathrm{H}$ - heavy intergranular carbides; Intra - intragranular carbides 


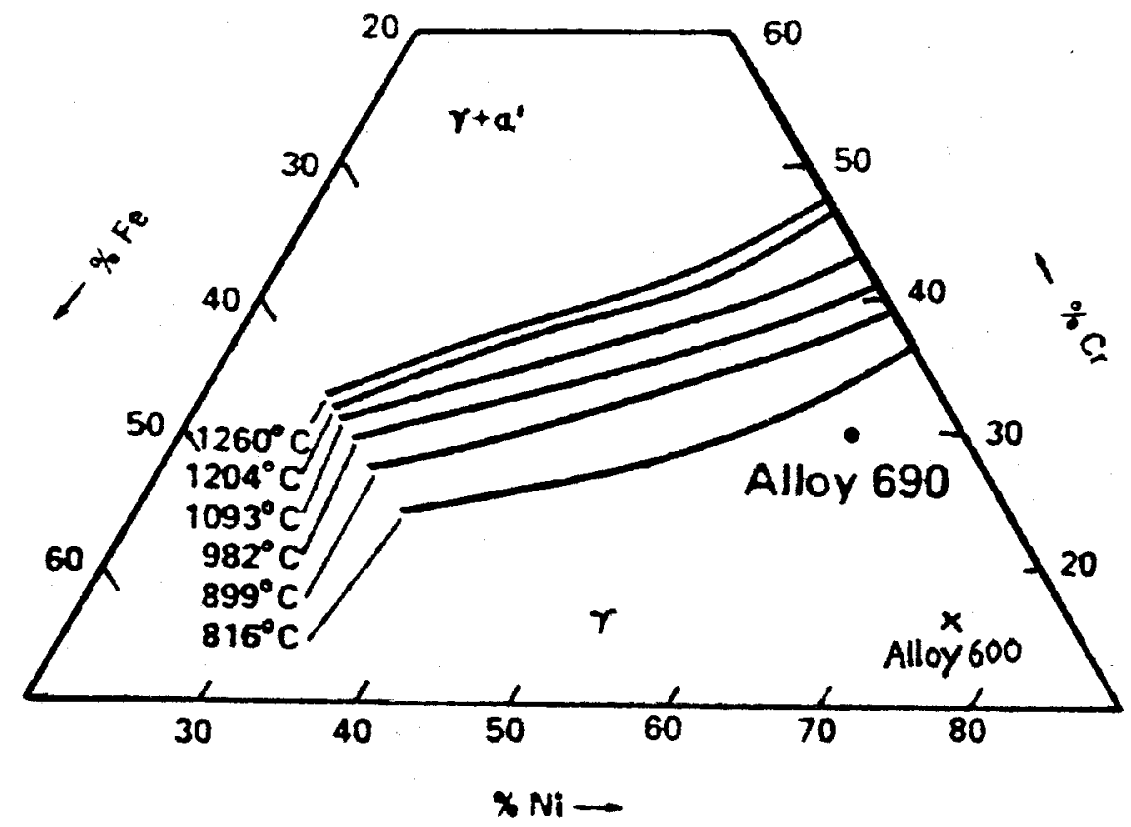

Figure 2-1 The Ni-Cr-Fe phase diagram showing the location of the $\gamma / \gamma+\alpha^{\prime}$ solvus at elevated temperatures from 816 to $1260^{\circ} \mathrm{C}\left(1500\right.$ to $\left.2300^{\circ} \mathrm{F}\right)$. The locations of Alloy 690 and Alloy 600 composition are marked on the diagram. ${ }^{[0]}$

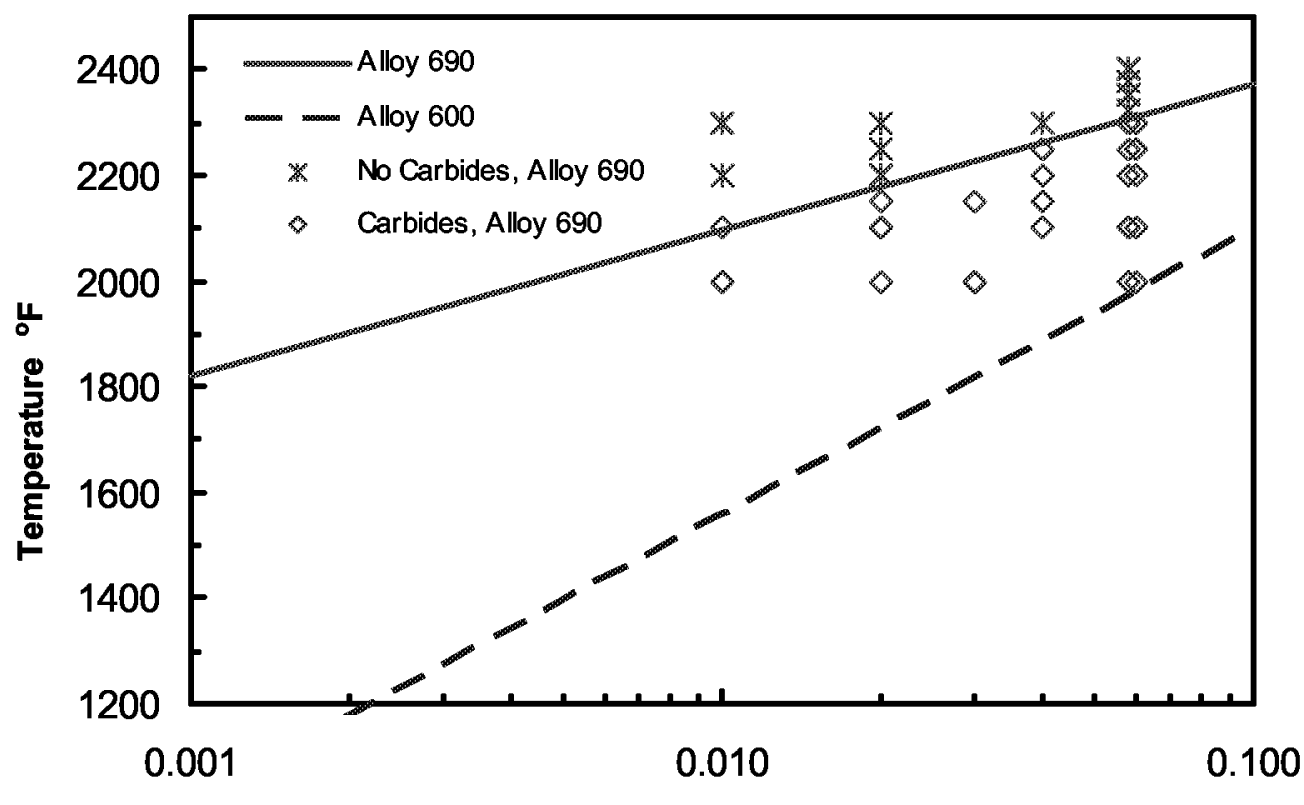

Carbon, wt\%

Figure 2-2 Carbon solubility diagram for Alloy 690 and Alloy 600, after Ref. 16. 


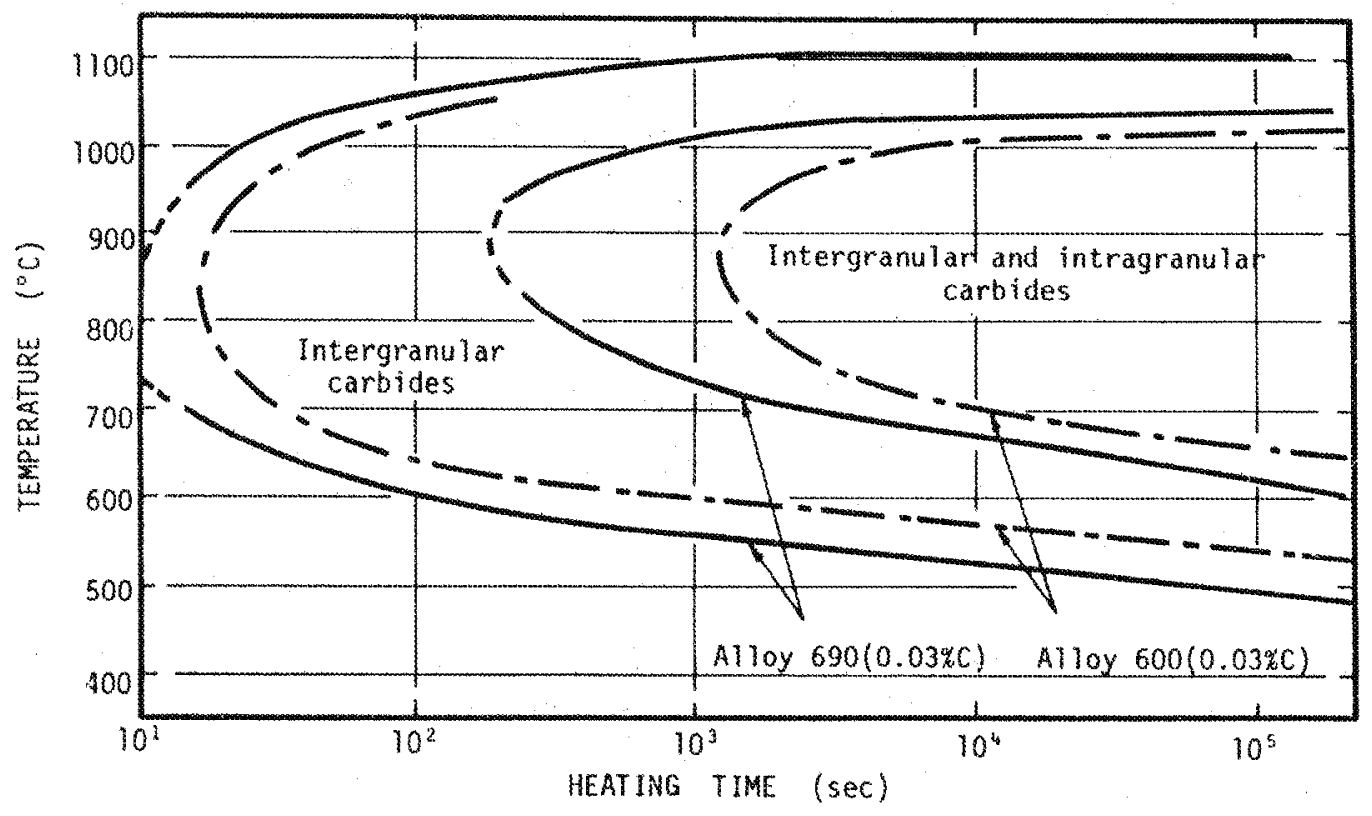

Figure 2-3 Precipitation of chromium carbides in Alloy 690 and Alloy 600, which were solution annealed at $1100^{\circ} \mathrm{C}\left(2012^{\circ} \mathrm{F}\right)$.

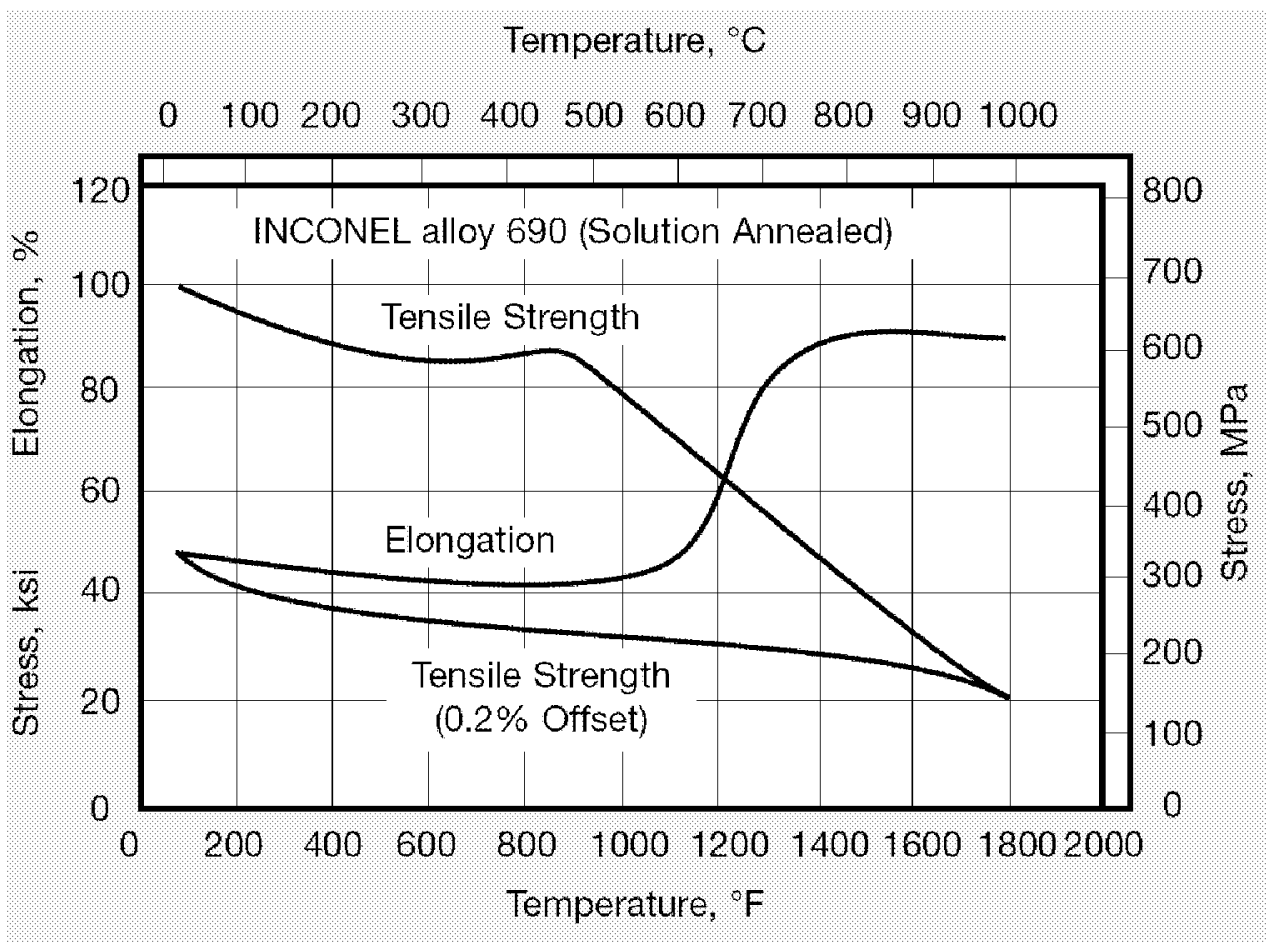

Figure 2-4 High-temperature tensile properties of annealed Alloy 690. Data a composite of cold worked and hot worked products in the annealed condition. ${ }^{[6]}$ 


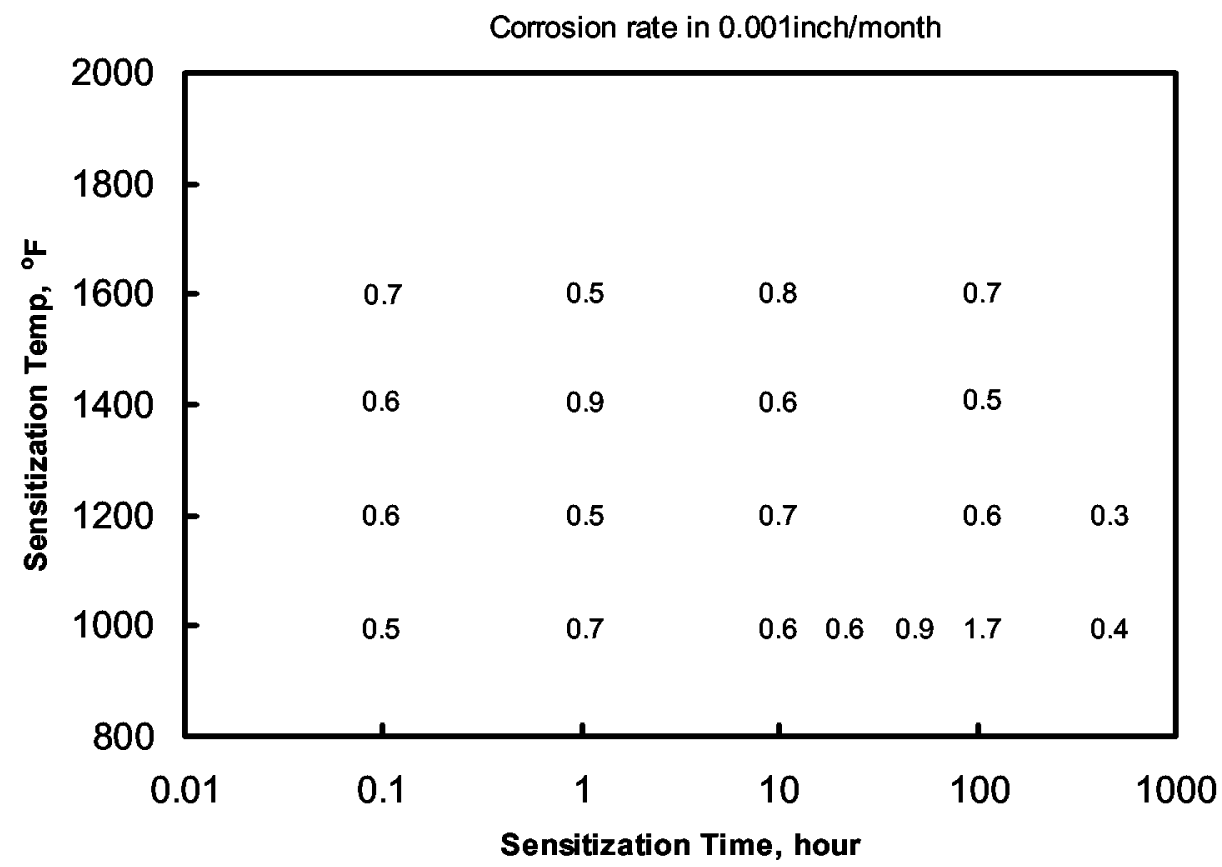

Figure 2-5 Time-Temperature-Sensitization diagram by Modified Huey Test, Alloy 690 Heat NX4459HG (0.06\%C), after Ref. 16.

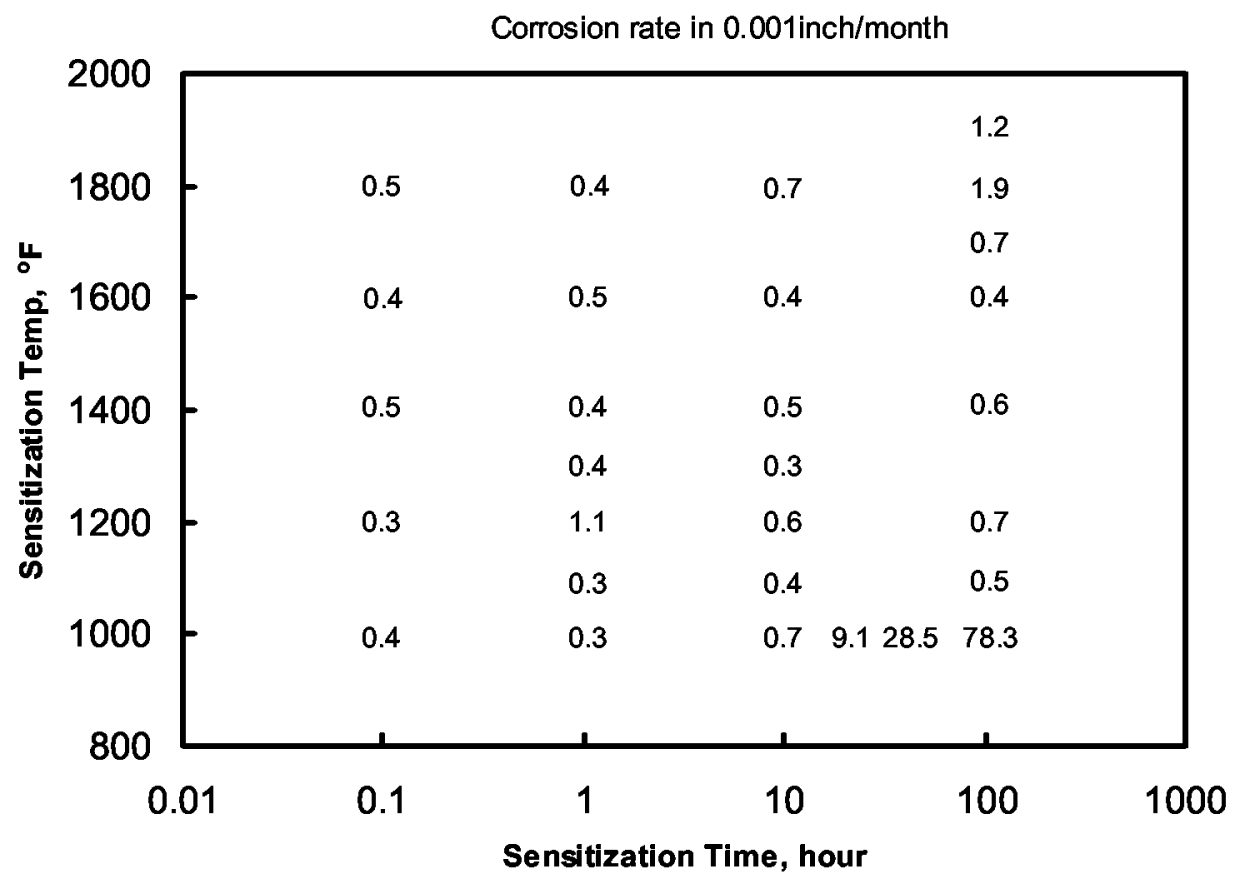

Figure 2-6 Time-Temperature-Sensitization diagram by Modified Huey Test, Alloy 690 Heat NX9217H (0.01\%C), after Ref. 16. 


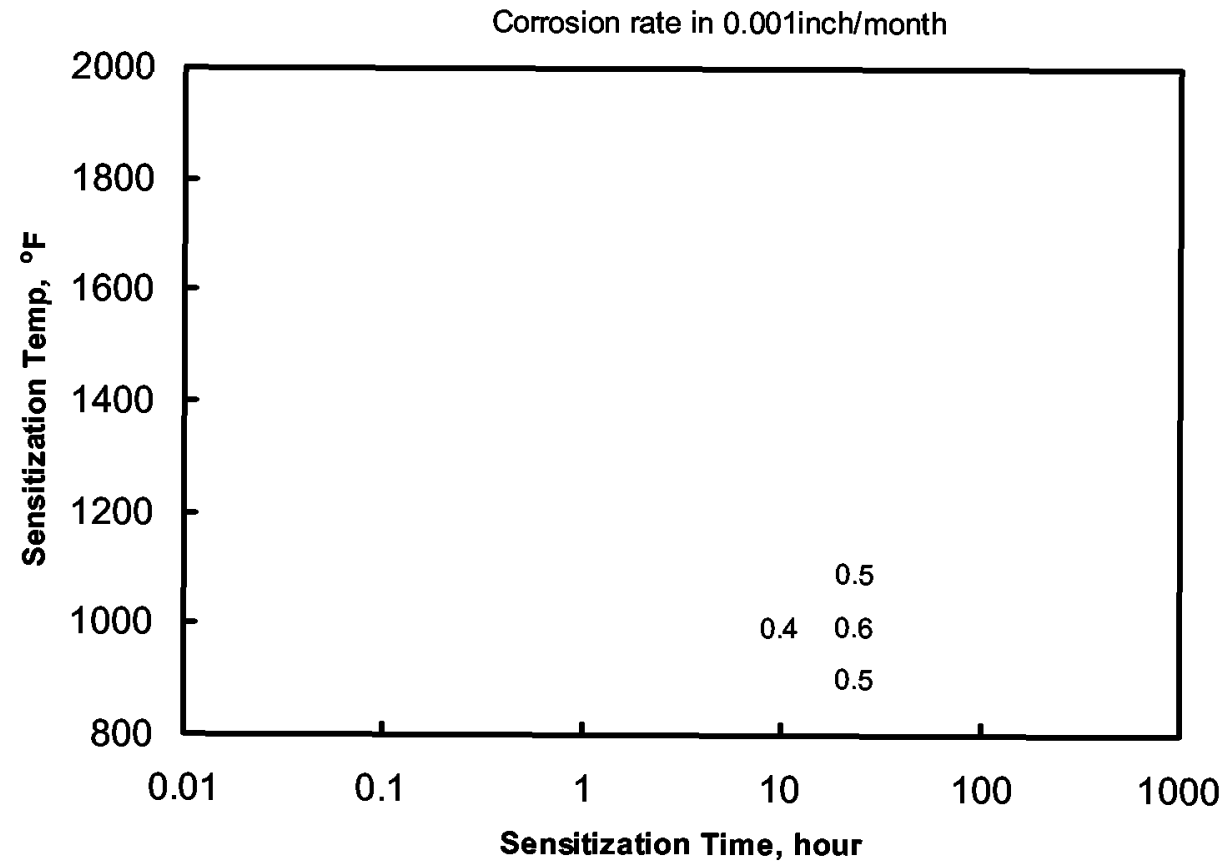

Figure 2-7 Time-Temperature-Sensitization diagram by Modified Huey Test, Alloy 690 Heat $\mathrm{NX9780H}(0.01 \% \mathrm{C})$, after Ref. 16. 


\section{CORROSION IN PRIMARY WATER}

\subsection{General Corrosion Tests in Primary Water}

This section summarizes the results of a comprehensive review of the available laboratory test data pertinent to general corrosion of Alloy 690 in PWR primary water. General corrosion can be defined as uniform deterioration of a metal surface by chemical or electrochemical reaction with the environment. Nickel-base Alloy 600 and Alloy 690 are essentially immune to general corrosion in a PWR environment due to the formation of an adherent Cr-rich oxide on the surface. The general corrosion rate of Alloy 690 in flowing primary water is of particular interest for PWR steam generator tubing materials. Material lost to the stream can become radioactive by coming in contact with the reactor core and then redeposit on the surfaces of the primary loop. Hence, the metal release rate has a strong implication for a plant's "ALARA" practice - to keep the total neutron dose to a level as low as reasonably achievable.

\subsubsection{SG Tubing by Sedricks et al. 1979}

Sedriks et al. evaluated Alloy 690 general corrosion in two simulated PWR primary water environments using a high velocity test loop. ${ }^{[9]}$ Borated water was added to simulate the primary side of the steam generator tubing and ammoniated water was used to adjust the $\mathrm{pH}$ value to simulate a secondary water environment. The loop test conditions and simulated PWR water chemistry are listed in Table 3-1. The Alloy 690 test specimens were fabricated from heat Y24A7L, with a composition listed in Table 3-2. The heat number and composition of the control specimens were not reported. The Alloy 690 test specimens and Alloy 600 and Alloy 800 control specimens were heat treated for $1 / 2$ hour at $980^{\circ} \mathrm{C}\left(1800^{\circ} \mathrm{F}\right)$ followed by air cooling. The surfaces were prepared by grinding on a wet 120 grit silicon carbide belt to a $0.75 \mu \mathrm{m}$ finish. The specimens were weighed and then exposed to the borated water for 2,250 hours and to the ammoniated water for 1,000 hours at $18 \mathrm{ft} / \mathrm{sec}(5.5 \mathrm{~m} / \mathrm{sec})$. After exposure, the specimens from the ammoniated water tests were descaled by cathodic charging in $5 \% \mathrm{H}_{2} \mathrm{SO}_{4}$ inhibited with quinoline ethiodide. The specimens from the borated water tests were descaled by the alkaline permanganate acid method. The terminology and reporting method followed NACE standard TM-02-74, covering the following terms:

1. "Descaled metal loss" (metal consumed): the difference between initial weight and weight after removal of adherent corrosion film.

2. "Corrosion film weight" (adherent corrosion film): the difference between the weight before descaling and the weight after descaling.

The difference between the descaled metal loss and the corrosion film weight represents the base metal lost to the stream. Alloys showing the least loss of material to the stream would be expected to produce the lowest activity levels in the PWR primary coolant system. The metal 
loss to the stream from the test is shown Figure 3-1. For the three alloys tested, Alloy 600, Alloy 690 , and Alloy 800, Figure 3-1 shows that the general corrosion rate decreases with an increasing $\mathrm{Cr}$ content. Alloy 690 , having the highest $\mathrm{Cr}$ content of the three, lost the least amount of material to the high velocity simulated PWR water. The observed corrosion films formed on Alloy 690 after the borated and ammoniated exposures were of the thin tarnish type and appeared to be extremely adherent to the base metal. The study reported a standard experimental error of about $25 \%$ and suggested Figure 3-1 should be used as an guide rather than precise corrosion rate measurements in a high temperature PWR water environment.

\subsubsection{SG Tubing by K. Smith et al. 1985}

K. Smith et al. investigated the corrosion rate and metal release rate of Alloy 690 and Alloy 600 SG tubing in flowing simulated PWR primary water. ${ }^{[1]}$ The Alloy 690 specimens were fabricated from the full length SG tubes (also called "pre-series" tubes) that were produced by an established industrial route. The three pre-industrial production Alloy 690 heats were intentionally chosen to span the limits of the specification requirements for $\mathrm{C}$ and $\mathrm{Cr}$ content. The chemical composition and mechanical properties of these three heats are listed in Table 3-3. The Alloy 690 specimens for the general corrosion tests were in the mill annealed condition (MA) as no difference between the MA and the thermally treated (TT) condition was expected. However, it was not reported which heats were used for fabricating the Alloy 690MA corrosion specimens. The chemical composition also was not provided for the Alloy 600 control materials. In addition, the detailed test conditions such as water flow rate and test temperature were not listed.

Weight changes before and after chemical de-filming were used to calculate the amount of total corrosion from the SG tube I.D. and the amount released to the stream. The corrosion rate and metal release rate curves shown in Figure 3-2 were constructed by fitting a regression equation to the data. The test results show that Alloy 690's general corrosion rate and metal release rate was reduced by a factor of 2 to 4 compared to Alloy 600 material.

\subsubsection{SG Tubing by Yonezawa et al. 1985}

Yonezawa et al. investigated the weight loss of Alloy 690, Alloy 600, and Alloy 800L SG tubing in simulated PWR primary water chemistry. ${ }^{[17]}$ The test coupons were made from split SG tubes. The test was conducted at $360^{\circ} \mathrm{C}\left(680^{\circ} \mathrm{F}\right)$ for up to 4,000 hours. The composition and heat treatment of the test material are listed in Table 3-4. The test condition and water chemistry are listed in Table 3-5. Results of the tests are shown in Table 3-6. Even though the data was scattered and the test duration was limited, the results showed that the general corrosion behavior of Alloy 690 and Alloy 600 in primary water is about the same.

\subsubsection{Esposito et al. 1991}

Esposito et al. investigated corrosion rate and metal release rate of Alloy 690 and Alloy 600 in a simulated PWR primary water environment with and without $\mathrm{Zn}$ addition ( $\mathrm{Zn}$ was used in other tests to assess effectiveness of $\mathrm{Zn}$ in mitigating PWSCC initiation) at $330^{\circ} \mathrm{C}\left(626^{\circ} \mathrm{F}\right) .^{[31]}$ The test conditions and autoclave water chemistry are summarized in Table 3-7. Test coupons were fabricated from Type 304, Type 316, Alloy 600MA, Alloy 600TT, Alloy 690TT, Alloy 750, and Stellite. The heat information and chemical composition were not reported. The test coupons 
were suspended in the autoclave and exposed for times up to 2,500 hours with or without adding zinc borate. Unlike in the general corrosion rate studies for SG tubing, the test coupons in this study were not subjected to any significant rate of coolant flow. At the conclusion of the test, some samples were descaled to a constant weight by cathodically stripping the oxide film.

The metal corrosion and corrosion release are calculated from the coupon weight change measurements.

Total metal corroded $=\mathrm{W}_{0}-\mathrm{W}_{\mathrm{d}}$

Oxide film weight $=\mathrm{W}_{\mathrm{a}}-\mathrm{W}_{\mathrm{d}}$

Metal release $=\left(\mathrm{W}_{0}-\mathrm{W}_{\mathrm{d}}\right)-70 \% *\left(\mathrm{~W}_{\mathrm{a}}-\mathrm{W}_{\mathrm{d}}\right)$

Where: $\mathrm{W}_{0}=$ original sample weight

$\mathrm{W}_{\mathrm{a}}=$ weight after coupon exposure

$\mathrm{W}_{\mathrm{d}}=$ weight after descaling

$70 \%$ is the assumption that metals in the oxide corrosion film represent $70 \%$ of the total film weight.

The above values are then divided by the specimen area to obtain the corrosion release per unit area. The average corrosion rate and corrosion release rate after 2,500 hours of exposure with and without zinc addition are listed in Table 3-8. The detailed general corrosion data from each specimen examined are listed Table 3-9. The test results clearly show that the Alloy 690TT has the lowest general corrosion rate among all the materials tested in PWR primary water both with and without zinc addition. The results also confirm that the general corrosion rate of $\mathrm{Fe}-\mathrm{Cr}-\mathrm{Ni}$ alloys in primary water environment decreases with increasing $\mathrm{Cr}$ content. In addition, the test results also indicate that zinc addition could significantly reduce the general corrosion rate of most commonly used materials in the PWR primary coolant system.

\subsection{Stress Corrosion Cracking Tests in Primary Water Relevant Conditions}

This section summarizes the results of a comprehensive review of the available laboratory test data pertinent to SCC in primary water relevant conditions for Alloy 690/152/52 materials. Most testing has been performed with Alloy 690 wrought materials with very few tests having been identified for Alloy 52 or Alloy 152 weld materials. Numerous investigations have been performed under a variety of PWR-relevant environmental conditions:

1. High temperature de-oxygenated (deaerated) water

2. Additions of boron, lithium, and hydrogen

3. Hydrogenated steam

4. Steam doped with chloride, fluoride, and sulfate anions

5. Additions of zinc 
The various test conditions cited in this report include temperatures to $680^{\circ} \mathrm{F}\left(360^{\circ} \mathrm{C}\right)$ water, dissolved oxygen levels $<20 \mathrm{ppb}$, tests in doped and undoped $752^{\circ} \mathrm{F}\left(400^{\circ} \mathrm{C}\right)$ steam, lithium concentrations up to $3.5 \mathrm{ppm}$, boron concentrations up to $1800 \mathrm{ppm}$, hydrogen concentrations up to $100 \mathrm{cc} / \mathrm{kg} \mathrm{H}_{2} \mathrm{O}$, and with the additions of chlorides and zinc. Even though the wording "simulated primary water conditions" was often used by the authors, it is clear, from the test conditions listed, that some test conditions employed were outside the normal range of primary water chemistry.

Accelerated testing has been performed on double U-bend (simulating crevice conditions), reverse U-bend (RUB), constant load tests (CLTs), four-point bend, and steam generator tubing mock-up specimens. The literature review is divided into four groups:

1. Deaerated water

2. Deaerated water with additions of boron and lithium

3. Steam with the addition of hydrogen

4. Steam with the addition of hydrogen and other impurities ("doped steam")

Section 4 provides an evaluation of these test data and a quantitative or semi-quantitative assessment of Alloy 690/152/52 material's PWSCC resistance improvement relative to Alloy $600 / 82 / 182$ material.

\subsubsection{Deaerated Water Testing}

\subsubsection{Double U-Bend Tests by Sedricks et al. 1979}

Sedriks et al. reported the results of double U-bend autoclave testing of Alloy 690 for resistance to stress corrosion cracking in a deaerated water environment at temperatures between $600{ }^{\circ} \mathrm{F}$ $\left(316^{\circ} \mathrm{C}\right)$ and $680^{\circ} \mathrm{F}\left(360^{\circ} \mathrm{C}\right)$ using Alloy 600 as the control material. ${ }^{[9]}$ The test conditions and water chemistry are listed in Table 3-10. The Alloy 690 heats used are listed in Table 3-2. The Alloy 600 control specimen heat number and composition were not reported. Alloy 690 and Alloy 600 specimens with both MA and TT heat treatments were tested. Details of the Alloy 600 and Alloy 690 product form, the double U-bend specimen size, design, and the loading stress were not reported.

None of the Alloy 690 specimens cracked under any of the test conditions listed in Table 3-10. Table 3-11 and Table 3-12 show that a wide variety of heat treatments, cold work, welding, and the presence of crevices were further evaluated at $600^{\circ} \mathrm{F}\left(316^{\circ} \mathrm{C}\right)$ under the test conditions of Test 1a and Test 3. None of the Alloy 690 specimens (creviced double U-bend) cracked while some Alloy 600 control specimens cracked under identical test conditions. Table 3-13 shows that increasing the test temperature to $650^{\circ} \mathrm{F}\left(360^{\circ} \mathrm{C}\right)$ and exposure time to 60 weeks $(\sim 10,000$ hours) (Test $1 b$ ) did not produce cracking in any Alloy 690 U-bend specimens. 


\subsubsection{C-Ring Test by A. Smith et al. 1989-1991}

A. Smith et al. reported stress corrosion tests on commercially produced Alloy 690 SG tubes. ${ }^{[32,}$

${ }^{33]}$ C-ring stress corrosion test specimens were fabricated per $\Lambda$ STM G $38^{[34]}$ from Alloy 690 tubes " $\mathrm{A}$ " and "E", which were annealed at $1040^{\circ} \mathrm{C}\left(1904^{\circ} \mathrm{F}\right)$ and thermally treated at $715^{\circ} \mathrm{C}$ $\left(1319^{\circ} \mathrm{F}\right)$ for 12 hours. The chemical composition of tubes " $\mathrm{A}$ " and " $\mathrm{E}$ " and their mechanical properties are summarized in Table 3-15. The C-ring specimens were tested in a variety of environmental conditions at $340^{\circ} \mathrm{C}\left(644^{\circ} \mathrm{F}\right)$, including pure deaerated water. In the pure water tests, the autoclave was pressurized to $10 \mathrm{bar}(1 \mathrm{MPa}$ or $145 \mathrm{psi})$ with hydrogen and then depressurized to 2 bar. No intergranular attack or stress corrosion cracking was noted after 1,500 hours of exposure. However, intergranular attack (IGA) was found in the C-ring specimens tested in caustic environments. Details of caustic IGA in Alloy $690 \mathrm{C}$-ring specimens by A. Smith et al. are provided in Section C.2.

\subsubsection{RUB by Norring et al. 1987-1991}

Norring et al. reported stress corrosion tests on reverse U-bend (RUB) specimens fabricated from Alloy 690 and Alloy 600 steam generator tubing in hydrogenated high temperature water. ${ }^{[35,36 \text {, }}$

37] The testing materials given by Ref. 35 and 36 are the following:

1. Alloy 690TT (thermally treated). Six tubes from two heats. The annealing heat treatment was 1 minute at either a low temperature of $900^{\circ} \mathrm{C}\left(1650^{\circ} \mathrm{F}\right)$ or a high temperature of $1090^{\circ} \mathrm{C}\left(1994^{\circ} \mathrm{F}\right)$. The thermal heat treatment was 12 hours at $715^{\circ} \mathrm{C}$ $\left(1320^{\circ} \mathrm{F}\right)$. The measured Vickers microhardness value was between 143 and $226 \mathrm{HV}$.

2. Alloy $690 \mathrm{MA}$ (mill annealed). Five tubes from the same heats as Alloy 690TT. One of the tubes was annealed at a low temperature of $900^{\circ} \mathrm{C}\left(1650^{\circ} \mathrm{F}\right)$. The measured Vickers microhardness values were between 160 and $220 \mathrm{HV}$.

3. Alloy $600 \mathrm{TT}$. One tube. The annealing heat treatment was at $990^{\circ} \mathrm{F}\left(1814^{\circ} \mathrm{F}\right) / 1$ minute and it was given a thermal heat treatment of $1320^{\circ} \mathrm{F} / 12$ hours.

4. Alloy 600MA SG tubes removed from Ringhals 2,3 , and 4 . Three tubes from each unit.

5. Alloy 600 tubes from heats NX1991 and NX2650, which were known to be susceptible to intergranular stress corrosion cracking.

6. Special production tubes of Alloy 600 from EPRI, which were produced from materials from three different vendors and annealed at $927^{\circ} \mathrm{C}\left(1700^{\circ} \mathrm{F}\right)$ or $1024^{\circ} \mathrm{C}$ $\left(1875^{\circ} \mathrm{F}\right)$.

\section{Carbide Precipitation}

Table 3-16 lists the heat chemical composition of selective elements for a few of the Alloy 690 and Alloy 600 materials used for fabricating RUB specimens. For these heats of materials, the grain boundary precipitation and chemistry were investigated by using analytic transmission 
electron microscopy (ATEM) and atom probe field ion microscopy (APFIM). Their findings are summarized below.

The precipitates observed by ATEM in Alloy 690TT and Alloy 690MA were exclusively the globular $\mathrm{M}_{23} \mathrm{C}_{6}$ type. The intergranular $\mathrm{M}_{23} \mathrm{C}_{6}$ precipitates showed a cube-face coincidence with one of the abutting grains. The intragranular $\mathrm{M}_{23} \mathrm{C}_{6}$ precipitates were often large and incoherent with the surrounding matrix. The intergranular carbide density was much higher in the Alloy 690TT than Alloy 690MA. $\mathrm{M}_{7} \mathrm{C}_{3}$ type intergranular and intragranular precipitates were always observed by ATEM in all Alloy 600 materials. The $\mathrm{M}_{7} \mathrm{C}_{3}$ type precipitates were usually globular, but elongated intergranular $\mathrm{M}_{7} \mathrm{C}_{3}$ precipitates were also found in the $A$ lloy 600 . Some intergranular $\mathrm{M}_{23} \mathrm{C}_{6}$ precipitates were also sometimes observed in Alloy 600. Energy dispersive $\mathrm{X}$-ray analysis (EDX) indicates that grain boundary $\mathrm{Cr}$ level was lowered by $3 \%$ in the Alloy 690MA and 6\% in the Alloy 690TT.

The atom probe technique identified four different types of grain boundary precipitates, $\mathrm{M}_{7} \mathrm{C}_{3}$, $\mathrm{M}_{23} \mathrm{C}_{6}, \mathrm{M}(\mathrm{CN})$, and $\mathrm{MB}$. The types of intergranular carbides identified by APFIM and their density are listed in Table 3-17. ${ }^{[3]}$ The $\mathrm{M}_{23} \mathrm{C}_{6}$ precipitates in Alloy 690 were much richer in $\mathrm{Cr}$ than the same precipitates in Alloy 600. Grain boundary Cr depletion was found to be less in Alloy 600 than in Alloy 690. Cr depletion in Alloy 600 was found only at grain boundaries decorated with $\mathrm{M}_{23} \mathrm{C}_{6}$ type precipitates. For example, the grain boundary $\mathrm{Cr}$ was lowered by $\sim 2 \%$ from the bulk concentration of $15.8 \%$ in the $\mathrm{BH}$ material. No $\mathrm{Cr}$ depletion was found at grain boundaries decorated only with $\mathrm{M}_{7} \mathrm{C}_{3}$ type precipitates in Alloy 600 .

\section{Alloy 690 RUB Test Results}

The testing was performed using RUB specimens regardless of the original tube diameter which ranged from 1/2" to 7/8". The distance between the legs of the specimens was kept constant at $25.4 \mathrm{~mm}(1 ")$. The testing was performed at $365^{\circ} \mathrm{C}\left(689^{\circ} \mathrm{F}\right)$ in two once-through autoclaves, whose environment conditions are listed in Table $3-18$. Slightly different autoclave hydrogen levels were reported in the references cited.

A total of 67 Alloy 690 RUB specimens from 11 tubes (including both TT and MA) were tested at $365^{\circ} \mathrm{C}\left(689^{\circ} \mathrm{F}\right)$. The breakdown of the Alloy 690 RUB specimens and test duration are listed in Table 3-19. Most of the Alloy 690 RUB specimens were tested up to 25,000 hours. However, Ref. 37 indicates the test was finally terminated after an accumulated 33,000 hours with none of them cracked. After 20,000 hours of exposure, some Alloy 690 RUB specimens were removed to verify that they did not contain microcracks. The examination showed that no such cracks existed. Based on a crack initiation activation energy of $50 \mathrm{kcal} / \mathrm{mole}$, the 33,000 hours at $365^{\circ} \mathrm{C}$ $\left(689^{\circ} \mathrm{F}\right)$ is equivalent to 20 times the 33,000 hours or 75 years at $320^{\circ} \mathrm{C}\left(608^{\circ} \mathrm{F}\right)$ using an Arrhenius temperature-activation relationship.

\section{$\underline{\text { Alloy } 600 \text { RUB Test Results }}$}

$A$ total of 106 Alloy 600 RUB specimens from 106 tubes were tested at $365^{\circ} \mathrm{C}\left(689^{\circ} \mathrm{F}\right)$. The breakdown of the Alloy 600 RUB specimens, test duration, and results is listed Table 3-20. Each of the mill annealed (MA) and some of the thermally treated (TT) Alloy 600 RUB specimens 
developed cracks with a Weibull characteristic time to cracking (63.2\% probability of cracking) ranging from 800 to 13,000 hours.

\subsubsection{CERT Tests of Alloy 690 and Alloy 600 by Angeliu et al. 1991}

Angeliu et al. reported CERT (constant extension rate test, also known as slow strain rate test or SSRT) results of high purity laboratory heats of Alloy 600 and Alloy 690 in argon and high purity deaerated water at $360^{\circ} \mathrm{C}\left(680^{\circ} \mathrm{F}\right) .^{[38,39]}$ The tensile specimens were fabricated from a cast ingot swaged to a 3.05 ( 0.12 ") $\mathrm{mm}$ rod stock. Cold work was introduced into all of the specimens using a two-step compression process. The gage section ( $2.2 \mathrm{~mm}$ dia. and $14.3 \mathrm{~mm}$ gage length) was compressed in the thickness direction by a two-step compression to produce a $30 \%$ reduction in thickness. The first compression step flattened the $2.2 \mathrm{~mm}$ dia. cylindrical gage section to a rectangular cross section of $1.7 \mathrm{~mm}$ thick. The specimens were then annealed to dissolve all carbon into solution and heat treated to produce approximately $100 \mu \mathrm{m}$ size grains (ASTM grain size 3.5). After annealing, a second compression step reduced the thickness from $1.7 \mathrm{~mm}$ to $1.2 \mathrm{~mm}$, or about a $30 \%$ thickness reduction. After final cold work, each specimen was ground and polished through $1 \mathrm{~mm}$ diamond paste. This type of deformation is known to enhance intergranular stress corrosion cracking (IGSCC) susceptibility in high temperature water.

The autoclave water chemistry and CERT testing conditions are provided in Table 3-22. After testing, the specimens were examined with a scanning electron microscope (SEM). The percentage of the fracture surface showing intergranular cracking was determined from SEM photographs at 60 to $80 \mathrm{X}$ magnifications. The nominal chemical composition, the annealing time and temperature, and the CERT test results in the argon atmosphere and in high temperature deaerated water are listed in Table 3-23 and Table 3-24, respectively.

The CERT results showed that the high temperature deaerated water enhanced the IG cracking susceptibility in the Alloy 600 (as opposed to behavior in argon) while having no effect on the Alloy 690 . The propensity to IG fracture was reduced with $\mathrm{Cr}$ content increasing from $5 \%$, to $16 \%$, and to $30 \%$ and carbon content increasing from $0.001 \%$ to $0.03 \%$ when tested in high temperature water. The improvement was attributed to an increase in creep resistance from increasing $\mathrm{Cr}$ content and a small amount of carbon in solution. The improvement from a carbon addition in Alloy 690 was less noticeable due to the improvement from Cr. The results show that Alloy 690 and Alloy 600 containing $0.03 \%$ carbon are both highly resistant to IG cracking $(0 \%$ IG) in the CERT test either in argon or deaerated water at $360^{\circ} \mathrm{C}\left(680^{\circ} \mathrm{F}\right)$. However, a slight amount of IG cracking (2\%) was detected in the Alloy 690 specimens containing very low carbon $(0.002 \%)$ tested both in argon and deaerated water at $360^{\circ} \mathrm{C}\left(680^{\circ} \mathrm{F}\right)$. Since the same small amount of (2\%) IG cracking was found in both argon and deaerated water environments, the intergranular cracking in Alloy 690 in this study should not be considered as an indication of Alloy 690 potential susceptibility to PWSCC. Angeliu et al. claimed this was the first reported instance of intergranular cracking of Alloy 690 material (albeit an ultra low carbon high purity laboratory grade) produced in deaerated environments. However, it is noted that Nakayama et al. reported intergranular cracking of Alloy 690 single U-bend specimens tested in hydrogen saturated water containing lithium and boric acid (see Section 3.3). 
In addition to CERT tests, Angeliu et al. also investigated surface oxide formation in the test coupons (the same as used for the CERT tests) after $\sim 100$ hour exposure to deaerated high temperature water. The test coupons, measuring $10 \mathrm{~mm} \times 6 \mathrm{~mm}$ by $0.5 \mathrm{~mm}$, were obtained by rolling the $3.05 \mathrm{~mm}$ rod stock to $0.5 \mathrm{~mm}$ thickness. The coupons were then solution annealed as was used for the CERT specimens. Unlike the CERT specimens, these coupons were not cold worked after the solution anneal. The coupons were ground with $\mathrm{SiC}$ paper and one side was polished to a mirror smooth finish. After exposure, the surface was cleaned and examined by Xray photoelectron spectroscopy (XPS) and scanning transmission electron microscopy (STEM). The surface oxide film was found to be a mixture of $\mathrm{Cr}_{2} \mathrm{O}_{3}$ and $\mathrm{Ni}(\mathrm{OH})_{2}$ phases. The oxide film thickness and predominant phase in the oxide film are summarized in Table 3-25. The ultra low carbon Alloy 600 (0.002\% carbon) was found to have a very thin $\mathrm{Cr}_{2} \mathrm{O}_{3}$ rich surface film. Increasing the carbon content from $0.002 \%$ to $0.03 \%$ caused the Alloy 600 film thickness to grow from $38 \mathrm{~nm}$ to $281 \mathrm{~nm}$, consisting mostly the $\mathrm{Ni}(\mathrm{OH})_{2}$ phase. The surface oxide film thickness in Alloy 690 contained predominantly fine grained $\mathrm{Cr}_{2} \mathrm{O}_{3}$. Increasing the carbon content from $0.002 \%$ to $0.03 \%$ caused the Alloy 690 film thickness to increase only slightly, from $46 \mathrm{~nm}$ to $58 \mathrm{~nm}$. It has been found that as the Cr content increases in high-nickel alloys, the repassivation rate (formation of $\mathrm{Cr}_{2} \mathrm{O}_{3}$ ) and IGSCC resistance are all increased. On the other hand, a thicker but less dense $\mathrm{Ni}(\mathrm{OH})_{2}$ film is more likely to contain defects, hence more likely to rupture and expose the metal underneath to environmental attack. In some instances, the hexagonal $\mathrm{Ni}(\mathrm{OH})_{2}$ plates were found to have grown into the grain boundary, offering the potential for intergranular crack nucleation.

\subsubsection{Deaerated Water With Li/B Testing}

\subsubsection{RUB Tests by K. Smith et al. 1985}

K. Smith et al. reported stress corrosion tests on reverse U-bend (RUB) specimens fabricated from Alloy 690 and Alloy 600 SG tubing in a simulated PWR primary water environment. ${ }^{[1]}$ The Alloy 690 RUB specimens were fabricated from full length SG tubes of three pre-industrial production heats. The full length SG tubes (also called "pre-series" tubes) were produced by an established industrial route. The three pre-industrial production Alloy 690 heats were intentionally chosen to span the limits of the specification requirements for $\mathrm{C}$ and $\mathrm{Cr}$ content. The chemical composition and mechanical properties of these three heats are listed in Table 3-3. The SG tube diameter was not listed. The chemical composition also was not provided for the Alloy 600 control heats.

The Alloy 690 and Alloy 600 were both tested in the MA and TT conditions for up to 16,000 hours at $360^{\circ} \mathrm{C}\left(680^{\circ} \mathrm{F}\right)$. Two kinds of autoclave water chemistry were used to simulate the beginning and end of fuel cycle PWR primary water chemistry. The autoclave water chemistry is listed in Table 3-14. The number of RUB specimens for each alloy condition was 10 . The test results are shown Figure 3-3. None of the Alloy 690 (TT or MA) RUB specimens developed cracks after 13,000 hours exposure under the beginning of fuel cycle condition and 16,000 hours under the end of fuel cycle condition. Alloy 600 RUB specimens of both TT and MA developed cracks under both the beginning and end of fuel cycle conditions. As expected, the Alloy 600 in 
the TT condition was evidently much more resistant to cracking than Alloy 600 in the MA condition.

\subsubsection{RUB and Constant Load Test by Yonezawa et al. 1985}

Yonezawa et al. conducted stress corrosion tests on reverse U-bend specimens fabricated from Alloy 690 and Alloy 600 SG tubing in both the TT and MA heat treatment conditions and shotpeened Alloy $800 \mathrm{~L}$ in simulated PWR primary water environment. ${ }^{[17]}$ The test was conducted at $360^{\circ} \mathrm{C}\left(680^{\circ} \mathrm{F}\right)$ for up to 12,000 hours. The composition and heat treatment of the test materials are listed in Table 3-4. The test condition and water chemistry are listed in Table 3-5. The diameter of the SG tubes used to fabricate the RUB specimens was not reported. RUB specimen testing stress levels, measured by X-ray diffraction analysis, were between 70 and $130 \mathrm{ksi}$. Figure 3-4 shows the measured stress vs. the crack detection time. Intergranular cracking was observed in the $20 \%$ pre-strained Alloy 600MA specimens after 300 hours of exposure and in the Alloy 600TT specimens after 800 hours of exposure. However, no cracking was observed in Alloy 690 and shot-peened Alloy 800 specimens after 12,000 hours of exposure time. It is noteworthy that the X-ray diffraction measured stresses in the Alloy 690 RUB specimen were higher than that of the cracked Alloy 600TT and MA specimens. The minimum stress level vs. minimum time-to-cracking curves were drawn for Alloy 600TT and Alloy 600MA on Figure 3-4. As expected, Alloy 600TT had a higher resistance to stress corrosion cracking than Alloy $600 \mathrm{MA}$ in the primary water.

In addition, Yonezawa et al. reported constant load (CL) stress corrosion cracking (SCC) test results at the same testing temperature and in the same primary water environment as for the RUB specimens. No details of the CL specimen geometry were provided. The constant load test results are shown in Figure 3-5, which indicates the loading stress was between approximately 60 and $90 \mathrm{ksi}$. Alloy 600MA developed SCC after 1,100 hours of exposure. However, no failure was observed of the Alloy 690TT CL specimens after approximately 7,000 hours of exposure.

\subsubsection{U-Bend Test of Alloy 690 by Nakayama et al. 1987}

Nakayama et al. performed single U-bend tests of Alloy 600, Alloy 690, and Alloy 800 in hydrogen saturated water. ${ }^{[40]}$ Various heats of Alloy 600 , Alloy 690, and Alloy 800 SG tubing were melted in a vacuum induction furnace and the resulting ingots were reduced to plates of 4$\mathrm{mm}$ thickness by forging and hot rolling. The chemical compositions of the Alloy 600 and the Alloy 690 SG tubing used are listed in Table 3-26. Single U-bend specimens of the dimension 2 $\mathrm{mm} \times 14 \mathrm{~mm} \times 65 \mathrm{~mm}$ were machined from the 4-mm plates of Alloy 690 and 600 in both solution annealed (MA) and thermally treated (TT) conditions. In addition, the specimens were given aging treatment at $500^{\circ} \mathrm{C}\left(932^{\circ} \mathrm{F}\right)$ for 24 and 100 hours to simulate 24 and 100 years of exposure at $300^{\circ} \mathrm{C}\left(572^{\circ} \mathrm{F}\right)$ based on the Larson-Miller equation. Details of Alloy 600 and Alloy 690 heat treatment and aging treatment are listed in Table 3-27.

The single U-bend specimens were tested in hydrogen saturated water containing $1000 \mathrm{ppm}$ boron and $2 \mathrm{ppm}$ lithium at $330^{\circ} \mathrm{C}\left(626^{\circ} \mathrm{F}\right)$ for 3000 hours. The solution was renewed every 250 hours. The test results (measured maximum crack depths) are listed in Table 3-28. Slight intergranular cracking was detected in two out of the four Alloy 690 conditions tested. The maximum intergranular crack depth was $70 \mu \mathrm{m}$ in Alloy 690TT with a 24-hour aging treatment 
and $30 \mu \mathrm{m}$ in Alloy 690MA with a 100-hour aging treatment. Cracking was more severe in Alloy 600 specimens while no Alloy 800 specimens developed cracks. In addition, SEM microscopy (the authors reported that SEM microscopy was used) showed that the intergranular cracks in Alloy 690TT (70 $\mu \mathrm{m}$ max. depth) were at the tips of dislocation pile-ups.

\subsubsection{CERT Test of Psaila-Dombrowski et al. 1995-1997}

Psaila-Dombrowski et al. reported the results of CERT tests in simulated primary water at $343^{\circ} \mathrm{C}$ $\left(650^{\circ} \mathrm{F}\right){ }^{[41,42]}$ The CERT test specimens were machined from Alloy 690 plate and Alloys 82, 182 , and 152 welds. The studies investigated the corrosion performance of welds connecting a steam generator divider plate to the weld buildup in a welded-in divider plate (WIDP) design. This weld region was believed to be possibly susceptible to primary water stress corrosion cracking due to a lack of post-weld stress relieving.

A number of weld build-ups and a composite plate were manufactured. The weld samples were fabricated in a manner consistent with SG fabrication practices in which Alloy 52 is used to attach the Alloy 690 plate to the Alloy 82 buildup. The mock-up composite plate began as a $60 \mathrm{~mm}$ (2.36") thick A 508 carbon steel plate. One edge of the $A 508$ plate was overlaid with a $5 \mathrm{~mm}$ thickness of Alloy 82 and then stress relieved. The test block was completed by making a modified double V-groove weld between the $5.5 \mathrm{~mm}$ thick Alloy 690 plate and the Alloy 82 overlay using Alloy 152. The plate was not stress relieved following the welding. The overall length of the composite weld plate was $\sim 1,000 \mathrm{~mm}$. CERT specimens were machined from Alloy 82, Alloy 152 and the heat affected zones (HAZ) between Alloy 82 and Alloy 152, and Alloy 152 and Alloy 600 (see Figure 3-6). The size and geometry of the CERT specimens are shown in Figure 3-7. The specimens were machined parallel to the fusion line. This would allow all the materials in the specimens to be evaluated for SCC susceptibility. If the specimens had been machined perpendicular to the fusion line, only the weakest material would undergo plastic deformation and hence be evaluated for SCC susceptibility. However, information on the chemical composition of the Alloy 82 and 152 weld metals and Alloy 690 plate and heat treatment condition of Alloy 690 were not reported.

The CERT tests were performed in an inverted 7.5 liter Alloy C-276 autoclave. The autoclave environment was to simulate a typical PWR Water Chemistry according to EPRI's PWR Primary Water Chemistry Guidelines. In addition, CERT tests were also performed in a faulted primary water chemistry. The faulted water had $150 \mathrm{ppb}$ of chloride by adding $\mathrm{NaCl}$ to the feed tank. The CERT tests were performed at a constant strain rate of either $5 \times 10^{-8}$ or $10^{-6} \mathrm{sec}^{-1}$. The water chemistry and test parameters are listed in Table 3-29. During the tests, the autoclave pressure preloaded the specimens to approximately $155 \mathrm{MPa}(22.5 \mathrm{ksi})$. This was not believed to affect the test results as this stress level was below $50 \%$ of the room temperature yield stress. After the test, the specimen fracture surface was examined by SEM for evidence of SCC.

The CERT test results are summarized in Table 3-30. During the Phase 1 tests at a strain rate of $10^{-6}$ $\mathrm{sec}^{-1}$, no evidence of SCC was found in any of the CERT specimens including those tested in the faulted water chemistry containing $150 \mathrm{ppb}$ chloride. The fracture surfaces examined by SEM were dimpled indicating ductile failure. In addition, specimens containing two different materials did not have step failures indicating failures at different times. However, SCC cracking was detected only 
in Alloy 82 in the CERT specimen containing both Alloy 82 and 152 weld metals when tested at the lower strain rate of $5 \times 10^{-8} \mathrm{sec}^{-1}$ in normal primary water (see Figure 3-8). No SCC cracking was observed in the Alloy 152 (also see Figure 3-9) and Alloy 690 specimens.

\subsubsection{RUB Test and Constant Load Test by Ogawa et al. 1997}

Ogawa et al. reported the results of reverse U-bend (RUB) tests and constant load tests on Alloy 600MA \& TT and Alloy 690TT SG tubes. ${ }^{[43]}$ The Alloy 600 and Alloy 690 SG tube size, material composition and heat treatment information are summarized in Table 3-31. The number of specimens and test temperature are summarized in Table 3-32.

\section{$\underline{\text { RUB Test }}$}

The RUB test temperature was $320^{\circ} \mathrm{C}\left(608^{\circ} \mathrm{F}\right)$ for the Alloy $600 \mathrm{MA} \&$ TT materials, and $360^{\circ} \mathrm{C}$ $\left(680^{\circ} \mathrm{F}\right)$ for the Alloy $690 \mathrm{TT}$ material. However, the RUB specimens were tested in slightly different primary water chemistries. The test results are summarized in Table 3-33.

In Phase 1, the RUB specimens were tested in the so-called optimum $\mathrm{pH}$ water chemistry (pH 7.3 at $285^{\circ} \mathrm{C}$ or $545^{\circ} \mathrm{F}, 280 \mathrm{ppm} \mathrm{B}$, and $\left.2.0 \mathrm{ppm} \mathrm{Li}\right)$ and in the reference $\mathrm{pH}$ water chemistry $(\mathrm{pH} 7.1$ at $285^{\circ} \mathrm{C}$ or $545^{\circ} \mathrm{F}, 500 \mathrm{ppm} \mathrm{B}$, and $2.0 \mathrm{ppm} \mathrm{Li}$ ). The tests in Phase 1 lasted up to 10,000 hours and the occurrence of PWSCC cracking was checked after 3000, 4190, 5000, 7000, and 10,000 hours. PWSCC was observed for the Alloy 600MA material prestrained at $20 \%, 15 \%, 10 \%$, and $5 \%$ under both $\mathrm{pH}$ conditions. PWSCC was also observed for the Alloy $600 \mathrm{TT}$ material prestrained at $20 \%$, $15 \%$, and $10 \%$ under the reference $\mathrm{pH}$ and for the $20 \%$ and $15 \%$ prestrain under the optimum $\mathrm{pH}$ environment. No PWSCC was observed for the $20 \%$ prestrained Alloy 690TT specimens tested at a higher temperature than the Alloy 600MA \& TT specimens.

In Phase 2, the RUB specimens were tested in the candidate water chemistry $\left(\mathrm{pH} 6.86\right.$ at $285^{\circ} \mathrm{C}$ or $545^{\circ} \mathrm{F}, 1600 \mathrm{ppm} \mathrm{B}$, and $\left.3.5 \mathrm{ppm} \mathrm{Li}\right)$ and in the reference water chemistry (pH 6.61 at $285^{\circ} \mathrm{C}$ or $545^{\circ} \mathrm{F}, 1600 \mathrm{ppm} \mathrm{B}$, and $2.0 \mathrm{ppm} \mathrm{Li}$ ). The tests in Phase 2 lasted up to 10,015 hours and the occurrence of PWSCC cracking was checked after 1356, 3000, 5005, 7,000, 8536 and 10,015 hours. The results were similar to those obtained in Phase 1. Both the prestrained Alloy 600MA and 600TT specimens cracked although the Alloy 600TT material was more resistant to PWSCC than the Alloy 600MA material. Again, no PWSCC was observed for the 20\% prestrained Alloy 690TT specimens tested at a higher temperature than the Alloy 600MA \& TT specimens.

\section{Constant Load Test}

The constant load specimens (uniaxial tensile specimens) were cut from the SG tube wall. The specimens were all loaded to $85 \mathrm{ksi}$. The test temperatures were $320^{\circ} \mathrm{C}\left(608^{\circ} \mathrm{F}\right)$ and $340^{\circ} \mathrm{C}\left(644^{\circ} \mathrm{F}\right)$ for the Alloy $600 \mathrm{MA} \& \mathrm{TT}$ specimens, and $360^{\circ} \mathrm{C}\left(680^{\circ} \mathrm{F}\right)$ for the Alloy $690 \mathrm{TT}$ specimens. The constant load specimens were tested in primary water chemistries identical to the ones used for the RUB specimens. The test results are summarized in Table 3-33.

None of the Alloy 600 specimens (10 each for MA \& TT condition) exhibited PWSCC at $320^{\circ} \mathrm{C}$ $\left(608^{\circ} \mathrm{F}\right)$ regardless of the water condition used after 10,000 hours exposure. In contrast, all of the 
Alloy 600 specimens (10 each for MA \& TT condition) exhibited PWSCC when tested at $340^{\circ} \mathrm{C}$ $\left(644^{\circ} \mathrm{F}\right)$ under both water conditions at the end of 10,000 hours exposure. None of the Alloy 690 specimens developed PWSCC after 10,000 hours at $360^{\circ} \mathrm{C}\left(680^{\circ} \mathrm{F}\right)$. Based on the $50 \mathrm{kcal} / \mathrm{mole}$ activation energy commonly used for Alloy 600 PWSCC initiation, the crack initiation time at $340^{\circ} \mathrm{C}\left(644^{\circ} \mathrm{F}\right)$ is only $25 \%$ of that at $320^{\circ} \mathrm{C}\left(608^{\circ} \mathrm{F}\right)$. Similarly, the 10,000 hour exposure at $360^{\circ} \mathrm{C}$ $\left(680^{\circ} \mathrm{F}\right)$ for Alloy 690 specimens would be equivalent to 36,600 hour exposure at $340^{\circ} \mathrm{C}\left(644^{\circ} \mathrm{F}\right)$. These results confirmed that PWSCC is a thermally-activated mechanism and Alloy 690 has a much higher PWSCC resistance compared to Alloy 600 of either MA or TT condition.

\subsubsection{RUB Tests by Angell et al. 1999}

Angell et al. performed RUB stress corrosion tests on Alloy 600 and Alloy 690 SG tubes in primary water chemistry both with and without zinc additions. ${ }^{[44]}$ The Alloy 600 and Alloy 690 SG tube information are listed in Table 3-36. The tests were performed at $350^{\circ} \mathrm{C}\left(662^{\circ} \mathrm{F}\right)$ in two phases with each phase lasting 7500 hours. Phase 1 was to simulate beginning of cycle primary water for a 12month fuel cycle and Phase 2 was to simulate beginning of cycle primary water for an 18-month fuel cycle. Zinc was added in the form of zinc acetate to a level of $40 \mathrm{ppb}$ to assess the effectiveness of such addition on PWSCC initiation.

The test conditions and test results are summarized in Table 3-37. The descriptions on the RUB specimen I.D. were vague and could not be associated directly with the chemical composition of the Alloy 600 and Alloy 690 SG tubes listed. Hence, the specimen heat number in Table 3-37 includes some guesswork. None of the Alloy 690 RUB specimens cracked either with or without the zinc additions while some of the Alloy 600 specimens cracked both with and without the zinc addition. Zinc addition seems to slightly improve cracking resistance of the Alloy 600 specimens while having no apparent affect on the already resistant Alloy 690 specimens. Phase 2 included some uncracked specimens carried forward from Phase 1 . However, for the Alloy 600 specimens, it was not mentioned if the cracked ones included the ones from Phase 1. For the Alloy 690 specimens, the maximum exposure time without failure was 15,000 hours.

\subsubsection{Studies by CEA and EdF}

A large research study was undertaken by the CEA in collaboration with EdF starting in 1987 to determine using accelerated testing the long term resistance of Alloy 690TT to SCC in PWR primary water. This followed a decision taken in France, as elsewhere, at the beginning of the 1980 's to replace Alloy 600 in certain PWR component items with Alloy 690TT. The following summary of this French work on Alloy 690TT is taken from the following proprietary reports; a CEA review written in $2002^{[45]}$, an EdF state of the art review in December $1995^{[46]}$, and two additional complementary EdF reports written in $1997^{[47]}$ and $2002^{[48]}$. English language reviews of much of this French work also appeared in the open literature in $1999^{[49]}$ and $2003^{[50]}$. An EDF proprietary report ${ }^{[51]}$ on a study of nickel-base weld metals including Alloys 152 and 52 is also summarized here. 


\subsection{CEA Technical Report RT-SCCME 618 Rev. $A^{[45]}-2002$}

Sixteen heats of Alloy 690 conforming to the French RCC-M 4105 standard (1988) were tested of which three were pre-production heats for R \& D purposes. A list of the materials tested in this program is given in Table 3-38; the chemical compositions are given in Table 3-39. All except one were made by Imphy, the remaining one being supplied by Huntington. One of the pre-series heats, WE092, was on the limit of the then current RCC-M specification with $30.9 \% \mathrm{Cr}, 0.037 \% \mathrm{C}$ and a low iron content of $7.3 \% \mathrm{Fe}$. Another pre-production heat, WE094, had high carbon, $0.031 \% \mathrm{C}$, and low iron, $8.5 \% \mathrm{Fe}$, while the remainder contained about $29 \% \mathrm{Cr}$, $10 \% \mathrm{Fe}$ and carbon contents between 0.015 and $0.025 \% \mathrm{C}$.

All sixteen heats of Alloy 690 were formed into $19.05 \mathrm{~mm}$ diameter SG tubes of wall thickness $1.09 \mathrm{~mm}$ by Valinox Nucléaire. The mill anneal (MA) in cracked ammonia of the pre-production heats WE092 and WE094 was initially performed at $980^{\circ} \mathrm{C}\left(1796^{\circ} \mathrm{F}\right)$ for 2 minutes and were then thermally treated (TT) at 700 to $730^{\circ} \mathrm{C}\left(1292\right.$ to $\left.1346^{\circ} \mathrm{F}\right)$. However, the mechanical properties were in excess of the specification requirements and so these two pre-production heats were mill annealed again at 1040 and $1070^{\circ} \mathrm{C}\left(1904\right.$ and $\left.1958^{\circ} \mathrm{F}\right)$ followed by a thermal treatment at 700 to $730^{\circ} \mathrm{C}\left(1292\right.$ to $\left.1346^{\circ} \mathrm{F}\right)$. The other industrial heats were mill annealed between 1040 and $1070^{\circ} \mathrm{C}\left(1904\right.$ and $\left.1958^{\circ} \mathrm{F}\right)$ also for 2 minutes and thermally treated under vacuum at 700 to $730^{\circ} \mathrm{C}$ for 5 hours. Tube straightening was then performed to ensure linearity was within specification and followed by internal sand blasting with corundum and external surface polishing with an abrasive band.

The unusual thermal history of the two pre-production heats WE092 and WE094 with the higher carbon contents was probably responsible for the small grain sizes of ASTM 10 to 11 and 9 to 10 respectively. On the internal surface of the two pre-production heats, the grain size was even smaller at ASTM 12 to 13 . These figures should be compared with ASTM 7 to 9 for the bulk material of the other heats and ASTM 10 to 12 on the internal surface. The internal surface layer with smaller grain size on the tube internal surfaces could be up to $30 \mu \mathrm{m}$ thick.

The metallurgical characterization of the SG tubes revealed a high degree of grain boundary carbide coverage (i.e., apparently continuous at a magnification of $1000 \mathrm{X}$ ) with the exception of the two pre-production heats with high carbon, WE092 and WE094, where it was classified as having a low linear density (less than 1 carbide in $10 \mu \mathrm{m}$ or 0.0039 inch). The low grain boundary carbide density of the two heats was considered to result from the unusual thermal history with the initial mill anneal at $980^{\circ} \mathrm{C}\left(1796^{\circ} \mathrm{F}\right)$. The intragranular carbide density of these two heats was classified as medium (i.e., between $2 \times 10^{-4}$ and $10^{-2} \mu \mathrm{m}^{-2}$ ) whereas for the others, with four exceptions, it was classified as low $\left(<2 \times 10^{-4} \mu \mathrm{m}^{-2}\right)$. Of the four exceptions, three were judged as having medium density of intragranular carbides and one, WF786, as having a high density of intragranular carbides $\left(>10^{-2} \mu \mathrm{m}^{-2}\right)$.

The residual stress and level of cold work were measured by X-rays on the internal surfaces of tubes from two heats, WE092 and another representative industrial heat. The level of cold work on the internal surface of both was observed to be about $15 \%$. The internal surface stresses were compressive at $-300 \mathrm{MPa}(-43.5 \mathrm{ksi})$ for WE092 and $-180(-26.1 \mathrm{ksi})$ to $-280 \mathrm{MPa}(40.6 \mathrm{ksi})$ for the other (with an estimated uncertainty of $\pm 65 \mathrm{MPa}$ or $\pm 9.4 \mathrm{ksi}$ ). 
Bulk $0.2 \%$ offset yield strengths were measured at room temperature on tensile specimens taken from the tubes. All were in specification (275 to $470 \mathrm{MPa}$ in RCC-M 4105) being typically between 300 and $360 \mathrm{MPa}$ except the pre-production heat, WE092, at $499 \mathrm{MPa}$ before its repeated heat treatment. Heat WE094 was just in specification at about $50 \mathrm{MPa}$ lower than WE092. After the two pre-production heats were given their second mill anneal at 1040 to $1070^{\circ} \mathrm{C}\left(1904\right.$ to $\left.1958^{\circ} \mathrm{F}\right)$ followed by a second thermal treatment, the yield strength was 464 MPa for WE092 and about 50MPa lower for WE094.

During preparation of the RUB specimens for the SCC tests, surface defects appeared where the deformation was greatest in the surface cold worked layers with low ductility. The deformation of the apex of a RUB is typically between 30 to $40 \%$. Thus the inner tube surface layer that was previously in compression would be transformed into very high tension due to the prior cold work. All measured surface stresses at the apex of the RUB specimens were above $1000 \mathrm{MPa}$ (145 ksi) and up to $1230 \pm 30 \mathrm{MPa}(178.4 \pm 4.4 \mathrm{ksi})$, the precise value depending on the heat of material. The surface defects were orientated mainly, but not exclusively, in the axial direction of the original tube, and were 5 to $100 \mu \mathrm{m}$ long and up to $20 \mu \mathrm{m}$ deep. The largest surface defects were found on specimens made from the pre-production heats WE092 and WE094. Due to the small grain size and magnification of the optical micrographs it is difficult to assert that the defects were definitely intergranular. An experiment was conducted in which RUB specimens were made after a surface layer $40 \mu \mathrm{m}$ thick was removed by electropolishing. These specimens did not show any surface defects, thus proving that the modified fine grain surface layer was at the origin of the defects formed on RUB specimens from the as-manufactured tubes. The surface stresses on the RUB specimens formed from the electropolished tubes were only about 5 to $10 \%$ lower than those from the as-manufactured tubes.

SCC testing was carried out in PWR primary water at $360^{\circ} \mathrm{C}\left(680^{\circ} \mathrm{F}\right)$ and $20 \mathrm{MPa}$ pressure in a static autoclave with the hydrogen concentration in the liquid phase controlled to between 23 and $35 \mathrm{ml} / \mathrm{kg}$ using a Pd/Ag thimble. The SCC tests lasted 90,000 hours in total but regular examinations (at intervals between 2,000 and 7,500 hours) of the RUB specimens in an SEM did not show any IGSCC or any propagation of the pre-formed mechanical surface defects. The trapped hydrogen content of the Alloy 690 specimens was measured and was usually about $2 \pm 0.5 \mathrm{ppm}$. (Similar concentrations of hydrogen were measured in several RUB specimens of Alloy 600 that were tested at the same time and that typically cracked within 5,000 hours. Other related studies have typically measured 2 to $5 \mathrm{ppm}$ hydrogen, which may be compared with those from slow strain rate tests of up to $35 \mathrm{ppm}$.)

Measurements of the surface residual stress on RUB specimens from seven of the sixteen heats of Alloy 690 showed that it reduced rapidly at the beginning of the SCC tests and stabilized at about 30 to $70 \%$ of the original value depending on the heat of material concerned. The largest percentage relaxation occurred in the pre-production heats WE092 and WE094. Below the surface, the stresses remained high between 600 and $800 \mathrm{MPa}$, again the precise value depending on the heat of material.

The hardness of each Alloy 690 specimen was measured during the exposure tests at $360^{\circ} \mathrm{C}$ $\left(680^{\circ} \mathrm{F}\right)$ and specimens were examined by TEM for any evidence of short range ordering to form $\mathrm{Ni}_{2} \mathrm{Cr}$, particularly in heats at the bottom end of the iron specification of $7 \% \mathrm{Fe}$. Note that some literature data suggest that after 100,000 hours at $360^{\circ} \mathrm{C}$ some short range ordering may occur at 
$7 \% \mathrm{Fe}$. In the present study, although a statistically significant slight increase in hardness of up to $\sim 30 \mathrm{HV}$ did occur, there was no evidence of $\mathrm{Ni}_{2} \mathrm{Cr}$ formation found by TEM. However, those heats with the highest $\mathrm{Ni} / \mathrm{Cr}$ atomic ratio and lowest Fe contents, heats WE092 and WE094, showed the highest increase (of $\sim 30 \mathrm{HV}$ ) in hardness.

No attempt was made in this CEA report to assess the practical implications of any of the experimental observations with regard to the suitability or longevity of Alloy 690TT for PWR service.

\subsection{EDF Report HT-44/95/013/A, 1995}

In order to quantify the resistance of Alloys 690TT (and 800) to SCC in PWR primary water, various types of laboratory tests were conducted in hydrogenated pure water at 325 and $360^{\circ} \mathrm{C}(617$ and $680^{\circ} \mathrm{F}$ ) and in PWR primary water at $360^{\circ} \mathrm{C}$ on specimens of steam generator tubing plus a lesser number of specimens of Alloy 690TT typical of upper head CRDM nozzles (Table 3-40 and Table 3-41). Chemical compositions and mechanical properties of the various heats of Alloy 690TT are given in Table 3-42 and Table 3-43 respectively.

As in the case of the parallel tests performed by the CEA, three categories of Alloy 690TT SG tube were tested; 4 experimental tubes from 3 heats supplied by Huntington, 5 pre-production tubes from 3 heats of which 2 were supplied by Imphy (WE092 and WE094) and one by Huntington, and 9 industrial tubes from 9 heats of which 2 were from Huntington and the remainder from Imphy/Tecphy. Various combinations of mill anneal conditions between 980 and $1070^{\circ} \mathrm{C}(1040$ to $1070^{\circ} \mathrm{C}$ in the case of the industrial tubes), mill anneal atmospheres (cracked ammonia or hydrogen) and final thermal treatment $\left(700^{\circ} \mathrm{C}\right.$ or $1292^{\circ} \mathrm{F}$ for 16 or 5 hours) were present among the $18 \mathrm{SG}$ tubes available for the study. All tubes were straightened prior to the thermal treatment where required. Many of the early tubes were sand blasted on the internal surface, and all were polished with an abrasive band on the external surface. The practice of sand blasting the internal tube surface with the objective of removing a nitrided layer from the cracked ammonia was discontinued in 1989 and subsequently a hydrogen atmosphere was adopted for the mill anneal. The tube diameters were mainly $19.05 \mathrm{~mm}\left(0.750^{\prime \prime}\right)$ with a $1.1 \mathrm{~mm}(0.043$ ") thick wall but some for replacement bundles for 900 MWe stations were $22.2 \mathrm{~mm}$ diameter with a $1.27 \mathrm{~mm}(0.050$ ") wall thickness. One of the Alloy 690 tubes was discovered to be contaminated during tube drawing by a phosphorus containing lubricant resulting in localized formation of $\mathrm{a} \mathrm{Cr}_{3} \mathrm{P}$ eutectic up to $15 \mu \mathrm{m}(0.0006$ ") deep and occasionally $40 \mu \mathrm{m}(0.0016 ")$ deep.

The Alloy 690TT specimens from forged CRDM nozzles came from one experimental and one industrial heat both supplied by Tecphy. Both products were subjected to a laboratory heat treatment at $715^{\circ} \mathrm{C}\left(1319^{\circ} \mathrm{F}\right)$ for 5 hours.

Concerning the chemical compositions, as noted earlier for the CEA study, one of the Alloy 690 heats, WE092, was deliberately fabricated with the carbon and chromium at the high end of the specification and iron at the low end of the specification for a study of short range ordering during thermal aging. The iron content of the two CRDM nozzle heats was relatively high at $10.5 \% \mathrm{Fe}$. 
The mechanical properties of the Alloy 690TT SG tubes were within the RCC-M 4105 specification with the exception of one pre-production heat that was initially mill annealed at $980^{\circ} \mathrm{C}\left(1796^{\circ} \mathrm{F}\right)$ prior to thermal treatment, as noted in the earlier summary of the CEA work. However, both preproduction Imphy heats WE092 and WE094 formed into tubes by Vallourec had $0.2 \%$ offset yield strengths significantly exceeding the EPRI recommended maximum of $379 \mathrm{MPa}(55.0 \mathrm{ksi})$ even when mill annealed at 1040 or $1060^{\circ} \mathrm{C}\left(1904\right.$ or $\left.1940^{\circ} \mathrm{F}\right)$ prior to thermal treatment. Two of the industrial tubes had $0.2 \%$ offset yield strengths close to the minimum limit recommended by EPRI.

The grain size and carbide morphologies of all heats were characterized. The intergranular carbide decoration was generally classified as "medium". The microstructures of two French pre-production heats WE092 and WE094 have already been described above in the companion CEA study (CEA Report RT618). Additional details concerning tubes mill annealed in cracked ammonia show that nitrided layers up to $20 \mu \mathrm{m}(0.0008$ ") thick were formed. The removal of these layers on the internal surface by sand blasting generated the cold work that then resulted in recrystallization during thermal treatment to form the tiny grains observed on the internal surface. The nitriding of the external surface disappeared during final polishing step. This whole problem was then circumvented with the adoption of hydrogen for the protective atmosphere during mill annealing although some occasional surface carburization was observed.

Concerning the two Alloy 690TT CRDM nozzles, the grain size varied between ASTM 3 and 6 and there was a tendency for the grain size to increase towards the internal surface. The carbide precipitation was entirely intergranular and attributed to a high solution anneal temperature of 1050 to $1080^{\circ} \mathrm{C}\left(1922\right.$ to $\left.1976^{\circ} \mathrm{F}\right)$.

Stress corrosion experiments were performed either in pure water at 325 or $360^{\circ} \mathrm{C}$ with an overpressure of 3 bar hydrogen or in PWR primary water $(1000 \mathrm{ppm} \mathrm{B,} 2 \mathrm{ppm} \mathrm{Li}$ and 0.16 to 0.5 bar hydrogen) at $360^{\circ} \mathrm{C}\left(680^{\circ} \mathrm{F}\right)$. RUB specimens were prepared from the steam generator tubes with initial stresses that varied between 850 and $1050 \mathrm{MPa}$ (, as measured by X-rays at $20^{\circ} \mathrm{C}$ $\left(68^{\circ} \mathrm{C}\right)$. Similar $19 \mathrm{~mm}\left(0.748^{\prime \prime}\right)$ diameter tubes were elecro-discharge machined (EDM) from the wall thickness of the CRDM nozzles and, after removal of the fused surface layer by electropolishing, were split longitudinally in half to be formed also into RUB specimens. In this case, the measured peak stresses were between 700 and $860 \mathrm{MPa}$ (102 and $125 \mathrm{ksi}$ ). SSRT and constant load tests on the SG tube materials were carried out using planar tensile specimens machined by EDM. In most cases for SSRT, but not constant load, these specimens were also electropolished to remove the fused layer as well as the surface layer of small grains present on the original internal surfaces of some tubes. Round gage SSRT and constant load specimens were machined from the CRDM nozzle materials, the surface cold worked layer in this case being removed by electropolishing only for the SSRT.

Each Alloy 690TT RUB specimen was inspected every 3000 to 4000 hours during the SCC tests along with a RUB of Alloy 600 that was inserted into each phase of testing; the latter Alloy 600 RUB typically cracked between 500 and 2,000 hours. Specimens of the experimental tubes were tested for a total of 38,000 hours in hydrogenated pure water at $325^{\circ} \mathrm{C}\left(617^{\circ} \mathrm{F}\right)$ and 46,000 hours in primary water at $360^{\circ} \mathrm{C}$. (Note that some preliminary tests in hydrogenated steam at $400^{\circ} \mathrm{C}$ were not pursued beyond 6,000 hours.) The specimens from the pre-production tubes were tested for 10,000 hours in hydrogenated pure water at $360^{\circ} \mathrm{C}$ and in PWR primary water for 25,000 hours at $360^{\circ} \mathrm{C}$ 
(and in the preliminary study in hydrogenated steam at $400^{\circ} \mathrm{C}$ for 6,000 hours). The specimens from the industrial production tubes had reached 10,000 hours in hydrogenated water at $360^{\circ} \mathrm{C}\left(680^{\circ} \mathrm{F}\right)$ and 35,000 hours in primary water at $360^{\circ} \mathrm{C}$ when the $\mathrm{EdF}$ report was written in 1995 (and 2600 hours in hydrogenated steam at $400^{\circ} \mathrm{C}$ in the preliminary study). The Alloy 690 RUB specimens prepared from the CRDM nozzles were tested for 12665 hours at $360^{\circ} \mathrm{C}$ in PWR primary water.

No SCC initiation was noted in any Alloy 690 RUB nor was any propagation detected of surface defects created when forming RUBs from a few of the SG tube materials, as described for the CEA study. In certain high magnification pictures of the pre-formed surface defects in the perturbed surface layers on Alloy 690TT, these pre-formed defects definitely appear to be predominantly intergranular. The surface stresses on the RUB specimens were observed to relax rapidly to between 30 and $70 \%$ of the starting value, as also noted in the CEA study (CEA Report RT618). The stress relaxation of the RUB specimens of Alloy 690 was more marked than was the case for Alloy 600 .

Slow strain rate tests were performed in argon and in PWR water at $360^{\circ} \mathrm{C}$ with a strain rate of $5 \times 10^{-8} \mathrm{sec}^{-1}$. No test in argon on electropolished Alloy 690TT specimens gave rise to any cracking but those heats of SG tubing with the retained perturbed inner surface layers showed surface fissures up to $10 \mu \mathrm{m}$ deep.

In PWR primary water, all SSRT on the same heats, with two exceptions, gave rise to short intergranular cracks 5 to $20 \mu \mathrm{m}$ ( 0.0002 " to 0.0008 ") deep independent of the surface preparation. This included the industrial production tubes of which the one with surface phosphorus contamination was not notably worse. The two exceptions were specimens from the pre-production heat WE092 and one of the industrial production heats. From multiple specimen tests on WE092, intergranular cracks in the necked region up to $45 \mu \mathrm{m}\left(0.0018^{\prime \prime}\right)$ deep were observed when electropolished and up to $120 \mu \mathrm{m}\left(0.0047^{\prime \prime}\right)$ deep from the as-received internal tube surface, whereas the depth of cracking outside the necked region varied from 10 to $65 \mu \mathrm{m}(0.0004$ " to 0.0026 "). The other exception was an industrial heat, WG592, of which only 2 specimens were tested, one electropolished and one where the industrial surface (sandblasted before thermal treatment) was retained. Cracking to a depth of $35 \mu \mathrm{m}(0.0014$ ") from the industrial sandblasted surface involved intergranular penetration throughout a very fine-grained recrystallized surface layer plus $\sim 1$ normal size grain depth thereafter. In the case of the electropolished surface of WG592, the observed crack depth of $20 \mu \mathrm{m}\left(0.0008^{\prime \prime}\right)$ was equivalent to only $\sim 1$ normal grain size. Note that 1 grain-depth penetrations were also observed in other cases (including Alloy 800), so that it is thus debatable whether the observed intergranular separations for Alloy 690TT were truly representative of PWSCC. For comparison, similar SSRTs on Alloy 600MA showed $80 \mu \mathrm{m}$ (0.003') deep cracks from electropolished surfaces and $500 \mu \mathrm{m}\left(0.020^{\prime \prime}\right)$ deep from as-received surfaces.

The SSRT specimens from the CRDM nozzles showed intergranular cracks that did not exceed one grain depth, in this case $70 \mu \mathrm{m}(0.0028$ ") maximum, independent of initial surface condition. This was judged to indicate that no significant SCC had occurred.

It was concluded by the EdF authors from all these SSRT results that IGSCC had been provoked to a limited extent in Alloy 690TT but resistance was clearly very high. It can be deduced from the results that the resistance of Alloy 690TT was usually more than an order of magnitude better than 
Alloy 600MA, with the exception of the Alloy 690TT heat with the out-of-specification carbon content, small grain size and poor intergranular carbide decoration, WE092, as described in the previous section.

Constant load tests in PWR primary water at $360^{\circ} \mathrm{C}\left(680^{\circ} \mathrm{F}\right)$ showed no cracking typical of SCC even on the worst pre-production Alloy 690TT tube (heat WE092) when loaded up to a nominal stress of $684 \mathrm{MPa}(99.2 \mathrm{ksi})$ for 10,900 hours. The same was true of Alloy 690 samples from the CRDM nozzles for periods up to 18,500 hours at a nominal stress of $580 \mathrm{MPa}(84.1 \mathrm{ksi})$.

\subsection{EDF Report HT-44/97/020/A, 1997}

This EDF report is in fact a copy of the $\mathrm{PhD}$ thesis of J-D Mithieux that was examined on October 29, 1997 at the Institut National Polytechnique de Grenoble. The objective of the work was to try to understand why Alloy 690 has such good resistance to stress corrosion in PWR primary water and to quantify its limits. In this context, the literature review by Mithieux cited a prior EdF supported PhD thesis by J. F. Kergaravat at the Institut National Polytechnique de Grenoble in which an Alloy 690TT steam generator tube was heat treated at $1100^{\circ} \mathrm{C}\left(2012^{\circ} \mathrm{F}\right)$ to take the carbides back into solution followed by a rapid quench. This material was observed to crack in PWR primary water, apparently during a slow strain rate test but with otherwise unspecified test conditions.

Since degradation of a protective film is generally considered an essential step for the development of stress corrosion, an experimental investigation of repassivation kinetics and substrate deformation behavior was undertaken. Repassivation kinetics of Alloys 600MA and 690TT were measured by a potential step technique in PWR primary water at $360^{\circ} \mathrm{C}$ and the macroscopic and intergranular creep rates were determined between $325^{\circ} \mathrm{C}$ and $400^{\circ} \mathrm{C}$. These were then correlated with results of RUB and SSRT experiments on the same heats. The essential results from this work were published in the open literature in $1999^{[49]}$.

The materials selected for the study were in the form of steam generator tubes from six heats of Alloy 600 steam generator tubes and five heats of Alloy 690TT, the latter including the French preproduction heat WE092 (with high carbon and chromium and low iron and the double heat treatment history). An additional forged bar of Alloy 690 was also studied. All the Alloy 600 heats and one experimental Alloy 690 heat were received in the mill annealed condition and were given thermal treatments, as necessary. Another heat treatment, $1100^{\circ} \mathrm{C}$ for 20 minutes followed by a water quench, was also used in some cases to ensure that the carbides were taken back into solution. The carbide morphologies (intergranular and intragranular) of all the heat/heat treatment combinations were examined and classified according to a standard EDF system described earlier.

The corrosion experiments were carried out in three different autoclave systems depending on whether the objective was electrochemical measurements, slow strain rate tests or long term exposure of RUB specimens. It should be noted that the hydrogen concentration was not the same in each system, being around 23 and $25 \mathrm{ml} / \mathrm{kg}$ for the first two types of test and $167 \mathrm{ml} / \mathrm{kg}$ for the experiments with RUB specimens (see Table 3-45). The hydrogen concentration was only fixed at the beginning of each test by a given overpressure at $125^{\circ} \mathrm{C}\left(257^{\circ} \mathrm{F}\right)$ and was apparently not measured continuously during the experiments at temperature in this particular work. 
For the electrochemical experiments, an external $\mathrm{Ag} / \mathrm{AgCl}$ reference electrode was employed. The specimens in the potential step experiments were first cathodically polarized at ECP- $310 \mathrm{mV}$ (after correction for a considerable IR drop in the comparatively low conductivity PWR primary water) for 300 seconds and then forced back rapidly to the original ECP in order to measure the repassivation current and its decay with time. When the re-oxidation transients were measured, it included a contribution from re-oxidation of adsorbed hydrogen on the surface produced during the preceding step. However, control experiments on platinum suggested a contribution of only $10 \%$ to the anodic current from hydrogen oxidation obtained on the nickel alloy surfaces. (Note, however, that the pre-existing oxidized surface cannot be completely reduced at $-310 \mathrm{mV}$ relative to the free corrosion potential since chromium containing oxides are still stable and it seems possible therefore that the re-oxidation transients may only have concerned an outer layer of nickel ferrite). The repassivation currents decreased with increasing hydrogen overpressure as expected. The decrease in repassivation rate between Alloy 600 and Alloy 690TT was found to be only a factor of two and it was concluded that it could not alone explain the difference in their susceptibility to stress corrosion.

The creep studies allowed a primary creep law to be quantified as a function of temperature from 325 to $400^{\circ} \mathrm{C}$, stress from 450 to $650 \mathrm{MPa}$, and material characteristics. Secondary creep does not occur at the temperatures of interest in PWRs. Grain boundary sliding was observed with the aid of scratches made with 4000 grade abrasive paper on a previously electropolished surface. The sliding of several tens of grains was observed on each specimen tested and averaged. The uncertainty in the average was up to $50 \%$ because of the variability observed in sliding rates depending on grain boundary orientation relative to the principal tensile stress.

The primary macroscopic creep rate in air for the mill annealed and thermally treated versions of Alloy 600 and 690TT followed the same parabolic law with the strain rate proportional to $t^{-0.47}$. For the solution annealed materials the strain rate was proportional to $\mathrm{t}^{-1}$, the difference being linked to the concentration of carbon in solution and the increased grain size. The activation energy for primary creep was observed to be $180 \mathrm{~kJ} / \mathrm{mole}$ for both the mill annealed and thermally treated Alloys 600 and 690TT. Thermal treatment of Alloys 600 and 690 caused the creep rate to increase by a factor between 3 and 9 depending on the heat (presumably due to the reduction in amount of interstitial carbon) although, for similar thermal mechanical treatments, the creep rate decreased with increasing density of grain boundary carbides. The increase in chromium content between 15 and $30 \%$ between Alloys 600 and 690 caused a decrease in macroscopic primary creep rate by about a factor of two for similar grain sizes and degrees of grain boundary decoration by carbides. Additional experiments were also carried out in PWR water at $360^{\circ} \mathrm{C}$. An increase in the creep rate by a factor of three relative to argon was observed and was interpreted as either an effect of hydrogen or of vacancy injection from surface oxidation.

In parallel, the intergranular creep resistance was measured and expressed in terms of intergranular viscosity, which is inversely proportional to the intergranular sliding rate. The intergranular viscosity increased strongly with the density of intergranular (carbide) precipitation. For example, the grain boundary sliding rate decreased by a factor of up to 20 between the same heats of Alloy 600 in the mill annealed and thermally treated conditions. However, the intergranular viscosity was only slightly affected by the chromium content. $\Lambda$ parameter called the fraction of intergranular deformation, defined by the ratio of the intergranular to total creep rate, was correlated with 
exponential functions of the observed density of intergranular carbides. In reality, the observed favorable effect of thermal treatment in increasing intergranular viscosity was more complex than simply an effect of intergranular carbides because at the same time the reduction in dissolved carbon also resulted in a change from homogeneous planar sliding to intense localized planar slip. The latter deformation greatly exceeded any contribution from grain boundary sliding.

A parametric equation was derived to evaluate intergranular viscosity as a function of easily measured microstructural parameters:

- the fractional grain boundary coverage by intergranular carbides divided by a constant for Alloy 600 or 690TT,

- the constant of proportionality for Alloy 600 or 690TT in the equation relating the macroscopic creep rate to stress, yield stress, temperature and time,

- the grain size.

The observed correlation between predicted and observed grain boundary sliding rates was satisfactory but with a scatter band of up to an order of magnitude. If the second parameter in the above list was not available experimentally, an alternative estimation was proposed based on the grain size and a characteristic constant for mill annealed Alloy 600, or thermally treated Alloy 600 or thermally treated Alloy 690.

Crack propagation rates measured during slow strain rate tests (SSRT) at a strain rate of $5 \times 10^{-8} \mathrm{sec}^{-1}$ in PWR primary water at $360^{\circ} \mathrm{C}$ (calculated from the total test time $-500 \mathrm{~h}$, the assumed time to initiation at that strain rate) were correlated with the resistance of the material to intergranular sliding (Figure 3-10 and Figure 3-11). The observed correlation ( $\mathrm{da} / \mathrm{dt}=5.7 \times 10^{4} \eta^{-0.76}$ ) over two orders of magnitude of crack growth rates between $5 \times 10^{-3}$ and $2 \times 10^{-1} \mu \mathrm{m} / \mathrm{h}$ was deemed satisfactory, albeit with two outliers corresponding to two solution annealed heats (of Alloy 600 and 690). (It may be noted that a correlation derived from the Alloy 690 points, taken alone above the detection limit for crack growth in Figure 3-10, would give rise to a steeper slope.) The correlation was, nevertheless, significantly better than that between the crack growth rate and the fractional grain boundary coverage by carbides, for example. Beyond $20 \%$ coverage of grain boundaries by carbides, crack growth rates were below $5 \times 10^{-3} \mu \mathrm{m} / \mathrm{h}$, which corresponds to the apparent "threshold" for cracking defined by the smallest detectable intergranular crack of $10 \mu \mathrm{m}$ in experiments lasting up to 2000 hours. However, cracking of one mill annealed and two thermally treated Alloy 690 heats above this "threshold" was observed, one of which being the pre-production heat WE092 extensively cited earlier. It is noted that the rates of crack propagation between $2 \times 10^{-2}$ and $10^{-1} \mu \mathrm{m} / \mathrm{h}$ in these three cases were calculated from intergranular crack extensions of 20 to 120 $\mu \mathrm{m}(0.0008$ " to 0.0047 "). The author concluded that there is a comparatively weak effect of chromium content and strong effect of intergranular precipitates on stress corrosion (propagation) susceptibility.

The same type of correlation but with more scatter between stress corrosion initiation times and intergranular viscosity $\left(\mathrm{t}_{\mathrm{i}}=3.07 \times 10^{-2} \eta^{-0.57}\right)$ was derived from results obtained using RUB specimens of Alloy 600 in PWR primary water at $360^{\circ} \mathrm{C}\left(680^{\circ} \mathrm{F}\right)$, (but note the very high hydrogen in these 
tests mentioned earlier). No crack initiation was observed in the case of Alloy 690TT after between 16,000 and 27,000 hours of test for the thermally treated heats and 52,000 hours for the mill annealed heat, despite having similar intergranular sliding rates to Alloy 600 with comparable intergranular carbide morphology. This difference in initiation resistance was attributed to an important effect of chromium content on crack initiation, the hypothesis being that less hydrogen entered the higher chromium material, particularly in the absence of dynamic straining. Thus Mithieux concluded with the opinion that understanding the role of chromium content on resistance to stress corrosion initiation under static loading in PWR primary water required significant further work, notably on hydrogen/metal interactions.

\subsection{EDF Report HT-29/02/001/A, 2002 $2^{[48]}$}

Although not explicitly stated in the EDF report, the text appears to be that of the PhD thesis of J-P Saulay ${ }^{[48]}$ following the preceding study by J-D Mithieux. Again, the goal was to understand and quantify the margin against the occurrence of stress corrosion cracking in Alloy 690TT compared to Alloy 600 in PWR primary water under very severe test conditions. The essential results from this work were published in the open literature in $2003 .^{[50]}$

The work was divided into two parts of which the first addressed the effects of shot peening and cold forming on the resistance of Alloy 690TT to stress corrosion cracking in PWR primary water. In the second part, a quantitative estimation of the margin against stress corrosion occurring in Alloy 690TT was made. To this end, an attempt was made to define the conditions under which Alloy 690TT may stress corrode in PWR primary water.

The materials selected for study were from the same batch (of steam generator tubes) as those described in the PhD thesis of J-D Mithieux. ${ }^{[47]}$ Three heats of Alloy 600 and three heats of Alloy 690TT were used of which the latter included the pre-production heat WE092, the industrial heat WG592 with a poor intergranular carbide structure that had showed $35 \mu \mathrm{m}$ of cracking in the work of Mithieux, and one industrial heat WE799 with an acceptable carbide structure (see Table 3-40 to Table 3-43). One of the Alloy 600 heats, which was mill annealed, also had a very well developed intergranular carbide structure and it too had not cracked significantly in the work of Mithieux, whereas the other two Alloy 600TT heats selected had cracked in the previous study. Cold worked surface layers were reported to be present on the internal and external layers of all the steam generator tube samples although data were shown only for one of each alloy type with the comment that the cold worked layers were twice as thick at up to $100 \mu \mathrm{m}$ on the Alloy 600 tube compared to the Alloy 690TT tube of heat WE092. These cold worked layers were removed by electropolishing in some cases prior to stress corrosion tests, however.

Tensile specimens were machined from the steam generator tubes by EDM; the fused layer was presumably also removed by electropolishing although this was not explicitly stated. Some were shot peened on one or both sides with glass beads to an Almen intensity of $27 \mathrm{~N}$, which resulted in compressive layers between 150 and $250 \mu \mathrm{m}(0.0059$ " and 0.098 ") thick and peak compressive stresses between -800 and $-1000 \mathrm{MPa}(-145 \mathrm{ksi})$. Other specimens were cold formed to create a Vshaped hump of height $6.5 \mathrm{~mm}$ in the middle of the gage section; the so-called "Smialowska" specimen. Two radii for the apex of the V-shaped hump of 1 and $2 \mathrm{~mm}$ were used. The microhardness was measured on the hump with peak values as high as $400-450 \mathrm{HV}$. 
The initial results of Saulay concerned the effects of shot peening on the stress corrosion resistance in PWR primary water at $360^{\circ} \mathrm{C}$ of the pre-production heat of Alloy 690TT (WE092). The same system of fixing the hydrogen overpressure at $125^{\circ} \mathrm{C}\left(257^{\circ} \mathrm{F}\right)$ before each SSRT was used as before in the work of Mithieux, which gave a dissolved hydrogen concentration of about $30 \mathrm{ml} / \mathrm{kg}$ (See Table 3-48). The strain rate was $2.5 \times 10^{-7}$ or $5 \times 10^{-8} \mathrm{sec}^{-1}$. Tests were conducted on specimens of WE092 either with the as-received steam generator tube surfaces, or electropolished, or shot peened. Typically, two tests per condition were conducted at $2.5 \times 10^{-7}$ and $5 \times 10^{-8} \mathrm{sec}^{-1}$ of which one was interrupted at a quarter to half of the test period of the companion test to specimen failure. Crack growth rates were calculated from each pair of results, and were usually based on observed crack depths between 10 and $120 \mu \mathrm{m}$ (Figure 3-11). (It is noteworthy that the crack depths observed at the lower strain rate were usually 10 to $30 \%$ deeper and certainly not several times deeper, as might have been expected.) Based on all the tests the author concluded that the cold worked layer present on tubes of heat WE092 caused the crack growth rate to be multiplied by a factor of 1.3 by comparison with an electropolished surface.

Shot peening on both sides of the specimens was concluded to decrease the resistance of the preproduction heat WE092 to stress corrosion cracking, based, it seems, on two cracked areas being observed rather than one on the as-received material, but the deduced growth rates were essentially the same. For the specimens of WE092 shot peened on one side, it was concluded that the crack depth increased by a factor of 2 due to shot peening compared to the as-received condition but this conclusion is difficult to support after examining the quantitative results. Two tests were also carried out on the industrial heat of Alloy 690TT (WG592) with intermediate quality carbide morphology from which it was deduced that the crack propagation rate in the intermediate quality Alloy 690 heat was nearly the same as in WE092 despite being "more resistant". Thus, prior shot peening had no effect on the stress corrosion resistance of the industrial production heat of Alloy 690 with intermediate intergranular carbide quality. The so-called rapid propagation phase was not observed on any shot peened specimen of Alloy 690TT in contrast to most similar tests on Alloy 600MA. These results may be compared with those for a rather resistant heat of Alloy 600TT where shot peening was observed to increase crack growth rates by a factor of 5 to 6 compared to electropolished surfaces and by a factor of 3 relative to the as-received steam generator tube surfaces. In addition, transition to the rapid propagation phase was also observed.

Five SSRT experiments were conducted at $5 \times 10^{-8} \mathrm{sec}^{-1}$ using the cold deformed specimens with the V-shaped hump, of which four were on the three heats of Alloy 690TT and one was on a nominally resistant heat of Alloy 600TT. Of the three heats of Alloy 690TT with a radius at the apex of the Vshaped hump of $1 \mathrm{~mm}$, the two heats with unacceptable or marginal intergranular carbide structure showed intergranular cracks to twice the depth (maximum of $225 \mu \mathrm{m}$ ) observed on the normal test specimens. On the other hand, the third industrial Alloy 690TT heat with good intergranular carbide morphology cracked to about a third of the depth of the other two, whereas the Alloy 600TT specimen with a V-shaped hump cracked almost all the way through the thickness. Thus, use of a cold deformed test specimen modified the observed stress corrosion behavior of Alloy 690TT in such a way that the authors concluded that no heat of Alloy 690TT could be considered completely immune to stress corrosion, although it was still very much better than even a rather resistant heat of Alloy 600TT. 
The second part of the study allowed a diagram showing lifetime to cracking of the experimental heat of Alloy 690TT (WE092) to be drawn as a function of strain rate, as published at the Environmental Degradation conference at Skamania Lodge in $2003 .^{[50]}$ It is based on an approach published previously by Boursier for Alloy 600 , the advantage of which was stated to be the ability to present both SSRT and constant load stress corrosion data on the same unified diagram (as a function of strain rate). Note that the development of stress corrosion in Alloy 600 is viewed as proceeding in three phases; crack initiation, "slow crack propagation" and "fast crack propagation" about an order of magnitude faster. The last of these steps is consistent with data obtained under linear elastic conditions using fracture mechanics specimens but is not always observed in SSRT using small tensile specimens. Thus SSRT specimen lifetimes usually tend to be dominated by a combination of "initiation" and "slow propagation".

In the present case, two domains in the development of cracking during SSRT were distinguished for certain heats of Alloy 690TT; initiation of a crack to a defined depth of $10 \mu \mathrm{m}(0.0004$ ") and a second phase of "slow propagation". The SSRT data used to construct the failure diagram for Alloy 690 were those obtained on the pre-production heat WE092 together with a single observation on the same heat at constant load interrupted after 10915 hours of exposure at $360^{\circ} \mathrm{C}\left(680^{\circ} \mathrm{F}\right)$ and a stress of $680 \mathrm{MPa}(98.6 \mathrm{ksi})$. The latter result is treated as a long term creep test with a primary creep rate at the 10915 hours point of $3.6 \times 10^{-10} \mathrm{sec}^{-1}$, as calculated from the study by Mithieux, and an assumption that a crack of $10 \mu \mathrm{m}$ was present at the end of the test. On a log-log plot of deformation rate versus time, loci or isodamage lines representing the same depth of stress corrosion cracking were added, for example at $10 \mu \mathrm{m}$ (representing initiation) and $100 \mu \mathrm{m}$ (Figure 3-12). To these loci are added the mechanical ductile rupture locus. In this way, the life of a component to a given crack depth, or rupture, can be predicted if the applied strain rate is known or from the primary creep rate at a given point during its decay at constant load.

For the constant load case, it was necessary to show, given the variable strain rate history during primary creep decay, that it was reasonable to use the creep rate at the point in time when the damage is comparable to that which would have been observed if that same (lower) strain rate had been maintained constant throughout life. With the aid of a slow strain rate test at two successive different strain rates $\left(2 \times 10^{-7}\right.$ and $\left.4 \times 10^{-9} \mathrm{sec}^{-1}\right)$ maintained for times (63 and 1800 hours respectively) that were insufficient to traverse the locus defining the $10 \mu \mathrm{m}$ crack depth marker of "initiation", it was shown that the exposure times for each step could be simply added together as if they were all at the lower strain rate. In other words, there was no perceived "history" effect in the specimens due to the preceding periods of dynamic strain not exceeding the total required to initiate a $10 \mu \mathrm{m}$ (0.0004") crack. In a second test at the two selected strain rates where the period at the faster strain rate exceeded that required to initiate a $10 \mu \mathrm{m}$ crack, a crack initiated in the first step then continued to propagate in the second step at the lower strain rate. Thus, once the effective initiation limit of 10 $\mu \mathrm{m}$ was crossed, further stress corrosion damage was cumulative and crack propagation followed the isodamage lines drawn on the failure diagram (Figure 3-12).

\subsection{Results Reported by Vaillant et al. 1999 ${ }^{[49]}$}

Vaillant et al. reported RUB and CERT results on Alloy 600MA \& TT and Alloy 690MA \& TT SG tubes in primary water. ${ }^{[49]}$ The carbon content and the heat treatment conditions of the six Alloy 600 tubes and five Alloy 690 SG tubes are listed in Table 3-44. The RUB and CERT test 
conditions are listed in Table 3-45. The number of test specimens for each heat or heat treatment was not reported.

\section{$\underline{\text { RUB Results }}$}

The RUB test was performed in a static autoclave at $360^{\circ} \mathrm{C}\left(680^{\circ} \mathrm{F}\right)$ with $100 \mathrm{cc}_{2} / \mathrm{kg} \mathrm{H} \mathrm{H}_{2} \mathrm{O}$. The $\mathrm{X}$-ray measured true stress level at the Alloy 600 specimen apex was between 750 and $1000 \mathrm{MPa}$ (109 and $145 \mathrm{ksi}$ ). Some shallow cracks (10 $\mu \mathrm{m}$ or 0.0004 " deep) appeared at the apex of the Alloy 690 RUB specimens after bending, but before immersion inside the autoclave. So the stress measured at the Alloy 690 RUB specimen apex surface was not well-defined. However, the stress level measured after removing the $10 \mu \mathrm{m}$ or 0.0004 " deep crack was the same as for the Alloy 600 RUB specimens. Hence, the stress at the tip of the short crack caused by bending is at least as high as the apex surface stress of the Alloy 600 RUB specimens.

The RUB specimens were removed periodically for inspection (every 500 hours for the Alloy 600 and an interval between 3000 to 6000 hours for the Alloy 690). If cracks were observed or suspected, the specimens were cut for metallurgical examination. Otherwise, the specimens were returned for continued testing. The test results shown on Figure 9 of Ref. 49 are summarized in Table 3-46. Except for 6E specimen, all the Alloy 600 RUB specimens developed cracks within 3,500 hours. The Alloy $6006 \mathrm{E}$ specimen did not develop cracks even after 36,000 hours of exposure. Within each Alloy 600 heat, the TT condition had a higher crack resistance than the MA condition. None of the Alloy 690 specimens tested cracked after 16,500, 25,000, or 54,000 hours of exposure. Results for the Alloy 690 heat 9.754 were not reported.

\section{$\underline{\text { CERT Results }}$}

Vaillant et al. considered the CERT test to be a test measuring the stress corrosion crack growth rate. The CERT tests were conducted at a strain rate of $5 \times 10^{-8} \mathrm{sec}^{-1}$. Significant intergranular cracking was observed on three Alloy 690 SG tubes that did not crack during the RUB tests. The reported depth of the intergranular cracks are listed in Table 3-46, which also lists the average crack growth rate (CGR) estimated from Ref. 49. The crack growth rates are also summarized in Figure 3-10. The CERT results from the Alloy 600 6E specimen and the Alloy 690TT 9.799 specimen did not crack. (Note: It is inferred that no intergranular cracking was observed on the two CERT specimens, even thought the report did not specifically use the word "intergranular cracking" or "environmental assisted cracking".) This was attributed to the high degree of intergranular carbide precipitation in these two SG tubes. Based on Figure 3-10, Vaillant et al. concluded that Alloy 690 did not necessarily have a lower CGR than Alloy 600. Vaillant et al. suggested that the CGR obtained in the CERT tests is mainly dependent on the grain boundary carbide precipitation and the creep rate while the crack initiation time in the RUB tests was mainly a function of $\mathrm{Cr}$ contents. The results and conclusions by Vaillant et al. are further discussed in Section 4.1.2.

\subsection{Results Reported by Boursier et al. 2003}

The investigation by Boursier et al. was an extension of an earlier study by Vaillant et al. in Ref. 49 with additional CERT tests. ${ }^{[50]}$ Boursier et al. investigated the effect of surface condition, strain rate, and localized strain on the SCC cracking of the CERT specimens in primary water at 
$360^{\circ} \mathrm{C}\left(680^{\circ} \mathrm{F}\right)$. The chemical composition and heat treatment conditions of the six Alloy 600 tubes and five Alloy $690 \mathrm{SG}$ tubes are listed in Table 3-47. These tubes were among the ones used for RUB and CERT tests in Ref. 49. The crack growth rates from the previous CERT tests are summarized in Figure 3-10. The CGR numbers are also listed in Table 3-46.

Boursier et al. performed the CERT tests at a strain rate between $5 \times 10^{-9}$ and $2.5 \times 10^{-7} \mathrm{sec}^{-1}$ and the constant load tests at a load between 603 and $684 \mathrm{MPa}(87$ and $99 \mathrm{ksi})$. The cross section of the specimens was $3.5 \mathrm{~mm} \times 1.1 \mathrm{~mm}$. To evaluate the surface condition on PWSCC, the specimens were tested in the as-received surface, electropolished surface, shot peened either on one side (surfaces) or on both sides (surfaces). In addition, some specimens were pressed to a hump (Smialowska-type specimens). The test environmental conditions are listed in Table 3-48. For the CERT tests, true stress and elongation were measured as a function of time. For the constant load tests, the elongation was measured. After the tests, the failed specimens' crack depth was measured by SEM. All failed CERT and constant load specimens tested in water exhibited the presence of a similar intergranular cracking morphology on the fracture surface (asreceived condition specimens, peened specimens, or pressed hump specimens). In contrast, tests conducted in an inert (argon or helium) environment showed entirely ductile fracture.

The CERT results of the experimental heat of Alloy 690 (690 Exp) are summarized in Table 3-49. The extent of the cracking in the specimens shot-peened on both surfaces was equivalent to that of the as-received condition. On the contrary, specimens shot-peened on one side had an increase of the stress corrosion cracking depth and a reduction of the test time. Similar results were also reported at lower strain rates. It was deduced that the cold work layer strongly influenced the slow propagation phase. The crack propagation rate measured in the shot peened state $(0.9 \mu \mathrm{m} / \mathrm{h})$ was higher than that measured in the as-received condition $(0.3 \mu \mathrm{m} / \mathrm{h})$. The effect of cold work on the initiation phase is more difficult to establish. It seemed that the surface cold work slightly increased the initiation time. The electropolishing removed the superficial surface cold worked layer from the SG tube fabrication process (straightening and grinding outer surface). Hence, the electropolished specimens were slightly better than the as-received condition specimens. Boursier et al. noted that there was no effect of shot-peening on the industrial Alloy 690 (690 Ind) as the same corrosion resistance was observed on the as-received material and the shot-peened specimens. However, as discussed in the previous (Vaillant et al.) section, the same concern should be raised as whether crack propagation rate estimated from CERT can be used to rank Alloy 690 or Alloy 600 PWSCC crack growth rate.

The effect of strain rate on the CERT results of the experimental heat of Alloy 690 (690 Exp) is shown in Figure 3-11. The crack growth rate increased with increasing applied strain rate in the CERT test. Table 3-49 also shows the effect of cold work on cracking of the CERT specimens. In the as-received condition, the industrial Alloy 690 (690 Ind.) and the high resistant heat Alloy 600 (600 Ref) showed much less cracking (shallower crack depth and longer cracking time) than the experimental Alloy 690 (690 Exp 1). The cold work caused more severe cracking in the pressed hump specimens, especially in the Alloy 600 (600 Ref. heat) which showed good cracking resistance in the as-received condition. [0]The humped specimen (i.e. with bulk cold work) from the industrial heat Alloy 690 (690 Ind.) had a cracking depth of $70 \mu \mathrm{m}$. No descriptions or micrographs were provided to confirm that the cracking was intergranular. Based on Table 3-48, Alloy 690 Ind. (coded as 9.799 in Table 3-48) had an ASTM grain size of No. 6 
to 7 , or 32 to $45 \mu \mathrm{m}$. Hence, the cracking depth is about 2 grains or less. Several Alloy 690 corrosion studies reviewed in this document (see Section 4.1.1) have shown that Alloy 690 is prone to shallow intergranular splitting from excessive mechanical straining. Hence, it may be possible that the shallow cracking in the Alloy 690 Ind. humped specimen could come from the pressing strain rather than being caused by IGSCC.

\subsection{EDF Report HT-44/98/016/A, 1998}

EDF has studied since 1993 the stress corrosion resistance of Alloys 52 and 152 in PWR primary water and compared the results to those obtained on various other nickel base weld deposits with chromium contents between $14.5 \% \mathrm{Cr}$ (Alloy 182) and 26\% Cr. Their resistance to stress corrosion in hydrogenated PWR primary water at $360^{\circ} \mathrm{C}$ was examined using very severe tests. ${ }^{[51]}$

The welds used in this work were fabricated using Alloy 182 coated electrodes, Alloy 82 TIG wire, Soudometal $22 \% \mathrm{Cr}$, Alloy 625 , Soudometal $26 \%$ Cr, Inco Alloy 152 , Soudometal $30 \% \mathrm{Cr}$, and Alloy 52 TIG wire. Several of these welding products were experimental alloys and, at the time, only Alloys 182,82 and 625 were considered to be industrial products. Initial fears of a reduction in the toughness of welds with $30 \%$ Cr proved to be unfounded whereas the main welding problem encountered at such high $\mathrm{Cr}$ levels was hot cracking. Some variations of chemical composition aswelded by comparison with the target values were observed, the most notable among them being a Cr content of the Alloy 52 weld of $25.5 \%$ instead of $30 \%$. The mechanical properties were all to specification. The samples for stress corrosion testing were machined from weldments that were not stress relieved.

The as-welded microstructures were studied. The Soudometal $22 \% \mathrm{Cr}$ weld showed some iron rich nodules resulting probably from a welding anomaly. For the products with $30 \% \mathrm{Cr}$, hot cracks up to $0.5 \mathrm{~mm}$ in length were reported. However, the example of Alloy 52 here was not apparently affected by hot cracking whereas the other two products with $30 \% \mathrm{Cr}$ were strongly affected. Based on comparisons with a previous study of hot cracking in Alloy 182, the presence of traces of low melting phases detectable by SEM, rounded grain edges, and absence of secondary crack branches was judged to be sufficient to distinguish hot cracks from stress corrosion cracks. However, it should be noted that today it is known such features may not necessarily always be present since one form of hot cracking in Alloy 52 is definitely linked to ductility dip cracking where no low melting point phase is involved. ${ }^{[51]}$

RUB specimens for stress corrosion testing were fabricated by EDM machining a half section of tube across the welding direction and then bending it like half a steam generator tube to form a RUB with the weld metal at the apex. Electropolishing was used to eliminate any surfaces resulting from EDM machining. Longitudinal stresses of 700 to $860 \mathrm{MPa}$ were measured by X-rays while the circumferential stresses were lower between 500 and $600 \mathrm{MPa}$. The tensile specimens for constant load tests and SSRT had round gage sections with the long dimension along the length of the weld. These specimens were also electropolished to eliminate any cold worked layers from machining. All testing was carried out in static autoclaves, the deaeration and hydrogen overpressure being established at $125^{\circ} \mathrm{C}$ (Table 3-45). For the RUB tests, the hydrogen concentration as measured via a $\mathrm{Pd} / \mathrm{Ag}$ thimble was $>100 \mathrm{ml} / \mathrm{kg}$ and for the SSRT $25 \mathrm{ml} / \mathrm{kg}$. The residual hydrogen at the end of test was also measured but not reported. 
Using RUB specimens, Alloy $182(14.5 \% \mathrm{Cr})$ was observed to be very susceptible to stress corrosion cracking and Alloy $82(18-20 \% \mathrm{Cr})$ was only slightly less sensitive. Cracks appeared in one of the Alloy 182 specimens at the first test interruption after 500 hours and the second was cracked after 1500 hours. The first specimen of Alloy 82 cracked after 2000 hours and all were cracked at 6500 hours. For chromium contents between 21 and $22 \% \mathrm{Cr}$, no stress corrosion crack initiation was observed, as was also the case for Alloys 52 and 152 in tests lasting between 18,000 and 27,000 hours. This general behavior was confirmed by constant load tests $(450$ to $514 \mathrm{MPa}$ or 0.8 to 0.9 of the UTS) on Alloys 182, 82 and 152. Two out of three specimens of Alloy 152 failed by creep rupture after 13,000 to 27,000 hours at $360^{\circ} \mathrm{C}$, however.

Slow strain rate tests at $5 \times 10^{-8} \mathrm{sec}^{-1}$ (after 50 hours initial exposure without applied stress) confirmed the high susceptibility of Alloy 182 to stress corrosion and the somewhat less severe susceptibility of Alloy 82 . An interrupted test on Alloy 182 revealed no initiation at $0.9 \%$ strain but rapid growth at about 20 to $40 \mu \mathrm{m} / \mathrm{h}$ along the dendrite direction between 1 and $3.4 \%$ strain. The rate of propagation deduced for Alloy 82 was 0.6 to $0.7 \mu \mathrm{m} / \mathrm{h}$. The resistance to stress corrosion cracking as measured by SSRT improved for chromium contents between 21 and $22 \% \mathrm{Cr}$ but susceptibility was nevertheless still significant. Cracking remained possible up to $25-26 \% \mathrm{Cr}$. On the other hand, the test program to date on Alloy 152 has shown no stress corrosion cracking despite the presence of welding defects (hot cracks) in the tested specimens. This conclusion does, however, depend strongly on the interpretation of the fractography and the ability to distinguish hot cracking from stress corrosion cracking. A companion study cited in the report refers to the testing of precracked DCB (double cantilever beam) specimens (by ETH) where stress corrosion crack growth in Alloy 182 was clearly observed but not in Alloy 152 after 4300 hours at $350^{\circ} \mathrm{C}$ in PWR primary water.

A more detailed study of the various stress corrosion properties of the weld deposit materials studied enabled the following deductions to be made:

- A chromium content greater than $22 \%$ is very beneficial as regards resistance to stress corrosion crack initiation under static load or constant deformation and at $30 \%$ in alloys 52 and 152 complete resistance was found.

- Nevertheless, depending on elements other than chromium and possibly the microstructure, a chromium content equal or greater than $21-22 \%$ and up to $26 \% \mathrm{Cr}$ cannot guarantee the absence of stress corrosion propagation from pre-existing defects, although in the case of Alloy $152(30 \% \mathrm{Cr})$ no propagation was observed.

The report concludes by saying that a better understanding of the good performance of nickel base weld deposits with $30 \% \mathrm{Cr}$ would necessitate a similar approach to that developed by EdF for the Alloy 690 base metal. France (Appendix B)

Framatome ANP (France) performed a comparative study of the resistance of Alloy 690TT and Alloy 600MA and TT to PWSCC using mock-ups representative of the tube expansion zones in 
the tubesheet of recirculating PWR steam generators. Several different types of manufacturing anomalies were reproduced in the mock-ups, over-size tube / tubesheet gaps, over-rolling, skip rolls in the tubesheet, and excessive kiss-rolling. The mock-ups were tested in the form of heated capsules containing deaerated, hydrogenated and demineralized water at $360^{\circ} \mathrm{C}\left(680^{\circ} \mathrm{F}\right)$.

\section{$\underline{\text { SG Tube Mock-Up Material }}$}

The Alloy 600 tubes were 3/4" diameter (WD281, MA \& TT) and 7/8" diameter (NX3335 MA). The Alloy 690 (WE094 TT) tubes were $3 / 4$ " diameter tubes manufactured in a pre-production run. The Alloy $690 \mathrm{TT}$ tubes were heat treated at $1040^{\circ} \mathrm{C}\left(1904^{\circ} \mathrm{F}\right)$ for $3 \mathrm{~min}+700^{\circ} \mathrm{C}\left(1292^{\circ} \mathrm{F}\right)$ for 5 hours. Both the Alloy 600 and Alloy 690 tubes were typical of manufacturing practice about 16 years ago. The chemical composition and the mechanical properties are listed in Table 3-56.

The grain size of the Alloy 690 at mid-thickness was aproximately10 $\mu \mathrm{m}$ but a perturbed layer was detected on the inner surface of the tube. This layer was characterized by a finer grain size of about $2 \mu \mathrm{m}$, the presence of dense carbide precipitates and a higher hardness. Microhardness measurements indicate that this perturbed surface layer is about 100 microns thick. This structure was typical of the pre-series heats, which were the only ones available when the mock-ups were manufactured. Since then, Alloy 690TT tubes used in steam generators have much more rigorous quality control and the inner surfaces are free of such perturbed layers.

\section{$\underline{\text { SG Tube Mock-Up Fabrication }}$}

The mock-ups were manufactured by Framatome-ANP in Chalon sur Saône using the same tools and procedures as those used for PWR steam generators. Each mock-up consisted of a SG tube section and a thick carbon-steel cylinder representing the top side of the tubesheet. The tube section was expanded into holes drilled in the carbon steel cylinder representing the tubesheet using a mechanical rolling tool. Four rolling steps were needed inside each carbon steel cylinder. A kiss-rolling step was then carried out on each side of the carbon steel cylinder. Thus, two roll transition zones were available on each mock-up, as represented in the Figure 3-17, which shows a cross section view of the standard mock-up design. In addition, between the two roll transition zones, several non-conformities such as a lack of overlap between two rolling steps or a skipped roll step were introduced in some cases. Such fabrication non-conformities were known to be extremely detrimental for primary water side cracking of tubes in the case of steam generators with Alloy 600 tube bundles.

The total number of roll transition zones manufactured from Alloy 690TT was 16 whereas 40 were manufactured from the Alloy 600 heats. The mock-ups (each comprising two roll transition zones) were identified with a number between 1 and 21 for the Alloy 600 mock-ups and between 501 and 508 for Alloy 690TT mock-ups. A letter (H or B) was also added to the identification number for each transition zone. An Alloy 600 plug was manual metal arc welded into each end of the mock-ups in order to form a capsule. During this operation, the tube was cooled in order to maintain the residual stresses in the roll transition zones introduced by the roll expansion. Each mock-up (capsule) was equipped with a small stainless steel tubing to allow the test environment to be introduced, a high pressure valve, a manometer and an external thermocouple inserted in the carbon steel sheet. 


\section{Test Procedure}

The test environment was high purity deaerated water with a hydrogen overpressure. This environment was chosen to facilitate good control of the test environmental parameters and also knowing that hydrogenated pure water is slightly more aggressive from the stress corrosion view point than PWR primary water that also contains lithium hydroxide and boric acid in varying concentrations throughout any given fuel cycle. The mock-ups were introduced into a furnace whose temperature was subsequently controlled at $360^{\circ} \mathrm{C}\left(680^{\circ} \mathrm{F}\right)$.

Throughout the exposure period at $360^{\circ} \mathrm{C}\left(680^{\circ} \mathrm{F}\right)$ the conductivity of the aqueous environment was less than $1 \mu \mathrm{S} / \mathrm{cm}$. After, the first and the sixth test periods of about 10,000 hours, the water from several mock-ups was sampled and analyzed. The results are given in Table 3-56. During the first 17000 hours of the exposure period, no hydrogen was injected in the mock-ups. Subsequently, an over pressure of hydrogen of 15 bar was added at the beginning of each test period and was renewed every 2 months when half of the over-pressure was lost by diffusion. Testing of the Alloy 690TT mock-ups lasted 100,000 hours at $360^{\circ} \mathrm{C}(10$ periods of 10,000 hours) and an internal total pressure between 210 and 230 bar was maintained. No leak occurred during this entire test duration on any mock-up. One mockup, 506, was extracted for destructive examination after 60,000 hours of test.

\section{Alloy 690TT SG Tube Surface Microcracks}

SEM surface examinations of non-flattened Alloy 690TT half tube revealed some tiny cracks on the inner tube surface in the transition zones of the kiss rolling. Their length was about $1.5 \mathrm{~mm}$ and their width $2 \mu \mathrm{m}$, on each side of the roll transition. Examination of the flattened half tube revealed the presence of many microcracks, some of the opened microcracks corresponded to those which were also observed before flattening but numerous others were new ones opened or created during the mechanical flattening operation. This type of flaw was also observed on parts of the tube which were not rolled, that is remote from the rolled zone. The microcracks were fully characterized by metallographic examination with SEM. They were intergranular and their length was always limited to the thickness of the perturbed surface layer on the internal surface of the tube (about $10 \mu \mathrm{m}$ thick in this case). The microcracks are concluded to be strain induced by rolling and are limited to the hard perturbed surface layer already present on the inside surface of the tube in the as-received condition. These microcracks were intergranular but did not propagate in the tube during exposure to hydrogenated water at $360^{\circ} \mathrm{C}\left(680^{\circ} \mathrm{F}\right)$ during 60,000 hours exposure. The same shallow intergranular splitting was also noticed by Miglin et al. in Alloy 690 RUB specimens tested in all-volatile treated (AVT) water. Miglin et al. concluded that these defects were due to mechanical strain rather than due to IGSCC (see Section C.1 for detail).

\section{$\underline{\text { Results }}$}

Eight mock-ups (16 different roll transition zones) were manufactured with Alloy 690TT tubing and tested in the same conditions as the Alloy 600 mock-ups. None of the Alloy 690TT mockups cracked even after exposure times extending up to 100,000 hours. Non-destructive and destructive examinations showed that no stress corrosion crack initiation or propagation had occurred, despite the simulated manufacturing anomalies that had caused such severe detrimental effects on PWSCC resistance of similar Alloy 600 mock-ups. Metallurgical examinations of the 
Alloy 690TT mock-ups confirmed that even when some mechanically-induced intergranular cracks were initiated by severe straining of a hard perturbed internal surface layer, such cracks did not propagate in hydrogenated water at $360^{\circ} \mathrm{C}\left(680^{\circ} \mathrm{F}\right)$ after exposure times up to 100,000 hours.

The results of the Alloy 600 mock-up are summarized in Table 3-57 and Table 3-58. The first leaks due to through-wall cracking appeared on the Alloy 600 MA mock-ups after exposure times as short as 800 hours. Alloy 600TT tubes seemed to have better resistance to PWSCC in the case of severe non conformities such as over-sized tube / tube sheet gaps but with normal roll transition parameters, no effect of the thermal treatment was observed. Nevertheless, there was a marked heat to heat effect on PWSCC (as is characteristic of field Alloy 600 PWSCC behavior) independent of roll transition fabrication characteristics.

Almost all the Alloy 600 mock-ups cracked. Of the 40 different roll transition zones that were tested, two were withdrawn without any leakage after short exposure times and four zones survived 30,000 hours (the maximum exposure time of the Alloy 600 mock-ups) without any leakage occurring. All the other roll transition zones cracked. The average time to leakage of the Alloy 600 mock-ups was 8,350 hours with a standard deviation equal to 6,600 hours. The most susceptible zones were roll transition zones with over-size tube / tube sheet gaps and / or with skip rolls inside the tube sheet (independent of the tube / tube sheet gap if skip rolls were present).

\subsubsection{Hydrogenated Steam Testing}

\subsubsection{RUB Test in Hydrogenated Steam by Sui et al. 1997}

Sui et al. reported the results of RUB stress corrosion tests on Alloy 600 and Alloy 690TT materials. $[52,53]$ The tests were performed in a hydrogen/steam mixture at $380^{\circ} \mathrm{C}\left(716^{\circ} \mathrm{F}\right)$ in a static autoclave. The Alloy 600 and Alloy 690 tube size, chemical composition, mechanical properties, and heat treatment information are listed in Table 3-34. The Alloy 600 and Alloy 690 SG tubes were cut into $96 \mathrm{~mm}$ lengths then split longitudinally into halves and holes were drilled at each end of the half tube for securing the bolts. The split half tubes were bent outward to form a radius of about $15 \mathrm{~mm}$. They were cleaned with methanol and boiling pure water immediately before testing.

The static autoclaves used for the tests had an internal volume of 1.3 liters. In the initial experiments, the test specimens were loaded into the autoclave with $100 \mathrm{ml}$ of deionized water and purged with hydrogen to achieve a low oxygen level. The autoclave was then pressurized to 0.3 $\mathrm{MPa}$ absolute (0.2 MPa gauge) with hydrogen at room temperature, and then heated to $380^{\circ} \mathrm{C}$ $\left(716^{\circ} \mathrm{F}\right)$. The operating pressure at $380^{\circ} \mathrm{C}\left(716^{\circ} \mathrm{F}\right)$ was $15.2 \mathrm{MPa}(2,205 \mathrm{psi})$ giving an estimated $\mathrm{H}_{2} / \mathrm{H}_{2} \mathrm{O}$ partial pressure ratio of 0.04 . The specimens were removed from the autoclave at various times for examination, and then returned for further testing, unless they were cracked. The specimen examination was performed using a binocular optical microscope and a scanning electron microscope.

The RUB test results are summarized in Table 3-35. Alloy 600 EPRI 1 and 2 heats were more susceptible to cracking than Heat 2682. Four of the five Alloy 600 specimens developed cracks in 2,578 hours of exposure. The specimen from Heat 2682 (in the as-received condition) did develop 
cracking after 2,578 hours. In contrast, the three Alloy 690TT specimens did not develop cracks after 3,000 hours of exposure. However, eventually, two specimens from Alloy 690 Heat B, which was deliberately mill annealed at unusually low temperature before the thermal treatment, developed intergranular cracking after 13,824 hours of exposure even though no cracks were observed after 12,600 hours. The cracks initiated on the I.D. surface of the split tube and propagated along the longitudinal axis of the tube. The largest crack was about $2 \mathrm{~mm}$ long and almost through the tube wall thickness $(0.97 \mathrm{~mm})$. Figure 3-13 shows the cracks observed in Alloy 690 specimen $5 \mathrm{R}$ from heat $\mathrm{B}$ without aging at $550^{\circ} \mathrm{C}\left(1022^{\circ} \mathrm{F}\right)$.

None of the eight specimens from Alloy 690 Heat $\Lambda$ developed any cracks. However, Figure 3-14 shows a short crack generated by flattening at room temperature one of the Alloy 690 RUB specimens from heat $\Lambda$ after 13,824 hours exposure. Sui et al. attributed this short crack to embrittlement of grain boundaries near the surface from the exposure. Further, Sui et al. suggest such a short crack to be indications of embrittled zones or "pre-damage zones" ahead of the intergranular crack tips.

Both heats of Alloy 690 were thermally treated at $\sim 715^{\circ} \mathrm{C}\left(1319^{\circ} \mathrm{F}\right)$ for 15 hours. However, the cracked Alloy 690 Heat $B$ was deliberately treated mill annealed at an unusually lower temperature than the un-cracked Alloy 690 Heat $\Lambda\left(1769^{\circ} \mathrm{F}\right.$ for Heat B vs. $1958^{\circ} \mathrm{F}$ for Heat $\left.\mathrm{A}\right)$. The lower mill anneal temperature resulted in less dissolved carbon available to precipitate in the grain boundaries upon the thermal heat treatment. The grain boundaries in Heat A were covered almost continuously by carbides, which were determined to be the $\mathrm{M}_{23} \mathrm{C}_{6}$ type by TEM. In contrast, the grain boundaries in Heat $\mathrm{B}$ were essentially free of intergranular carbide coverage. Heat $\mathrm{B}$ also had a higher content of $A 1$, which tend to result in a finer grain size and therefore a lower density of intergranular carbides in Heat B even further. The average grain size was $25 \mu \mathrm{m}$ (ASTM No. 7.5) for Heat $A$ and $15 \mu \mathrm{m}$ (ASTM No. 9.0) or less for Heat B. The small grain size of Heat $B$ was reflected in its higher room temperature yield strength. The strain distributions in the RUB specimens were measured by grids engraved on the inner and out surfaces of the specimens. Although Alloy 690 had a smaller tube diameter, both RUBs were bent with the tooling designed to fit Alloy $600 \mathrm{SG}$ tubes. As a result, the Alloy 690 RUB specimens were stretched to a higher strain level in the transverse direction (normal to the tube axis). The RUB results by Sui et al. suggest that Alloy 690 could be susceptible to IGSCC in a hydrogenated steam environment if the final mill anneal temperature is too low to cause intergranular carbide precipitation upon the subsequent thermal heat treatment.

\subsubsection{RUB Test in Hydrogenated Steam by Framatome ANP, Germany} (Appendix A)

Framatome ANP (Germany) performed accelerated RUB tests in $400^{\circ} \mathrm{C}\left(752^{\circ} \mathrm{F}\right)$ hydrogenated steam. The hydrogen partial pressure was $1.1 \mathrm{bar}(16 \mathrm{psi})$ at a total pressure of $200 \mathrm{bar}$ ( 2900 psi). The chemical composition and mechanical properties of the Alloy 690 TT and Alloy 600 MA SG tubes used are summarized in6 Table 3-53. To simulate a malfunctioning rolling tool, $50 \%$ of the RUB specimens (three specimens per material) were deliberately scored with actual tools used during manufacturing. These surface marks were introduced into the internal surfaces of split tube sections prior to bending. The scores were shaped in the form of longitudinal and circumferential grooves with a width of approximately $1 \mathrm{~mm}(0.04$ ") and a depth ranging from 
$20 \%$ to a maximum of $40 \%$ of the tube's wall thickness. The scoring process and the actual depth of grooves were controlled with surface profilometry.

The RUB test in the hot hydrogenated steam lasted up to 405 days (9,720 hours) with inspection intervals after 14, 30 and 60 days. The inspections were performed visually using a stereomicroscope at magnifications ranging from $25 \mathrm{X}$ to $40 \mathrm{X}$. The level of detection for crack indications using a stereomicroscope at the above mentioned magnifications is approximately $150 \mu \mathrm{m}(0.006 ")$. The first inspection after 14 days revealed that all scored and non-scored Alloy 600MA RUBs had developed cracking. The cracking exhibited a multi-directional nature and occurred predominantly in an area associated with the apex of the RUB specimens. After cracking was observed in Alloy 600MA RUBs, the specimens were removed and testing was resumed with Alloy 690TT specimens only. None of the Alloy 690TT RUB specimens revealed any crack indications, even after a total exposure time of 405 days ( 9,720 hours). Table 3-54 summarizes the results obtained during the hot steam test for both materials in the scored and non-scored condition. After the RUB tests, metallographic examination of a scored and nonscored specimen of each material was conducted. Vickers microhardness measurements $(100 \mathrm{~g}$ load-HV0.1) were conducted at selected locations.

The Alloy 600MA specimens exhibited PWSCC on numerous locations, which appeared independent of the presence of surface marks/scores. The crack progression occurred in an intergranular manner normal to the tube surfaces. Some locations exhibited through-wall defects. Vickers microhardness readings in the Alloy 600MA ranged from 290HV to $307 \mathrm{HV}$. Immediately adjacent to the mechanically-induced scores the microstructure yielded hardness ranging from $337 \mathrm{HV}$ to $345 \mathrm{HV}$.

The Alloy 690TT's microstructure appeared as expected to be, a semi-continuous to a continuous network of grain boundary precipitates as a result of mill annealing and the subsequent thermal treatment. The grain size was determined according to ASTM E 112 and showed relatively large variations since it ranged between 5 and 7 . No crack indications were found in this material confirming the findings from visual inspection. Vickers microhardness readings ranged from $260 \mathrm{HV}$ to $278 \mathrm{HV}$, approximately 30 points lower than that for the Alloy 600MA. Locations immediately adjacent to the scores yielded numbers ranging from $327 \mathrm{HV}$ to $335 \mathrm{HV}$, which is only 10 points lower than that of the Alloy 600MA.

PWSCC in Alloy 600MA tubing was observed in row $1 \mathrm{U}$-bends of actual SGs after approximately one year of plant operation. The configuration of a RUB specimen is comparable to a row $1 \mathrm{U}$-bend tube. However, the tighter bend radius and the split-tube configuration of the RUB specimens accelerate the time necessary to initiate cracking by a factor of 2 to 3 , if compared to an actual row 1 U-bend. Thus, the time necessary to initiate cracking in an actual row $1 \mathrm{U}$-bend under hot steam test conditions is 14 to 21 days. Based on the geometry of a row 1 U-bend, the conclusion can be drawn that one year of plant operation corresponds to approximately 20 days under hot steam test conditions. The 405 days test duration without cracking corresponds to approximately 20 years of plant operation for a row 1 U-bend. 


\subsubsection{Doped Steam Testing}

\subsubsection{Four-Point Bend Tests of Alloys 52M, 182, and 600 in Doped} Hydrogenated Steam by Jacko et al. 2003

Jacko et al. performed accelerated test of Alloys 52M, 182 and 600 weld mock-ups at $400^{\circ} \mathrm{C}$ $\left(752^{\circ} \mathrm{F}\right)$ in steam-plus-hydrogen doped with fluoride, chloride and sulfate anions. ${ }^{\text {[54] }}$ The objective of the test was to demonstrate the adequacy of the weld repair made to the reactor vessel outlet nozzle-to-pipe safe-end weld at Ringhals 4 in 2002. The Alloy 52M used for the repair is an improved version of Alloy 52 as used for the fusion welding of Alloy 690 component items. It is stated by Jacko et al. that the composition is modified from that of Alloy 52 by lowering $\mathrm{Al}$ and $\mathrm{Ti}$ and increasing the $\mathrm{Nb}+\mathrm{Ta}$ concentration; this is done to avoid slag and oxide inclusions in the multipass weldments. The chemical composition of the Alloys 52M, 182, and 600 used for the test mockups is summarized in Table 3-50.

A schematic drawing of the cross section of the Alloy 52M test specimens prepared to simulate the repair is shown in Figure 3-15. The right side of the specimen represents the AISI Type 316 safe end, while the left side represents the AWS Type 308-clad ASME SA-508 steel nozzle. The rectangular outline indicates the location of the specimen removed by machining for the accelerated corrosion testing. The Alloy 182 weld metal mockups for the companion tests were prepared in a slightly different manner. These specimens were removed from a full section mockup; that is, an $895-\mathrm{mm}$ OD pipe with $80-\mathrm{mm}$ thick wall. A number of different heats of Alloy 182 welding electrodes were used to make this full-scale nozzle weld. Table 3-50 lists the composition of a typical Alloy 182 heat used. Control specimens of Alloy 600 were fabricated from archived sections of a CRDM nozzle. This material was from Heat WF 147. This heat of Alloy 600 was noted by Jacko et al. as having exhibited moderate resistance to stress corrosion cracking in a previous test program.

The specimens were prepared as flat plates and bolt-loaded in specially designed four-point bending fixture as shown in Figure 3-16. The Alloy 182 weld specimens and the Alloy 52M weld specimens have the same dimensions. They were $180-\mathrm{mm}$ long $\mathrm{x} 40-\mathrm{mm}$ wide $\mathrm{x} 9-\mathrm{mm}$ thick plates in which the welds were transverse to the long dimension. The Alloy 600 specimens were $102-\mathrm{mm}$ long $\mathrm{x} 19-\mathrm{mm}$ wide $\mathrm{x} 3.8-\mathrm{mm}$ thick strips. The specimens were taken at locations of varying depths from the surface. The microstructure has been observed to vary through the wall of the nozzle. This permits the possibility that the SCC response may be influenced by heterogeneity of the microstructure or possible differences in the manufacturing-related deformation. Two strain/stress levels were tested in this program.

1. The lower level was $0.35 \%$ strain. This corresponds to the strain at approximately the $0.2 \%$ offset yield strength of the material because residual stresses associated with welds are typically around the yield strength.

2. The second strain/stress level was intended to exaggerate the strain conditions in order to represent a situation where the use of multiple weld passes might contribute to cyclic hardening of the material. Thus a strain level of $1 \%$ was selected and cyclic compression/tension loading was used. These specimens were first strained in 
compression to $-1 \%$ total strain by bending. The specimens were then deformed back to the original configuration and restrained in tension to $+1 \%$ strain.

In a four-point bend specimen configuration (Figure 3-16), the stresses and strains are constant between the inner supports. With the bent beam configuration, the entire weld and all microstructural features can be located within the inner supports, ensuring that the strain (and stress) is uniform, and that SCC is less likely to initiate at a location unique to the test article configuration. The stresses measured for these specimens at various stages in the test program are summarized in Table 3-51. These elastic stresses were calculated, using the $400^{\circ} \mathrm{C}$ elastic modulus of Alloy $600(195.3 \mathrm{GPa})$, from the strains released as the specimens were unloaded. The "low" stress values are approximately equal to the yield strengths of the test materials, typically in the range from 320 to $440 \mathrm{MPa}$. These stresses remained, even at the completion of the autoclave exposures; stress relaxation did not appear to be a significant factor. The residual stresses for the "high" stress specimens averaged 431 to $456 \mathrm{MPa}$ for the Alloy 600 and Alloy $52 \mathrm{M}$ specimens. Significantly higher stresses, 568 to $586 \mathrm{MPa}$, were measured for the Alloy 182 specimens, related perhaps to the higher yield strength and higher initial work-hardening rate for this weld metal.

A $400^{\circ} \mathrm{C}$ high-pressure steam-plus-hydrogen environment was selected for the accelerated corrosion test environment. To enhance the aggressiveness of this environment, the steam is raised from water that is "doped" with $30 \mathrm{ppm}$ each of the anions $\mathrm{Cl}^{-}, \mathrm{F}^{-}$and $\mathrm{SO}_{4}^{-2}$, each of which is added as sodium salts. The hydrogen partial pressure is controlled at approximately $75 \mathrm{kPa}$ with the total steam pressure at $20 \mathrm{MPa}$. This environment has been used for over fifteen years as a means to accelerate the simulated PWSCC of nickel-base alloys. In a recent accelerated test program, $400^{\circ} \mathrm{C}$ doped steam tests were performed on Alloy $600 \mathrm{CRDM}$ nozzle penetrations removed from Ringhals $2 .{ }^{[55]}$ The cumulative SCC initiation probability statistics from this experiment were compared to those for the initial PWSCC observed in service at Ringhals 2 . This analysis indicated that the degradation observed after 89,000 effective full-power hours $(\mathrm{EFPH})$ at $317^{\circ} \mathrm{C}\left(603^{\circ} \mathrm{F}\right)$ was essentially duplicated in 289 hours of exposure to $400^{\circ} \mathrm{C}\left(752^{\circ} \mathrm{F}\right)$ doped steam, an acceleration factor of 308 relative to primary water at $317^{\circ} \mathrm{C}\left(603^{\circ} \mathrm{F}\right)$. The Ringhals 4 reactor outlet nozzle operates at $322.8^{\circ} \mathrm{C}\left(613^{\circ} \mathrm{F}\right)$. Hence, the acceleration factor for the $400^{\circ} \mathrm{C}$ doped steam relative to this service temperature has to be adjusted to 195 to recognize this temperature difference (using $\mathrm{Q}=55 \mathrm{kcal} / \mathrm{mole}^{[55]}$ ). Thus, a cumulative exposure time of 1800 hours - on the order of eleven weeks of cumulative autoclave exposure time- is equivalent to 40 effective full-power years (EFPY) of operation of the Ringhals 4 nozzle. Regular inspections of the specimens were performed at convenient intervals. During these inspections, specimens were ultrasonically cleaned and given a fluorescent dye-penetrant examination. Posttest examinations of the specimens included dye-penetrant inspections and inspections of the surfaces by optical microscopy. Metallographic examinations were used to further characterize cracking or other features of interest.

The four-point bend test results are summarized in Table 3-52. After a cumulative exposure of 2051 hours (equivalent to 45.6 EFPY), no environmental degradation was detected on the surface of any of the Alloy 52M welds. In the inspection after a cumulative exposure of 1343 hours, short ( 0.16 and $0.20-\mathrm{mm}$ in length) indications were observed on the surface of the two high-strain Alloy 52M specimens. These indications did not change in subsequent exposures. 
Metallographic cross-sectioning indicated these to be shallow hot-microfissures that were present from the weld preparation, but were not clearly identified in the earlier examinations.

In addition to the Alloy 52M specimens, four Alloy 182 weld specimens were tested; two at low strain and two at high strain, Table III. After a cumulative exposure of 214 hours, a number of cracks were observed in both of the high-strain specimens. These cracks ranged from as short as $0.25 \mathrm{~mm}$ to $3.0 \mathrm{~mm}$ in length. The low-strain specimens first exhibited stress corrosion cracking at the 450-hour interim inspection. During a subsequent 148-hour exposure, these cracks grew to a maximum length of $4.0 \mathrm{~mm}$. The initial cracking was observed after 214 hours, with a subsequent exposure of approximately 150 hours more. The total crack depth is on the order of $1.4 \mathrm{~mm}$.

Six Alloy 600 specimens were also tested. Four of these were exposed in the autoclave containing the Alloy 52M weld specimens, and two were exposed in the autoclave containing the Alloy 182 weld specimens. Two specimens were strained to $0.35 \%$, whereas the remaining four were strained to $1 \%$. The four specimens exposed with the Alloy $52 \mathrm{M}$ specimens accrued a total exposure of 1801 hours (equivalent to 40.1 EFPY). The two low-strain specimens and one of the four high-strain specimens did not crack; the remaining high-strain specimen exhibited a short SCC crack at 598 hours. After a total of 1343 hours, this crack had grown to a length of $5 \mathrm{~mm}$, at which time the specimen was removed for characterization, including destructive metallographic sectioning. One of the high-strain Alloy 600 specimens exposed with the Alloy 182 weld specimens was cracked after 301 hours; a 5-mm long array of cracking was seen. The other highstrain specimen in this autoclave showed a similar, but smaller (2.7-mm long) crack array after 450 hours.

As noted above, the only indications found in the simulated Alloy 52M weld repairs were two microfissures, apparently residual from the specimen manufacturing process. Such microfissures are not unusual for austenitic nickel-base alloy welds. Visual and dye-penetrant inspections are generally successful in identifying these features, but they are typically classified as non-relevant through NB 5350 of ASME Code Section III. In general, these small microfissures are not observed to participate in the initiation or propagation of environmental cracking. Cracking of the Alloy 600 specimens was limited to three of the four specimens strained $1 \%$. The archived heat of CRDM nozzle from which this material was taken exhibits moderate resistance to SCC in laboratory tests; hence, these results are reasonable. Even though the cracking was less severe than in the Alloy 182 weld specimens, the cracks initiated in times $(214,365$ and 598 hours) that were only a fraction of the 2051-hour cumulative exposure time of the Alloy 52M weld specimens, which did not crack.

\subsection{Low Temperature Crack Propagation (LTCP)}

Brown and Mills investigated fracture behavior of Alloys 690 and 600 and their weld metals EN82H (Alloy 82) and EN52 (Alloy 52) in low and high temperature hydrogenated and alkali treated water. $^{[56,57,58]}$ EN82H and EN82 are military specifications of Alloy 82. EN82H contains a higher content of carbon than EN82. The chemical compositions of the materials tested are listed in Table 3-59. The carbon content of the EN82H heats tested was $\sim 0.04 \%$, which was within the ASME Section II limit of $0.10 \%$ max. for Alloy 82 (see Table 2-2). Fracture toughness tests were performed on deeply precracked cracked compact (CT) specimens. The CT 
specimens were machined from a $50.8 \mathrm{~mm}$ ( 2 inch) thick Alloy 600MA plate and a $76.2 \mathrm{~mm}(3$ inch) dia. Alloy 690TT bar. The Alloy $600 \mathrm{MA}$ plate was annealed at $982^{\circ} \mathrm{C}\left(1800^{\circ} \mathrm{F}\right)$ and the Alloy $690 \mathrm{TT}$ was annealed at $1074^{\circ} \mathrm{C}\left(1965^{\circ} \mathrm{F}\right)$ and thermally treated at $718^{\circ} \mathrm{C}\left(1324^{\circ} \mathrm{F}\right)$ for 10 hours. The EN82H and EN52 weld metals were fabricated using a manual gas-tungsten arc (GTA) weld process to join 25.4-mm (1-inch) thick Alloys 600 and 690 plates or to join 50.8$\mathrm{mm}$ (2-inch) thick plates. Welds were fabricated by three manufacturers using a pure argon shield gas or an argon-hydrogen shield gas. The weld CT-specimens were machined and tested for fracture resistance in the as-welded condition.

The fracture toughness tests were performed at $54^{\circ} \mathrm{C}\left(129^{\circ} \mathrm{F}\right)$ and $338^{\circ} \mathrm{C}\left(640^{\circ} \mathrm{F}\right)$ in air and in alkali-treated deionized water with a hydrogen concentration ranging from 15 to $200 \mathrm{cc} \mathrm{H}_{2} / \mathrm{kg}$ $\mathrm{H}_{2} \mathrm{O}$. All test materials exhibited excellent fracture toughness at $338^{\circ} \mathrm{C}\left(640^{\circ} \mathrm{F}\right)$ undergoing ductile failure. The fracture toughness of Alloy 600 was mostly unaffected in the $54^{\circ} \mathrm{C}\left(129^{\circ} \mathrm{F}\right)$ water and maintained a ductile failure mechanism. Alloy 690, EN82H, and EN52 showed dramatic decreases in fracture toughness in $54^{\circ} \mathrm{C}\left(129^{\circ} \mathrm{F}\right)$ water transitioning from ductile tearing to intergranular cracking. This intergranular cracking was reproduced in hydrogen-precharged specimens tested in air. The low temperature embrittlement was attributed to hydrogen buildup in the crack tip, causing embrittlement which changed the crack propagation mechanism from ductile dimple rupture to intergranular. Such an embrittlement phenomenon was termed "low temperature crack propagation (LTCP). The main conclusions of the studies are summarized below:

1. The high hydrogen concentration in the water does not affect the $J$ value in high temperature water since the high temperature facilitates hydrogen diffusion, hence avoiding a build-up of hydrogen at the crack tip.

2. The high hydrogen concentration in the water at low temperatures appears to affect the $J$ value, due to a hydrogen embrittlement type phenomenon. As the hydrogen concentration is lowered, the $\mathrm{J}$ values increase.

3. There appears to be a large scatter in the data, particularly for tests at $54^{\circ} \mathrm{C}\left(129^{\circ} \mathrm{F}\right)$, apparently attributable to weld manufacturer.

4. High loading rates in $54^{\circ} \mathrm{C}\left(129^{\circ} \mathrm{F}\right)$ water yield similar $\mathrm{J}$ values compared to low loading rates in $338^{\circ} \mathrm{C}\left(640^{\circ} \mathrm{F}\right)$ water. This indicates that diffusion and accumulation of hydrogen at the crack tip is the cause of embrittlement at low temperature.

5. Modest toughness and ductility is nevertheless retained at low temperatures in Alloy 690 . As a result, LTCP is not a primary design concern for Alloy 690.

It should be noted that LTCP is not considered a crack initiation mechanism but is rather a potential mechanism for an existing crack to propagate. No LTCP related failures of Alloy 690 or its weld metals have ever been reported in PWRs or in any actual field applications. Based on these results, LTCP could only become operative at temperatures below approximately $149^{\circ} \mathrm{C}$ $\left(300^{\circ} \mathrm{F}\right)$. LTCP is not considered to be a concern under normal PWR operating conditions due to 
the operating temperature of $550^{\circ} \mathrm{F}$ to $650^{\circ} \mathrm{F}$. Furthermore, the hydrogen concentration used in the above mentioned studies was four to five times the normal hydrogen concentration found in primary water. LTCP is probably not a concern under shutdown conditions due to the significantly lower hydrogen concentrations present, when compared to the hydrogen level used in the studies.

Symons studied the effect of hydrogen charging on Alloy 690 plate ${ }^{[59]}$ Both solution annealed and thermally treated Alloy 690 subsize tension specimens and compact tension (CT) specimens were charged in pure hydrogen autoclave at $337^{\circ} \mathrm{C}\left(639^{\circ} \mathrm{F}\right)$ for four weeks. The hydrogen concentration was measured at 38 to $60 \mathrm{ppm}(\mathrm{wt} \%)$. The tensile specimens were tested at a strain rate $4 \times 10^{-4} \mathrm{sec}^{-1}$ at room temperature and the CT specimens were tested according to ASTM E 819-89 at room temperature. The test results showed that hydrogen addition reduced Alloy 690 ductility and fracture toughness. The degree of embrittlement was more severe for the thermally treated Alloy 690 than solution annealed Alloy 690. The increased embrittlement was attributed to a combination of an elevated local hydrogen concentration (hydrogen trapping) by grain boundary carbides and an increased stress level at the carbides/matrix interface due to larger carbide precipitates. Intergranular cracking was more extensive in precracked CT specimens than in tensile specimens. The hydrostatic stress, which increases the intergranular cracking tendency, is much higher in CT specimens than in tensile specimens.

Lenartova studied Alloys 600, 690, 800 and Type 321 stainless steel cathodically charged with hydrogen to 30 or $115 \mathrm{ppm} .{ }^{[60]}$ The charged tensile specimens were tested at a strain rate of $10^{-7}$ $\mathrm{sec}^{-1}$ at room temperature. The solution annealed Alloys 690, 800 and Type 321 did not show any intergranular cracking but Alloy 600 did show some sensitivity to IG hydrogen embrittlement even without grain boundary carbides. When carbides were precipitated on grain boundaries (accompanied by phosphorus segregation as reported by the author) of Alloys 600 , 690 and Type 321 stainless steel, intergranular cracking was observed to increase with increasing hydrogen content and could be suppressed by extracting the hydrogen. However, Alloy $800 \mathrm{did}$ not show any intergranular cracking whatever the heat treatment or state of precipitation on grain boundaries. The critical concentration for mainly intergranular hydrogen cracking in the nickel alloys and stainless steel with GB carbides was about $30 \mathrm{ppm}$ whereas below $5 \mathrm{ppm}$ the ductility and fracture surfaces were very similar to those of the as-received condition. Note that in PWR primary water the average hydrogen concentration attained in austenitic metals is $<2 \mathrm{ppm}$.

It is clear from other studies of low temperature cracking of Alloy 600 in PWR primary water or after cathodic hydrogen charging that the grain boundary carbide morphology of such benefit to PWSCC resistance has exactly the opposite effect on low temperature hydrogen embrittlement. ${ }^{[60]}$ Considerable benefit from improved grain boundary carbide morphology is obvious from practical operating experience to date with thermally treated Alloy 600 and Alloy 690 whereas the opposite effect would have occurred if LTCP had been a dominant failure mode. Thus, it is concluded that LTCP is unlikely to become a practical concern for Alloy 690, and Alloy 152, and Alloy 52 weld metals. 


\subsection{Corrosion Fatigue}

Psaila-Dombrowski et al. performed S-N fatigue tests for Alloy 690 plate and Alloys 82, 182, and 152 weld metals in air and in simulated primary water at $315^{\circ} \mathrm{C}\left(600^{\circ} \mathrm{F}\right)$ and fatigue crack growth rate tests for Alloys 82 and 52 weld metals in simulated primary water at $315^{\circ} \mathrm{C}\left(600^{\circ} \mathrm{F}\right) .^{[42]} \mathrm{The}$ simulated primary water chemistry is listed in Table 3-29. A number of weld build-ups and a composite plate were manufactured. The weld samples were fabricated in a manner consistent with SG fabrication practices in which Alloy 52 is used to attach the Alloy 690 plate to the Alloy 82 buildup. The mock-up composite plate began as a $60 \mathrm{~mm}$ (2.36") thick A 508 carbon steel plate. One edge of the $A 508$ plate was overlaid with a $5 \mathrm{~mm}$ thickness of Alloy 82 and then stress relieved. The test block was completed by making a modified double $\mathrm{V}$-groove weld between the $5.5 \mathrm{~mm}$ thick Alloy 690 plate and the Alloy 82 overlay using Alloy 152 . The plate was not stress relieved following the welding. The overall length of the composite weld plate was $\sim 1,000 \mathrm{~mm}$. However, information on the chemical composition of the Alloy 82 and 152 weld metals and Alloy 690 plate and heat treatment condition of Alloy 690 were not reported.

A modified tensile specimen (see Figure 3-18) was used to conduct the low cycle fatigue tests. The orientation of the specimens was such that the axes of the specimens were perpendicular to the direction of welding. In all cases, the gauge sections of the specimens contained only the test material of interest. The tests were conducted in a 76 liter autoclave using a load frame with high lateral stiffness to maintain alignment of the specimen during testing. Most fatigue tests were completed using a strain range of 0.008 and a mean strain of 0 . However, several tests were performed at different strain levels to expand the data base. With one exception, all tests in the simulated primary water were performed at a strain rate of $0.001 \mathrm{sec}^{-1}$. Higher strain rates were used in the air tests because no effect of frequency was expected in an air environment.

The fatigue test results (see Table 3-60 and Figure 3-19) showed that the Alloy 690 fatigue life in the primary water decreased by about $40 \%$ compared to the fatigue life in air. However, it was still well above the ASME design curve. The fatigue properties of Alloy 690 in the primary water and in air were in good agreement with predictions made using the following model for Alloy 600 at 150 to $350^{\circ} \mathrm{C}\left(302\right.$ to $\left.662^{\circ} \mathrm{F}\right)$.

$$
\begin{array}{ll}
\text { In air, } & \operatorname{Ln}\left(\mathrm{N}_{25}\right)=6.94-1.776 \operatorname{Ln}\left(\varepsilon_{\mathrm{a}}-0.12\right)+0.498 \\
\text { In water, } & \operatorname{Ln}\left(\mathrm{N}_{25}\right)=6.94-1.776 \operatorname{Ln}\left(\varepsilon_{\mathrm{a}}-0.12\right)+0.498-0.401
\end{array}
$$

Where, $\mathrm{N}_{25}$ - the fatigue life defined as the number of cycles for the peak tensile stress to drop $25 \%$ from its initial value $\varepsilon_{\mathrm{a}}$ - the applied strain amplitude in \%

Figure 3-19 also shows that the Alloy 82 weld metal exhibited the highest fatigue life among the four materials tested in air. In primary water, all four materials exhibited similar fatigue lives, which were all well above the ASME design curve. Thus, it appears that the primary water has a measurable influence on fatigue life at the strain range and rates used in the study. However, additional fatigue data under other test conditions should be obtained to provide a more complete characterization. 
The fatigue crack growth rate tests used standard ASTM precracked 1T compact tension (CT) specimens. The specimens were fabricated with an orientation where crack growth was normal to the welding direction. The results of the test were presented as crack growth rate as a function of stress intensity range $(\Delta \mathrm{K})$ and loading frequency as shown in Table 3-61 and Figure 3-20. The test data showed that the cycle-based crack growth rate varied inversely with loading frequency for both Alloy 52 and Alloy 82 weld metals, but the variation was higher for Alloy 82 than Alloy 52 . In evaluating the crack growth data for the Alloy 82 at $\Delta K=36 \mathrm{ksi}$ in, it was evident that the data separated into two groups. One group exhibited crack growth rates somewhat higher than the other group. The group of higher growth rates was obtained from a second Alloy 82 specimen taken very near the location of the first Alloy 82 specimen. The reason for the difference in crack growth rate was not clear, but it might indicate that a measurable degree of variation exists in the crack growth properties as a function of locations in the weld. Alloy 52 exhibited a better fatigue crack growth resistance than Alloy 82 in the primary water, but the magnitude of the difference was observed to vary as a function of specimen orientation. Thus, it was not clear if the difference was statistically significant. Compared to the available fatigue crack growth rates in air, the fatigue crack growth rates were typically accelerated by factors of 5 to 20 in the primary water. 
Table 3-1 High Velocity Loop Test Conditions by Sedricks et al. ${ }^{[9]}$

\begin{tabular}{|c|c|c|c|}
\hline \multicolumn{3}{|c|}{ Loop Test Conditions } & PWR Steam Generator \\
\hline Temperature & \multicolumn{2}{|c|}{$600^{\circ} \mathrm{F}\left(316^{\circ} \mathrm{C}\right)$} & $\sim 610^{\circ} \mathrm{F}$ \\
\hline Pressure & \multicolumn{2}{|c|}{2000 psig (13.8 MPa) } & 〜2200 psig \\
\hline Flow Rate & \multicolumn{2}{|c|}{$18 \mathrm{ft} / \mathrm{sec}(5.5 \mathrm{~m} / \mathrm{sec})$} & $\sim 20 \mathrm{ft}$ \\
\hline \multicolumn{3}{|c|}{ Loop Water Chemistry } & \\
\hline & Borated Water & Ammoniated Water & EPRI Guidelines, Primary Water ${ }^{[62]}$ \\
\hline Hydrogen & $25 \mathrm{cc} \mathrm{STP} \mathrm{H}_{2} / \mathrm{kg} \mathrm{H}_{2} \mathrm{O}$ & $25 \mathrm{cc} \mathrm{STP} \mathrm{H}_{2} / \mathrm{kg} \mathrm{H} \mathrm{H}_{2} \mathrm{O}$ & 25 - $35 \mathrm{cc} \mathrm{STP} \mathrm{H}_{2} / \mathrm{kg} \mathrm{H} \mathrm{H}_{2} \mathrm{O}$ \\
\hline Oxygen & $0-15 \mathrm{ppb}$ & $0-15 \mathrm{ppb}$ & $<5 \mathrm{ppb}$ \\
\hline $\mathrm{H}_{3} \mathrm{BO}_{3}$ & 1500 ppm & -- & $0-10,000$ ppm \\
\hline $\mathrm{LiOH}$ & 0.7 ppm & -- & 3.5 ppm \\
\hline $\mathrm{pH}$ & 5.5 & $9.5-10.9$ by ammonia & $\mathrm{pH}>6.9$ at $77^{\circ} \mathrm{F}$ \\
\hline Loop Volume & 8.5 gal (32.3 liter) & 8.5 gal (32.3 liter) & -- \\
\hline
\end{tabular}

Table 3-2 Chemical Composition of Alloy 690 Heats (wt\%) Used by Sedricks et al. ${ }^{[0]}$

\begin{tabular}{|c|c|c|c|c|c|c|c|c|c|c|c|c|c|c|}
\hline Heat & Ref & $\mathrm{Ni}$ & $\mathrm{Cr}$ & $\mathrm{Fe}$ & C & Mn & Si & $S$ & $\mathrm{Ti}$ & $\begin{array}{c}\mathrm{Nb}+ \\
\mathrm{Ta}\end{array}$ & $\mathrm{Cu}$ & $\mathrm{P}$ & Al & Mo \\
\hline Y24A7L & 9 & Bal. & 29.9 & 8.7 & 0.02 & & & & & & & & & \\
\hline $\mathrm{NX} 10 \mathrm{C} 1 \mathrm{H}$ & 9 & Bal. & 30.8 & 9.6 & 0.03 & & & & & & & & & \\
\hline $\mathrm{NX} 4458 \mathrm{H}$ & 9 & Bal. & 27.9 & 8.8 & 0.01 & & & & & & & & & \\
\hline $\mathrm{NX20C4H}$ & 9 & Bal. & 30.2 & 9.0 & 0.02 & & & & & & & & & \\
\hline $\mathrm{NX} 4460 \mathrm{H}$ & 9 & Bal. & 28.3 & 8.9 & 0.06 & & & & & & & & & \\
\hline $\mathrm{T}-57177$ & 9 & Bal. & 29.3 & 10.1 & 0.05 & & & & & & & & & \\
\hline T-99016 & 9 & Bal. & 29.3 & 11.4 & 0.07 & & & & & & & & & \\
\hline T-53176 & 9 & Bal. & 28.8 & 12.4 & 0.07 & & & & & & & & & \\
\hline T-53838 & 9 & Bal. & 28.3 & 12.1 & 0.07 & & & & & & & & & \\
\hline T-61540 filler & 9 & Bal. & 29.3 & 11.7 & 0.06 & & & & & & & & & \\
\hline
\end{tabular}


Table 3-3 Chemical Composition (wt\%) of Alloy 690 Heats Used by K. Smith et al. ${ }^{[1]}$

\begin{tabular}{|c|c|c|c|c|c|c|c|c|c|c|c|c|c|c|}
\hline Heat & $\mathrm{Ni}$ & $\mathrm{Cr}$ & $\mathrm{Fe}$ & C & $\mathrm{Mn}$ & $\mathrm{Si}$ & $S$ & $\mathrm{Ti}$ & $\begin{array}{c}\mathrm{Nb}+ \\
\mathrm{Ta}\end{array}$ & $\mathrm{Cu}$ & $\mathbf{P}$ & Al & Mo & Co \\
\hline Heat 1 & 58.8 & 28.9 & 10.2 & 0.016 & 0.15 & 0.24 & 0.001 & 0.33 & & 0.17 & 0.011 & 0.31 & & 0.04 \\
\hline Heat 2 & 61.2 & 29.1 & 8.6 & 0.028 & 0.24 & 0.30 & 0.002 & 0.25 & & 0.01 & 0.005 & 0.28 & & 0.01 \\
\hline Heat 3 & 60.4 & 30.9 & 7.2 & 0.038 & 0.28 & 0.32 & 0.002 & 0.25 & & 0.01 & 0.005 & 0.33 & & 0.01 \\
\hline
\end{tabular}

Mechanical Properties: Mill annealed at $1040^{\circ} \mathrm{F}\left(1904^{\circ} \mathrm{F}\right)+$ thermally treated at $700^{\circ} \mathrm{C}\left(1292^{\circ} \mathrm{F}\right)$ for 5 hours

\begin{tabular}{|l|l|l|l|l|l|l|}
\hline \multirow{2}{*}{ Heat } & \multicolumn{2}{|l|}{ Room Temp 0.2\% Yield Strength } & \multicolumn{3}{l|}{ Room Temp Tensile Strength } & \multicolumn{2}{l|}{$350^{\circ} \mathrm{C}\left(662^{\circ} \mathrm{F}\right) 0.2 \%$ Yield Strength } \\
\cline { 2 - 7 } & $\mathrm{MPa}$ & $\mathrm{ksi}$ & $\mathrm{MPa}$ & $\mathrm{ksi}$ & $\mathrm{MPa}$ & $\mathrm{ksi}$ \\
\hline Heat 1 & 344 & 49.9 & 739 & 107.2 & 269 & 39.0 \\
\hline Heat 2 & 438 & 63.5 & 814 & 118.0 & 364 & 52.8 \\
\hline Heat 3 & 444 & 64.4 & 829 & 120.2 & 357 & 51.8 \\
\hline
\end{tabular}

Table 3-4 Chemical Composition (wt\%), Heat Treatment of Specimens Used by Yonezawa et al. ${ }^{[17]}$

\begin{tabular}{|l|c|c|c|c|c|c|c|c|c|c|c|c|c|c|}
\hline \multicolumn{1}{|c|}{ Heat } & $\mathrm{Ni}$ & $\mathrm{Cr}$ & $\mathrm{Fe}$ & $\mathrm{C}$ & $\mathrm{Mn}$ & $\mathrm{Si}$ & $\mathrm{S}$ & $\mathrm{Ti}$ & $\begin{array}{c}\mathrm{Nb}+ \\
\mathrm{Ta}\end{array}$ & $\mathrm{Cu}$ & $\mathrm{P}$ & $\mathrm{Al}$ & $\mathrm{Mo}$ & $\mathrm{Co}$ \\
\hline Alloy 690 & 59.86 & 30.10 & 8.94 & 0.020 & 0.34 & 0.23 & & 0.24 & & & & & & \\
\hline Alloy 600 & 74.50 & 15.90 & 8.51 & 0.027 & 0.30 & 0.35 & & 0.19 & & & & & & \\
\hline Alloy $800 \mathrm{~L}$ & 33.65 & 21.20 & 42.9 & 0.020 & 0.62 & 0.49 & & 0.42 & & & & & & \\
\hline
\end{tabular}

\begin{tabular}{|l|l|l|l|}
\hline & Annealing Temp & Thermal Treatment & Other \\
\hline Alloy 690MA & $950^{\circ} \mathrm{C}\left(1742^{\circ} \mathrm{F}\right)$ & -- & --- \\
\hline Alloy 690TT & $1075^{\circ} \mathrm{C}\left(1967^{\circ} \mathrm{F}\right)$ & $700^{\circ} \mathrm{C}\left(1292^{\circ} \mathrm{F}\right)$ for 15 hours & --- \\
\hline Alloy 600MA & $975^{\circ} \mathrm{C}\left(1787^{\circ} \mathrm{F}\right)$ & -- & --- \\
\hline Alloy 600TT & $920^{\circ} \mathrm{C}\left(1688^{\circ} \mathrm{F}\right)$ & $700^{\circ} \mathrm{C}\left(1292^{\circ} \mathrm{F}\right)$ for 15 hours & --- \\
\hline Alloy 800L & $925^{\circ} \mathrm{C}\left(1697^{\circ} \mathrm{F}\right)$ & -- & Slight cold worked \& shot peened. \\
\hline Alloy 800L & $925^{\circ} \mathrm{C}\left(1697^{\circ} \mathrm{F}\right)$ & -- & --- \\
\hline
\end{tabular}


Table 3-5 Test Condition for General Corrosion and RUB Specimens by Yonezawa et al. ${ }^{[1]}$

\begin{tabular}{|c|c|}
\hline Temperature & $360^{\circ} \mathrm{C}\left(680^{\circ} \mathrm{F}\right)$ \\
\hline Hydrogen & $30 \mathrm{cc} / \mathrm{kg} \mathrm{H} \mathrm{H}_{2} \mathrm{O} \mathrm{STP}$ \\
\hline Oxygen & $<5 \mathrm{ppb}$ \\
\hline $\mathrm{H}_{3} \mathrm{BO}_{3}$ & $500 \mathrm{ppm}$ \\
\hline $\mathrm{LiOH}$ & $1-2 \mathrm{ppm}$ \\
\hline $\mathrm{pH}$ & Not listed \\
\hline
\end{tabular}

Table 3-6 General Corrosion by Yonezawa et al. ${ }^{[1]]}$

\begin{tabular}{|l|c|c|}
\hline & $\begin{array}{c}\text { Weight Loss }\left(\mathrm{mg} / \mathrm{cm}^{2}\right) \text { after } 1000 \text { hours at } \\
360^{\circ} \mathrm{C}\left(680^{\circ} \mathrm{F}\right)\end{array}$ & $\begin{array}{c}\text { Weight Loss }\left(\mathrm{mg} / \mathrm{cm}^{2}\right) \text { after } 4000 \text { hours at } \\
360^{\circ} \mathrm{C}\left(680^{\circ} \mathrm{F}\right)\end{array}$ \\
\hline Alloy 690MA & Not tested & 0.02 \\
\hline Alloy 690TT & 0.07 & 0.02 \\
\hline Alloy 600MA & 0.10 & 0.03 \\
\hline Alloy 600TT & 0.13 & 0.02 \\
\hline Alloy 800L & 0.13 & 0.03 \\
\hline
\end{tabular}


Table 3-7 Autoclave Test Conditions Used by Esposito et al. ${ }^{[3]}$

\begin{tabular}{|l|l|l|}
\hline & Without Zinc & With Zinc \\
\hline Temperature & $330^{\circ} \mathrm{C}\left(626^{\circ} \mathrm{F}\right)$ & $330^{\circ} \mathrm{C}\left(626^{\circ} \mathrm{F}\right)$ \\
\hline Pressure & $2600 \mathrm{psi}(17.9 \mathrm{MPa})$ & $2600 \mathrm{psi}(17.9 \mathrm{MPa})$ \\
\hline Hydrogen & $25 \mathrm{cc} / \mathrm{kg} \mathrm{H} \mathrm{O}_{2} \mathrm{O}$ & $25 \mathrm{cc} / \mathrm{kg} \mathrm{H} \mathrm{O}_{2}$ \\
\hline Oxygen & Not listed & Not listed \\
\hline $\mathrm{H}_{3} \mathrm{BO}_{3}$ & $1200 \mathrm{ppm}$ & $1200 \mathrm{ppm}$ \\
\hline LiOH & $2.2 \mathrm{ppm}$ & $2.2 \mathrm{ppm}$ \\
\hline pH & Not listed & Not listed \\
\hline $\begin{array}{l}\text { Feed rate from make- } \\
\text { up tank }\end{array}$ & $300 \mathrm{cc} / \mathrm{hour}$ & $300 \mathrm{cc} / \mathrm{hour}$ \\
\hline Zinc Borate & None & $50 \mathrm{ppb}$ \\
\hline
\end{tabular}

Table 3-8 General Corrosion Rate in Primary Water by Esposito ${ }^{[31]}$

\begin{tabular}{|l|c|c|c|c|}
\hline & \multicolumn{2}{|c|}{$\begin{array}{c}\text { Corrosion Rate, 2500 hour Average } \\
\mathrm{mg} / \mathrm{dm}^{2} / \mathrm{month}\end{array}$} & \multicolumn{2}{c|}{$\begin{array}{c}\text { Metal Release Rate, 2500 hour Average } \\
\mathrm{mg} / \mathrm{dm}^{2} / \mathrm{month}\end{array}$} \\
\hline & With Zinc & Without Zinc & With Zinc & Without Zinc \\
\hline $304 \mathrm{SS}$ & 1.1 & 3.5 & 0.1 & 1.3 \\
\hline $316 \mathrm{SS}$ & 1.3 & 3.5 & 0.1 & 1.4 \\
\hline 600MA & 1.5 & 2.6 & 0.3 & 0.8 \\
\hline $600 \mathrm{TT}$ & 0.5 & 2.1 & 0.2 & 0.9 \\
\hline $690 \mathrm{TT}$ & 0.2 & 1.3 & 0.1 & 0.6 \\
\hline X-750 & 0.6 & 2.6 & 0.2 & 1.2 \\
\hline Stellite & 0.4 & 14.7 & 0.1 & 12.0 \\
\hline
\end{tabular}


Table 3-9 General Corrosion Data in PWR Primary Water by Esposito et al. ${ }^{[31]}$

\begin{tabular}{|c|c|c|c|c|c|c|c|c|}
\hline & \multicolumn{4}{|c|}{ Without Zinc Addition } & \multicolumn{4}{|c|}{ With Zinc Addition } \\
\hline Material & $\begin{array}{l}\text { Exposure } \\
\text { Time } \\
\text { (hour) }\end{array}$ & $\begin{array}{l}\text { Metal } \\
\text { Loss } \\
\left(\mathrm{mg} / \mathrm{dm}^{2}\right)\end{array}$ & $\begin{array}{l}\text { Oxide } \\
\text { Remaining } \\
\left(\mathrm{mg} / \mathrm{dm}^{2}\right)\end{array}$ & $\begin{array}{l}\text { Metal } \\
\text { Release } \\
\left(\mathrm{mg} / \mathrm{dm}^{2}\right)\end{array}$ & $\begin{array}{l}\text { Exposure } \\
\text { Time } \\
\text { (hour) }\end{array}$ & $\begin{array}{l}\text { Metal } \\
\text { Loss } \\
\left(\mathrm{mg} / \mathrm{dm}^{2}\right)\end{array}$ & $\begin{array}{l}\text { Oxide } \\
\text { Remaining } \\
\left(\mathrm{mg} / \mathrm{dm}^{2}\right)\end{array}$ & $\begin{array}{l}\text { Metal } \\
\text { Release } \\
\left(\mathrm{mg} / \mathrm{dm}^{2}\right)\end{array}$ \\
\hline 304 SS & 500 & 4.04 & 3.37 & 1.68 & 500 & 1.70 & 1.81 & 0.43 \\
\hline 304 SS & 2500 & 13.64 & 11.48 & 5.61 & 2500 & 3.75 & 4.77 & 0.41 \\
\hline 304 SS & 2500 & 11.05 & 11.17 & 3.23 & -- & -- & -- & -- \\
\hline 316 SS & 2500 & 12.37 & 10.66 & 4.91 & 2500 & 4.34 & 5.53 & 0.47 \\
\hline 600MA & 500 & 4.26 & 5.41 & 0.47 & -- & -- & -- & -- \\
\hline $600 \mathrm{MA}$ & 2500 & 7.61 & 7.46 & 2.39 & 2500 & 6.66 & 7.50 & 1.42 \\
\hline 600MA & 2500 & 10.49 & 10.32 & 3.27 & 2500 & 3.77 & 4.43 & 0.66 \\
\hline $600 \mathrm{MA}$ & 2500 & 10.83 & 10.33 & 3.60 & -- & -- & --- & -- \\
\hline 600MA & 2500 & 6.88 & 6.39 & 2.41 & - & - & --- & --- \\
\hline $600 T T$ & 500 & 1.00 & 1.50 & -0.05 & 500 & 0.33 & 0.03 & 0.10 \\
\hline $600 T T$ & 1300 & 6.66 & 6.66 & 2.00 & 1300 & 1.33 & 1.66 & 0.17 \\
\hline $600 T \mathrm{~T}$ & 2500 & 7.16 & 5.83 & 3.10 & 2500 & 1.83 & 1.66 & 0.67 \\
\hline $690 T T$ & 500 & 0.81 & 1.29 & -0.09 & 500 & 0.50 & 1.00 & -0.20 \\
\hline $690 \mathrm{TT}$ & 1300 & 3.28 & 3.44 & 0.87 & 1300 & 0.49 & 1.31 & -0.40 \\
\hline $690 T T$ & 2500 & 4.50 & 3.33 & 2.17 & 2500 & 0.81 & 1.93 & -0.50 \\
\hline$X-750$ & 2500 & 8.93 & 7.06 & 3.99 & 2500 & 2.00 & 1.87 & 0.69 \\
\hline Stellite & - & -- & - & -- & 800 & 1.98 & 1.85 & 0.69 \\
\hline Stellite & 2500 & 61.80 & 16.00 & 50.60 & 2500 & 3.68 & 3.82 & 1.00 \\
\hline Stellite & 2500 & 74.90 & 25.50 & 57.10 & 2500 & 1.22 & 1.22 & 0.37 \\
\hline
\end{tabular}


Table 3-10 Double U-Bend Test Conditions Used by Sedricks ${ }^{[9]}$

\begin{tabular}{|c|c|c|c|c|c|}
\hline Autoclave Test & Test 1a & Test $\mathbf{1 b}$ & Test 2 & Test 3 & Test 4 \\
\hline Alloy 690 Heat & Y24A7L & $\mathrm{N} \times 4458 \mathrm{H}, \mathrm{N} \times 4460 \mathrm{H}$ & Not reported & Y24A7L & Not reported \\
\hline Test Time & 48 weeks & 60 weeks & 96 weeks & 48 weeks & 18 weeks \\
\hline Temperature & $600^{\circ} \mathrm{F}\left(316^{\circ} \mathrm{C}\right)$ & $680^{\circ} \mathrm{F}\left(360^{\circ} \mathrm{C}\right)$ & $620^{\circ} \mathrm{F}\left(326^{\circ} \mathrm{C}\right)$ & $600^{\circ} \mathrm{F}\left(316^{\circ} \mathrm{C}\right)$ & $600^{\circ} \mathrm{F}\left(316^{\circ} \mathrm{C}\right)$ \\
\hline Water source & \multicolumn{2}{|c|}{$\begin{array}{l}\text { Distilled-deionized water, receptivity }>1 \\
\qquad \mathrm{M} \Omega-\mathrm{cm}\end{array}$} & $\begin{array}{l}\text { Add } 60 \text { ppm } \\
\mathrm{Na}_{2} \mathrm{HOP}_{4}\end{array}$ & $\begin{array}{l}\text { Distilled-deionized } \\
\text { water }\end{array}$ & $\begin{array}{l}\text { Add } 10 \mathrm{~g} \text { lead for } \\
1.8 \text { liter water }\end{array}$ \\
\hline $\mathrm{pH}$ & \multicolumn{3}{|c|}{$\mathrm{pH} 10$ adjusted with $\mathrm{NH}_{4} \mathrm{OH}$} & $\mathrm{pH}$ unadjusted & $\mathrm{pH}$ unadjusted \\
\hline $\begin{array}{l}\text { Deaeration } \\
\text { Method }\end{array}$ & $\begin{array}{c}\text { Ar pressurizing- } \\
\text { aspirating; } \\
\text { bubbling } \mathrm{Ar}\end{array}$ & $\mathrm{H}_{2}$ and catalyst $\mathrm{N}_{2} \mathrm{H}_{4}$ & $\begin{array}{l}\text { Bubbling } \mathrm{N}_{2} \\
\text { hydrazine }\end{array}$ & $\begin{array}{l}\text { Ar pressurizing- } \\
\text { aspirating; } \\
\text { Steaming }\end{array}$ & $\begin{array}{l}\text { Ar pressurizing- } \\
\text { aspirating }\end{array}$ \\
\hline Oxygen & $\sim 20$ ppb & $<20 \mathrm{ppb}$ & $10-20 \mathrm{ppb}$ & $0-5 \mathrm{ppb}$ & $\sim 20 \mathrm{ppb}$ \\
\hline Flow Rate & No flow & $0.3 \mathrm{gal} / \mathrm{hour}$ & No flow & No flow & No flow \\
\hline Hydrogen & None & Not reported & Not reported & None & None \\
\hline $\mathrm{H}_{3} \mathrm{BO}_{3}$ & None & None & None & None & None \\
\hline $\mathrm{LiOH}$ & None & None & None & None & None \\
\hline
\end{tabular}


Table 3-11 Double U-Bend (creviced) Test Results Under Test 1a Condition in Table 3-10

\begin{tabular}{|c|c|c|c|c|c|}
\hline & $\begin{array}{l}\text { Heat Treatment } \\
\text { Code (a) }\end{array}$ & $\begin{array}{l}\text { Number of } \\
\text { Specimens }\end{array}$ & $\begin{array}{l}\text { Test duration } \\
\text { (week) }\end{array}$ & $\begin{array}{l}\text { No. cracked Specimens / } \\
\text { No. destructively examined }\end{array}$ & $\begin{array}{l}\text { Max. Attack } \\
\text { Depth }\end{array}$ \\
\hline \multirow{8}{*}{$\begin{array}{l}\text { Alloy } 690 \text {, } \\
\text { Heat No. } \\
\text { Y24A7L }\end{array}$} & MA & 2 & 48 & $0 / 2$ & 0 \\
\hline & $M A+L$ & 2 & 48 & $0 / 2$ & 0 \\
\hline & $M A+A 1$ & 2 & 48 & $0 / 2$ & 0 \\
\hline & CR & 2 & 48 & $0 / 2$ & 0 \\
\hline & $A 1+L$ & 2 & 48 & $0 / 2$ & 0 \\
\hline & $A 3+L$ & 2 & 48 & $0 / 2$ & 0 \\
\hline & $A 2+W(1 / 2 ")$ & 2 & 18 & $0 / 2$ & 0 \\
\hline & $A 2+W\left(1^{\prime \prime}\right)$ & 2 & 18 & $0 / 2$ & 0 \\
\hline \multirow{5}{*}{$\begin{array}{l}\text { Alloy } 600 \text {, One } \\
\text { heat. Heat No. } \\
\text { not listed. }\end{array}$} & $\mathrm{CR}+\mathrm{A} 1$ & 2 & 48 & $0 / 2$ & 0 \\
\hline & $M A+C R$ & 2 & 18 & $1 / 2$ & $2.79 \mathrm{~mm}$ \\
\hline & Not listed & 2 & 48 & $0 / 2$ & 0 \\
\hline & $A 1+L$ & 2 & 48 & $0 / 2$ & 0 \\
\hline & $\mathrm{A} 3+\mathrm{L}$ & 2 & 48 & $0 / 2$ & 0 \\
\hline
\end{tabular}

(a) Heat treatment code:

MA - Mill annealed

CR - cold rolled $40 \%$

A $1-1$ hour at $2000^{\circ} \mathrm{F} /$ water quench

$\mathrm{A} 2-1$ hour at $2100^{\circ} \mathrm{F} /$ water quench

A3 -1 hour at $2200^{\circ} \mathrm{F} /$ water quench

$\mathrm{L}-2$ hours at $1200^{\circ} \mathrm{F} /$ air cool

$\mathrm{W}$ (thickness) = manual gas tungsten-arc welded at indicated thickness with matching filler . 
Table 3-12 Double U-Bend (creviced) Test Results Under Test 3 Condition in Table 3-10

\begin{tabular}{|c|c|c|c|c|c|}
\hline & $\begin{array}{l}\text { Heat Treatment } \\
\text { Code (a) }\end{array}$ & $\begin{array}{l}\text { Number of } \\
\text { Specimens }\end{array}$ & $\begin{array}{l}\text { Test duration } \\
\text { (week) }\end{array}$ & $\begin{array}{l}\text { No. cracked Specimens / } \\
\text { No. destructively examined }\end{array}$ & $\begin{array}{l}\text { Max. Attack } \\
\text { Depth }\end{array}$ \\
\hline \multirow{9}{*}{$\begin{array}{l}\text { Alloy } 690, \\
\text { Heat No. } \\
\text { Y24A7L }\end{array}$} & MA & 4 & 48 & $0 / 4$ & 0 \\
\hline & $M A+L$ & 4 & 48 & $0 / 4$ & 0 \\
\hline & $\mathrm{A} 1$ & 4 & 48 & $0 / 4$ & 0 \\
\hline & A2 & 6 & 48 & $0 / 6$ & 0 \\
\hline & $\mathrm{A} 1+\mathrm{L}$ & 4 & 48 & $0 / 4$ & 0 \\
\hline & $A 3+L$ & 4 & 48 & $0 / 4$ & 0 \\
\hline & $\mathrm{CR}$ & 4 & 48 & $0 / 4$ & 0 \\
\hline & $\mathrm{A} 2+\mathrm{W}\left(1 / 2^{\prime \prime}\right)$ & 4 & 48 & $0 / 4$ & 0 \\
\hline & $A 2+W(1 ")$ & 2 & 48 & $0 / 2$ & 0 \\
\hline \multirow{3}{*}{$\begin{array}{l}\text { Alloy } 600 \text {, One } \\
\text { heat. Heat No. } \\
\text { not listed. }\end{array}$} & MA & 4 & 48 & $1 / 4$ & $2 \mathrm{mil}(0.05 \mathrm{~mm})$ \\
\hline & A1 & 4 & 48 & $1 / 4$ & $5 \mathrm{mil}(0.12 \mathrm{~mm})$ \\
\hline & $\mathrm{A} 1+\mathrm{L}$ & 4 & 48 & $0 / 4$ & 0 \\
\hline
\end{tabular}

(a) Heat treatment code:

MA - Mill annealed

CR - cold rolled $40 \%$

$\mathrm{A} 1-1$ hour at $2000^{\circ} \mathrm{F} /$ water quench

A2 - 1 hour at $2100^{\circ} \mathrm{F} /$ water quench

A3 -1 hour at $2200^{\circ} \mathrm{F} /$ water quench

$\mathrm{L}-2$ hours at $1200^{\circ} \mathrm{F} /$ air cool

W (thickness) $=$ manual gas tungsten-arc welded at indicated thickness with matching filler .

Table 3-13 Double U-Bend (Creviced) Test Results Under Test 1b Condition in Table 3-10

\begin{tabular}{|c|c|c|c|c|c|c|}
\hline & $\begin{array}{l}\text { Heat } \\
\text { Treatment } \\
\text { Code }^{(a)}\end{array}$ & Heat No. & $\begin{array}{l}\text { Number of } \\
\text { Specimens }\end{array}$ & $\begin{array}{l}\text { Test } \\
\text { duration } \\
\text { (week) }\end{array}$ & $\begin{array}{c}\text { No. cracked Specimens / } \\
\text { No. destructively } \\
\text { examined }\end{array}$ & $\begin{array}{l}\text { Max. } \\
\text { Attack } \\
\text { Depth }\end{array}$ \\
\hline \multirow{3}{*}{$\begin{array}{l}\text { Alloy } \\
690\end{array}$} & M & $\mathrm{N} \times 4458 \mathrm{H}, \mathrm{NX} 4460 \mathrm{H}$ & 4 & 60 & $0 / 4$ & 0 \\
\hline & A4 & One of the above two heats & 2 & 60 & $0 / 2$ & 0 \\
\hline & $\mathrm{A} 4+\mathrm{L} 4$ & One of the above two heats & 2 & 60 & $0 / 2$ & 0 \\
\hline
\end{tabular}

(a) Heat treatment code:

$\mathrm{M}-0.5$ hour at $1850^{\circ} \mathrm{F} / \mathrm{air} \mathrm{cool}$

A4 -1 hour at $2050^{\circ} \mathrm{F} /$ water quench

L4 - 1 hour at $1250^{\circ} \mathrm{F}$ /air cool 
Table 3-14 SG Tubing Reverse U-Bend Test Conditions Use by K. Smith et al. ${ }^{[1]}$

\begin{tabular}{|l|l|l|}
\hline & Beginning of Fuel Cycle & End of Fuel Cycle \\
\hline Temperature & $360^{\circ} \mathrm{C}\left(680^{\circ} \mathrm{F}\right)$ & $360^{\circ} \mathrm{C}\left(680^{\circ} \mathrm{F}\right)$ \\
\hline Hydrogen & $3.8 \mathrm{ppm}$ dissolved $\mathrm{H}_{2}(240 \mathrm{KPa}$ over pressure $)$ & $3.8 \mathrm{ppm}$ dissolved $\mathrm{H}_{2}(240 \mathrm{KPa}$ over pressure $)$ \\
\hline Oxygen & Not listed & Not listed \\
\hline $\mathrm{H}_{3} \mathrm{BO}_{3}$ & $1200 \mathrm{ppm}$ & $200 \mathrm{ppm} \mathrm{B}$ \\
\hline $\mathrm{LiOH}$ & $2.0 \mathrm{ppm}$ & $0.5 \mathrm{ppm}$ \\
\hline $\mathrm{pH}$ & Not listed & Not listed \\
\hline
\end{tabular}

Table 3-15 Chemical Composition (wt\%) of Alloy 690 Heats Used by A. Smith et al. ${ }^{[32]}$

\begin{tabular}{|l|c|c|c|c|c|c|c|c|c|c|c|c|c|c|}
\hline \multicolumn{1}{|c|}{ Heat } & $\mathrm{Ni}$ & $\mathrm{Cr}$ & $\mathrm{Fe}$ & $\mathrm{C}$ & $\mathrm{Mn}$ & $\mathrm{Si}$ & $\mathrm{S}$ & $\mathrm{Ti}$ & $\begin{array}{c}\mathrm{Nb}+ \\
\mathrm{Ta}\end{array}$ & $\mathrm{Cu}$ & $\mathrm{P}$ & $\mathrm{Al}$ & $\mathrm{Mo}$ & $\mathrm{Co}$ \\
\hline Tube A & 60. & 30. & 9.0 & 0.022 & 0.35 & 0.25 & 0.003 & 0.38 & & 0.01 & 0.01 & 0.03 & & 0.01 \\
\hline Tube $\mathrm{E}$ & 60. & 29. & 10. & 0.015 & 0.36 & 0.28 & 0.001 & 0.36 & & 0.01 & 0.01 & 0.13 & & 0.02 \\
\hline Tube F & 60. & 30. & 9.2 & 0.019 & 0.35 & 0.35 & 0.003 & 0.36 & & 0.01 & 0.01 & 0.02 & & 0.01 \\
\hline
\end{tabular}

Mechanical Properties:

Tubes A and E: Milled annealed at $1040^{\circ} \mathrm{F}\left(1904^{\circ} \mathrm{F}\right)+$ thermally treated at $715^{\circ} \mathrm{C}\left(1319^{\circ} \mathrm{F}\right)$ for 12 hours Tube F: Milled annealed at $1070^{\circ} \mathrm{F}\left(1958^{\circ} \mathrm{F}\right)+$ thermally treated at $725^{\circ} \mathrm{C}\left(1337^{\circ} \mathrm{F}\right)$ for 15 hours

Tubes $\mathrm{A}$ and $\mathrm{E}$ tested in deaerated water; Tubes $\mathrm{A}, \mathrm{E}$, and $\mathrm{F}$ tested in deaerated caustic water.

\begin{tabular}{|l|l|l|l|l|l|l|l|}
\hline \multirow{2}{*}{ Heat } & \multicolumn{2}{|l|}{$0.2 \%$ Yield Strength } & \multicolumn{2}{l|}{ Tensile Strength } & \multicolumn{2}{l|}{ Grain Size } & \multicolumn{2}{l|}{$\begin{array}{l}\text { Vickers Hardness Number } \\
\text { (VHN) }\end{array}$} \\
\cline { 2 - 9 } & $\mathrm{MPa}$ & $\mathrm{ksi}$ & $\mathrm{MPa}$ & $\mathrm{ksi}$ & $\mu \mathrm{m}^{(\mathrm{a})}$ & ASTM $^{(\mathrm{a})}$ & \\
\hline Tube A & 357 & 51.8 & 771 & 112 & 27.66 & 7.5 & 197 \\
\hline Tube E & 320 & 46.4 & 724 & 105 & 28.35 & 7.5 & 193 \\
\hline Tube F & 335 & 48.6 & 736 & 107 & 30.50 & 7.0 & 179 \\
\hline
\end{tabular}

(a) Unit of grain size was not listed; $\mu \mathrm{m}$ is judged to be the only plausible unit.

(b) Load used not reported. 
Table 3-16 Chemical Composition (wt\%) of Alloys 600 and 690 Use by Norring et al. ${ }^{[35,36,3]}$

\begin{tabular}{|c|c|c|c|c|c|c|c|c|}
\hline \multirow{2}{*}{$\begin{array}{l}\text { Matl. }{ }^{\text {(a) }} \\
\text { Heat } \\
\text { Code }\end{array}$} & \multirow{2}{*}{ Material } & \multirow{2}{*}{ Heat Treatment Condition } & \multirow{2}{*}{$\mathrm{C} \%$} & \multirow{2}{*}{$\mathrm{Cr} \%$} & \multirow{2}{*}{$\mathbf{P} \%$} & \multirow{2}{*}{$\mathrm{B} \%$} & \multicolumn{2}{|c|}{$0.2 \%$ off-set yield } \\
\hline & & & & & & & $\mathrm{MPa}$ & ksi \\
\hline BL & Alloy $600 \mathrm{MA}$ & $927^{\circ} \mathrm{C}\left(1700^{\circ} \mathrm{F}\right) / 3-5 \mathrm{~min}$ & 0.038 & 15.8 & 0.012 & 0.0026 & 389 & 56.4 \\
\hline BH & Alloy $600 \mathrm{MA}$ & $1024^{\circ} \mathrm{C}\left(1875^{\circ} \mathrm{F}\right) / 3-5 \mathrm{~min}$ & 0.038 & 15.8 & 0.012 & 0.0026 & 292 & 42.4 \\
\hline $\begin{array}{l}\mathrm{BH}- \\
\text { RUB }^{(b)}\end{array}$ & Alloy 600MA & $\begin{array}{l}1024^{\circ} \mathrm{C}\left(1875^{\circ} \mathrm{F}\right) / 3-5 \mathrm{~min}+ \\
365^{\circ} \mathrm{C} \text { for } 13,500 \text { hours }\end{array}$ & 0.038 & 15.8 & 0.012 & 0.0026 & 292 & 42.4 \\
\hline E & Alloy 600 & See Note (c) & 0.022 & 16.6 & 0.004 & $<0.0002$ & 322 & 46.7 \\
\hline IP & Alloy $600 \mathrm{TT}$ & $\begin{array}{l}990^{\circ} \mathrm{C}\left(1814^{\circ} \mathrm{F}\right) / 1 \mathrm{~min}+ \\
725^{\circ} \mathrm{C}\left(1319^{\circ} \mathrm{F}\right) / 12 \text { hours }\end{array}$ & 0.026 & 16.6 & 0.004 & $<0.0002$ & 313 & 45.4 \\
\hline PP & Alloy $690 T T$ & $\begin{array}{l}1080^{\circ} \mathrm{C}\left(1976^{\circ} \mathrm{F}\right) / 1 \mathrm{~min}+ \\
725^{\circ} \mathrm{C}\left(1319^{\circ} \mathrm{F}\right) / 5 \text { hours }\end{array}$ & 0.020 & 29.9 & 0.006 & $<0.0002$ & 318 & 46.1 \\
\hline$F$ & Alloy 690MA & $1060^{\circ} \mathrm{C}\left(1940^{\circ} \mathrm{F}\right) / 1 \mathrm{~min}$ & 0.023 & 29.9 & 0.005 & $<0.0002$ & 380 & 55.1 \\
\hline
\end{tabular}

(a) The same heats were also used for RUB testing. See Tables Table 3-19, Table 3-20, and Table 3-21.

(b) $\mathrm{BH}-\mathrm{RUB}$ was identical to $\mathrm{BH}$, except it was removed after testing at $365^{\circ} \mathrm{C}\left(689^{\circ} \mathrm{F}\right)$ for 13,500 hours.

(c) Records indicate that " $E$ " is thermally treated. However, its microstructure is found to be indicative of a mill annealed material $\left(990^{\circ} \mathrm{C}\right.$ or $1814^{\circ} \mathrm{F}$ for 1 minute).

Table 3-17 Grain Boundary Chemical and Precipitates Evaluation ${ }^{[37]}$

\begin{tabular}{|c|c|c|c|c|c|}
\hline $\begin{array}{l}\text { Matl. (a) } \\
\text { Heat } \\
\text { Code }\end{array}$ & Material & Heat Treatment Condition & $\begin{array}{l}\text { Weibull Crack } \\
\text { Initiation time }\end{array}$ & $\begin{array}{l}\text { Grain Boundary } \\
\text { Carbide Type } \\
\text { by Atom Probe }\end{array}$ & $\begin{array}{l}\text { Grain Boundary } \\
\text { Carbide Density } \\
(1 / \mu \mathrm{m})\end{array}$ \\
\hline BL & Alloy 600MA & $927^{\circ} \mathrm{C}\left(1700^{\circ} \mathrm{F}\right) / 3-5 \mathrm{~min}$ & 1,050 hours $^{(d)}$ & MB & $0-0.1$ \\
\hline BH & Alloy 600MA & $1024^{\circ} \mathrm{C}\left(1875^{\circ} \mathrm{F}\right) / 3-5 \mathrm{~min}$ & 12,000 hours $^{(d)}$ & $\mathrm{M}(\mathrm{CN})$ & $0.5-2$ \\
\hline $\begin{array}{l}\text { BH- } \\
\text { RUB }^{(b)}\end{array}$ & Alloy 600MA & $\begin{array}{l}1024^{\circ} \mathrm{C}\left(1875^{\circ} \mathrm{F}\right) / 3-5 \min + \\
365^{\circ} \mathrm{C} \text { for } 13,500 \text { hours }\end{array}$ & 12,000 hours $^{(d)}$ & Not listed & $0.5-2$ \\
\hline E & Alloy 600 & See Note (c) & 10,500 hours & Not listed & $0-0.1$ \\
\hline IP & Alloy $600 T T$ & $\begin{array}{l}990^{\circ} \mathrm{C}\left(1814^{\circ} \mathrm{F}\right) / 1 \text { min }+ \\
725^{\circ} \mathrm{C}\left(1319^{\circ} \mathrm{F}\right) / 12 \text { hours }\end{array}$ & $\begin{array}{l}2 \text { out of } 4 \\
\text { specimens } \\
\text { cracked after } \\
23,000 \text { hours }\end{array}$ & $\mathrm{M}_{23} \mathrm{C}_{6}$ & $3-8$ \\
\hline$P^{(f)}$ & Alloy $690 \mathrm{TT}$ & $\begin{array}{l}1080^{\circ} \mathrm{C}\left(1976^{\circ} \mathrm{F}\right) / 1 \text { min }+ \\
725^{\circ} \mathrm{C}\left(1319^{\circ} \mathrm{F}\right) / 5 \text { hours }\end{array}$ & $>23,000$ hours $^{(\theta)}$ & $\mathrm{M}_{23} \mathrm{C}_{6}, \mathrm{M}_{7} \mathrm{C}_{3}$ & $3-8$ \\
\hline $\mathrm{F}$ & Alloy 690MA & $1060^{\circ} \mathrm{C}\left(1940^{\circ} \mathrm{F}\right) / 1 \mathrm{~min}$ & $>33,000$ hours $^{(e)}$ & Not listed & $0.1-1$ \\
\hline
\end{tabular}

(a) The same heats were also used for RUB testing. See Tables Table 3-19, Table 3-20, and Table 3-21.

(b) $\mathrm{BH}-\mathrm{RUB}$ was identical to $\mathrm{BH}$, except it was removed after testing at $365^{\circ} \mathrm{C}$ for 13,500 hours.

(c) Records indicate that " $E$ " is thermally treated. However, its microstructure is found to be indicative of a mill annealed material $\left(990^{\circ} \mathrm{C}\right.$ or $1814^{\circ} \mathrm{F}$ for $\left.1 \mathrm{~min}\right)$.

(d) The numbers 1050 hours and 12,000 hours appear to be rounded from the same materials in Table 3-21.

(e) None of the RUB specimens were cracked at the termination of the testing.

(f) PP was listed twice with different type of grain boundary carbides in the reference. 
Table 3-18 SG Tubing Reverse U-Bend Test Conditions Use by Norring et al.

\begin{tabular}{|c|c|c|}
\hline Reference $^{(a)}$ & Ref. 35 & Ref. 37 \\
\hline Temperature & $365^{\circ} \mathrm{C}\left(689^{\circ} \mathrm{F}\right)$ & $365^{\circ} \mathrm{C}\left(689^{\circ} \mathrm{F}\right)$ \\
\hline Hydrogen & $4-5 \mathrm{ppm}$ (Activity $4-5 \mathrm{kPa}$ ) & $50 \mathrm{cc} \mathrm{H}_{2} / \mathrm{kg} \mathrm{H}_{2} \mathrm{O}$ (Activity $5.9 \mathrm{kPa}$ ) \\
\hline Oxygen & $<5 \mathrm{ppb}$ & $<5 \mathrm{ppb}$ \\
\hline Outlet & $0.09-0.15 \mu \mathrm{s} / \mathrm{cm}$ & $0.08-0.11 \mu \mathrm{s} / \mathrm{cm}$ \\
\hline Impurities & Not listed & $\begin{array}{l}\mathrm{SO}_{4}{ }^{2-}<20 \mathrm{ppb} \\
\mathrm{Cl}^{-}<15 \mathrm{ppb} \\
\mathrm{F}^{-}<20 \mathrm{ppb}\end{array}$ \\
\hline
\end{tabular}

(a) For the same investigation, the test condition reported was slightly different in the referenced papers.

Table 3-19 Alloy 690 Reverse U-Bend Test Results by Norring et al. ${ }^{[36,3]}$

\begin{tabular}{|l|l|l|l|l|l|l|}
\hline $\begin{array}{l}\text { Matl. Heat } \\
\text { Code }\end{array}$ & $\begin{array}{l}\text { Tube } \\
\text { Dia. }\end{array}$ & $\begin{array}{l}\text { Specimen } \\
\text { Number }\end{array}$ & Anneal Temp & TT or MA & $\begin{array}{l}\text { Duration } \\
\text { (hours) }\end{array}$ & Test Result \\
\hline A & $3 / 4^{\prime \prime}$ & 8 & $>1000^{\circ} \mathrm{C}\left(1832^{\circ} \mathrm{F}\right)$ & TT & 25,000 & No IGSCC \\
\hline B & $3 / 4^{\prime \prime}$ & 7 & $>1000^{\circ} \mathrm{C}\left(1832^{\circ} \mathrm{F}\right)$ & TT & 25,000 & No IGSCC \\
\hline D & $3 / 4^{\prime \prime}$ & 8 & $>1000^{\circ} \mathrm{C}\left(1832^{\circ} \mathrm{F}\right)$ & TT & 25,000 & No IGSCC \\
\hline PP & $3 / 4^{\prime \prime}$ & 6 & $>1000^{\circ} \mathrm{C}\left(1832^{\circ} \mathrm{F}\right)$ & TT & 23,000 & No IGSCC \\
\hline $\mathrm{C}$ & $3 / 4^{\prime \prime}$ & 6 & $<1000^{\circ} \mathrm{C}\left(1832^{\circ} \mathrm{F}\right)$ & TT & 25,000 & No IGSCC \\
\hline I & $3 / 4^{\prime \prime}$ & 6 & $<1000^{\circ} \mathrm{C}\left(1832^{\circ} \mathrm{F}\right)$ & TT & 25,000 & No IGSCC \\
\hline F & $3 / 4^{\prime \prime}$ & 6 & $>1000^{\circ} \mathrm{C}\left(1832^{\circ} \mathrm{F}\right)$ & MA & 33,000 & No IGSCC \\
\hline $\mathrm{H}$ & $3 / 4^{\prime \prime}$ & 6 & $>1000^{\circ} \mathrm{C}\left(1832^{\circ} \mathrm{F}\right)$ & MA & 25,000 & No IGSCC \\
\hline G & $3 / 4^{\prime \prime}$ & 6 & $<1000^{\circ} \mathrm{C}\left(1832^{\circ} \mathrm{F}\right)$ & MA & 25,000 & No IGSCC \\
\hline Y & $1 / 2^{\prime \prime}$ & 4 & $<1000^{\circ} \mathrm{C}\left(1832^{\circ} \mathrm{F}\right)$ & MA & 20,500 & No IGSCC \\
\hline $\mathrm{Z}$ & $1 / 2^{\prime \prime}$ & 4 & $<1000^{\circ} \mathrm{C}\left(1832^{\circ} \mathrm{F}\right)$ & MA & 20,500 & No IGSCC \\
\hline
\end{tabular}

(a) The test duration is based on Figure 1 of Ref. 36, except for "PP" and "F" which is based on Ref. 37. The 23,000 hours for "PP" and 33,000 hours for "F" are the total accumulated test time at the termination of the test. Hence, it is probable that many other Alloy 690 RUB specimens listed in the table also accumulated 33,000 hours at the test termination without cracking. 
Table 3-20 Alloy 600 Reverse U-Bend Test Results by Norring et al. ${ }^{[36]}$

\begin{tabular}{|c|c|c|c|c|c|c|}
\hline $\begin{array}{l}\text { Matl. Heat } \\
\text { Code }\end{array}$ & $\begin{array}{l}\text { Tube } \\
\text { Dia. }\end{array}$ & $\begin{array}{l}\text { Specimen } \\
\text { Number }\end{array}$ & Anneal Temp & TT or MA & $\begin{array}{l}\text { Duration (a) } \\
\text { (hours) }\end{array}$ & Test Result \\
\hline V & $7 / 8^{n}$ & 7 & Not listed & MA & 2,500 & IGSCC \\
\hline W & $7 / 8^{\prime \prime}$ & 3 & Not listed & MA & 1,600 & IGSCC \\
\hline K & $7 / 8^{\prime \prime}$ & 4 & Removed from PWR & MA & 800 & IGSCC \\
\hline $\mathbf{L}$ & $7 / 8^{n}$ & 4 & Removed from PWR & MA & 1,200 & IGSCC \\
\hline M & $7 / 8^{n}$ & 4 & Removed from PWR & MA & 1,500 & IGSCC \\
\hline $\mathbf{N}$ & $3 / 4^{\prime \prime}$ & 5 & Removed from PWR & MA & 7,000 & IGSCC \\
\hline 0 & $3 / 4^{\prime \prime}$ & 3 & Removed from PWR & MA & 6,500 & IGSCC \\
\hline $\mathbf{P}$ & $3 / 4^{\prime \prime}$ & 5 & Removed from PWR & MA & 7,000 & IGSCC \\
\hline $\mathbf{R}$ & $3 / 4 "$ & 5 & Removed from PWR & MA & 5,500 & IGSCC \\
\hline S & $3 / 4^{\prime \prime}$ & 5 & Removed from PWR & MA & 7,500 & IGSCC \\
\hline $\mathrm{T}$ & $3 / 4^{\prime \prime}$ & 5 & Removed from PWR & MA & 3,500 & IGSCC \\
\hline EB & $3 / 4^{\prime \prime}$ & 2 & Removed from PWR & MA & 6,800 & IGSCC \\
\hline EC & $3 / 4^{\prime \prime}$ & 2 & Removed from PWR & MA & 6,800 & IGSCC \\
\hline ED & $3 / 4^{\prime \prime}$ & 2 & Removed from PWR & MA & 3,600 & IGSCC \\
\hline EL & $3 / 4^{\prime \prime}$ & 4 & $<1000^{\circ} \mathrm{C}\left(1832^{\circ} \mathrm{F}\right)$ & MA & 7,700 & IGSCC \\
\hline SL & $3 / 4 "$ & 7 & $<1000^{\circ} \mathrm{C}\left(1832^{\circ} \mathrm{F}\right)$ & MA & 4,700 & IGSCC \\
\hline $\mathrm{HL}$ & $3 / 4^{\prime \prime}$ & 7 & $<1000^{\circ} \mathrm{C}\left(1832^{\circ} \mathrm{F}\right)$ & MA & 3,000 & IGSCC \\
\hline BL & $3 / 4^{\prime \prime}$ & 7 & $<1000^{\circ} \mathrm{C}\left(1832^{\circ} \mathrm{F}\right)$ & MA & 1,051 & IGSCC \\
\hline SH & $3 / 4^{\prime \prime}$ & 3 & $>1000^{\circ} \mathrm{C}\left(1832^{\circ} \mathrm{F}\right)$ & MA & 13,000 & IGSCC \\
\hline $\mathrm{HH}$ & $3 / 4^{\prime \prime}$ & 3 & $>1000^{\circ} \mathrm{C}\left(1832^{\circ} \mathrm{F}\right)$ & MA & 11,800 & IGSCC \\
\hline BH & $3 / 4 "$ & 3 & $>1000^{\circ} \mathrm{C}\left(1832^{\circ} \mathrm{F}\right)$ & MA & 11,920 & IGSCC \\
\hline VA & $7 / 8^{\prime \prime}$ & 4 & $>1000^{\circ} \mathrm{C}\left(1832^{\circ} \mathrm{F}\right)$ & TT & 15,500 & No IGSCC \\
\hline$E$ & $3 / 4^{\prime \prime}$ & 8 & $>1000^{\circ} \mathrm{C}\left(1832^{\circ} \mathrm{F}\right)$ & TT & 10,500 & IGSCC \\
\hline EA & $3 / 4^{\prime \prime}$ & 2 & Removed from PWR & TT & 12,000 & No IGSCC \\
\hline $\mathrm{EE}$ & $3 / 4 "$ & 2 & Removed from PWR & TT & 12,000 & No IGSCC \\
\hline
\end{tabular}

(a) For Alloy 600 specimens that developed IGSCC, the time is the Weibull scale parameter. Both the Weibull scale parameter or test time is estimated from Figure 1 of Ref. 36, except for BL and BH which were listed. 
Table 3-21 Alloy 600 Crack Initiation Time from Reverse U-Bend Test by Norring ${ }^{[35]}$

\begin{tabular}{|l|l|c|}
\hline Alloy 600 SG Tube source & Tube Diameter & Weibull crack initiation time (hour) \\
\hline PWR Ringhals 2 & $7 / 8^{\prime \prime}$ & 910 \\
\hline PWR Ringhals 3 & $3 / 4^{\prime \prime}$ & 5,620 \\
\hline PWR Ringhals 4 & $3 / 4^{\prime \prime}$ & 4,590 \\
\hline Alloy 600MA & $7 / 8^{\prime \prime}$ & 1,440 \\
\hline Alloy 600TT & $3 / 4^{\prime \prime}$ & $\mathbf{8 , 0 6 0}$ \\
\hline EPRI Provided B\&WTP & Not listed & 740 \\
\hline EPRI Provided Huntington & Not listed & 2,480 \\
\hline EPRI Provided Sandvik & Not listed & 3,490 \\
\hline
\end{tabular}


Table 3-22 CERT Test Conditions Use by Angeliu et al. ${ }^{[38]}$

\begin{tabular}{|l|l|l|}
\hline & Hydrogenated water & High Purity Argon \\
\hline Strain rate & $3 \times 10^{-7} \mathrm{sec}^{-1}$ Initial & $3 \times 10^{-7} \mathrm{sec}^{-1}$ Initial \\
\hline Temperature & $360^{\circ} \mathrm{C}\left(680^{\circ} \mathrm{F}\right)$ & $360^{\circ} \mathrm{C}\left(680^{\circ} \mathrm{F}\right)$ \\
\hline Hydrogen & $16 \mathrm{cc} \mathrm{H} / \mathrm{kg} \mathrm{H} \mathrm{O}_{2}$ or $0.1 \mathrm{MPa}$ & - \\
\hline Oxygen & $<10 \mathrm{ppb}$ & -- \\
\hline Outlet & $0.09-0.15 \mu \mathrm{s} / \mathrm{cm}$ & -- \\
\hline Impurities & $18 \mathrm{~m} \Omega$ & -- \\
\hline
\end{tabular}

Table 3-23 CERT Results (Tested in Argon) by Angeliu et al. ${ }^{[38]}$

\begin{tabular}{|c|c|c|c|c|c|c|c|}
\hline \multirow{2}{*}{ Type } & \multirow{2}{*}{ Chemical Composition } & \multirow{2}{*}{ Annealing Temp ${ }^{(a)}$} & \multicolumn{2}{|c|}{ Ultimate Tensile } & \multirow{2}{*}{$\begin{array}{c}\text { Elong. } \\
\%\end{array}$} & \multirow{2}{*}{$\begin{array}{l}\% \text { IG } \\
\text { Fracture }\end{array}$} & \multirow{2}{*}{$\begin{array}{l}\text { Hours to } \\
\text { Failure }\end{array}$} \\
\hline & & & $\mathrm{MPa}$ & ksi & & & \\
\hline & $\mathrm{Ni}-5 \% \mathrm{Cr}-9 \% \mathrm{Fe}-0.0001 \% \mathrm{C}$ & $900^{\circ} \mathrm{C}\left(1652^{\circ} \mathrm{F}\right)$ & 416 & 60 & 8.9 & 20 & 77 \\
\hline Alloy 600 & $\mathrm{Ni}-16 \% \mathrm{Cr}-9 \% \mathrm{Fe}-0.001 \% \mathrm{C}$ & $1100^{\circ} \mathrm{C}\left(2012^{\circ} \mathrm{F}\right)$ & 524 & 76 & 11.4 & 14 & 106 \\
\hline Alloy 600 & $\mathrm{Ni}-16 \% \mathrm{Cr}-9 \% \mathrm{Fe}-0.002 \% \mathrm{C}$ & $1100^{\circ} \mathrm{C}\left(2012^{\circ} \mathrm{F}\right)$ & 610 & 88 & 10.0 & $<3$ & 93 \\
\hline Alloy 600 & $\mathrm{Ni}-16 \% \mathrm{Cr}-9 \% \mathrm{Fe}-0.03 \% \mathrm{C}$ & $1100^{\circ} \mathrm{C}\left(2012^{\circ} \mathrm{F}\right)$ & 642 & 93 & 21.9 & 0 & 186 \\
\hline Alloy 690 & $\mathrm{Ni}-30 \% \mathrm{Cr}-9 \% \mathrm{Fe}-0.002 \% \mathrm{C}$ & $1050^{\circ} \mathrm{C}\left(1922^{\circ} \mathrm{F}\right)$ & 580 & 84 & 11.6 & 2 & 105 \\
\hline Alloy 690 & $\mathrm{Ni}-30 \% \mathrm{Cr}-9 \% \mathrm{Fe}-0.03 \% \mathrm{C}$ & $1200^{\circ} \mathrm{C}\left(2192^{\circ} \mathrm{F}\right)$ & 678 & 98 & 14.5 & 0 & 157 \\
\hline
\end{tabular}

(a) Annealing time was 20 minutes for all specimens. Annealing was performed before introducing the $30 \%$ cold work. 
Table 3-24 CERT Results (Tested in Deaerated Water) by Angeliu et al. ${ }^{[38]}$

\begin{tabular}{|c|c|c|c|c|c|c|c|}
\hline \multirow{2}{*}{ Type } & \multirow{2}{*}{ Chemical Composition } & \multirow{2}{*}{ Annealing Temp ${ }^{(a)}$} & \multicolumn{2}{|c|}{ Ultimate Tensile } & \multirow{2}{*}{$\begin{array}{c}\text { Elong. } \\
\%\end{array}$} & \multirow{2}{*}{$\begin{array}{l}\% \text { IG } \\
\text { Fracture }\end{array}$} & \multirow{2}{*}{$\begin{array}{l}\text { Hours to } \\
\text { Failure }\end{array}$} \\
\hline & & & $\mathrm{MPa}$ & ksi & & & \\
\hline & $\mathrm{Ni}-5 \% \mathrm{Cr}-9 \% \mathrm{Fe}-0.0001 \% \mathrm{C}$ & $900^{\circ} \mathrm{C}\left(1652^{\circ} \mathrm{F}\right)$ & 374 & 54 & 6.8 & 42 & 66 \\
\hline Alloy 600 & $\mathrm{Ni}-16 \% \mathrm{Cr}-9 \% \mathrm{Fe}-0.001 \% \mathrm{C}$ & $1100^{\circ} \mathrm{C}\left(2012^{\circ} \mathrm{F}\right)$ & 494 & 72 & 12.9 & 21 & 125 \\
\hline Alloy 600 & $\mathrm{Ni}-16 \% \mathrm{Cr}-9 \% \mathrm{Fe}-0.002 \% \mathrm{C}$ & $1100^{\circ} \mathrm{C}\left(2012^{\circ} \mathrm{F}\right)$ & 570 & 83 & 9.2 & 14 & 78 \\
\hline Alloy 600 & $\mathrm{Ni}-16 \% \mathrm{Cr}-9 \% \mathrm{Fe}-0.03 \% \mathrm{C}$ & $1100^{\circ} \mathrm{C}\left(2012^{\circ} \mathrm{F}\right)$ & 612 & 89 & 25.1 & 0 & 219 \\
\hline Alloy 690 & $\mathrm{Ni}-30 \% \mathrm{Cr}-9 \% \mathrm{Fe}-0.002 \% \mathrm{C}$ & $1050^{\circ} \mathrm{C}\left(1922^{\circ} \mathrm{F}\right)$ & 579 & 84 & 14.5 & 2 & 137 \\
\hline Alloy 690 & $\mathrm{Ni}-30 \% \mathrm{Cr}-9 \% \mathrm{Fe}-0.03 \% \mathrm{C}$ & $1200^{\circ} \mathrm{C}\left(2192^{\circ} \mathrm{F}\right)$ & 655 & 95 & NA & 0 & 180 \\
\hline
\end{tabular}

(a) Annealing time was 20 minutes for all specimens. Annealing was performed before introducing the $30 \%$ cold work.

Table 3-25 Oxide Film on Coupons Exposed to $680^{\circ} \mathrm{F}$ Deaerated Water for $\sim 100$ hours ${ }^{[38]}$

\begin{tabular}{|l|l|l|l|l|l|}
\hline Type & Chemical Composition & $\begin{array}{l}\text { Annealing Temp } \\
\text { (a) }\end{array}$ & $\begin{array}{l}\text { lon } \\
\text { Implantation }\end{array}$ & $\begin{array}{l}\text { Film Thickness } \\
(\mathrm{nm})\end{array}$ & $\begin{array}{l}\text { Predominant Phase } \\
\text { in the Oxide Film }\end{array}$ \\
\hline Alloy 600 & $\mathrm{Ni}-16 \% \mathrm{Cr}-9 \% \mathrm{Fe}-0.002 \% \mathrm{C}$ & $1100^{\circ} \mathrm{C}\left(2012^{\circ} \mathrm{F}\right)$ & None & 38 & $\mathrm{Cr}_{2} \mathrm{O}_{3}$ \\
\hline Alloy 600 & $\mathrm{Ni}-16 \% \mathrm{Cr}-9 \% \mathrm{Fe}-0.03 \% \mathrm{C}$ & $1100^{\circ} \mathrm{C}\left(2012^{\circ} \mathrm{F}\right)$ & $\mathrm{None}$ & 281 & $\mathrm{Ni}(\mathrm{OH})_{2}$ \\
\hline Alloy 690 & $\mathrm{Ni}-30 \% \mathrm{Cr}-9 \% \mathrm{Fe}-0.002 \% \mathrm{C}$ & $1050^{\circ} \mathrm{C}\left(1922^{\circ} \mathrm{F}\right)$ & None & 46 & $\mathrm{Cr}_{2} \mathrm{O}_{3}$ \\
\hline Alloy 690 & $\mathrm{Ni}-30 \% \mathrm{Cr}-9 \% \mathrm{Fe}-0.03 \% \mathrm{C}$ & $1200^{\circ} \mathrm{C}\left(2192^{\circ} \mathrm{F}\right)$ & None & 58 & $\mathrm{Cr}_{2} \mathrm{O}_{3}$ \\
\hline
\end{tabular}

(a) Annealing time was 20 minutes for all specimens. Coupon surface was ground and polished after annealing and before exposure to high temperature deaerated water.

Table 3-26 Chemical Composition of Alloys 600 and 690 SG Tubing Used by Nakayama et al. ${ }^{[40]}$

\begin{tabular}{|c|c|c|c|c|c|c|c|c|c|c|c|c|c|c|}
\hline Heat & $\mathrm{Ni}$ & $\mathrm{Cr}$ & $\mathrm{Fe}$ & $\mathrm{C}$ & $\mathrm{Mn}$ & $\mathrm{Si}$ & $\mathrm{S}$ & $\mathrm{Ti}$ & $\begin{array}{c}\mathrm{Nb}+ \\
\mathrm{Ta}\end{array}$ & $\mathrm{Cu}$ & $\mathrm{P}$ & $\mathrm{Al}$ & $\mathrm{Mo}$ & $\mathrm{Co}$ \\
\hline No. 15,600 & Bal. & 15.26 & 8.22 & 0.025 & 0.51 & 0.30 & 0.0035 & 0.20 & & 0.09 & 0.010 & 0.32 & & 0.002 \\
\hline No. 16,600 & Bal. & 15.73 & 8.35 & 0.038 & 0.50 & 0.27 & 0.0036 & 0.20 & & 0.10 & 0.009 & 0.29 & & 0.078 \\
\hline No. 17,690 & Bal. & 29.65 & 9.50 & 0.034 & 0.40 & 0.38 & 0.0097 & 0.40 & & 0.10 & 0.009 & 0.39 & & 0.079 \\
\hline No. 18,690 & Bal. & 29.34 & 9.20 & 0.034 & 0.40 & 0.37 & 0.0027 & 0.79 & & 0.10 & 0.009 & 0.40 & & 0.078 \\
\hline
\end{tabular}


Table 3-27 Heat Treatment of Alloys 600 and 690 SG Tubing Used by Nakayama et al. ${ }^{[40]}$

\begin{tabular}{|c|c|c|c|}
\hline Heat & Solution Heat Treatment & Thermal Treatment & Aging \\
\hline Alloy 600MA & 0.5 -hour at $1050^{\circ} \mathrm{C}\left(1922^{\circ} \mathrm{F}\right)$, water quench & -- & \multirow{2}{*}{$\begin{array}{l}24,100 \text { hours at } 500^{\circ} \mathrm{C} \\
\left(932^{\circ} \mathrm{F}\right) \text {, and } 1000 \text { hours } \\
\text { at } 350^{\circ} \mathrm{C}\left(662^{\circ} \mathrm{F}\right)\end{array}$} \\
\hline Alloy $600 \mathrm{TT}$ & 0.5 -hour at $950^{\circ} \mathrm{C}\left(1742^{\circ} \mathrm{F}\right)$, water quench & 15 -hour at $700^{\circ} \mathrm{C}\left(1292^{\circ} \mathrm{F}\right)$ & \\
\hline Alloy $690 \mathrm{MA}$ & 0.5 -hour at $1100^{\circ} \mathrm{C}\left(2012^{\circ} \mathrm{F}\right)$, water quench & -- & \multirow{2}{*}{$\begin{array}{l}24,100 \text { hours at } 500^{\circ} \mathrm{C} \\
\left(932^{\circ} \mathrm{F}\right)\end{array}$} \\
\hline Alloy $690 \mathrm{TT}$ & 0.5 -hour at $1100^{\circ} \mathrm{C}\left(2012^{\circ} \mathrm{F}\right)$, water quench & 15 -hour at $700^{\circ} \mathrm{C}\left(1292^{\circ} \mathrm{F}\right)$ & \\
\hline
\end{tabular}

Table 3-28 Single U-Bend Test Results in Hydrogen Saturated Water by Nakayama et al. ${ }^{[40]}$

\begin{tabular}{|l|c|c|c|}
\hline \multirow{2}{*}{\multicolumn{1}{c|}{ Heat }} & \multicolumn{3}{|c|}{ Max. Crack Depth, $\mu \mathrm{m}$} \\
\cline { 2 - 4 } & 100 hours at $500^{\circ} \mathrm{C}\left(932^{\circ} \mathrm{F}\right)$ & 24 hours at $500^{\circ} \mathrm{C}\left(932^{\circ} \mathrm{F}\right)$ & 1000 hours at $350^{\circ} \mathrm{C}\left(662^{\circ} \mathrm{F}\right)$ \\
\hline Alloy 800 (0.3\%Ti) & 0 & 0 & 0 \\
\hline Alloy 600MA & 130 & 90 & 170 \\
\hline Alloy 600TT & 90 & 30 & 60 \\
\hline Alloy 690MA & 30 & 0 & - \\
\hline Alloy 690TT & 0 & 70 & - \\
\hline
\end{tabular}


Table 3-29 Test Conditions Use by Psaila-Dombrowski et al. ${ }^{[41,42]}$

\begin{tabular}{|l|l|l|}
\hline & $\begin{array}{l}\text { Primary water chemistry for CERT, S/N } \\
\text { fatigue test, and fatigue crack growth rate } \\
\text { test }\end{array}$ & Faulted primary water chemistry for CERT only \\
\hline Strain rate for CERT & $5 \times 10^{-8}$ or $10^{-6} \mathrm{sec}^{-}$ & $5 \times 10^{-8}$ or $10^{-6} \mathrm{sec}^{-1}$ \\
\hline Temperature & $\begin{array}{l}343^{\circ} \mathrm{C}\left(650^{\circ} \mathrm{F}\right) \text { for CERT } \\
315^{\circ} \mathrm{C}\left(600^{\circ} \mathrm{F}\right) \text { for fatigue tests }\end{array}$ & $343^{\circ} \mathrm{C}\left(650^{\circ} \mathrm{F}\right)$ \\
\hline Hydrogen & $>20 \mathrm{cc} \mathrm{H}_{2} / \mathrm{kg} \mathrm{H}_{2} \mathrm{O}$ & $>20 \mathrm{cc} \mathrm{H}_{2} / \mathrm{kg} \mathrm{H}_{2} \mathrm{O}$ \\
\hline Oxygen & Not listed & Not listed \\
\hline LiOH & $2.2 \mathrm{ppm}+/-0.1 \mathrm{ppm}$ & $2.2 \mathrm{ppm}+/-0.1 \mathrm{ppm}$ \\
\hline $\left.\begin{array}{l}\mathrm{B} \\
\left(\mathrm{H}_{3} \mathrm{BO}\right.\end{array}\right)$ & $\begin{array}{l}1000 \mathrm{ppm}+/-25 \mathrm{ppm} \\
(\sim 5700 \mathrm{ppm})\end{array}$ & $\begin{array}{l}1000 \mathrm{ppm}+/-25 \mathrm{ppm} \\
(\sim 5700 \mathrm{ppm})\end{array}$ \\
\hline $\mathrm{pH}$, room temp & $6.5+/-0.2$ & $6.5+/-0.2$ \\
\hline & & $150 \mathrm{ppb}$ chloride \\
\hline
\end{tabular}

Table 3-30 CERT Test Results by Psaila-Dombrowski et al. ${ }^{[41,42]}$

\begin{tabular}{|c|c|c|c|c|c|c|}
\hline Water & $\begin{array}{l}\text { Strain } \\
\text { Rate }\end{array}$ & Results & Alloy 82 Weld $^{(a)}$ & 82/152 HAZ & Alloy 152 Weld & $152 / 690 \mathrm{HAZ}$ \\
\hline \multirow{3}{*}{$\begin{array}{l}\text { Phase 1, } \\
\text { Normal }\end{array}$} & \multirow{3}{*}{$10^{-6} \mathrm{~s}^{-1}$} & Max. stress, MPa (ksi) & $586(85)$ & $552(80)$ & $552(80)$ & $621(90)$ \\
\hline & & Time to failure, hour & 135 & 125 & 140 & 130 \\
\hline & & SCC & No & No & No & No \\
\hline \multirow{3}{*}{$\begin{array}{l}\text { Phase 1, } \\
\text { Normal }\end{array}$} & \multirow{3}{*}{$10^{-6} \mathrm{~s}^{-1}$} & Max. stress, MPa (ksi) & $586(85)$ & $565(82)$ & $655(95)$ & $620(90)$ \\
\hline & & Time to failure, hour & 155 & 125 & 100 & 150 \\
\hline & & SCC & No & No & No & No \\
\hline \multirow{3}{*}{$\begin{array}{l}\text { Phase 1, } \\
\text { Faulted }\end{array}$} & \multirow{3}{*}{$10^{-6} \mathrm{~s}^{-1}$} & Max. stress, MPa (ksi) & $572(83)$ & $552(80)$ & $586(85)$ & $572(80)$ \\
\hline & & Time to failure, hour & 140 & 140 & 140 & 140 \\
\hline & & SCC & No & No & No & No \\
\hline \multirow{3}{*}{$\begin{array}{l}\text { Phase 2, } \\
\text { Normal }\end{array}$} & \multirow{3}{*}{$\begin{array}{l}5 \times 10^{-8} \\
\mathrm{~s}^{-1}\end{array}$} & Max. stress, MPa (ksi) & $467(68)$ & $483(70)$ & $591(86)$ & $427(62)$ \\
\hline & & Time to failure, hour & Did not fail ${ }^{(b)}$ & Did not fail ${ }^{(b)}$ & Did not fail ${ }^{(b)}$ & Did not fail ${ }^{(b)}$ \\
\hline & & ScC & $\begin{array}{l}\text { Yes, secondary } \\
\text { cracks }\end{array}$ & $\begin{array}{l}\text { Yes, cracks in } \\
\text { Alloy } 82\end{array}$ & No & No \\
\hline
\end{tabular}

(a) Average value of two specimens.

(b) These specimens did not fail during the 4122 hours of test duration. 
Table 3-31 Alloy 690 and Alloy 690 SG Tubing Used by Ogawa et al. ${ }^{[43]}$

\begin{tabular}{|l|c|c|l|l|}
\hline \multirow{2}{*}{} & \multicolumn{2}{|c|}{ SG Tub Size } & \multicolumn{2}{c|}{ Heat Treatment } \\
\cline { 2 - 5 } & $\begin{array}{c}\text { I.D. dia. } \\
(\mathrm{mm})\end{array}$ & $\begin{array}{c}\text { Wall } \\
\text { Thickness } \\
(\mathrm{mm})\end{array}$ & $\begin{array}{l}\text { Solution Heat Treatment /Mill } \\
\text { Anneal }\end{array}$ & Thermal Treatment \\
\hline $600 \mathrm{MA}$ & $\begin{array}{c}22.23 \\
\mathrm{~mm}\end{array}$ & 1.27 & $925^{\circ} \mathrm{C}\left(1697^{\circ} \mathrm{F}\right)$ & - \\
\hline $600 \mathrm{TT}$ & $\begin{array}{c}22.23 \\
\mathrm{~mm}\end{array}$ & 1.27 & $925^{\circ} \mathrm{C}\left(1697^{\circ} \mathrm{F}\right)$ & $700^{\circ} \mathrm{C}\left(1292^{\circ} \mathrm{F}\right) / 15$ hours \\
\hline $690 \mathrm{TT}$ & $\begin{array}{c}22.23 \\
\mathrm{~mm}\end{array}$ & 1.27 & $1075^{\circ} \mathrm{C}\left(1967^{\circ} \mathrm{F}\right)$ & $700^{\circ} \mathrm{C}\left(1292^{\circ} \mathrm{F}\right) / 15$ hours \\
\hline
\end{tabular}

\begin{tabular}{|l|c|c|c|c|c|c|c|c|c|c|c|c|c|c|}
\hline \multicolumn{1}{|c|}{ Heat } & $\mathrm{Ni}$ & $\mathrm{Cr}$ & $\mathrm{Fe}$ & $\mathrm{C}$ & $\mathrm{Mn}$ & $\mathrm{Si}$ & $\mathrm{S}$ & $\mathrm{Ti}$ & $\begin{array}{c}\mathrm{Nb}+ \\
\mathrm{Ta}\end{array}$ & $\mathrm{Cu}$ & $\mathrm{P}$ & $\mathrm{Al}$ & $\mathrm{Mo}$ & $\mathrm{Co}$ \\
\hline 600MA\&TT & 74.30 & 16.35 & 8.2 & 0.028 & 0.30 & 0.33 & 0.001 & & & $0.0^{\text {(a) }}$ & & & & \\
\hline 690TT & 60.15 & 30.35 & Bal. & $\mathbf{0 . 0 2 1}$ & $\mathbf{0 . 3 3}$ & 0.35 & 0.001 & & & 0.01 & & & & \\
\hline
\end{tabular}

(a) $0.0 \%$ was the number listed for $\mathrm{Cu}$ in the reference.

Table 3-32 RUB and Constant Load Specimens Used by Ogawa et al. ${ }^{[43]}$

\begin{tabular}{|l|l|l|}
\hline & \multicolumn{1}{|c|}{ Reverse U-Bend } & Uniaxial Constant Load \\
\hline Alloy $600 \mathrm{MA}$ & $\begin{array}{l}\text { Tested at } 320^{\circ} \mathrm{C}\left(608^{\circ} \mathrm{F}\right), 10 \mathrm{RUB} \text { specimens for each } \\
\text { prestraining level of } 0,5 \%, 10 \%, 15 \%, 20 \%\end{array}$ & $\begin{array}{l}\text { Stressed to } 85 \mathrm{ksi} \text {, tested at } 320^{\circ} \mathrm{C}\left(608^{\circ} \mathrm{F}\right) \\
\text { and } 340^{\circ} \mathrm{C}\left(644^{\circ} \mathrm{F}\right), 10 \text { specimens each temp }\end{array}$ \\
\hline Alloy 600TT & Same as for Alloy $600 \mathrm{MA}$ & Same as for Alloy $600 \mathrm{MA}$ \\
\hline Alloy 690TT & $\begin{array}{l}\text { Tested at } 360^{\circ} \mathrm{C}\left(680^{\circ} \mathrm{F}\right), 10 \mathrm{RUB} \text { specimens for } \\
\text { prestraining level of } 20 \%\end{array}$ & $\begin{array}{l}\text { Stressed to } 85 \mathrm{ksi} \text {, tested at } 360^{\circ} \mathrm{C}\left(680^{\circ} \mathrm{F}\right), 5 \\
\text { specimens }\end{array}$ \\
\hline
\end{tabular}


Table 3-33 RUB and Constant Load Test Results by Ogawa et al. ${ }^{[43]}$

Phase 1 RUB Results

\begin{tabular}{|c|c|c|c|c|c|c|c|c|c|c|c|c|}
\hline & \multirow{2}{*}{ Temp } & \multirow{2}{*}{$\begin{array}{c}\text { Prestrain } \\
\text { hours }\end{array}$} & \multicolumn{5}{|c|}{ Ref. pH (500 ppm B, 2.0 ppm Li) } & \multicolumn{5}{|c|}{ Optimum pH (280 ppm B, 2.0 ppm Li) } \\
\hline & & & 3000 & 4190 & 5000 & 7000 & 10000 & 3000 & 4190 & 5000 & 7000 & 10000 \\
\hline \multirow{5}{*}{ 600MA } & \multirow{5}{*}{$\begin{array}{l}320^{\circ} \mathrm{C} \\
\left(608^{\circ} \mathrm{F}\right)\end{array}$} & $20 \%$ & $3 / 10$ & $4 / 10$ & $5 / 10$ & $9 / 10$ & $10 / 10$ & $2 / 10$ & $3 / 10$ & $4 / 10$ & $7 / 10$ & $10 / 10$ \\
\hline & & $15 \%$ & $1 / 10$ & $2 / 10$ & $4 / 10$ & $8 / 10$ & $10 / 10$ & $0 / 10$ & $1 / 10$ & $2 / 10$ & $5 / 10$ & $8 / 10$ \\
\hline & & $10 \%$ & $0 / 10$ & $0 / 10$ & $3 / 10$ & $7 / 10$ & $9 / 10$ & $0 / 10$ & $1 / 10$ & $2 / 10$ & $4 / 10$ & $6 / 10$ \\
\hline & & $5 \%$ & $0 / 10$ & $0 / 10$ & $0 / 10$ & $1 / 10$ & $3 / 10$ & $0 / 10$ & $0 / 10$ & $0 / 10$ & $0 / 10$ & $2 / 10$ \\
\hline & & 0 & $0 / 10$ & $0 / 10$ & $0 / 10$ & $0 / 10$ & $0 / 10$ & $0 / 10$ & $0 / 10$ & $0 / 10$ & $0 / 10$ & $0 / 10$ \\
\hline \multirow{5}{*}{ 600TT } & \multirow{5}{*}{$\begin{array}{l}320^{\circ} \mathrm{C} \\
\left(608^{\circ} \mathrm{F}\right)\end{array}$} & $20 \%$ & $0 / 10$ & $1 / 10$ & $2 / 10$ & $5 / 10$ & $10 / 10$ & $0 / 10$ & $0 / 10$ & $0 / 10$ & $2 / 10$ & $6 / 10$ \\
\hline & & $15 \%$ & $0 / 10$ & $0 / 10$ & $0 / 10$ & $1 / 10$ & $6 / 10$ & $0 / 10$ & $0 / 10$ & $0 / 10$ & $1 / 10$ & $4 / 10$ \\
\hline & & $10 \%$ & $0 / 10$ & $0 / 10$ & $0 / 10$ & $0 / 10$ & $1 / 10$ & $0 / 10$ & $0 / 10$ & $0 / 10$ & $0 / 10$ & $0 / 10$ \\
\hline & & $5 \%$ & $0 / 10$ & $0 / 10$ & $0 / 10$ & $0 / 10$ & $0 / 10$ & $0 / 10$ & $0 / 10$ & $0 / 10$ & $0 / 10$ & $0 / 10$ \\
\hline & & 0 & $0 / 10$ & $0 / 10$ & $0 / 10$ & $0 / 10$ & $0 / 10$ & $0 / 10$ & $0 / 10$ & $0 / 10$ & $0 / 10$ & $0 / 10$ \\
\hline 690TT & $\begin{array}{l}360^{\circ} \mathrm{C} \\
\left(680^{\circ} \mathrm{F}\right)\end{array}$ & $20 \%$ & $0 / 10$ & $0 / 10$ & $0 / 10$ & $0 / 10$ & $0 / 10$ & $0 / 10$ & $0 / 10$ & $0 / 10$ & $0 / 10$ & $0 / 10$ \\
\hline
\end{tabular}

Phase 2 RUB Results

\begin{tabular}{|c|c|c|c|c|c|c|c|c|c|c|c|c|c|c|}
\hline & \multirow{2}{*}{ Temp } & \multirow{2}{*}{$\begin{array}{l}\text { Prestrain } \\
\text { hours }\end{array}$} & \multicolumn{6}{|c|}{ Reference pH (1600 ppm B, 2.0 ppm Li) } & \multicolumn{6}{|c|}{ Candidate pH (1600 ppm B, 3.5 ppm Li) } \\
\hline & & & 1356 & 3000 & 5005 & 7000 & 8536 & 10015 & 1356 & 3000 & 5005 & 7000 & 8536 & 10015 \\
\hline \multirow{5}{*}{ 600MA } & \multirow{5}{*}{$\begin{array}{l}320^{\circ} \mathrm{C} \\
\left(608^{\circ} \mathrm{F}\right)\end{array}$} & $20 \%$ & $0 / 10$ & $8 / 10$ & $10 / 10$ & & & & $0 / 10$ & $6 / 10$ & $7 / 10$ & $8 / 10$ & $8 / 10$ & $8 / 10$ \\
\hline & & $15 \%$ & $0 / 10$ & $2 / 10$ & $9 / 10$ & $10 / 10$ & & & $0 / 10$ & $4 / 10$ & $8 / 10$ & $9 / 10$ & $9 / 10$ & $9 / 10$ \\
\hline & & $10 \%$ & $0 / 10$ & $1 / 10$ & $5 / 10$ & $7 / 10$ & $8 / 10$ & $9 / 10$ & $0 / 10$ & $0 / 10$ & $5 / 10$ & $7 / 10$ & $7 / 10$ & $8 / 10$ \\
\hline & & $5 \%$ & $0 / 10$ & $0 / 10$ & $0 / 10$ & $1 / 10$ & $1 / 10$ & $2 / 10$ & $0 / 10$ & $0 / 10$ & $0 / 10$ & $0 / 10$ & $2 / 10$ & $3 / 10$ \\
\hline & & 0 & $0 / 10$ & $0 / 10$ & $0 / 10$ & $0 / 10$ & $0 / 10$ & $0 / 10$ & $0 / 10$ & $0 / 10$ & $0 / 10$ & $0 / 10$ & $0 / 10$ & $0 / 10$ \\
\hline \multirow{5}{*}{$600 T 1$} & \multirow{5}{*}{$\begin{array}{l}320^{\circ} \mathrm{C} \\
\left(608^{\circ} \mathrm{F}\right)\end{array}$} & $20 \%$ & $0 / 10$ & $0 / 10$ & $3 / 10$ & $5 / 10$ & $7 / 10$ & $9 / 10$ & $0 / 10$ & $0 / 10$ & $3 / 10$ & $4 / 10$ & $7 / 10$ & $9 / 10$ \\
\hline & & $15 \%$ & $0 / 10$ & $0 / 10$ & $1 / 10$ & $6 / 10$ & $9 / 10$ & $9 / 10$ & $0 / 10$ & $0 / 10$ & $1 / 10$ & $4 / 10$ & $5 / 10$ & $6 / 10$ \\
\hline & & $10 \%$ & $0 / 10$ & $0 / 10$ & $0 / 10$ & $0 / 10$ & $0 / 10$ & $0 / 10$ & $0 / 10$ & $0 / 10$ & $0 / 10$ & $0 / 10$ & $0 / 10$ & $0 / 10$ \\
\hline & & $5 \%$ & $0 / 10$ & $0 / 10$ & $0 / 10$ & $0 / 10$ & $0 / 10$ & $0 / 10$ & $0 / 10$ & $0 / 10$ & $0 / 10$ & $0 / 10$ & $0 / 10$ & $0 / 10$ \\
\hline & & 0 & $0 / 10$ & $0 / 10$ & $0 / 10$ & $0 / 10$ & $0 / 10$ & $0 / 10$ & $0 / 10$ & $0 / 10$ & $0 / 10$ & $0 / 10$ & $0 / 10$ & $0 / 10$ \\
\hline 690Tा & $\begin{array}{l}360^{\circ} \mathrm{C} \\
\left(680^{\circ} \mathrm{F}\right)\end{array}$ & $20 \%$ & $0 / 10$ & $0 / 10$ & $0 / 10$ & $0 / 10$ & $0 / 10$ & $0 / 10$ & $0 / 10$ & $0 / 10$ & $0 / 10$ & $0 / 10$ & $0 / 10$ & $0 / 10$ \\
\hline
\end{tabular}

(a) $x / 10-x$ is the accumulated number of specimens cracked. 10 is the total number of RUB specimens tested.

Phase 1 Constant Load Test Results, Tested up to 10,000 hours

\begin{tabular}{|l|l|c|l|l|l|l|}
\hline & \multicolumn{1}{|c|}{ Temp. } & $\begin{array}{c}\text { Specimens } \\
\text { Number }\end{array}$ & $\begin{array}{c}\text { Ref. pH }(500 \mathrm{ppm} \mathrm{B}, \\
2.0 \mathrm{ppm} \mathrm{Li})\end{array}$ & $\begin{array}{c}\text { Optimum pH (280 } \\
\text { ppm B, 2.0 ppm Li) }\end{array}$ & $\begin{array}{c}\text { Reference pH (1600 } \\
\text { ppm B, 2.0 ppm Li) }\end{array}$ & $\begin{array}{c}\text { Candidate pH (1600 } \\
\text { ppm B, 3.5 ppm Li) }\end{array}$ \\
\hline $\begin{array}{l}\text { Alloy } \\
600 \mathrm{MA}\end{array}$ & $320^{\circ} \mathrm{C}\left(608^{\circ} \mathrm{F}\right)$ & 10 & None cracked & None cracked & None cracked & None cracked \\
\cline { 2 - 7 } & $340^{\circ} \mathrm{C}\left(644^{\circ} \mathrm{F}\right)$ & 10 & All cracked & All cracked & All cracked & All cracked \\
\hline $\begin{array}{l}\text { Alloy } \\
600 \mathrm{TT}\end{array}$ & $320^{\circ} \mathrm{C}\left(608^{\circ} \mathrm{F}\right)$ & 10 & None cracked ${ }^{(\mathrm{c})}$ & None cracked & None cracked & None cracked \\
\cline { 2 - 7 } & $340^{\circ} \mathrm{C}\left(644^{\circ} \mathrm{F}\right)$ & 10 & All cracked & All cracked & All cracked & All cracked \\
\hline $\begin{array}{l}\text { Alloy } \\
690 \mathrm{TT}\end{array}$ & $360^{\circ} \mathrm{C}\left(680^{\circ} \mathrm{F}\right)$, & 5 & None cracked & None cracked & None cracked & None cracked \\
\hline
\end{tabular}


(b) Number of specimens tested under each water condition.

(c) "None cracked" indicate no PWSCC observed in any specimens after 10,000 hours. 
Table 3-34 Alloy 690 and Alloy 690 SG Tubing Used by Sui et al. ${ }^{[52]}$

\begin{tabular}{|l|c|c|l|l|l|}
\hline \multirow{2}{*}{} & \multicolumn{2}{|c|}{ SG Tub Size } & \multicolumn{3}{c|}{ Material Processing History in the As-Received Condition } \\
\cline { 2 - 6 } & $\begin{array}{c}\text { I.D. dia. } \\
(\mathrm{mm})\end{array}$ & $\begin{array}{c}\text { Wall } \\
\text { Thickness } \\
(\mathrm{mm})\end{array}$ & $\begin{array}{l}\text { Intermediate Mill } \\
\text { Annealing }\end{array}$ & Final Mill Anneal & Thermal Treatment \\
\hline $600(2682)$ & 15.10 & 1.00 & Unknown & Unknown & Unknown \\
\hline 600 (EPRI 1) & 15.10 & 1.00 & Unknown & $1025^{\circ} \mathrm{C}\left(1877^{\circ} \mathrm{F}\right)$ & Unknown \\
\hline 600 (EPRI 2) & 15.10 & 1.00 & Unknown & $925^{\circ} \mathrm{C}\left(1697^{\circ} \mathrm{F}\right)$ & Unknown \\
\hline 690 (A) & 14.97 & 0.97 & $1100^{\circ} \mathrm{C}\left(2012^{\circ} \mathrm{F}\right) / 3 \mathrm{~min}$. & $1070^{\circ} \mathrm{C}\left(1958^{\circ} \mathrm{F}\right) / 2 \mathrm{~min}$. & $725^{\circ} \mathrm{C}\left(1337^{\circ} \mathrm{F}\right) / 15$ hours \\
\hline $690(\mathrm{~B})$ & 14.97 & 0.97 & Unknown & $965^{\circ} \mathrm{C}\left(1769^{\circ} \mathrm{F}\right) / 4 \mathrm{~min}$. & $715^{\circ} \mathrm{C}\left(1319^{\circ} \mathrm{F}\right) / 15$ hours \\
\hline
\end{tabular}

\begin{tabular}{|l|c|c|c|c|c|c|c|c|c|c|c|c|c|c|}
\hline \multicolumn{1}{|c|}{ Heat } & $\mathrm{Ni}$ & $\mathrm{Cr}$ & $\mathrm{Fe}$ & $\mathrm{C}$ & $\mathrm{Mn}$ & $\mathrm{Si}$ & $\mathrm{S}$ & $\mathrm{Ti}$ & $\begin{array}{c}\mathrm{Nb}+ \\
\mathrm{Ta}\end{array}$ & $\mathrm{Cu}$ & $\mathrm{P}$ & $\mathrm{Al}$ & $\mathrm{Mo}$ & $\mathrm{Co}$ \\
\hline 600 (2682) & 74.36 & 15.50 & 9.29 & 0.024 & 0.25 & 0.30 & 0.001 & & & 0.28 & & & & \\
\hline 600 (EPRI 1) & 75.0 & 15.8 & 8.0 & 0.039 & 0.26 & 0.31 & 0.002 & & & 0.01 & & & & \\
\hline 600 (EPRI 2) & 75.0 & 15.8 & 8.0 & 0.038 & 0.26 & 0.32 & 0.001 & & & 0.01 & & & & \\
\hline 690 (A) & 59.5 & 30.0 & 9.2 & 0.019 & 0.35 & 0.35 & 0.003 & & & 0.01 & & 0.02 & & \\
\hline 690 (B) & 59.7 & 28.9 & 10.2 & 0.019 & 0.36 & 0.32 & 0.001 & & & 0.02 & & 0.14 & & \\
\hline
\end{tabular}

Room Temperature Mechanical Properties

\begin{tabular}{|c|c|c|c|c|c|}
\hline \multirow{2}{*}{ Heat } & \multicolumn{2}{|c|}{$0.2 \%$ Yield Strength } & \multicolumn{2}{|c|}{ Tensile Strength } & \multirow{2}{*}{$\begin{array}{l}\text { Elongation } \\
\%\end{array}$} \\
\hline & $\mathrm{MPa}$ & ksi & $\mathrm{MPa}$ & ksi & \\
\hline $600(2682)$ & 365 & 53 & 744 & 108 & 36 \\
\hline 600 (EPRI 1) & 292 & 42 & 679 & 98 & 47 \\
\hline 600 (EPRI 2) & 389 & 56 & 737 & 107 & 37 \\
\hline $690(A)$ & 335 & 49 & 736 & 107 & 42 \\
\hline 690 (B) & 452 & 66 & 798 & 116 & 40 \\
\hline
\end{tabular}


Table 3-35 RUB Test Results in Hydrogen/Steam at $716^{\circ} \mathrm{F}$ by Sui et al. ${ }^{[52,53]}$ C - Cracked; NC - Not cracked; IG - Slight intergranular cracking; SA - Slight intergranular attack

Alloy 600 RUB Test Results

\begin{tabular}{|c|c|c|c|c|c|c|c|c|}
\hline \multicolumn{9}{|c|}{ Alloy oud RUD Iest Resuls } \\
\hline \multirow{2}{*}{ Specimen } & \multirow{2}{*}{ Heat } & \multirow{2}{*}{$\begin{array}{l}\text { Heat Treatment in addition to the } \\
\text { listed in Table 3-34 }\end{array}$} & \multicolumn{6}{|c|}{ Result After Hours of Exposure } \\
\hline & & & 552 & 625 & 905 & 1416 & 2026 & 2578 \\
\hline \multicolumn{9}{|c|}{ Autoclave 1} \\
\hline $1 \mathrm{U}$ & 2682 & As-received & & $\mathrm{NC}$ & NC & NC & NC & NC \\
\hline $2 \mathrm{U}$ & 2682 & $925^{\circ} \mathrm{C}\left(1697^{\circ} \mathrm{C}\right) / 4-\mathrm{min}$. & & $\mathrm{NC}$ & NC & $\mathrm{NC}$ & NC & $\mathrm{C}$ \\
\hline $3 U$ & 2682 & $5 \%$ Elong., $925^{\circ} \mathrm{C}\left(1697^{\circ} \mathrm{C}\right) / 4-\min$. & & SA & IG & IG & IG & $\mathrm{C}$ \\
\hline $4 U$ & 2682 & $\begin{array}{l}10 \% \text { elongation }+925^{\circ} \mathrm{C}\left(1697^{\circ} \mathrm{F}\right) / \\
4-\mathrm{min}\end{array}$ & & SA & IG & IG & IG & $\mathrm{C}$ \\
\hline $5 \mathrm{U}$ & & $15 \%$ Elong., $925^{\circ} \mathrm{C}\left(1697^{\circ} \mathrm{C}\right) / 4-\mathrm{min}$. & & SA & IG & IG & IG & $\mathrm{NC}$ \\
\hline $6 U$ & EPRI I & As-received & & $\mathrm{NC}$ & NC & $\mathrm{C}$ & & \\
\hline $7 U$ & EPRI 1 & $5 \%$ Elong., $925^{\circ} \mathrm{C}\left(1697^{\circ} \mathrm{C}\right) / 4-\min$. & & NC & NC & $\mathrm{C}$ & & \\
\hline $8 \mathrm{U}$ & EPRI 2 & As-received & & $\mathrm{NC}$ & NC & $\mathrm{C}$ & & \\
\hline $9 \mathrm{U}$ & EPRI 2 & $5 \%$ Elong., $925^{\circ} \mathrm{C}\left(1697^{\circ} \mathrm{C}\right) / 4-\mathrm{min}$. & & & & & & \\
\hline \multicolumn{9}{|c|}{ Autoclave S2 } \\
\hline $10 U$ & EPRI I & $450^{\circ} \mathrm{C}\left(842^{\circ} \mathrm{F}\right) / 60$ hours & $\mathrm{NC}$ & & & & & \\
\hline $11 U$ & EPRI 2 & $450^{\circ} \mathrm{C}\left(842^{\circ} \mathrm{F}\right) / 60$ hours & C & & & & & \\
\hline
\end{tabular}

Alloy 690 RUB Test Results, Autoclave S1

\begin{tabular}{|c|c|c|c|c|c|c|c|c|c|c|c|c|}
\hline & \multirow{2}{*}{$\begin{array}{l}690 \\
\text { Heat }\end{array}$} & \multirow{2}{*}{$\begin{array}{l}\text { Heat Treatment in addition to the } \\
\text { listed in Table 3-34 }\end{array}$} & \multicolumn{10}{|c|}{ Examination after Hours of Exposure } \\
\hline & & & 500 & 1000 & 1500 & 2000 & 3000 & 4000 & 4500 & 7000 & 12600 & 13824 \\
\hline $1 \mathrm{R}$ & A & As-received & NC & NC & NC & $\mathrm{NC}$ & NC & $\mathrm{NC}$ & NC & $\mathrm{NC}$ & NC & NC \\
\hline $2 \mathrm{R}$ & A & $550^{\circ} \mathrm{C}\left(1022^{\circ} \mathrm{F}\right) / 30$ hours & NC & $\mathrm{NC}$ & NC & NC & NC & NC & NC & NC & NC & NC \\
\hline $3 R$ & A & $10 \%$ Elong., $925^{\circ} \mathrm{C}\left(1697^{\circ} \mathrm{C}\right) / 4-\mathrm{min}$. & NC & NC & NC & $\mathrm{NC}$ & NC & NC & $\mathrm{NC}$ & $\mathrm{NC}$ & NC & NC \\
\hline $4 \mathrm{R}$ & A & $\begin{array}{l}10 \% \text { Elong., } 925^{\circ} \mathrm{C}\left(1697^{\circ} \mathrm{C}\right) / 4-m i n . \\
+550^{\circ} \mathrm{C}\left(1022^{\circ} \mathrm{F}\right) / 30 \text { hours }\end{array}$ & NC & NC & NC & NC & NC & NC & NC & $\mathrm{NC}$ & NC & NC \\
\hline 5R & B & As-received & NC & NC & NC & NC & $\mathrm{NC}$ & NC & NC & NC & NC & C \\
\hline 6R & B & $550^{\circ} \mathrm{C}\left(1022^{\circ} \mathrm{F}\right) / 60$ hours & NC & NC & NC & $\mathrm{NC}$ & NC & NC & NC & NC & NC & C \\
\hline
\end{tabular}

Alloy 690 RUB Test Results, Autoclave S2

\begin{tabular}{|c|c|c|c|c|c|c|c|c|c|}
\hline & \multirow{2}{*}{$\begin{array}{l}690 \\
\text { Heat }\end{array}$} & \multirow{2}{*}{$\begin{array}{l}\text { Heat Treatment in addition to the } \\
\text { listed in Table 3-34 }\end{array}$} & \multicolumn{7}{|c|}{ Examination after Hours of Exposure } \\
\hline & & & 500 & 1500 & 2500 & 3000 & 5500 & 11000 & 12324 \\
\hline $7 R$ & A & $\begin{array}{l}10 \% \text { Elong., } 925^{\circ} \mathrm{C}\left(1697^{\circ} \mathrm{C}\right) / 4-m i n . \\
+550^{\circ} \mathrm{C}\left(1022^{\circ} \mathrm{F}\right) / 10 \text { hours }\end{array}$ & NC & NC & $\mathrm{NC}$ & NC & NC & $\mathrm{NC}$ & $\mathrm{NC}$ \\
\hline $8 \mathrm{R}$ & A & $\begin{array}{l}10 \% \text { Elong., }+550^{\circ} \mathrm{C}\left(1022^{\circ} \mathrm{F}\right) / 100 \\
\text { hours }\end{array}$ & NC & NC & $\mathrm{NC}$ & NC & NC & $\mathrm{NC}$ & NC \\
\hline $9 \mathrm{R}$ & A & Same as $7 \mathrm{R}$ & NC & NC & NC & NC & $\mathrm{NC}$ & NC & NC \\
\hline $10 R$ & A & Same as $8 \mathrm{R}$ & NC & NC & $\mathrm{NC}$ & NC & NC & NC & NC \\
\hline
\end{tabular}


Table 3-36 Alloy 690 and Alloy 690 SG Tubing Used by Angell et al. ${ }^{[4]}$

\begin{tabular}{|c|c|c|c|c|c|c|c|c|c|c|c|c|c|c|}
\hline Heat & $\mathrm{Ni}$ & $\mathrm{Cr}$ & $\mathrm{Fe}$ & C & $\mathrm{Mn}$ & Si & $S$ & $\mathrm{Ti}$ & $\begin{array}{c}\mathrm{Nb}+ \\
\mathrm{Ta}\end{array}$ & $\mathrm{Cu}$ & $\mathbf{P}$ & Al & Mo & Co \\
\hline $\begin{array}{l}96834 \\
\text { Alloy } 600\end{array}$ & 74.91 & 15.83 & 8.09 & 0.038 & 0.26 & 0.3 & 0.001 & & & 0.01 & & & & 0.02 \\
\hline $\begin{array}{l}752246 \\
\text { Alloy } 690\end{array}$ & 59.4 & 30.1 & 9.23 & 0.02 & 0.35 & 0.37 & 0.003 & & & 0.01 & 0.009 & & & 0.01 \\
\hline
\end{tabular}

\begin{tabular}{|l|l|l|r|r|r|r|l|}
\hline \multirow{2}{*}{ Heat } & \multirow{2}{*}{ Size } & Heat Treatment & $0.2 \%$ Yield Strength & \multicolumn{2}{l|}{ Tensile Strength } & \multicolumn{2}{l|}{ Elongation } \\
\cline { 4 - 8 } & & & $\mathrm{MPa}$ & $\mathrm{ksi}$ & $\mathrm{MPa}$ & $\mathrm{ksi}$ & $\%$ \\
\hline 96834, Alloy 600MA & $19.1 \mathrm{~mm}$ O.D. dia. & Mill Anneal & 390 & 57 & 737 & 107 & 37 \\
\hline 752246, Alloy 690TT & $17.5 \mathrm{~mm}$ O.D. dia. & Thermally Treated & 326 & 47 & 747 & 108 & 37 \\
\hline
\end{tabular}

Table 3-37 RUB Test Conditions and Results $\left(662^{\circ} \mathrm{F}\right)$ by Angell et al. ${ }^{[4]}$

\begin{tabular}{|c|c|c|c|c|}
\hline & \multicolumn{2}{|c|}{$\begin{array}{l}\text { Phase 1, simulating beginning of cycle water for a } \\
\text { 12-month fuel cycle }\end{array}$} & \multicolumn{2}{|c|}{$\begin{array}{l}\text { Phase 2, simulating beginning of cycle water } \\
\text { for an 18-month fuel cycle }\end{array}$} \\
\hline & Without zinc & With zinc & Without zinc & With zinc \\
\hline Zinc & - & $40 \mathrm{ppb}$ & -- & $40 \mathrm{ppb}$ \\
\hline Temperature & \multicolumn{2}{|l|}{$350^{\circ} \mathrm{C}\left(662^{\circ} \mathrm{F}\right)$} & \multicolumn{2}{|l|}{$350^{\circ} \mathrm{C}\left(662^{\circ} \mathrm{F}\right)$} \\
\hline Hydrogen & \multicolumn{2}{|c|}{$25-50 \mathrm{cc} \mathrm{H}_{2} / \mathrm{kg} \mathrm{H} \mathrm{H}_{2} \mathrm{O}$ or $0.1 \mathrm{MPa}$} & \multicolumn{2}{|c|}{$25-50 \mathrm{cc} \mathrm{H}_{2} / \mathrm{kg} \mathrm{H} \mathrm{H}_{2} \mathrm{O}$ or $0.1 \mathrm{MPa}$} \\
\hline B & \multicolumn{2}{|c|}{$1200 \mathrm{mg} / \mathrm{kg} \mathrm{B}$ as $\mathrm{H}_{3} \mathrm{BO}_{3}$} & \multicolumn{2}{|c|}{$1800 \mathrm{mg} / \mathrm{kg} \mathrm{B}$ as $\mathrm{H}_{3} \mathrm{BO}_{3}$} \\
\hline Li & \multicolumn{2}{|c|}{$2.2 \mathrm{mg} / \mathrm{kg} \mathrm{Li}$ as $\mathrm{LiOH}$} & \multicolumn{2}{|c|}{$3.5 \mathrm{mg} / \mathrm{kg} \mathrm{Li}$ as $\mathrm{LiOH}$} \\
\hline $\mathrm{pH}$ & \multicolumn{2}{|c|}{6.75 at $292^{\circ} \mathrm{C}$ and 7.10 at $350^{\circ} \mathrm{C}$} & \multicolumn{2}{|c|}{6.75 at $292^{\circ} \mathrm{C}$ and 7.10 at $350^{\circ} \mathrm{C}$} \\
\hline
\end{tabular}

\begin{tabular}{|c|c|c|c|c|c|c|c|}
\hline \multirow{3}{*}{ Specimen I.D. } & \multirow{3}{*}{ Heat } & \multicolumn{2}{|c|}{ Phase 1} & \multicolumn{4}{|c|}{ Phase 2} \\
\hline & & \multirow{2}{*}{$\begin{array}{l}\text { Without zinc } \\
7500 \text { hours }\end{array}$} & \multirow{2}{*}{$\begin{array}{c}\text { With zinc } \\
7500 \text { hours }\end{array}$} & \multicolumn{2}{|c|}{ Without zinc } & \multicolumn{2}{|c|}{ With zinc } \\
\hline & & & & 5500 hours & 7500 hours & 5500 hours & 7500 hours \\
\hline $\begin{array}{l}\text { Alloy } 600 \\
\text { Studsvik }\end{array}$ & $\begin{array}{l}96834,{ }^{(c)} \\
\text { Alloy } 600 \mathrm{MA}\end{array}$ & $1 / 6$ & $2 / 6$ & $3 / 6^{(a)}$ & $3 / 6^{(a)}$ & $1 / 6^{(a)}$ & $1 / 6^{(a)}$ \\
\hline $\begin{array}{l}\text { Alloy } 690 \\
\text { Studsvik }\end{array}$ & $\begin{array}{l}752246,{ }^{(\mathrm{c})} \\
\text { Alloy } 690 \mathrm{TT}\end{array}$ & $0 / 6$ & $0 / 6$ & $0 / 4^{(a)}$ & $0 / 4^{(a)}$ & $0 / 4^{(a)}$ & $0 / 4^{(a)}$ \\
\hline $\begin{array}{l}\text { Alloy } 600 \\
\text { Westinghouse }\end{array}$ & Not listed & - & -- & $0 / 4$ & $3 / 4$ & $0 / 4$ & $2 / 4$ \\
\hline
\end{tabular}

(a) Include two uncracked specimens carried forward from Phase 1. However, for Alloy 600, it was not mentioned if the cracked ones in Phase 2 included the ones from Phase 1. For Alloy 690, the maximum specimen exposure time without failure was 15,000 hours.

(b) $x / y-x$ is the accumulated number of specimens cracked; $y$ is the total number of RUB specimens tested.

(c) The descriptions on the RUB specimen I.D. were vague and could not be associated directly with the chemical composition of the Alloy 600 and Alloy 690 SG tubes listed. Hence, the specimen heat number was an educated guess. 
Table 3-38 Origin and thermal treatments of Alloy 690 materials tested by the CEA ${ }^{[45]}$

\begin{tabular}{|c|c|c|c|}
\hline Tube* & Manufacturer & Heat number & $\begin{array}{c}\text { Final Heat Treatment } \\
\text { (atmosphere } \mathrm{NH}_{3} \text { ) }\end{array}$ \\
\hline $\begin{array}{c}\text { Pre-series SG } \\
\text { tube }\end{array}$ & Imphy & WE 092** & $\begin{array}{l}980^{\circ} \mathrm{C} 2 \mathrm{~min} \\
+700-730^{\circ} \mathrm{C} 5 \mathrm{~h}\end{array}$ \\
\hline $\begin{array}{c}\text { Pre-series SG } \\
\text { tube }\end{array}$ & Imphy & WE 092 & $\begin{array}{l}1040-1070^{\circ} \mathrm{C} 2 \mathrm{~min} \\
+700-730^{\circ} \mathrm{C} 5 \mathrm{~h}\end{array}$ \\
\hline $\begin{array}{c}\text { Pre-series SG } \\
\text { tube }\end{array}$ & Imphy & WE 094** & $\begin{array}{l}980^{\circ} \mathrm{C} 2 \mathrm{~min} \\
+700-730^{\circ} \mathrm{C} 5 \mathrm{~h}\end{array}$ \\
\hline $\begin{array}{c}\text { Pre-series SG } \\
\text { tube }\end{array}$ & Imphy & WE 094** & $\begin{array}{l}1040-1070^{\circ} \mathrm{C} 2 \mathrm{~min} \\
+700-730^{\circ} \mathrm{C} 5 \mathrm{~h}\end{array}$ \\
\hline $\begin{array}{c}\text { Pre-series SG } \\
\text { tube }\end{array}$ & Huntington & NX 3238 & $\begin{array}{l}1040-1070^{\circ} \mathrm{C} 2 \mathrm{~min} \\
+700-730^{\circ} \mathrm{C} 5 \mathrm{~h}\end{array}$ \\
\hline $\begin{array}{l}\text { Industrial } \\
\text { SG tube }\end{array}$ & Imphy & WF 754 & $\begin{array}{l}1040-1070^{\circ} \mathrm{C} 2 \mathrm{~min} \\
+700-730^{\circ} \mathrm{C} 5 \mathrm{~h}\end{array}$ \\
\hline $\begin{array}{l}\text { Industrial } \\
\text { SG tube }\end{array}$ & Imphy & WF 771 & $\begin{array}{l}1040-1070^{\circ} \mathrm{C} 2 \mathrm{~min} \\
+700-730^{\circ} \mathrm{C} 5 \mathrm{~h}\end{array}$ \\
\hline $\begin{array}{l}\text { Industrial } \\
\text { SG tube }\end{array}$ & Imphy & WE 773 & $\begin{array}{r}1040-1070^{\circ} \mathrm{C} 2 \mathrm{~min} \\
+700-730^{\circ} \mathrm{C} 5 \mathrm{~h}\end{array}$ \\
\hline $\begin{array}{l}\text { Industrial } \\
\text { SG tube }\end{array}$ & Imphy & WF 779 & $\begin{array}{l}1040-1070^{\circ} \mathrm{C} 2 \mathrm{~min} \\
+700-730^{\circ} \mathrm{C} 5 \mathrm{~h}\end{array}$ \\
\hline $\begin{array}{l}\text { Industrial } \\
\text { SG tube }\end{array}$ & Imphy & WF 783 & $\begin{array}{l}1040-1070^{\circ} \mathrm{C} 2 \mathrm{~min} \\
+700-730^{\circ} \mathrm{C} 5 \mathrm{~h}\end{array}$ \\
\hline $\begin{array}{l}\text { Industrial } \\
\text { SG tube }\end{array}$ & Imphy & WF 786 & $\begin{array}{l}1040-1070^{\circ} \mathrm{C} 2 \mathrm{~min} \\
+700-730^{\circ} \mathrm{C} 5 \mathrm{~h}\end{array}$ \\
\hline $\begin{array}{c}\text { Industrial } \\
\text { SG tube }\end{array}$ & Imphy & WF 793 & $\begin{array}{l}1040-1070^{\circ} \mathrm{C} 2 \mathrm{~min} \\
+700-730^{\circ} \mathrm{C} 5 \mathrm{~h}\end{array}$ \\
\hline $\begin{array}{l}\text { Industrial } \\
\text { SG tube }\end{array}$ & Imphy & WF 816 & $\begin{array}{l}1040-1070^{\circ} \mathrm{C} 2 \mathrm{~min} \\
+700-730^{\circ} \mathrm{C} 5 \mathrm{~h}\end{array}$ \\
\hline $\begin{array}{l}\text { Industrial } \\
\text { SG tube }\end{array}$ & Imphy & WF 825 & $\begin{array}{l}1040-1070^{\circ} \mathrm{C} 2 \mathrm{~min} \\
+700-730^{\circ} \mathrm{C} 5 \mathrm{~h}\end{array}$ \\
\hline $\begin{array}{l}\text { Industrial } \\
\text { SG tube }\end{array}$ & Imphy & WF 826 & $\begin{array}{l}1040-1070^{\circ} \mathrm{C} 2 \mathrm{~min} \\
+700-730^{\circ} \mathrm{C} 5 \mathrm{~h}\end{array}$ \\
\hline $\begin{array}{l}\text { Industrial } \\
\text { SG tube }\end{array}$ & Imphy & WF 833 & $\begin{array}{l}1040-1070^{\circ} \mathrm{C} 2 \mathrm{~min} \\
+700-730^{\circ} \mathrm{C} 5 \mathrm{~h}\end{array}$ \\
\hline $\begin{array}{l}\text { Industrial } \\
\text { SG tube }\end{array}$ & Imphy & WF 837 & $\begin{array}{l}1040-1070^{\circ} \mathrm{C} 2 \mathrm{~min} \\
+700-730^{\circ} \mathrm{C} 5 \mathrm{~h}\end{array}$ \\
\hline
\end{tabular}

*: All tubes straightened, sand blasted on ID and OD polished.

** Heats WE 092 and WE 094 were originally heat treated at $980^{\circ} \mathrm{C}+700^{\circ} \mathrm{C}$ before the heat treatment indicated in the table. 
Table 3-39 Chemical Compositions of Alloy 690 Materials Tested by the CEA ${ }^{[45]}$

\begin{tabular}{|c|c|c|c|c|c|c|c|c|c|c|c|c|c|c|}
\hline $\begin{array}{c}\text { Heat } \\
\text { Number }\end{array}$ & $\begin{array}{l}\text { Materials } \\
\text { analyzed }\end{array}$ & $\mathrm{Ni}$ & $\mathrm{Cr}$ & $\mathrm{Fe}$ & C & Mn & $\mathrm{Si}$ & $\mathrm{S}$ & $P$ & $\mathrm{Cu}$ & Co & $\mathrm{Al}$ & Ti & $\mathbf{N}$ \\
\hline $\begin{array}{l}\text { RCCM } 4105 \\
\text { specification }\end{array}$ & & $\geq 58$ & $28-31$ & $7-11$ & $\begin{array}{l}0.01- \\
0.04\end{array}$ & .0 .50 & $\cdot 0.50$ & .0 .015 & .0025 & .0 .50 & .0 .10 & .0 .50 & .0 .50 & - \\
\hline WE 092 & sample & 60.4 & 30.9 & 7.3 & 0.037 & 0.28 & 0.32 & 0.002 & 0.005 & - & - & - & 0.22 & - \\
\hline WE 094 & sample & 61.1 & 29.2 & 8.5 & 0.028 & 0.24 & 0.32 & 0.002 & 0.005 & 0.01 & 0.01 & 0.39 & 0.24 & - \\
\hline NX 3238 & sample & 58.8 & 28.9 & 102 & 0.016 & 0.15 & 0.24 & 0.001 & 0.011 & 0.17 & 0.04 & 0.31 & 0.33 & - \\
\hline WF 754 & $\begin{array}{l}\text { ingot top } \\
\text { ingot base }\end{array}$ & $\begin{array}{l}59.9 \\
59.9\end{array}$ & $\begin{array}{l}28.9 \\
28.8\end{array}$ & $\begin{array}{l}10.2 \\
10.2 \\
\end{array}$ & $\begin{array}{l}0.016 \\
0.016\end{array}$ & $\begin{array}{l}0.30 \\
0.30\end{array}$ & $\begin{array}{l}0.31 \\
0.34 \\
\end{array}$ & $\begin{array}{l}0.001 \\
0.001 \\
\end{array}$ & $\begin{array}{l}0.008 \\
0.008 \\
\end{array}$ & $\begin{array}{l}0.014 \\
0.014 \\
\end{array}$ & $\begin{array}{l}0.014 \\
0.014\end{array}$ & $\begin{array}{l}0.19 \\
0.16\end{array}$ & $\begin{array}{l}0.31 \\
0.40\end{array}$ & 0.026 \\
\hline WF 771 & sample & 59.7 & 28.5 & 10.7 & 0.025 & 0.33 & 0.30 & 0.005 & 0.009 & 0.005 & 0.016 & 0.16 & 0.27 & - \\
\hline WF 773 & sample & 60.4 & 28.4 & 10.3 & 0.020 & 0.24 & 028 & 0.005 & 0.005 & 0.014 & 0.009 & 0.16 & 0.17 & - \\
\hline WF 779 & $\begin{array}{l}\text { ingot top } \\
\text { sample } \\
\text { ingot base }\end{array}$ & $\begin{array}{l}59.6 \\
60.6 \\
59.6\end{array}$ & $\begin{array}{l}28.9 \\
28.5 \\
28.8\end{array}$ & $\begin{array}{l}10.5 \\
10.2 \\
10.5\end{array}$ & $\begin{array}{l}0.021 \\
0.022 \\
0.024\end{array}$ & $\begin{array}{l}0.32 \\
0.30 \\
0.31\end{array}$ & $\begin{array}{l}0.26 \\
0.28 \\
0.26 \\
\end{array}$ & $\begin{array}{l}0.001 \\
0005 \\
0.001\end{array}$ & $\begin{array}{l}0.009 \\
0.008 \\
0.010\end{array}$ & $\begin{array}{l}0.008 \\
0.005 \\
0.009 \\
\end{array}$ & $\begin{array}{l}0.014 \\
0.011 \\
0.014\end{array}$ & $\begin{array}{l}0.11 \\
0.19 \\
0.14\end{array}$ & $\begin{array}{l}0.25 \\
0.15 \\
0.35\end{array}$ & 0.034 \\
\hline WF 783 & $\begin{array}{l}\text { ingot top } \\
\text { sample } \\
\text { ingot base }\end{array}$ & $\begin{array}{l}59.5 \\
60.4 \\
59.5 \\
\end{array}$ & $\begin{array}{l}29.7 \\
29.1 \\
29.7 \\
\end{array}$ & $\begin{array}{l}9.8 \\
9.5 \\
9.8 \\
\end{array}$ & $\begin{array}{l}0.019 \\
0.016 \\
0.020 \\
\end{array}$ & $\begin{array}{l}0.33 \\
0.29 \\
0.32 \\
\end{array}$ & $\begin{array}{l}0.29 \\
0.31 \\
0.26\end{array}$ & $\begin{array}{l}0.001 \\
0.005 \\
0.001\end{array}$ & $\begin{array}{l}0.008 \\
0.005 \\
0.008\end{array}$ & $\begin{array}{l}0.012 \\
0.005 \\
0.007\end{array}$ & $\begin{array}{l}0.010 \\
0.009 \\
0.011\end{array}$ & $\begin{array}{l}0.09 \\
0.14 \\
0.09\end{array}$ & $\begin{array}{l}0.27 \\
0.17 \\
0.28 \\
\end{array}$ & 0.041 \\
\hline WF 786 & $\begin{array}{l}\text { ingot top } \\
\text { sample } \\
\text { ingot base }\end{array}$ & $\begin{array}{l}59.6 \\
60.3 \\
59.6 \\
\end{array}$ & $\begin{array}{l}29.1 \\
28.6 \\
29.1 \\
\end{array}$ & $\begin{array}{l}10.3 \\
10.2 \\
10.3 \\
\end{array}$ & $\begin{array}{l}0.021 \\
0.018 \\
0.021 \\
\end{array}$ & $\begin{array}{l}0.26 \\
0.23 \\
0.27 \\
\end{array}$ & $\begin{array}{l}0.24 \\
0.27 \\
0.26 \\
\end{array}$ & $\begin{array}{r}0.001 \\
0.005 \\
0.001 \\
\end{array}$ & $\begin{array}{l}0.008 \\
0.005 \\
0.008\end{array}$ & $\begin{array}{l}0.016 \\
0.014 \\
0.016 \\
\end{array}$ & $\begin{array}{l}0.012 \\
0.010 \\
0.011 \\
\end{array}$ & $\begin{array}{l}0.10 \\
0.12 \\
0.12\end{array}$ & $\begin{array}{l}0.27 \\
0.14 \\
0.29\end{array}$ & 0.044 \\
\hline WF 816 & $\begin{array}{l}\text { ingot top } \\
\text { ingot base }\end{array}$ & $\begin{array}{l}59.4 \\
59.5\end{array}$ & $\begin{array}{l}29.1 \\
29.0\end{array}$ & $\begin{array}{l}10.5 \\
10.5\end{array}$ & $\begin{array}{l}0.022 \\
0.025\end{array}$ & $\begin{array}{l}0.33 \\
0.33 \\
\end{array}$ & $\begin{array}{l}0.29 \\
0.26\end{array}$ & $\begin{array}{l}0.001 \\
0.001\end{array}$ & $\begin{array}{l}0.008 \\
0.009 \\
\end{array}$ & $\begin{array}{l}0.007 \\
0.011\end{array}$ & $\begin{array}{l}0.011 \\
0.011 \\
\end{array}$ & $\begin{array}{l}0.11 \\
0.12 \\
\end{array}$ & $\begin{array}{l}0.24 \\
0.30 \\
\end{array}$ & 0.037 \\
\hline WF 825 & $\begin{array}{l}\text { ingot top } \\
\text { ingot base }\end{array}$ & $\begin{array}{l}59.4 \\
59.5 \\
\end{array}$ & $\begin{array}{l}28.9 \\
28.8 \\
\end{array}$ & $\begin{array}{l}10.6 \\
10.6\end{array}$ & $\begin{array}{l}0.021 \\
0.022\end{array}$ & $\begin{array}{l}0.35 \\
0.34\end{array}$ & $\begin{array}{l}0.30 \\
0.25\end{array}$ & $\begin{array}{l}0.001 \\
0.001\end{array}$ & $\begin{array}{l}0.008 \\
0.009\end{array}$ & $\begin{array}{l}0.010 \\
0.005 \\
\end{array}$ & $\begin{array}{l}0.011 \\
0.012 \\
\end{array}$ & $\begin{array}{l}0.12 \\
0.14\end{array}$ & $\begin{array}{l}0.25 \\
0.30\end{array}$ & 0.036 \\
\hline WF 826 & sample & 59.4 & 29.1 & 10.6 & 0.019 & 0.31 & 0.28 & 0.005 & 0.006 & 0.006 & 0.014 & 0.14 & 0.17 & - \\
\hline WF 833 & $\begin{array}{c}\text { ingot top } \\
\text { sample } \\
\text { ingot base }\end{array}$ & $\begin{array}{l}59.4 \\
59.7 \\
59.4 \\
\end{array}$ & $\begin{array}{l}29.0 \\
28.9 \\
28.9 \\
\end{array}$ & $\begin{array}{l}10.6 \\
10.4 \\
10.6\end{array}$ & $\begin{array}{l}0.021 \\
0.020 \\
0023\end{array}$ & $\begin{array}{l}0.33 \\
0.31 \\
0.33\end{array}$ & $\begin{array}{l}0.29 \\
0.31 \\
0.26\end{array}$ & $\begin{array}{l}0.001 \\
0.005 \\
0.001\end{array}$ & $\begin{array}{l}0.009 \\
0.008 \\
0.009\end{array}$ & $\begin{array}{l}0.005 \\
0.006 \\
0.008 \\
\end{array}$ & $\begin{array}{l}0.012 \\
0.014 \\
0.012 \\
\end{array}$ & $\begin{array}{l}0.10 \\
0.16 \\
0.15 \\
\end{array}$ & $\begin{array}{l}0.26 \\
0.24 \\
0.31 \\
\end{array}$ & 0.035 \\
\hline WF 837 & $\begin{array}{l}\text { ingot top } \\
\text { sample } \\
\text { Ingot base }\end{array}$ & $\begin{array}{l}59.1 \\
59.2 \\
59.2\end{array}$ & $\begin{array}{l}29.1 \\
29.0 \\
29.0\end{array}$ & $\begin{array}{l}10.8 \\
10.7 \\
10.8\end{array}$ & $\begin{array}{l}0.022 \\
0.020 \\
0.019\end{array}$ & $\begin{array}{l}0.31 \\
0.35 \\
0.32\end{array}$ & $\begin{array}{l}0.27 \\
0.26 \\
0.23\end{array}$ & $\begin{array}{l}0001 \\
0.005 \\
0.001\end{array}$ & $\begin{array}{l}0.007 \\
0.006 \\
0.009\end{array}$ & $\begin{array}{r}0.005 \\
0.006 \\
-0.009\end{array}$ & $\begin{array}{l}0.011 \\
0.014 \\
0.012\end{array}$ & $\begin{array}{l}0.09 \\
0.10 \\
0.12\end{array}$ & $\begin{array}{l}0.22 \\
0.29 \\
0.27 \\
\end{array}$ & 0.029 \\
\hline
\end{tabular}


Table 3-40 Origins and heat treatments of Alloy 690 SG tube materials tested by EdF ${ }^{[46]}$

\begin{tabular}{|c|c|c|c|c|c|c|}
\hline Alloy 690 & Manufacturer & Process & Heat number & Tube Maker & $\begin{array}{c}\text { Final heat treatment } \\
\text { (Mill anneal atmosphere) }\end{array}$ & $\begin{array}{c}\text { Diameter/ } \\
\text { thickness (mm) }\end{array}$ \\
\hline \multirow{7}{*}{$\begin{array}{l}\text { Experimental } \\
\text { SG tube** }\end{array}$} & Huntington & AOD? & NX $4458 \mathrm{H}$ & Huntington & $1095^{\circ} \mathrm{C}$ & $12.7 / 1.35$ \\
\hline & \multirow[t]{2}{*}{ Huntington } & \multirow[t]{2}{*}{ VAR } & \multirow[t]{2}{*}{ NX 40C5 HS } & \multirow{2}{*}{$\begin{array}{l}\text { Westinghouse/ } \\
\text { Vallourec }\end{array}$} & $1040^{\circ} \mathrm{C}\left(\mathrm{H}_{2}\right)$ & \multirow{2}{*}{$22.2 / 1.27$} \\
\hline & & & & & $1040^{\circ} \mathrm{C}+16 \mathrm{~h} \times 700^{\circ} \mathrm{C}$ & \\
\hline & \multirow[t]{2}{*}{ Huntington } & \multirow[t]{2}{*}{ AOD } & \multirow[t]{2}{*}{ NX $9780 \mathrm{H}$} & \multirow{2}{*}{$\begin{array}{c}\text { Westinghouse/ } \\
\text { Vallourec }\end{array}$} & $1045^{\circ} \mathrm{C}\left(\mathrm{H}_{2}\right)$ & \multirow[t]{2}{*}{$22.2 / 1.27$} \\
\hline & & & & & $1045^{\circ} \mathrm{C}+16 \mathrm{~h} \times 700^{\circ} \mathrm{C}$ & \\
\hline & \multirow[t]{2}{*}{ Huntington } & \multirow[t]{2}{*}{ AOD } & \multirow[t]{2}{*}{ NX $9780 \mathrm{H}$} & \multirow{2}{*}{$\begin{array}{c}\text { Westinghouse/ } \\
\text { Vallourec }\end{array}$} & $980^{\circ} \mathrm{C}\left(\mathrm{H}_{2}\right)$ & \multirow{2}{*}{$22.2 / 1.27$} \\
\hline & & & & & $980^{\circ} \mathrm{C}+16 \mathrm{~h} \times 700^{\circ} \mathrm{C}$ & \\
\hline \multirow{5}{*}{$\begin{array}{l}\text { Pre-series } \\
\text { SG tube** }\end{array}$} & Huntington & - & NX 3238 & Vallourec & $\begin{array}{c}1040^{\circ} \mathrm{C}\left(\mathrm{NH}_{3}\right) \\
+5 \mathrm{hx} \times 00 \mathrm{C}\end{array}$ & $19.07 / 1.1$ \\
\hline & Imphy & ESR & WE 094 & Vallourec & $\begin{array}{l}1040^{\circ} \mathrm{C}\left(\mathrm{NH}_{3}\right) \\
+5 \mathrm{~h} \times 700^{\circ} \mathrm{C}\end{array}$ & $19.07 / 1.1$ \\
\hline & Imphy & ESR & WE 092 & Vallourec & $\begin{array}{l}980^{\circ} \mathrm{C}\left(\mathrm{NH}_{3}\right) \\
+5 \mathrm{~h} \times 700 \mathrm{C}\end{array}$ & $19.05 / 1.1$ \\
\hline & Imphy & ESR & WE 092 & Vallourec & $\begin{array}{r}1060^{\circ} \mathrm{C}\left(\mathrm{NH}_{3}\right) \\
+5 \mathrm{~h} \times 700^{\circ} \mathrm{C}\end{array}$ & $19.05 / 1.1$ \\
\hline & Imphy & ESR & WE 092 & Vallourec & $\begin{array}{r}1040^{\circ} \mathrm{C}\left(\mathrm{NH}_{3}\right) \\
+5 \mathrm{~h} \mathrm{x} 700^{\circ} \mathrm{C}\end{array}$ & $19.05 / 1.1$ \\
\hline \multirow{9}{*}{$\begin{array}{l}\text { Industrial } \\
\text { SG tube** }\end{array}$} & Imphy & ESR & WF 511 & Vallourec & $\begin{array}{c}1040^{\circ} \mathrm{C} \text { to } 1070^{\circ} \mathrm{C}\left(\mathrm{NH}_{3}\right) \\
+5 \mathrm{~h} \mathrm{x} 700 \mathrm{C}\end{array}$ & $19.05 / 1.1$ \\
\hline & Imphy & ESR & WF 517 & Vallourec & $\begin{array}{l}1040 \text { to } 1070^{\circ} \mathrm{C}\left(\mathrm{NH}_{3}\right) \\
+5 \mathrm{~h} \mathrm{x} 700^{\circ} \mathrm{C}\end{array}$ & $19.05 / 1.1$ \\
\hline & Imphy & ÉSR & WF 754 & Vallourec & $\begin{array}{l}1040 \text { to } 1070^{\circ} \mathrm{C}\left(\mathrm{H}_{2}\right) \\
+5 \mathrm{~h} \times 700^{\circ} \mathrm{C}\end{array}$ & $19.05 / 1.1$ \\
\hline & Imphy & ESR & WF 816 & Vallourec & $\begin{array}{l}1040 \text { to } 1070^{\circ} \mathrm{C}\left(\mathrm{H}_{2}\right) \\
+5 \mathrm{~h} \times 7001 \mathrm{C}\end{array}$ & $19.05 / 1.1$ \\
\hline & Huntington & - & NX 4814 & Vallourec & $\begin{array}{l}1040 \text { to } 1070^{\circ} \mathrm{C}\left(\mathrm{NH}_{3}\right) \\
+5 \mathrm{~h} \times 700^{\circ} \mathrm{C}\end{array}$ & $19.05 / 1.1$ \\
\hline & Huntington & - & NX 4817 & Vallourec & $\begin{array}{l}1040 \text { to } 1070^{\circ} \mathrm{C}\left(\mathrm{NH}_{3}\right) \\
+5 \mathrm{~h} \times 700^{\circ} \mathrm{C}\end{array}$ & $19.05 / 1.1$ \\
\hline & Tecphy & ÉSR & WH 799 & Valinox & $\begin{array}{l}1060 \text { to } 1080^{\circ} \mathrm{C}\left(\mathrm{H}_{2}\right) \\
+5 \mathrm{~h} \mathrm{x} 700^{\circ} \mathrm{C}\end{array}$ & $22,2 / 1.27$ \\
\hline & Tecphy & ESR & WG 592 & Valinox & $\begin{array}{l}1040 \text { to } 1080^{\circ} \mathrm{C}\left(\mathrm{H}_{2}\right) \\
+5 \mathrm{~h} \times 700^{\circ} \mathrm{C}\end{array}$ & $19.05 / 1.1$ \\
\hline & Tecphy & ÉSR & WJ 741 & Valinox & $\begin{array}{l}1060 \text { to } 1080^{\circ} \mathrm{C}\left(\mathrm{H}_{2}\right) \\
\quad+5 \mathrm{~h} \times 700^{\circ} \mathrm{C}\end{array}$ & $22.2 / 1.27^{*}$ \\
\hline
\end{tabular}

s: AOD : Argon Oxygen Decarburization -VAR: Vacuum Arc Remelting - ESR : Electroslag Remelting. $s^{*}$ :Tube surface contaminated with phosphate during fabrication.

**: All tubes straightened, sand blasted on ID (except NX 4817 and WH 799) and OD polished. 
Table 3-41 Origins and Heat Treatments of Alloy 690 CRDM Nozzles Tested by EdF ${ }^{[46]}$

\begin{tabular}{|c|c|c|c|c|c|c|c|c|}
\hline $\begin{array}{l}\text { CRDM } \\
\text { nozzles }\end{array}$ & Manufacturer & Process & Heat Number & Tube maker & $\begin{array}{c}\text { Extrusion } \\
\text { temperature } \\
\left({ }^{\circ} \mathrm{C}\right)\end{array}$ & $\begin{array}{l}\text { Solution anneal and heat } \\
\text { treatment temperatures }\end{array}$ & & $\begin{array}{r}\text { Diameter / } \\
\text { thickness } \\
(\mathbf{m m})\end{array}$ \\
\hline Experimental & Tecphy & ESR & WJ 151 & Valinox & $1110-1230$ & $1050+5 \mathrm{~h} \times 715^{\circ} \mathrm{C}$ & $\begin{array}{l}\text { - Pre-straighten in a press } \\
1 \text { straightening pass with } \\
\text { hyperbolic rolls }\end{array}$ & $109 / 21,5$ \\
\hline Industrial & Tecphy & ESR & WJ 172 & Valinox & $1110-1210$ & $\begin{array}{c}1080 \\
+5 \mathrm{~h} \times 715^{\circ} \mathrm{C}\end{array}$ & $\begin{array}{l}\text { - Pre-straighten in a press } \\
\text { - } 2 \text { straightening passes with } \\
\text { VALTI rolls }\end{array}$ & $110 / 23$ \\
\hline
\end{tabular}


Table 3-42 Chemical compositions of Alloy 690 materials tested by EdF ${ }^{[46]}$

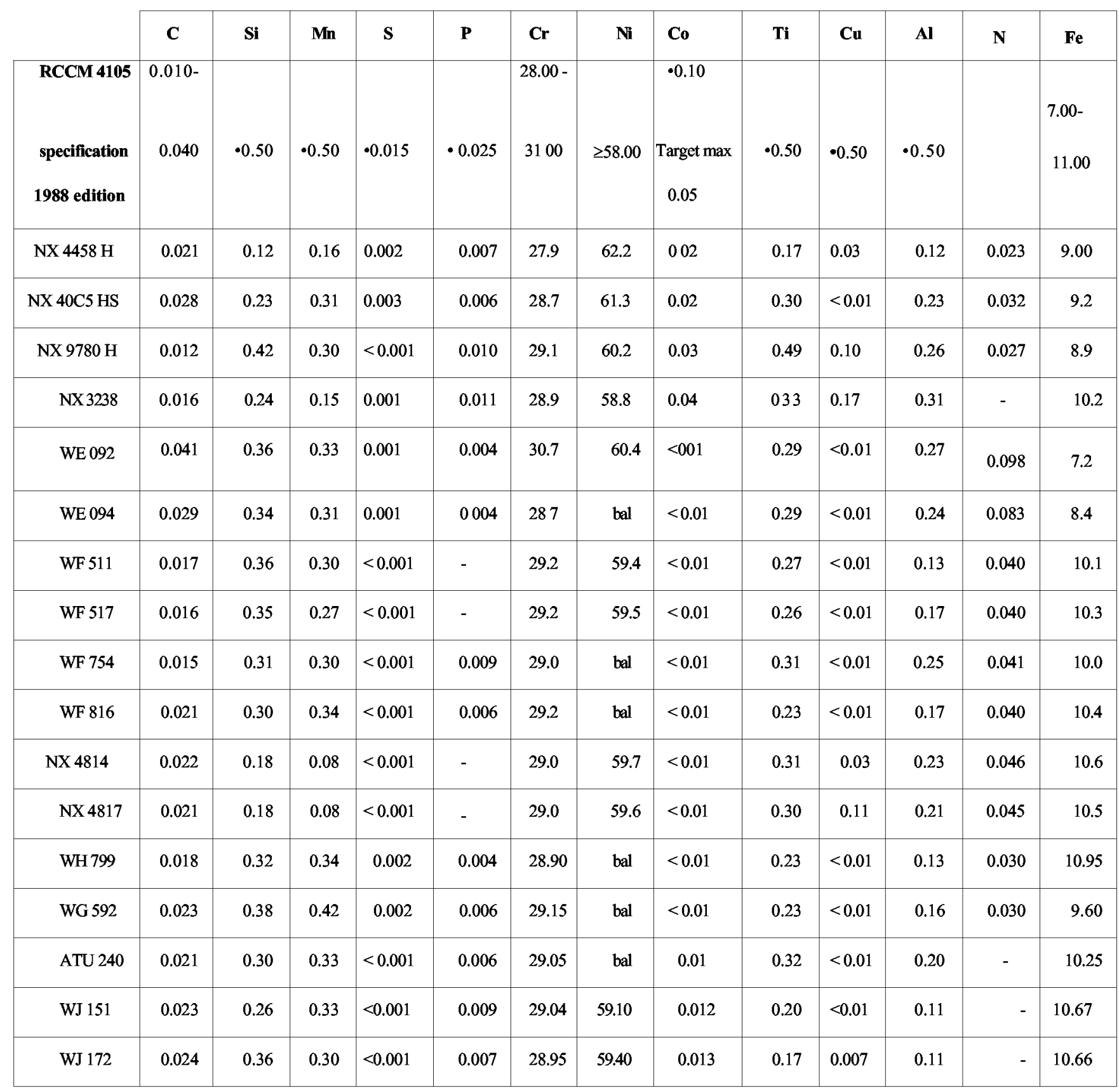


Table 3-43 Mechanical properties of Alloy 690 materials tested by EdF ${ }^{[4]}$

\begin{tabular}{|c|c|c|c|c|c|c|c|}
\hline \multirow{2}{*}{$\begin{array}{r}\text { Heat } \\
\text { Number }\end{array}$} & \multirow{2}{*}{$\begin{array}{l}\text { Mill anneal temperature } \\
\left({ }^{\circ} \mathrm{C}\right)\end{array}$} & \multicolumn{3}{|c|}{ Tensile properties at $20^{\circ} \mathrm{C}$} & \multicolumn{3}{|c|}{ Tensile properties at $350^{\circ} \mathrm{C}$} \\
\hline & & $\begin{array}{l}\mathrm{Rp}_{\mathrm{O} .2} \\
(\mathrm{MPa})\end{array}$ & $\begin{array}{c}\mathrm{R}_{\mathrm{m}} \\
(\mathrm{MPa})\end{array}$ & $\begin{array}{c}\mathrm{El} \\
(\%)\end{array}$ & $\begin{array}{c}\mathrm{Rp}_{2} \\
(\mathrm{MPa})\end{array}$ & $\begin{array}{r}\mathrm{R}_{\mathrm{m}} \\
(\mathrm{MPa})\end{array}$ & $\begin{array}{l}\mathrm{El} \\
(\%)\end{array}$ \\
\hline \multicolumn{2}{|c|}{ RCC-M 4105 + FM 684} & $\begin{array}{c}275 \\
\cdot 470\end{array}$ & $\geq 630$ & $\geq 30$ & $\geq 230$ & - & - \\
\hline NX 3238 & 1040 & 325 & 758 & 46 & 259 & 631 & 44 \\
\hline WE 094 & 1040 & 419 & 825 & 37 & 358 & 723 & 36 \\
\hline WE 092 & 980 & $\underline{499}$ & 957 & 40 & 417 & 732 & 36 \\
\hline WE 092 & 1060 & 447 & 849 & 36 & 391 & 709 & 34 \\
\hline WE 092 & 1040 & 464 & 880 & 36 & 398 & 750 & 30 \\
\hline WF 511 & 1040 to 1070 & 324 & 744 & 51 & - & - & - \\
\hline WF 517 & 1040 to 1070 & 308 & 720 & 53 & - & - & - \\
\hline WF 754 & 1040 to 1070 & 304 & 727 & 46 & $\begin{array}{c}232 \text { to } \\
244\end{array}$ & $\begin{array}{c}589 \text { to } \\
616\end{array}$ & - \\
\hline WF 816 & 1040 to 1070 & 360 & 755 & 42 & 280 & 626 & 38 \\
\hline NX 4814 & 1040 to 1070 & 359 & 778 & 45 & - & - & - \\
\hline NX 4817 & 1040 to 1070 & 355 & 776 & 47 & - & - & - \\
\hline WH 799 & 1060 to 1080 & $\begin{array}{l}307 \\
305\end{array}$ & $\begin{array}{l}708 \\
705\end{array}$ & $\begin{array}{l}49 \\
51\end{array}$ & $\begin{array}{l}246 \\
244\end{array}$ & $\begin{array}{l}590 \\
586\end{array}$ & 45 \\
\hline WG 592 & 1040 to 1080 & $\begin{array}{l}331 \\
329\end{array}$ & $\begin{array}{l}750 \\
747\end{array}$ & $\begin{array}{l}43 \\
44\end{array}$ & $\begin{array}{l}271 \\
273\end{array}$ & $\begin{array}{l}637 \\
637\end{array}$ & $\begin{array}{l}36 \\
39\end{array}$ \\
\hline ATU 240 & 1060 to 1080 & $\begin{array}{l}307 \\
313\end{array}$ & $\begin{array}{l}708 \\
716\end{array}$ & $\begin{array}{l}49 \\
49\end{array}$ & $\begin{array}{l}253 \\
249\end{array}$ & $\begin{array}{l}595 \\
592\end{array}$ & $\begin{array}{l}46 \\
44\end{array}$ \\
\hline WJ 151 & - & $\frac{230}{228}$ & $\begin{array}{l}607 \\
610\end{array}$ & $\begin{array}{l}57 \\
57\end{array}$ & $\frac{180}{179}$ & $\begin{array}{l}502 \\
501\end{array}$ & $\begin{array}{l}59 \\
57\end{array}$ \\
\hline WJ 172 & - & $\begin{array}{l}347 \\
347\end{array}$ & $\begin{array}{l}678 \\
681\end{array}$ & $\begin{array}{l}45 \\
44\end{array}$ & $\begin{array}{l}292 \\
287\end{array}$ & $\begin{array}{l}557 \\
554\end{array}$ & $\begin{array}{l}44 \\
46\end{array}$ \\
\hline
\end{tabular}


Table 3-44 Alloy 690 and Alloy 690 SG Used by Vaillant et al. ${ }^{[49]}$

\begin{tabular}{|c|c|c|c|c|c|c|c|c|}
\hline \multirow{2}{*}{ Heat } & \multirow{2}{*}{$\% \mathrm{C}$} & \multirow{2}{*}{ Heat Treatment } & $\begin{array}{l}\text { YS } \\
20^{\circ} \mathrm{C}\end{array}$ & $\begin{array}{c}\mathrm{YS} \\
350^{\circ} \mathrm{C} \\
\end{array}$ & $\begin{array}{l}\text { UTS } \\
350^{\circ} \mathrm{C} \\
\end{array}$ & $\begin{array}{l}\text { Elong } \\
350^{\circ} \mathrm{C}\end{array}$ & $\begin{array}{c}\mathrm{GB} \\
\text { Carbide } \\
\end{array}$ & $\begin{array}{l}\text { Grain } \\
\text { Size }\end{array}$ \\
\hline & & & $\mathrm{MPa}$ & $\mathrm{MPa}$ & $\mathrm{MPa}$ & $\%$ & $\%$ & ASTM \\
\hline \multirow{2}{*}{$\begin{array}{l}6 \mathrm{E} \\
\text { Alloy } 600\end{array}$} & \multirow{2}{*}{0.033} & $1070^{\circ} \mathrm{C}$ & 340 & 280 & 670 & 48 & 24 & \multirow{2}{*}{8} \\
\hline & & $1070^{\circ} \mathrm{C}+700^{\circ} \mathrm{C}$ & 315 & 360 & 610 & & 25 & \\
\hline \multirow{2}{*}{$\begin{array}{l}6 P \\
\text { Alloy } 600\end{array}$} & \multirow{2}{*}{0.016} & $980^{\circ} \mathrm{C}$ & 340 & 300 & 680 & 40 & 10 & \multirow{2}{*}{9} \\
\hline & & $980^{\circ} \mathrm{C}+700^{\circ} \mathrm{C}$ & 330 & 255 & 650 & & 14 & \\
\hline \multirow{2}{*}{$\begin{array}{l}6 \mathrm{~L} \\
\text { Alloy } 600\end{array}$} & \multirow{2}{*}{0.026} & $980^{\circ} \mathrm{C}$ & 380 & 330 & 710 & 35 & 4 & \multirow{2}{*}{10} \\
\hline & & $980^{\circ} \mathrm{C}+700^{\circ} \mathrm{C}$ & 365 & 290 & 680 & & 8 & \\
\hline \multirow{2}{*}{$\begin{array}{l}6.242 \\
\text { Alloy } 600\end{array}$} & \multirow{2}{*}{0.030} & $930^{\circ} \mathrm{C}$ & 333 & 290 & 680 & 42 & 7 & \multirow{2}{*}{10} \\
\hline & & $930^{\circ} \mathrm{C}+700^{\circ} \mathrm{C}$ & & & & & 11 & \\
\hline \multirow{2}{*}{$\begin{array}{l}6.285 \\
\text { Alloy } 600\end{array}$} & \multirow{2}{*}{0.033} & $940^{\circ} \mathrm{C}$ & 310 & 263 & 670 & 42 & 7 & \multirow{2}{*}{9} \\
\hline & & $940^{\circ} \mathrm{C}+700^{\circ} \mathrm{C}$ & & & & & 10 & \\
\hline \multirow{2}{*}{$\begin{array}{l}6.287 \\
\text { Alloy } 600\end{array}$} & \multirow{2}{*}{0.034} & $900^{\circ} \mathrm{C}$ & 325 & 275 & 680 & 40 & 6 & \multirow{2}{*}{9} \\
\hline & & $900^{\circ} \mathrm{C}+700^{\circ} \mathrm{C}$ & & & & & 8 & \\
\hline $\begin{array}{l}9 \mathrm{G} \\
\text { Alloy } 690\end{array}$ & 0.012 & $980^{\circ} \mathrm{C}$ & 410 & 330 & 690 & 40 & 3 & 3 \\
\hline $\begin{array}{l}9.092 \\
\text { Alloy } 690\end{array}$ & 0.041 & $\begin{array}{l}980^{\circ} \mathrm{C}+700^{\circ} \mathrm{C} \times 5 \text { hours and } \\
1060^{\circ} \mathrm{C}+700^{\circ} \mathrm{C} \times 5 \text { hours }\end{array}$ & 447 & 391 & 709 & 34 & 12 & 10 \\
\hline $\begin{array}{l}9.592 \\
\text { Alloy } 690\end{array}$ & 0.023 & $1040 / 1080^{\circ} \mathrm{C}+700^{\circ} \mathrm{C}$ & 330 & 272 & 673 & 38 & 13 & $9-10$ \\
\hline $\begin{array}{l}9.754 \\
\text { Alloy } 690\end{array}$ & 0.015 & $1040 / 1070^{\circ} \mathrm{C}+700^{\circ} \mathrm{C}$ & 304 & 238 & 608 & & 23 & 6 \\
\hline $\begin{array}{l}9.799 \\
\text { Alloy } 690\end{array}$ & 0.018 & $1060 / 1080^{\circ} \mathrm{C}+700^{\circ} \mathrm{C}$ & 306 & 245 & 588 & 45 & 34 & $6-7$ \\
\hline
\end{tabular}

$9 \mathrm{G}=\mathrm{N} \times 9780 \mathrm{H}$

$9.092=$ WE 092

$9.592=$ WG 592

$9.754=$ WF 754

$9.799=$ WH 799 
Table 3-45 RUB and CERT Test Conditions by Vaillant et al. ${ }^{[4]]}$

\begin{tabular}{|l|l|l|}
\hline & RUB & CERT \\
\hline Temperature & $360^{\circ} \mathrm{C}\left(680^{\circ} \mathrm{F}\right)$ & $360^{\circ} \mathrm{C}\left(680^{\circ} \mathrm{F}\right)$ \\
\hline Hydrogen & $100 \mathrm{cc} \mathrm{H}_{2} / \mathrm{kg} \mathrm{H}_{2} \mathrm{O}$ & $25-30 \mathrm{cc} \mathrm{H}_{2} / \mathrm{kg} \mathrm{H}_{2} \mathrm{O}$ \\
\hline B & $1000 \mathrm{ppm} \mathrm{B}$ as H $\mathrm{BO}_{3}$ & $1000 \mathrm{ppm} \mathrm{B}$ as $\mathrm{H}_{3} \mathrm{BO}_{3}$ \\
\hline $\mathrm{Li}$ & $2 \mathrm{ppm} \mathrm{Li}$ as LiOH & $2 \mathrm{ppm} \mathrm{Li}$ as LiOH \\
\hline $\mathrm{pH}$ & Not reported & Not reported \\
\hline & & $5 \times 10^{-8} \mathrm{sec}^{-1}$ strain rate \\
\hline
\end{tabular}

Table 3-46 RUB and CERT Test Results by Vaillant et al. ${ }^{[49]}$

\begin{tabular}{|c|c|c|c|c|c|}
\hline & & \multicolumn{2}{|c|}{ RUB Test } & \multicolumn{2}{|c|}{ CERT Test } \\
\hline Heat & Material & Hours $^{(a)}$ & Results & Intergranular Crack Depth & CGR, $\mu \mathrm{m} /$ hour $^{(b)}$ \\
\hline $6 \mathrm{E}$ & $600 \mathrm{TT}$ & 36,000 & Not cracked & No intergranular cracking & $4.49 \mathrm{E}-03^{(\mathrm{c})}$ \\
\hline 6P & $600 \mathrm{MA}$ & 3,000 & Cracked & Yes, depth not listed & $2.15 \mathrm{E}-02$ \\
\hline 6P & 600TT & 3,500 & Cracked & Yes, depth not listed & 1.11E-02 \\
\hline $6 \mathrm{~L}$ & $600 \mathrm{MA}$ & 1,000 & Cracked & Yes, depth not listed & $6.02 \mathrm{E}-02$ \\
\hline $6 \mathrm{~L}$ & $600 \mathrm{TT}$ & 3,000 & Cracked & Yes, depth not listed & $9.86 \mathrm{E}-02$ \\
\hline 6.242 & $600 \mathrm{MA}$ & 500 & Cracked & Yes, depth not listed & $1.45 \mathrm{E}-01$ \\
\hline 6.242 & $600 \mathrm{TT}$ & 1,500 & Cracked & Yes, depth not listed & 8.30E-02 \\
\hline 9.092 & 690TT & 25,000 & Not cracked & $120 \mu \mathrm{m}\left(0.0047^{\prime \prime}\right)$ & $1.42 \mathrm{E}-01$ \\
\hline 9.592 & 690TT & 16,500 & Not cracked & $20-35 \mu \mathrm{m}\left(0.0008 "-0.0014^{\prime \prime}\right)$ & $2.15 \mathrm{E}-02$ \\
\hline 9.799 & 690TT & 16,500 & Not cracked & No intergranular cracking & $2.92 \mathrm{E}-03^{(\mathrm{c})}$ \\
\hline $9 \mathrm{G} 4$ & 690MA & 54,000 & Not cracked & $20-35 \mu \mathrm{m}\left(0.0008^{\prime \prime}-0.0014 "\right)$ & 1.81E-02 \\
\hline
\end{tabular}

(a) Test hours is based on Ref. 49.

(b) Average crack growth rate (CGR) is estimated based on Ref. 49.

(c) Below the detection limit of $10 \mu \mathrm{m}$ in 2000 hours or $5.00 \mathrm{E}-03$. 
Table 3-47 SG Tubes Used by Boursier et al. ${ }^{[50]}$

\begin{tabular}{|c|c|c|c|c|c|c|}
\hline SG Tubes ${ }^{(a)}$ & Note $^{(b)}$ & Eq. of Ref. $49^{(a)}$ & Heat Treatment & $\% \mathrm{Cr}$ & $\% \mathrm{Fe}$ & $\% \mathrm{C}$ \\
\hline 690 Exp1 & Experiment heat & $\begin{array}{l}9.092 \\
\text { Alloy } 690 \mathrm{TT}\end{array}$ & $\begin{array}{l}980^{\circ} \mathrm{C}+700^{\circ} \mathrm{C} \text { and } 1060^{\circ} \mathrm{C}+ \\
700^{\circ} \mathrm{C} \times 5 \text {-hour }\end{array}$ & \multirow{2}{*}{30.7} & \multirow{2}{*}{7.2} & \multirow{2}{*}{0.041} \\
\hline 690 Exp2 & Experiment heat & $\begin{array}{l}9.092 \\
\text { Alloy } 690 \mathrm{TT}\end{array}$ & $\begin{array}{l}980^{\circ} \mathrm{C}+700^{\circ} \mathrm{C} \text { and } 1040^{\circ} \mathrm{C}+ \\
700^{\circ} \mathrm{C} \times 5 \text {-hour }\end{array}$ & & & \\
\hline 690 Ind & Industrial (commercial) & $\begin{array}{l}9.799 \\
\text { Alloy } 690 \mathrm{TT}\end{array}$ & $1060^{\circ} \mathrm{C}+700^{\circ} \mathrm{C} \times 5$-hour & 28.9 & 10.95 & 0.018 \\
\hline $600 \mathrm{~A}$, ref. & $\begin{array}{l}\text { Reference heat, } \\
\text { (high resistant heat) }\end{array}$ & $\begin{array}{l}6 \mathrm{E} \\
\text { Alloy 600MA }\end{array}$ & $1070^{\circ} \mathrm{C}$ & 16.3 & 7.82 & 0.033 \\
\hline $\begin{array}{l}600 \mathrm{~B} \\
\text { sensitive }\end{array}$ & $\begin{array}{l}\text { PWSCC sensitive } \\
\text { (low resistant heat) }\end{array}$ & $\begin{array}{l}6.242 \\
\text { Alloy } 600 \mathrm{MA}\end{array}$ & $930^{\circ} \mathrm{C}$ & 16.05 & 9.20 & 0.030 \\
\hline
\end{tabular}

\begin{tabular}{|c|c|c|c|c|c|c|c|}
\hline \multirow[t]{2}{*}{ SG Tubes ${ }^{(a)}$} & \multirow{2}{*}{ SG Code in Ref. $49^{(a)}$} & $\begin{array}{c}Y S \\
20^{\circ} \mathrm{C} \\
\end{array}$ & $\begin{array}{l}\text { UTS } \\
20^{\circ} \mathrm{C} \\
\end{array}$ & $\begin{array}{l}\text { Elong } \\
20^{\circ} \mathrm{C} \\
\end{array}$ & $\begin{array}{c}\mathrm{YS} \\
350^{\circ} \mathrm{C} \\
\end{array}$ & $\begin{array}{c}\text { UTS } \\
350^{\circ} \mathrm{C} \\
\end{array}$ & $\begin{array}{l}\text { Elong } \\
350^{\circ} \mathrm{C} \\
\end{array}$ \\
\hline & & $\mathrm{MPa}$ & $\mathrm{MPa}$ & $\%$ & $\mathrm{MPa}$ & $\mathrm{MPa}$ & $\%$ \\
\hline 690 Exp1 & $\begin{array}{l}9.092 \\
\text { Alloy } 690 \mathrm{TT}\end{array}$ & 447 & 849 & 36 & 391 & 709 & 34 \\
\hline 690 Exp2 & $\begin{array}{l}9.092 \\
\text { Alloy } 690 \mathrm{TT}\end{array}$ & 464 & 880 & 36 & 398 & 750 & 30 \\
\hline 690 Ind & $\begin{array}{l}9.799 \\
\text { Alloy } 690 \mathrm{TT}\end{array}$ & 305 & 705 & 50 & 245 & 588 & 45 \\
\hline $600 \mathrm{~A}$, ref. & $\begin{array}{l}6 \mathrm{E} \\
\text { Alloy } 600 \mathrm{MA}\end{array}$ & 340 & 710 & 38 & 280 & 670 & 48 \\
\hline $600 \mathrm{~B}$, sensitive & $\begin{array}{l}6.242 \\
\text { Alloy } 600 \mathrm{MA}\end{array}$ & 333 & 716 & 42 & 290 & 680 & 42 \\
\hline
\end{tabular}

(a) These SG tube were also used in Ref. 49, but were referred by different codes.

(b) Based on the results from Ref. 49, Alloy 690 Ind has a higher PWSCC resistance than Alloy 690 Exp. Alloy 600 $A$ is a very PWSCC resistant heat while Alloy $600 \mathrm{~B}$ is a low resistant heat.

Table 3-48 CERT and Constant Load Test Conditions by Boursier et al. ${ }^{[50]}$

\begin{tabular}{|l|l|l|}
\hline & CERT Test & Constant Load Test \\
\hline Temperature & $360^{\circ} \mathrm{C}\left(680^{\circ} \mathrm{F}\right)$ & $360^{\circ} \mathrm{C}\left(680^{\circ} \mathrm{F}\right)$ \\
\hline Hydrogen & $30 \mathrm{cc} \mathrm{H}_{2} / \mathrm{kg} \mathrm{H}_{2} \mathrm{O}$ & $30 \mathrm{cc} \mathrm{H} / \mathrm{kg} \mathrm{H}_{2} \mathrm{O}$ \\
\hline B & $1000 \mathrm{ppm} \mathrm{B}$ as H $\mathrm{BO}_{3}$ & $1000 \mathrm{ppm} \mathrm{B}$ as $\mathrm{H}_{3} \mathrm{BO}_{3}$ \\
\hline $\mathrm{Li}$ & $2 \mathrm{ppm} \mathrm{Li}$ as LiOH & $2 \mathrm{ppm} \mathrm{Li}$ as LiOH \\
\hline $\mathrm{pH}$ & Not reported & Not reported \\
\hline & $5 \times 10^{-9}-2.5 \times 10^{-7} \sec ^{-1}$ strain rate & 603 to $684 \mathrm{MPa}(87$ to $99 \mathrm{ksi})$ \\
\hline
\end{tabular}


Table 3-49 Alloy 690 CERT Test Results by Boursier et al. ${ }^{[0]}$

$360^{\circ} \mathrm{C}\left(680^{\circ} \mathrm{F}\right)$ Primary water, Strain rate $2.5 \times 10^{-7} \mathrm{sec}^{-1}$

\begin{tabular}{|l|l|l|l|l|l|l|l|l|}
\hline \multirow{2}{*}{$\begin{array}{l}\text { Surface } \\
\text { condition }\end{array}$} & \multicolumn{2}{|l|}{ As-received } & \multicolumn{2}{l|}{ Electropolished } & \multicolumn{2}{l|}{ 1-Side Shot Peened } & \multicolumn{2}{l|}{ 2-Side Shot Peened } \\
\cline { 2 - 10 } & $\begin{array}{l}\text { Hours to } \\
\text { cracking }\end{array}$ & $\begin{array}{l}\text { Crack } \\
\text { depth } \mu \mathrm{m}\end{array}$ & $\begin{array}{l}\text { Hours to } \\
\text { cracking }\end{array}$ & $\begin{array}{l}\text { Crack } \\
\text { depth } \mu \mathrm{m}\end{array}$ & $\begin{array}{l}\text { Hours to } \\
\text { cracking }\end{array}$ & $\begin{array}{l}\text { Crack } \\
\text { depth } \mu \mathrm{m}\end{array}$ & $\begin{array}{l}\text { Hours to } \\
\text { cracking }\end{array}$ & $\begin{array}{l}\text { Crack } \\
\text { depth } \mu \mathrm{m}\end{array}$ \\
\hline $690 \operatorname{Exp} 1$ & 291 & 90 & 286 & 40 & -- & - & 250 & 74 \\
\hline $690 \operatorname{Exp} 2$ & 307 & 47 & - & - & 258 & 105 & 250 & 50 \\
\hline
\end{tabular}

$360^{\circ} \mathrm{C}\left(680^{\circ} \mathrm{F}\right)$ Primary water, Strain rate $5 \times 10^{-8} \mathrm{sec}^{-1}$

\begin{tabular}{|l|l|l|l|l|}
\hline \multirow{2}{*}{$\begin{array}{l}\text { Surface } \\
\text { condition }\end{array}$} & \multicolumn{3}{|c|}{ As received } & \multicolumn{2}{c|}{ Cold Pressed Hump (R=1) } \\
\cline { 2 - 6 } & Hours to cracking & Crack depth $\mu \mathrm{m}$ & hours to cracking & Crack depth $\mu \mathrm{m}$ \\
\hline 690 Exp 1 & 1341 & 120 & 669 & 225 \\
\hline 690 Ind & 2202 & 5 & 934 & 70 \\
\hline $600 \mathrm{~A}$ & 2208 & 10 & 343 & 1087 \\
\hline
\end{tabular}

$\operatorname{Exp} 1$ and $\operatorname{Exp} 2=W E 092$ (solution annealed at 1060 and $1040^{\circ} \mathrm{C}$ respectively before $T T$ at $700^{\circ} \mathrm{C}$ ), Ind $=$ WH 799

Table 3-50 Alloys 52M, 182, 600 Used by Jacko et al. ${ }^{[54]}$

\begin{tabular}{|l|c|c|c|c|c|c|c|c|c|c|c|c|c|c|}
\hline Alloy & $\mathrm{Ni}$ & $\mathrm{Cr}$ & $\mathrm{Fe}$ & $\mathrm{C}$ & $\mathrm{Mn}$ & $\mathrm{Si}$ & $\mathrm{S}$ & $\mathrm{Ti}$ & $\begin{array}{c}\mathrm{Nb}+ \\
\mathrm{Ta}\end{array}$ & $\mathrm{Cu}$ & $\mathrm{P}$ & $\mathrm{Al}$ & Mo & Other \\
\hline $\begin{array}{l}52 \mathrm{M}^{(\mathrm{a})} \\
\text { Y9570 }\end{array}$ & 60.10 & 30.13 & 8.50 & 0.020 & 0.92 & 0.03 & 0.001 & 0.22 & 0.93 & 0.03 & 0.003 & 0.08 & 0.02 & $<0.50$ \\
\hline $\begin{array}{l}182^{(\mathrm{b})} \\
\text { WC46F5 }\end{array}$ & 68.90 & 13.95 & 8.04 & 0.042 & 6.63 & 0.43 & 0.002 & 0.47 & 1.41 & 0.01 & 0.004 & & & $<0.50$ \\
\hline $\begin{array}{l}600 \\
\text { WF } 147\end{array}$ & 73.07 & 15.65 & 9.65 & 0.033 & 0.78 & 0.29 & 0.001 & & & 0.02 & 0.009 & & & \\
\hline
\end{tabular}

(a) Heat number Y9570, batch 50249/1. Additional elements: $\mathrm{B}-0.004 \%, \mathrm{Zr}-0.006 \%$.

(b) Additional element: $\mathrm{Co}-0.18 \%$. 
Table 3-51 Calculated Stress in the Four-Point Bend Specimens Used by Jacko et al. ${ }^{[54]}$

\begin{tabular}{|c|c|c|c|c|}
\hline \multirow{2}{*}{ Alloy } & & \multicolumn{3}{|c|}{ Residual Stress, MPa ${ }^{\text {(a) }}$} \\
\cline { 3 - 5 } & & Pre-test after furnace relief & Mid-test & Post-test \\
\hline \multirow{2}{*}{ Alloy 52M } & High & n/a & n/a & 331 \\
\cline { 2 - 5 } & Low & 433 & 384 & 568 \\
\hline \multirow{2}{*}{ Alloy 182 } & High & 586 & n/a & 441 \\
\cline { 2 - 5 } & Low & 433 & n/a & 452 \\
\hline \multirow{2}{*}{ Alloy 600 } & High & 456 & 436 & 392 \\
\cline { 2 - 5 } & Low & 326 & 396 \\
\hline
\end{tabular}

(a) Stresses calculated from measured strains using $\mathrm{E}$ at $400^{\circ} \mathrm{C}$ of Alloy 600 ) $=195.3 \mathrm{GPa}$.

Table 3-52 Four-Point Bend Test Results by Jacko et al. ${ }^{[54]}$

\begin{tabular}{|r|r|l|l|c|c|l|c|}
\hline $\begin{array}{c}\text { Autoclave } \\
\text { Exposure }\end{array}$ & \multicolumn{2}{|c|}{$\begin{array}{c}\text { Equivalent } \\
\text { Exposure }\end{array}$} & \multicolumn{2}{|c|}{ Alloy 52M } & \multicolumn{2}{c|}{ Alloy 182} & \multicolumn{2}{c|}{ Alloy 600} \\
\hline \multicolumn{1}{|c|}{ Hours } & EFPY & Low Strain & High Strain & Low Strain & High Strain & Low Strain & High Strain \\
\hline 124 & 2.8 & $0 / 2$ & $0 / 2$ & $0 / 2$ & $0 / 2$ & $0 / 2$ & $0 / 4$ \\
\hline 214 & 4.8 & $0 / 2$ & $0 / 2$ & -- & $2 / 2$ & -- & - \\
\hline 269 & 6.0 & $0 / 2$ & $0 / 2$ & $0 / 2$ & $2 / 2$ & $0 / 2$ & $1 / 4$ \\
\hline 418 & 9.3 & $0 / 2$ & $0 / 2$ & -- & & $0 / 2$ & $1 / 4$ \\
\hline 450 & 10.0 & $0 / 2$ & $0 / 2$ & $2 / 2$ & & -- & $2 / 4$ \\
\hline 598 & 13.3 & $0 / 2$ & $0 / 2$ & $2 / 2$ & & $0 / 2$ & $3 / 4$ \\
\hline 889 & 19.8 & $0 / 2$ & $0 / 2$ & & & $0 / 2$ & $3 / 4$ \\
\hline 1343 & 29.9 & $0 / 2$ & $0 / 2$ & & & $0 / 2$ & $3 / 4$ \\
\hline 1801 & 40.1 & $0 / 2$ & $0 / 2$ & & & $0 / 2$ & $3 / 4$ \\
\hline 2051 & 45.6 & $0 / 2$ & $0 / 2$ & & & -- & - \\
\hline
\end{tabular}

(a) Equivalent EFPYs for the Ringhals 4 outlet nozzle temperature of $322.8^{\circ} \mathrm{C}\left(613^{\circ} \mathrm{F}\right)$ relative to hours at the $400^{\circ} \mathrm{C}$ doped steam to this service.

(a) $x / y-x$ is the accumulated number of specimens cracked; $y$ is the total specimen number. 
Table 3-53 Alloys 690TT and 600MA Used by Framatome ANP, Germany [App. A]

\begin{tabular}{|l|c|c|c|c|c|c|c|c|c|c|c|c|c|c|}
\hline Alloy & $\mathrm{Ni}$ & $\mathrm{Cr}$ & $\mathrm{Fe}$ & $\mathrm{C}$ & $\mathrm{Mn}$ & $\mathrm{Si}$ & $\mathrm{S}$ & $\mathrm{Ti}$ & $\begin{array}{c}\mathrm{Nb}+ \\
\mathrm{Ta}\end{array}$ & $\mathrm{Cu}$ & $\mathrm{P}$ & $\mathrm{Al}$ & $\mathrm{Mo}$ & Other \\
\hline $\begin{array}{l}\text { Alloy } \\
690 \mathrm{TT}, \\
754380\end{array}$ & 59.40 & 29.95 & 9.45 & 0.019 & 0.32 & 0.35 & 0.001 & 0.30 & & 0.010 & 0.008 & 0.025 & 0.01 & \\
\hline $\begin{array}{l}\text { Alloy } \\
\text { 600MA, } \\
752677\end{array}$ & 72.7 & 16.55 & 9.19 & 0.027 & 0.80 & 0.29 & 0.003 & 0.29 & & 0.010 & 0.008 & 0.14 & $\mathrm{~N} / \mathrm{A}$ & \\
\hline
\end{tabular}

(a) Additional element: Co $-0.012 \%$ for Alloy $690 \mathrm{TT}$, $0.011 \%$ for Alloy $600 \mathrm{MA}$. N - $0.025 \%$ for Alloy 690 .

\begin{tabular}{|l|c|c|c|c|c|}
\hline & $0.2 \%$ Yield Strength & Tensile Strength & Elongation (2") & outer diameter & wall thickness \\
\hline $\begin{array}{l}\text { Alloy 690TT } \\
\text { heat 754380 }\end{array}$ & $\begin{array}{c}349 \mathrm{MPa} \\
(51 \mathrm{ksi})\end{array}$ & $\begin{array}{c}746 \mathrm{MPa} \\
(108 \mathrm{ksi})\end{array}$ & $44 \%$ & $\begin{array}{c}19.05 \mathrm{~mm} \\
\left(3 / 4^{\prime \prime}\right)\end{array}$ & $\begin{array}{c}1.09 \mathrm{~mm} \\
\left(0.043^{\prime \prime}\right)\end{array}$ \\
\hline $\begin{array}{l}\text { Alloy 600MA } \\
\text { heat 752677 }\end{array}$ & $\begin{array}{c}399 \mathrm{MPa} \\
(58 \mathrm{ksi})\end{array}$ & $\begin{array}{c}715 \mathrm{MPa} \\
(104 \mathrm{ksi})\end{array}$ & $42 \%$ & $\begin{array}{c}22.23 \mathrm{~mm} \\
\left(7 / 8^{\prime \prime}\right)\end{array}$ & $\begin{array}{c}1.27 \mathrm{~mm} \\
\left(0.05^{\prime \prime}\right)\end{array}$ \\
\hline
\end{tabular}

Table 3-54 RUB Test Results by Framatome ANP, Germany [App. A]

\begin{tabular}{|c|c|c|c|c|c|c|}
\hline Material & $\begin{array}{c}\text { scored } \\
\text { surface }\end{array}$ & $\begin{array}{c}\text { total No. of } \\
\text { specimens }\end{array}$ & $\begin{array}{c}\text { cracked } \\
\text { RUBs after } \\
14 \text { days }\end{array}$ & $\begin{array}{c}\text { cracked } \\
\text { RUBs after } \\
30 \text { days }\end{array}$ & $\begin{array}{c}\text { cracked RUBs } \\
\text { after 60 days }\end{array}$ & $\begin{array}{c}\text { cracked RUBs } \\
\text { after 405 days }\end{array}$ \\
\hline \multirow{2}{*}{$\begin{array}{c}\text { Alloy 690TT } \\
\text { heat 754380 }\end{array}$} & yes & 3 & $0 / 3$ & $0 / 3$ & $0 / 3$ & $0 / 3$ \\
\cline { 2 - 7 } & no & 3 & $0 / 3$ & $0 / 3$ & $0 / 3$ & $0 / 3$ \\
\hline \multirow{2}{*}{$\begin{array}{l}\text { Alloy 600MA } \\
\text { heat 752677 }\end{array}$} & yes & 3 & $3 / 3$ & - & - & - \\
\cline { 2 - 7 } & no & 3 & $3 / 3$ & - & - & - \\
\hline
\end{tabular}


Table 3-55 Alloys 690TT and 600MA\&TT Used by Framatome ANP, France [App. B]

\begin{tabular}{|c|c|c|c|c|c|c|c|c|c|c|c|c|c|c|}
\hline Alloy & $\mathrm{Ni}$ & $\mathrm{Cr}$ & $\mathrm{Fe}$ & C & Mn & Si & $S$ & $\mathrm{Ti}$ & $\begin{array}{c}\mathrm{Nb}+ \\
\mathrm{Ta}\end{array}$ & $\mathrm{Cu}$ & $\mathrm{P}$ & Al & Mo & Other \\
\hline $\begin{array}{c}\text { Alloy } \\
600, \\
\text { WD281 }\end{array}$ & 73.40 & 16.03 & 8.89 & 0.035 & 0.81 & 0.33 & 0.001 & 0.21 & & 0.01 & 0.010 & 0.25 & & \\
\hline $\begin{array}{c}\text { Alloy } \\
600, \\
\text { NX3335 }\end{array}$ & 75.11 & 15.76 & 8.45 & 0.03 & 0.14 & 0.16 & $\stackrel{<}{0.005}$ & 0.10 & & 0.11 & 0.010 & 0.081 & & \\
\hline $\begin{array}{c}\text { Alloy } \\
690, \\
\text { WE094 }\end{array}$ & 61.29 & 28.99 & 8.75 & 0.027 & 0.23 & 0.28 & 0.002 & 0.25 & & 0.01 & 0.005 & 0.17 & & \\
\hline
\end{tabular}

(a) Additional element: Co - $\mathbf{0 . 0 1 3 \%}$ for WD2810, 0.036\% for NX3335, and $0.01 \%$ for WE094. N - 0.0158\% \% for WE094.

\begin{tabular}{|c|c|c|c|c|c|c|}
\hline & \multicolumn{2}{|c|}{$0.2 \%$ Yield Strength, MPa } & \multicolumn{2}{c|}{ Tensile Strength, MPa } & \multicolumn{2}{c|}{ Elongation, \% } \\
\cline { 2 - 7 } & $20^{\circ} \mathrm{C}$ & $343^{\circ} \mathrm{C}\left(650^{\circ} \mathrm{F}\right)$ & $20^{\circ} \mathrm{C}$ & $343^{\circ} \mathrm{C}\left(650^{\circ} \mathrm{F}\right)$ & $20^{\circ} \mathrm{C}$ & $343^{\circ} \mathrm{C}\left(650^{\circ} \mathrm{F}\right)$ \\
\hline Alloy 600, WD281 & 339 & 262 & 723 & 675 & 41.7 & 39.1 \\
\hline Alloy 600, NX3335 & 329 & 266 & 721 & 623 & 41.3 & 36.1 \\
\hline Alloy 690, WE094 & 419 & 358 & 825 & 723 & 37 & 36 \\
\hline
\end{tabular}

Table 3-56 Chemical analysis of the aqueous environment in the mock-ups after the 6th test period of 10,000 hours [App. B]

\begin{tabular}{|c|c|c|c|c|}
\hline Mock-up & \multicolumn{2}{|c|}{$501+503+504+507$} & \multicolumn{2}{c|}{$502+505+506+508$} \\
\hline & $1^{\text {st }}$ period & $6^{\text {th }}$ period & $1^{\text {st }}$ period & $6^{\text {th }}$ period \\
\hline $\mathrm{Cl}^{-}(\mathrm{mg} / \mathrm{kg})$ & 0.7 & 0.46 & 0.4 & 0.57 \\
\hline $\mathrm{F}^{-}(\mathrm{mg} / \mathrm{kg})$ & 0.08 & 0.56 & 0.25 & 0.05 \\
\hline $\mathrm{Na}^{+}(\mathrm{mg} / \mathrm{kg})$ & 0.19 & 0.43 & 0.14 & 0.10 \\
\hline $\mathrm{SiO}_{2}(\mathrm{mg} / \mathrm{kg})$ & 0.71 & 4.3 & 0.43 & 4.8 \\
\hline
\end{tabular}


Table 3-57 Results for all mock-ups fabricated from Alloy 600 heat WD281 [App. B]

\begin{tabular}{|c|c|c|c|c|c|c|c|c|}
\hline Mock-up & Heat treatment & $\begin{array}{c}\text { T/TS } \\
\text { Gap } \\
(\mathrm{mm})\end{array}$ & $\begin{array}{l}\text { Kiss rolling } \\
\quad(\mathrm{mm})\end{array}$ & Skip roll & $\begin{array}{l}\text { Intended } \\
\text { Over-roll } \\
(\mathrm{mm})\end{array}$ & $\begin{array}{c}\text { Measured } \\
\text { Over-roll (mm) }\end{array}$ & Duration (h) & Result \\
\hline 1B & \multirow{2}{*}{ MA } & \multirow{2}{*}{0.4} & \multirow{2}{*}{0} & \multirow{2}{*}{ no } & +3 & +10 & 14400 & $\mathrm{RTZ}$ \\
\hline $1 \mathrm{H}$ & & & & & -1.5 & 0 & 20250 & $\mathrm{RTZ}$ \\
\hline $2 \mathrm{~B}$ & \multirow{2}{*}{ MA } & \multirow{2}{*}{0.4} & \multirow{2}{*}{0} & \multirow{2}{*}{ no } & - & - & - & - \\
\hline $2 \mathrm{H}$ & & & & & +6 & +6 & 22800 & $\mathrm{RTZ}$ \\
\hline $3 \mathrm{~B}$ & \multirow{2}{*}{ TT } & \multirow{2}{*}{0.4} & \multirow{2}{*}{0.15} & \multirow{2}{*}{ no } & +20 & - & 10000 & $\mathrm{RTZ}$ \\
\hline $3 \mathrm{H}$ & & & & & -1.5 & +1 & 18400 & $\mathrm{RTZ}$ \\
\hline $5 \mathrm{~B}$ & \multirow{2}{*}{ MA } & \multirow{2}{*}{0.4} & \multirow{2}{*}{0.15} & \multirow{2}{*}{ yes } & +20 & +8 & 1500 & SR \\
\hline $5 \mathrm{H}$ & & & & & -1.5 & 4 & 10600 & $\mathrm{RTZ}$ \\
\hline $6 \mathrm{~B}$ & \multirow{2}{*}{ MA } & \multirow{2}{*}{0.4} & \multirow{2}{*}{$\begin{array}{l}0.15 \\
0.30\end{array}$} & \multirow{2}{*}{ yes } & -1.5 & 0 & \multirow{2}{*}{1900} & \multirow{2}{*}{ SR } \\
\hline $6 \mathrm{H}$ & & & & & +20 & +23 & & \\
\hline $7 \mathrm{~B}$ & \multirow{2}{*}{ TT } & \multirow{2}{*}{0.4} & \multirow{2}{*}{0.30} & \multirow{2}{*}{ yes } & +20 & +26 & 11100 & $\mathrm{OZ}$ \\
\hline $7 \mathrm{H}$ & & & & & -1.5 & +3 & 11000 & $\mathrm{SR}$ \\
\hline $8 \mathrm{~B}$ & MA & 0.4 & 0.30 & no & +20 & +23 & 11750 & $\mathrm{RTZ}$ \\
\hline $8 \mathrm{H}$ & 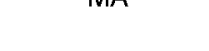 & 0.4 & 0.00 & 10 & -1.5 & +2 & 12850 & $\mathrm{RTZ}$ \\
\hline $10 \mathrm{~B}$ & $\pi$ & & & & +1.5 & - & & \\
\hline $10 \mathrm{H}$ & 11 & 0.4 & 0.30 & no & -1.5 & - & 34000 & No leak \\
\hline $11 \mathrm{~B}$ & $T$ & 04 & 030 & $n$ & +20 & +22 & 10750 & $\mathrm{RTZ}$ \\
\hline $11 \mathrm{H}$ & 列 & 0.4 & 0.50 & 110 & +20 & & 10500 & $\mathrm{RTZ}$ \\
\hline $12 \mathrm{~B}$ & MA & 04 & 030 & no & +20 & +24 & 20000 & $\mathrm{RTZ}$ \\
\hline $12 \mathrm{H}$ & (10. & - & 6.00 & 10 & +1.5 & - & 30000 & No leak \\
\hline 14B & $M A$ & 095 & 015 & $n$ & +1.5 & +1.5 & 1300 & $\mathrm{RTZ}$ \\
\hline $14 \mathrm{H}$ & IVI & 0.00 & 0.10 & 100 & -1.5 & +2 & 800 & $\mathrm{RTZ}$ \\
\hline $15 B$ & $M A$ & 095 & 15 & no & +20 & +23 & 3800 & $\mathrm{RTZ}$ \\
\hline $15 \mathrm{H}$ & & & . & w & +20 & +23 & 4050 & $\mathrm{RTZ}$ \\
\hline $16 \mathrm{~B}$ & $\pi$ & 0.95 & 015 & no & +1.5 & +7 & 3500 & 07 \\
\hline $16 \mathrm{H}$ & 11 & 0.90 & 0.10 & no & -1.5 & +2 & 3500 & 02 \\
\hline $17 \mathrm{~B}$ & $\pi$ & 095 & 015 & $n$ & +20 & & 5400 & $\mathrm{RTZ}$ \\
\hline $17 \mathrm{H}$ & 列 & 0.50 & 0.13 & 110 & +20 & +23 & 5900 & $\mathrm{RTZ}$ \\
\hline $18 \mathrm{~B}$ & MA & 0.95 & 0.30 & no & +20 & +23 & 4000 & No leak \\
\hline $18 \mathrm{H}$ & 列 & 0.00 & 0.00 & $\pi$ & +20 & +23 & 4000 & $\mathrm{RTZ}$ \\
\hline $19 \mathrm{~B}$ & MA & 0.95 & 030 & no & -1.5 & +1 & 1600 & 07 \\
\hline $19 \mathrm{H}$ & IVA & 0.50 & 0.00 & 110 & +1.5 & +6 & & \\
\hline $20 \mathrm{~B}$ & $\pi$ & 0.95 & 0.30 & no & +1.5 & & 1800 & $\mathrm{RTZ}$ \\
\hline $20 \mathrm{H}$ & 正 & 0.00 & 0.00 & 10 & -1.5 & +2 & 1500 & $\mathrm{RTZ}$ \\
\hline $21 \mathrm{~B}$ & MA & 095 & 030 & ves & +20 & +25 & 3800 & $\mathrm{RTZ}$ \\
\hline $21 \mathrm{H}$ & IVIA & 0.50 & 0.00 & $y=s$ & +1.5 & +2 & 3000 & No leak \\
\hline
\end{tabular}


Table 3-58 Results for all mock-ups fabricated from Alloy 600 heat NX3335 [App. B]

\begin{tabular}{|c|c|c|c|c|c|c|c|}
\hline Mock-up & $\begin{array}{c}\text { Heat } \\
\text { treatment }\end{array}$ & $\begin{array}{c}\text { T/TS } \\
\text { Gap } \\
(\mathrm{mm})\end{array}$ & $\begin{array}{l}\text { Kiss rolling } \\
(\mathrm{mm})\end{array}$ & Skip roll & Intended Over-roll (mm) & Duration (h) & Result \\
\hline $4 \mathrm{~B}$ & \multirow{2}{*}{ MA } & \multirow{2}{*}{0.4} & \multirow{2}{*}{0.30} & \multirow{2}{*}{ No } & +20 & 19600 & RTZ \\
\hline $4 \mathrm{H}$ & & & & & +1.5 & 27000 & RTZ \\
\hline 9B & \multirow{2}{*}{ MA } & \multirow{2}{*}{0.95} & \multirow{2}{*}{0.30} & \multirow{2}{*}{ No } & +20 & 11300 & RTZ \\
\hline $9 \mathrm{H}$ & & & & & +20 & 12150 & RTZ \\
\hline
\end{tabular}

Note: RTZ : cracked in roll transition zone - SR : cracked in skip roll - OZ : cracked in overlap zone

Table 3-59 Chemical Composition of Alloys 600, 690, 82, and 52 Tested by Brown and Mills ${ }^{[56,5]}$

\begin{tabular}{|l|c|c|c|c|c|c|c|c|c|c|c|c|c|c|}
\hline \multicolumn{1}{|c|}{ Heat } & $\mathrm{Ni}$ & $\mathrm{Cr}$ & $\mathrm{Fe}$ & $\mathrm{C}$ & $\mathrm{Mn}$ & $\mathrm{Si}$ & $\mathrm{S}$ & $\mathrm{Ti}$ & $\begin{array}{c}\mathrm{Nb}+ \\
\mathrm{Ta}\end{array}$ & $\mathrm{Cu}$ & $\mathrm{P}$ & $\mathrm{Al}$ & $\mathrm{Mo}$ & $\mathrm{Co}$ \\
\hline EN82, heat 1 & 73.2 & 18.7 & 1.5 & 0.007 & 2.4 & $<0.1$ & 0.0007 & 0.4 & & 0.006 & $<0.001$ & 0.09 & & $<0.1$ \\
\hline EN82H, heat 2 & 76.3 & 19.93 & 0.68 & 0.037 & 2.73 & 0.06 & 0.001 & 0.32 & 2.44 & 0.11 & 0.014 & & & 0.02 \\
\hline EN82H, heat 3 & 72.9 & 20.00 & 1.10 & 0.04 & 2.90 & 0.06 & 0.002 & 0.41 & 2.52 & 0.02 & 0.003 & & & \\
\hline EN82H, heat 4 & 73.6 & 19.75 & 0.73 & 0.04 & 2.93 & 0.09 & $<0.001$ & 0.30 & 2.51 & 0.07 & 0.004 & & & \\
\hline EN82H, heat 5 & 73.7 & 19.54 & 0.77 & 0.04 & 2.92 & 0.18 & 0.001 & 0.30 & 2.49 & 0.02 & 0.002 & & & \\
\hline EN82H, heat 6 & 72.8 & 19.8 & 1.31 & 0.041 & 2.87 & 0.07 & 0.004 & 0.28 & 2.5 & 0.07 & 0.003 & & & \\
\hline EN52 & 60.4 & 28.97 & 8.98 & 0.03 & 0.23 & 0.17 & $<0.001$ & 0.56 & & $<0.01$ & 0.004 & 0.63 & & 0.01 \\
\hline Alloy 600, plate & 75.4 & 15.54 & 7.76 & 0.07 & 0.25 & 0.29 & $<0.001$ & 0.35 & & 0.11 & 0.007 & 0.17 & & 0.04 \\
\hline Alloy 690, bar & 59.8 & 29.54 & 8.25 & 0.026 & 0.29 & 0.01 & 0.0005 & 0.32 & & 0.01 & 0.001 & 0.31 & & $<0.0$ \\
\hline
\end{tabular}

(a) EN82 heat 1 is the as-welded chemistry. All other EN82 and EN52 were the filler metal chemistry. 
Table 3-60 Low Cycle Fatigue Test Results by Psaila-Dombrowski et al. ${ }^{[42]}$

\begin{tabular}{|c|c|c|c|c|c|c|c|c|c|c|c|}
\hline I.D. & Env. & $\begin{array}{l}\text { Strain } \\
\text { Rate }\end{array}$ & $\begin{array}{c}\text { Strain } \\
\text { Range } \\
\%\end{array}$ & $\begin{array}{c}\text { Strain } \\
\text { Amp. } \\
\%\end{array}$ & $\begin{array}{c}\text { Life } \\
\text { Cycles } \\
\text { (1000s) }\end{array}$ & I.D. & Env. & $\begin{array}{l}\text { Strain } \\
\text { Rate }\end{array}$ & $\begin{array}{c}\text { Strain } \\
\text { Range } \\
\%\end{array}$ & $\begin{array}{c}\text { Strain } \\
\text { Amp. } \\
\%\end{array}$ & $\begin{array}{c}\text { Life } \\
\text { Cycles } \\
\text { (1000s) }\end{array}$ \\
\hline $690-11$ & Air & 0.016 & 0.4 & 0.2 & $>221.3$ & $82-13$ & Air & 0.048 & 1.2 & 0.6 & 21.1 \\
\hline $690-12$ & Air & 0.016 & 0.4 & 0.2 & 120.0 & $82-9$ & Air & 0.032 & 0.8 & 0.4 & 40.3 \\
\hline $690-15$ & Air & 0.001 & 0.4 & 0.2 & $>203.7$ & $82-10$ & Air & 0.032 & 0.8 & 0.4 & 77.24 \\
\hline $690-7$ & Air & 0.048 & 1.2 & 0.6 & 8.75 & $82-2$ & Water & 0.001 & 0.9 & 0.45 & 11.32 \\
\hline $690-8$ & Air & 0.048 & 1.2 & 0.6 & 7.49 & $82-3$ & Water & 0.001 & 0.8 & 0.4 & 15.4 \\
\hline $690-14$ & Air & 0.048 & 1.2 & 0.6 & 7.15 & $82-4^{(a)}$ & Water & 0.001 & 0.8 & 0.4 & 14.61 \\
\hline $690-9$ & Air & 0.032 & 0.8 & 0.4 & 16.04 & $82-5$ & Water $r^{(b)}$ & 0.0001 & 0.8 & 0.4 & 9.61 \\
\hline $690-10$ & Air & 0.032 & 0.8 & 0.4 & 19.1 & $52-1$ & Air & 0.016 & 0.8 & 0.4 & 24.12 \\
\hline $690-13$ & Air & 0.032 & 0.8 & 0.4 & 16.45 & $52-2$ & Air & 0.016 & 0.8 & 0.4 & 10.15 \\
\hline $690-1$ & Water & 0.001 & 0.8 & 0.4 & 10.17 & $52-3$ & Air & 0.016 & 0.8 & 0.4 & 18.17 \\
\hline $82-15$ & Air & 0.024 & 0.6 & 0.3 & 552.8 & $52-4$ & Water & 0.001 & 0.8 & 0.4 & 10.14 \\
\hline $82-8$ & Air & 0.024 & 0.6 & 0.3 & $>633.0$ & $52-5$ & Water & 0.001 & 0.8 & 0.4 & 8.17 \\
\hline $82-14$ & Air & 0.048 & 1.2 & 0.6 & 10.8 & $152-4$ & Air & 0.032 & 0.8 & 0.4 & 13.4 \\
\hline $82-12$ & Air & 0.048 & 1.2 & 0.6 & 21.65 & $152-1$ & Water & 0.001 & 0.8 & 0.4 & 11.6 \\
\hline
\end{tabular}

(a) Test conducted at $59^{\circ} \mathrm{C}\left(138^{\circ} \mathrm{F}\right)$.

(b) $\mathrm{Li}(0.2 \mathrm{ppm})$ and $\mathrm{pH}(5.62)$ in the autoclave effluent did not meet chemistry specification.

Table 3-61 Fatigue Crack Growth Rate Test Results by Psaila-Dombrowski et al. ${ }^{[4]}$

Alloys 82 and 52 Weld Metals

\begin{tabular}{|l|c|c|c|c|c|c|c|c|c|}
\hline $\begin{array}{c}\text { Specimen } \\
\text { I.D. }\end{array}$ & $\begin{array}{c}\Delta \mathrm{K} \\
(\mathrm{ksi} \text { in) }\end{array}$ & $\begin{array}{c}\text { Stress } \\
\text { Ratio } \\
(\mathrm{R})\end{array}$ & Frequency & $\begin{array}{c}\text { CGR } \\
\text { (in/cycle) }\end{array}$ & $\begin{array}{c}\text { Specimen } \\
\text { I.D. }\end{array}$ & $\begin{array}{c}\Delta \mathrm{K} \\
(\mathrm{ksi} \text { Vin) }\end{array}$ & $\begin{array}{c}\text { Stress } \\
\text { Ratio } \\
(\mathrm{R})\end{array}$ & $\begin{array}{c}\text { Frequency } \\
\text { CGR } \\
(\mathrm{in} / \mathrm{cycle})\end{array}$ \\
\hline 82 & 20 & 0.5 & 1 & $1.0 \mathrm{E}-5$ & 82 & 36 & 0.1 & 0.001 & $4.0 \mathrm{E}-5$ \\
\hline 82 & 20 & 0.5 & 0.1 & $1.4 \mathrm{E}-5$ & $82 \mathrm{CT} 2$ & 36 & 0.1 & 0.01 & $8.6 \mathrm{E}-5$ \\
\hline 82 & 20 & 0.5 & 0.01 & $1.6 \mathrm{E}-5$ & $82 \mathrm{CT} 2$ & 36 & 0.1 & 0.001 & $1.1 \mathrm{E}-4$ \\
\hline 82 & 20 & 0.5 & 0.0018 & $2.1 \mathrm{E}-5$ & $82 \mathrm{CT} 2$ & 36 & 0.1 & 0.0001 & $3.1 \mathrm{E}-4$ \\
\hline 82 & 20 & 0.5 & 0.00018 & $4.8 \mathrm{E}-5$ & $52 \mathrm{CT} 1$ & 36 & 0.1 & 1 & $2.0 \mathrm{E}-5$ \\
\hline 82 & 36 & 0.1 & 1 & $3.2 \mathrm{E}-5$ & $52 \mathrm{CT} 1$ & 36 & 0.1 & 0.1 & $2.1 \mathrm{E}-5$ \\
\hline 82 & 36 & 0.1 & 0.1 & $3.9 \mathrm{E}-5$ & $52 \mathrm{CT} 1$ & 36 & 0.1 & 0.01 & $2.1 \mathrm{E}-5$ \\
\hline 82 & 36 & 0.1 & 0.01 & $4.0 \mathrm{E}-5$ & $52 \mathrm{CT} 1$ & 36 & 0.1 & 0.001 & $2.5 \mathrm{E}-5$ \\
\hline
\end{tabular}




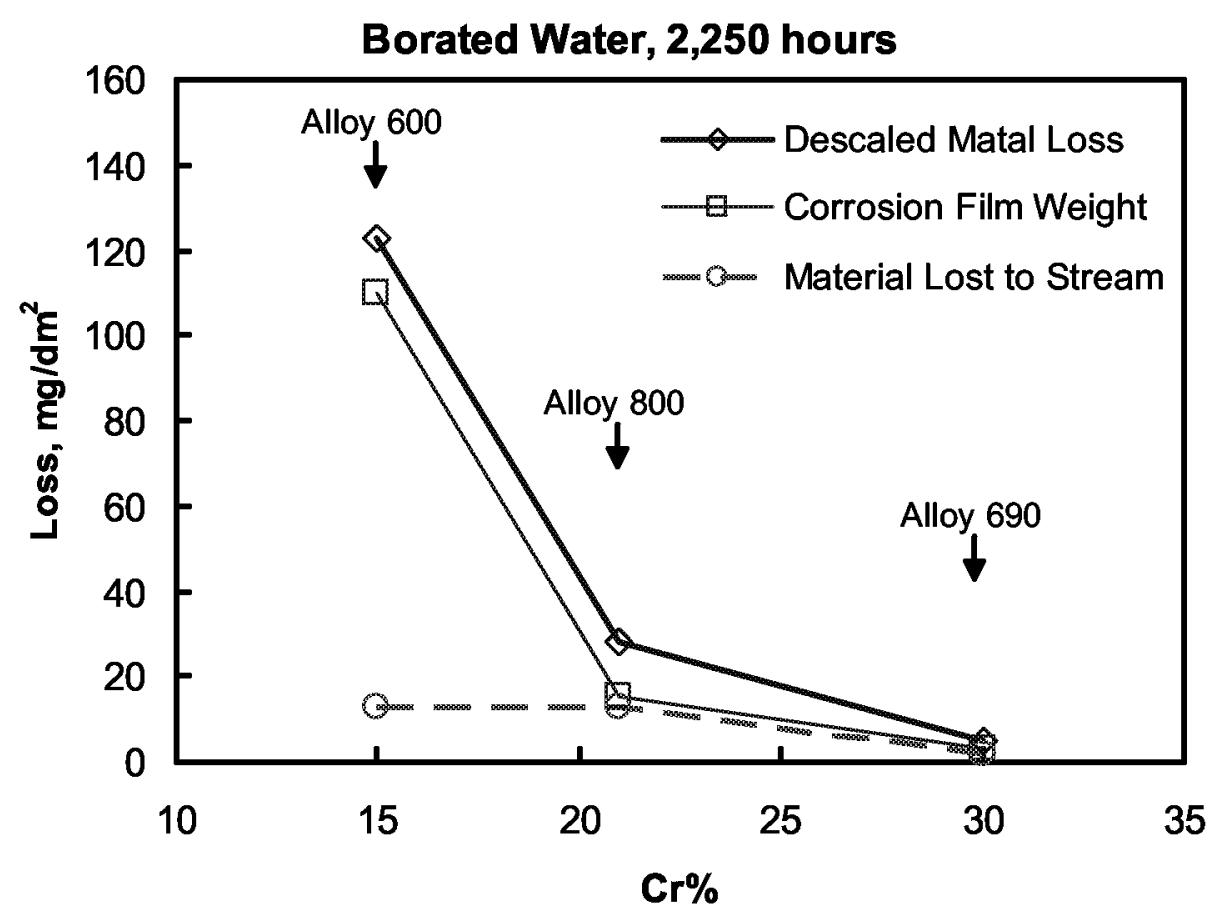

Figure 3-1 Comparison of material lost to stream in $316^{\circ} \mathrm{F}\left(600^{\circ} \mathrm{F}\right)$ deaerated water flowing at a velocity of $18 \mathrm{ft} / \mathrm{sec}(5.5 \mathrm{~m} / \mathrm{sec})$. After Ref. 9.

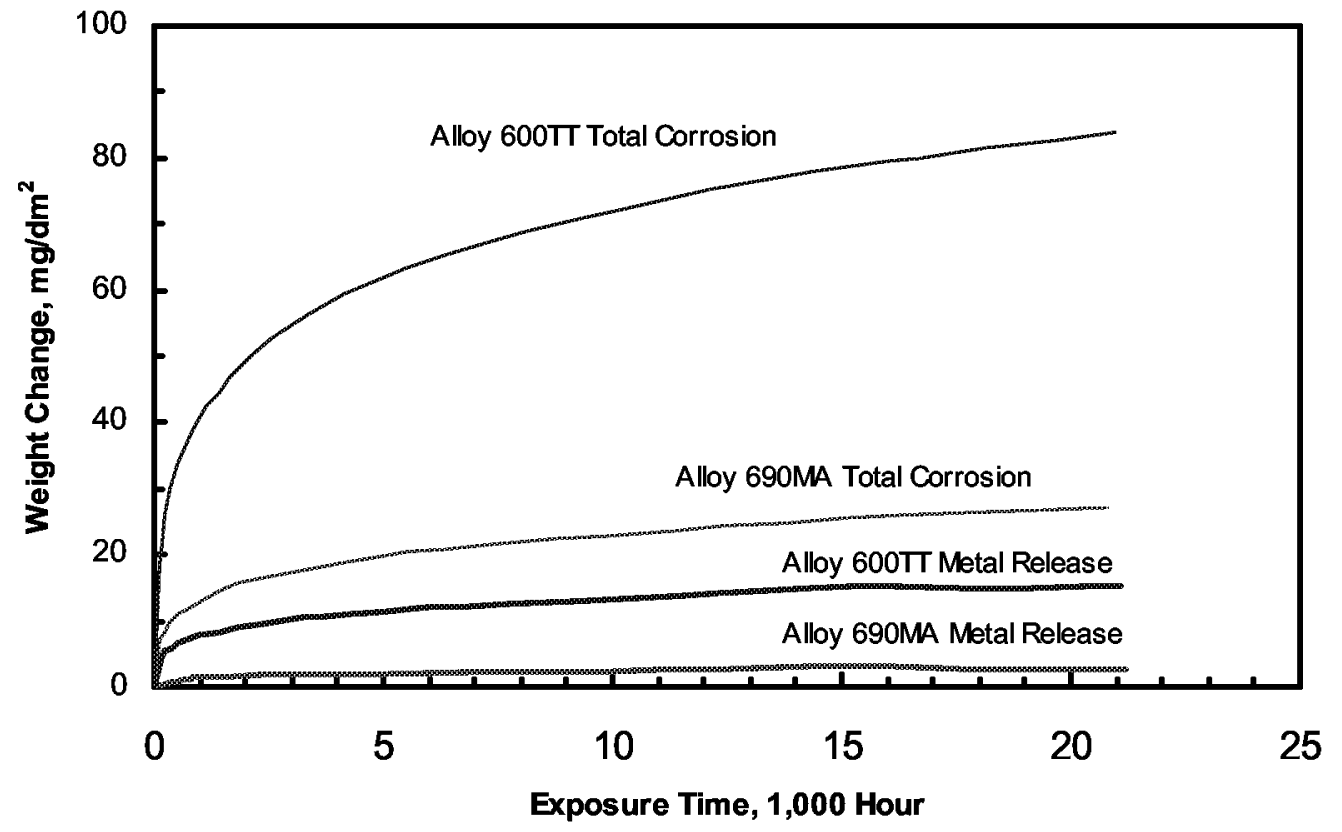

Figure 3-2 Comparison of general corrosion and material release to stream in simulated high temperature PWR primary water. After Ref. 11. 
End Fuel Cycle Water Chemistry

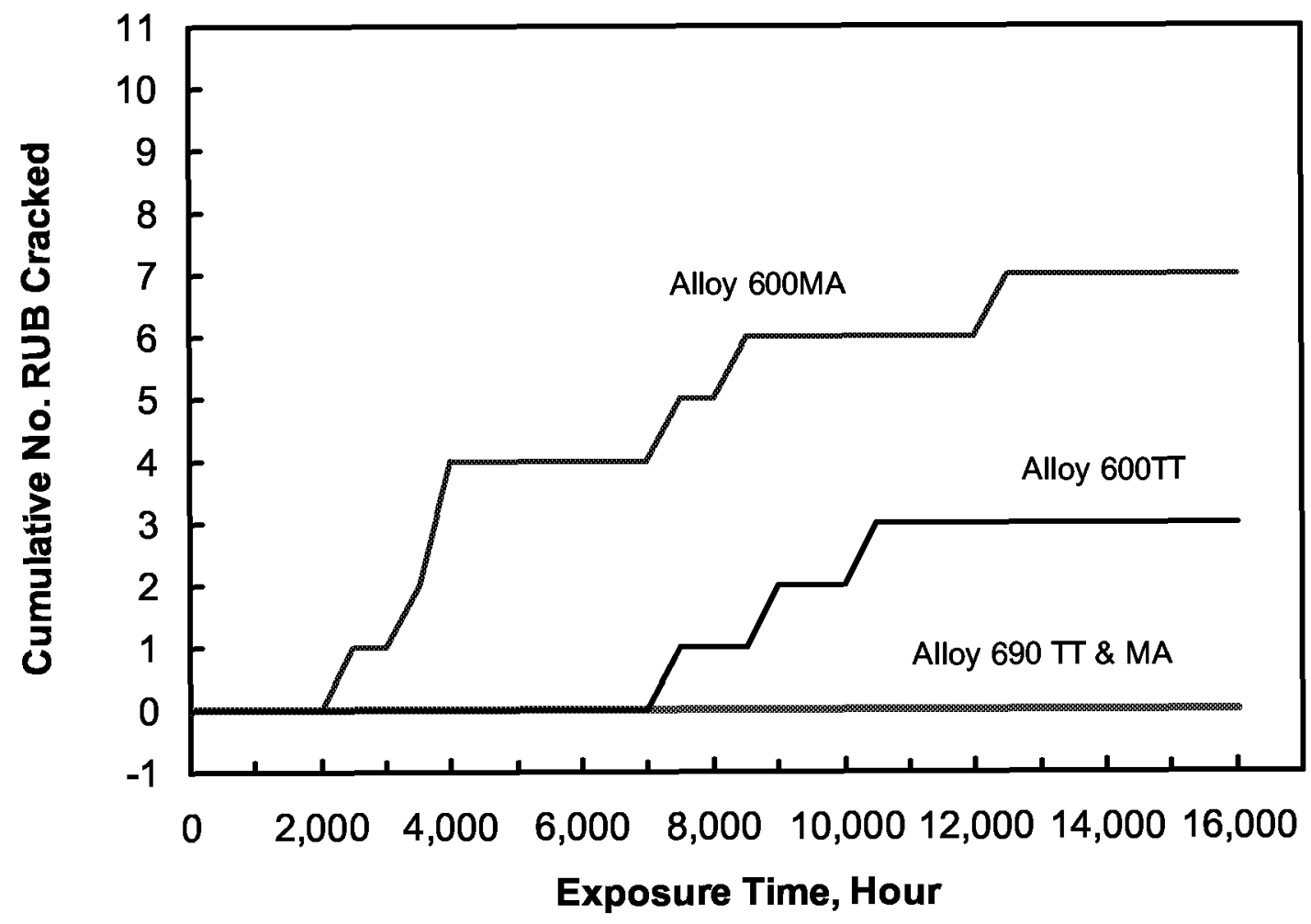

Beginning Fuel Cycle Water Chemistry

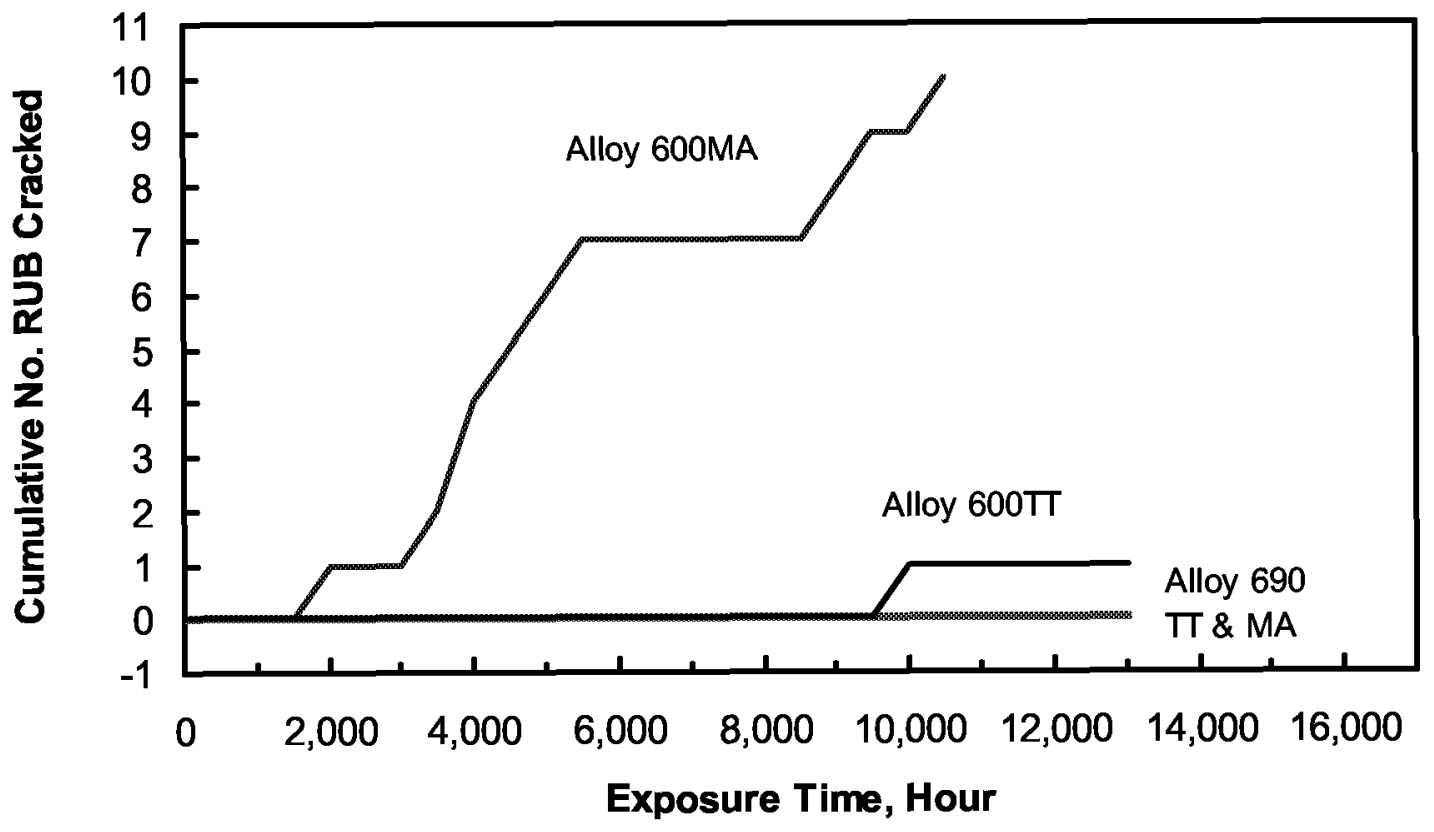

Figure 3-3 Cumulative number of RUB specimens cracked as function of test time by $\mathrm{K}$. Smith. None of the Alloy 690 TT and MA cracked. The number of RUB specimens for each series is 10. ${ }^{[1]}$ 


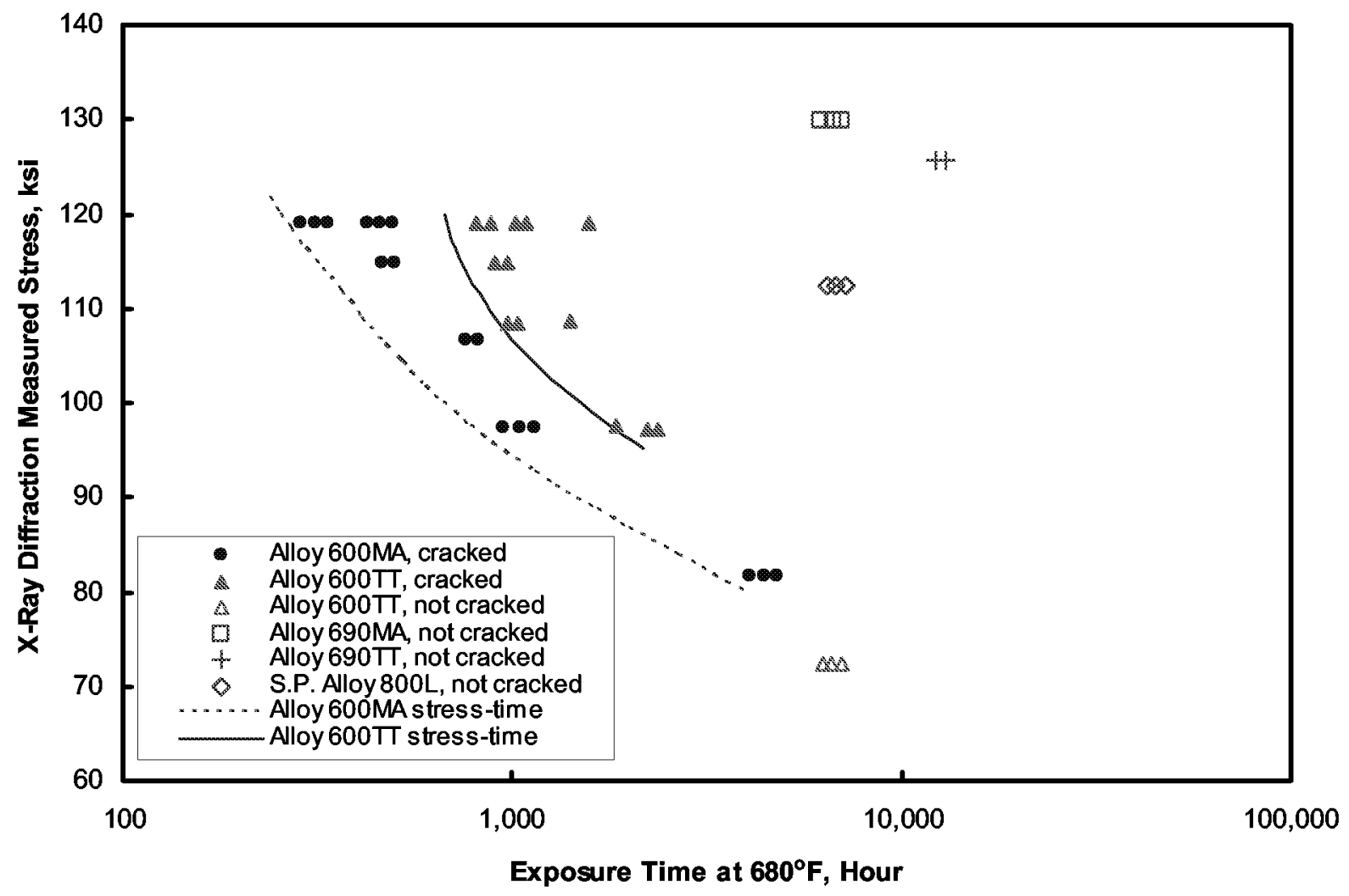

Figure 3-4 Testing of RUB Specimens in simulated primary water at $680^{\circ} \mathrm{F}\left(360^{\circ} \mathrm{C}\right)$. The stress was measured by X-ray diffraction. After Ref. 17.

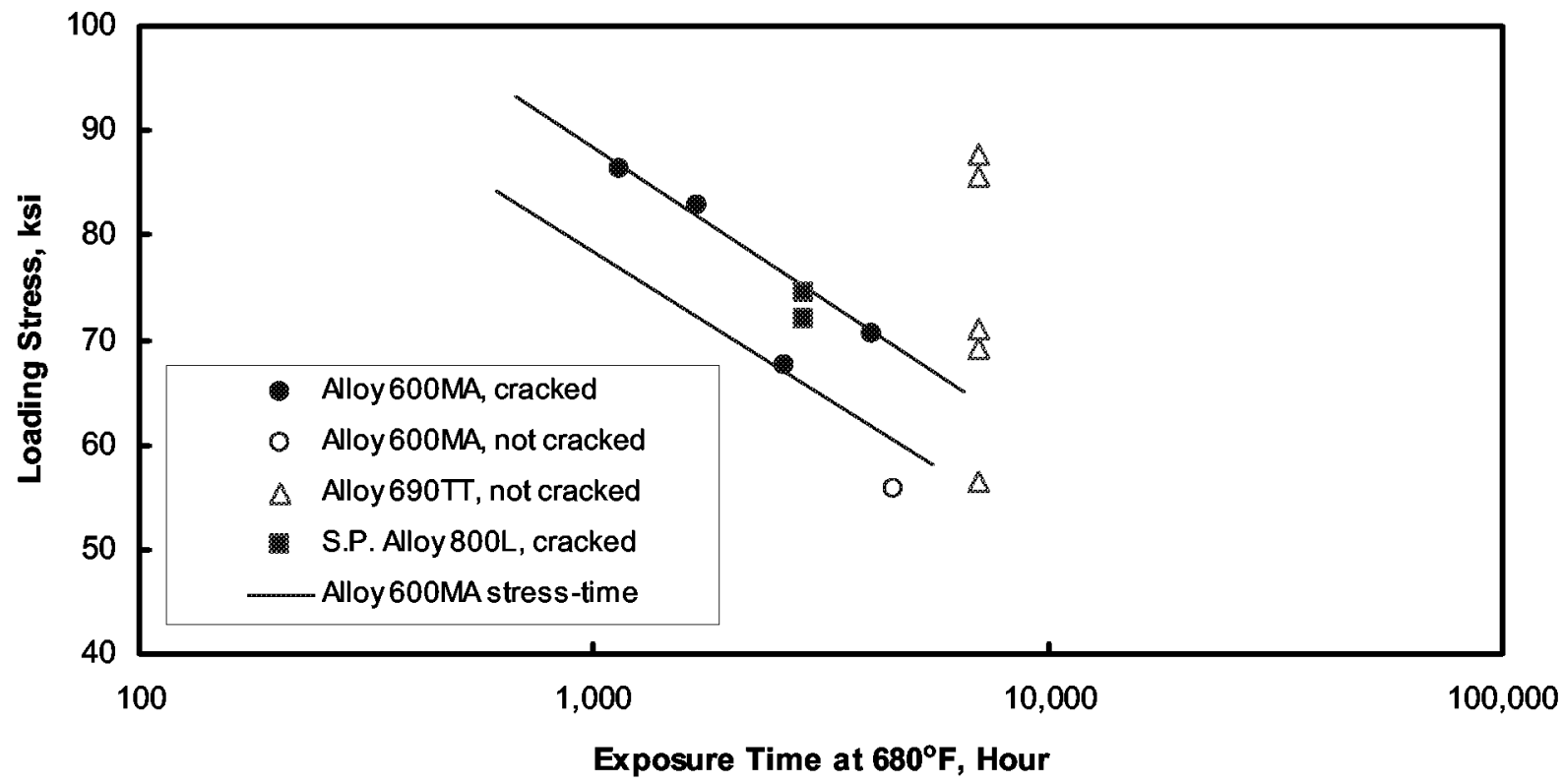

Figure 3-5 Constant load test $(\mathrm{CLT})$ in simulated primary water at $680^{\circ} \mathrm{F}\left(360^{\circ} \mathrm{C}\right)$. The stress level was measured by X-ray diffraction. After Ref. 17. 


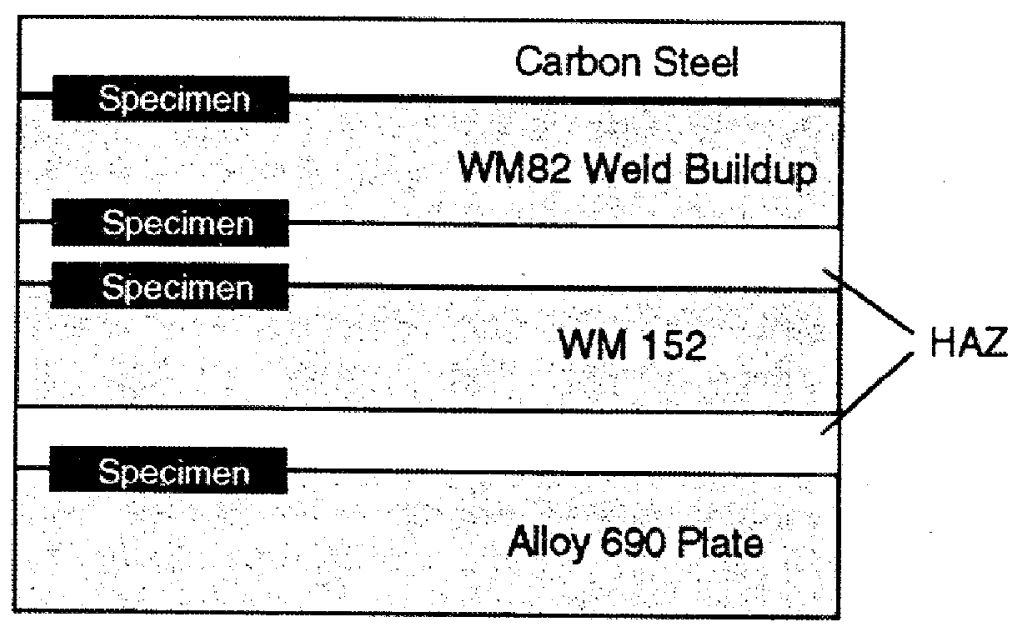

Figure 3-6 Schematic of weld mock-up block indicating the location and orientation of CERT specimens. ${ }^{[4]}$

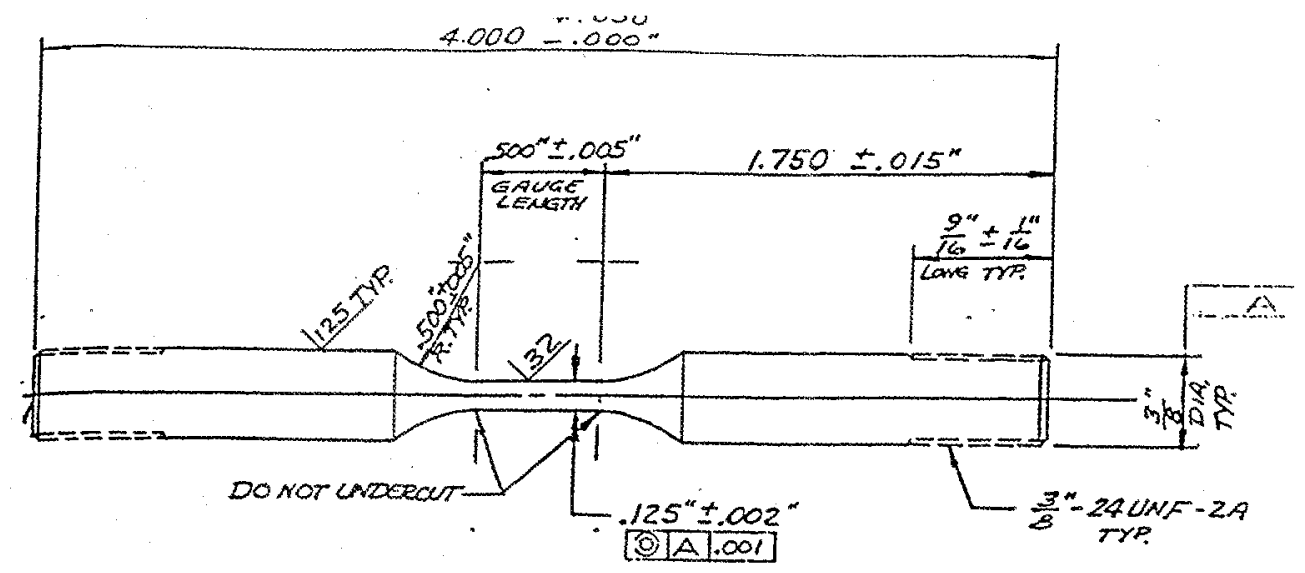

Figure 3-7 CERT specimen design. ${ }^{[42]}$ 

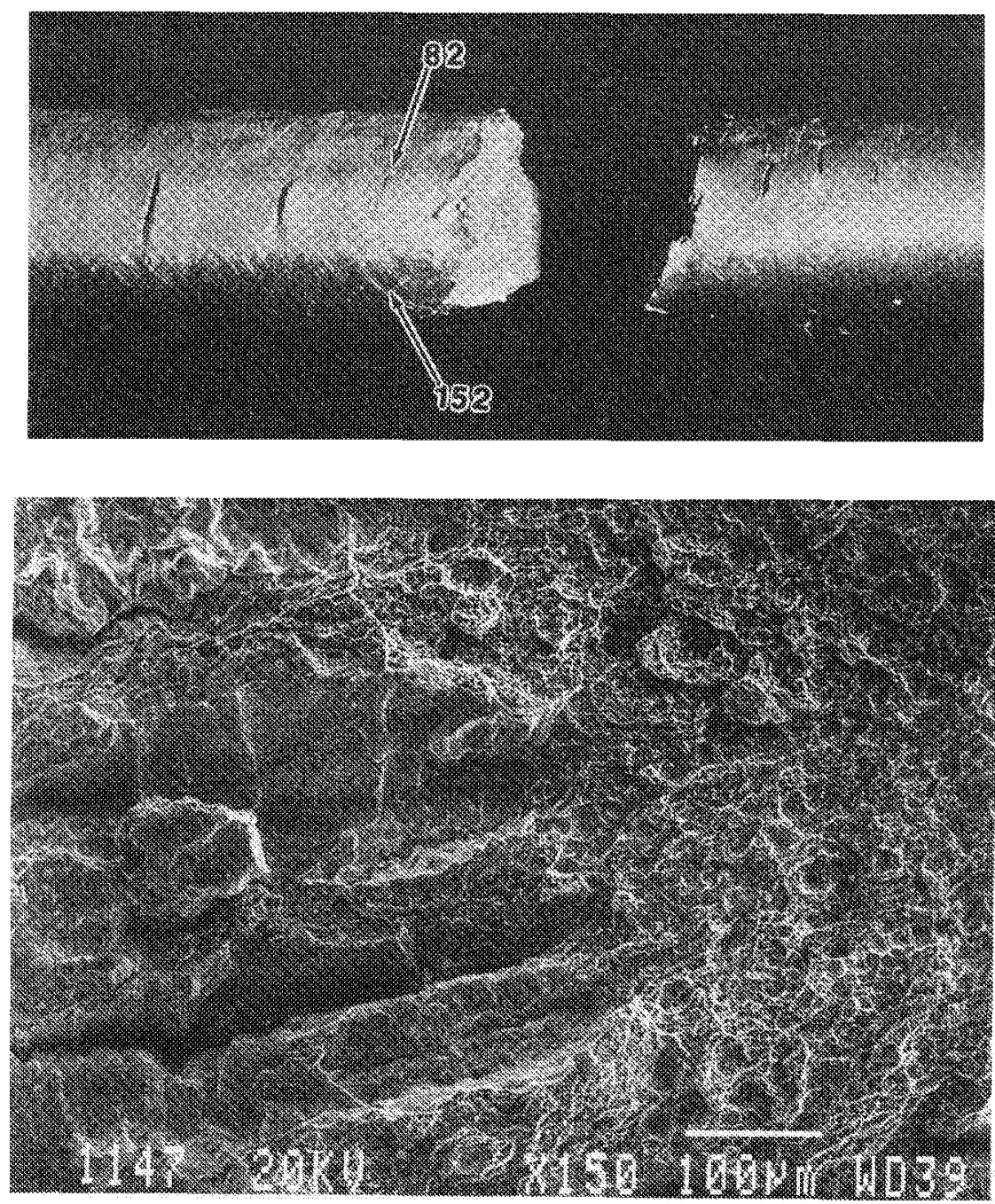

Figure 3-8 Above, Alloy 82/Alloy 152 CERT specimen surface after testing in water showed several cracks in Alloy 82. Below, SEM micrograph of the final fracture surface showed a ductile dimpled fracture surface in Alloy 152 and a brittle intergranular crack surface in Alloy $82^{[42]}$

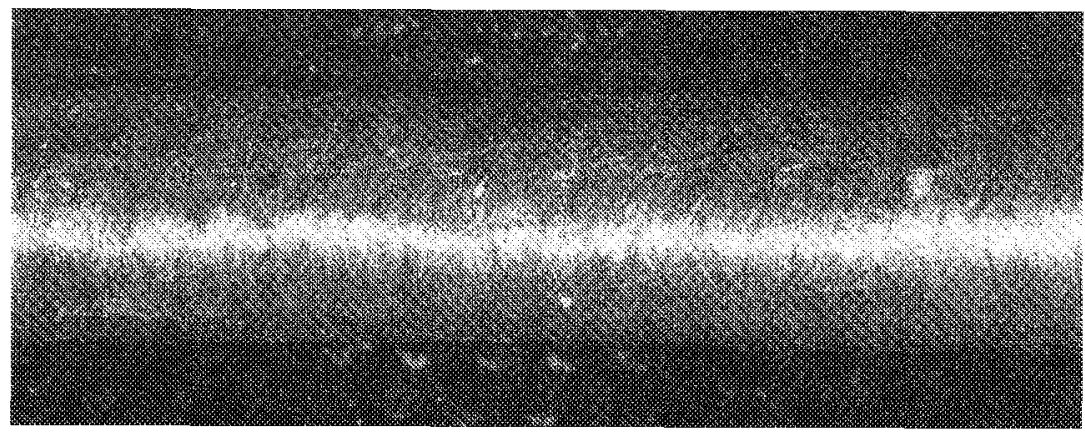

Figure 3-9 Alloy 152 CERT specimen surface after testing in water. No cracks were seen. ${ }^{[42]}$ 


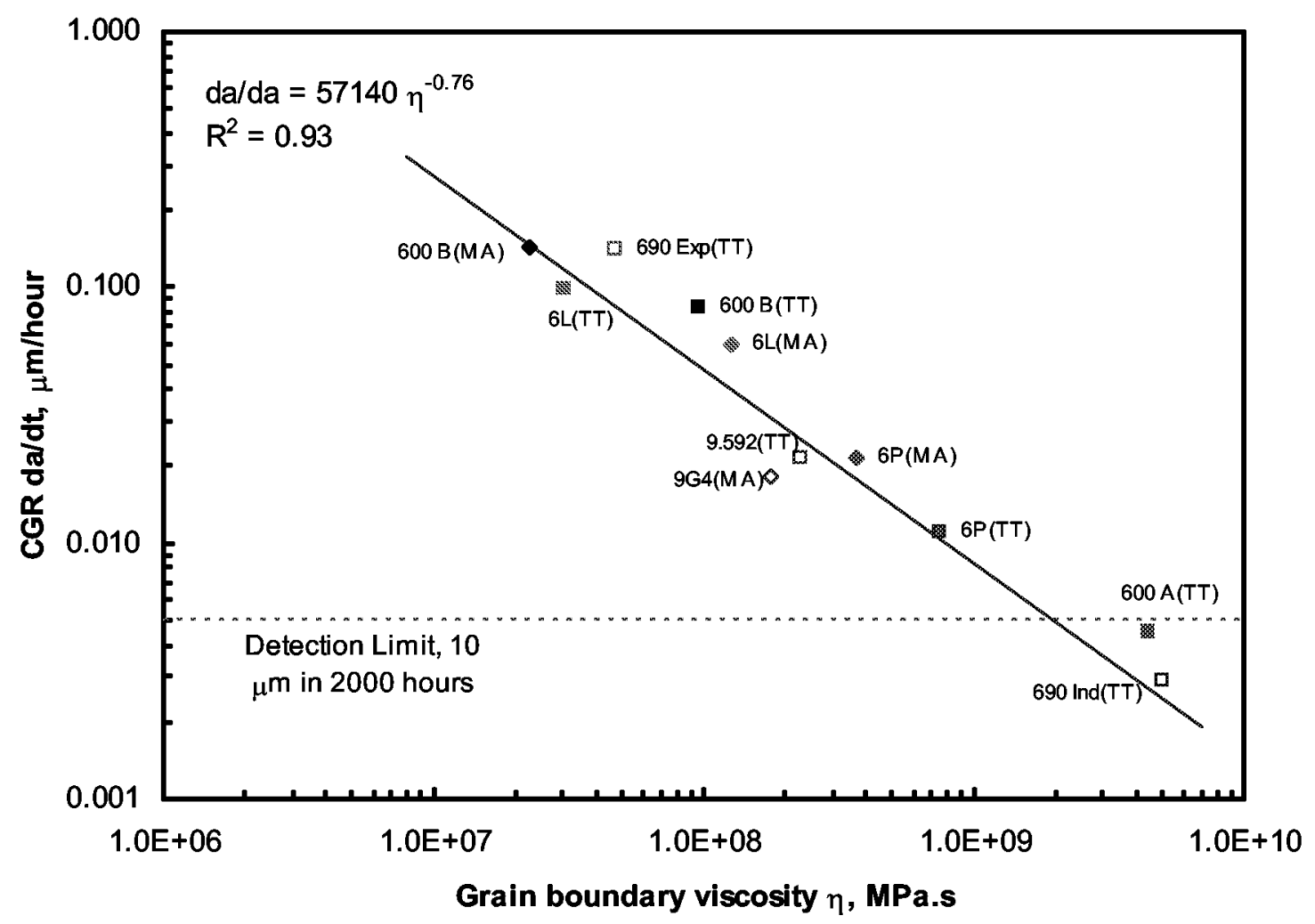

Figure 3-10 PWSCC crack growth rate (CGR) in CERT tests at $360^{\circ} \mathrm{C}\left(680^{\circ} \mathrm{F}\right)$ versus the grain boundary (creep) viscosity. After Figure 1 of Ref. 50.

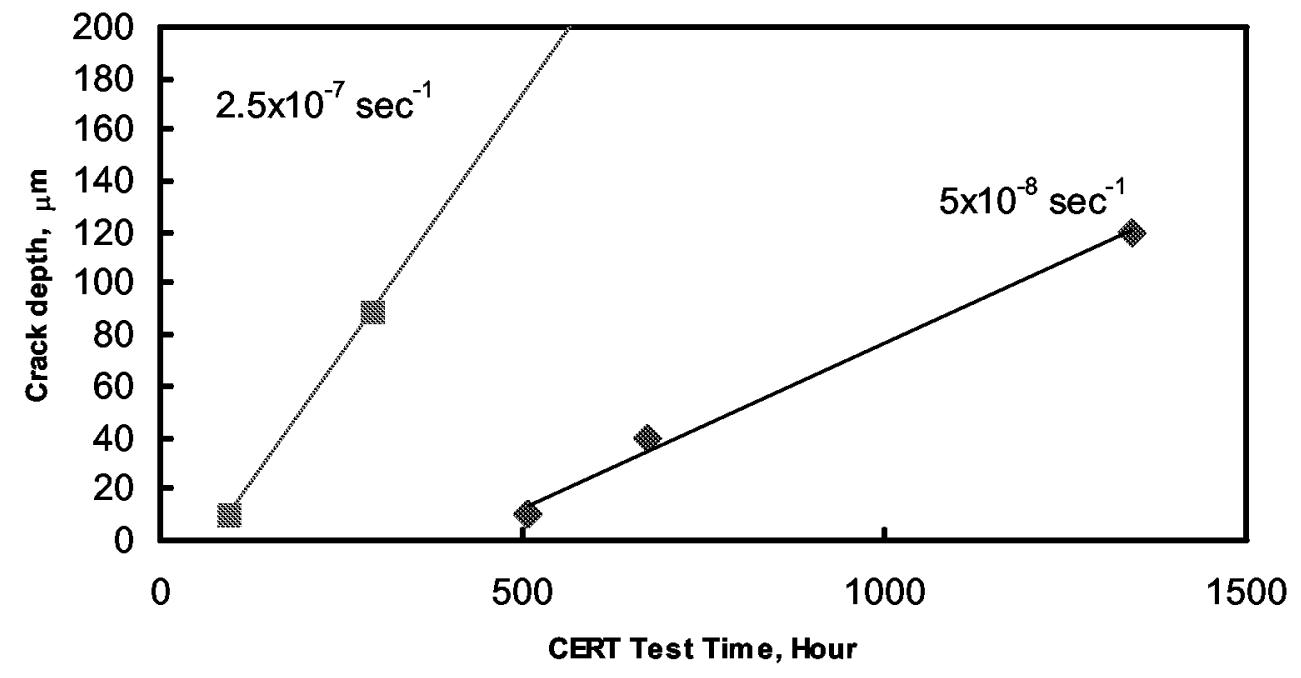

Figure 3-11 PWSCC crack depth in CERT test of Alloy 690 Exp 1 material at $360^{\circ} \mathrm{C}\left(680^{\circ} \mathrm{F}\right)$. After Figure 4 of Ref. 50. 


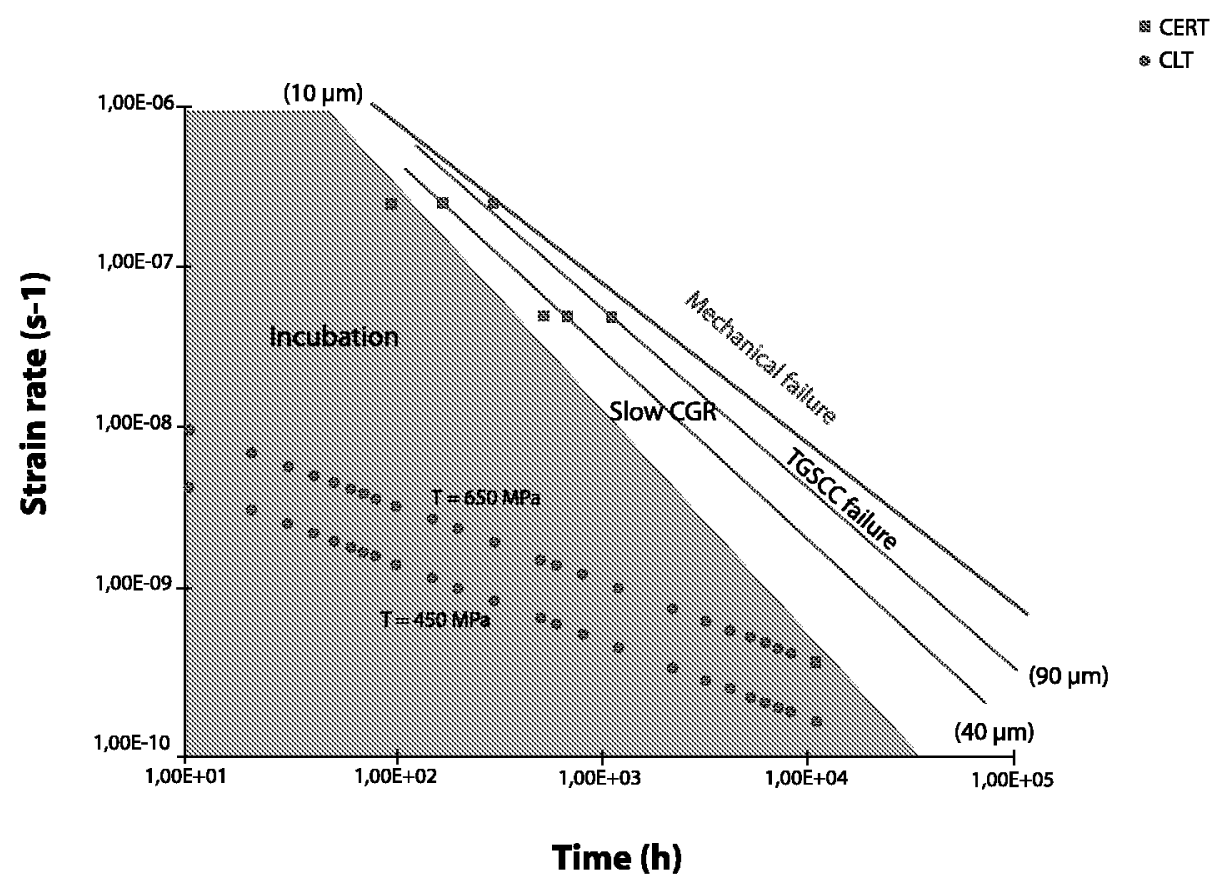

Figure 3-12 Fields of cracking for CERTs and constant load tests as a function of time and strain rate (Experimental alloy 690 in the as-received condition, hydrogenated PWR primary water at $\left.360^{\circ} \mathrm{C}\right) . .^{[50]}$ 


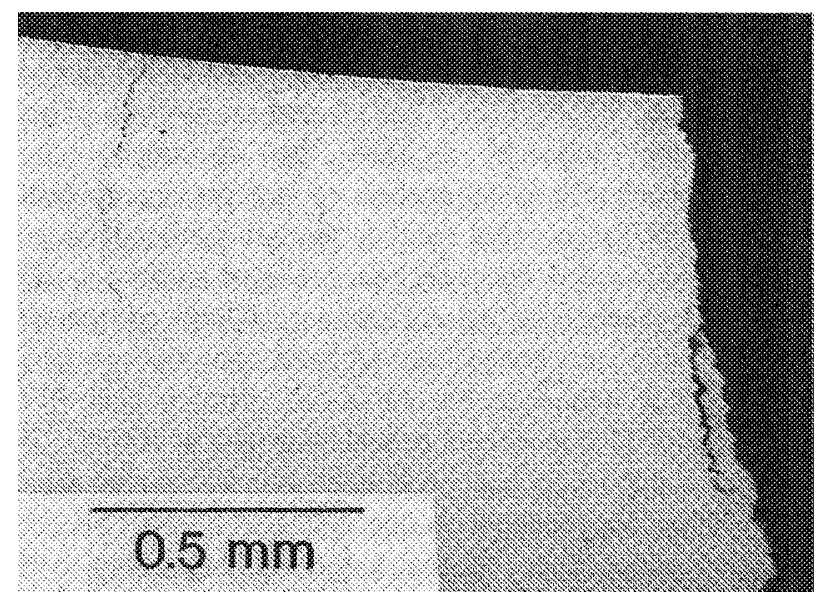

Figure 3-13 Cracks observed in Alloy 690 RUB specimen 5R (from Heat B) after 13,824 hours exposure in hydrogenated steam at $380^{\circ} \mathrm{C}\left(716^{\circ} \mathrm{F}\right) .{ }^{[52]}$

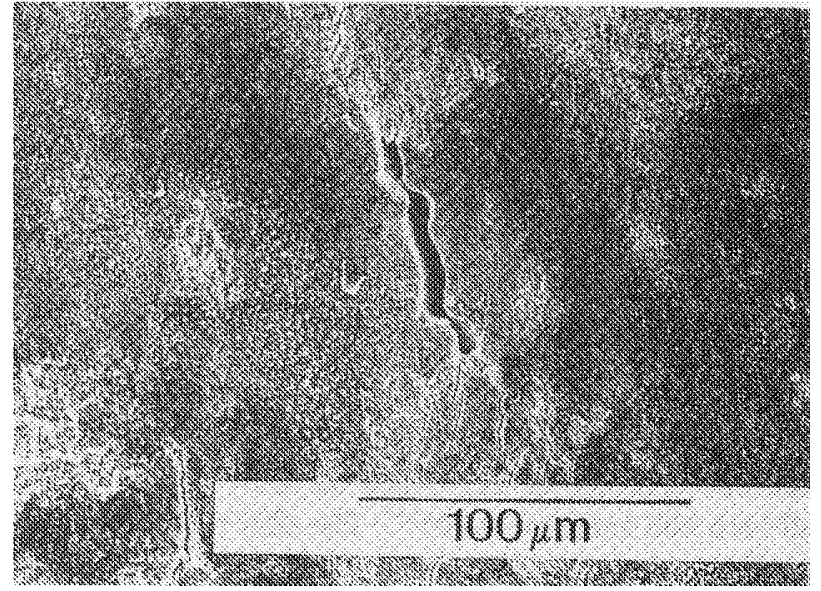

Figure 3-14 Short crack on the RUB specimen I.D. surface produced by flattening at room temperature. The RUB specimen was from Alloy 690 Heat $A$ (the heat did not develop intergranular cracking) and had been exposed to hydrogenated steam at $380^{\circ} \mathrm{C}\left(716^{\circ} \mathrm{F}\right)$ for 13,824 hours. ${ }^{[52]}$ 


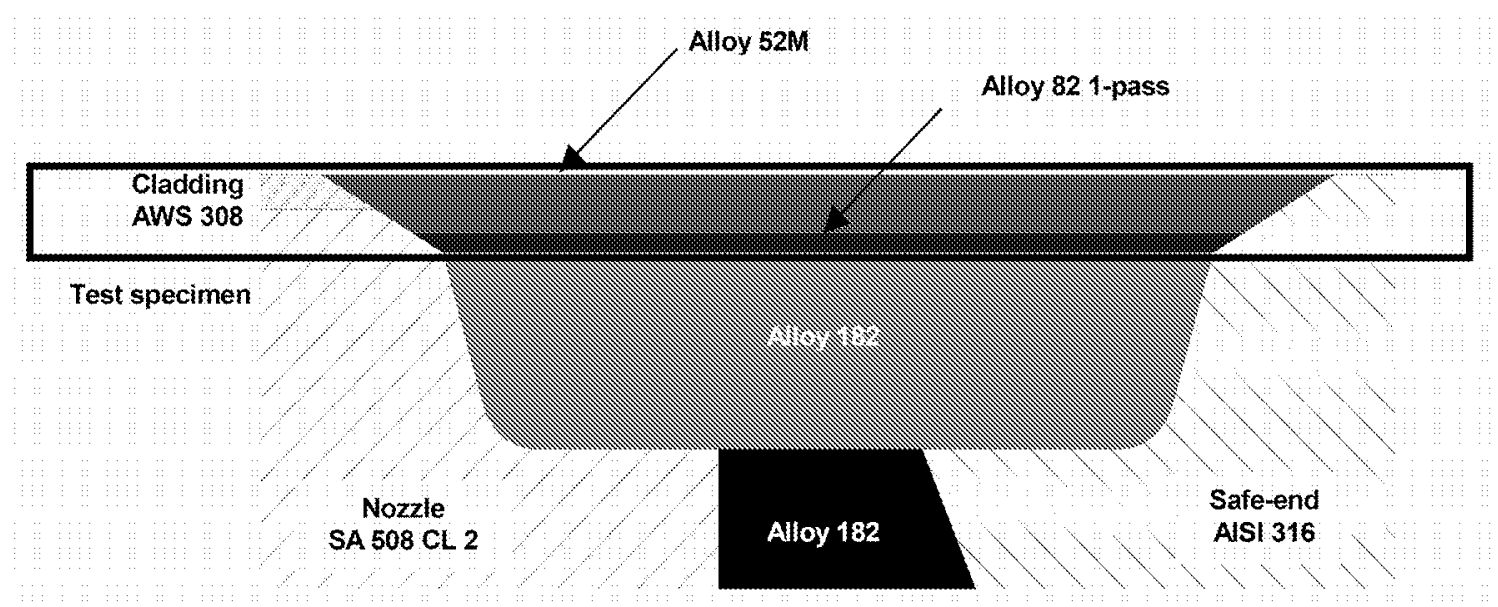

Figure 3-15 Sketch of Alloy 52M Weld Mock-up. ${ }^{[54]}$

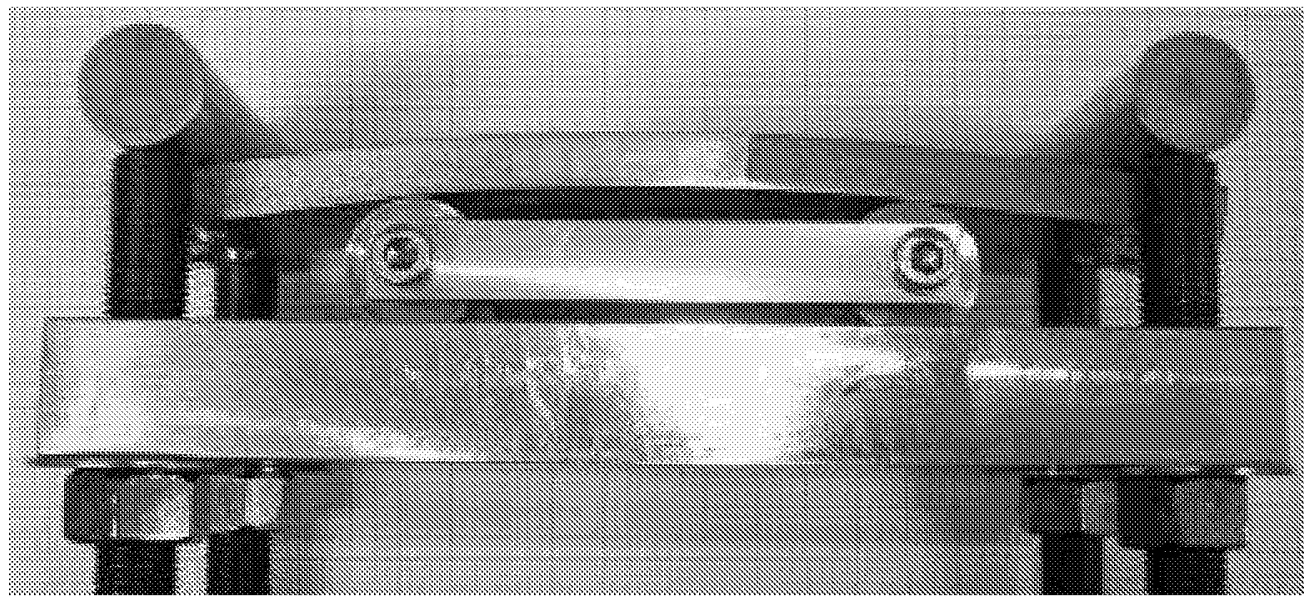

Figure 3-16 Four-Point Bend Specimen Configuration. ${ }^{[54]}$ 


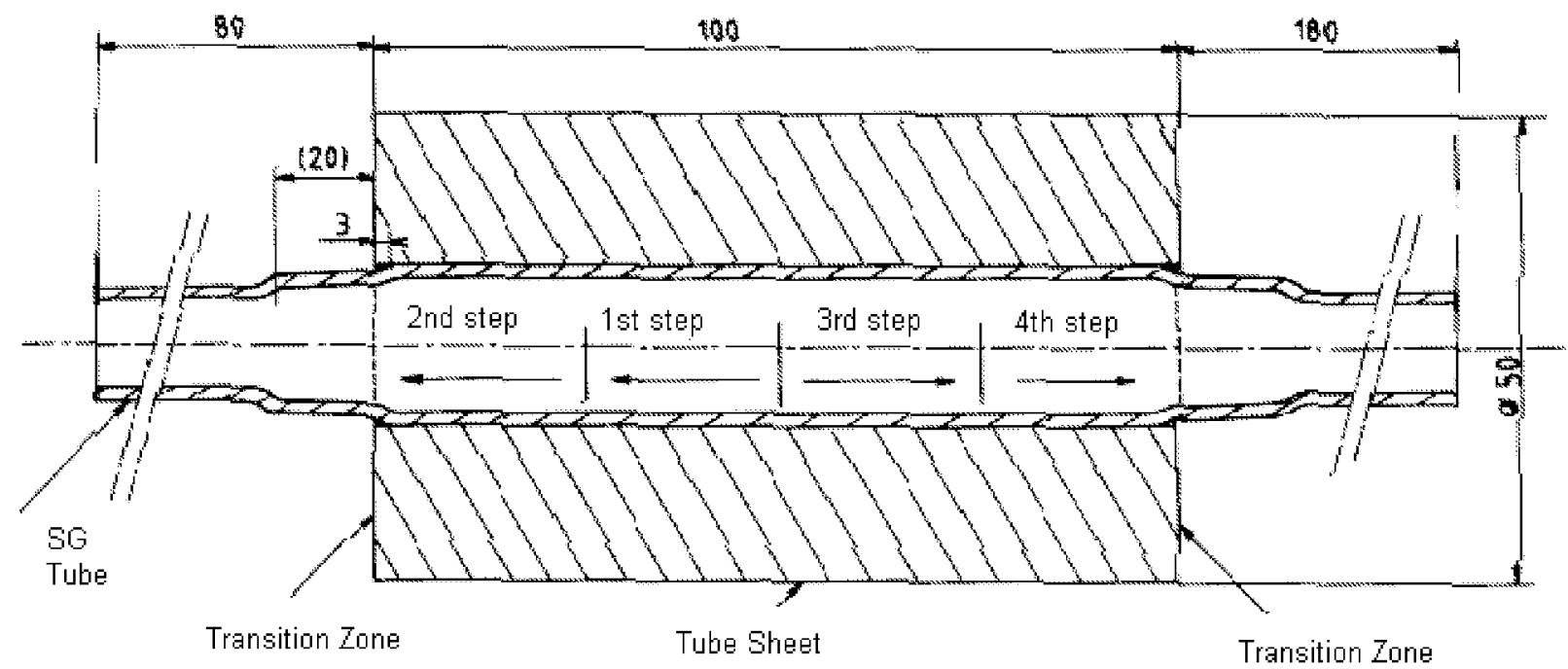

Figure 3-17 SG Tube Mock-Up [App. B]

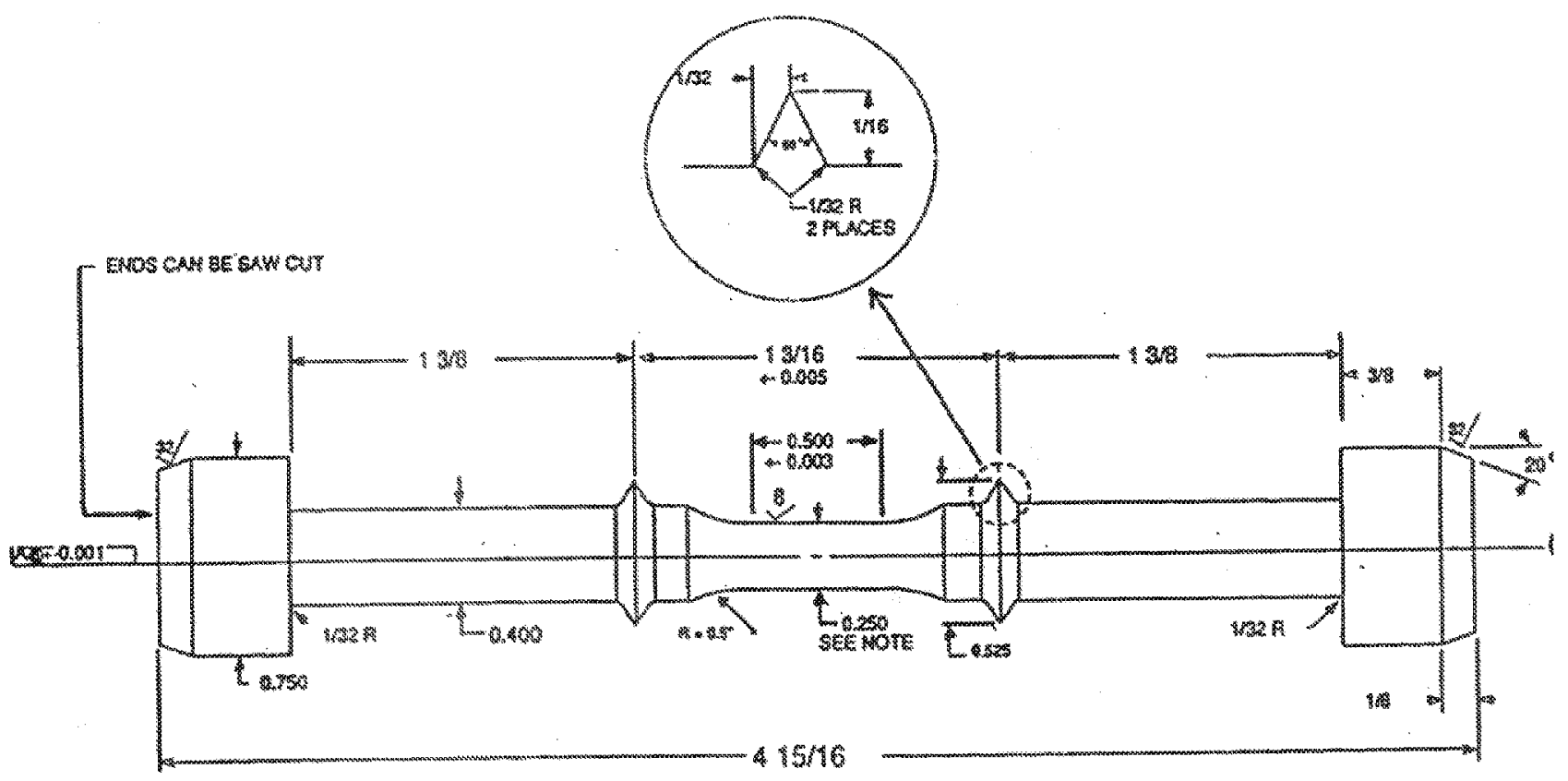

Figure 3-18 SG Low cycle fatigue specimen geometry. ${ }^{[42]}$ 


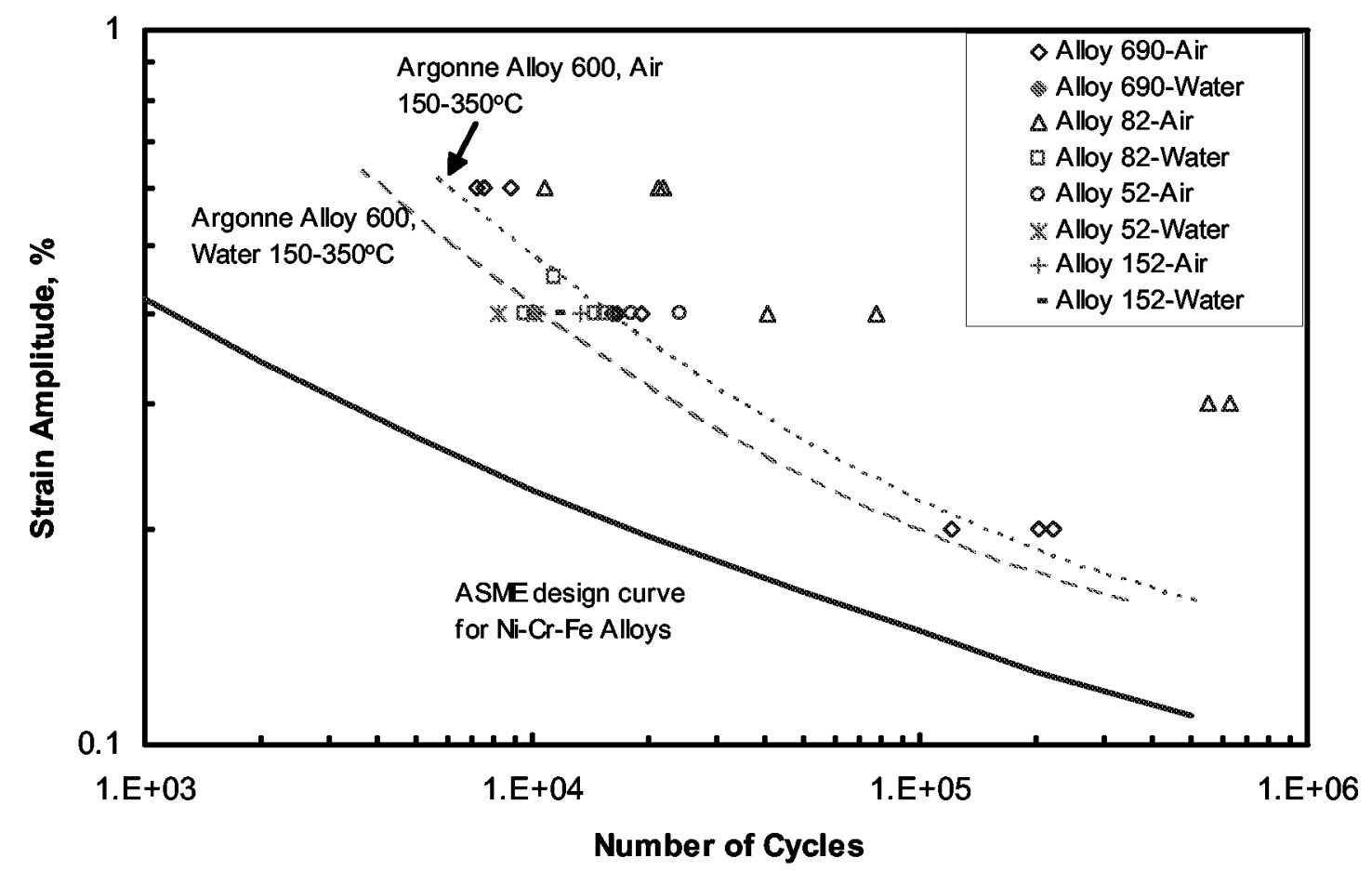

Figure 3-19 Plot of S/N fatigue properties of Alloy 690 and Alloys 52, 152, and 82 weld metals. Test were conducted at $600^{\circ} \mathrm{F}$. After Ref. 42 .

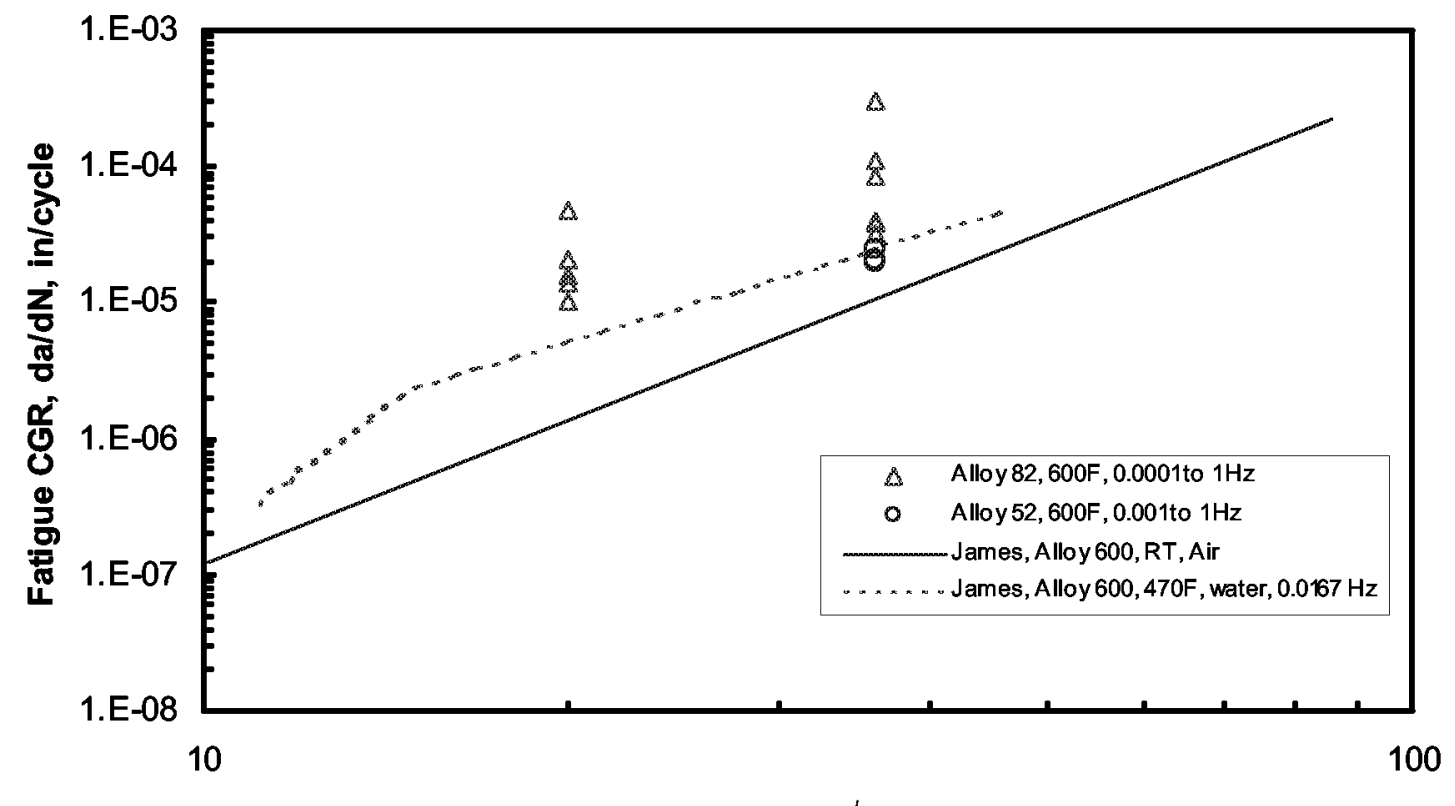

$\Delta K, \mathbf{k s i} \sqrt{ }$ in

Figure 3-20 Plot of fatigue crack growth properties of Alloys 52 and 82 weld metals. After Ref. 42. 



\section{IIscussion}

\subsection{Alloy 690/152/52 Test Results}

The first published stress corrosion cracking test results on Alloy 690 material in deaerated high temperature water containing $20 \mathrm{ppb}$ or less dissolved $\mathrm{O}_{2}$ were reported by Sedriks et al. of Inco in $1979 .^{[9]}$ No cracking was produced in any of the Alloy 690MA U-bend specimens fabricated after a maximum exposure of 10,000 hours at $680^{\circ} \mathrm{F}\left(360^{\circ} \mathrm{C}\right)$. Impressed by this test outcome, Sedriks et al. were among the first to suggest that, in high temperature deaerated water, Alloy 690 was effectively "immune" to the stress corrosion cracking that had been observed in all other high nickel alloys, including Alloy 600, tested in this environment. It is noted that a majority of the Alloy 600MA specimens in Sedricks' high temperature deaerated water tests did not develop cracking by the end of the tests, which may be an indication that the testing condition was not aggressive enough or the duration of the tests was not long enough. Airey investigated Alloy 600 PWSCC in pure hydrogenated water and primary water (containing boric acid and lithium). ${ }^{[63]}$ The results showed that SCC initiation time was shorter in pure water than in primary water. Hence, a pure hydrogenated water environment can be considered slightly more aggressive than hydrogenated water containing boric acid and lithium when testing for susceptibility to PWSCC.

Since that time, laboratories in several countries have employed progressively more severe forms of stress corrosion testing under more and more aggressive conditions and to longer test durations in order to assess Alloy 690's resistance to PWSCC. Most of these studies have confirmed that Alloy 690 material has extremely high PWSCC resistance as no cracking was produced in the Alloy 690 specimens at the termination of testing in the vast majority of cases. Section 3.2 has reviewed 15 different studies of Alloy 690 PWSCC in high temperature deaerated water either with or without boric acid and lithium. Approximately 300 U-bend, Double U-bend, and constant load specimens from about 40 heats of Alloy 690 have been tested. The carbon content ranged from $0.001 \%$ to $0.065 \%$ and the heat treatment included MA, TT, and thermally aged conditions. Only one study included Alloy 52 weld metal and one study included Alloy 152 weld metal. The very few cases where cracking of Alloy 690 and Alloy 52 material were reported and the reasons why they are not representative of in-service PWR conditions are further discussed immediately below.

\subsubsection{Single U-Bend Test in Saturated Hydrogen Water with $B / L i$}

In 1987, Nakayama et al. reported results of Alloy 690 single U-bend tests in "saturated" hydrogenated water containing $1000 \mathrm{ppm}$ boron and $2 \mathrm{ppm}$ lithium at $330^{\circ} \mathrm{C}\left(626^{\circ} \mathrm{F}\right)$ for 3000 hours. ${ }^{[40]}$ Slight intergranular cracking was detected in two out of the four Alloy 690 conditions tested. The maximum intergranular crack depth was $70 \mu \mathrm{m}\left(0.0028^{\prime \prime}\right)$ in the Alloy 690TT material with an aging treatment of 24 hours at $500^{\circ} \mathrm{C}\left(932^{\circ} \mathrm{F}\right)$ and $30 \mu \mathrm{m}\left(0.0012^{\prime \prime}\right)$ in the Alloy $690 \mathrm{MA}$ material with an aging treatment of 100 hours at $500^{\circ} \mathrm{C}\left(932^{\circ} \mathrm{F}\right)$. The Alloy 690 grain size was not reported, but the $70 \mu \mathrm{m}$ maximum intergranular crack depth would correspond to 
two grains deep for a typical grain size of ASTM No. 6.5. Hence, these cracks were shallow and more comparable to an intergranular attack (IGA) depth than to the much deeper PWSCC cracks routinely seen in Alloy 600 material.

In addition, SEM examinations revealed that the intergranular cracks in the Alloy 690TT specimen (70 $\mu \mathrm{m}$ max. depth) were at the tips of dislocation pile-ups. This indicates that the Alloy 690 intergranular cracking could be caused by mechanical strain from U-bending rather than caused by PWSCC. It is noteworthy that similar mechanically induced surface intergranular cracks have been observed in bent Alloy 690 and Alloy 52 specimens in several other studies. These observations and attributed causes are summarized in Table 4-1 for a side-by-side comparison. It is evident from these reports that Alloy 690 and Alloy 52 can be prone to develop surface defects or intergranular microfissuring induced by plastic straining from bending. Shallow surface modified layers from SG tubing fabrication processes are seemingly responsible for this mechanical cracking propensity. The CEA and EdF studies (see Section 3.2) showed that the plastic strain at the apex of the RUB is typically between 30 to $40 \%$. This level of plastic straining approaches the room temperature ductility limit of Alloy 690. In addition, Alloy 690 has a slight drop in ductility when temperature is increased from room temperature to $600^{\circ} \mathrm{F}$ (see Figure 2-4). Alloy 690 also has a higher cold work hardening rate as shown in Figure 4-1, which plots the Vickers hardness number as a function of cold reduction percentage. Hence, an Alloy 690 surface is expected to be more sensitive to work hardening during the cold work fabrication steps. Any highly cold worked surface layer is likely to re-crystallize during thermal treatment and is observed to be more prone to developing surface defects compared to Alloy 600 . However, the studies listed in Table 4-1 demonstrated that these surface defects or microfissures did not propagate (by PWSCC) by the end of the tests. Hence, it appears that the short IG cracking reported by Nakayama et al. was also due to strain applied during the specimen bending.

In addition to the factors discussed above, the Alloy 690 plate used to fabricate the U-bend specimens tested by Nakayama et al. was made from remelted (in a vacuum induction furnace) Alloy 690 SG tubing. Only the chemical compositions of the Alloy 690 SG tubing were reported. It is unclear whether the remelting might have caused changes in the Alloy 690 chemical composition. Interestingly, these Alloy 690 heats contained a rather high aluminum content of 0.39 or $0.40 \%$ (Note, aluminum is not specified in ASME Section II and is often unreported). A. Smith et al. reported that aluminum increases the Alloy 690 propensity to caustic IGA ${ }^{[32,33]}$ (also see Appendix C, Section C.2.2). Unfortunately, the Alloy 690 microstructure (cracked or not cracked) was not examined to confirm that the thermal treatment had produced intergranular carbide precipitations.

\subsubsection{CERT Tests in Hydrogenated Water with or without B/Li}

Other than the studies by Nakayama et al., and the CEA and EDF tests using high deformation U-bend or RUB specimens in which only mechanical surface intergranular cracking was detected, reports of intergranular cracking in deaerated water originate from CERT tests at strain rates on the order of $10^{-7} \mathrm{sec}^{-1}$ or less. CERT tests are very severe tests for evaluating susceptibility of Alloy 600 or Alloy 690 to stress corrosion cracking. The specimens are loaded well past the original yield strength to maintain a continuous (constant) plastic strain rate, and are often continued until the specimens fail by ductile overload, if nothing else. Such continuous 
plastic deformation situations are not encountered in nuclear power plants. Angeliu et al. produced intergranular cracking in a $0.002 \%$ carbon laboratory heat of Alloy 690 in deaerated water at $360^{\circ} \mathrm{C}\left(680^{\circ} \mathrm{F}\right)$ during CERT tests. ${ }^{[38,39]}$ Since the same small amount of intergranular cracking $(2 \%)$ was also produced in argon, the intergranular cracking in the deaerated water should not be considered an indication of Alloy 690 susceptibility to PWSCC.

Other than the study by Angeliu et al, a study by CEA and EdF (Vaillant et al.) also reported Alloy 690 cracking during CERT tests. Vaillant et al. considered the CERT test as a test measuring the stress corrosion crack growth rate rather than crack initiation. Based on Figure 3-10, Vaillant et al. concluded that Alloy 690 material did not necessarily have a lower CGR than Alloy 600 material. Vaillant et al. suggested that the CGR obtained in the CERT tests is mainly dependent on the grain boundary carbide precipitation and the creep rate while the crack initiation time in the RUB tests was mainly a function of Cr contents. It is noted that the most susceptible Alloy 690 heat in this study was a pre-production heat and a heat treatment that gave rise to a very low density of grain boundary carbides.

Compact tension (CT) specimens, wedge opening load (WOL) specimens, double cantilever beam (DCB) specimens, or other forms of precracked specimens per ASTM E 399 or E 813 are commonly used for PWSCC CGR testing of Alloy 600 or Alloy 182 materials. ${ }^{[64,65]}$ During the CGR test, the specimen is loaded under plane strain condition to a predetermined stress intensity factor which does not increase during the test. On the other hand, the tensile load in CERT tests increases with test time to keep the elongation rate constant. Hence, CERT tests are very different from the typical CGR tests used for Alloy 600 and Alloy 182 materials. In addition, Alloy 690 is known to be susceptible to SCC in deaerated caustic water. The DCB tests conducted by Kawamura et al. showed (see Figure C-4) that, at a stress intensity up to 75 $\mathrm{MPa} \sqrt{\mathrm{m}}$, the CGR of Alloy 690TT is approximately $1 / 100$ th of Alloy 600MA in deaerated caustic water (see Appendix C, Section C.2). It is obvious from this literature review, that additional test data are needed to support the statement that "Alloy 690 does not necessarily have a lower CGR than Alloy 600 in primary water."

\subsubsection{RUB Test in Hydrogenated Steam}

In 1997, Sui et al. reported stress corrosion cracking of Alloy 690 specimens in hydrogenated steam at $380^{\circ} \mathrm{C}\left(716^{\circ} \mathrm{F}\right) .{ }^{[52,53]}$ Two RUB specimens from the same heat of Alloy 690 developed cracks between 12,600 and 13,824 hours of exposure at $716^{\circ} \mathrm{F}$. Both heats of Alloy 690 had been thermally treated at $\sim 715^{\circ} \mathrm{C}\left(1319^{\circ} \mathrm{F}\right)$ for 15 hours. However, the cracked Alloy 690 Heat B had an unusually (deliberately) low final mill anneal temperature compared to the un-cracked Alloy 690 Heat A $\left(1769^{\circ} \mathrm{F}\right.$ vs. $1958^{\circ} \mathrm{F}$ ). The average grain size was $25 \mu \mathrm{m}$ (ASTM No. 7.5 ) for Heat $\Lambda$ and $15 \mu \mathrm{m}$ (ASTM No. 9.0) or less for Heat B. The small grain size in Heat B is reflected in its higher room temperature yield strength. All the grain boundaries in Heat $\mathrm{A}$ had an almost continuous carbide coverage. The carbides were determined to be the $\mathrm{M}_{23} \mathrm{C}_{6}$ type rather than $\mathrm{M}_{7} \mathrm{C}_{3}$ by TEM. In contrast, Heat B was essentially free of intergranular carbides.

The cracked Alloy 690 heat, Heat B, also had a higher aluminum content $(0.14 \%)$, which tends to result in a finer grain size and therefore a lower density of intergranular carbides. Interestingly, the Alloy 690 heats used by Nakayama et al. also contained a rather high aluminum content. The results 
reported by Sui et al. show that Alloy 690 could be susceptible to IGSCC in a hydrogenated steam environment and potentially susceptible to PWSCC if the final mill anneal temperature is too low to produce intergranular carbide precipitation upon subsequent thermal heat treatment, or in the event of re-crystallization after thermal treatment. Because such a low temperature solution anneal heat treatment is prohibited by material specifications for Alloy 690 (or Alloy 600) for use in PWRs and the intergranular carbide precipitation must be verified by optical microscopy and/or SEM, cracking of the type seen by Sui et al. will be prevented. On the other hand, re-crystallization may be a detrimental factor to take into account for the heat affected zones of welds. In any event, the times to failure at $380^{\circ} \mathrm{C}\left(716^{\circ} \mathrm{F}\right)$ reported by Sui et al are such that when extrapolated to normal PWR operating temperatures using an Arrhenius relationship and a standard value of the activation energy for PWSCC the predicted lives (equivalent to $98 \mathrm{EFPYs}$ at $600^{\circ} \mathrm{F}$ based on the $50 \mathrm{kcal} / \mathrm{mole}$ PWSCC activation energy commonly used for Alloy 600, see Table 4-3) would be well in excess of current expectations for plant life extension. Nevertheless, this apparent susceptibility induced by the absence of grain boundary carbides is a potential weakness of Alloy 690 that requires further investigation.

\subsection{Weibull and Weibayes Analyses of the Test Results}

The results of the laboratory tests reviewed in Section 3.2 are examined to obtain a quantitative or semi-quantitative assessment of Alloy 690's resistance to PWSCC relative to Alloy 600. This is desirable for developing a statistically-based estimation of a hypothetical PWSCC event in Alloy 690 component items that can be used in selecting and justifying an inspection method for Alloy 690 component items.

The two-parameter Weibull distribution of Eq. 4-1 is by far the most widely used distribution for stress corrosion cracking analysis. ${ }^{[66]}$

$$
F(t)=1-e^{-\left(\frac{t}{\theta}\right)^{\beta}}
$$

where: $F(t)=$ the cumulative fraction of cracking by time $(t)$.

$\theta=$ the characteristic time (scale parameter) equal to the time to a $63.2 \%$ cumulative fraction of cracking.

$\beta=$ slope or shape parameter

$\mathrm{e}=2.71828$, the base for natural logarithms.

The significance of $\beta$ is briefly summarized below:

$$
\begin{array}{ll}
\beta<1 & \text { Implies infant mortality, failure rate decrease with time. } \\
\beta=1 & \text { Implies random failure. } \\
1<\beta<4 & \text { Implies early wear out. }
\end{array}
$$

$\beta>4 \quad$ Implies old age and rapid wear out. A steeper $\beta$ means less material variation or tighter quality control. A steeper $\beta$ means subsequent failures will occur quickly after the first failure. 
Weibull analysis has been used to analyze the failures of the Alloy 600 control specimens in the studies reviewed in Section 3.2. If sufficient data were reported or available, a best-fit regression analysis has been performed to determine the Weibull characteristic time $(\theta)$ and slope $(\beta)$.

In addition to Weibull analysis for the Alloy 600 control specimens, a Weibayes analysis (an estimated Weibull) has been used for the Alloy 690 specimens that did not develop cracking by the end of the test period. In the Weibayes method, the slope is assumed to be the same as that from the Alloy 600 analysis. The Alloy 690 specimen characteristic time $\theta$ is estimated by Eq. $4-2 .^{[66]}$

$$
\theta=\left[\sum_{i=1}^{N} \frac{t_{i}^{\beta}}{r}\right]^{1 / \beta}
$$

where: $\beta=$ the slope or shape parameter from Alloy 600 .

$t_{i}=$ test time of each Alloy 690 specimen tested.

$N=$ total number of Alloy 690 specimens tested.

$r=$ number of Alloy 690 specimens cracked.

As no constant deformation (deflection) or constant load Alloy 690 specimen developed SCC cracks by the end of the test period (except in one study in hydrogenated steam at $380^{\circ} \mathrm{C}\left(716^{\circ} \mathrm{F}\right)$, it is conservatively assumed that the first (i.e., $r=1$ ) Alloy 690 specimen failure could occur immediately should the test continue. The confidence level that the true Alloy 690 Weibull line lies to the right of the Weibayes line is $63 \%$. The failure number $r$ can be set to produce any level of confidence desired. For example, Weibest uses 0.693 for $r$ to produce a confidence level of $50 \%$, which is less conservative than the $63 \%$ confidence level used by Weibayes.

Figure 4-2 is the Weibull plot of the Alloy 600 RUB test results at $680^{\circ} \mathrm{F}$ reported by K. Smith et al. The differences in the water chemistry used (beginning-of-fuel-cycle vs. end-of-fuel-cycle) have little impact on the Alloy 600 (one heat) RUB cracking compared to the heat treatment (see Figure 3-3). Hence, the Alloy 600 RUB cracking data in the two primary water environments are combined in Figure 4-2. The Alloy 690 Weibayes characteristic life is calculated based on a total population of 40 RUB specimens from three different heats in either the MA or TT condition since there was no failure of any Alloy 690 RUB specimens. The Alloy 690 Weibayes line in Figure 4-2 assumes a slope of $5.0(\beta=5.0)$.

Figure 4-3 and Figure 4-4 are the Weibull plots of the Alloy 600 RUB results at $689^{\circ} \mathrm{F}$ reported by Norring et al. Figure 4-3 plots Alloy 600 RUB results of different heats of SG tubing while Figure 4-4 plots the Alloy 600 RUB results of EPRI special production tubes. Figure 4-4 shows that the Alloy $600 \mathrm{MA}$ annealed at $1875^{\circ} \mathrm{F}$ has a higher PWSCC resistance than the Alloy $600 \mathrm{MA}$ annealed at $1700^{\circ} \mathrm{F}$. Figure $4-5$ compares the influence of the SG tubing diameter on the time to cracking. Even though the RUBs were from the same heats, the 7/8" dia. RUB developed cracking much earlier than the 3/4" dia. RUB. This difference in time to cracking was attributed to different stress levels after the reverse bending of different diameter tubing. ${ }^{[35]}$ However, no stress calculations or measurements were reported. The Alloy 690 Weibayes characteristic life is calculated based on a total population of 67 RUB specimens from three different heats of Alloy 690 . These specimens were heat treated in the MA or TT condition with additional variations in heat treatment temperature and duration. None of the 67 Alloy 690 RUB specimens developed cracking after 20,500 to 33,000 
hours of exposure. The Alloy 690 Weibayes line in Figure 4-3, Figure 4-4, and Figure 4-5 assumes a slope of $5.0(\beta=5.0)$.

Figure 4-6(a) and Figure 4-6(b) are the Weibull plots of Alloy 600MA constant load test (CLT) specimens at $644^{\circ} \mathrm{F}$ in four primary water chemistries reported by Ogawa et al. Details of the Alloy 600TT CLT specimens tested at $644^{\circ} \mathrm{F}$ were not reported. The plots in Figure 4-6 show that a slight variation in primary water condition has little effect on the Alloy 600MA cracking behavior. Hence, the Alloy 600MA CLT $\left(644^{\circ} \mathrm{F}\right)$ data are combined and re-plotted in Figure 4-7. None of the Alloy 690TT CLT specimens tested at $680^{\circ} \mathrm{F}$ or of the Alloy 600MA and TT CLT specimens tested at $608^{\circ} \mathrm{F}$ cracked. The Alloy 690 Weibayes characteristic life is calculated based on a total population of 20 CLT specimens tested in the four variations of primary water chemistry. The Alloy 690 $\left(680^{\circ} \mathrm{F}\right)$ and Alloy $600\left(608^{\circ} \mathrm{F}\right)$ Weibayes lines in Figure 4-7 assume a slope of $5.0(\beta=5.0)$.

In addition to the CLT tests, Ogawa conducted RUB tests in the same primary water conditions. Examination of Table 3-33 showed that variation of the primary water did not have a significant impact on the Alloy 600 RUB specimens cracking. Hence, the RUB test data from the four primary water chemistries are combined before applying the Weibull analysis. Figure 4-8 and Figure 4-9 plot the results of the RUB specimens prestrained to $0 \%, 5 \%, 10 \%, 15 \%$, and $20 \%$ and tested at $608^{\circ} \mathrm{F}$ for the Alloy $600 \mathrm{MA}$ and the Alloy $600 \mathrm{TT}$, respectively. Figure 4-10 compares the results of $20 \%$ prestrained RUB specimens from the Alloy 690TT, the Alloy 600TT, and the Alloy 600MA materials. None of the Alloy 690TT specimens tested at the higher temperature of $680^{\circ} \mathrm{F}$ developed cracking after 10,000 hours of exposure. The Alloy 690TT Weibayes characteristic life is calculated based on a total population of 40 RUB specimens. The Alloy 690 Weibayes line assumes a slope of $5.0(\beta=5.0)$.

The RUB tests in primary water at $680^{\circ} \mathrm{F}$ reported by Vaillant et al. are evaluated with Weibull analysis. The RUB specimens from different heats of Alloy 600 are separated into the MA and TT conditions The results are plotted in Figure 4-11. None of the Alloy 690TT and Alloy 690MA specimens developed cracking after up to 54,000 hours of exposure. The Alloy 690 Weibayes characteristic life is calculated based on a combined TT and MA population of 4 RUB specimens listed in the report. The Alloy 690 Weibayes line assumes a slope of $5.0(\beta=5.0)$.

The results of the SG mockups tested in deaerated, hydrogenated water at $680^{\circ} \mathrm{F}$ by Framatome ANP, France are plotted in Figure 4-12. None of the Alloy 690TT mockups developed any cracking after 100,000 hours of exposure. The Alloy 690 Weibayes line assumes a slope of $5.0(\beta=5.0)$.

The results of the Weibull and Weibayes analyses are used in the next section for estimating the improvement factor $\left(\mathrm{IF}_{\mathrm{R}}\right)$ of Alloy 690 relative to the Alloy 600 in PWR primary water conditions.

\subsection{Improvement Factor by Weibull Analysis}

The Weibull parameters of Alloy 600 materials tested with Alloy 690 are listed in Table 4-2. Using the Weibull analysis, the relative improvement factor, $\mathrm{IF}_{\mathrm{R}}$, can be defined by Eq. 4-3. 


$$
I F_{R}=\frac{\text { Weibayes }(r=1) 0, \text { Alloy } 690}{\text { Weibull } 0, \text { Alloy } 600}
$$

Hence, $\mathrm{IF}_{\mathrm{R}}$ is the ratio of the time to a $63.2 \%$ cumulative fraction of failure between the Alloy 690 and the Alloy 600 specimens being tested. Transformation of Eq. 4-1 yields Eq. 4-4, which in turn produces Eq. 4-5.

$$
\begin{aligned}
& t=\theta\left[\frac{1}{1-F(t)}\right]^{\left(\frac{1}{\beta}\right)} \\
& \left.\frac{t_{690}}{t_{600}}\right|_{\text {to a given } F(t)}=\frac{\theta_{690}}{\theta_{600}}
\end{aligned}
$$

Eq. 4-5 shows that, if the Alloy 690 Weibayes line assumes the same Weibull distribution slope $(\beta)$ as for the Alloy 600 (either TT or MA condition), the $\mathrm{IF}_{\mathrm{R}}$ to any cumulative fraction of cracking would be a constant. However, the slope of Alloy 690, although unknown due to a lack of cracking in the tests, may not vary as much as seen in Alloy 600 materials. Assuming a small Weibull slope value for Alloy 690 can result in a higher Weibayes $\theta$ (hence a higher $\mathrm{IF}_{\mathrm{R}}$ ), making the $\mathrm{IF}_{\mathrm{R}}$ less conservative. $\Lambda$ review of the Alloy 600 Weibull plots indicates that the slope increases with increasing cracking resistance, i.e., Alloy 600TT tend to have a higher $\beta$ than Alloy 600MA in the same investigation. However, significant variation exists in PWSCC susceptibility of different heats of Alloy 600. The variation in the Alloy 600 material can be seen in Figure 4-13, which plots the Weibull $\theta$ vs. $\beta$ listed in Table 4-2 except the data in Figure 4-5 which are derived from the data in Figure 4-3 and Figure 4-4. The average $\beta$ for Alloy 600MA is 4.12 while the average $\beta$ for Alloy $600 \mathrm{TT}$ is 3.28 . Hence, the slope for the Alloy 690 Weibayes line arbitrarily set to 5.0 is higher than the average value $\beta$ for Alloy 600 . This introduces additional conservatism in the calculation of the Alloy 690 Weibayes $\theta$. No differentiation is made in this case between Alloy 690 in the MA condition and in the TT condition because neither has cracked in the hydrogenated, deaerated water. Therefore, the improvement factor, $\mathrm{IF}_{\mathrm{R}}$, is redefined as

$$
I F_{R}=\frac{\text { Weibayes }(r=1, \beta=5.0) \theta, \text { Alloy } 690}{\text { Weibull } 0, \text { Alloy } 600}
$$

The resulting $\mathrm{IF}_{\mathrm{R}}$ values are listed in Table 4-2. The Alloy 600 test data shown in Figure 4-7 and Figure 4-10 are normalized per the Arrhenius relationship of Eq. $4-7$ to $680^{\circ} \mathrm{F}$, the Alloy 690 test temperature in the same study. Overall, the average $\mathrm{IF}_{\mathrm{R}}$ of Alloy 690 listed in Table 4-2 is 26.5 relative to Alloy $600 \mathrm{MA}$ and 13.3 relative to Alloy $600 \mathrm{TT}$.

$$
\frac{t}{t_{r e f}} \propto \exp \left[\frac{Q_{i}}{R}\left(\frac{1}{T}-\frac{1}{T_{r e f}}\right)\right]
$$


where $Q_{i}=50 \mathrm{kcal} / \mathrm{mole}$.

\subsection{Improvement Factor with Minimum Alloy 600 Crack Time}

Unfortunately, not all the studies reviewed here had either obtained or reported sufficient data to allow a Weibull or Weibayes analysis. In order to include these data, an alternative way to calculate the improvement factor using Eq. 4-8 can be used:

$$
I F_{R}=\frac{\text { Test Time of Alloy } 690}{\text { Timeto firstcracking in Alloy } 600}
$$

Here, the time to first cracking in Alloy 600 refers to the time when the first failure in the Alloy 600 control specimens was observed. The following factors are considered for the $\mathrm{IF}_{\mathrm{R}}$ values determined from Eq. 4-8.

1. The PWSCC Alloy 600 resistance has been observed to vary greatly and depend on several factors. Some Alloy 600 TT specimens like the Alloy 690 specimens did not develop any cracking by the end of the test duration. Hence, the calculated $\mathrm{IF}_{\mathrm{R}}$ is relative to Alloy 600 materials that are highly susceptible to PWSCC, such as Alloy 600MA with low mill anneal temperature and a high degree of intragranular carbides. The $\mathrm{IF}_{\mathrm{R}}$ so calculated would be a more realistic improvement factor, somewhat less conservative than that by Eq. 4-6.

2. The $\mathrm{IF}_{\mathrm{R}}$ calculated per Eq. 4-8 is still considered conservative because the actual cracking time of the Alloy 600 specimens was less than the accumulated test time at inspection intervals. Often, the first Alloy 600 specimen cracking was observed at the first scheduled inspection interval. In addition, the actual cracking time of Alloy 690 specimens can be much longer than the test duration, if they ever develop cracking at all.

The resulting $\mathrm{IF}_{\mathrm{R}}$ values calculated by Eq. 4-8 are listed in Table 4-3 and Table 4-4. In addition, the equivalent EFPYs at $600^{\circ} \mathrm{F}$ for each test is also determined per Eq. 4-8. This normalization has no affect on the $\mathrm{IF}_{\mathrm{R}}$ per Eq. 4-8 except when the Alloy 600 and Alloy 690 specimens in the same study were tested at different temperatures. The average $\mathrm{IF}_{\mathrm{R}}$ of Alloy 690 relative to Alloy 600 in Table 4-3 and Table 4-4 per Eq. 4-8 is 27.1 , which is about the same as the 26.5 relative to Alloy $600 \mathrm{MA}$ from the Weibull analysis per Eq. 4-6. Figure 4-14 plots the duration of the test for Alloy 690 vs. the $\mathrm{IF}_{\mathrm{R}}$ listed in Table 4-3 and Table 4-4. The $\mathrm{IF}_{\mathrm{R}}$ is seen to increase with increasing test time, indicating that the $\mathrm{IF}_{\mathrm{R}}$ is limited by the test duration.

\subsection{Alloy 690/152/52 Material Operating Experience in PWRs}

Over the past thirty years, PWSCC of Alloy 600/182/82 material has become an increasingly significant problem in PWRs. As shown in Table 1-1, PWSCC was first detected in Alloy 600 steam generator tubing in 1971. The first report of PWSCC in a pressure boundary penetration was the leak from a pressurizer level nozzle in 1986. Both of these instances occurred after approximately 2 years of service. These initial reports have subsequently been followed by similar occurrences at other PWRs using Alloy 600/182/82 materials for the same component 
items. These problems have led to significantly increased inspection efforts, have contributed to the early replacement of many steam generators, have led to long forced outages to repair problems at some units, and have resulted in the expenditure of a significant amount of engineering effort to determine the root cause of the problems, develop inspection and repair methods, and develop strategic plans to manage the problems.

In addition to the initial occurrences of Alloy $600 / 182 / 82$ PWSCC given in Table $1-1$, the following steam generator tubing failures are highlighted:

1. Cracking of Obrigheim steam generator tubes (1971) after approximately 2 years of service. ${ }^{[67]}$ This was the first instance of PWSCC of Alloy 600MA.

2. Cracking of Kori-2 steam generator tubes (1986) after nearly 3 years of service. This was the first occurrence of PWSCC in a steam generator fabricated with Alloy 600TT tubing. ${ }^{[68]}$

3. Cracking of steam generator mechanical tube plug at North Anna 1 (1989) after just over 3 years of service. ${ }^{[9]}$ This was the first occurrence of PWSCC of Alloy 600TT plugging material.

4. Cracking was identified at Oconee Nuclear Station-1 (1995) after about 8 years of operation. ${ }^{[68]}$ This was the first instance of PWSCC in stress relieved OTSG (OnceThrough Steam Generator) tubing.

It seems quite clear that a PWR steam generator is a very demanding material application, involving high temperature, high stress and strain at roll transitions and at tight U-bends, and a primary water environment that facilitates stress corrosion cracking (at a corrosion potential close to the equilibrium potential of the $\mathrm{Ni} / \mathrm{NiO}$ equilibrium). In addition, the number of $\mathrm{SG}$ tubes per PWR varies between 8,000 and 30,000. Hence, steam generator tubing is statistically favored to be the first component item to show PWSCC. Operating experience indicates that a PWSCC-susceptible Alloy 600 material (low temperature mill annealed) cracks in approximately 2 years of operation in this application. Even improved Alloy 600 materials (high temperature mill annealed and thermally treated or high temperature mill annealed and stress relieved) also may be susceptible to cracking in as little as 3 to 8 years of operation.

As shown in Section 3, Alloy 690 material appears to be highly resistant to PWSCC when laboratory tested in conditions where Alloy 600 material tested under the same conditions routinely showed comparatively rapid cracking. Also, as shown in Table 4-5, a number of steam generators manufactured with Alloy 690 tubing material have been in service for significant times without crack indications due to PWSCC. The oldest steam generators with Alloy 690 tubing have been operating for approximately 14 years with no reported signs of PWSCC degradation. There are now 73 PWR units worldwide, with 2-4 steam generators per unit, operating with Alloy 690 steam generator tubing (as of December 2003).

Table 4-6 provides a listing of both replacement and original equipment component items utilizing Alloy 690/152/52 materials. The replacement pressurizer heater sleeves at Calvert 
Cliffs-2 have been in operation for about 12 years and visual inspections have not identified any problems to date. In addition, a complete NDE inspection of the Bugey-3 replacement RV head CRDM nozzles was performed in 2002 (after 10 years of service), which did not reveal any defects. ${ }^{[70]}$

Currently, there has been only one known instance of field repairs with Alloy 152/52 that later showed to be inadequate. In the fall of 2001, three Alloy 600 CRDM nozzles (\#51, \#62, and \#63) on the North Anna Unit 2 reactor vessel head showed evidence of leakage. Subsequent NDE identified crack-like indications in the vicinity of the Alloy 182 butter and Alloy $82 \mathrm{~J}$-groove weld of the three CRDM nozzles. A boat sample was removed from the Alloy 182 butter and Alloy $82 \mathrm{~J}$-groove weld interface region of CRDM nozzle \#62. The boat sample showed that cracking was confined to the Alloy 182 butter region. The root cause evaluation concluded that the cracking most likely originated from hot cracking of the Alloy 182 butter during plant construction. PWSCC probably contributed to, but was not believed to be a primary cause of the cracking. The three CRDM nozzles were repaired by an Alloy 52 overlay weld (with at least two layers of Alloy 52) to isolate the original Alloy 182/82 surface from the primary water environment. ${ }^{[71]}$ The overlay of the CRDM J-groove weld at North Anna Unit 2 in 2001 was the first field application of this repair technique to CRDM nozzles. Post repair dye penetrant examination results were acceptable. During North Anna Unit 2's 2002 Fall refueling outage, the three CRDM nozzles repaired in 2001 were re-examined by dye penetrant examinations, which revealed the new indications.

An evaluation concluded that the new indications were attributable to two causes. The first cause was the surface flapping performed prior to the dye penetrant examinations in 2002 . The second cause was that the Alloy 52 weld overlay in the 2001 repair did not cover the entire exposed Alloy 182/82 surface. As part of the evaluation, a boat sample was removed from CRDM nozzle \#51 and examined in a hot cell. Figure 4-15 shows a sketch of the radial location of the boat sample relative to the J-groove weld, butter, and stainless steel cladding. The boat sample's long axis was tangential to the circular Alloy 52 weld overlay. Figure 4-15 also shows the weld metals determined by EDS on the as-received surface. Examination of the boat sample revealed cracking (also termed fissuring) associated exclusively with the interface between the weld beads, where the underlying Alloy $182 / 82$ weld metal was susceptible to reheat cracking as a result of excessive dilution ( $>30 \%$ ). It was found that the reheat cracking in the Alloy $182 / 82$ propagated into the thin layer of Alloy 52 at the edge of the repair weld bead. However, no hot cracking was observed in the Alloy 52 weld overlay on top of the Type 308 stainless steel cladding, where the Alloy 52 dilution was limited. It was concluded that none of the cracking in the boat sample was due to environmental conditions and the embedded flaw repair method is acceptable if the entire J-groove weld and buttering is covered by the Alloy 52 weld overlay. ${ }^{\text {[72] }}$ Therefore, it is concluded that the indications found in or near the Alloy 52 weld overlay to the CRDM nozzle J-groove welds at North Anna Unit 2 were not caused by PWSCC, and hence are not an indication of Alloy 52 susceptibility to PWSCC.

Obviously a number of additional improvements to fabrication practice have also been made to reduce the likelihood of initiating PWSCC with Alloy 690/152/52 materials. These include optimizing component item construction practices, optimizing material melting and manufacturing practices, and reducing residual stresses. However, the excellent operating 
experience to date with Alloy 690/152/52 materials provides reasonable assurance that these alloys are very highly resistant to PWSCC. 
Table 4-1 Summary of Surface IG Cracking in Alloy 690 and Alloy 52 Specimens

\begin{tabular}{|c|c|c|c|}
\hline Ref. & Matl. & Description of Surface IG Cracks and Defects & Attributed Cause \\
\hline $\begin{array}{l}\text { Miglin, }{ }^{[88]} \\
1986\end{array}$ & $\begin{array}{l}\text { Alloy 690MA\&TT } \\
\text { SG Tubing }\end{array}$ & $\begin{array}{l}\text { Longitudinal shallow and blunt defects were found on the } \\
\text { I.D. surface of the Alloy } 690 \text { RUB apex. These defects } \\
\text { were not typical of IGSCC. Metallographic examinations } \\
\text { showed that some of these defects appeared to be like } \\
\text { mechanical grooves while others appeared to be } \\
\text { separation along the grain boundaries. No evidence of } \\
\text { further IGSCC cracking emanating from the base of these } \\
\text { defects were found. SEM examinations of archive Alloy } \\
690 \text { RUB specimens found similar longitudinal defects, but } \\
\text { they were shorter in length than those detected after the } \\
\text { AVT autoclave exposure ( } 0.1 \text { to } 0.35 \text { mm long in archive } \\
\text { Alloy } 690 \text { RUB vs. } 1.0 \text { mm in Alloy } 690 \text { RUB after the } \\
\text { AVT exposure). The less strained leg portions of the RUB } \\
\text { specimens were free from these defects. }\end{array}$ & $\begin{array}{l}\text { The growth in length } \\
\text { observed was due to an } \\
\text { opening process of closed or } \\
\text { partially closed defects. } \\
\text { During the high temperature } \\
\text { exposure, the surface oxide } \\
\text { growth (in the defects) would } \\
\text { enhance an opening process } \\
\text { by a wedging effect to give } \\
\text { an appearance of } \\
\text { longitudinal growth. }\end{array}$ \\
\hline $\begin{array}{l}\text { Sui, }^{[52]} \\
1997\end{array}$ & $\begin{array}{l}\text { Alloy 690TT SG } \\
\text { Tubing }\end{array}$ & $\begin{array}{l}\text { Short IG cracks (see Figure } 3-14 \text {, depth not reported) on } \\
\text { the RUB specimen I.D. surface produced by flattening at } \\
\text { room temperature. The RUB specimen had been exposed } \\
\text { to hydrogenated steam at } 380^{\circ} \mathrm{C}\left(716^{\circ} \mathrm{F}\right) \text { for } 13,824 \text { hours. }\end{array}$ & $\begin{array}{l}\text { Embrittlement of grain } \\
\text { boundaries near the surface } \\
\text { from the exposure. }\end{array}$ \\
\hline $\begin{array}{l}\text { Vaillant, }{ }^{[49]} \\
1999\end{array}$ & $\begin{array}{l}\text { Alloy 690TT SG } \\
\text { Tubing }\end{array}$ & $\begin{array}{l}\text { Shallow cracks ( } 10 \mu \mathrm{m} \text { or } 0.0004 \text { " deep) appeared at the } \\
\text { apex of the Alloy } 690 \text { RUB specimens after bending, but } \\
\text { before immersion inside the autoclave. So the stress } \\
\text { measured in the Alloy } 690 \text { RUB specimen apex surface } \\
\text { was not well-defined. However, the stress level measured } \\
\text { after removing the } 10 \mu \text { m deep crack was the same as for } \\
\text { the Alloy } 600 \text { RUB specimens. Hence, the stress at the tip } \\
\text { of the short crack caused by bending is at least as high as } \\
\text { the apex surface stress of the Alloy } 600 \text { RUB specimens. } \\
\text { No crack growth observed in the Alloy } 690 \text { RUB } \\
\text { specimens during the testing. }\end{array}$ & $\begin{array}{l}\text { Cracking was due to } \\
\text { bending. }\end{array}$ \\
\hline $\begin{array}{l}\text { Framatome, } \\
\text { France } \\
2003 \\
\text { [App. B] }\end{array}$ & $\begin{array}{l}\text { Alloy } 690 \mathrm{TT}, \mathrm{SG} \\
\text { Tubing }\end{array}$ & $\begin{array}{l}\text { IG cracks on the inner tube surface in the transition zones } \\
\text { of the kiss rolling ( } 1.5 \mathrm{~mm} \text { and their width } 2 \mu \mathrm{m} \text {, see } \\
\text { Appendix } \mathrm{B} \text { for details). Examination of the flattened half } \\
\text { tube revealed the presence of many microcracks, some of } \\
\text { the opened microcracks corresponded to those which } \\
\text { were also observed before flattening but numerous others } \\
\text { were new ones opened or created during the mechanical } \\
\text { flattening operation. This type of flaw was also observed } \\
\text { on parts of the tube which were not rolled, that is remote } \\
\text { from the rolled zone. The crack depth was always limited } \\
\text { to the thickness of the perturbed surface layer on the } \\
\text { internal surface of the tube (about } 10 \mu \mathrm{m} \text { thick in this } \\
\text { case). These microcracks were intergranular but did not } \\
\text { propagate in the tube during exposure to hydrogenated } \\
\text { water at } 360^{\circ} \mathrm{C} \text { during } 60,000 \text { hours exposure. }\end{array}$ & $\begin{array}{l}\text { Strain induced by rolling and } \\
\text { are limited to the hard } \\
\text { perturbed surface layer } \\
\text { already present on the inside } \\
\text { surface of the tube in the as- } \\
\text { received condition. }\end{array}$ \\
\hline Jacko ${ }^{[54]}$ & Alloy $52 \mathrm{M}$ & $\begin{array}{l}\text { After } 1343 \text { hours, short }(0.16 \text { and } 0.20-\mathrm{mm} \text { in length) } \\
\text { indications were observed on the surface of the two high- } \\
\text { strain Alloy } 52 \mathrm{M} \text { four-point bend specimens. These } \\
\text { indications did not change in subsequent exposures. }\end{array}$ & $\begin{array}{l}\text { Metallographic cross- } \\
\text { sectioning indicated these to } \\
\text { be shallow hot-microfissures } \\
\text { that were present from the } \\
\text { weld preparation, but were } \\
\text { not clearly identified in the } \\
\text { earlier examinations. }\end{array}$ \\
\hline
\end{tabular}


Table 4-2 Weibull Analysis for Alloy 600 Tested With Alloy 690

\begin{tabular}{|c|c|c|c|c|c|c|c|c|}
\hline Figure & Matl. & Heat & Test & Environ. & $\begin{array}{l}\text { Temp } \\
\left({ }^{\circ} \mathrm{F}\right)\end{array}$ & $\begin{array}{l}\text { Weibull, } \theta \\
\text { (hour) }\end{array}$ & $\begin{array}{c}\text { Weibull } \\
\text { slope, } \\
\beta^{(a)}\end{array}$ & $I F_{R}{ }^{(b)}$ \\
\hline Figure 4-2 & 690MA\&TT & Pre-series 3 Heats & RUB & $\begin{array}{l}\text { Deaerated } \\
\text { water + B + Li }\end{array}$ & 680 & 30,950 & 5.00 & N/A \\
\hline Figure 4-2 & $600 \mathrm{MA}$ & No info & RUB & $\begin{array}{l}\text { Deaerated } \\
\text { water + B + Li }\end{array}$ & 680 & 8,112 & 1.96 & 3.8 \\
\hline Figure 4-2 & $600 T T$ & No info & RUB & $\begin{array}{l}\text { Deaerated } \\
\text { water }+\mathrm{B}+\mathrm{Li}\end{array}$ & 680 & 14,539 & 5.08 & 2.1 \\
\hline $\begin{array}{l}\text { Figure 4-3 } \\
\text { Figure 4-4 } \\
\text { Figure 4-5 }\end{array}$ & 690MA\&TT & Many heats & RUB & $\begin{array}{l}\text { Deaerated } \\
\text { water }\end{array}$ & 689 & 59,748 & 5.00 & N/A \\
\hline Figure 4-3 & 600 & $\begin{array}{l}\text { PWR Ringhals 2, } \\
7 / 8 " \text { dia. }\end{array}$ & RUB & $\begin{array}{l}\text { Deaerated } \\
\text { water }\end{array}$ & 689 & 910 & 1.74 & 65.7 \\
\hline Figure 4-3 & $600 \mathrm{MA}$ & $\begin{array}{l}\text { Alloy 600MA, 7/8" } \\
\text { dia. }\end{array}$ & RUB & $\begin{array}{l}\text { Deaerated } \\
\text { water }\end{array}$ & 689 & 1,440 & 3.91 & 41.5 \\
\hline Figure 4-3 & 600 & $\begin{array}{l}\text { PWR Ringhals 4, } \\
3 / 4 " \text { dia. }\end{array}$ & RUB & $\begin{array}{l}\text { Deaerated } \\
\text { water }\end{array}$ & 689 & 4,590 & 2.47 & 13.0 \\
\hline Figure 4-3 & 600 & $\begin{array}{l}\text { PWR Ringhals } 3 \text {, } \\
3 / 4 \text { " dia. }\end{array}$ & RUB & $\begin{array}{l}\text { Deaerated } \\
\text { water }\end{array}$ & 689 & 5,620 & 6.05 & 10.6 \\
\hline Figure 4-3 & $600 T T$ & $\begin{array}{l}\text { Alloy } 600 \mathrm{TT} \\
3 / 4 " \text { dia }\end{array}$ & RUB & $\begin{array}{l}\text { Deaerated } \\
\text { water }\end{array}$ & 689 & 8,060 & 5.52 & 7.4 \\
\hline Figure 4-4 & $600 \mathrm{MA}$ & $\begin{array}{l}\text { EPRI Provided } \\
\text { B\&WTP, } 1700^{\circ} \mathrm{F}\end{array}$ & RUB & $\begin{array}{l}\text { Deaerated } \\
\text { water }\end{array}$ & 689 & 740 & 4.53 & 80.7 \\
\hline Figure 4-4 & $600 \mathrm{MA}$ & $\begin{array}{l}\text { EPRI Provided } \\
\text { Huntington, } 1700^{\circ} \mathrm{F}\end{array}$ & RUB & $\begin{array}{l}\text { Deaerated } \\
\text { water }\end{array}$ & 689 & 2,480 & 10.43 & 24.1 \\
\hline Figure 4-4 & $600 \mathrm{MA}$ & $\begin{array}{l}\text { EPRI Provided } \\
\text { Sandvik, } 1700^{\circ} \mathrm{F}\end{array}$ & RUB & $\begin{array}{l}\text { Deaerated } \\
\text { water }\end{array}$ & 689 & 3,490 & 5.77 & 17.1 \\
\hline Figure 4-4 & $600 \mathrm{MA}$ & $\begin{array}{l}\text { EPRI Provided } \\
\text { B\&WTP, } 1875^{\circ} \mathrm{F}\end{array}$ & RUB & $\begin{array}{l}\text { Deaerated } \\
\text { water }\end{array}$ & 689 & 10,260 & 5.48 & 5.8 \\
\hline Figure 4-4 & $600 \mathrm{MA}$ & $\begin{array}{l}\text { EPRI Provided } \\
\text { Sandvik, } 1875^{\circ} \mathrm{F}\end{array}$ & RUB & $\begin{array}{l}\text { Deaerated } \\
\text { water }\end{array}$ & 689 & 10,990 & 5.27 & 5.4 \\
\hline Figure 4-5 & 600 & $\begin{array}{l}\text { 7/8" dia., Ringhals } \\
2, N X 1991, N X \\
2650\end{array}$ & RUB & $\begin{array}{l}\text { Deaerated } \\
\text { water }\end{array}$ & 689 & 1,118 & 1.91 & 53.4 \\
\hline Figure 4-5 & 600 & $\begin{array}{l}3 / 4 \text { " dia. Ringhals } 3 \\
\text { and } 4\end{array}$ & RUB & $\begin{array}{l}\text { Deaerated } \\
\text { water }\end{array}$ & 689 & 5,397 & 3.05 & 11.1 \\
\hline Figure 4-7 & 690MA\&TT & One heat & CLT & $\begin{array}{l}\text { Deaerated } \\
\text { water + B + Li }\end{array}$ & 680 & 18,206 & 5.00 & N/A \\
\hline \multirow{2}{*}{ Figure 4-7 } & \multirow{2}{*}{$600 \mathrm{MA}$} & \multirow{2}{*}{ One heat } & \multirow{2}{*}{ CLT } & \multirow{2}{*}{$\begin{array}{l}\text { Deaerated } \\
\text { water + B + Li }\end{array}$} & 644 & 5,358 & 5.91 & -- \\
\hline & & & & & 680 & $1464^{(c)}$ & 5.91 & 12.4 \\
\hline Figure 4-10 & $690 T T$ & One heat & $\begin{array}{l}\text { RUB 20\% } \\
\text { prestrain }\end{array}$ & $\begin{array}{l}\text { Deaerated } \\
\text { water + B + Li }\end{array}$ & 680 & 20,913 & 5.00 & N/A \\
\hline \multirow{2}{*}{ Figure 4-10 } & \multirow{2}{*}{$600 \mathrm{MA}$} & \multirow{2}{*}{ One heat } & \multirow{2}{*}{$\begin{array}{l}\text { RUB 20\% } \\
\text { prestrain }\end{array}$} & \multirow{2}{*}{$\begin{array}{l}\text { Deaerated } \\
\text { water + B + Li }\end{array}$} & 608 & 6,051 & 2.10 & - \\
\hline & & & & & 680 & $414^{(c)}$ & 2.10 & 51.2 \\
\hline \multirow{2}{*}{ Figure 4-10 } & \multirow{2}{*}{$600 T T$} & \multirow{2}{*}{ One heat } & \multirow{2}{*}{$\begin{array}{l}\text { RUB 20\% } \\
\text { prestrain }\end{array}$} & \multirow{2}{*}{$\begin{array}{l}\text { Deaerated } \\
\text { water + B + Li }\end{array}$} & 608 & 9,530 & 3.64 & -- \\
\hline & & & & & 680 & 652 & 3.64 & 32.2 \\
\hline
\end{tabular}


Section 4-Discussion

\begin{tabular}{|l|l|l|l|l|c|c|c|c|}
\hline Figure 4-11 & 690TT & Four heats & RUB & $\begin{array}{l}\text { Deaerated } \\
\text { water + B + Li }\end{array}$ & 680 & 54,284 & 5.00 & N/A \\
\hline Figure 4-11 & 600MA & Three heats & RUB & $\begin{array}{l}\text { Deaerated } \\
\text { water + B + Li }\end{array}$ & 680 & 1,776 & 1.04 & 30.6 \\
\hline Figure 4-11 & 600TT & Four heats & RUB & $\begin{array}{l}\text { Deaerated } \\
\text { water + B + Li }\end{array}$ & 680 & 3,945 & 1.85 & 13.8 \\
\hline Figure 4-12 & 690TT & One heat & $\begin{array}{l}\text { SG Mock- } \\
\text { up }\end{array}$ & $\begin{array}{l}\text { Deaerated } \\
\text { water }\end{array}$ & 680 & 174,110 & 5.00 & N/A \\
\hline Figure 4-12 & 690MA & WD281 & $\begin{array}{l}\text { SG Mock- } \\
\text { up }\end{array}$ & $\begin{array}{l}\text { Deaerated } \\
\text { water }\end{array}$ & 680 & 8,954 & 0.95 & 19.4 \\
\hline Figure 4-12 & $690 T 1$ & WD281 & $\begin{array}{l}\text { SG Mock- } \\
\text { up }\end{array}$ & $\begin{array}{l}\text { Deaerated } \\
\text { water }\end{array}$ & 680 & 11,199 & 1.28 & 15.5 \\
\hline Figure 4-12 & $690 T$ & NX3335 & $\begin{array}{l}\text { SG Mock- } \\
\text { up }\end{array}$ & $\begin{array}{l}\text { Deaerated } \\
\text { water }\end{array}$ & 680 & 20,231 & 2.29 & 8.6 \\
\hline
\end{tabular}

(a) $\theta$ is time to Weibull $63.2 \%$ cumulative failure for Alloy 600 and the equivalent Weibayes for Alloy 690 .

(b) $\mathrm{IF}_{\mathrm{R}}$ per Eq. 4-6.

(c) The equivalent time at $680^{\circ} \mathrm{F}$ per Eq. 4-7 based a PWSCC crack initiation time of $50 \mathrm{kcal} / \mathrm{mole}$. 
Table 4-3 Summary of Alloy 690 Primary Water Stress Corrosion Test Data

\begin{tabular}{|c|c|c|c|c|c|c|c|c|c|c|}
\hline Ref. & Test & Test Environ. & $\begin{array}{c}\text { Test } \\
\text { Temp } \\
\left({ }^{\circ} \mathrm{F}\right)\end{array}$ & $\begin{array}{c}\text { Alloy } 690 \\
\text { Heat Number }\end{array}$ & $\begin{array}{l}\text { Alloy } 690 \\
\text { Heat Cond. }\end{array}$ & $\begin{array}{l}\text { Total } \\
\text { Speci } \\
\text { No. }{ }^{(a)}\end{array}$ & $\begin{array}{c}\text { Test Time } \\
\text { at test temp. } \\
\text { (hour) }\end{array}$ & $\begin{array}{c}\text { Eq. Test } \\
\text { Time at } \\
600^{\circ} \mathrm{F}^{(\mathbf{b})} \\
\text { (year) }\end{array}$ & $\begin{array}{c}\text { Time to } \\
\text { First Alloy } \\
600 \text { failure } \\
\text { (hour) }\end{array}$ & $\begin{array}{c}\text { Improve } \\
\text { Factor } \\
\left(\mathrm{IF}_{\mathrm{R}}\right)\end{array}$ \\
\hline \multirow{2}{*}{ Sedricks [9] } & $\begin{array}{l}\text { Double } \\
\text { U-Bend }\end{array}$ & $\begin{array}{l}\text { Deaerated } \\
\text { water }\end{array}$ & 600 & Y24A7L & $\begin{array}{l}\text { MA, TT, } \\
\text { MA+CW, } \\
\text { MA+Weld }\end{array}$ & 52 & 8064 & 0.9 & 3024 & 2.7 \\
\hline & $\begin{array}{l}\text { Double } \\
\text { U-Bend }\end{array}$ & $\begin{array}{l}\text { Deaerated } \\
\text { water }\end{array}$ & 680 & 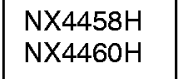 & MA, TT & 8 & 8064 & 23.2 & $\begin{array}{l}\text { No } 600 \\
\text { control }\end{array}$ & $\mathrm{N} / \mathrm{A}$ \\
\hline \multirow{2}{*}{ K. Smith [11] } & \multirow{2}{*}{ RUB } & \multirow{2}{*}{$\begin{array}{l}\text { Deaerated } \\
\text { water + B + } \\
\mathrm{Li}\end{array}$} & \multirow{2}{*}{680} & \multirow{2}{*}{$\begin{array}{l}\text { Three pre- } \\
\text { series, } \\
\text { Heats 1-3 }\end{array}$} & \multirow{2}{*}{$\mathrm{MA}, \mathrm{TT}$} & 20 & 13000 & 29.9 & 1500 & 6.5 \\
\hline & & & & & & 20 & 16000 & 36.8 & 2000 & 6.4 \\
\hline \multirow{3}{*}{ Yonezawa [17] } & \multirow[b]{2}{*}{ RUB } & \multirow{3}{*}{$\begin{array}{l}\text { Deaerated } \\
\text { water + B + } \\
\text { Li }\end{array}$} & \multirow{3}{*}{680} & \multirow{3}{*}{$\begin{array}{l}\text { One Alloy } \\
690 \text { heat }\end{array}$} & MA & 3 & 6600 & 15.2 & \multirow{2}{*}{340} & 19.4 \\
\hline & & & & & $\pi$ & 2 & 12000 & 27.6 & & 35.3 \\
\hline & CLT & & & & $\pi$ & 5 & 7000 & 16.1 & 1144 & 6.1 \\
\hline $\begin{array}{l}\text { A. Smith } \\
{[32,33]}\end{array}$ & C-Ring & $\begin{array}{l}\text { Deaerated } \\
\text { water }\end{array}$ & 644 & $\begin{array}{l}\text { Two } \\
\text { industrial } \\
\text { heats A, E }\end{array}$ & $\pi$ & 2 & 1500 & 0.9 & $\begin{array}{l}\text { No } 600 \\
\text { control }\end{array}$ & $N / A$ \\
\hline \multirow{4}{*}{$\begin{array}{l}\text { Norring } \\
{[35,36,37]}\end{array}$} & \multirow{4}{*}{ RUB } & \multirow{4}{*}{$\begin{array}{l}\text { Deaerated } \\
\text { water }\end{array}$} & \multirow{4}{*}{689} & $\mathrm{~F}$ & MA & 6 & 33000 & 103.6 & \multirow{4}{*}{800} & 41.3 \\
\hline & & & & $\begin{array}{l}\mathrm{H}, \mathrm{G}, \mathrm{A}, \mathrm{B}, \\
\mathrm{D}, \mathrm{C}, \mathrm{I}\end{array}$ & $\mathrm{MA}, \mathrm{TT}$ & 47 & 25000 & 78.5 & & 31.3 \\
\hline & & & & PP & $\pi$ & 6 & 23000 & 72.2 & & 28.8 \\
\hline & & & & $Y, Z$ & MA & 8 & 20500 & 64.3 & & 25.6 \\
\hline \multirow{2}{*}{ Ogawa [43] } & RUB & \multirow{2}{*}{$\begin{array}{l}\text { Deaerated } \\
\text { water + B + } \\
\text { Li }\end{array}$} & \multirow{2}{*}{680} & \multirow{2}{*}{$\begin{array}{l}\text { One Alloy } \\
690 \text { heat }\end{array}$} & \multirow{2}{*}{ Tा } & 40 & 10000 & 23.0 & 3000 & 3.3 \\
\hline & CLT & & & & & 20 & 10000 & 23.0 & $1142^{(c)}$ & 8.8 \\
\hline Angell [44] & RUB & $\begin{array}{l}\text { Deaerated } \\
\text { water + B + } \\
\text { Li with or } \\
\text { without } Z n\end{array}$ & 662 & 752246 & $\pi$ & 20 & 7500 & 9.1 & 5500 & 1.4 \\
\hline Vaillant [49] & RUB & $\begin{array}{l}\text { Deaerated } \\
\text { water + B + } \\
\text { Li }\end{array}$ & 680 & $\begin{array}{l}9.092 \text { Exp } \\
9.592 \text { Exp } \\
9.799 \text { Ind } \\
9 G 4\end{array}$ & TT, MA & 4 & 54000 & 124.1 & 500 & 108 \\
\hline $\begin{array}{l}\text { Framatome, } \\
\text { France } \\
\text { [App. B] }\end{array}$ & $\begin{array}{l}\text { SG } \\
\text { Mockup }\end{array}$ & $\begin{array}{l}\text { Deaerated } \\
\text { water }\end{array}$ & 680 & $\begin{array}{l}\text { WE094, } \\
\text { Pre-series }\end{array}$ & $\pi$ & 16 & 100000 & 229.8 & 800 & 125 \\
\hline
\end{tabular}

(a) Total number of specimens of similar heat treatment and test condition and duration.

(b) The equivalent test time at $600^{\circ} \mathrm{F}$ for Alloy 690 is calculated based a PWSCC crack initiation time of $50 \mathrm{kcal} / \mathrm{mole}$ (Eq 4-7).

(c) 1142 hours is the equivalent of the 4179 hours failure time at $644^{\circ} \mathrm{F}$ for the Alloy 600 control CLT specimens based on Eq. 4-7. Only two of four Alloy 600 MA series results were reported. Hence, the time to the first Alloy 600 failure could be less than 4179 hours. 
Table 4-4 Summary of Alloy 690 Hydrogenated and Doped Hydrogenated Steam Stress Corrosion Test Data

\begin{tabular}{|c|c|c|c|c|c|c|c|c|c|c|}
\hline Test Ref. & Test & Test Environ. & $\begin{array}{c}\text { Test } \\
\text { Temp } \\
\left({ }^{\circ} \mathrm{F}\right)\end{array}$ & $\begin{array}{c}\text { Alloy } 690 \\
\text { Heat Number }\end{array}$ & $\begin{array}{l}\text { Alloy } 690 \\
\text { Heat Cond. }\end{array}$ & $\begin{array}{l}\text { Total } \\
\text { Speci } \\
\text { No. }^{\left({ }^{2}\right)}\end{array}$ & $\begin{array}{c}\text { Test Time } \\
\text { at test temp. } \\
\text { (hour) }\end{array}$ & $\begin{array}{c}\text { Eq. Test } \\
\text { Time at } \\
600^{\circ} \mathrm{F}^{(b)} \\
\text { (year) }\end{array}$ & $\begin{array}{c}\text { Time to } \\
\text { First Alloy } \\
600 \text { failure } \\
\text { (hour) }\end{array}$ & $\begin{array}{c}\text { Improve. } \\
\text { Factor } \\
\text { (IF) }\end{array}$ \\
\hline \multirow{3}{*}{ Sui [52] } & \multirow{3}{*}{$R \cup B$} & \multirow{3}{*}{$\mathrm{H}_{2}$ Steam } & \multirow{3}{*}{716} & $690(A)$ & $\pi$ & 1 & 13824 & 107.4 & \multirow{3}{*}{552} & 25.0 \\
\hline & & & & \multirow{2}{*}{$690(B)$} & $\pi$ & 1 & $12600^{(\mathrm{c})}$ & 97.9 & & 22.8 \\
\hline & & & & & TT+aged & 1 & $12600^{(\mathrm{c})}$ & 97.9 & & 22.8 \\
\hline \multirow{2}{*}{ Jacko [54] } & $\begin{array}{l}\text { 4-point } \\
\text { Bend } \\
1 \% \\
\text { strain }\end{array}$ & \multirow{2}{*}{$\begin{array}{l}\mathrm{H}_{2} \text { Steam } \\
+30 \mathrm{ppm} \\
\text { for each } \\
\mathrm{Cl}^{-}, \mathrm{F}^{-} \\
\mathrm{SO}_{4}^{-2}\end{array}$} & \multirow{2}{*}{752} & \multirow{2}{*}{$\begin{array}{l}\text { Alloy 52M } \\
\text { Weld, } \\
\text { Y9570 }\end{array}$} & \multirow{2}{*}{ Weld } & 2 & 2051 & 50.1 & $214^{(\mathrm{d})}$ & 9.6 \\
\hline & $\begin{array}{l}\text { 4-point } \\
\text { Bend } \\
0.3 \% \\
\text { strain }\end{array}$ & & & & & 2 & 2051 & 50.1 & $450^{(d)}$ & 4.6 \\
\hline \multirow{2}{*}{$\begin{array}{l}\text { Framatome, } \\
\text { Germany } \\
{[\text { App. A] }}\end{array}$} & RUB & \multirow{2}{*}{$\mathrm{H}_{2}$ Steam } & \multirow{2}{*}{752} & \multirow{2}{*}{754380} & \multirow{2}{*}{$\mathrm{TT}$} & 3 & 9720 & 237.4 & 336 & 28.9 \\
\hline & $\begin{array}{l}\text { RUB } \\
\text { surface } \\
\text { scored }\end{array}$ & & & & & 3 & 9720 & 237.4 & 336 & 28.9 \\
\hline
\end{tabular}

(a) Total number of specimens of similar heat treatment and test condition and duration.

(b) The equivalent test time at $600^{\circ} \mathrm{F}$ for Alloy 690 is calculated based a PWSCC crack initiation time of $50 \mathrm{kcal} / \mathrm{mole}$ (Eq. 4).

(c) Two of the three Alloy 690 specimens in Sui's investigation cracked after 13824 hours of testing. To be conservative, it is assumed here that these two Alloy 690 specimens developed crack soon after the previous examination made after accumulating 12600 hours. None of the other Alloy 690 specimens in this table failed during the test duration.

(d) The Alloy 52M is compared with Alloy 182. 
Table 4-5 List of Operating Steam Generators Manufactured with Alloy 690 Tubing ${ }^{[68]}$

(As of December 2003)

\begin{tabular}{|l|l|}
\hline Installation Date & PWR \\
\hline 1989 & D.C. Cook-2, Indian Point-3, Ringhals-2 \\
\hline 1990 & Dampierre-1 \\
\hline 1991 & Ohi-3 \\
\hline 1992 & Penly-2 \\
\hline 1993 & Millstone-2, North Anna-1, Beznau-1, Ohi-4 \\
\hline 1994 & Mihama-2, Takahama-2, Genkai-1, V.C. Summer, Gravelines-1, Daya Bay-1, Daya Bay-2, \\
\hline 1995 & Ohi-1, Tihange-1, North Anna-2, Ringhals-3, Dampierre-3, St. Laurent-B1, Sizewell-B \\
\hline 1996 & Mihama-1, Takahama-1, Doel-4, Catawba-1, Ginna, Gravelines-2 \\
\hline 1997 & McGuire-1, McGuire-2, Point Beach-2, Mihama-3, Ohi-2, Tricastin-2, Genkai-4 \\
\hline 1998 & Byron-1, St. Lucie-1, Tihange-3, Braidwood-1, Kori-1, Ikata-1, Tricastin-1 \\
\hline 1999 & Beznau-2 \\
\hline 2000 & $\begin{array}{l}\text { Farley-1, D.C. Cook-1, Krsko, South Texas Project-1, Arkansas Nuclear One-2, Chooz-B1, } \\
\text { Civaux-1, Civaux-2, Gravelines-4 }\end{array}$ \\
\hline 2001 & Genkai-2, Ikata-2, Kewaunee, Shearon Harris, Farley-2, Tihange-2 \\
\hline 2002 & Tricastin-3, Fessenheim-1, Chooz-B2, Calvert Cliffs-1, South Texas Project-2 \\
\hline 2003 & Calvert Cliffs-2, Palo Verde-2, Sequoyah-1, Oconee-1, St-Laurent Des Eaux B \\
\hline & \\
\hline
\end{tabular}


Table 4-6 List of Alloy 690/152/52 Reactor Coolant System (Excluding Steam Generators) Original Equipment or Replacement Component Items and Welds

As of December $2003^{(a)}$

\begin{tabular}{|c|c|c|c|}
\hline Component Item & $\begin{array}{l}\text { In-Service } \\
\text { Date }\end{array}$ & PWR & Material \\
\hline \multirow{2}{*}{$\begin{array}{l}\text { Pressurizer Heater } \\
\text { Sleeves }\end{array}$} & 1990 & Calvert Cliffs-2 & Alloy 690 Tubing \\
\hline & 2003 & Palo Verde-2 & $\begin{array}{l}\text { Alloy } 690 \text { Tubing and Alloy } 52 \\
\text { Weld }\end{array}$ \\
\hline \multirow{9}{*}{$\begin{array}{l}\text { Pressurizer Instrument } \\
\text { Nozzles }\end{array}$} & 1990 & Calvert Cliffs-2 & \multirow{3}{*}{ Alloy 690 Tubing } \\
\hline & 1992 & $\begin{array}{l}\text { Palo Verde-1,San Onofre-3, } \\
\text { San Onofre-2, Palo Verde-1 }\end{array}$ & \\
\hline & 1993 & St. Lucie-2, Palo Verde-2 & \\
\hline & 1994 & Palo Verde-3, St. Lucie-2 & \multirow{6}{*}{$\begin{array}{l}\text { Alloy } 690 \text { Tubing and Alloy } 52 \\
\text { Weld }\end{array}$} \\
\hline & 1995 & San Onofre-3, St. Lucie-1 & \\
\hline & 1997 & San Onofre-2, San Onofre-3 & \\
\hline & 1998 & Calvert Cliffs-2, San Onofre-3 & \\
\hline & 1999 & San Onofre-3 & \\
\hline & 2001 & Waterford-3 & \\
\hline \multirow[t]{4}{*}{$\begin{array}{l}\text { RV Head CRDM } \\
\text { Nozzles/Welds }^{(b)}\end{array}$} & 1992 & Bugey-3 & \multirow[t]{4}{*}{$\begin{array}{l}\text { Alloy } 690 \text { Tubing and Alloy } \\
152 / 52 \text { Weld }\end{array}$} \\
\hline & 1994 & $\begin{array}{l}\text { Bugey-5, Blaiyais-1, Gravelines-4, } \\
\text { Bugey-2 }\end{array}$ & \\
\hline & 1995 & $\begin{array}{l}\text { Blayais-2, St. Alban-1, Flamanville-1, } \\
\text { Gravelines-3, Blaiyais-3, Tricastin-1 }\end{array}$ & \\
\hline & 1996 & $\begin{array}{l}\text { Tricastin-4, Paluel-4, St. Laurent-B2, } \\
\text { Blaiyais-4, Dampierre-1, Fessenheim-1, } \\
\text { St. Alban-2 }\end{array}$ & \\
\hline
\end{tabular}




\begin{tabular}{|c|c|c|c|}
\hline Component Item & $\begin{array}{l}\text { In-Service } \\
\text { Date }\end{array}$ & PWR & Material \\
\hline & 1997 & $\begin{array}{l}\text { Bugey-4, Dampierre-2, Dampierre-4, } \\
\text { Belleville-2, Cruas-4, Gravelines-5 }\end{array}$ & \\
\hline & 1998 & $\begin{array}{l}\text { Flamanville-2, Dampierre-3, Paluel-3, } \\
\text { Cattenom-2, Fessenheim-2, Cruas-2 }\end{array}$ & \\
\hline & 1999 & Chooz-B1, Chooz-B2 & \\
\hline & 2000 & Civaux-1, Civaux-2 & \\
\hline & 2002 & North Anna-2 & \\
\hline & 2003 & $\begin{array}{l}\text { North Anna-1, Surry-1, Oconee-1, } \\
\text { Oconee-3, Ginna, Three Mile Island-1, } \\
\text { Crystal River-3, Surry-2 }\end{array}$ & \\
\hline \multirow{7}{*}{ Hot Leg Piping Nozzles } & 1993 & San Onofre-2, Palo Verde-2 & Alloy 690 Tubing \\
\hline & 1995 & San Onofre-3, St. Lucie-1 & \multirow{6}{*}{$\begin{array}{l}\text { Alloy } 690 \text { Tubing and Alloy } 52 \\
\text { Weld }\end{array}$} \\
\hline & 1997 & San Onofre-2, San Onofre-3 & \\
\hline & 2000 & ANO-1 & \\
\hline & 2001 & Waterford-3 & \\
\hline & 2002 & Palo Verde-1, Palo Verde-3 & \\
\hline & 2003 & St. Lucie-2, Davis-Besse & \\
\hline $\begin{array}{l}\text { Cold Leg Piping } \\
\text { Nozzles }\end{array}$ & 1997 & San Onofre-2, San Onofre-3 & $\begin{array}{l}\text { Alloy } 690 \text { Tubing and Alloy } 52 \\
\text { Weld }\end{array}$ \\
\hline RV Nozzle Butt Welds & 2000 & V.C. Summer & $\begin{array}{l}\text { Alloy } 690 \text { Forging and Alloy } 52 \\
\text { Weld }\end{array}$ \\
\hline $\begin{array}{l}\text { Pressurizer Manway } \\
\text { Diaphragm Plate Weld }\end{array}$ & 2002 & Catawba-1 & Alloy $152 / 52$ Weld \\
\hline $\begin{array}{l}\text { Pressurizer Surge } \\
\text { Nozzle Weld }\end{array}$ & 2003 & TMI-1 & $\begin{array}{l}\text { Alloy } 52 \text { Weld Overlay (O.D. of } \\
\text { Pipe) }\end{array}$ \\
\hline
\end{tabular}




\begin{tabular}{|l|l|l|l|}
\hline Component Item & $\begin{array}{l}\text { In-Service } \\
\text { Date }\end{array}$ & PWR & Material \\
\hline $\begin{array}{l}\text { RV Lower Head BMI } \\
\text { Nozzles }\end{array}$ & 2000 & Civaux-1, Civaux-2 & $\begin{array}{l}\text { Alloy 690 Tubing and Alloy } \\
152 / 52 \text { Weld }\end{array}$ \\
\hline & 2003 & South Texas-1 & $\begin{array}{l}\text { Alloy } 690 \text { Tubing and Alloy 52 } \\
\text { Weld }\end{array}$ \\
\hline
\end{tabular}

(a) Table entries are based on the information currently available. Additional replacements may exist, which are not included in this table.

(b) This list represents complete RV closure head replacements. Numerous CRDM nozzle repairs on various existing RV closure heads are also in service at this time. 


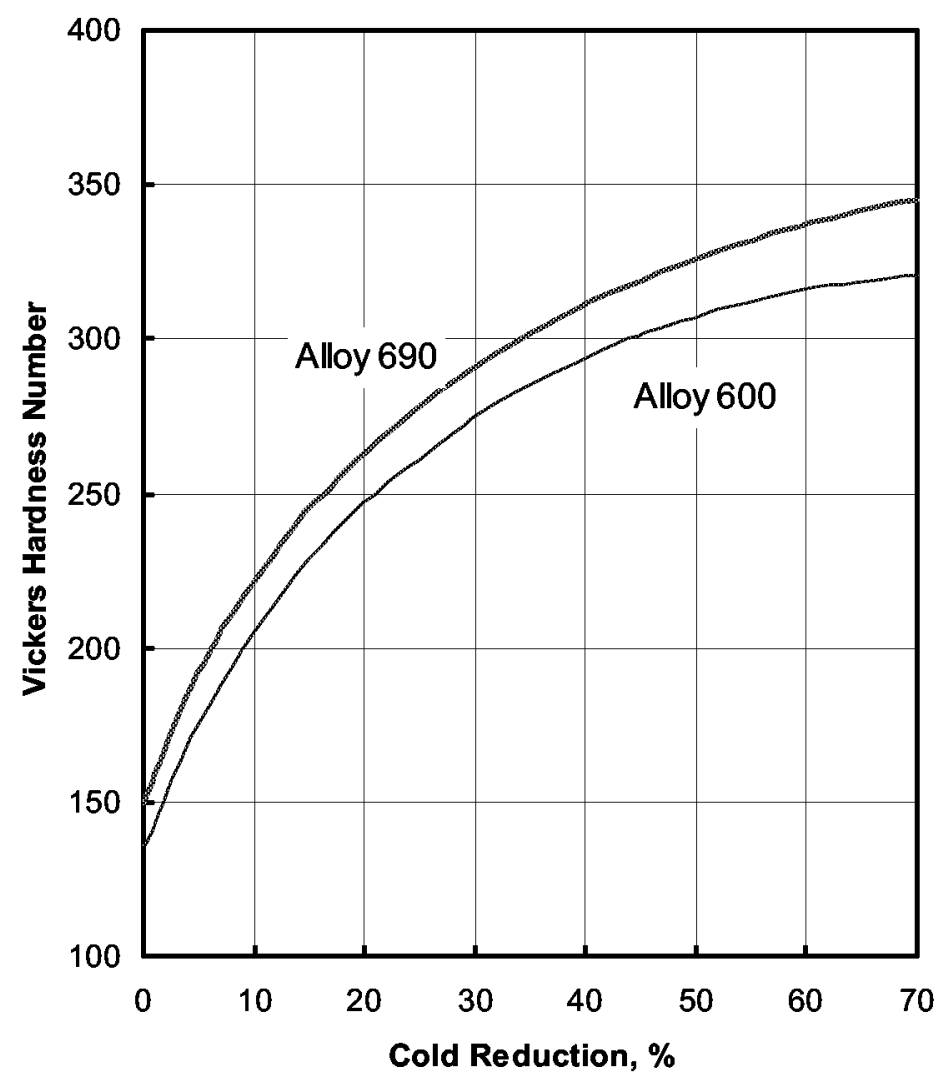

Figure 4-1 Vickers hardness number as a function of cold reduction \%. Alloy 690 has a higher work-hardening rate than Alloy 600. After Ref. 6. 


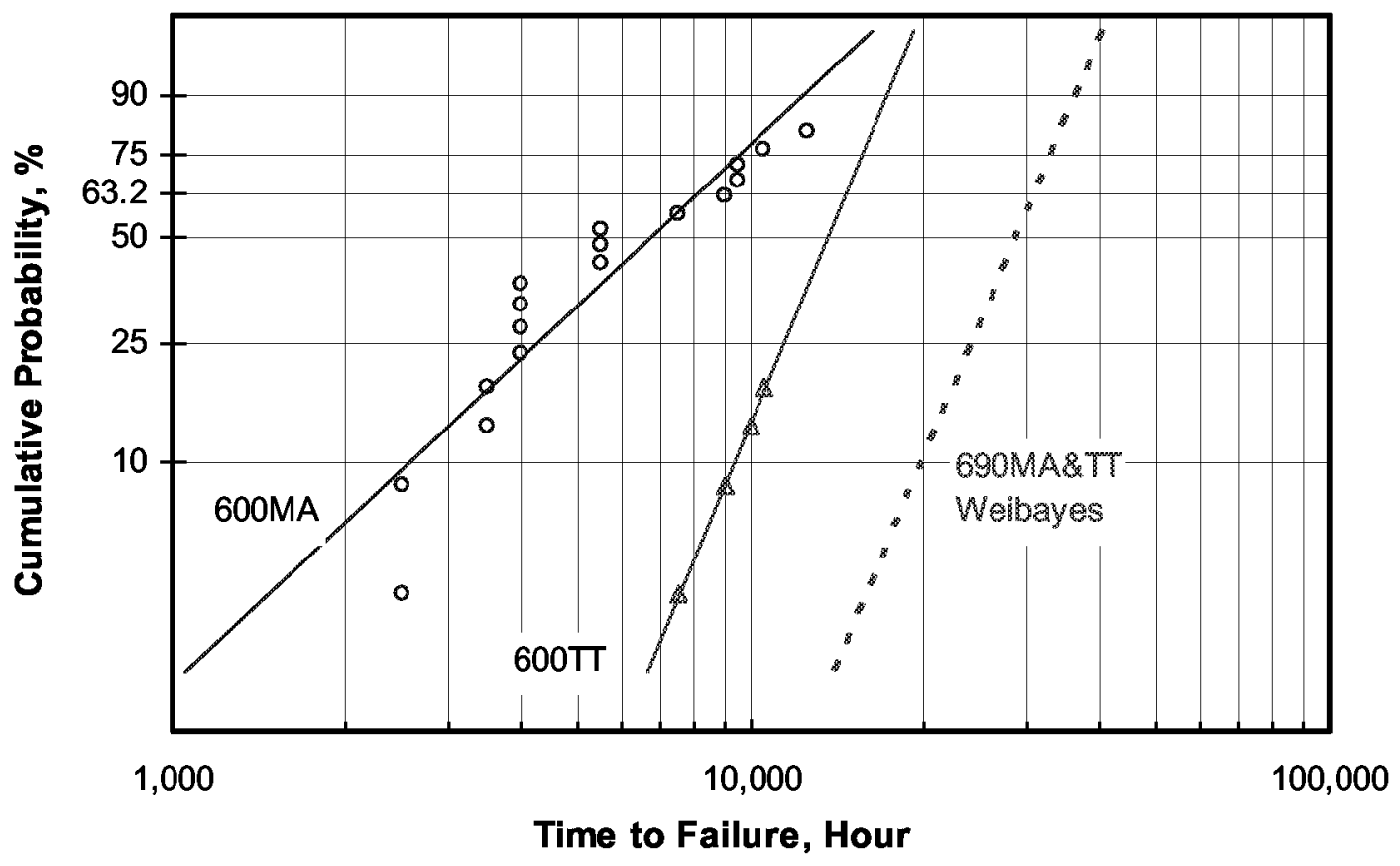

Figure 4-2 Weibull plot of Alloy 600 RUB results in primary water at $680^{\circ} \mathrm{F}$ reported by $\mathrm{K}$. Smith et al. (shown in Figure 3-3). The test data in the beginning-fuel-cycle and the endfuel-cycle water have been combined. The Alloy 690 (three heats) Weibayes line assumes $\beta=5.0$.

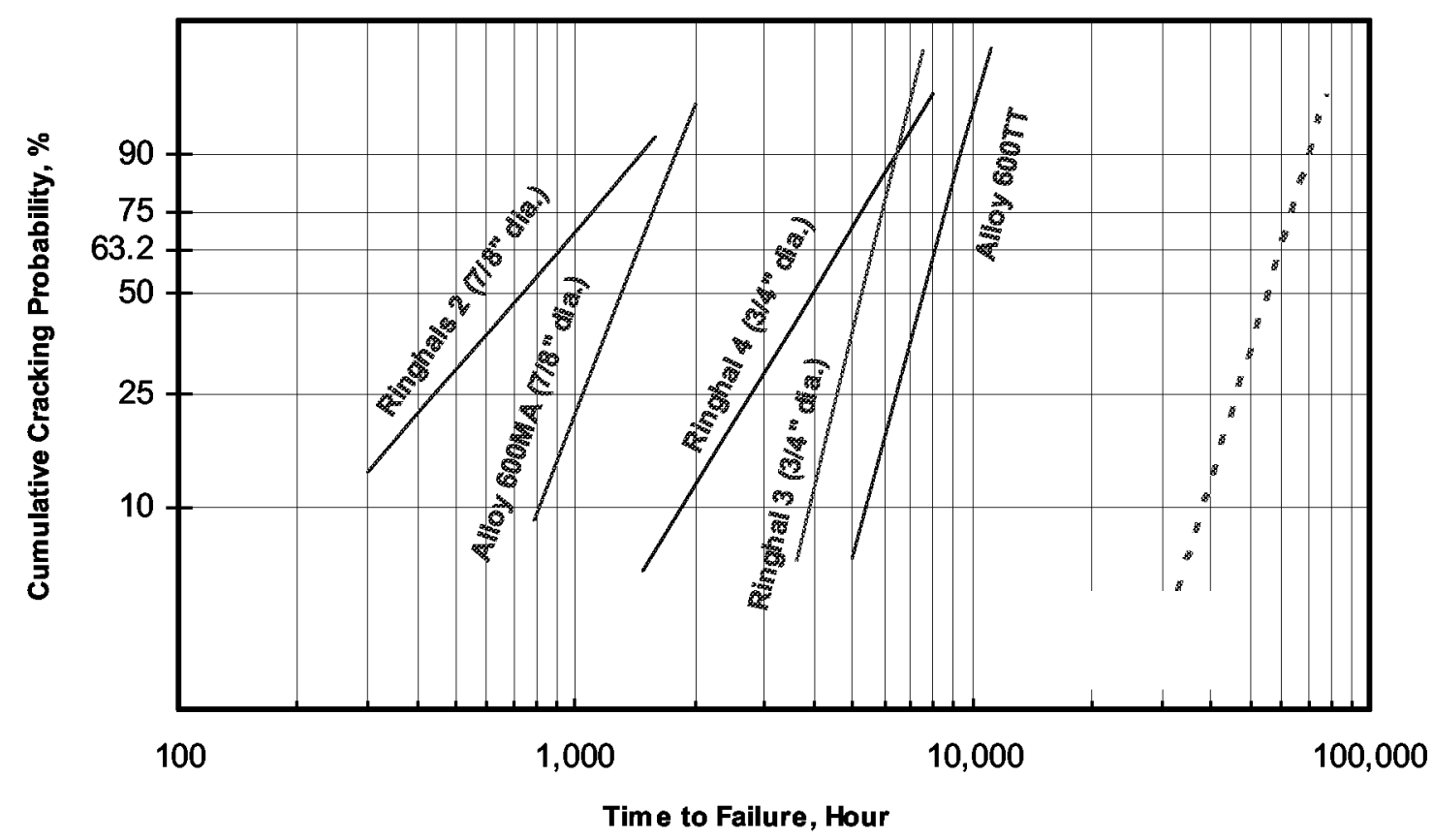

Figure 4-3 Weibull plot of different heats of Alloy 600 RUB results in deaerated water at $689^{\circ} \mathrm{F}$ reported by Norring et al. The Alloy 690 (many heats) Weibayes line assumes $\beta=\mathbf{5 . 0}$. 


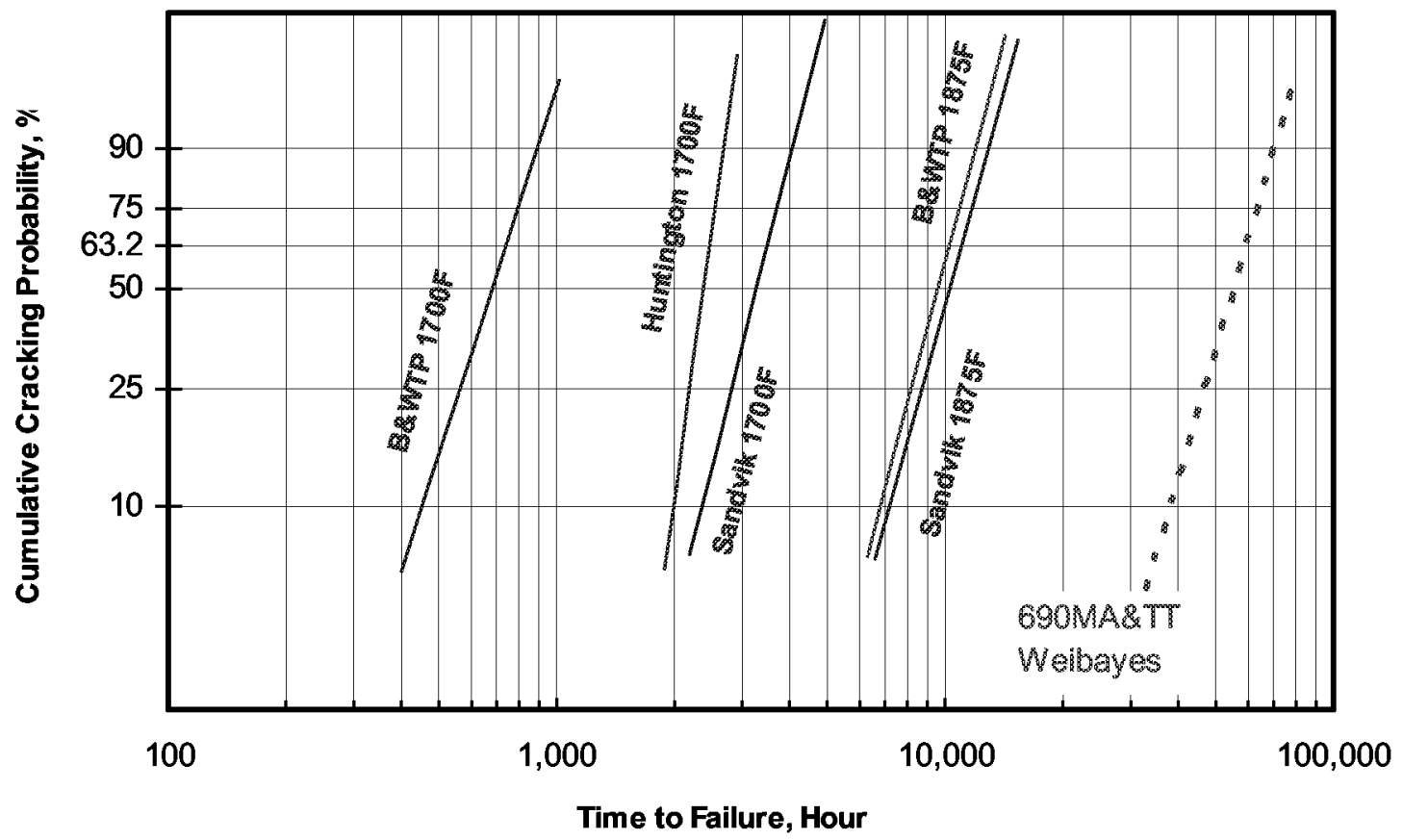

Figure 4-4 Weibull plot of different EPRI special production heats of Alloy 600 RUB results in deaerated water at $689^{\circ} \mathrm{F}$ reported by Norring et al. The Alloy 690 (many heats) Weibayes line assumes $\beta=5.0$.

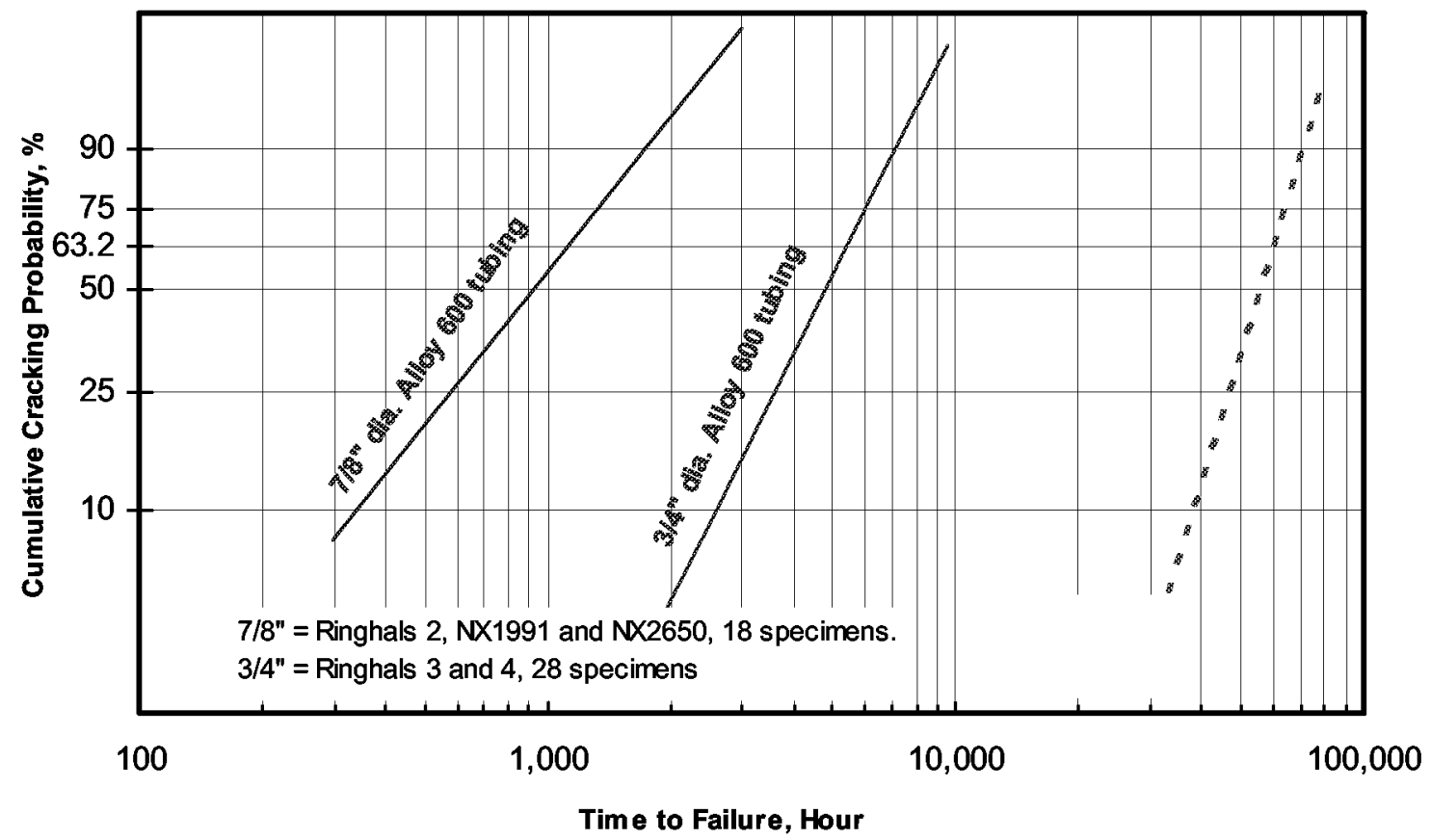

Figure 4-5 Weibull comparison between 7/8" dia. and 3/4" dia. Alloy 600 RUB results in deaerated water at $689^{\circ} \mathrm{F}$ reported by Norring et al. The Alloy 690 (many heats) Weibayes line assumes $\beta=5.0$. 

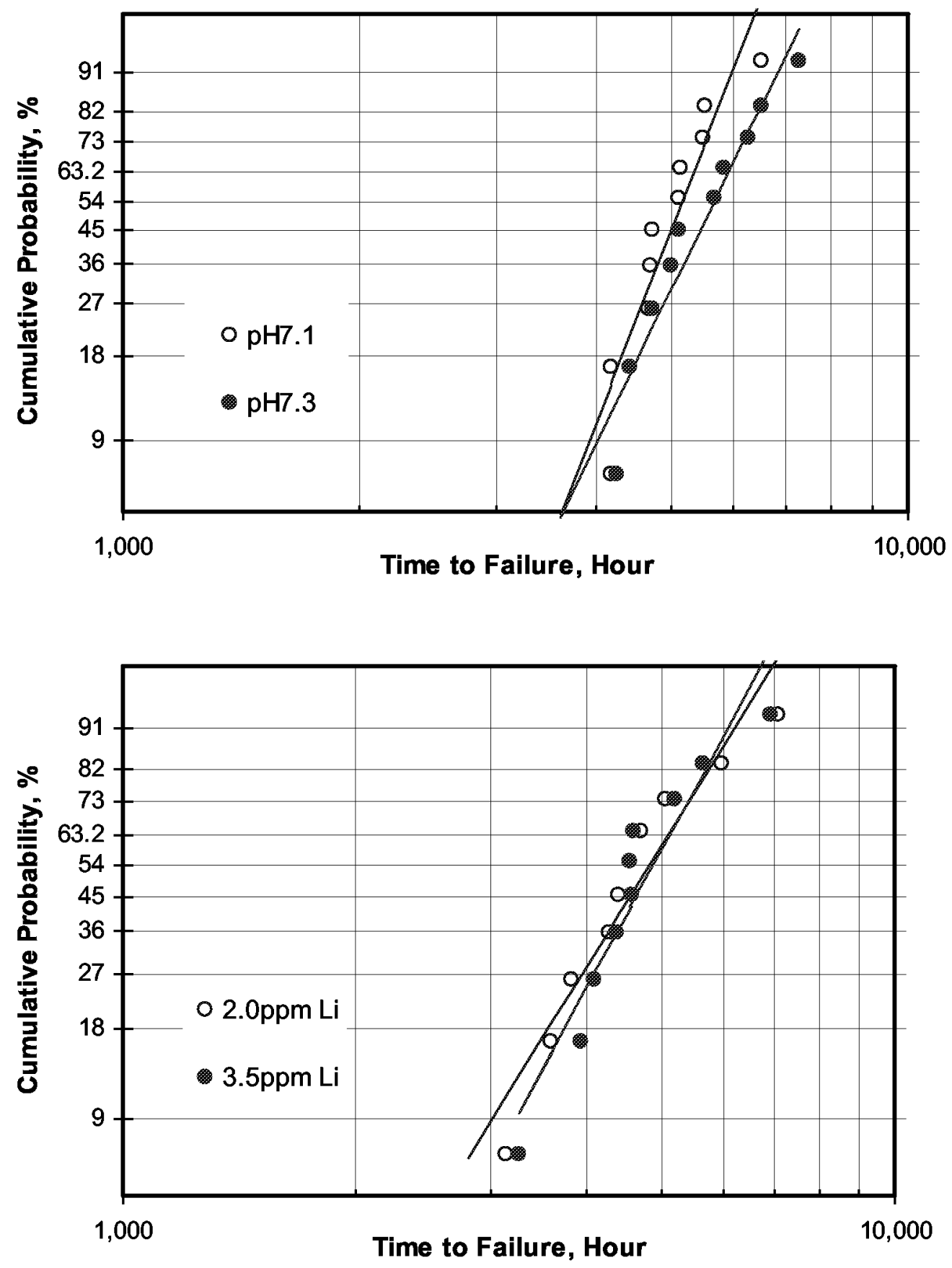

Figure 4-6 Weibull plots of Alloy 600MA (one heat) during constant load test (CLT) at 85.3 $\mathrm{ksi}, 644^{\circ} \mathrm{F}$ reported by Ogawa et al. (a) Results in the optimum $(\mathrm{pH}=7.1)$ and reference $\mathrm{pH}$ $(\mathrm{pH}=7.3)$ primary water chemistry. (b) Results in the candidate $(2.0 \mathrm{ppm} \mathrm{Li})$ and reference primary water chemistry (3.5 ppm Li). The Alloy 600MA CLT specimens showed similar cracking behavior in the four variations of primary water chemistry. 


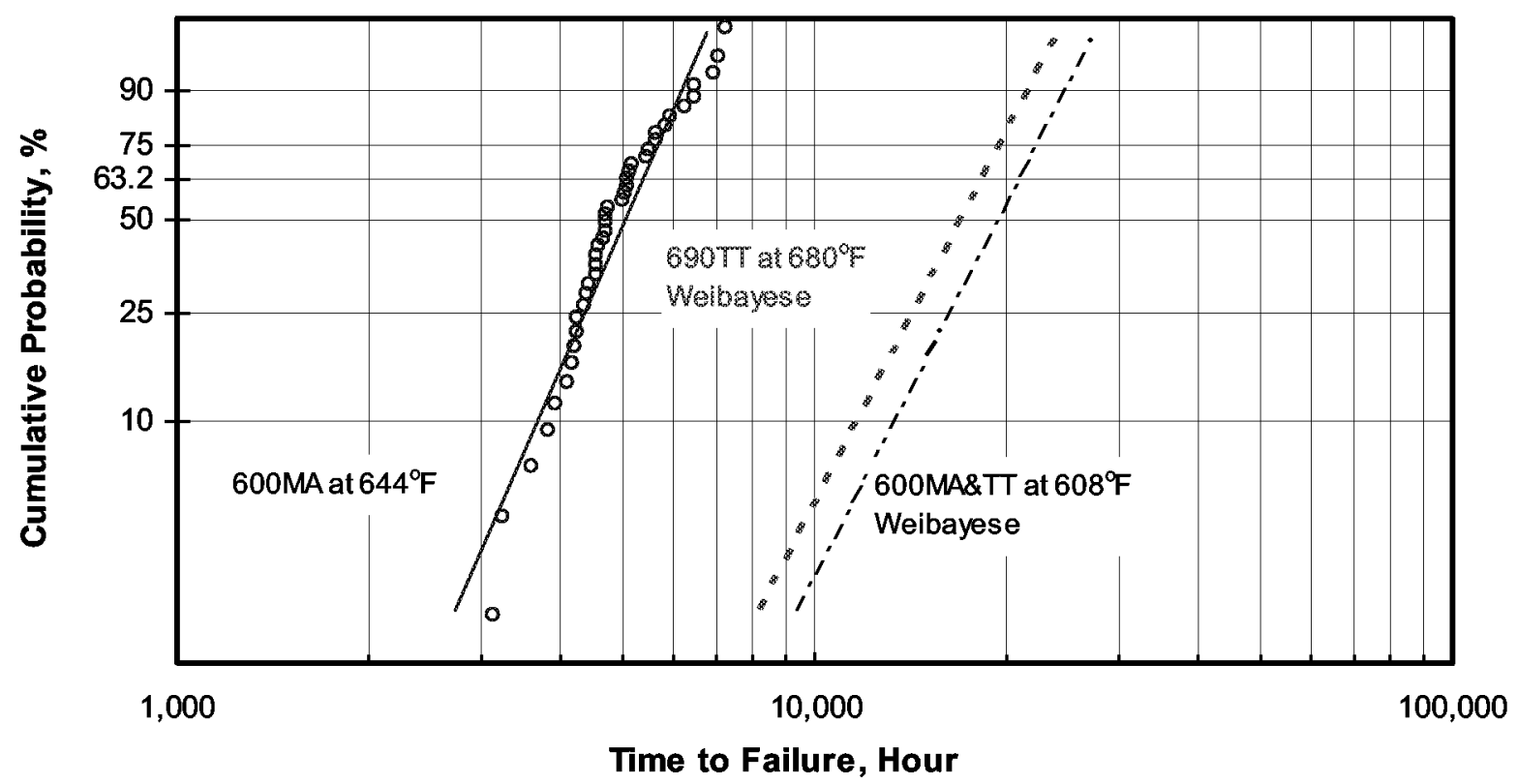

Figure 4-7 Weibull plots of Alloy 600MA (one heat) CLT results at $85.3 \mathrm{ksi}, 644^{\circ} \mathrm{F}$ in primary water reported by Ogawa et al. No failure was observed in all Alloy 600MA\&TT CLT specimens tested at $608^{\circ} \mathrm{F}$ and in the Alloy 690TT (one heat) CLT specimens tested at $680^{\circ} \mathrm{F}$. The Weibayes lines for the Alloy 690TT and Alloy 600MA\&TT assume $\beta=5.0$.

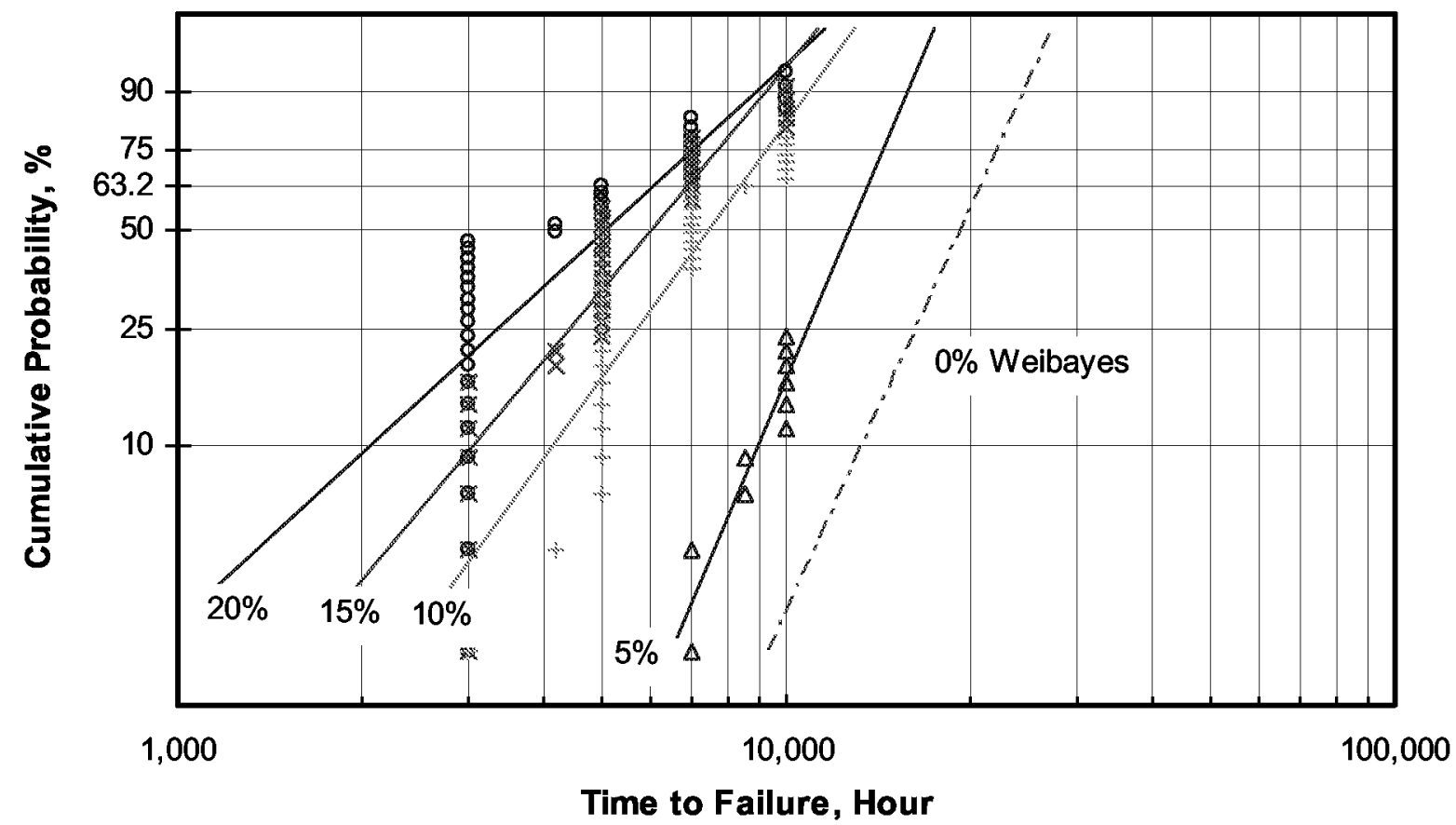

Figure 4-8 Weibull plot of Alloy 600MA (one heat) RUB results at $608{ }^{\circ} \mathrm{F}$ in primary water reported by Ogawa et al. The RUB specimens were prestrained to different levels. The Weibayes line for the $0 \%$ prestrain (no failure) assumes $\beta=\mathbf{5 . 0}$. 


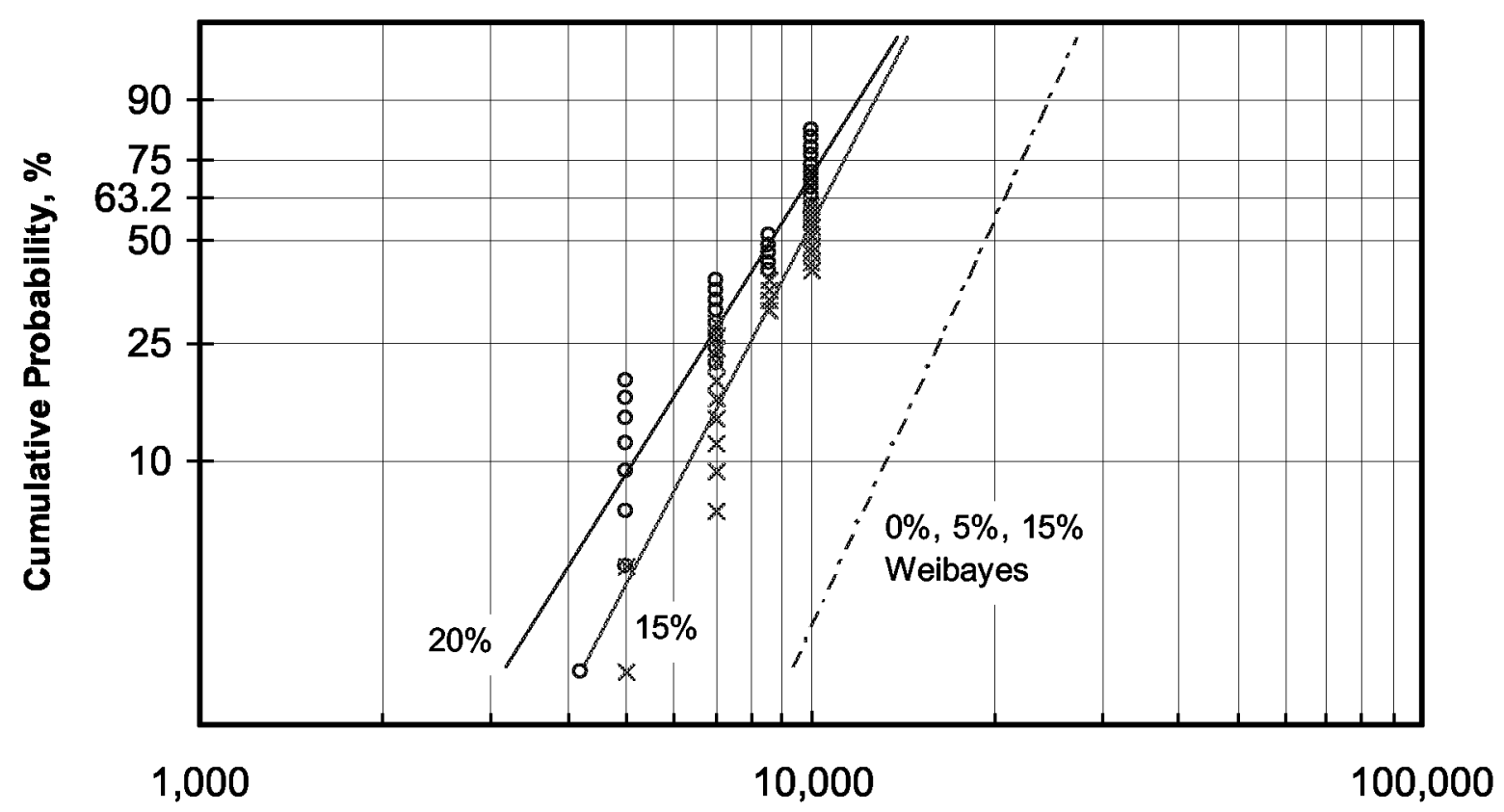

Time to Failure, Hour

Figure 4-9 Weibull plot of Alloy 600TT (one heat) RUB results at $608{ }^{\circ} \mathrm{F}$ in primary water reported by Ogawa et al. The RUB specimens were prestrained to different levels. The Weibayes line for the $0 \%, 5 \%$, and $15 \%$ prestrain (no failure) assume $\beta=5.0$.

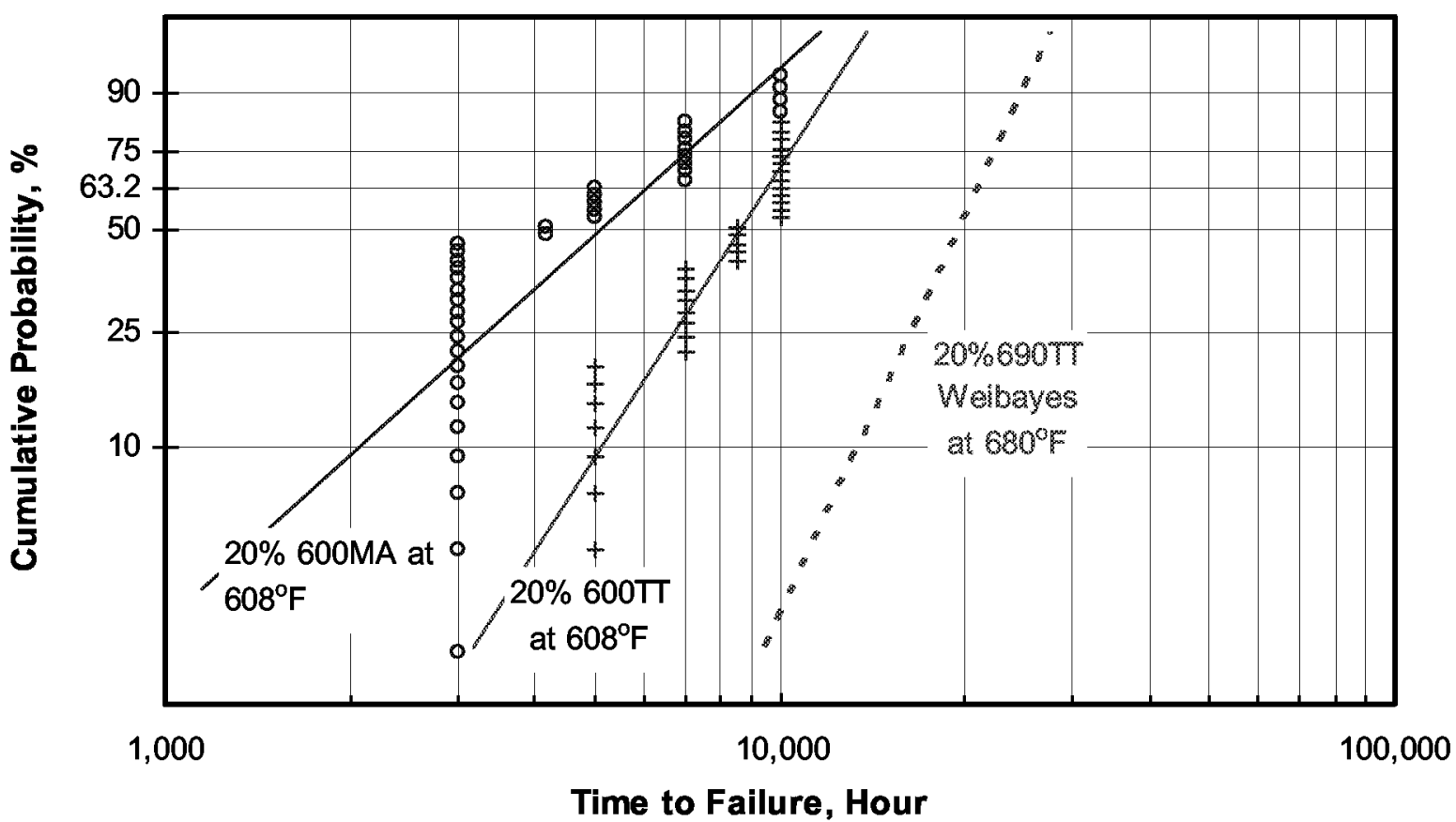

Figure 4-10 Comparison of the 20\% prestrained RUB from Alloy 600MA\&TT (tested at $608^{\circ} \mathrm{F}$ ) and from Alloy $690 \mathrm{TT}$ (tested at $680^{\circ} \mathrm{F}$ ) in primary water reported by Ogawa et al. The Alloy 690TT Weibayes line for the assume $\beta=5.0$. 


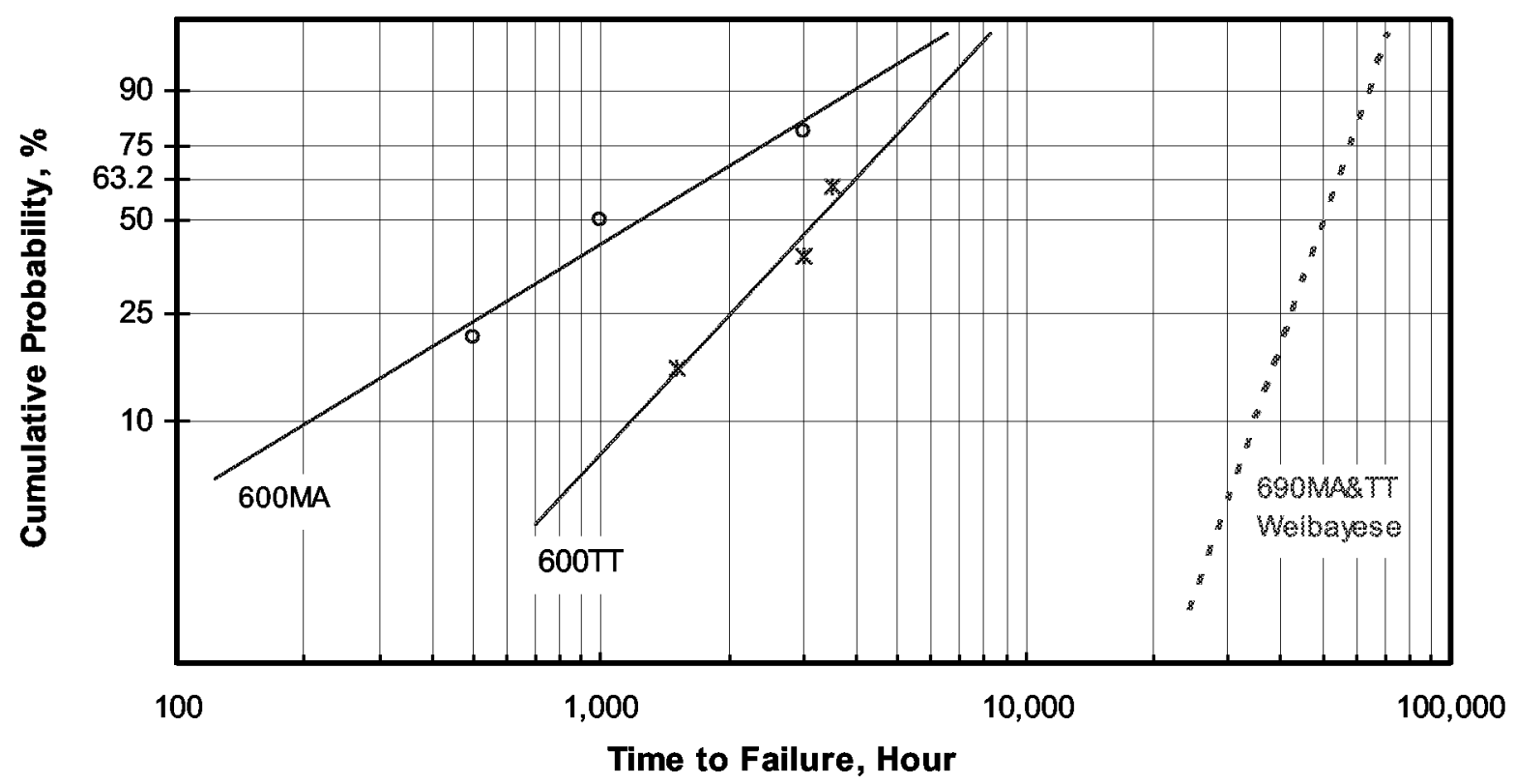

Figure 4-11 Weibull plot of RUB results at $680^{\circ} \mathrm{F}$ in primary water reported by Vaillant et al. The Alloy 600 RUB specimens were from four different heats in the MA and TT conditions. The Alloy 690 RUB specimens, from four different heats in the TT and MA conditions, experienced no failure after up to 54,000 hours of exposure. The Alloy 690 Weibayes line assumes $\beta=5.0$.

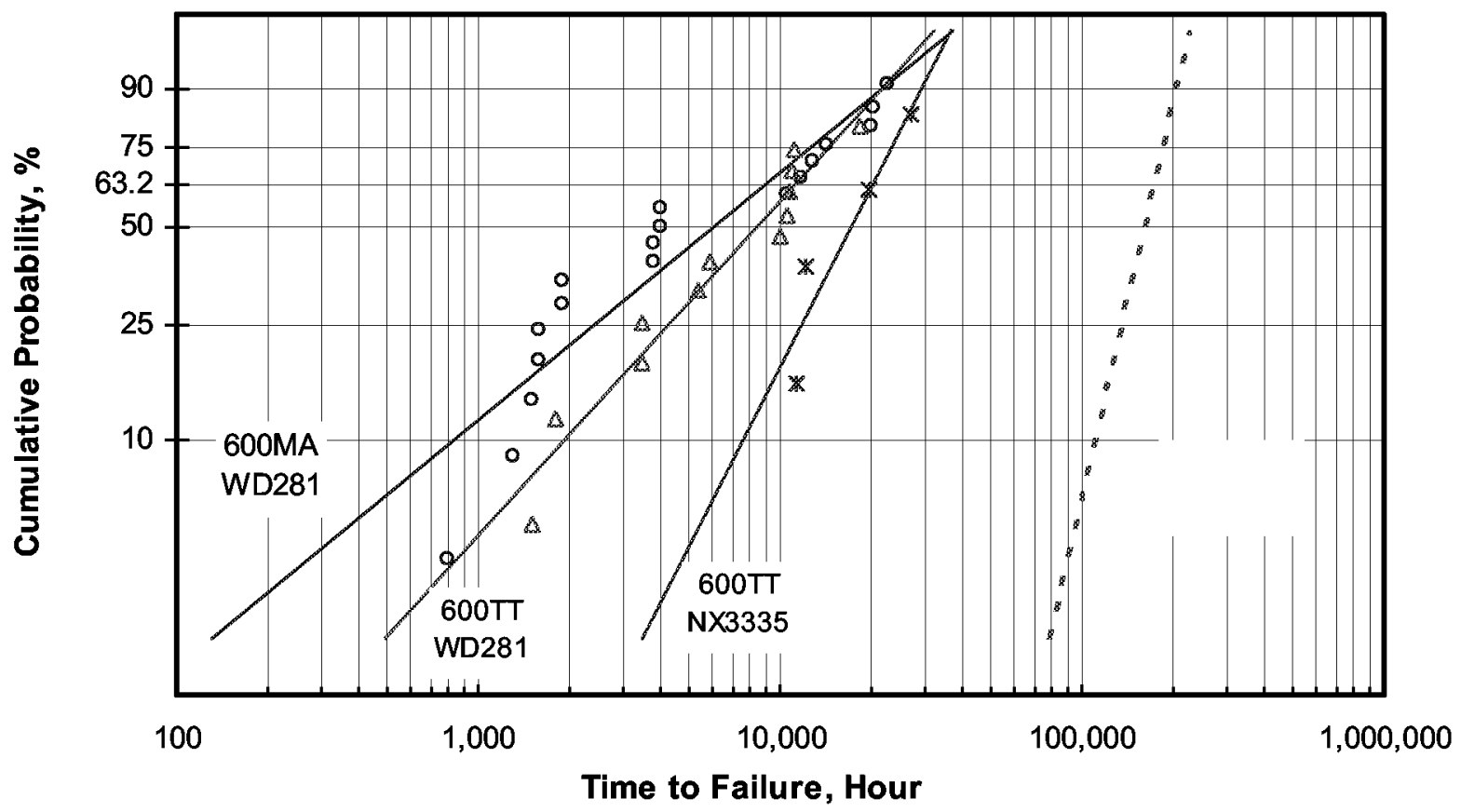

Figure 4-12 Weibull plot of SG mockups tested in deaerated water at $680^{\circ} \mathrm{F}$ by Framatome ANP, France. Alloy 690TT SG mockups experienced no failure after 100,000 hours of exposure. The Alloy 690 Weibayes line assumes $\beta=5.0$. 


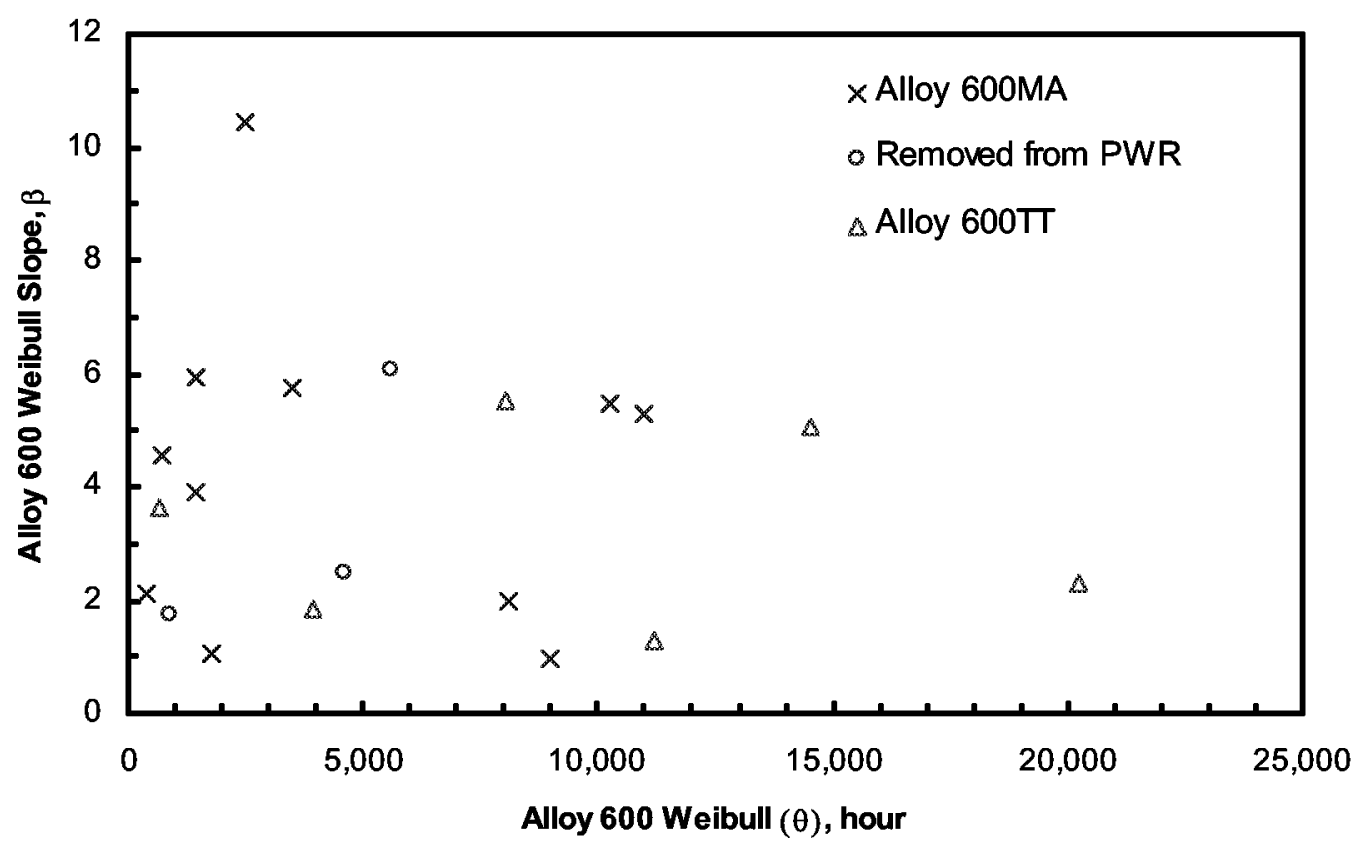

Figure 4-13 Weibull $\theta$ and $\beta$ for Alloy 600 listed in Table 4-2.

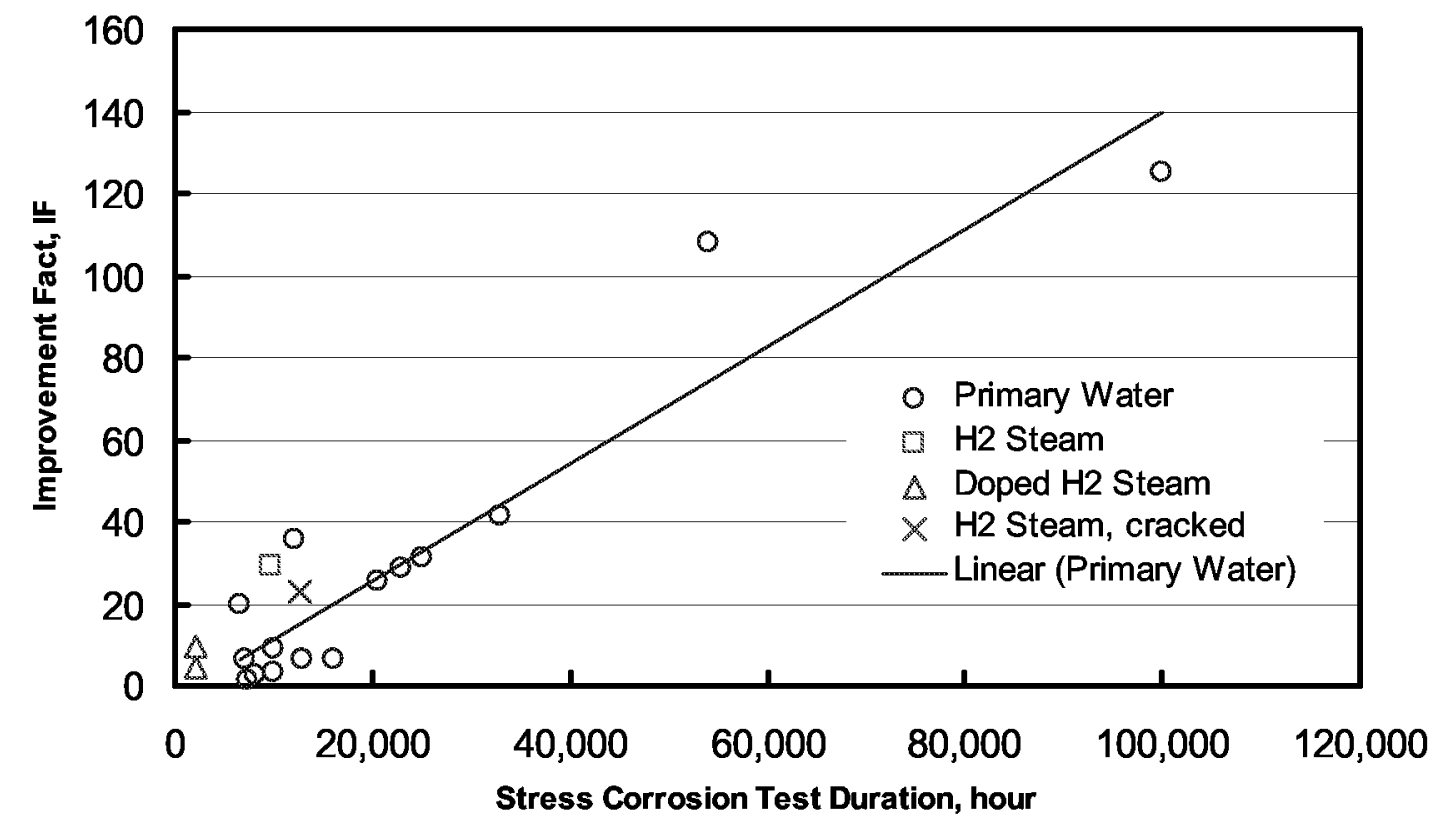

Figure 4-14 Improvement factors listed in Table 4-3 and Table 4-4 per Eq. 4-8. 

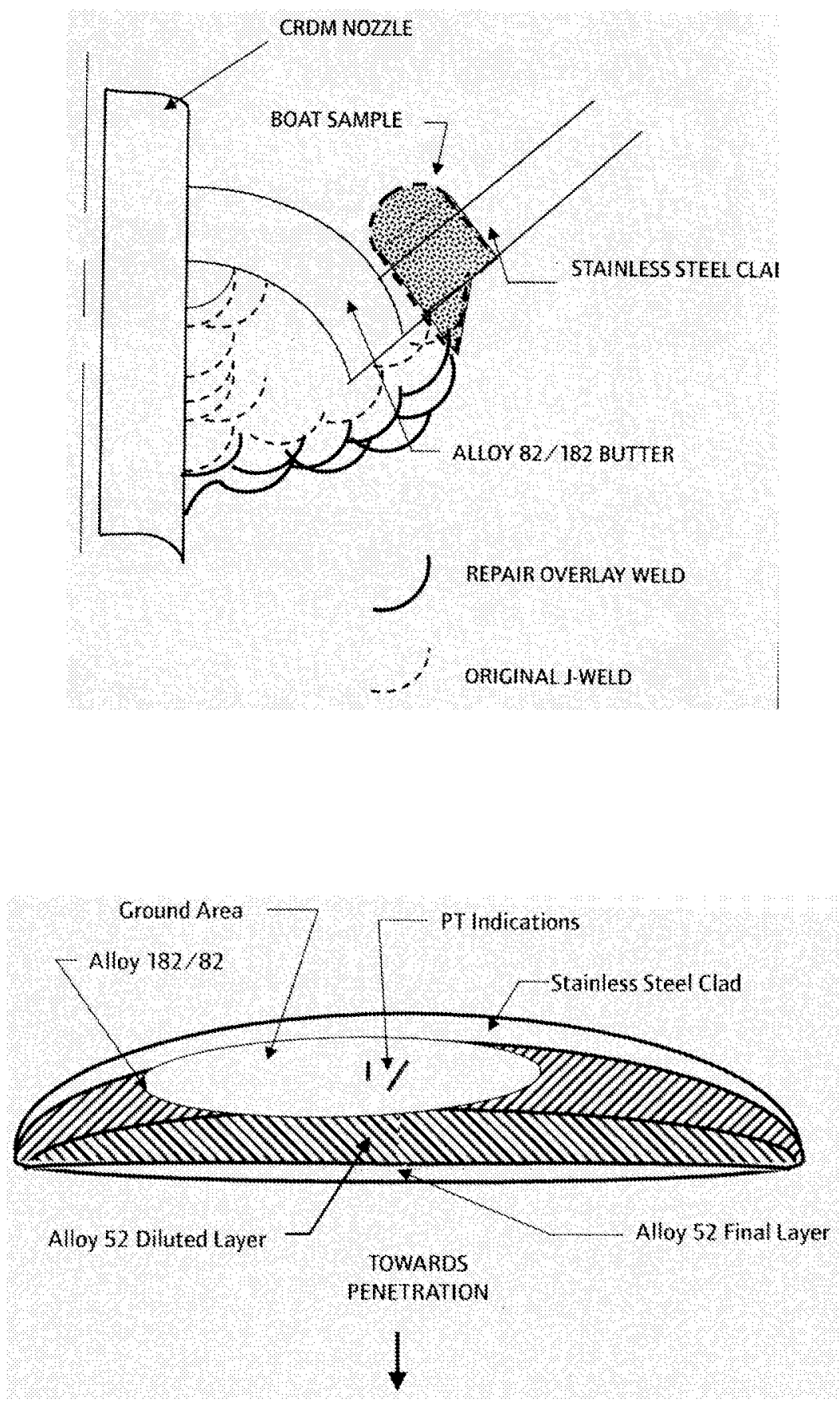

Figure 4-15 Boat Sample Removed from North Anna Unit 2, CRDM Nozzle \#51 in 2002. Above, a sketch of the boat removal location with respect to the Alloy 52 weld overlay repair made in 2001 . Below, a sketch of the wetted surface (plan view) with the weld materials determined by EDS analysis. ${ }^{[2]}$ 



\section{SUMMARY AND CONCLUSIONS}

Over the last thirty years, PWSCC has been observed in numerous Alloy 600 component items and associated welds. The occurrence of PWSCC has been responsible for significant downtime and replacement power costs. Notable examples of equipment failures in the U.S. include extended outages and emergency repairs or replacements at Calvert Cliffs, V.C. Summer, Oconee Nuclear Station, Davis-Besse, and North Anna. Repairs and replacements have generally utilized wrought Alloy 690 material and its compatible weld metals (Alloy 152 and Alloy 52), which have been shown to be very highly resistant to PWSCC in laboratory experiments and free from cracking in operating reactors over periods already up to nearly 15 years.

Since many cases of PWSCC in Alloy 600 have occurred after very long incubation periods, even if there have often been short term premature failures, it is nevertheless prudent for the PWR industry to question, test and quantify the longevity of wrought Alloy 690 material and its weld metals (Alloys 52 and 152) with respect to aging degradation by corrosion in primary water environments. Such an assessment has obvious implications for the anticipated service life of Alloy 690 replacement component items, e.g., RV closure head CRDM/CEDM nozzles, and the specification of appropriate inspection regimes. To this end, the present report evaluates available field and laboratory data on potential Alloy 690/152/52 corrosion degradation, particularly PWSCC, and provides a technical basis for development of future inspection requirements for thick-walled component items made of these alloys. Developing a coherent approach for the use and inspection of Alloy 690/152/52 materials should provide a significant benefit in the regulatory arena.

\subsection{Summary of Laboratory and Field Data}

Most laboratory testing has been performed with wrought Alloy 690 materials, with very few tests having been identified for Alloy 52 or Alloy 152 weld materials. Numerous investigations have been performed under a variety of environmental conditions relevant to the PWR primary circuit:

1. High temperature de-oxygenated (deaerated) and hydrogenated water

2. Simulated PWR primary water

3. Hydrogenated steam

4. Hydrogenated steam doped with chloride, fluoride, and sulfate anions

5. Additions of injurious impurities or of potentially mitigating substances such as zinc

The various test conditions cited in this report, including those for the previously unreported, long-term studies described in $A$ ppendices $A$ and $B$, cover temperatures up to $680^{\circ} \mathrm{F}\left(360^{\circ} \mathrm{C}\right)$ water, dissolved oxygen levels $<20 \mathrm{ppb}$, tests in doped and undoped $752^{\circ} \mathrm{F}\left(400^{\circ} \mathrm{C}\right)$ steam, 
lithium concentrations up to $3.5 \mathrm{ppm}$, boron concentrations up to $1800 \mathrm{ppm}$, hydrogen concentrations up to $100 \mathrm{cc} / \mathrm{kg} \mathrm{H}_{2} \mathrm{O}$, and additions of chlorides and zinc.

A number of tests have also been performed to determine the general corrosion rate and metal release rate for Alloy 690 material in primary water. All studies agree that the general corrosion rate and metal release rate of nickel-base alloys decrease with an increasing chromium concentration in the alloy. The general corrosion rate and metal release rate of Alloy 690 material has been shown to be 2 to 4 times lower than Alloy 600 material.

Accelerated stress corrosion testing has been performed on double U-bend (simulating crevice conditions), reverse U-bend (RUB), constant load test (CLT), four-point bend, and steam generator tubing mock-up specimens. The results of these accelerated stress corrosion tests have shown Alloy 690 and its weld metals to be extraordinarily resistant to cracking. In high temperature deaerated, hydrogenated water, no Alloy 690 material specimen at constant load or deformation has exhibited stress corrosion cracking at testing times up to 100,000 hours at a temperature of $680^{\circ} \mathrm{F}\left(360^{\circ} \mathrm{C}\right)$. In this timeframe, most Alloy $600 \mathrm{MA}$ and TT control specimens had developed cracking, often after relatively short periods. A test duration of 100,000 hours at $680^{\circ} \mathrm{F}$ is equivalent to approximately 230 years at $600^{\circ} \mathrm{F}$, assuming the same activation energy of $50 \mathrm{kcal} / \mathrm{mole}$ for PWSCC crack initiation in Alloy 690. This means that Alloy 690 material is not expected to develop PWSCC during any feasible operating lifetime of PWRs.

No cracking of Alloy 690 and its weld metals has been observed under most other test conditions pertinent to primary water, or even under some non-primary water conditions, e.g. oxygenated conditions (up to $16 \mathrm{ppm}$ ) and creviced conditions. This includes material with carbon contents ranging from $0.001 \%$ to $0.065 \%$, in the mill annealed or thermally treated condition, with and without surface cold work, including material that exhibited surface microcracks before testing.

Two approaches have been used to provide a quantitative estimate of the improvement for Alloy 690 relative to Alloy 600 materials. The first method estimates the relative improvement factor, $\mathrm{IF}_{\mathrm{R}}$, based on a Weibull/Weibayes analysis. Using this method, the average $\mathrm{IF}_{\mathrm{R}}$ of Alloy 690 material is 26.5 relative to Alloy 600MA material and 13.3 relative to Alloy 600TT material. Since not all the studies either obtained or reported sufficient test data to allow a Weibull type analysis, a second, simpler method was also used, based on the ratio of the total Alloy 690 material test time (without cracking being observed) over the time to the first Alloy 600 material failure. Using this approach, the average $\mathrm{IF}_{\mathrm{R}}$ of Alloy 690 relative to Alloy 600 is 27.1, i.e., about the same as the factor obtained for Alloy $600 \mathrm{MA}$ material by the first method. In addition, the $\mathrm{IF}_{\mathrm{R}}$ is clearly seen to be limited by the maximum test duration for the Alloy 690 specimens, rather than actual PWSCC failures in this material.

Hence, the relative improvement factor for Alloy 690 can be conservatively estimated to be at least 26 relative to Alloy 600MA and 13 relative to Alloy 600TT material, based on the accelerated testing performed to date in high temperature deaerated water. Furthermore, it is anticipated that these factors will increase in the future as Alloy 690 material test data to longer test durations become available and are confirmed by the future in-service inspection results.

Alloy 690 and its weld metals have been utilized in a number of PWR replacement component items, such as steam generator tubing, pressurizer heater sleeves, and RV closure head 
CRDM/CEDM nozzles. Alloy 690 steam generator tubing has been in service for approximately 14 calendar years (i.e., since 1989), pressurizer heater sleeves have been in service for over 12 calendar years (i.e., since 1990), and CRDM nozzles have been in service for over 10 calendar years (i.e., since 1992). Alloy 52 weld material initially was used for a pressurizer nozzle replacement application in 1992 and has been in service now for over 10 years. No stress corrosion degradation of the Alloy 690 materials has been observed in any replacement application to date.

Nevertheless, some tests have shown that cracking of Alloy 690 materials is possible, either under certain extreme testing conditions that are not found in PWRs, or with experimental, pre-production materials (often with atypical heat treatments and chemical compositions). For example, in a deaerated and hydrogenated high temperature water environment, intergranular cracking has been observed during CERT experiments at a strain rate on the order of $10^{-7} \mathrm{sec}^{-1}$ or less. CERT is a very severe laboratory technique for evaluating susceptibility to stress corrosion cracking. The specimens are loaded well past the yield point to produce continuous, slow plastic deformation and eventually fail by ductile overload. Such mechanical loading is not directly relevant to component operating conditions in nuclear power plants.

Two isolated studies have reported some minor amounts of apparent stress corrosion cracking on highly strained specimens under static loading in simulated PWR water or hydrogenated steam. (It is noted that minor cracking observed in CERT specimens is excluded based on the discussion in Section 4.1.2) In 1987, Nakayama et al. ${ }^{[40]}$ reported slight intergranular cracking in Alloy 690 single U-bends tested in hydrogen saturated water containing $1000 \mathrm{ppm}$ boron and $2 \mathrm{ppm}$ lithium at $330^{\circ} \mathrm{C}\left(626^{\circ} \mathrm{F}\right)$ for 3000 hours. However, this shallow intergranular cracking was atypical of PWSCC, and probably more consistent with microfissuring from mechanical straining. Hence, these results should not be considered a real indication of Alloy 690 PWSCC susceptibility.

In 1997, Sui et al. reported stress corrosion cracking of two Alloy 690 specimens after long exposure times $(13,824 \mathrm{~h})$ in hydrogenated steam at $380^{\circ} \mathrm{C}\left(716^{\circ} \mathrm{F}\right) .^{[52,53]}$ However, the cracked Alloy 690 Heat $\mathrm{B}$ had an intentionally unusual microstructure with very few intergranular carbides compared to an un-cracked Alloy 690 Heat A with normal intergranular carbide coverage. These results suggest that Alloy 690 could be made susceptible to SCC in a hydrogenated steam environment (and therefore potentially susceptible to PWSCC) with out-of-specification thermomechanical processing. Since such processing is prohibited by Alloy 690 material ordering specifications, and intergranular carbide precipitation must be verified by optical and/or SEM microscopy, cracking as seen by Sui et al. should not occur for Alloy 690 material as used in PWRs. The work nevertheless exposes a potential weakness if, for some reason, the material is recrystallized without taking the carbides back into solution (as could conceivably happen, e.g., in a weld heat affected zone). Although such effects require further investigation, it is noted that extrapolation of the above failure times observed in steam at $380^{\circ} \mathrm{C}$ to normal PWR operating temperatures, using the normal Arrhenius activation energy approach, would still predict comfortable margins against failure over foreseeable PWR plant lifetimes, even for Alloy 690 with non-standard carbide morphology.

Although it is not the purpose of this report to assess the secondary-side corrosion behavior of Alloy 690, Appendix $\mathrm{C}$ reviews the main points of the extensive work that has been carried out in connection with replacement SG tubing in relevant environments. In summary, even though it 
cannot be considered immune to IGA/SCC, Alloy 690TT material has nevertheless demonstrated far superior IGA/SCC resistance compared to Alloy 600MA or Alloy 600TT materials under most conditions pertinent to faulted secondary water. Lead-doped caustic water is an exception here. Furthermore, Alloy 690 appears to be just as resistant to IGSCC in all volatile treatment (AVT) water as it is to PWSCC in primary water.

\subsection{Gaps in the Test Data}

This literature review has also identified some apparent information gaps in the study of the corrosion behavior of Alloy 690 and its weld metals for PWR service:

1. Alloy 52 and 152 weld metals

Only one investigation each has been reported concerning PWSCC testing of Alloy 152 and Alloy 52M weld metals. In 2003, two Alloy 600 bottom mounted instrumentation (BMI) nozzles (\#1 and \#46) at South Texas Project (STP) Unit 1 were identified to have leaked primary water. Laboratory examinations of a boat sample removed from BMI nozzle \#1 revealed intergranular cracking consistent with PWSCC in the Alloy 600 nozzle portion of the boat sample. According to Ref 73, STP attributed the cracking to be most likely initiated by lack-of-fusion defects or other types of fabrication defects in the Alloy $182 \mathrm{~J}$-groove weld. Although Alloy 690/152/52 was not involved in the cracked BMI nozzles at STP Unit 1, the STP BMI incident has heightened industry awareness to the possibility of PWSCC initiation due to Alloy 152/52 weld defects, and the potential to propagate flaws in the Alloy 152/52 weld metal and into the Alloy 690 base metal. As mentioned in Section 2.1 of the present report, modified versions of Alloy 152/52 with improved weldability are currently being developed. Clearly, additional studies need to be performed on these materials, in particular using the latest composition of Alloy 152/52 weld metal. In addition, the Alloy 152/52 weld studies need to examine weld metal dilution, mainly the lowering of chromium content near the weld interface with carbon steel and stainless steel base metal, and its impact on PWSCC resistance.

2. Effects of product form (plate, tube, rolled bar, forged bar, and extruded bar)

Nearly all testing has been performed with specimens obtained from steam generator tubing. Only one investigation has been performed with an Alloy 690 plate, one with a laboratory heat cast and rolled into bar, and one with a forged Alloy 690 material. Further consideration of product form is desirable, especially in conjunction with the following item 3 .

3. Subtle changes in chemical composition and thermo-mechanical processing effects on surface finish.

The studies by Angeliu and Vaillant identify the need for further investigation into the possible effect of subtle changes in the chemical composition of Alloy 690 material (e.g., low $\mathrm{Fe}$ and high $\mathrm{C}$ and $\mathrm{Al}$ ). Processing effects which could lead to intergranular micro-fissuring at Alloy 690 surfaces also need to be better understood and avoided, although the existing data do not suggest that this would result in susceptibility to PWSCC. 
4. Crack growth rates of base metal, HAZ, and weld metals

Given the welcome difficulties in initiating cracking of Alloy 690 and its weld metals, no plausible estimates of crack growth rates are available at this time. Consideration of advanced testing techniques may be required to permit quantification of realistic factors of improvement in crack growth rate for these highly PWSCC resistant materials. This consideration would be pertinent, e.g., to repaired Alloy 600 component items where cracks may initiate in residual Alloy 600 or 182 material and grow towards Alloy 690 or its compatible weld metals. Some recent test results also indicate that the crack growth rate in HAZs of Alloy 600 TT material may be up to 30 times faster than in the thermally treated base material. ${ }^{[7]}$ Further studies should be conducted to evaluate the effect, if any, of such modified microstructures on Alloy 690 TT materials.

\section{Pitting and crevice corrosion}

Some testing of Alloy 690 has been performed with double U-bend specimens to simulate crevice conditions and minimal testing has also been performed to evaluate pitting. Both of these forms of corrosion need to be further investigated with regard to faulted secondary-side environments, but are not an issue in PWR primary water.

\section{Corrosion fatigue}

Only one study appears to have been performed on Alloy 690 and its weld metals concerning the combined effects of exposure to primary water and fatigue. The results suggest that models developed for Alloy 600 may also be applicable here, but additional work would be appropriate.

\section{LTCP (low temperature crack propagation)}

Although it is not the subject of this report, a brief synopsis of the available information has been provided. Additional efforts may be needed to confirm its lack of relevance for Alloys $690 / 152 / 52$ in PWR primary water, even though the available operating experience does not suggest that a practical problem exists.

\subsection{Conclusions}

1. Some 300 U-bend, Double U-bend, and constant load specimens from about 40 heats of Alloy 690 have been tested typically in primary water, deaerated water, or hydrogenated steam. The carbon content ranged from $0.001 \%$ to $0.065 \%$ and the heat treatment included MA, TT, and thermally aged conditions. The vast majority of the Alloy 690 specimens in both MA and TT conditions did not develop cracking after exposure times as long as 100,000 hours. In the same studies, most of the Alloy 600 specimens in both 
MA and TT conditions developed PWSCC, often after relatively brief periods. These laboratory test results demonstrate that Alloy 690 is very highly resistant to PWSCC.

2. Cracking of Alloy 690 was observed only in two of the above studies. In one case, two Alloy 690 RUB specimens from a single Alloy 690 heat, which was deliberately solution annealed at unusually low temperature to prevent grain boundary carbide precipitation, developed intergranular cracking after at least 12,600 hours in hydrogenated steam at $380^{\circ} \mathrm{C}\left(716^{\circ} \mathrm{F}\right)$. Such cracking should not occur for properly heat treated Alloy 690 in PWRs. Furthermore, extrapolation to normal PWR operating temperatures would predict comfortable margins against failure within foreseeable PWR plant lifetimes, even for Alloy 690 with non-standard carbide morphology. In the second study, very shallow intergranular cracks were observed in Alloy 690 single U-bend specimens exposed to hydrogen-saturated water containing $1000 \mathrm{ppm}$ boron and $2 \mathrm{ppm}$ lithium at $330^{\circ} \mathrm{C}$ $\left(626^{\circ} \mathrm{F}\right)$ for 3000 hours. However, this cracking was atypical of PWSCC, and probably more consistent with microfissuring from mechanical straining, as reported in several other Alloy 690 studies. Hence, this result should not be considered a real indication of Alloy 690 PWSCC susceptibility.

3. Based on the duration of the laboratory test, two methods have been used to provide a quantitative estimate of $\mathrm{IF}_{\mathrm{R}}$, the improvement factor for Alloy 690 relative to Alloy 600 . The first method, based on a Weibull analysis, provides an average $\mathrm{IF}_{\mathrm{R}}$ of 26.5 relative to Alloy 600MA material and 13.3 relative to Alloy 600TT material. The second method, based on the ratio of the Alloy 690 material test time over the time to the first Alloy 600 material failure, provides an average $\mathrm{IF}_{\mathrm{R}}$ of 27.1. The $\mathrm{IF}_{\mathrm{R}}$ is seen to increase with increasing test time, indicating that the $\mathrm{IF}_{\mathrm{R}}$ is limited by the test duration. Hence, the average $\mathrm{IF}_{\mathrm{R}}$ values listed are very conservative estimates (or underestimates) of the actual improvement of Alloy 690 relative to Alloy 600.

4. In a hydrogenated high temperature water environment, minor intergranular cracking has been observed during CERT experiments at a strain rate on the order of $10^{-7} \mathrm{sec}^{-1}$ or less, particularly for experimental heats of Alloy 690 . However, CERT is a very severe laboratory technique for evaluating susceptibility to SCC, involving mechanical loading that is not directly relevant to component operating conditions in nuclear power plants.

5. These laboratory test results have been confirmed by the excellent field experience with Alloy 690 for up to fourteen years, and with Alloys 52 and 152 for up to twelve years. Worldwide, numerous PWR units now operate with steam generators having Alloy 690 tubing and many other component items containing Alloys 690 and its weld metals, most notably replacement penetration nozzles in pressurizers and RPV heads, have been in operation since the early 1990s. To date, there have been no indications of PWSCC in any of the Alloy 690 component items in service.

6. Many corrosion studies of Alloy 690 conducted in environments pertinent to (faulted) PWR secondary water have also been reviewed in order to provide a comprehensive comparison with Alloy 600 . Even though it cannot be considered immune to IGA/SCC, Alloy 690TT material has nevertheless demonstrated far superior IGA/SCC resistance 
compared to Alloy 600MA or Alloy 600TT materials under most conditions and appears to be just as resistant to IGSCC in AVT water as it is to PWSCC in primary water.

In summary, it is concluded that wrought Alloy 690 and its weld metals (Alloys 52 and 152) are acceptable and highly corrosion-resistant replacement materials for Alloy 600 and its weld metals in PWRs, although limited, further testing is needed to examine some specific knowledge gaps that have been identified. Wherever possible, the existing laboratory test data have been evaluated to estimate the improvement factor of Alloy 690 relative to Alloy 600 . Average improvement factors of at least 26 relative to Alloy 600MA material and 13 relative to Alloy $600 \mathrm{TT}$ material can be derived, but these numbers are clearly conservative, due to an absence of PWSCC in most Alloy 690 specimens within the test duration.

In addition, Alloy 690 service experience in PWRs has been reviewed to augment the laboratory findings. Based on both laboratory and field data, it is concluded that Alloy 690 and its weld metals Alloys 52 and 152 are very unlikely to develop PWSCC during extended PWR plant lifetimes $\left(60^{+}\right.$years). Hence, the PWSCC inspection regimes developed in recent years for thickwalled component items made of Alloys 600,182 , and 82 would be unnecessarily stringent if applied in exactly the same way to comparable component item locations involving Alloy 690 and its weld metals. A separate inspection program, commensurate with the magnitude of improvement in PWSCC resistance already demonstrated, should be developed. It is anticipated that this could be further refined as additional laboratory results and field inspection data become available. 



\section{A effects of surface defects onthe PWSCC BEHAVIOR OF 690TT AND 600MA - A FRAMATOME ANP (GERMANY) REPORT}

\section{A.1 Introduction}

Alloy 600 and its weld metals 182 and 82 are considered to be immune to chloride-induced stress corrosion cracking (SCC) and were chosen as an alternative material for key component items such as steam generator (SG) tubes by most nuclear power plant suppliers in the sixties. However, as observed by Coriou ${ }^{[75,76,77]}$ and co-workers the nickel base Alloy 600 is not immune to high temperature pure water cracking (see Figure A-1). According to Shah ${ }^{[78]}$ primary water stress corrosion cracking (PWSCC) is a thermally activated, intergranular cracking mechanism that generally follows the principles of "regular" SCC, since it only occurs if the following three conditions are simultaneously fulfilled and maintained: susceptible material condition, corrosive environment and the presence of tensile stresses (see Figure A-2).

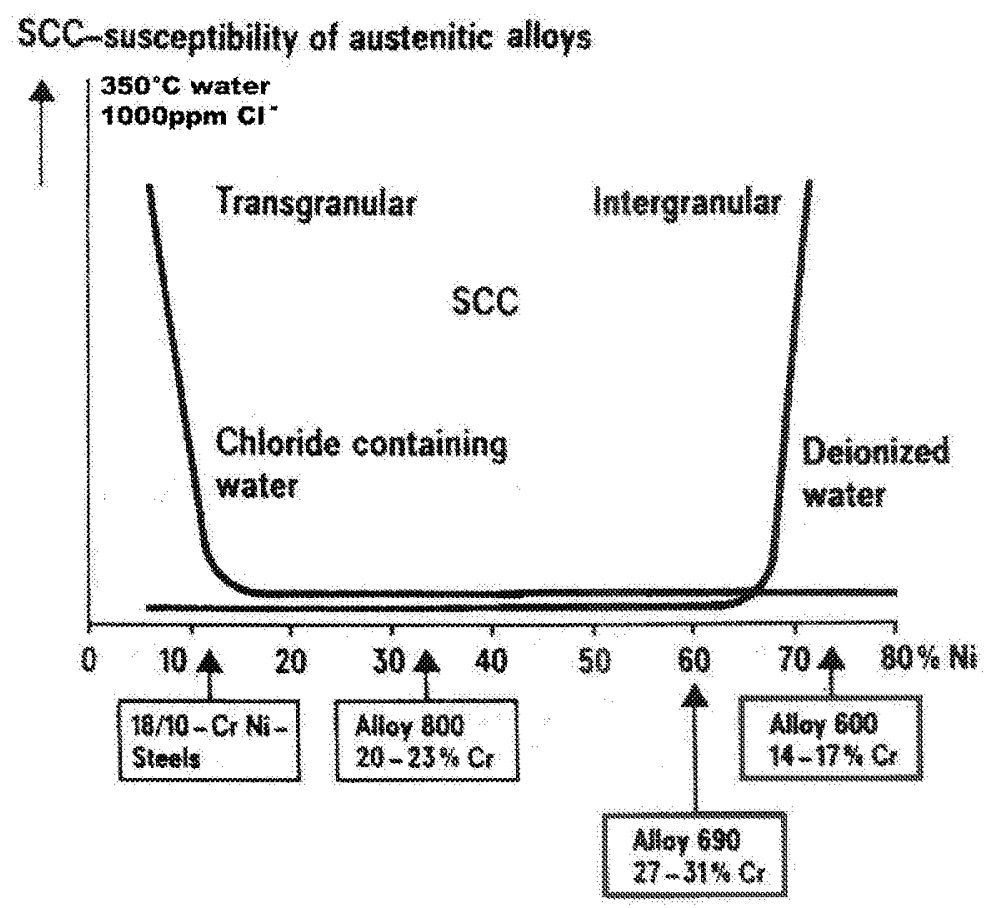

Figure A-1 Schematic diagram showing the influence of nickel content on the cracking behavior of different alloys when stressed slightly above yield strength in $350^{\circ} \mathrm{C}$ water (demineralized or 1000 ppm Cl- ); according to Coriou [75] 


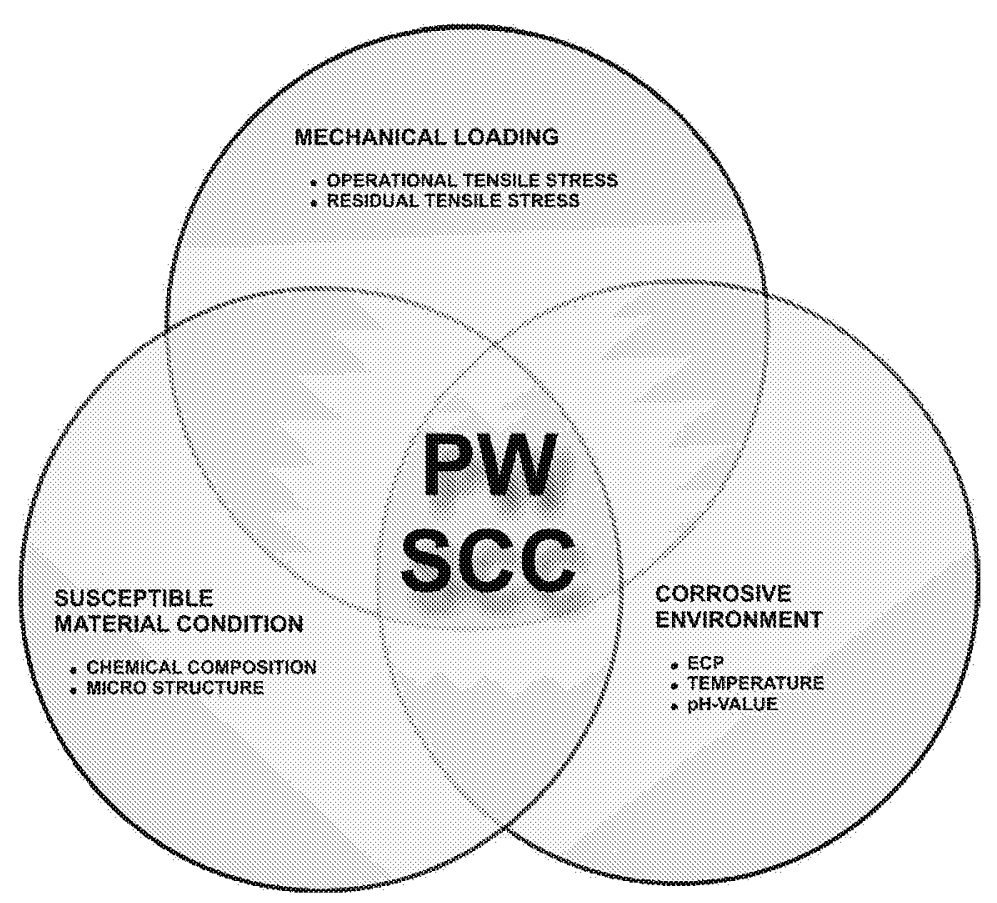

Figure A-2 Schematic The PWSCC system and the necessary conditions for cracking to occur.

According to [79] this type of environmentally-assisted cracking was experienced in the field preferentially in SG tubes manufactured from Alloy 600 being in a low temperature mill annealed condition (LTMA). This condition is characterized by high yield strength and discontinuous intergranular and intragranular carbide precipitation. High temperature mill annealed (HTMA) or thermal treated (TT) Alloy 600 exhibits an increased resistance to PWSCC. The most decisive factors affecting PWSCC of Alloy 600 SG tubes were found to be: ${ }^{[79]}$

- Material properties (annealing temperature, mechanical properties, grain size, microstructure)

- Residual tensile stresses originating from cold work

- Coolant temperature

- Water chemistry (hydrogen content and possible lithium concentration, pH-value)

Despite extensive research carried out since the sixties, the primary reason leading to PWSCC is not fully understood. However, in the recent past several theoretical models describing PWSCC of Alloy 600 have been developed and proposed. The explicit discussion of these models would exceed the scope of this investigation. However, for completeness some of the theoretical approaches are listed below. Therefore, PWSCC may be caused by one or more of the following:

- a hydrogen induced cracking mechanism ${ }^{[80,81]}$ 
- an anodic dissolution at crack tips ${ }^{[82]}$

- a thermally activated dislocation creep mechanism ${ }^{[83]}$

- an internal oxidation model ${ }^{[84]}$

The widespread occurrence of PWSCC in PWR component items manufactured from Alloy 600 and recently also in Alloy 182/82 has led to its replacement with Alloy 690 and its corresponding weld metals $152 / 52$.

However, safety authorities are reluctant to relax stringent inspection regimes that are based on Alloy 600 degradation of key component items such as RPV Head Penetrations. There is strong economic incentive to quantify the margin of improvement resulting from the application of Alloy 690/152/52 versus Alloy 600/182/82. In addition to the technical basis document summarizing the current state of knowledge and operating experience with Alloy 690 this report describes one particular testing technique allowing a quantification of the improved PWSCC resistance of Alloy 690 in comparison to Alloy 600.

\section{A.2 Objective}

The primary objective of this experiment was to evaluate the corrosion behavior of mechanically marked/scored Alloy 600MA and Alloy 690TT SG tubing under primary water conditions. Also the quantification of the margin of improvement provided by Alloy 690TT was part of this investigation.

The experiments were performed in the context of actual indications found during manufacture of replacement SGs. Inspection with eddy current techniques showed indications in some of the SG tubing material at the roll-in zone in the tubesheet. The indications, in the form of internal surface defects, most likely originated from a malfunctioning roller/roller cage during manufacturing when SG tubes are rolled into the tubesheet and/or a special tool for pulling the polymer device used for plugging tubes.

The defects appeared as longitudinal and circumferential scratches/scores with a maximum depth of $80 \%$ of the nominal tube's wall thickness. Applicable procedures required the tube to be plugged if scores were identified at a depth greater than $40 \%$ of the nominal wall thickness. Thus, this particular experiment was focused on the corrosion behavior of tubes with surface marks between $20 \%$ and $40 \%$ of the nominal wall thickness and whether such tubes could go into service with a satisfactory performance under primary water conditions. The experiments included the following tasks:

- Comparative hot steam testing using Reverse U-bend Specimens (RUB);

- Metallography at selected locations removed from one RUB specimen of each material;

- Vickers microhardness measurements

- Photographic documentation 


\section{A.3 Experimental Procedure}

\section{A.3.1 Test Materials}

\section{A.3.1.1 Alloy 600MA - Mill Annealed}

A custom mill anneal by Sandvik at a relatively low temperature ranging from $850^{\circ} \mathrm{C}$ to $900^{\circ} \mathrm{C}$ resulted in a more susceptible material condition. This approach was chosen in order to utilize this particular heat as a susceptible reference material for numerous exposure tests.

\section{A.3.1.2 Alloy 690TT - Thermally Treated}

This material condition comprised mill annealing at a nominal temperature of $1080^{\circ} \mathrm{C}$ and a subsequent thermal treatment at $715^{\circ} \mathrm{C}$. This was performed in order to achieve the desired, more corrosion resistant microstructure with a semi-continuous network of grain-boundary carbide precipitates.

Table $\Lambda-1$ and Table $\Lambda-2$ below summarize the chemical composition and mechanical properties of the corresponding materials.

Table A-1 Chemical composition of Alloy 600MA and Alloy 690TT

\begin{tabular}{|c|c|c|c|c|c|c|c|c|c|c|c|c|c|c|}
\hline \multicolumn{15}{|c|}{ CHEMICAL COMPOSITION (wt.\%) } \\
\hline Element & C & Si & Mn & $\mathbf{P}$ & $\mathbf{s}$ & $\mathrm{Cr}$ & $\mathbf{N i}$ & Mo & $\mathbf{T i}$ & $\mathrm{Cu}$ & Co & Al & $\mathbf{N}$ & Fe \\
\hline $\begin{array}{l}\text { Aloy } 690 T T \\
\text { heat } 754380\end{array}$ & 0.019 & 0.35 & 0.32 & 0.008 & 0.001 & 29.95 & 59.40 & 0.01 & 0.30 & 0.010 & 0.012 & 0.025 & 0.025 & 9.45 \\
\hline $\begin{array}{l}\text { Alloy 600MA } \\
\text { heat } 752677\end{array}$ & 0.027 & 0.29 & 0.80 & 0.008 & 0.003 & 16.55 & 72.7 & N/A & 0.29 & 0.010 & 0.011 & 0.14 & N/A & 9.19 \\
\hline
\end{tabular}

Table A-2 Mechanical properties and SG tube dimensions of Alloy 600MA and Alloy 690TT

\begin{tabular}{|c|c|c|c|c|c|}
\hline \multicolumn{6}{|c|}{ MECHANICAL PROPERTIESIDIMENSIONS } \\
\hline & $0.2 \%$ Yield Strength & Tensile Strength & Elongation (2") & outer diameter & wall thickness \\
\hline $\begin{array}{l}\text { Alloy } 690 T T \\
\text { heat } 754380\end{array}$ & $\begin{array}{c}349 \mathrm{MPa} \\
(51 \mathrm{ksi})\end{array}$ & $\begin{array}{l}746 \mathrm{MPa} \\
(108 \mathrm{ksi})\end{array}$ & $44 \%$ & $\begin{array}{c}19.05 \mathrm{~mm} \\
(0.75 ")\end{array}$ & $\begin{array}{l}1.09 \mathrm{~mm} \\
\left(0.043^{\prime \prime}\right)\end{array}$ \\
\hline $\begin{array}{l}\text { Alloy } 600 \mathrm{MA} \\
\text { heat } 752677\end{array}$ & $\begin{array}{c}399 \mathrm{MPa} \\
(58 \mathrm{ksi})\end{array}$ & $\begin{array}{l}715 \mathrm{MPa} \\
(104 \mathrm{ksi})\end{array}$ & $42 \%$ & $\begin{array}{c}22.23 \mathrm{~mm} \\
\left(0.875^{\prime \prime}\right)\end{array}$ & $\begin{array}{c}1.27 \mathrm{~mm} \\
\left(0.05^{\prime \prime}\right)\end{array}$ \\
\hline
\end{tabular}

Note: The above data shown in Table A-1 and Table A-2 originates from Sandvik mill certificates L93013 and L87001 for Alloy 690TT and Alloy 600MA, respectively. 


\section{A.3.2 Hot Steam Testing}

Hot steam testing represents an accelerated laboratory test ${ }^{[85]}$ utilized for drastically reducing crack incubation times of nickel-base alloys such as Alloy 600MA. Incubation times of typically several years observed in the field are reduced down to several days. The high cracking susceptibility during this particular test is primarily attributed to:

- Specimen exposure to a temperature of $400^{\circ} \mathrm{C}\left(752^{\circ} \mathrm{F}\right)$

- Specimen exposure to suitable steam conditions with hydrogen partial pressure of 1.1 bar (16 psi) and total pressure of $200 \mathrm{bar}(2900 \mathrm{psi})$

- Utilization of highly cold worked RUB specimens (with and without surface marks)

\section{A.3.3 Test Specimens}

For this comparative hot steam test of SG materials, split tube RUBs were used. RUBs are prepared from longitudinally split SG tube sections that are bent around a mandrel in a manner exposing the internal tube surface outward. For ensuring a representative and reproducible stress condition, a special bending procedure was established using a custom-built bending device as shown in Figure A-3. To maintain a defined stress state during testing, the RUB legs are held in place by socket head cap screws of the same material that are bolted to a machined metal bar. A typical example of one RUB specimen and an overview of all tested samples is shown in Figure A-4and Figure A-5.

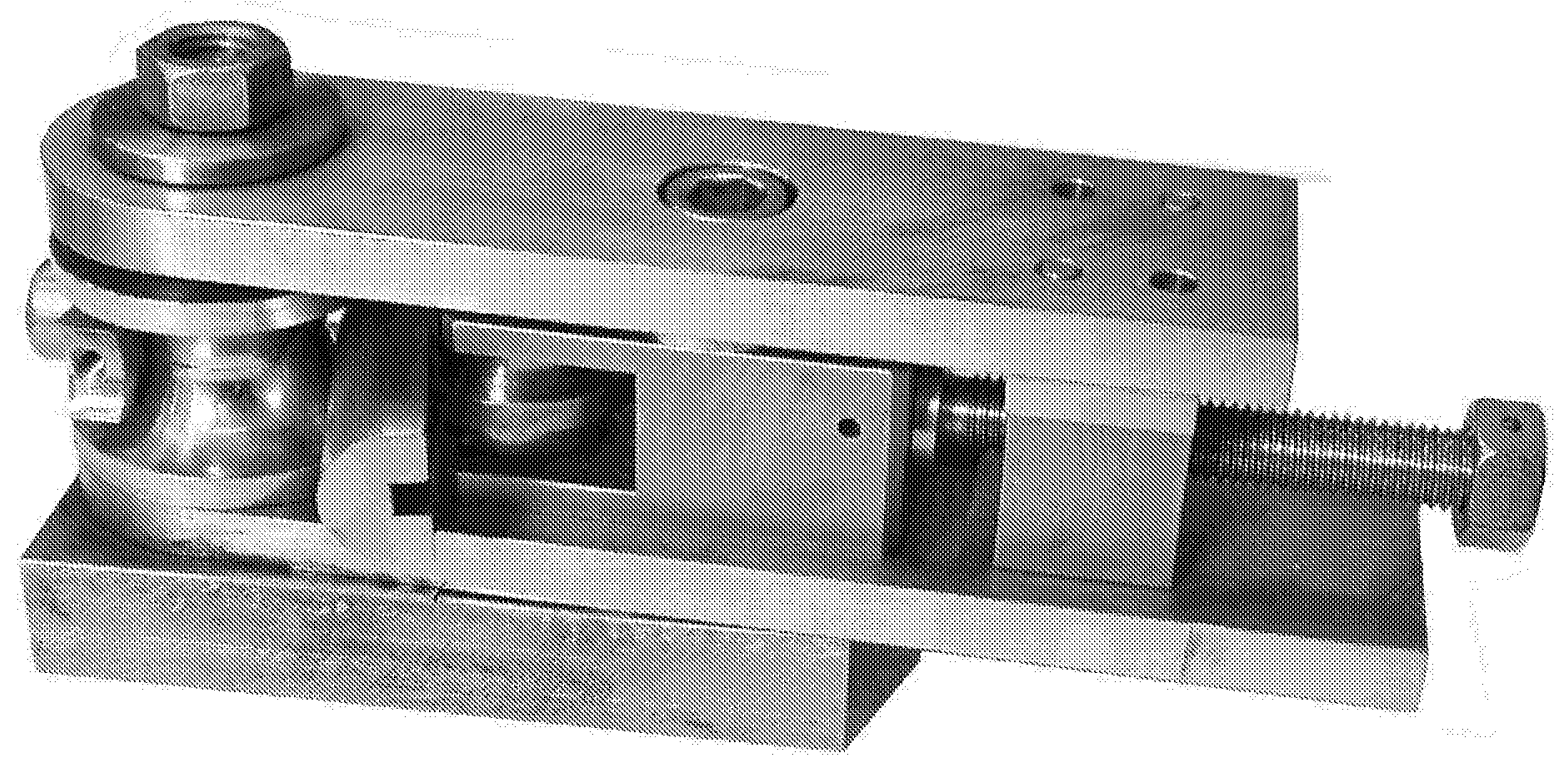

Figure A-3 Bending device used for RUB manufacturing 


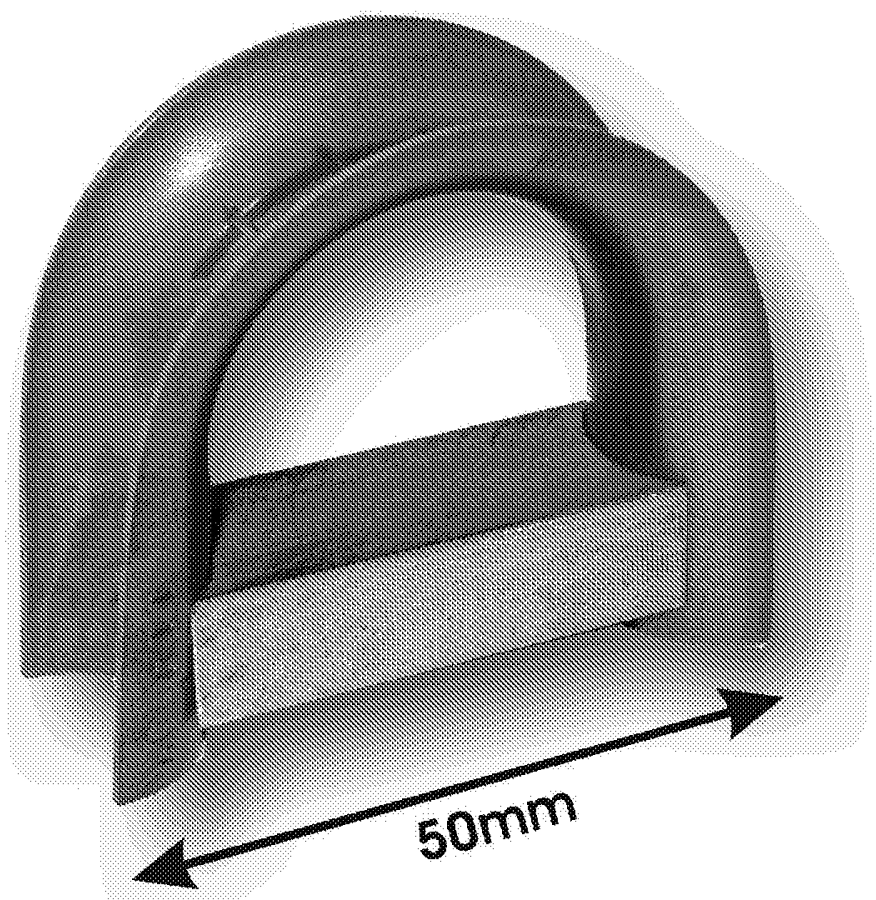

Figure A-4 Typical RUB specimen manufactured by bending a split SG tube.

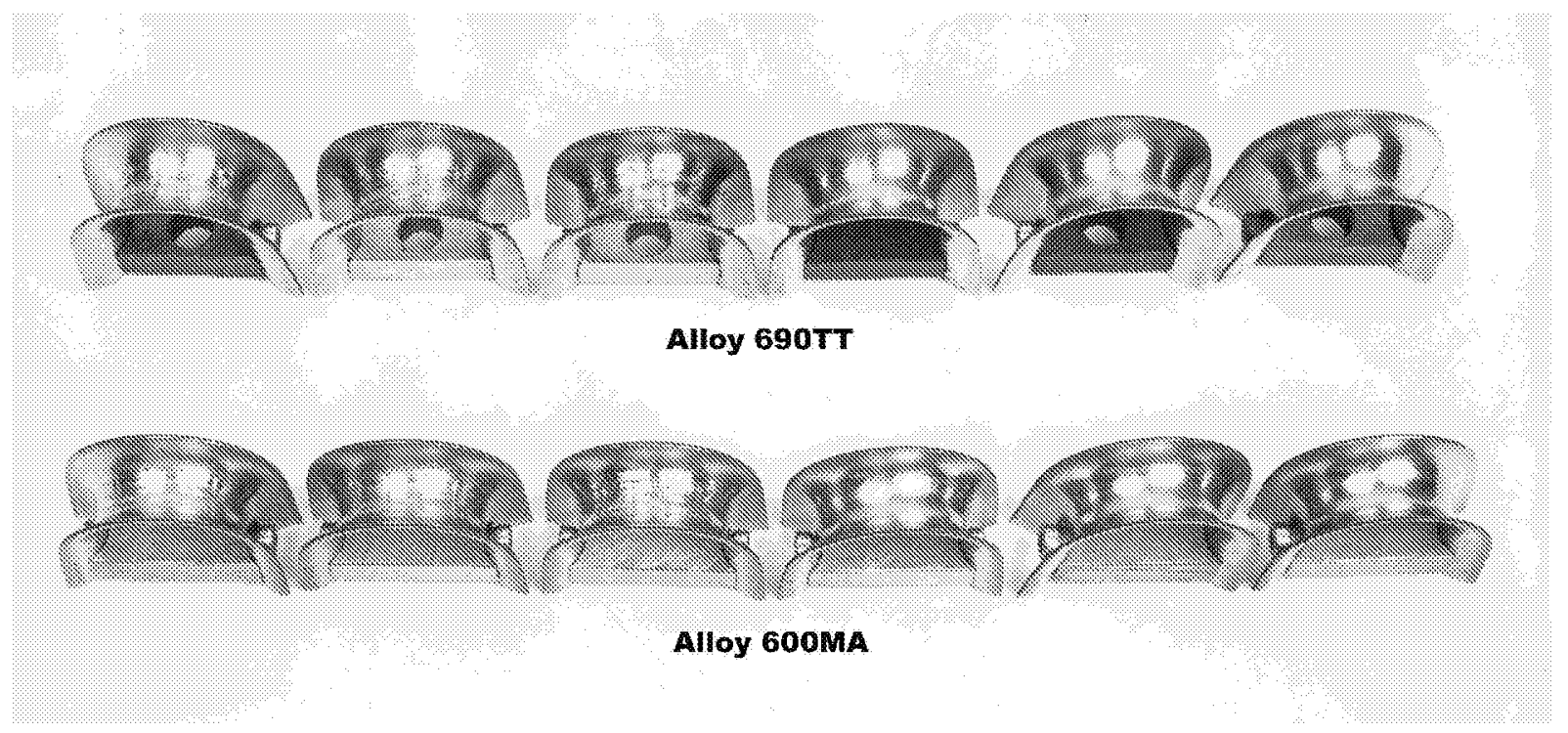

Figure A-5 View of total number of test specimens

To simulate a malfunctioning rolling tool, $50 \%$ of the RUBs (three specimens per material) were deliberately scored with actual tools used during manufacturing. These surface marks were introduced into the internal surfaces of split tube sections prior to bending. The scores were shaped in the form of longitudinal and circumferential grooves with a width of approximately $1 \mathrm{~mm}(0.04$ ") and a depth ranging from $20 \%$ to a maximum of $40 \%$ of the tube's wall thickness as shown in Figure A-6. The scoring process and the actual depth of grooves were controlled with surface profilometry. However, due to the hardware set-up of 
the surface profilometer, only readings of circumferential grooves were performed. A typical example of a profilometry printout obtained from a 690TT RUB specimen is displayed in Figure $\Lambda-7$.

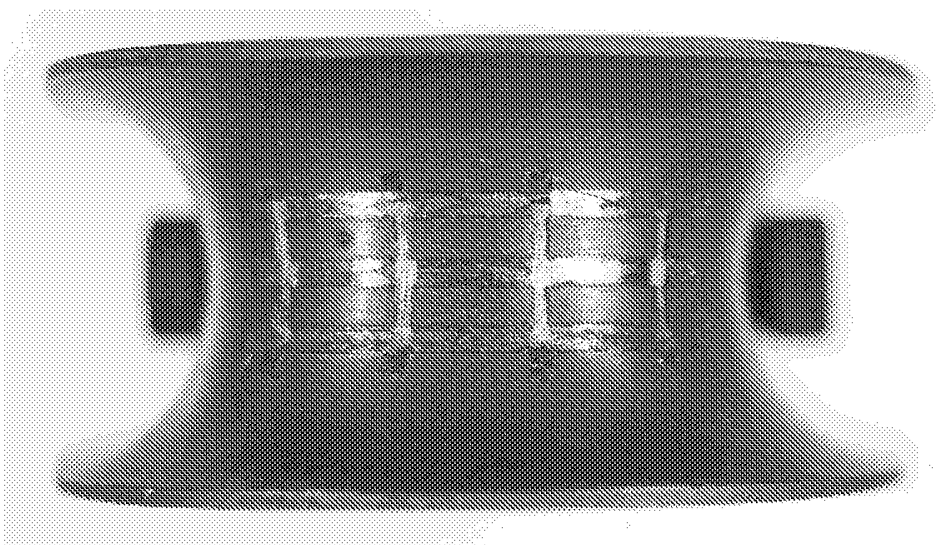

Figure A-6 Top view of scored RUB specimen showing the nature and orientation of grooves

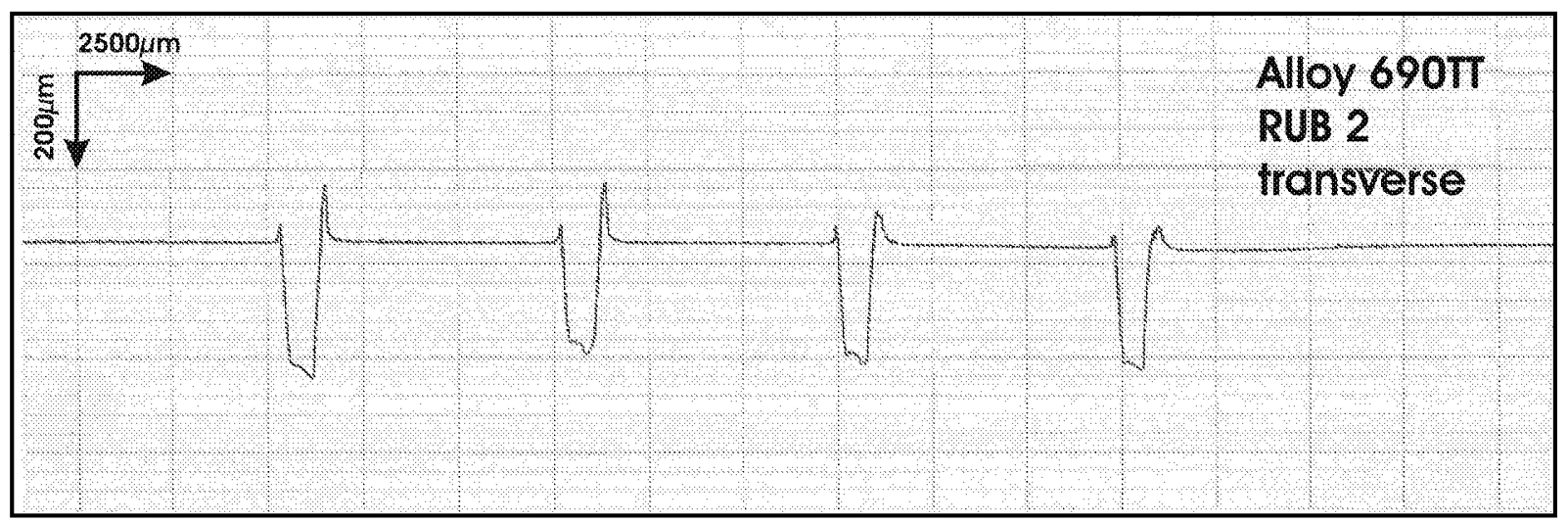

Figure A-7 Typical printout obtained during surface profilometry. The groove depth of this particular sample is approximately $280 \mu \mathrm{m}$, which corresponds to $26 \%$ of the nominal wall thickness.

\section{A.4 Results}

\section{A.4.1 Visual Inspection of RUB Specimens}

The total duration of this hot steam test was 405 days with inspection intervals after 14,30 and 60 days. The inspections were performed visually using a stereomicroscope at magnifications ranging from $25 \mathrm{X}$ to $40 \mathrm{X}$. It should be noted that the level of detection for crack indications using a stereomicroscope at the above mentioned magnifications is approximately $150 \mu \mathrm{m}\left(0.006^{\prime \prime}\right)$.

The first inspection after 14 days revealed that all scored and non-scored Alloy 600MA RUBs had developed cracking. The cracking exhibited a multi-directional nature and occurred predominantly in an area associated with the apex of the RUB specimens. A typical example of crack indications 
in a scored and non-scored RUB specimen is displayed in Figure A-8 and Figure A-9. After cracking was observed in Alloy 600MA RUBs, the specimens were removed and testing was resumed with Alloy 690TT specimens only.

All of the Alloy 690TT RUB specimens did not reveal any crack indications, even after a total exposure time of 405 days. Table A-3 below summarizes the results obtained during the hot steam test for both materials in the scored and non-scored condition, respectively:

Table A-3 Results of hot steam test with RUB specimens

\begin{tabular}{|l|c|c|c|c|c|c|}
\hline \multicolumn{2}{|c|}{ PWSCC Behavior of Alloy 600MA and Alloy 690Tा } \\
\hline \multirow{2}{*}{ Material } & $\begin{array}{c}\text { scored } \\
\text { surface }\end{array}$ & $\begin{array}{c}\text { total No. of } \\
\text { specimens }\end{array}$ & $\begin{array}{c}\text { cracked } \\
\text { RUBs after 14 } \\
\text { days }\end{array}$ & $\begin{array}{c}\text { cracked } \\
\text { RUBs after 30 } \\
\text { days }\end{array}$ & $\begin{array}{c}\text { cracked } \\
\text { RUBs after } 60 \\
\text { days }\end{array}$ & $\begin{array}{c}\text { cracked } \\
\text { RUBs after } \\
\mathbf{4 0 5} \text { days }\end{array}$ \\
\hline \multirow{2}{*}{$690 \mathrm{TT}$} & yes & 3 & $0 / 3$ & $0 / 3$ & $0 / 3$ & $0 / 3$ \\
\cline { 2 - 7 } & no & 3 & $0 / 3$ & $0 / 3$ & $0 / 3$ & $0 / 3$ \\
\hline \multirow{2}{*}{$600 \mathrm{MA}$} & yes & 3 & $3 / 3$ & - & - & - \\
\cline { 2 - 7 } & no & 3 & $3 / 3$ & - & - & - \\
\hline
\end{tabular}

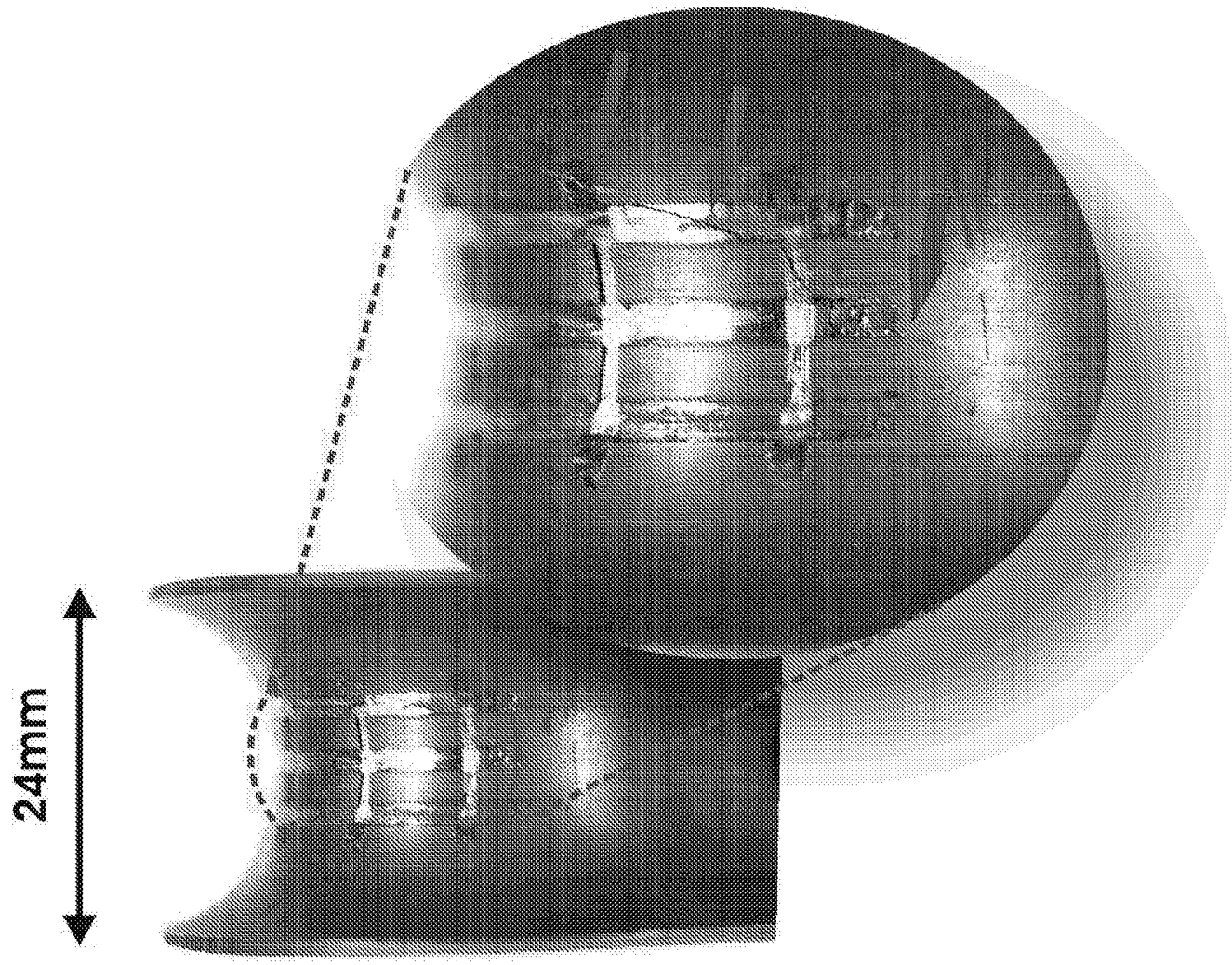

Figure A-8 Typical appearance of cracking observed in the scored Alloy 600MA specimens as indicated by the red arrows 


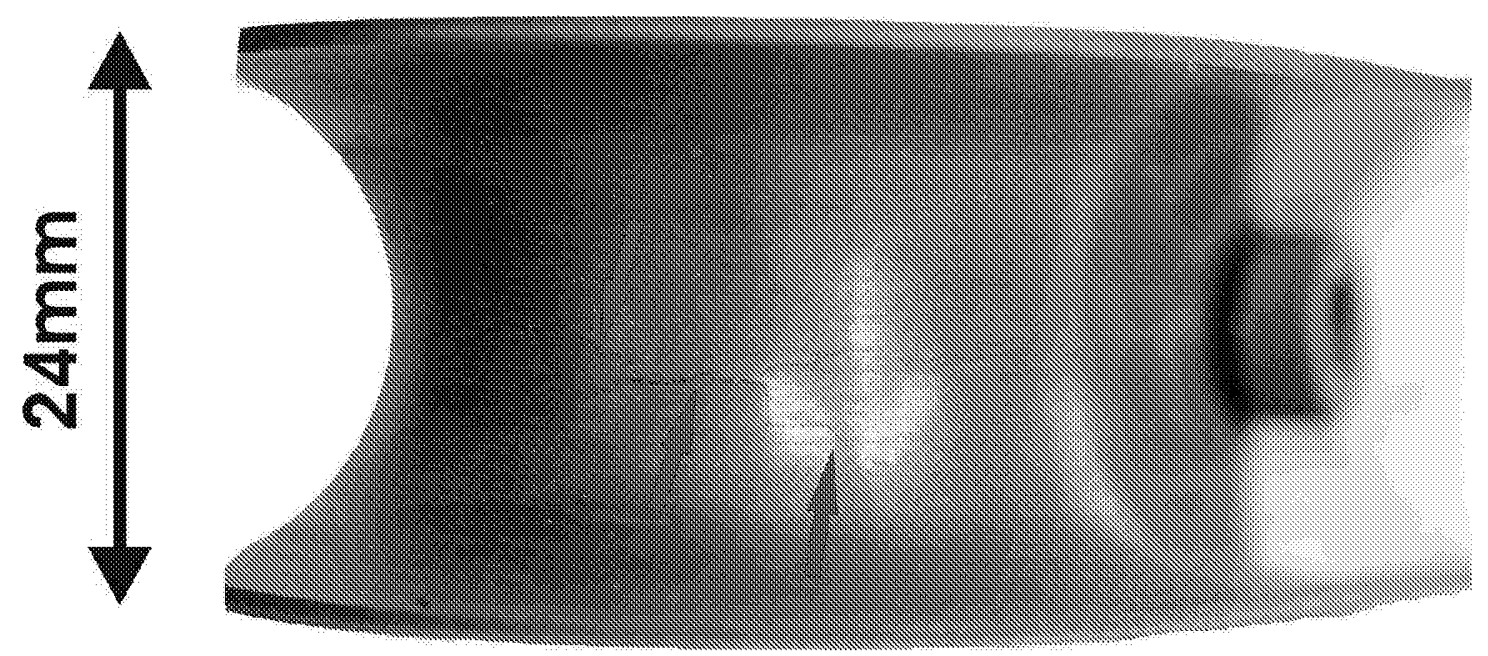

Figure A-9 Typical appearance of cracking observed in the non-scored Alloy 600MA specimens as indicated by the red arrows.

\section{A.4.2 Metallography/Microhardness Measurements}

Metallographic examination of a scored and non-scored specimen of each material was conducted. The samples were mounted into bakelite and polished to a $1 \mu \mathrm{m}$ surface finish. After etching (approximate etchant composition: $25 \%$ Ethanol, $<5 \% \mathrm{HNO}, 16 \% \mathrm{HCl}$ ) the microstructure was evaluated at high magnifications with a metallograph. Also Vickers microhardness measurements (100g load $-\mathrm{HV} 0.1$ ) were conducted at selected locations.

\section{A.4.2.1 Alloy 600MA}

The microstructural examination of this material disclosed semi-continuous to a discontinuous grain boundary precipitates as a result of the final mill anneal at temperatures between $850^{\circ} \mathrm{C}$ and $900^{\circ} \mathrm{C}$. The grain size was determined according to ASTM E 112 and was found to be 8.5 (see Figure A-10 to Figure A-13). 


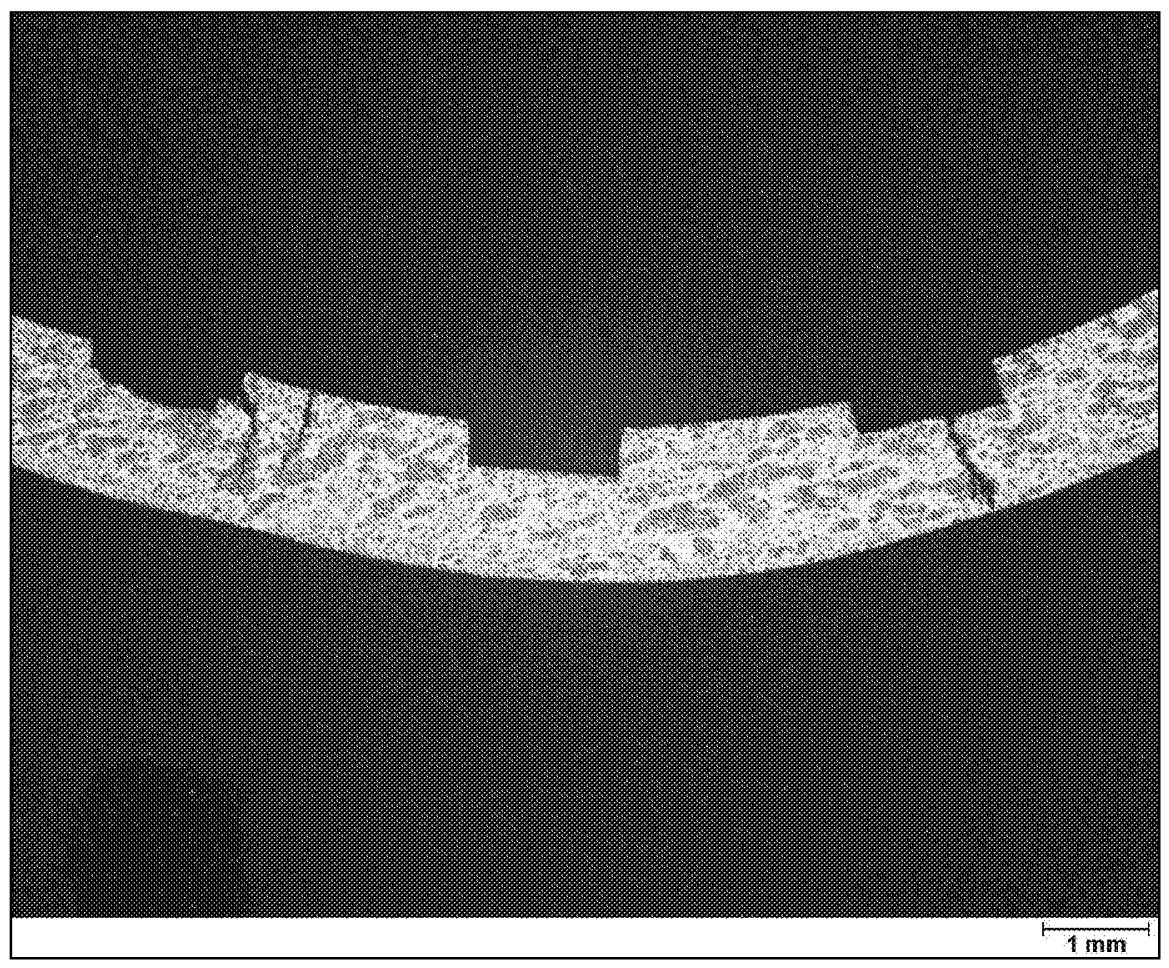

Figure A-10 Typical view of scored Alloy 600MA metallographic specimen exhibiting numerous cracks, some of which had developed into through-wall defects.

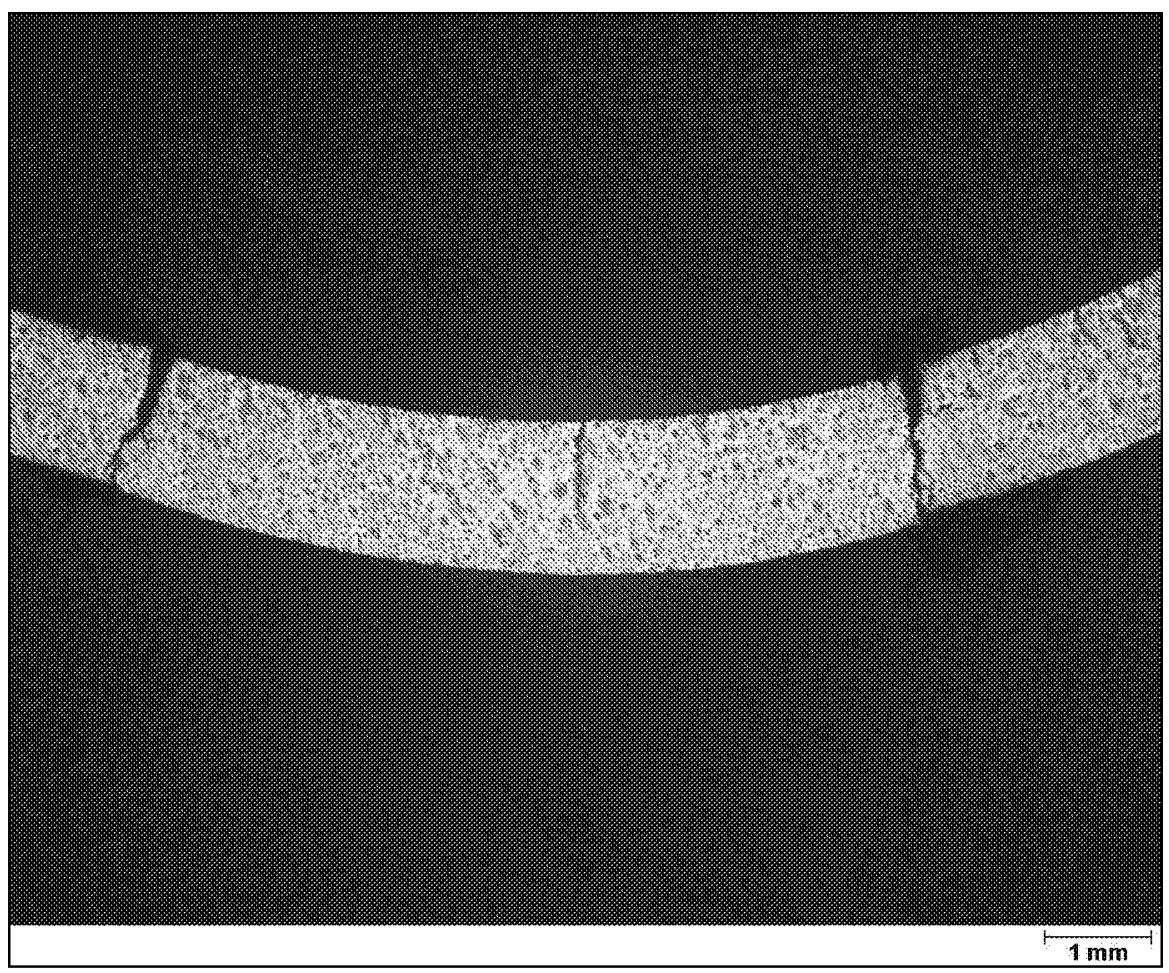

Figure A-11 Typical view of non-scored Alloy 600MA metallographic specimen exhibiting numerous cracks, some of which had developed into through-wall defects. 


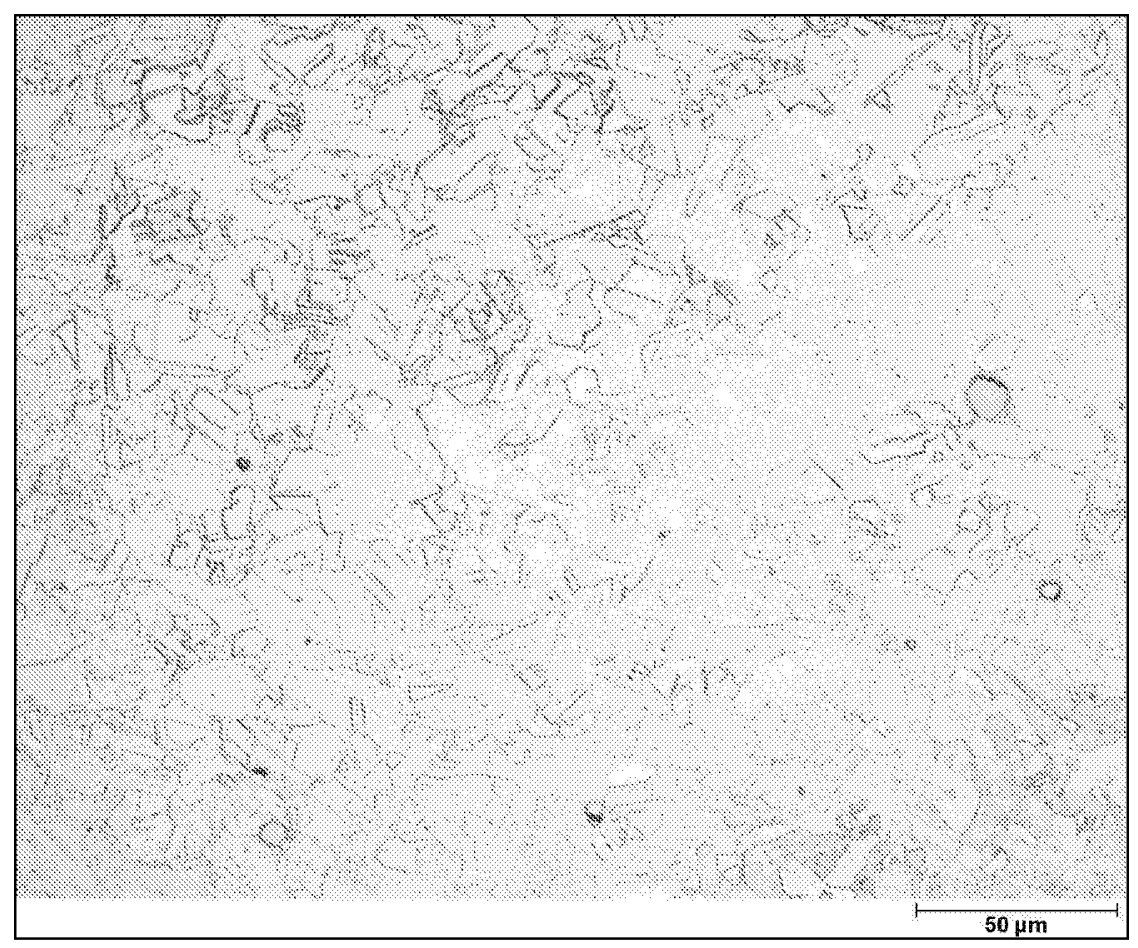

Figure A-12 General microstructure found in Alloy 600MA specimens displaying a typical austenitic appearance. The grain size according ASTM E 112 was determined to be 8.5.

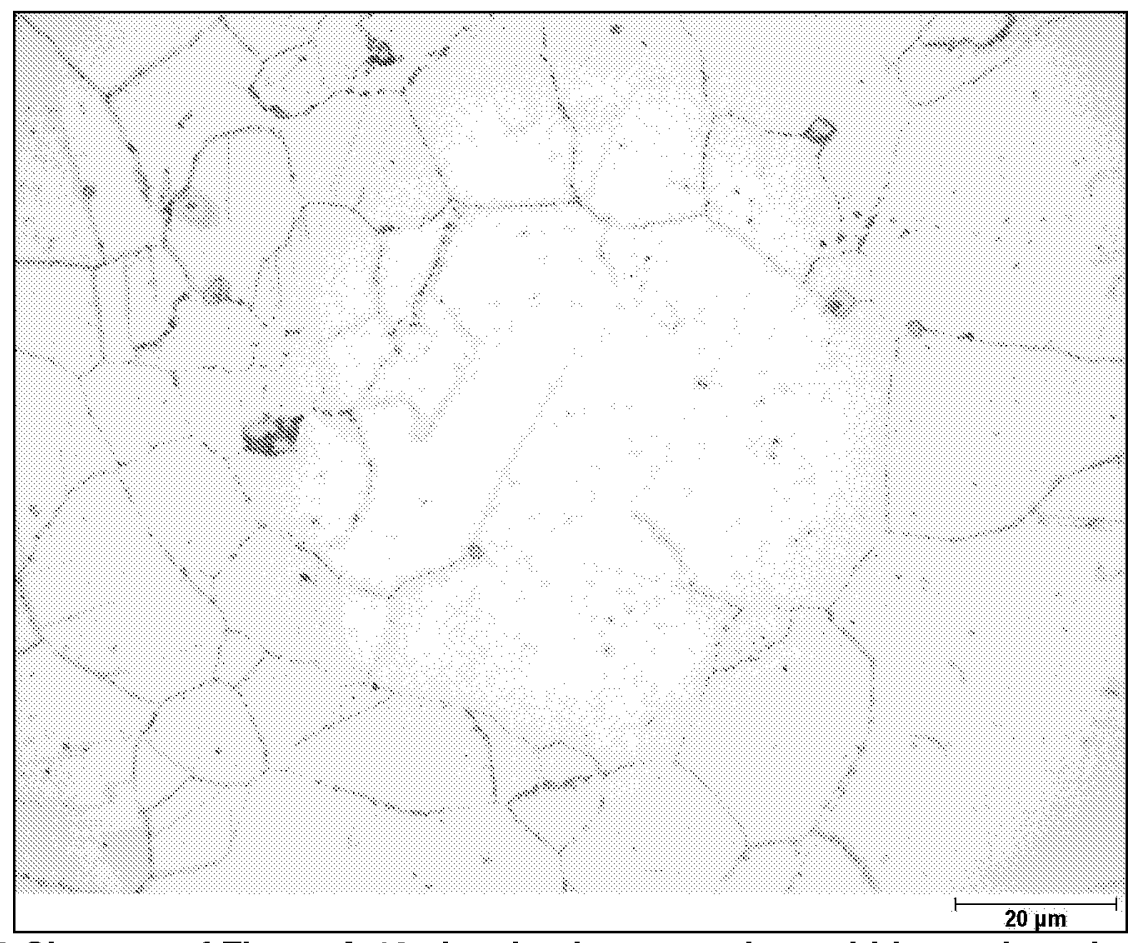

Figure A-13 Close up of Figure A-12 showing intragranular carbides and semi-continuous to discontinuous grain boundary carbide precipitates as a result of custom mill annealing at temperatures between $850^{\circ} \mathrm{C}$ and $900^{\circ} \mathrm{C}$ 
Alloy 600MA specimens exhibited PWSCC on numerous locations, which appeared absolutely independent from the presence of surface marks/scores. The crack progression occurred in an intergranular manner normal to the tube surfaces. Some locations exhibited through-wall defects. Typical examples of cracking found in the Alloy 600MA specimens are shown in Figure A-14 to Figure A-16.

Vickers microhardness readings ranged from $290 \mathrm{HV}$ to $307 \mathrm{HV}$ for the bulk microstructure. Immediately adjacent to the mechanically-induced scores the microstructure yielded hardness ranging from $337 \mathrm{HV}$ to $345 \mathrm{HV}$

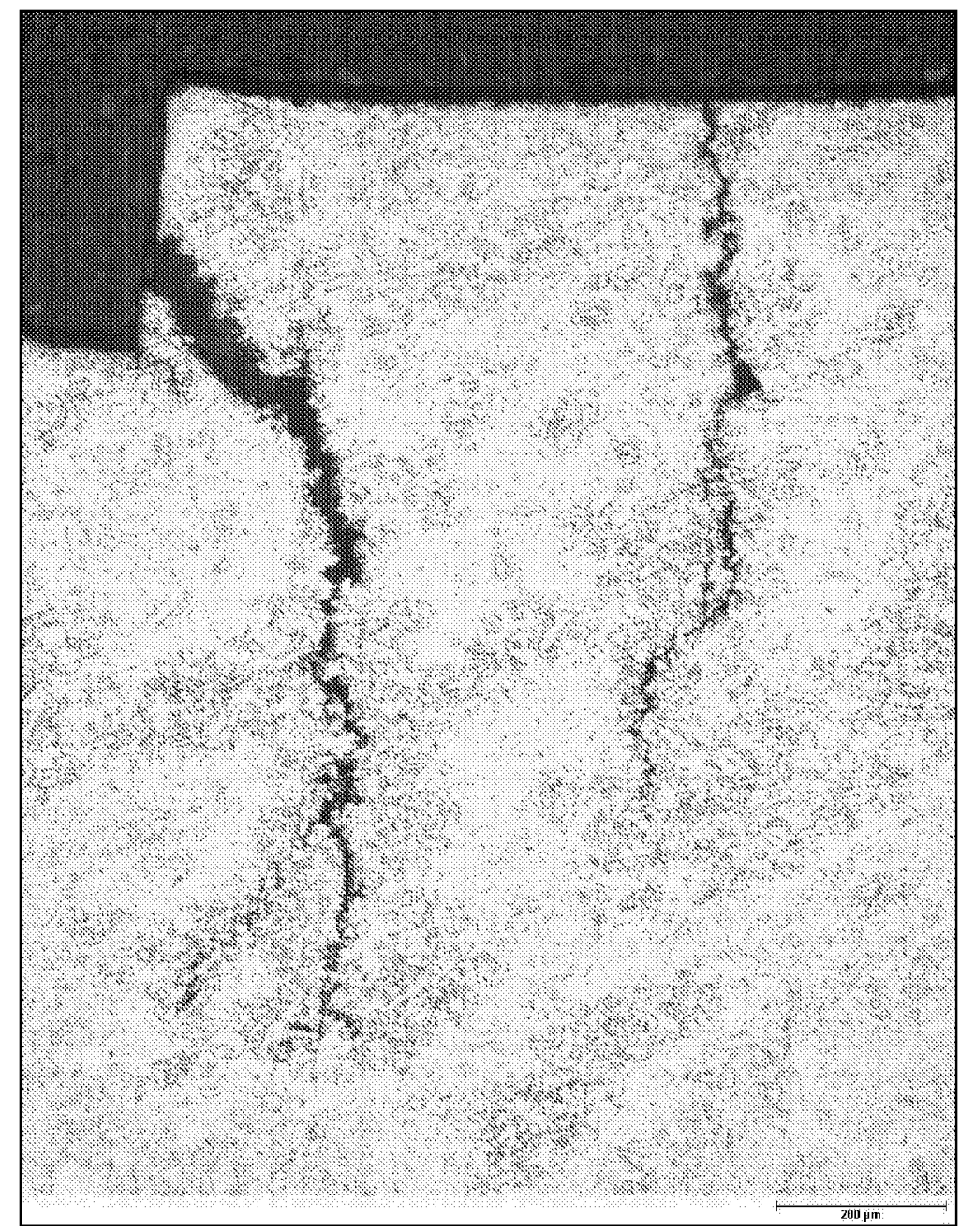

Figure A-14 Typical view of PWSCC found in the scored Alloy 600MA material; cracking initiated on the highly cold worked external specimen surface (formerly the internal SG tube surface); the crack propagation occurred in an intergranular manner. 


\section{Appendix A - Framatome ANP (Germany) Report}

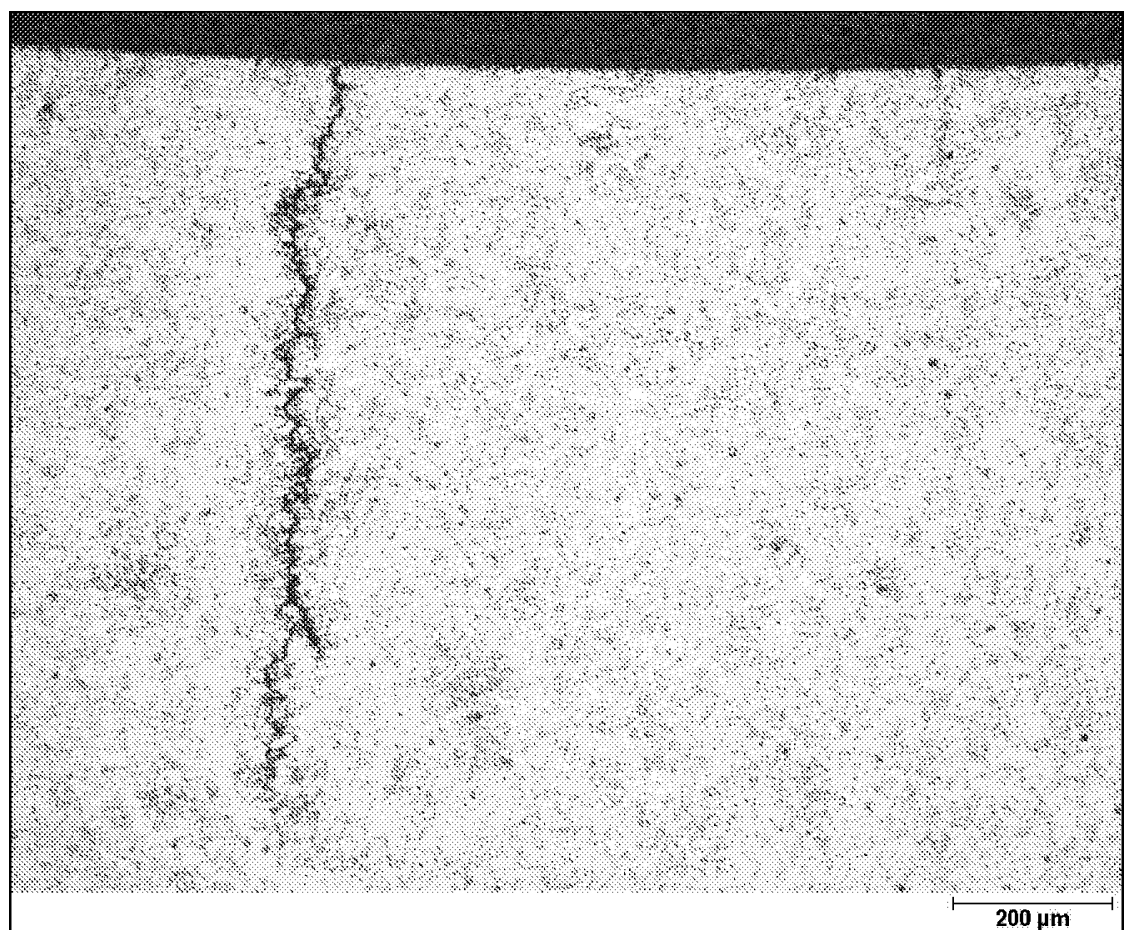

Figure A-15 Typical view of PWSCC found in the non-scored Alloy 600MA specimens also displaying an intergranular crack progression mode.

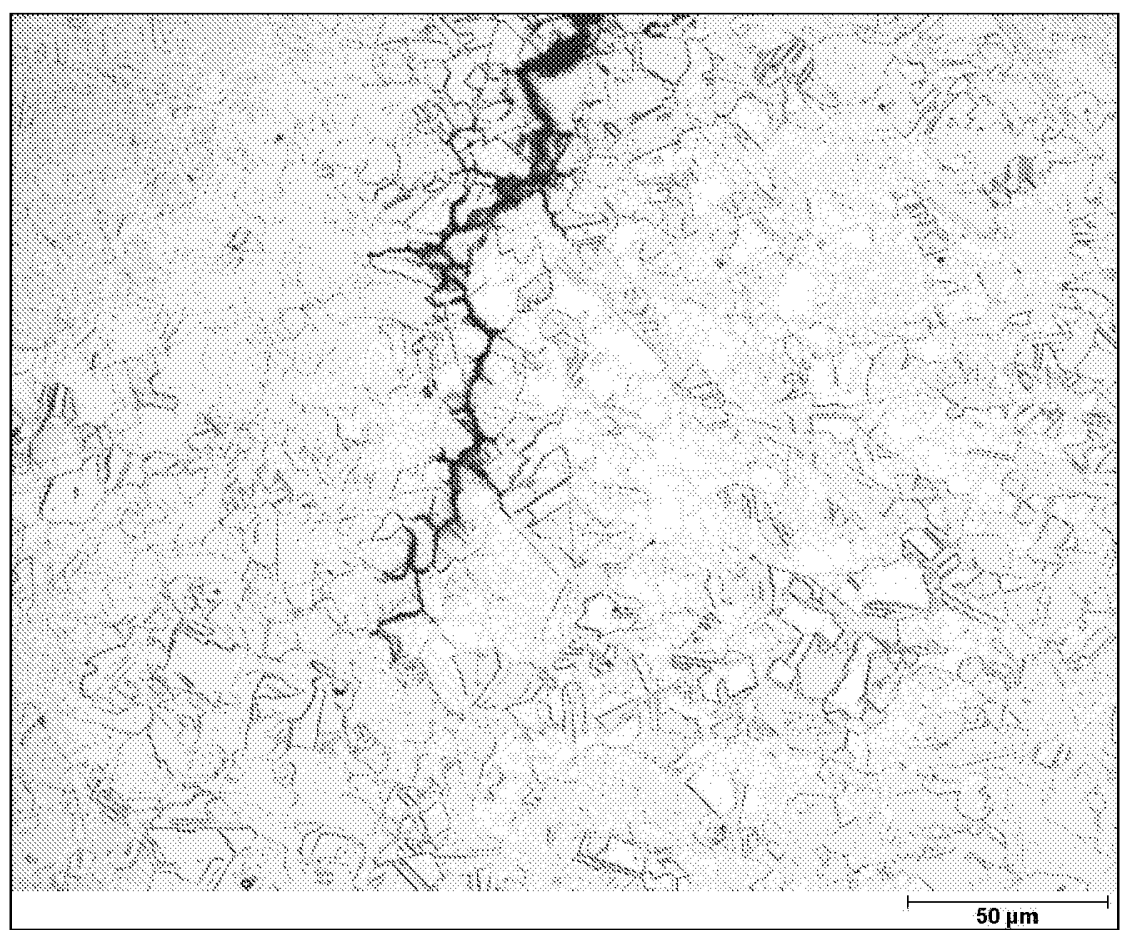

Figure A-16 Close-up of typical crack tip found in Alloy 600MA; the crack progression clearly occurred in an intergranular manner. 


\section{A.4.2.2 Alloy $690 \mathrm{TT}$}

The microstructure of this material appeared sound and did not show any anomalies. As expected, the matrix disclosed a semi-continuous to a continuous network of grain boundary precipitates as a result of mill annealing and the subsequent thermal treatment. The grain size was determined according to ASTM E 112 and showed relatively large variations since it ranged between 5 and 7 . No crack indications were found in this material confirming the findings from visual inspection (see Figure A-17 to Figure A-21).

With a microhardness range from $260 \mathrm{HV}$ to $278 \mathrm{HV}$ for the bulk microstructure, Alloy 690TT disclosed numbers approximately 30 points lower if compared with Alloy 600MA. Locations immediately adjacent to the scores yielded numbers ranging from $327 \mathrm{HV}$ to $335 \mathrm{HV}$, which is approximately 10 points lower if compared to Alloy 600MA.

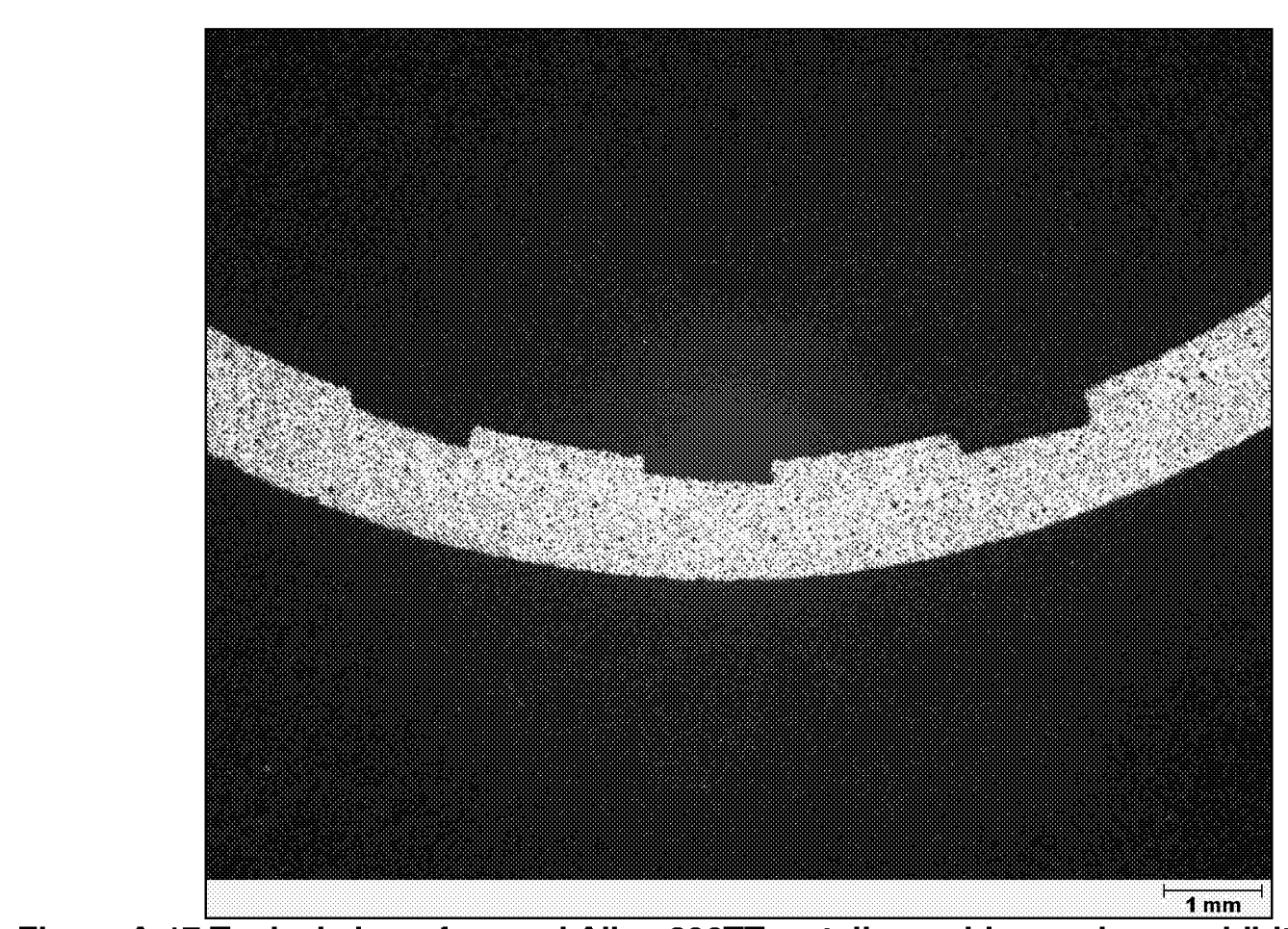

Figure A-17 Typical view of scored Alloy 690TT metallographic specimen exhibiting no PWSCC. 


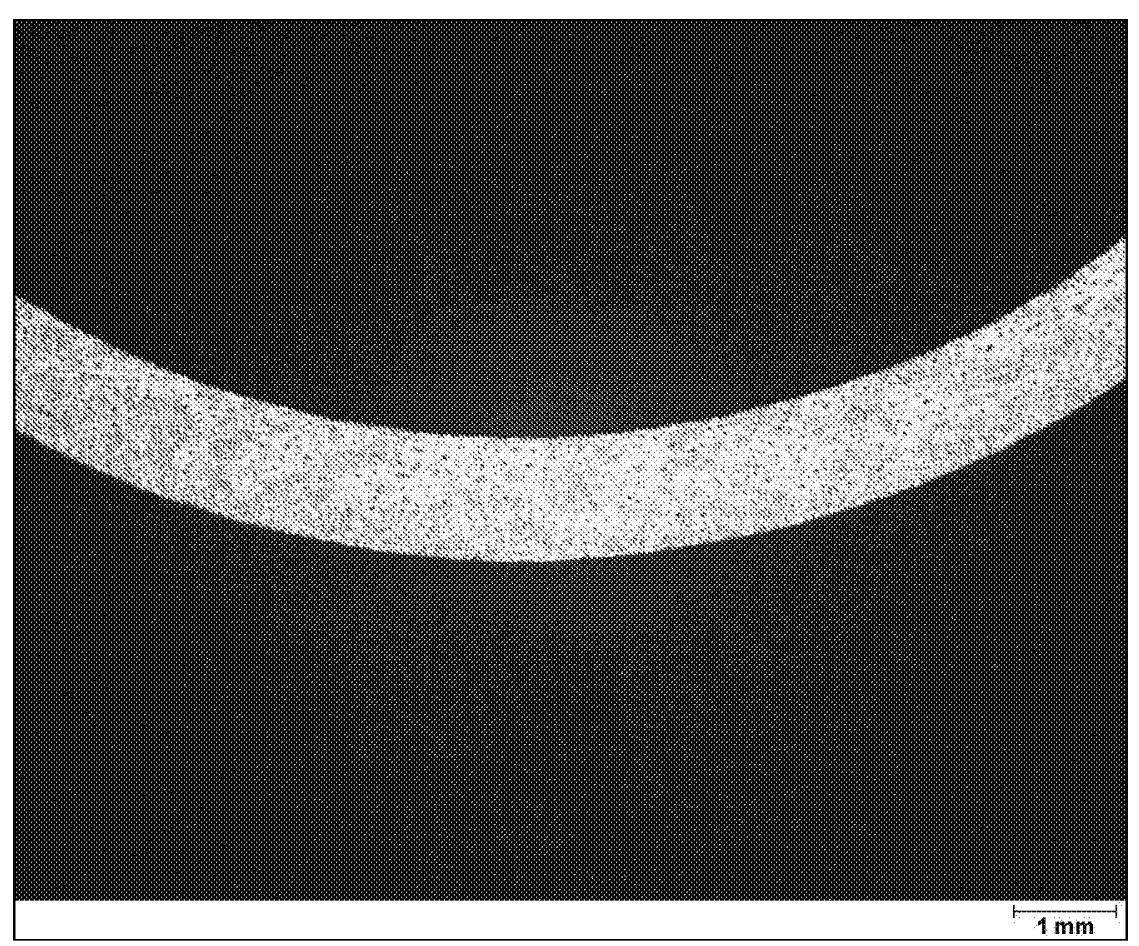

Figure A-18 Typical view of non-scored Alloy $690 T$ T metallographic specimen exhibiting no PWSCC.

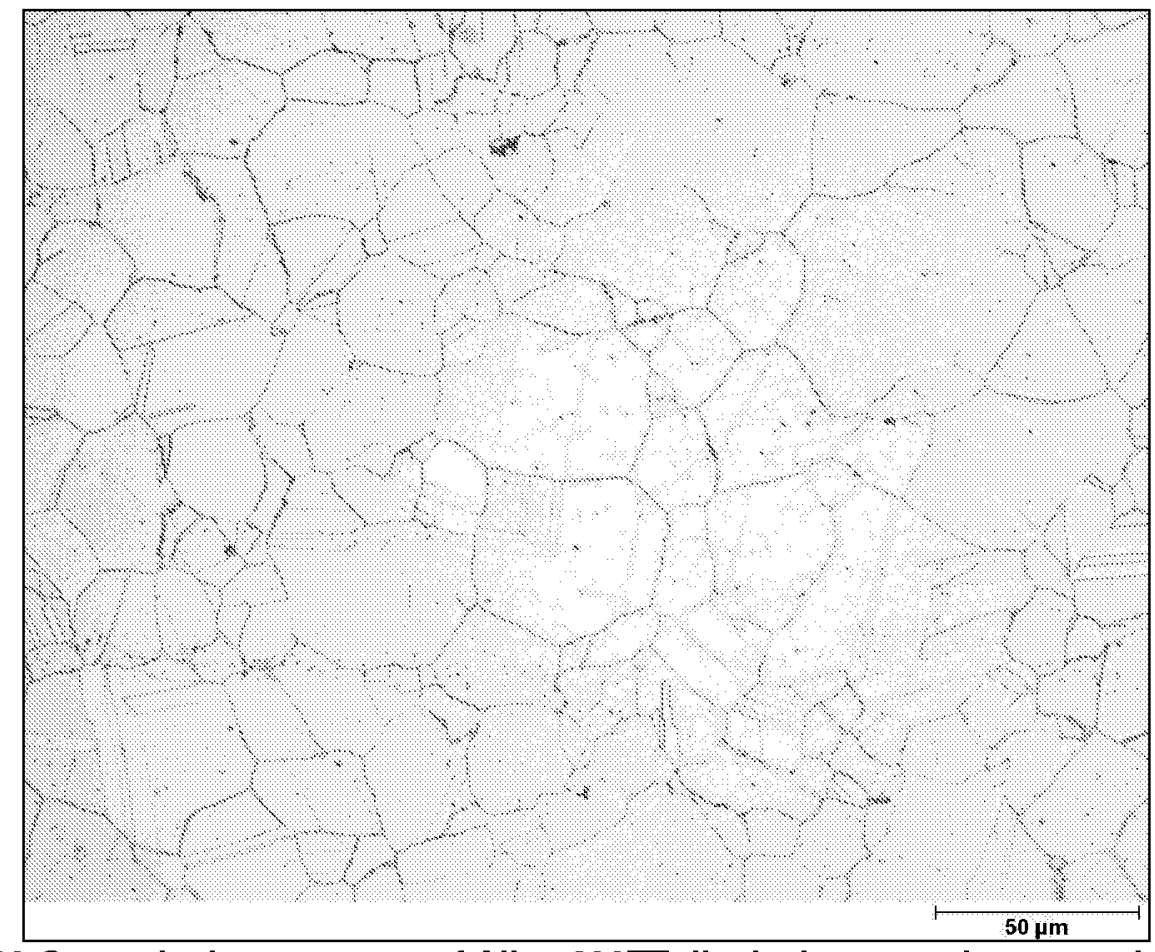

Figure A-19 General microstructure of Alloy 690TT displaying some intragranular carbides and a semi-continuous to continuous network of grain boundary carbide precipitates as a result of the thermal treatment. The grain size for this material ranged between 5 and 7 . 


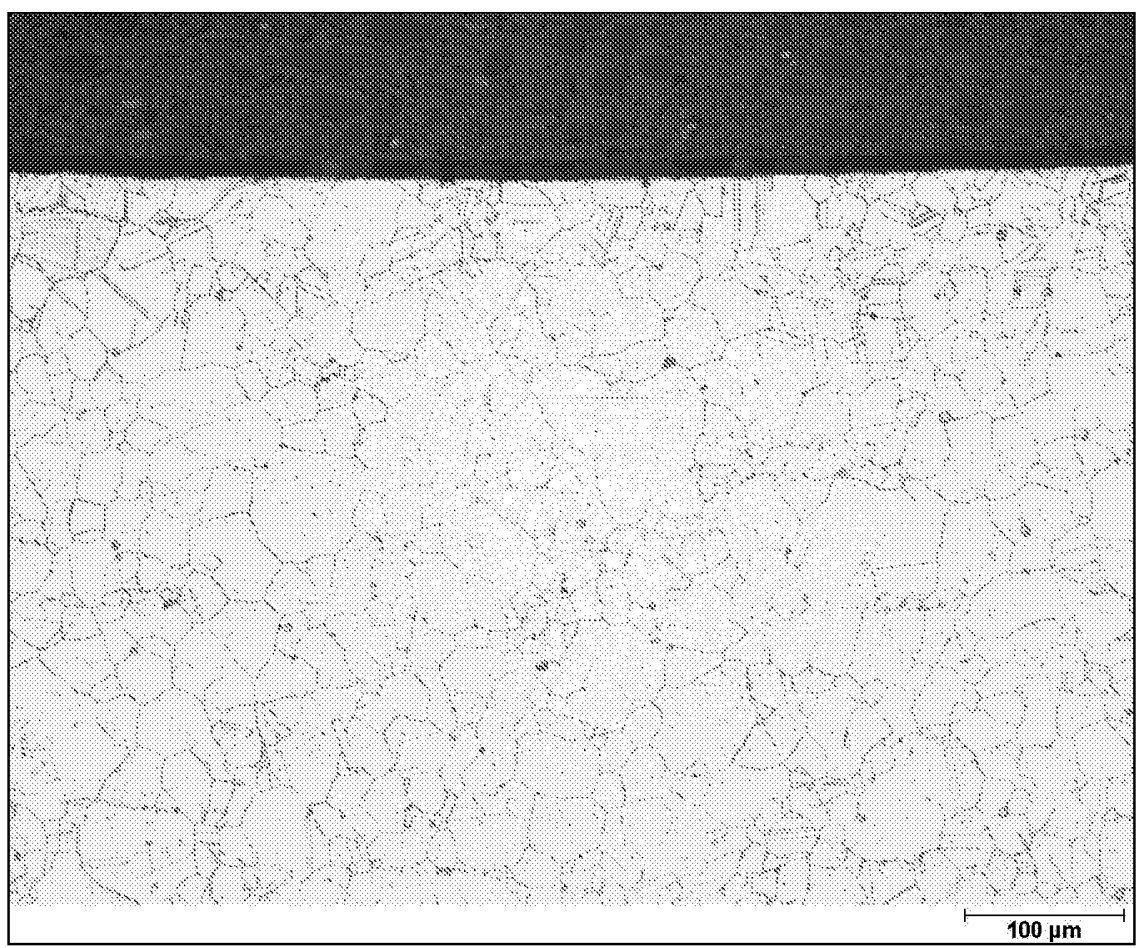

Figure A-20 Non-scored Alloy 690TT specimen showing no PWSCC.

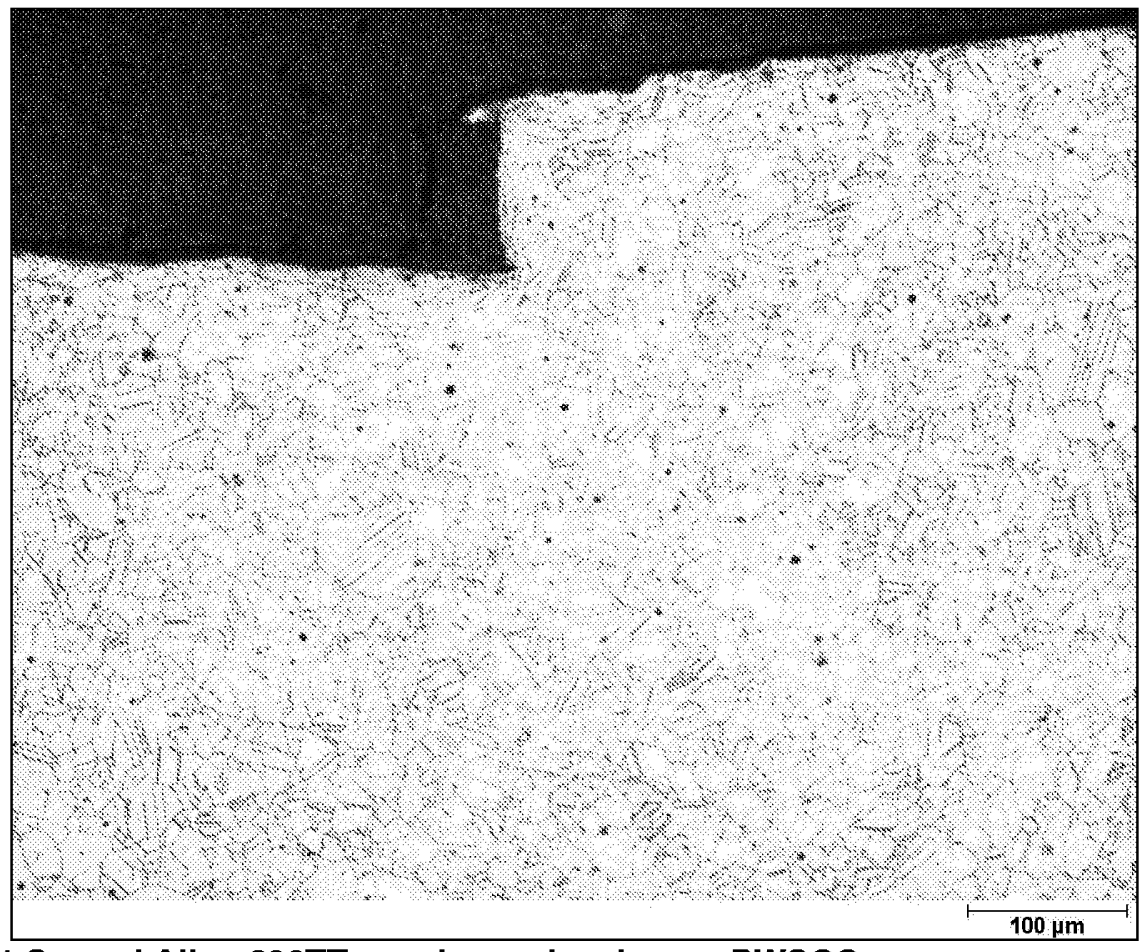

Figure A-21 Scored Alloy 690TT specimen showing no PWSCC. 


\section{A.5 Conclusions}

\section{A.5.1 Improvement Factor}

One objective of this evaluation was to present the results in terms of an "improvement factor" or IFR of Alloy 690TT relative to Alloy 600MA. In this particular study the improvement factor was to be generated as follows:

$$
I F_{R}=\frac{\text { time to crack in 690TT }}{\text { time to crack in 600MA }}
$$

Since no crack initiation for Alloy 690TT was observed within the total test duration of 405 days, the improvement factor as stipulated above could not be established. However, for this particular investigation a modified improvement factor was found:

$$
I F_{R \text { mod. }}=\frac{\text { max. exposure time } 690 \mathrm{TT}}{\text { time to crack in } 600 \mathrm{MA}}=\frac{405 d}{14 d} \approx 30
$$

\section{A.5.2 Quantification of Experimental Data/Margin of Improvement}

The hot steam test using RUB specimens proved to be a suitable test to compare the two materials. It allowed a distinct differentiation between Alloy 600MA and Alloy 690TT with respect to their PWSCC behavior. Unlike initial concerns, the high degree of cold work and the corresponding residual stresses inherent to this type of test with RUB specimens did not diminish the benefit provided by Alloy 690TT.

RUBs manufactured from Alloy 600MA exhibited PWSCC after an exposure time of only 14 days (the actual crack initiation might have occurred even earlier, but the first inspection interval was stipulated after 14 days). These findings in Alloy 600MA were independent from the presence of surface marks/scores since they were observed at the same level of severity in scored and non-scored samples. The crack formation occurred predominantly at the RUB's apex corresponding to a highly cold worked area.

In contrast, Alloy 690TT showed no cracking in all of the specimens, even after a total exposure time of 405 days. Both, the scored and the non-scored specimens remained unaffected. Findings gained during this experiment correspond with results presented by Gimond ${ }^{[86]}$. There, non-scored 690TT RUBs were exposed to very similar conditions $\left(400^{\circ} \mathrm{C} ; 1\right.$ bar $\mathrm{H}_{2}$ partial pressure) and did not show any indications of PWSCC after a total exposure time of 6000h (250 days). 


\section{A.5.3 Comparability of Experimental Data to In-Service Conditions}

The time necessary to initiate cracking in Alloy 600MA RUBs can be reduced down to several days under laboratory conditions by means of hot steam techniques (i.e. temperature, defined hydrogen pressure).

PWSCC in Alloy 600MA tubing was observed in row $1 \mathrm{U}$-bends of actual SGs after approximately one year of plant operation. According to [87], the configuration of a RUB specimen is comparable to a row 1 U-bend tube. However, the tighter bend radius and the splittube configuration of the RUB specimens accelerate the time necessary to initiate cracking by a factor of 2 to 3 , if compared to an actual row 1 U-bend. Thus, the time necessary to initiate cracking in an actual row 1 U-bend under hot steam test conditions is 14 to 21 days. Based on the geometry of a row 1 U-bend, the conclusion can be drawn that one year of plant operation corresponds to approximately 20 days under hot steam test conditions. With respect to this last statement, an exposure to hot steam under laboratory conditions for 405 days without cracking corresponds to approximately 20 years of plant operation for a row $1 \mathrm{U}$-bend. 


\section{$B$ TESTS ON MOCK-UPS REPRESENTATIVE OF ROLLING ZONES OF STEAM GENERATOR TUBES IN HIGH TEMPERATURE, HYDROGENATED, PURE WATER AT $360^{\circ} \mathrm{C}$ - A FRAMATOME ANP (FRANCE) REPORT}

\section{B.1 Introduction}

The widespread occurrence of Primary Water Stress Corrosion Cracking (PWSCC) of Alloy 600 in PWRs has led manufacturers to propose its replacement for many key component items such as steam generator (SG) tubes and reactor vessel (RV) upper head penetration nozzles by Alloy 690. Despite the excellent operating experience to date with Alloy 690 (up to 15 years in the case of the replacement of SG tube bundles and up to 10 years for replacement RV upper heads), safety authorities worldwide have been reluctant to relax stringent inspection regimes imposed to manage the degradation of Alloy 600 in PWR primary water service. Consequently, there is a strong economic incentive to develop and quantify the margin of improvement resulting from the use of alloy 690 replacement materials with the immediate aim of relaxing the number and extent of costly non-destructive examinations.

The present report deals with the results of a long term study of the resistance to PWSCC of mock-ups representative of the roll transitions of SG tubes close to the tubesheet, comparing the performance of Alloys 690 and 600. Mock-ups were manufactured using three tube materials; Alloy 600 MA, Alloy 600 TT and Alloy 690 TT. The Alloy 600 tubes were standard products used for SG manufacture. The Alloy 690 TT tubes are a pre-series lot from a tube mill later used for production runs. The pre-series lot of Alloy 690 TT (WE092) was considered to be potentially more sensitive to PWSCC than the standard tubes produced thereafter based on standard comparative laboratory tests such as the slow strain rate test (SSRT). The tests reported here were performed during a 15 year period; the destructive examinations of the mockups were completed during 2002. 


\section{B.2 Experimental}

\section{B.2.1 Materials}

Four heats of SG tubing were used in this program:

Alloy 600 tubes:

WD281 MA: 3/4" diameter tubes manufactured by Vallourec (now Valinox) SA from ingots made by Imphy SA

WD281 TT: $3 / 4$ " diameter tubes manufactured by Vallourec (now Valinox) SA from ingots made by Imphy SA. These tubes were thermally treated.

NX3335 MA: 7/8" diameter tubes manufactured by Huntington Alloys (now Special Metals).

These tubes were typical of manufacturing practice $\sim 16$ years ago with a mill annealing temperature at $980^{\circ} \mathrm{C}$ and the thermal treatment was $700^{\circ} \mathrm{C}$ for 15 hours.

Alloy 690 tubes:

WE094 TT: 3/4" diameter tubes manufactured in a pre-production run by Imphy SA. Again, the tubes were typical of manufacturing practice about 16 years ago. The origin and thermal history of this particular heat has been extensively discussed in Section 3.2.2.7. The tubes were mill annealed at $980^{\circ} \mathrm{C}$ and thermally treated at $700^{\circ} \mathrm{C}$ and then mill annealed again as follows: $1040^{\circ} \mathrm{C} / 3 \mathrm{~min}$ then $700^{\circ} \mathrm{C} / 5$ hours in order to ensure the mechanical properties were within specification. As a consequence, the grain size was unusually small and the carbides were mainly intragranular rather than intergranular as described in Section 3.2.2.7.

Table B-1 shows the chemical composition of the different heats of material used in this study while Table B-2 gives the mechanical properties.

The grain size of the Alloy 690 at mid-thickness was aproximately10 $\mu$ m (ASTM \#10) but a perturbed layer was detected on the inner surface of the tube. This layer was characterized by a finer grain size of about $2 \mu \mathrm{m}$ (ASTM \#15), the presence of dense carbide precipitates and a higher hardness. Figure B-1 shows, as an example, a view of the microstructure at mid thickness, and in Figure B-2 a typical view of the inside perturbed layer. Figure B-3 shows measurements of the hardness across the tube thickness revealing the increased hardness near the inner surface over about 100 microns in depth. This structure was typical of the pre-series heats, which were the only ones available when the mock-ups were manufactured. Since then, Alloy 690 TT tubes used in steam generators have been given much more rigorous quality control and the inner surfaces are free of such perturbed layers. 
Table B-1 Chemical composition of the tested materials

\begin{tabular}{|c|c|c|c|c|c|}
\hline Element & $\begin{array}{c}\text { RCCM M4101 } \\
\text { Specification } \\
\text { Alloy 600 }\end{array}$ & WD281 & NX3335 & $\begin{array}{c}\text { RCCM M4105 } \\
\text { Specification } \\
\text { Alloy 690 }\end{array}$ & WE094 \\
\hline $\mathbf{C}$ & $0.010 / 0.050$ & 0.035 & 0.03 & $0.010 / 0.030$ & 0.027 \\
\hline $\mathbf{S i}$ & $<0.50$ & 0.33 & 0.16 & $<0.50$ & 0.28 \\
\hline $\mathbf{S}$ & $<0.015$ & 0.001 & $<0.005$ & $<0.010$ & 0.002 \\
\hline $\mathbf{P}$ & $<0.025$ & 0.010 & 0.010 & $<0.010$ & 0.005 \\
\hline $\mathrm{Mn}$ & $<1$ & 0.81 & 0.14 & $<0.50$ & 0.23 \\
\hline $\mathrm{Ni}$ & $>72.00$ & 73.40 & 75.11 & $>58.00$ & 61.29 \\
\hline $\mathrm{Cr}$ & $14.00 / 17.00$ & 16.03 & 15.76 & $28.00 / 31.00$ & 28.99 \\
\hline $\mathrm{Cu}$ & $<0.50$ & 0.01 & 0.11 & $<0.50$ & 0.01 \\
\hline $\mathrm{Co}$ & $<0.10$ & 0.013 & 0.036 & $<0.035$ & 0.01 \\
\hline $\mathrm{Ti}$ & $<0.50$ & 0.21 & 0.10 & $<0.50$ & 0.25 \\
\hline $\mathbf{A l}$ & $<0.50$ & 0.25 & 0.081 & $<0.50$ & 0.17 \\
\hline $\mathrm{Fe}$ & $6.00 / 10.00$ & 8.89 & 8.45 & $8.00 / 11.00$ & 8.75 \\
\hline $\mathbf{N}$ & - & 0.0158 & - & $<0.05$ & - \\
\hline
\end{tabular}

Table B-2 Mechanical properties of the tested materials

\begin{tabular}{|c|c|c|c|c|}
\hline \multicolumn{2}{|c|}{ Parameter } & WD281 MA & NX3335 & WE094 \\
\hline $\begin{array}{c}\text { Yield strength } \\
\text { (MPa) }\end{array}$ & $\mathbf{2 0 ^ { \circ } \mathbf { C }}$ & 339 & 329 & 419 \\
\cline { 2 - 5 } & $\mathbf{3 4 3}^{\circ} \mathbf{C}$ & 262 & 266 & 358 \\
\hline \multirow{2}{*}{$\begin{array}{c}\text { Ultimate strength } \\
\text { (MPa) }\end{array}$} & $\mathbf{2 0}^{\circ} \mathbf{C}$ & 723 & 721 & 825 \\
\cline { 2 - 5 } & $\mathbf{3 4 3}^{\circ} \mathbf{C}$ & 675 & 623 & 723 \\
\hline \multirow{2}{*}{ Elongation (\%) } & $\mathbf{2 0}^{\circ} \mathbf{C}$ & 41.7 & 41.3 & 37 \\
\cline { 2 - 5 } & $\mathbf{3 4 3}^{\circ} \mathbf{C}$ & 39.1 & 36.1 & 36 \\
\hline
\end{tabular}




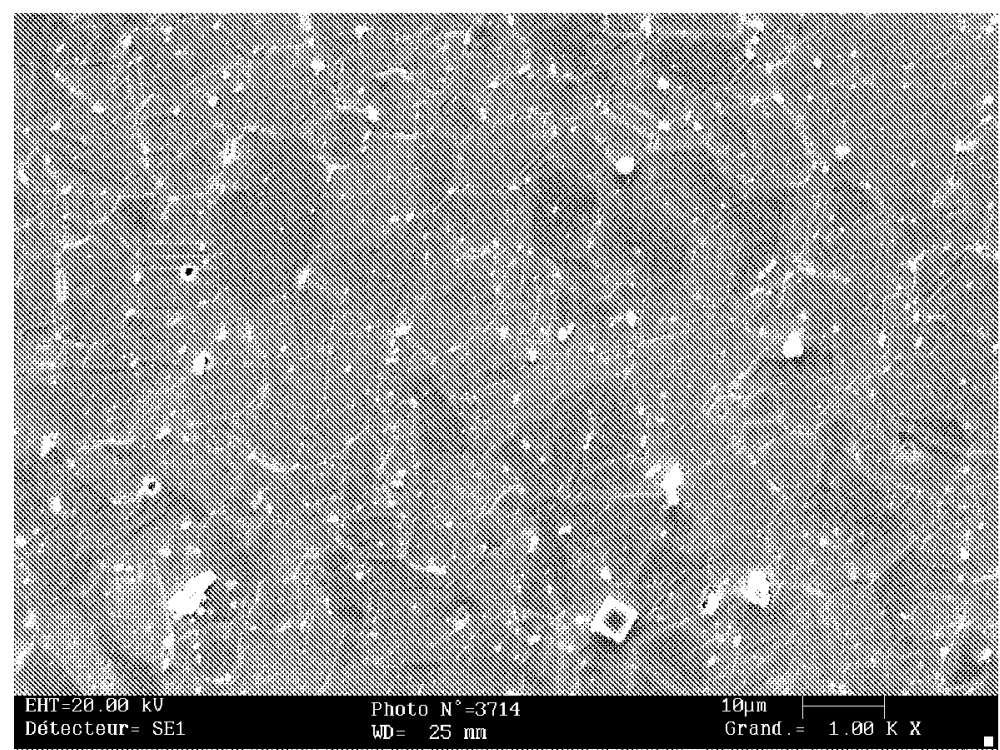

Figure B-1 Structure of the Alloy 690 TT WE 094 tube at mid thickness.
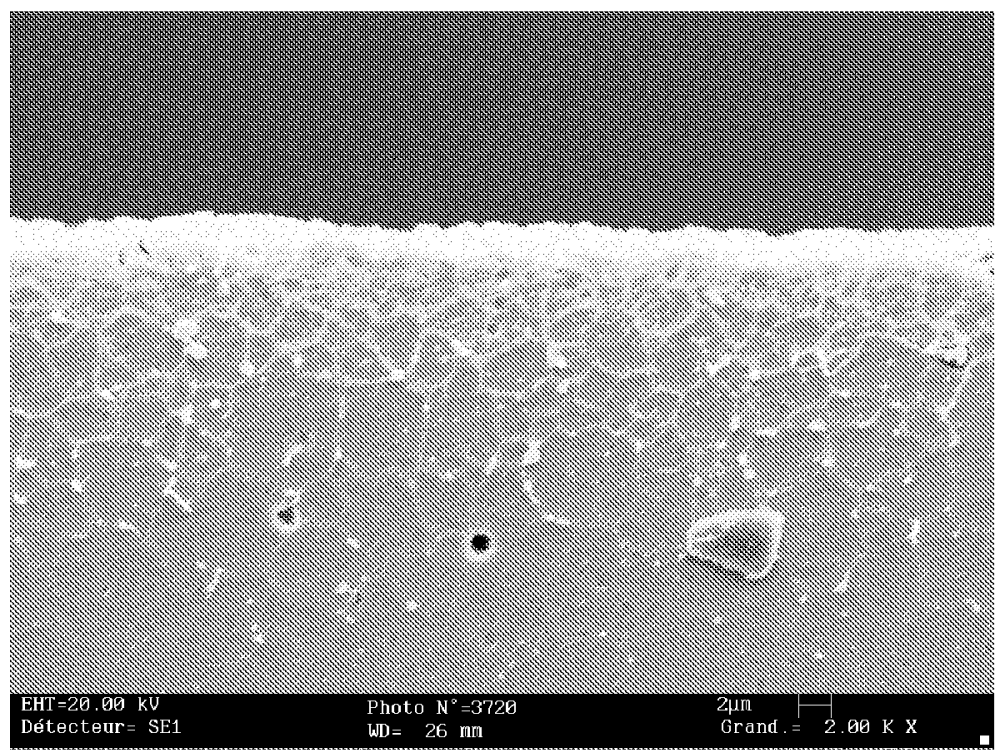

Figure B-2 Structure of the Alloy 690 TT WE 094 tube at the inner surface. 


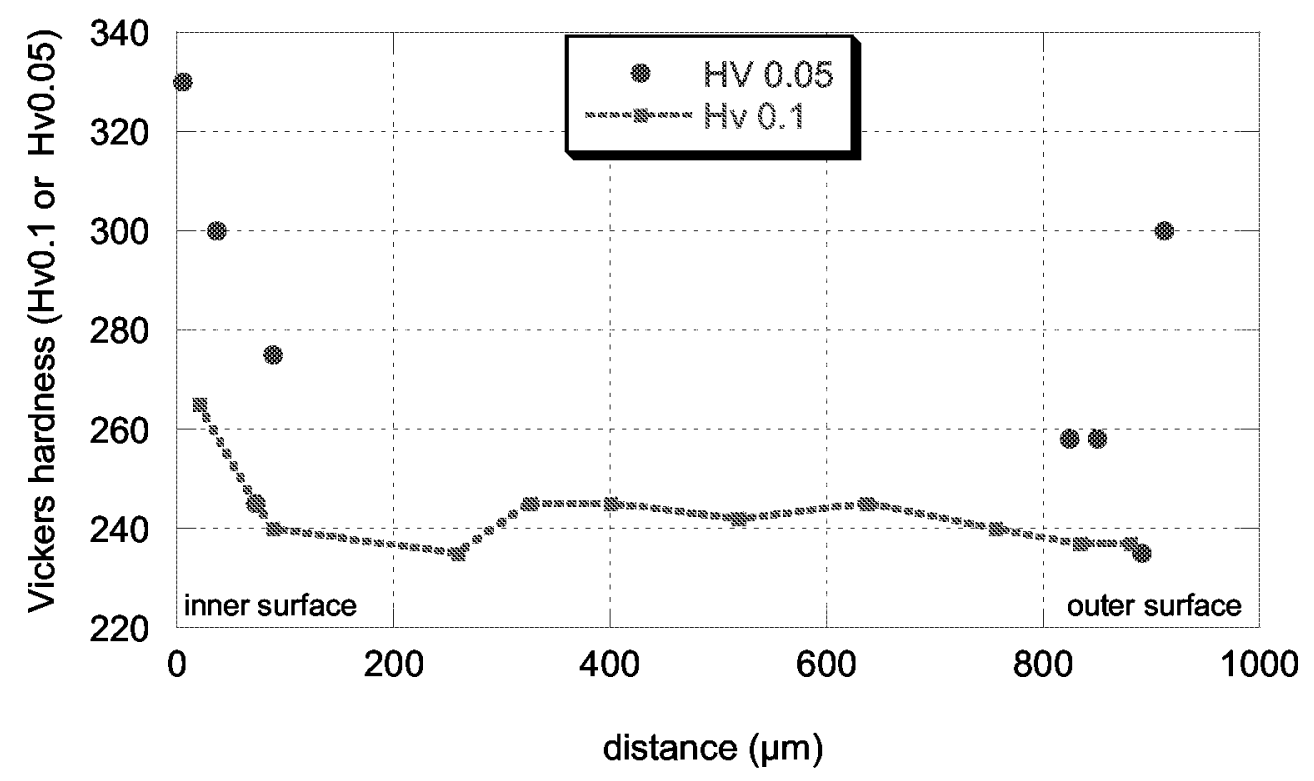

Figure B-3 Hardness across the Alloy 690 TT WE 094 tube wall thickness.

\section{B.2.2 Mock-up manufacture}

The mock-ups were manufactured by Framatome-ANP at the factory located in Chalon sur Saône using the same tools and procedures as those used for PWR steam generators. Each mockup consisted of a SG tube section and a thick carbon-steel cylinder representing the top side of the tubesheet. The tube section was expanded into holes drilled in the carbon steel cylinder representing the tubesheet using a mechanical rolling tool. Four rolling steps were needed inside each carbon steel cylinder. A kiss-rolling step was then carried out on each side of the carbon steel cylinder. Thus, two roll transition zones were available on each mock-up, as represented in Figure B-4, which shows a cross section view of the standard mock-up design. In addition, between the two roll transition zones, several nonconformities such as a lack of overlap between two rolling steps or a skipped roll step were introduced in some cases. Such fabrication nonconformities were known to be extremely detrimental for primary water side cracking of tubes in the case of steam generators with Alloy 600 tube bundles; see Section B-4.

Kiss rolling, illustrated in Figure B-4, is the process by which of a double step is introduced between the diameter of the free span of an SG tube and the expanded tube diameter in the tube sheet. During the roll expansion of many thousands of tubes, it is possible to miss a step in the roll expansion in the tube sheet, which is known as a "skip roll". If the expanded roll diameter of the tube in the tube sheet projects above $-4 \mathrm{~mm}$ with respect to the tube sheet upper surface, this is known as an "over-roll".

All the mock-ups were characterized by profilometry using eddy current or ultrasonic techniques. 


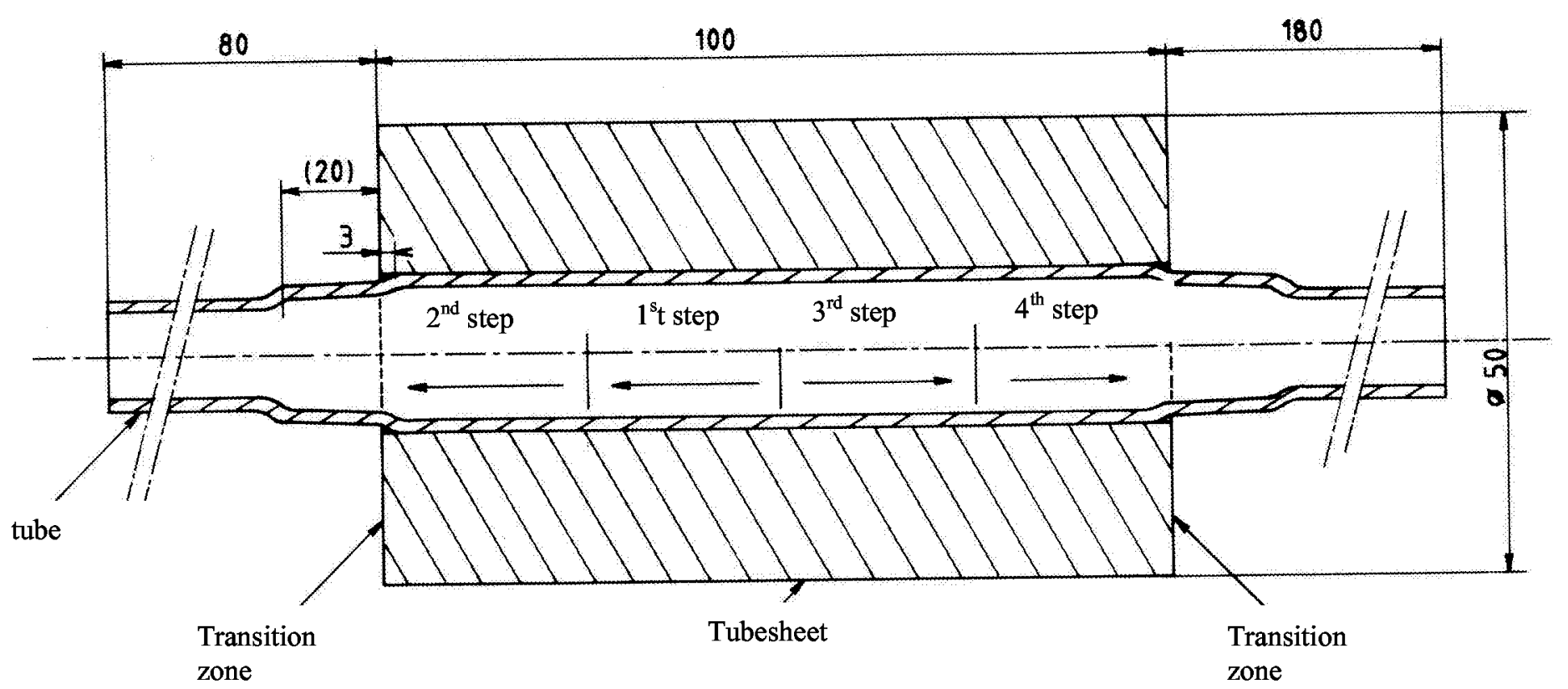

Figure B-4 Sketch of a standard mock-up (dimensions in $\mathbf{m m}$ ).

The total number of roll transition zones manufactured from Alloy 690 TT was 16 whereas 40 were manufactured from the Alloy 600 heats. The mock-ups (each comprising two roll transition zones) were identified with a number between 1 and 21 for the Alloy 600 mock-ups and between 501 and 508 for Alloy 690 TT mock-ups. A letter (H or B, corresponding to the upper or lower orientation in the furnace, respectively) was also added to the identification number for each transition zone.

An Alloy 600 plug was manual metal arc welded into each end of the mock-ups in order to form a capsule. During this operation, the tube was cooled in order to maintain the residual stresses in the roll transition zones introduced by the roll expansion. Each mock-up (capsule) was equipped with small stainless steel tubing to allow the test environment to be introduced, a high pressure valve, a manometer and an external thermocouple inserted in the carbon steel sheet as shown in Figure B-5. 


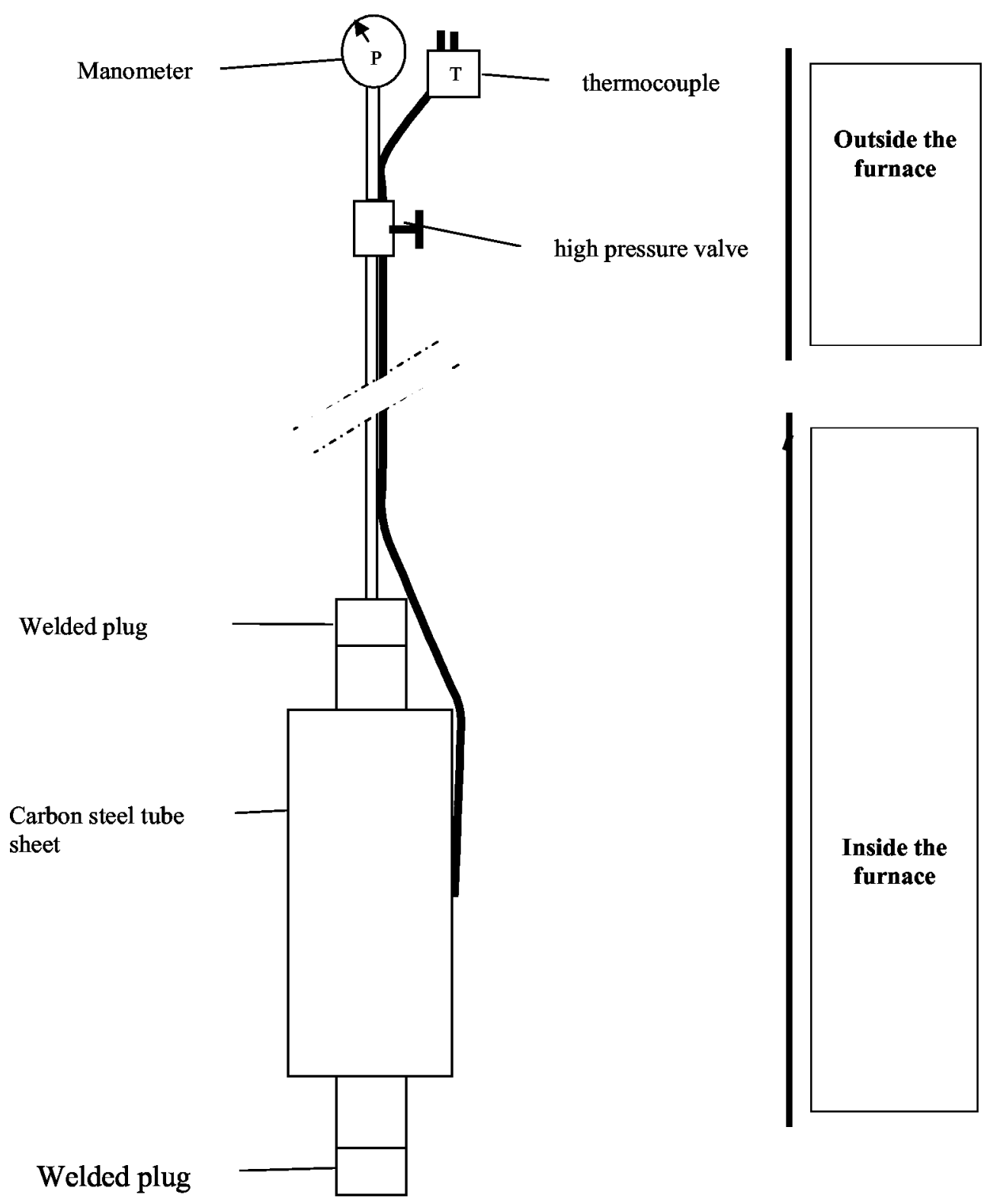

Figure B-5 Schematic representation of the mock-ups for long-term exposure tests.

\section{B.2.3 Test procedure}

A specific test procedure was defined for the preparation of the long-term exposure tests including intermediate interruptions for capsule inspection and renewal of the test environment.

The test environment was high purity deaerated water with a hydrogen overpressure. This environment was chosen to facilitate good control of the test environmental parameters and also knowing that hydrogenated pure water is slightly more aggressive from the stress corrosion viewpoint than PWR primary water that also contains lithium hydroxide and boric acid in varying concentrations throughout any given fuel cycle. The single parameter used to monitor 
the quality of the aqueous environment was a measure of conductivity because the total volume of the capsules was too small for repeated sampling for chemical analyses.

The mock-ups were introduced into a furnace whose temperature was subsequently controlled at $360^{\circ} \mathrm{C}$. Before heating, the mock-ups were carefully washed with demineralized and deaerated water at room temperature (RT) until the conductivity was lower than $1 \mu \mathrm{S} / \mathrm{cm}$ and then subsequently at 200 and $290^{\circ} \mathrm{C}$ until the conductivity of the effluent washing water was lower than $2 \mu \mathrm{S} / \mathrm{cm}$.

The test procedure at the beginning of each exposure period comprised the following steps:

- Filling the mock-up/capsule; Evacuation of the air and introduction of a specified volume $\left(35 \mathrm{~cm}^{3}\right)$ of high purity demineralized water (conductivity $<0.5 \mu \mathrm{S} / \mathrm{cm}$ ). Removal of the residual atmosphere with a vacuum pump during 1 hour in order to deaerate the aqueous environment.

- Verification of leak-tightness: Introduce argon at a pressure of 170 bars. Monitor the total pressure during 48 hours; a decrease of pressure less than 20 bar was acceptable.

- Conditioning: Reduce the argon pressure to 10 bars and inject hydrogen up to a total pressure of 35 bars.

- Heating up: Place the mock-up in the furnace and heat to $360^{\circ} \mathrm{C}$.

\section{B.2.4 Monitoring the mock-up's during exposure tests}

During the exposure period at $360^{\circ} \mathrm{C}$, the total pressure of each mock-up/capsule was between 190 and 210 bars. The temperature control assured a temperature of $360^{\circ} \mathrm{C} \pm 3^{\circ} \mathrm{C}$ for each individual mock-up. During the exposure period, the total pressure and the temperature of each mock-up was monitored twice a day. Every 4 to 6 weeks, each mock-up was cooled to RT and the overpressure was adjusted to 35 bars by hydrogen injection.

If the total pressure of any mock-up decreased for any reason, it was cooled to RT outside the furnace and the internal pressure of the mock-up concerned was then increased to 180 bar with argon. Leakage of any gas was revealed and localized by bubbling in a water container. If the leak was located in the roll expanded zone, a destructive examination was carried out. For leaks located in the transition zones ( $\mathrm{H}$ or $\mathrm{B}$ ), the mock-up was machined in such a way as to isolate the cracked zone and to allow the other part to be sealed and pressurized as a single-zone mockup for a further exposure period. If the leak was located in the tubesheet (at a transition zone of a skipped roll step or between two roll steps without overlap, for example) the mock-up was destructively examined in its entirety. Cracks were located by ultrasonic testing (UT) or Eddy Current testing (ET) inspection and were then characterized by liquid dye-penetrant testing (PT) and by optical binocular examination of flattened half-tubes. Subsequently, any cracks were examined by Scanning Electron Microscopy (SEM). 


\section{B.3 Alloy 690 TT Mock-Up Results}

\section{B.3.1 Test Results}

Table B-3 gives fabrication details of all the tested mock-ups (with two rolling transition zones on each mockup).

Table B-3 Characteristics of the Alloy 690 TT mock-ups.

\begin{tabular}{|c|c|c|c|c|}
\hline \multirow{2}{*}{ Mock-up } & \multicolumn{2}{|c|}{ Rolling } & \multirow{2}{*}{$\begin{array}{c}\text { Kiss-roll } \\
\text { expansion } \\
\varnothing(\mathrm{mm})\end{array}$} & \multirow{2}{*}{ Skip-roll } \\
\hline & $\begin{array}{c}\text { Tube /tubesheet } \\
\text { gap }(\mathbf{m m})\end{array}$ & Over-roll (mm) & & \\
\hline $501 \mathrm{H}$ & 0.4 & -1.5 & 0.15 & \multirow{2}{*}{ No } \\
\hline $501 \mathrm{~B}$ & 0.4 & -1.5 & 0.30 & \\
\hline $502 \mathrm{H}$ & 0.4 & +1.5 & 0.15 & \multirow{2}{*}{ No } \\
\hline 502 B & 0.4 & +1.5 & 0.30 & \\
\hline $503 \mathrm{H}$ & 0.4 & +20 & 0.15 & \multirow{2}{*}{ No } \\
\hline $503 \mathrm{~B}$ & 0.4 & +20 & 0.30 & \\
\hline $504 \mathrm{H}$ & 0.4 & -1.5 & 0.15 & \multirow{2}{*}{ Yes } \\
\hline $504 \mathrm{~B}$ & 0.4 & +20 & 0.30 & \\
\hline $505 \mathrm{H}$ & 0.95 & -1.5 & 0.15 & \multirow{2}{*}{ No } \\
\hline 505 B & 0.95 & -1.5 & 0.30 & \\
\hline $506 \mathrm{H}$ & 0.95 & +1.5 & 0.15 & \multirow{2}{*}{ No } \\
\hline $506 \mathrm{~B}$ & 0.95 & +1.5 & 0.30 & \\
\hline $507 \mathrm{H}$ & 0.95 & +20 & 0.15 & \multirow{2}{*}{ No } \\
\hline 507 B & 0.95 & +20 & 0.30 & \\
\hline $508 \mathrm{H}$ & 0.95 & -1.5 & 0.15 & \multirow{2}{*}{ Yes } \\
\hline $508 \mathrm{~B}$ & 0.95 & +20 & 0.30 & \\
\hline
\end{tabular}


The rolling conditions can be summarized as follows:

3 zones with standard specification rolling and kiss-rolling, nominal tube/ tubesheet gap ( 0.4 $\mathrm{mm}$ ), nominal over-roll (between -1.5 and $+1.5 \mathrm{~mm}$ ), no non conformity in tubesheet

8 zones with high tube/tubesheet gap $(0.95 \mathrm{~mm})$,

8 zones with excessive kiss-roll expansion $(0.30 \mathrm{~mm})$,

6 zones with excessive over-roll (about $20 \mathrm{~mm}$ ),

2 mock-ups with a skip-roll.

Throughout the exposure period at $360^{\circ} \mathrm{C}$ the conductivity of the aqueous environment was less than $1 \mu \mathrm{S} / \mathrm{cm}$. After, the first and the sixth test periods of about 10,000 hours, the water from several mock-ups was sampled and analyzed. The results are given in Table B-4.

\section{Table B-4 Chemical analysis of the aqueous environment in the mock-ups after the $1^{\text {st }}$ and $6^{\text {th }}$ test period of 10,000 hours}

\begin{tabular}{|c|c|c|c|c|}
\hline Mock-up & \multicolumn{2}{|c|}{$\mathbf{5 0 1 + 5 0 3 + 5 0 4 + 5 0 7}$} & \multicolumn{2}{c|}{$\mathbf{5 0 2 + 5 0 5 + 5 0 6 + 5 0 8}$} \\
\hline & $\begin{array}{c}1^{\text {st }} \\
\text { period }\end{array}$ & $\begin{array}{c}\mathbf{6}^{\text {th }} \\
\text { period }\end{array}$ & $\begin{array}{c}\mathbf{1}^{\text {st }} \\
\text { period }\end{array}$ & $\begin{array}{c}\mathbf{6}^{\text {th }} \\
\text { period }\end{array}$ \\
\hline $\left.\mathbf{C l}^{-} \mathbf{m g} / \mathbf{k g}\right)$ & 0.7 & 0.46 & 0.4 & 0.57 \\
\hline $\mathbf{F}$ (mg/kg) & 0.08 & 0.56 & 0.25 & 0.05 \\
\hline $\mathbf{N a}^{+}(\mathbf{m g} / \mathbf{k g})$ & 0.19 & 0.43 & 0.14 & 0.10 \\
\hline $\mathbf{S i O}_{\mathbf{2}} \mathbf{( m g / k g )}$ & 0.71 & 4.3 & 0.43 & 4.8 \\
\hline
\end{tabular}

During the first 17,000 hours of the exposure period, no hydrogen was injected in the mock-ups. Subsequently, an overpressure of hydrogen of 15 bar was added at the beginning of each test period and was renewed every 2 months when half of the over-pressure was lost by diffusion.

Testing of the Alloy 690 TT mock-ups lasted 100,000 hours at $360^{\circ} \mathrm{C}$ (10 periods of 10,000 hours) and an internal total pressure between 210 and 230 bar was maintained. No leak occurred during this entire test duration on any mock-up. One mockup, 506, was extracted for destructive examination after 60,000 hours of test. 


\section{B.3.2 Mock-up examinations}

\section{B.3.2.1 Examination of mock-up 506 after 60,000 hours exposure}

\section{Liquid dye-penetrant test}

A liquid dye-penetrant test was performed after splitting the mock-up longitudinally into two half tubes. One was preserved and the other was flattened with the aim of opening up any existing flaws. Figure B-6 shows the two half tubes. No indication of any kind was observed on the two half tubes. However, a pink coloration was observed on the flattened tube and was probably due to small flaws that are homogeneously dispersed on the perturbed inner surface of the tube, as revealed by later more detailed examinations. 


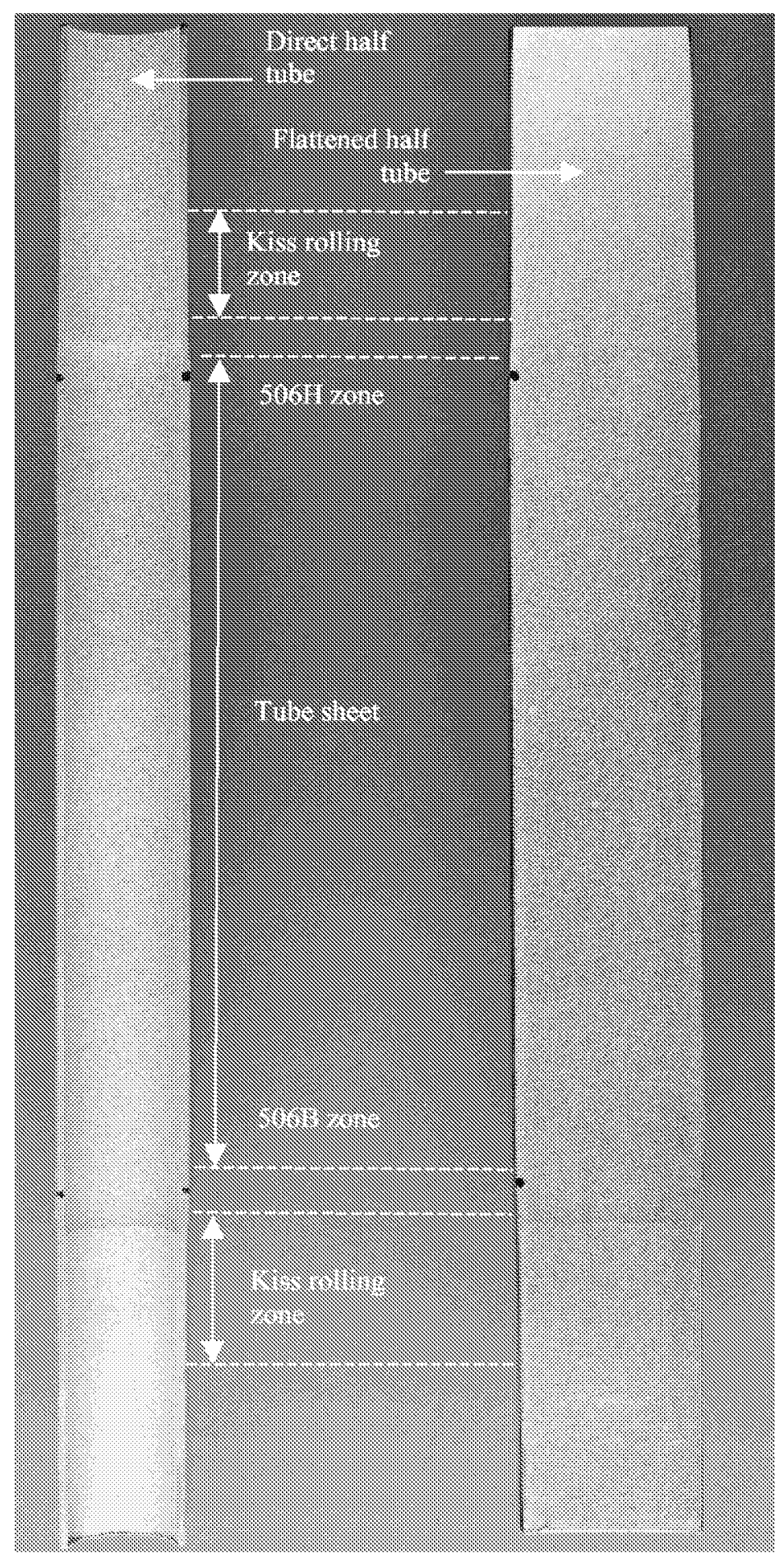

Figure B-6 Liquid penetrant test on mock-up 506. View of the two half tubes after splitting the mock-up longitudinally (the right hand half is flattened, the other is not flattened). 


\section{$\underline{\text { SEM surface observations }}$}

The internal surface of the two half tubes was examined by SEM. Special attention was paid to detecting possible small flaws in the different roll transition zones.

On the non-flattened half tube, some tiny cracks were observed on the inner tube surface in the transition zones of the kiss rolling. Their length was about $1.5 \mathrm{~mm}$ and their width $2 \mu \mathrm{m}$. Figure B-7, Figure B-8, and Figure B-9 show examples of such microcracks at the limit of the rolling zone on each side of the roll transition $(506 \mathrm{~B}$ and $506 \mathrm{H})$. 


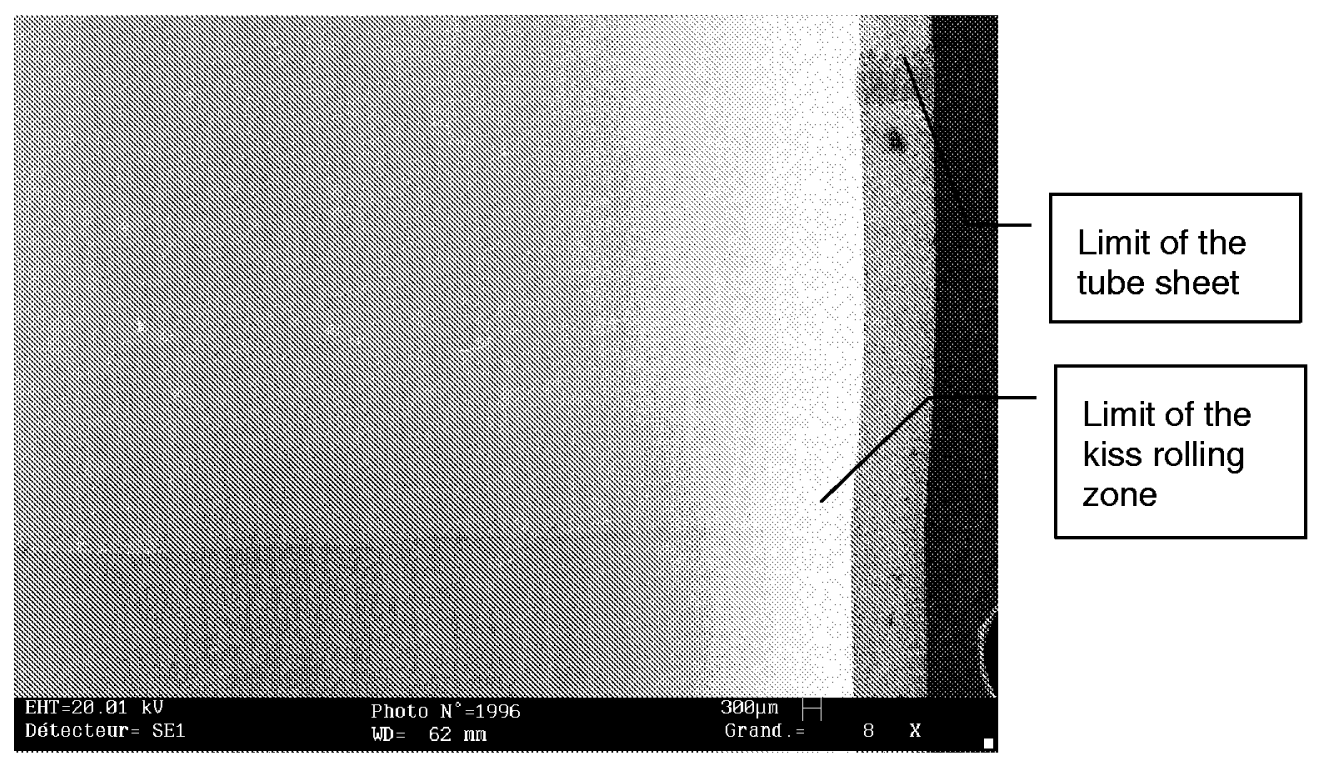

Figure B-7 Macrograph of the non-flattened half tube at the limit of the rolling zone 506B.

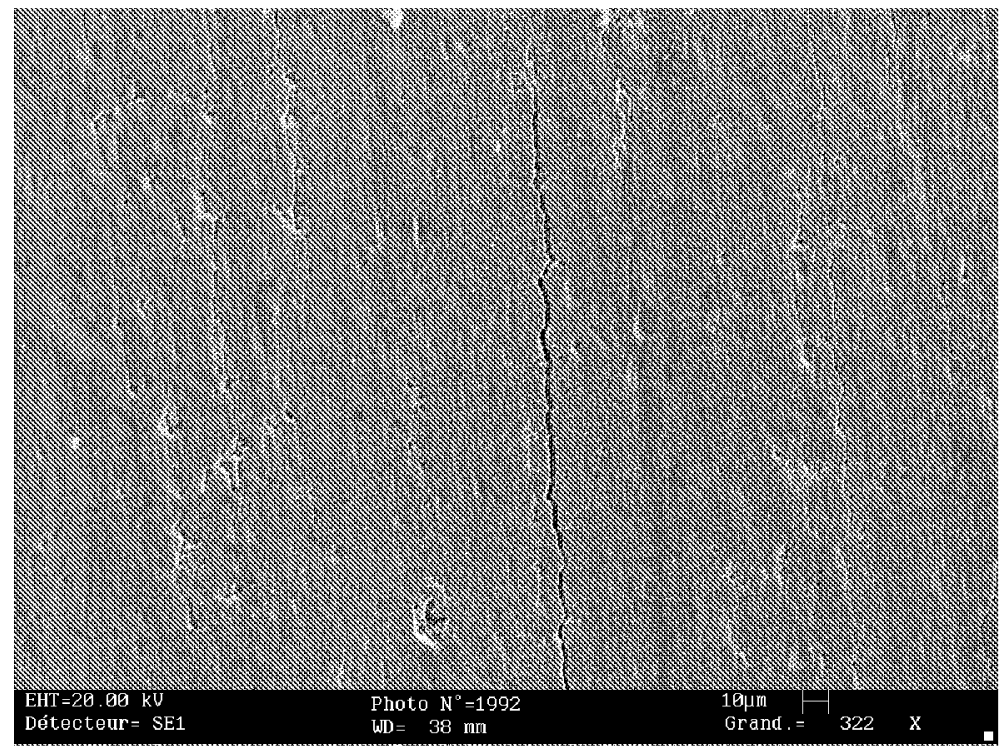

Figure B-8 SEM view of the inner surface of the non-flattened half tube at the limit of the rolling zone 506B. 


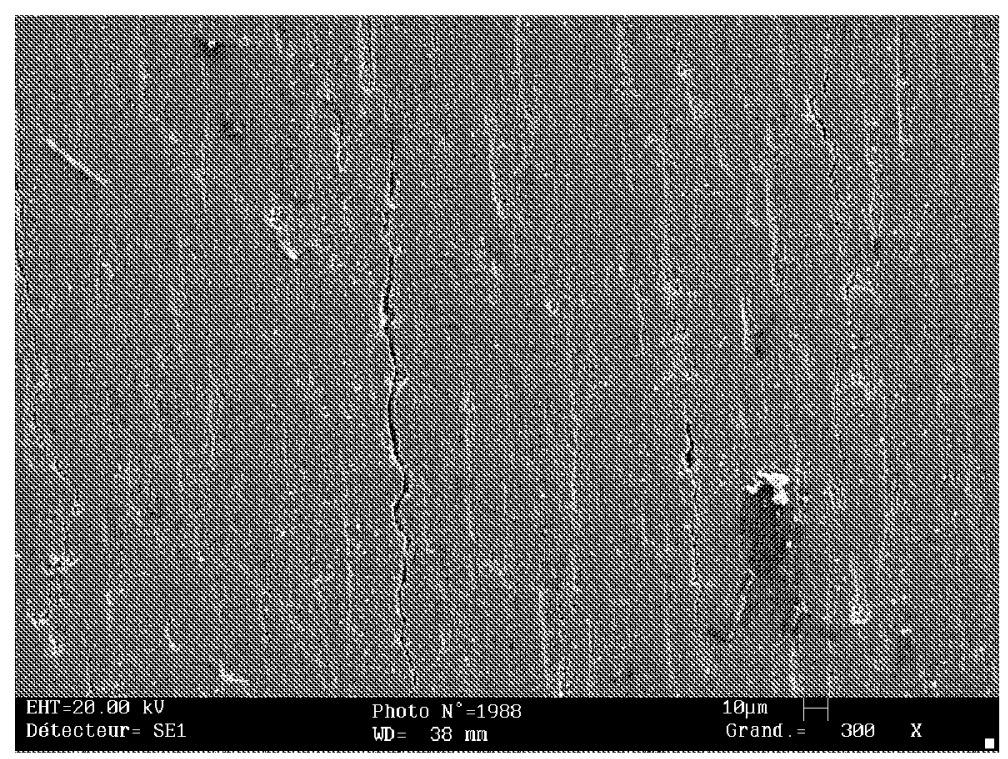

Figure B-9 SEM view of the inner surface of the non flattened half tube at the rolling zone limit $506 \mathrm{H}$.

Examination of the flattened half tube revealed the presence of many microcracks. Figure B-10 and Figure B-11 show views of the limiting edges of the kiss rolling of 506B: some of the opened microcracks corresponded to those that were also observed before flattening but numerous others were new ones opened or created during the mechanical flattening operation. This type of flaw was also observed on parts of the tube which were not rolled, which is remote from the rolled zone. 


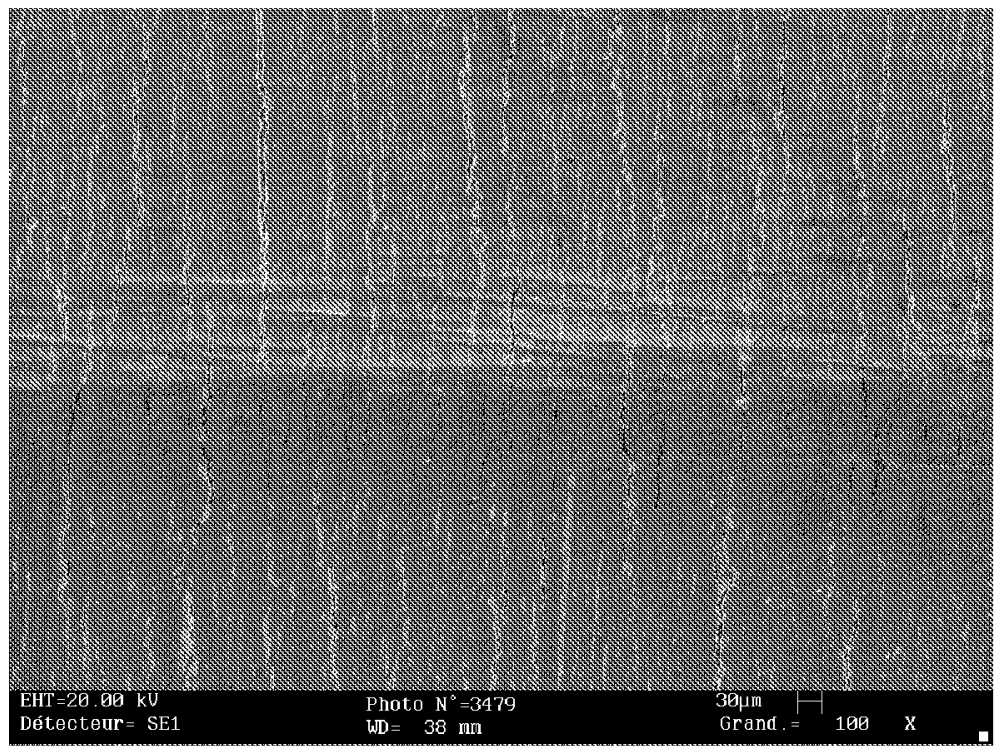

Figure B-10 Limit of the kiss rolling zone of the flattened half tube 506B (Maximum length of the microcracks: $1.5 \mathrm{~mm}$ ).

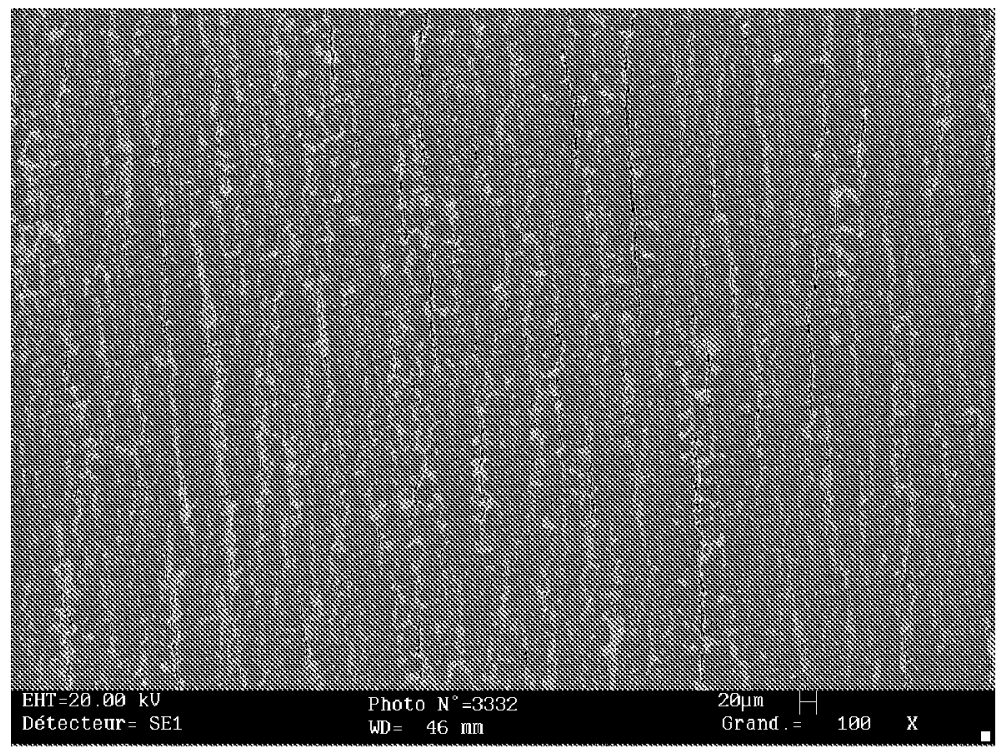

Figure B-11 Limit of the rolling zone of the flattened half tube 506B (Maximum length of the microcracks: $0.5 \mathrm{~mm}$ ). 


\section{$\underline{\text { SEM metallographic examination }}$}

The microcracks were fully characterized by metallographic examination. They were intergranular and their length was always limited to the thickness of the perturbed surface layer on the internal surface of the tube (about $10 \mu \mathrm{m}$ thick in this case). Figure B-12 and Figure B-13 show examples of such flaws observed at the limit of the kiss rolling zone of 506B.

For comparison, Figure B-14 and Figure B-15show typical microcracks observed in a sample taken away from the rolled zone of the flattened half tube. These cracks were also observed to be limited to the perturbed surface layer.

The conclusions of these examinations were:

The wide microcracks were due to the strain induced by rolling and were limited to the hard perturbed surface layer already present on the inside surface of the tube in the as-received condition.

These microcracks were intergranular but did not propagate in the tube during exposure to hydrogenated water at $360^{\circ} \mathrm{C}$ during 60,000 hours exposure. 


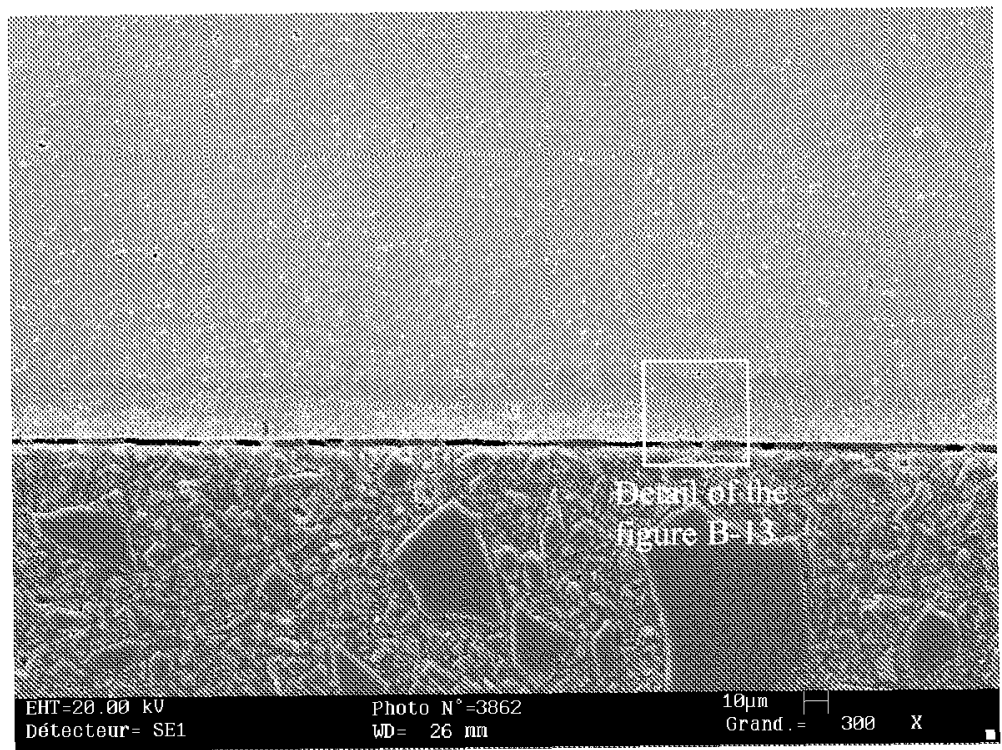

Figure B-12 SEM view of a etched circumferential cross section at the limit of rolling zone 506B.

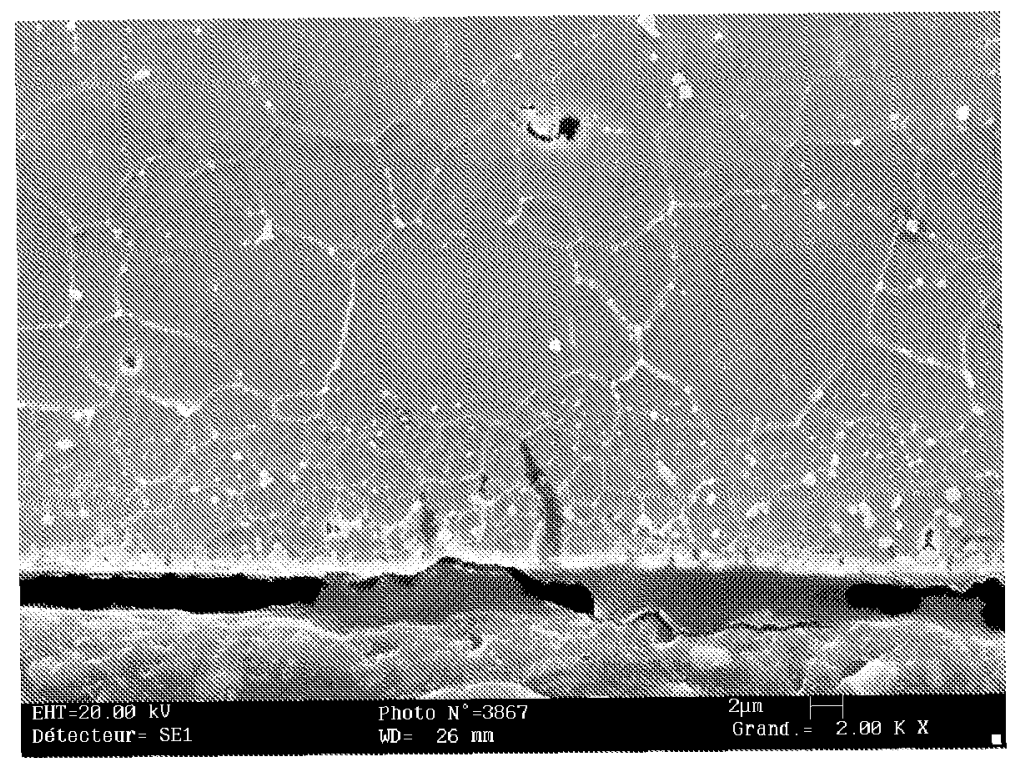

Figure B-13 SEM view of a etched circumferential cross section of the limit of rolling zone 506B. Detailed view. 


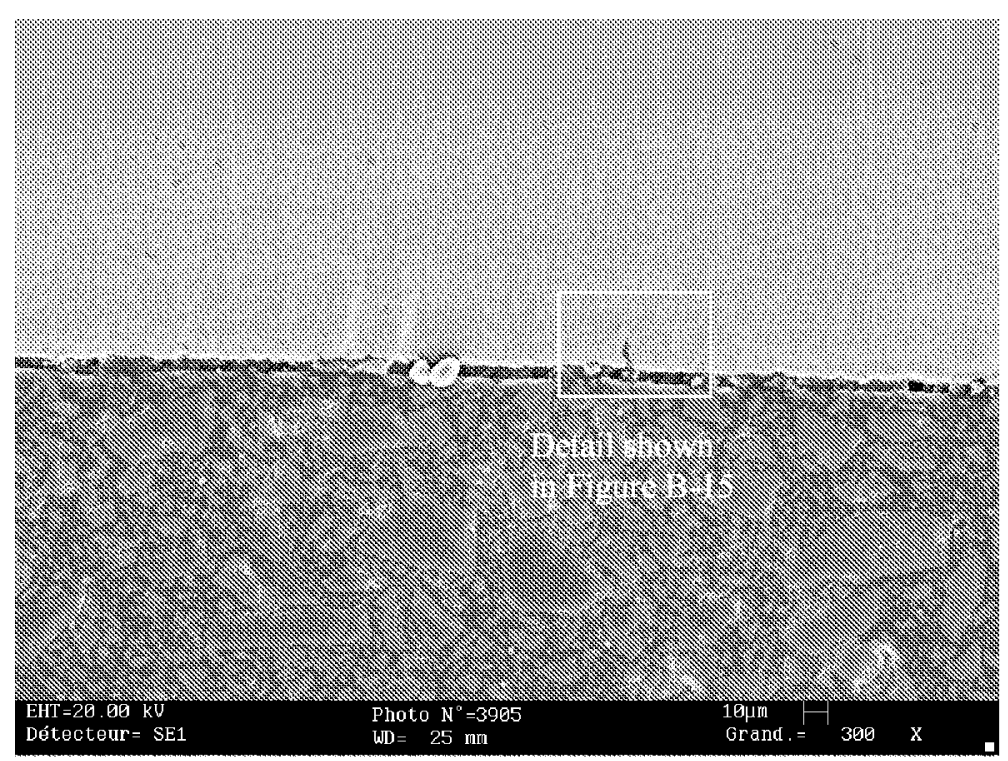

Figure B-14 SEM view of a circumferential cross section of the tube outside the rolling zone (unetched surface).

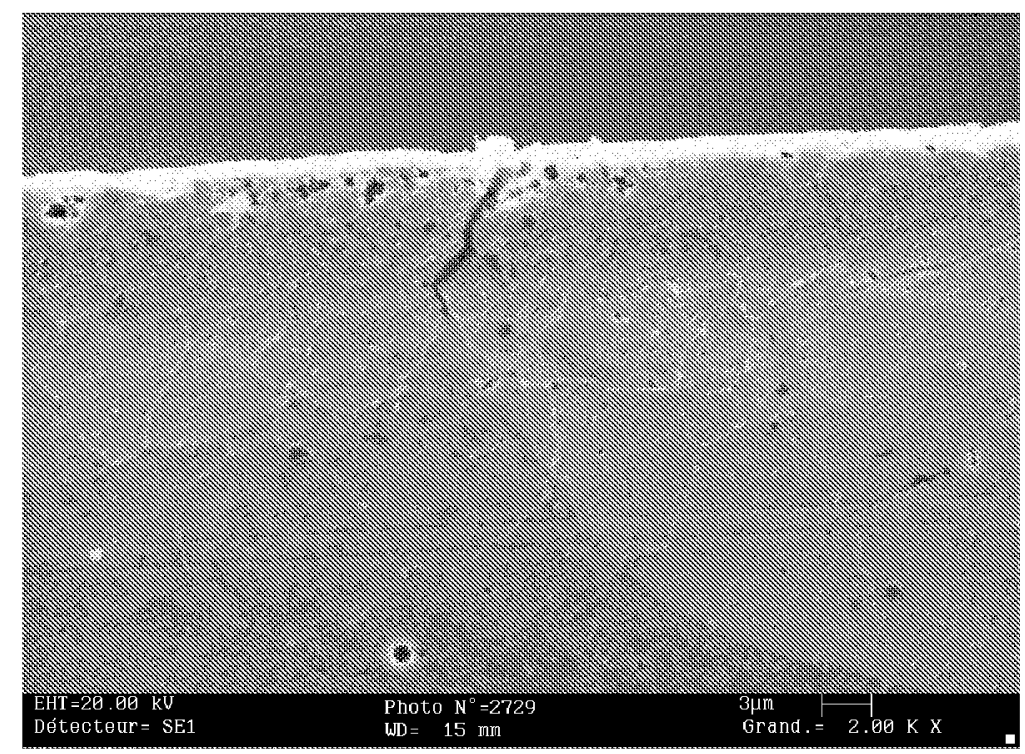

Figure B-15 SEM view of a circumferential cross section of the tube remote from the rolling zone. Detailed view. 
Study of the evolution of the metallurgical structure

The possibility that the microstructure evolved during the exposure test at $360^{\circ} \mathrm{C}$ was examined. A test for IGA susceptibility according to the ASTM A 262 Practice C standard was used. Several coupons were taken from an area remote from the rolled part of the tube of mock-up 506 and from a reference tube of the same heat. Following ASTM A 262 Practice C, they were tested in boiling $25 \%$ nitric acid solution for 48 hours and mass losses were measured. The results are presented in Table B-5.

Table B-5 Mass loss results after the IGA susceptibility test following ASTM A 262 Practice C on Alloy 690 TT tubes

\begin{tabular}{|c|c|}
\hline Material & $\begin{array}{c}\text { Mass loss } \\
\left(\mathbf{m g} / \mathbf{d m}^{2} / \mathrm{day}\right)\end{array}$ \\
\hline Reference tube. As received & 8.75 \\
\hline Reference tube. As received & 9.4 \\
\hline Reference tube. Polished & 1.83 \\
\hline Mock-up 506 tube & 37.9 \\
\hline Mock-up 506 tube & 39.7 \\
\hline Mock-up 506 polished tube & 1.37 \\
\hline
\end{tabular}

The surfaces of the tube coupons were compared, as shown in Figure B-16 and Figure B-17 for the as-received coupons (\# 1 and 4 ) after the nitric acid test. Extensive intergranular attack was observed on the two samples. 


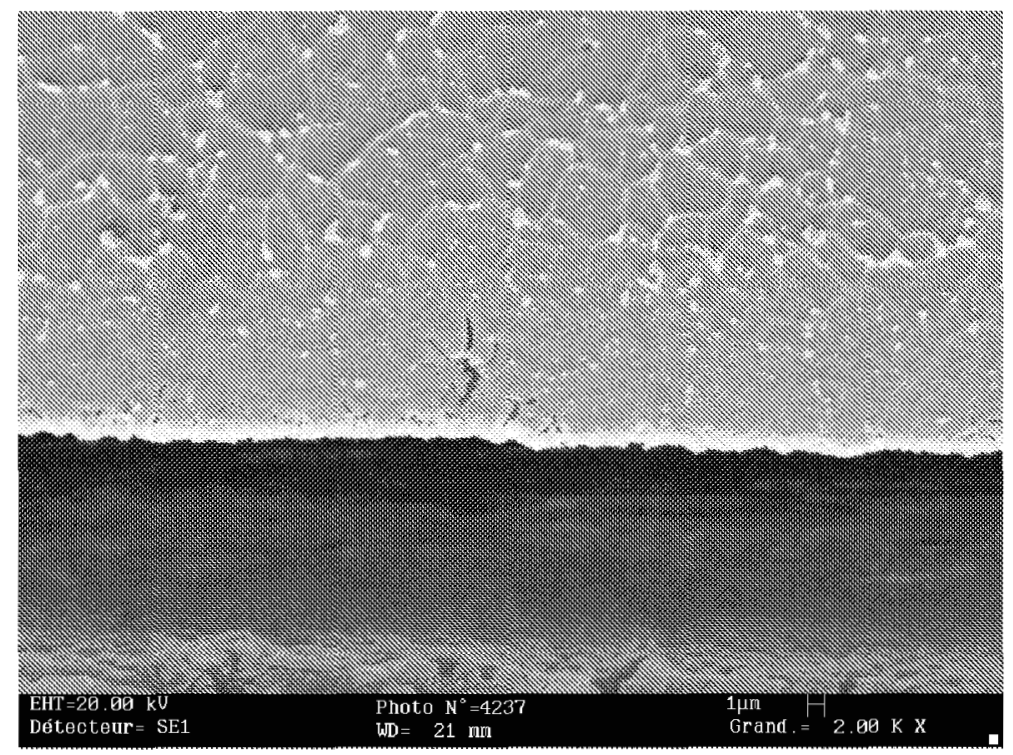

Figure B-16 Reference tube of heat WE094. SEM view of an etched cross section after IGA susceptibility test.

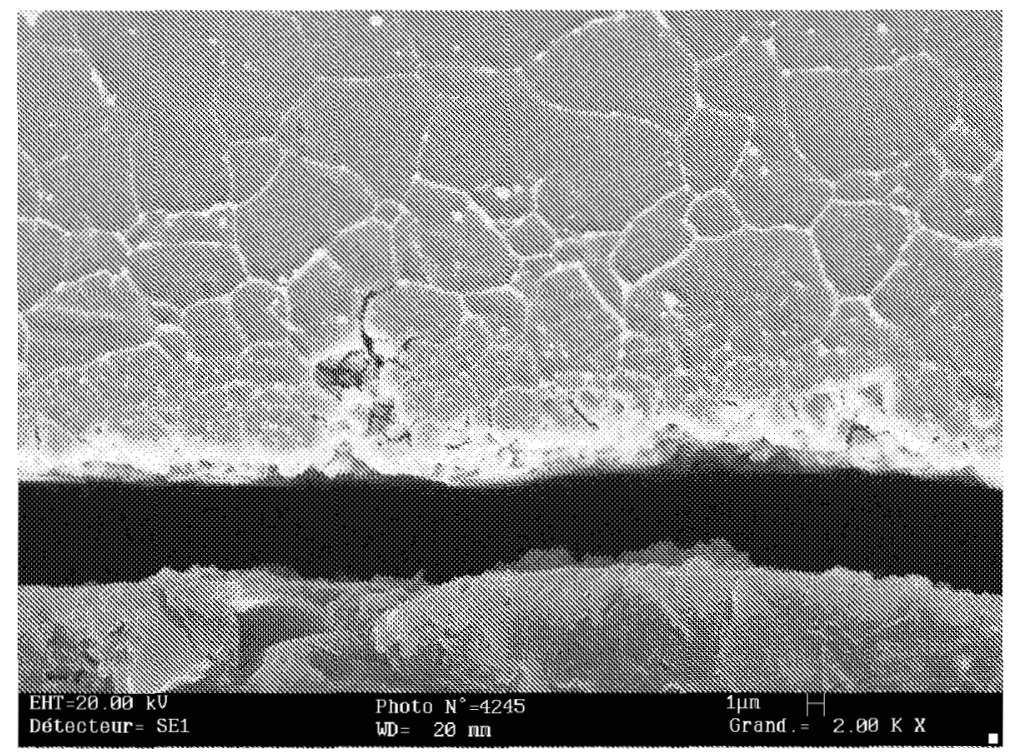

Figure B-17 SEM view of an etched cross section of unstrained tube from mockup 506 after IGA susceptibility test.

The IGA was limited to the thickness of the perturbed surface layer and the mass losses of the polished coupons showed clearly that only the surfaces were sensitized. The mass loss was higher for the coupons of the tube tested for 60,000 hours at $360^{\circ} \mathrm{C}$. Therefore, it seemed that long-term aging at $360^{\circ} \mathrm{C}$ had slightly increased the sensitization of the surface layer of the material. 
B.3.2.2 Examination of mock-ups 502 and 508 after 100,000 hours exposure

The characteristics of these two mock-ups are described in the Table B-6.

Table B-6 Characteristics of mock-ups \#502 and \#508

\begin{tabular}{|c|c|c|c|c|}
\hline \multirow{2}{*}{ Mock-up } & \multicolumn{2}{|c|}{ Rolling } & \multirow{2}{*}{$\begin{array}{c}\text { Kiss rolling } \\
\text { expansion } \\
\varnothing(\mathrm{mm})\end{array}$} & \multirow{2}{*}{ Skip-roll } \\
\hline & $\begin{array}{l}\text { Tube /tubesheet } \\
\text { gap }(\mathrm{mm})\end{array}$ & Over-roll (mm) & & \\
\hline $502 \mathrm{H}$ & 0.4 & +1.5 & 0.15 & \multirow{2}{*}{ No } \\
\hline 502 B & 0.4 & +1.5 & 0.30 & \\
\hline $508 \mathrm{H}$ & 0.95 & -1.5 & 0.15 & \multirow{2}{*}{ Yes } \\
\hline $508 \mathrm{~B}$ & 0.95 & +20 & 0.30 & \\
\hline
\end{tabular}

Mock-up 502 was manufactured with no fabrication anomaly whereas mock-up \#508 had two major non-conformities: a high tube/tubesheet gap and a skip roll. These anomalies were found to be very detrimental for stress corrosion resistance in the case of the Alloy 600 mock-ups (see Section B-4).

These two mock-ups were tested during 100,000 hours at $360^{\circ} \mathrm{C}$ and were examined to look for possible evolution of cracks or metallurgical structure after long-term exposure, in comparison to the mock-up \#506 tested for 60,000 hours. 


\section{Liquid penetrant test}

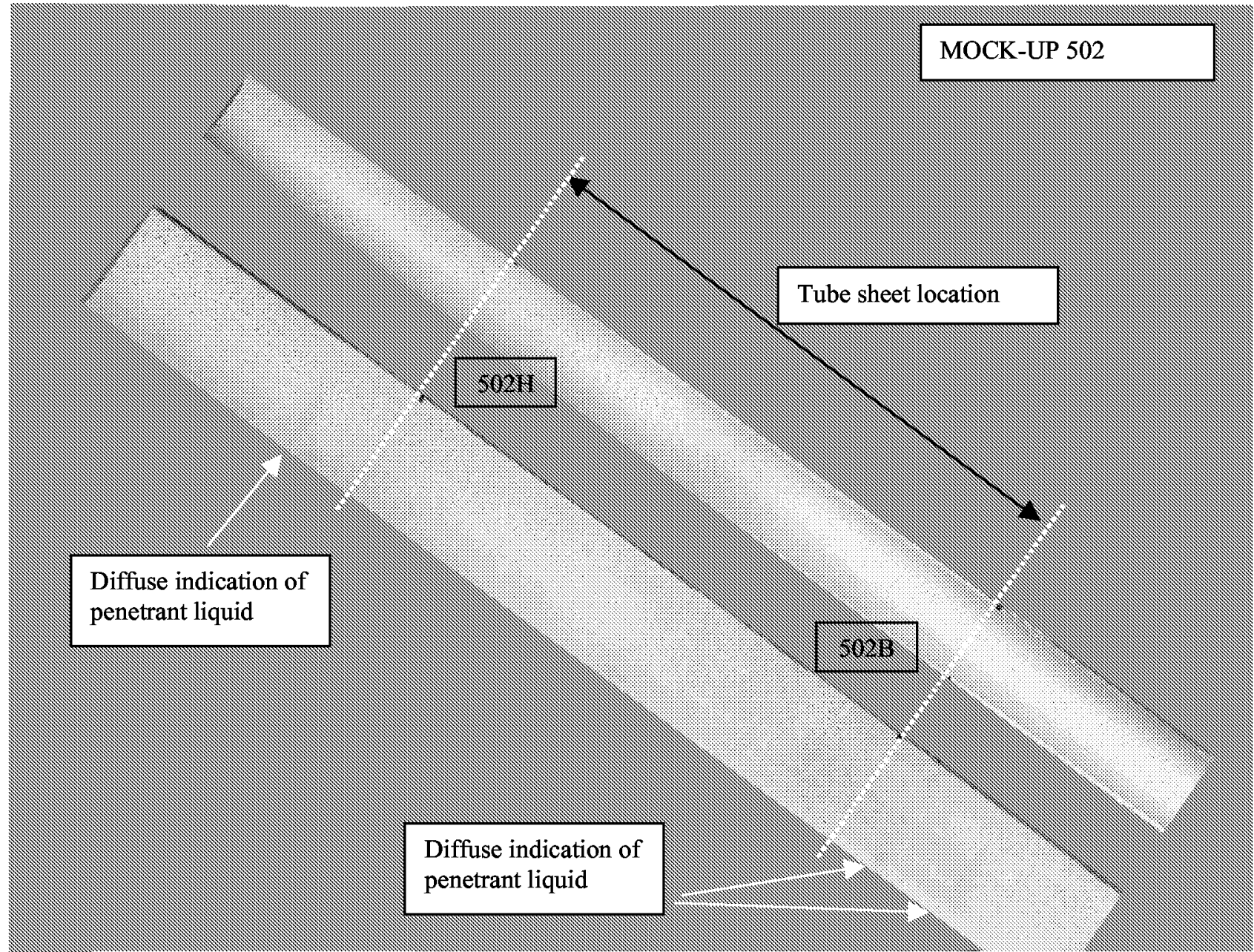

Figure B-18 Liquid penetrant test on mock-up \#502. View of the two half tubes, (one is flattened, the other is not flattened).

After the liquid penetrant test, diffuse indications appeared in the transition zone of the rolling and kiss rolling zone on each mock-up, as observed previously. Figure B-18 shows these features for mock-up \#502. Some diffuse indications were visible on the flattened half tube and, to a lesser extent, on the other non-flattened half tube. However, no clear indications of flaws or cracks were detected on them.

\section{$\underline{\text { SEM surface examination }}$}

In the same way as for mock-up \#506, the internal surfaces of the two mock-ups \#502 and \#508 exposed for 100,000 hours were examined using SEM. The general appearance of the unstrained tube is presented in Figure B-19. Two types of flaw were identified: some small cavities (diameter: 40 to $50 \mu \mathrm{m}$ ), corresponding to scale particles and small holes (diameter of 2 to $5 \mu \mathrm{m}$ ) corresponding to locations of drop out of other inclusions. 


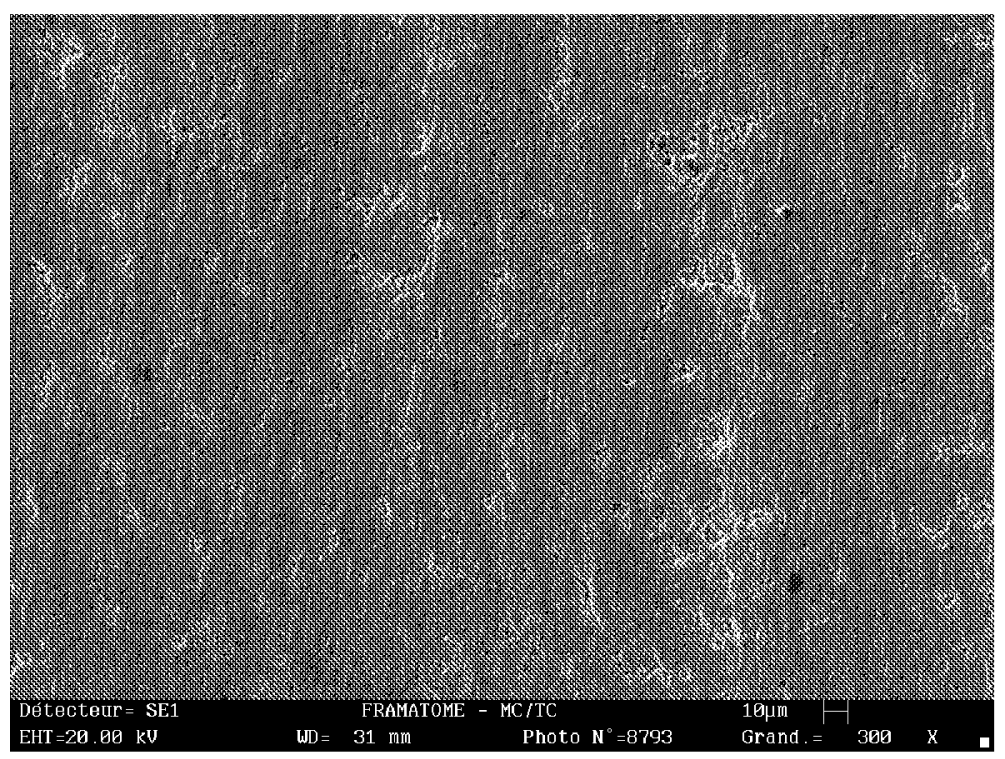

Figure B-19 SEM view of the inner surface of the tube in an unrolled zone. (Non flattened half tube).

After flattening, some microcracks were again observed (see Figure A-20), of which some were related to loss of scale particles.

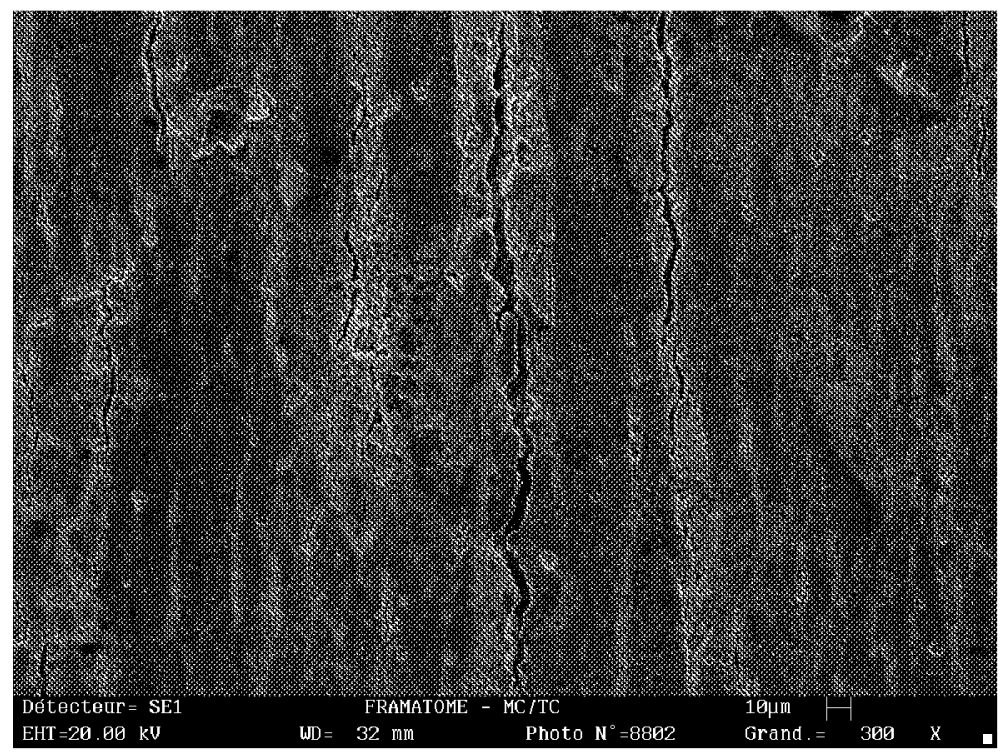

Figure B-20 SEM view of the inner surface of the tube in an unrolled zone. (Flattened half tube).

In the rolling transition zones, some fine cracks were also observed as before on the nonflattened tube (Figure B-21) but many more were detected on the corresponding flattened half tube (Figure B-22). 


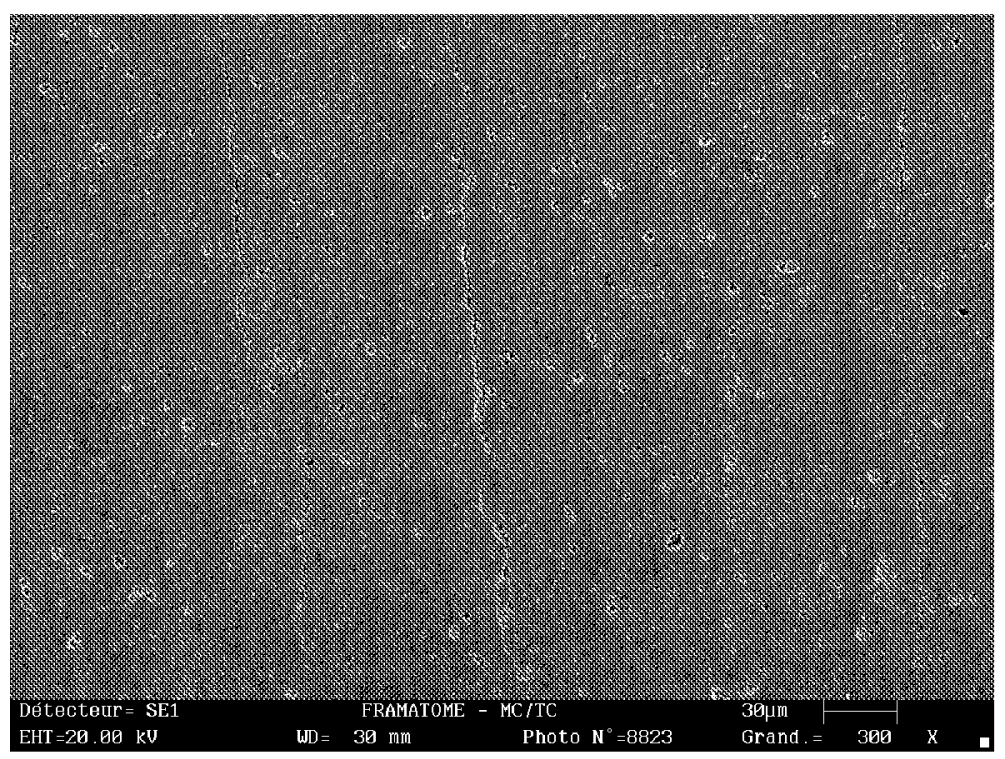

Figure B-21 Mock-up \#508B. SEM view of the inner surface of the non-flattened half tube at the limit of the rolling zone.

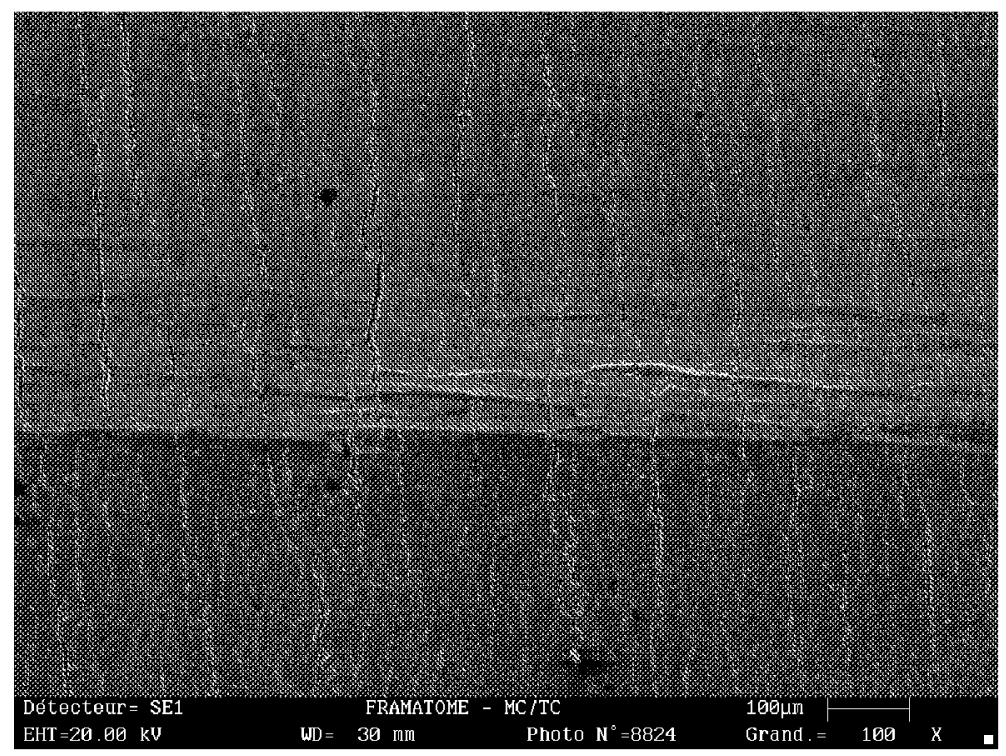

Figure B-22 Mock-up \#508B. SEM view of the inner surface of the flattened half tube at the limit of the rolling zone.

On a metallographic cross section, the cracks appear blunt at the tip and were limited to the perturbed surface layer (Figure B-23 and Figure B-24). 


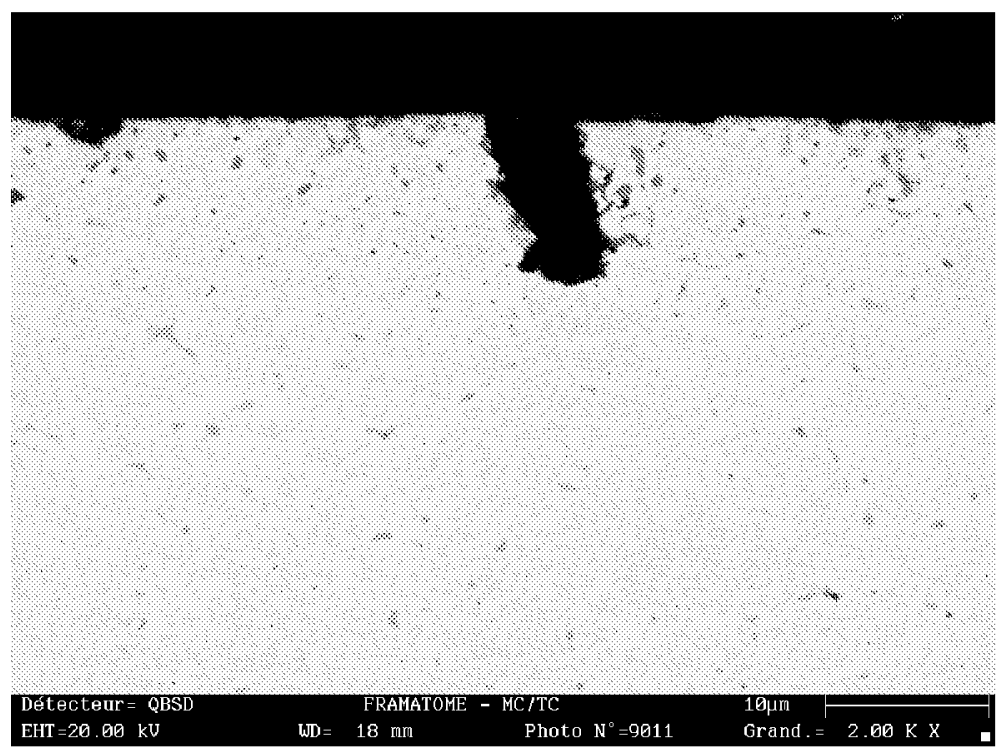

Figure B-23 Mock-up \#508B. SEM view of the non etched circumferential cross section through the rolling limit zone.

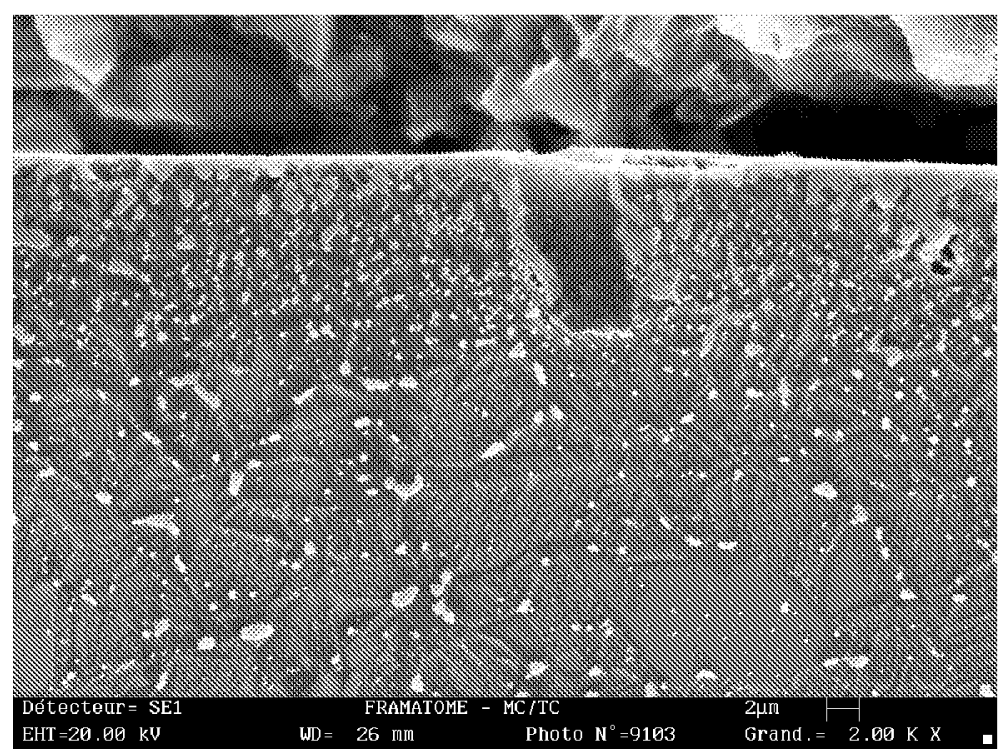

Figure B-24 Mock-up \#508B. SEM view of the etched circumferential cross section at the limit of the rolling zone 


\section{B.3.3 Conclusions}

The main conclusions of the examinations of the mock-ups manufactured with Alloy 690 TT tubing, tested in $360^{\circ} \mathrm{C}$ hydrogenated water are:

- 16 roll transition zones were tested and did not show any leakage after up to 100,000 hours of test;

- Different roll transition manufacturing anomalies were tested: large tube / tubesheet gaps, skip rolls, large over rolls, large kiss rolling. None of these had any detrimental effect on the stress corrosion cracking resistance under the test conditions used;

- No stress corrosion cracks were found to initiate during the tests despite the presence of manufacturing anomalies known to be detrimental in the case of Alloy 600 tubing;

- The bulk Alloy $690 \mathrm{TT}$ material was not sensitized by the aging at $360^{\circ} \mathrm{C}$ during 100,000 hours, but a perturbed surface layer between 10 and $100 \mu \mathrm{m}$ thick was shown to be slightly sensitized before testing and became significantly more sensitized after the longterm aging at $360^{\circ} \mathrm{C}$;

- The Alloy 690 TT material used for the mock-ups came from a pre-production heat which exhibited an inner perturbed layer (fine grain size, dense carbide precipitation, higher hardness). This perturbed material exhibited reduced ductility on the inner tube surface and was susceptible to intergranular microcracking when strained. This microcracking was limited to the thickness of the perturbed surface layer and they did not propagate in hydrogenated water at $360^{\circ} \mathrm{C}$ during 100,000 hours. 


\section{B.4 Alloy 600 TT Mock-Up Results}

\section{B.4.1 Test Results}

Table B-7 gives the as-manufactured characteristics of all the mock-ups that were tested.

The rolling conditions examined can be summarized as follows:

7 zones with standard specification rolling and kiss-rolling, nominal tube / tubesheet gap (0.4 $\mathrm{mm}$ ), nominal over-roll (between -1.5 and $+1.5 \mathrm{~mm}$ ), no in-tubesheet non-conformity.

33 roll transition zones out of specification of which:

21 zones with high over-roll (up to $26 \mathrm{~mm}$ ),

4 roll transitions without kiss rolling,

21 zones with high kiss rolling expansion $(0.30 \mathrm{~mm})$,

4 mock-ups with a skip-roll in the tubesheet,

18 zones with a high tube / tubesheet gap $(0.95 \mathrm{~mm})$,

2 mock-ups with lack of roll overlap in the tubesheet. 
Table B-7 Characteristics of the tested mock-ups

\begin{tabular}{|c|c|c|c|c|c|c|c|}
\hline Mock-up & Heat & $\begin{array}{l}\text { Thermal } \\
\text { Treatment }\end{array}$ & $\begin{array}{l}\text { Tube to } \\
\text { tubesheet } \\
\text { gap (mm) }\end{array}$ & $\begin{array}{c}\text { Rolling } \\
\text { area }\end{array}$ & $\begin{array}{l}\text { Over- } \\
\text { roll } \\
(\mathrm{mm})\end{array}$ & $\begin{array}{l}\text { Kiss-roll } \\
\text { expansion } \\
(\mathrm{mm})\end{array}$ & $\begin{array}{c}\text { In-tubesheet } \\
\text { non } \\
\text { conformity }\end{array}$ \\
\hline \multirow[t]{2}{*}{1} & \multirow[t]{2}{*}{ WD 281} & \multirow[t]{2}{*}{ MA } & \multirow[t]{2}{*}{0.4} & $1 \mathrm{H}$ & -1.5 & 0 & \\
\hline & & & & 1B & 3 & 0 & \\
\hline \multirow[t]{2}{*}{2} & \multirow[t]{2}{*}{ WD 281} & \multirow[t]{2}{*}{ MA } & \multirow[t]{2}{*}{0.4} & $2 \mathrm{~B}$ & +6 & 0 & \\
\hline & & & & $2 \mathrm{~B}$ & +20 & 0 & \\
\hline \multirow[t]{2}{*}{3} & \multirow[t]{2}{*}{ WD 281} & \multirow[t]{2}{*}{ TT } & \multirow[t]{2}{*}{0.4} & $3 \mathrm{H}$ & -1.5 & 0.15 & \\
\hline & & & & 3B & +20 & 0.15 & \\
\hline \multirow[t]{2}{*}{4} & \multirow[t]{2}{*}{ NX3335 } & \multirow[t]{2}{*}{ MA } & \multirow[t]{2}{*}{0.4} & $4 \mathrm{H}$ & +1.5 & 0.30 & \\
\hline & & & & $4 \mathrm{~B}$ & +20 & 0.30 & \\
\hline \multirow[t]{2}{*}{5} & \multirow[t]{2}{*}{ WD281 } & \multirow[t]{2}{*}{ MA } & \multirow[t]{2}{*}{0.4} & $5 \mathrm{H}$ & -1.5 & 0.15 & \multirow[t]{2}{*}{ Skip roll } \\
\hline & & & & $5 B$ & +20 & 0.15 & \\
\hline \multirow[t]{2}{*}{6} & \multirow[t]{2}{*}{ WD 281} & \multirow[t]{2}{*}{ MA } & \multirow[t]{2}{*}{0.4} & $6 \mathrm{H}$ & -1.5 & 0.15 & \multirow[t]{2}{*}{ Skip roll } \\
\hline & & & & $6 \mathrm{~B}$ & +20 & 0.30 & \\
\hline \multirow[t]{2}{*}{7} & \multirow[t]{2}{*}{ WD 281} & \multirow[t]{2}{*}{ TT } & 0.4 & $7 \mathrm{H}$ & -1.5 & 0.15 & Skip roll \\
\hline & & & & $7 \mathrm{~B}$ & +20 & 0.30 & \\
\hline 8 & WD 281 & MA & 0.4 & $8 \mathrm{H}$ & -1.5 & 0.15 & \\
\hline & & & & $8 \mathrm{~B}$ & +20 & 0.30 & \\
\hline 9 & NX3335 & MA & 0.95 & $9 \mathrm{H}$ & +20 & 0.30 & \\
\hline & & & & $9 \mathrm{~B}$ & +20 & 0.30 & \\
\hline 10 & WD 281 & TT & 0.4 & $10 \mathrm{H}$ & -1.5 & 0.30 & \\
\hline & & & & $10 \mathrm{~B}$ & +1.5 & 0.30 & \\
\hline 11 & WD 281 & TT & 0.4 & $11 \mathrm{H}$ & +20 & 0.30 & \\
\hline & & & & $11 \mathrm{~B}$ & +20 & 0.30 & \\
\hline 12 & WD 281 & MA & 0.4 & $12 \mathrm{H}$ & +1.5 & 0.30 & \\
\hline & & & & $12 \mathrm{~B}$ & +20 & 0.30 & \\
\hline 14 & WD 281 & MA & 0.95 & $14 \mathrm{H}$ & -1.5 & 0.15 & \\
\hline & & & & 14B & +1.5 & 0.15 & \\
\hline 15 & WD 281 & MA & 0.95 & $15 \mathrm{H}$ & +20 & 0.15 & \\
\hline & & & & $15 B$ & +20 & 0.15 & \\
\hline 16 & WD 281 & $\mathrm{TT}$ & 0.95 & $16 \mathrm{H}$ & -1.5 & 0.15 & Lack of \\
\hline & & & & $16 \mathrm{~B}$ & +1.5 & 0.15 & \\
\hline & WD 281 & TT & 0.95 & $17 \mathrm{H}$ & +20 & 0.15 & \\
\hline
\end{tabular}




\begin{tabular}{|c|c|c|c|c|c|c|c|}
\hline 17 & WD 281 & TT & 0.95 & $17 \mathrm{H}$ & +20 & 0.15 & \\
\hline \multirow[t]{2}{*}{18} & \multirow[t]{2}{*}{ WD 281} & \multirow[t]{2}{*}{ MA } & \multirow[t]{2}{*}{0.95} & $18 \mathrm{~B}$ & +20 & 0.38 & \\
\hline & & & & $18 \mathrm{~B}$ & +20 & 0.30 & \\
\hline \multirow[t]{2}{*}{19} & \multirow[t]{2}{*}{ WD 281} & \multirow[t]{2}{*}{ MA } & \multirow[t]{2}{*}{0.95} & $19 \mathrm{H}$ & -1.5 & 0.30 & \multirow{2}{*}{$\begin{array}{l}\text { Lack of } \\
\text { overlap }\end{array}$} \\
\hline & & & & $19 \mathrm{~B}$ & +1.5 & 0.30 & \\
\hline \multirow[t]{4}{*}{20} & \multirow[t]{2}{*}{ WD 281} & \multirow[t]{2}{*}{$\mathrm{TT}$} & \multirow[t]{2}{*}{0.95} & $20 \mathrm{H}$ & -1.5 & 0.30 & \\
\hline & & & & $20 \mathrm{~B}$ & +1.5 & 0.30 & \\
\hline & & & & $21 \mathrm{H}$ & +1.5 & 0.30 & \\
\hline & & & & $21 \mathrm{~B}$ & +20 & 0.30 & \\
\hline
\end{tabular}

The profilometry of each mock-up was verified by ET or UT inspection techniques. All specific as-manufactured characteristics of each mock-up were thus identified and recorded. For example, in Figure B-25 and Figure B-26, a part of the mock-up 21H (by ET), with a skip roll inside the tubesheet and a part of the mock-up 3H (by UT), with a normal kiss-roll transition are identified. For mock-up $3 \mathrm{H}$, the determination of the profile at different angular coordinates shows clearly that the kiss-rolling process was not homogeneous on the whole circumference of the tube.

As described earlier, the test environment was pure, hydrogenated, demineralized water with an initial conductivity of less than $1 \mu \mathrm{S} / \mathrm{cm}$. After, a test period of about 10,000 hours, the water environment from several mock-ups was sampled and analyzed. The results are given in Table B-8.

Table B-8 Chemical analyses of the water environment from several mock-ups after a test period of 10,000 hours

\begin{tabular}{|c|c|c|c|c|}
\hline Mock-up & \#1 & \#8 & \# 10 & \# 12 \\
\hline $\mathrm{Cl}^{-}(\mathbf{m g} / \mathbf{k g})$ & 0.7 & 0.9 & 0.4 & 0.5 \\
\hline$F^{\prime}(\mathrm{mg} / \mathbf{k g})$ & 0.4 & 0.4 & 0.9 & 0.8 \\
\hline $\mathrm{Na}^{+}(\mathrm{mg} / \mathrm{kg})$ & 0.2 & 0.15 & 0.15 & 0.15 \\
\hline $\mathrm{SiO}_{2}(\mathrm{mg} / \mathrm{kg})$ & 5.3 & 9.2 & 7.1 & 7.2 \\
\hline $\begin{array}{l}\text { Cond. }(\mu S / \\
\mathrm{cm})\end{array}$ & 4.54 & 5.55 & 6.25 & 8.33 \\
\hline
\end{tabular}




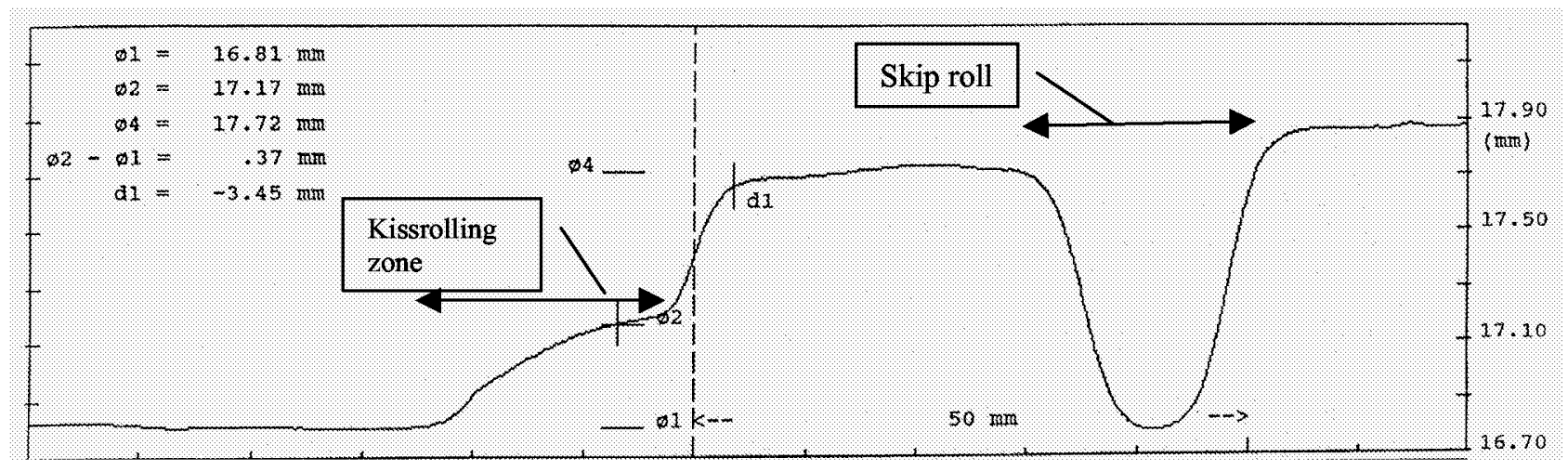

Figure B-25 Profilometry of mock-up $21 \mathrm{H}$ determined by an eddy current technique. 


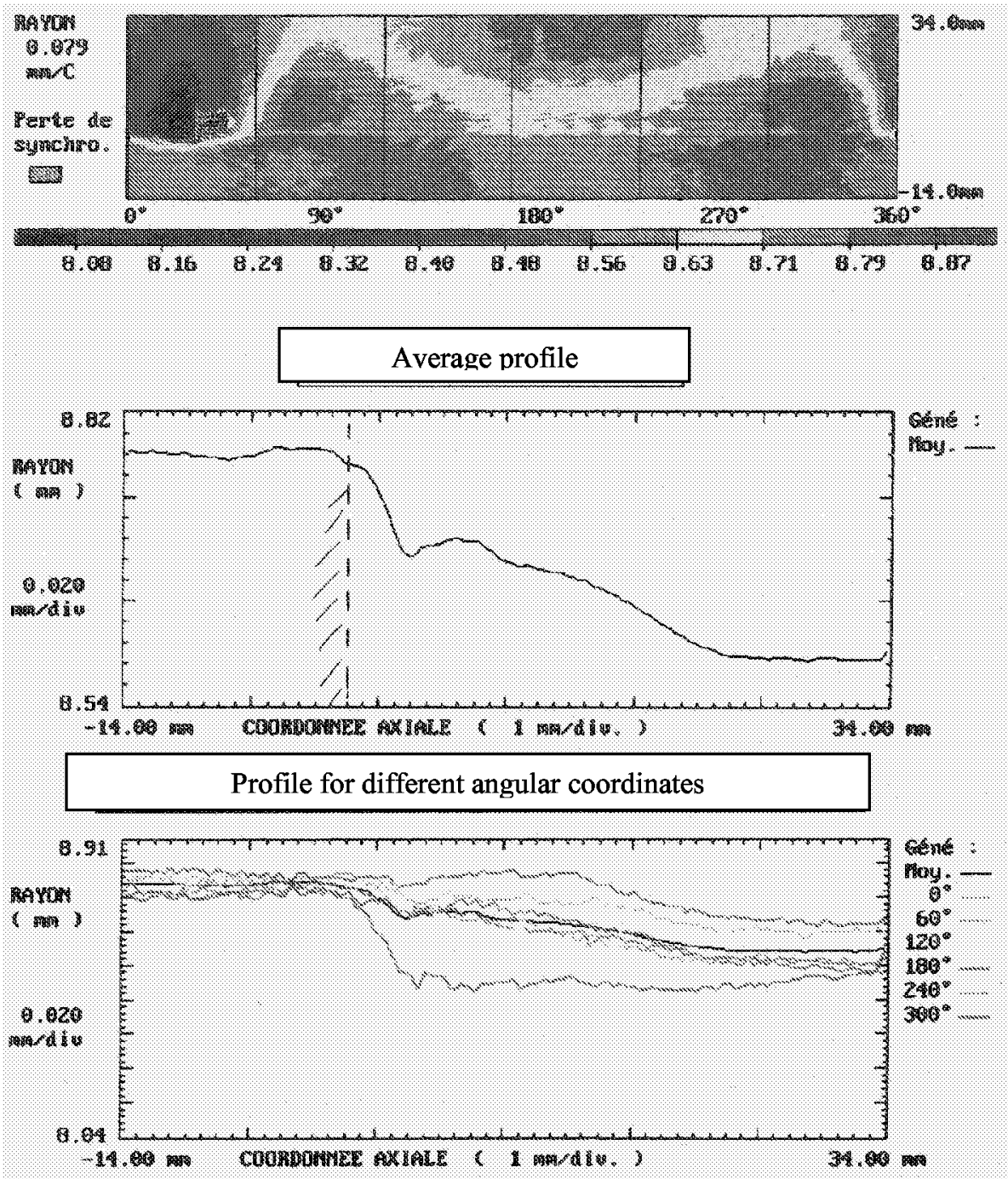

Figure B-26 Profilometry of mock-up.

Table B-9 and Table B-10 give the principal characteristics and test durations for all the Alloy 600 mock-ups. The column marked "result" in these tables gives the locations (see footnote to Table B-10) of the observed through-wall cracks leading to loss of pressure in the capsules.

Table B-9 Results for all mock-ups fabricated from Alloy 600 heat WD281

\begin{tabular}{|c|c|c|c|c|c|c|c|c|}
\hline Mock-up & $\begin{array}{c}\text { Heat } \\
\text { treatment }\end{array}$ & $\begin{array}{c}\text { T/TS } \\
\text { Gap } \\
(\mathrm{mm})\end{array}$ & $\begin{array}{l}\text { Kiss } \\
\text { rolling } \\
(\mathrm{mm})\end{array}$ & $\begin{array}{l}\text { Skip } \\
\text { roll }\end{array}$ & $\begin{array}{c}\text { Intended } \\
\text { Over-roll } \\
(\mathrm{mm})\end{array}$ & $\begin{array}{l}\text { Measured } \\
\text { Over-roll } \\
(\mathrm{mm})\end{array}$ & $\begin{array}{l}\text { Duration } \\
\text { (h) }\end{array}$ & Result \\
\hline $1 B$ & \multirow{2}{*}{ MA } & \multirow{2}{*}{0.4} & \multirow{2}{*}{0} & \multirow{2}{*}{ no } & +3 & +10 & 14400 & $\mathrm{RTZ}$ \\
\hline $1 \mathrm{H}$ & & & & & -1.5 & 0 & 20250 & RTZ \\
\hline 2B & \multirow{2}{*}{ MA } & \multirow{2}{*}{0.4} & \multirow{2}{*}{0} & \multirow{2}{*}{ no } & - & - & - & - \\
\hline $2 \mathrm{H}$ & & & & & +6 & +6 & 22800 & $\mathrm{RTZ}$ \\
\hline
\end{tabular}




\begin{tabular}{|c|c|c|c|c|c|c|c|c|}
\hline $3 B$ & \multirow{2}{*}{ TT } & \multirow{2}{*}{0.4} & \multirow{2}{*}{0.15} & \multirow{2}{*}{ no } & +20 & - & 10000 & $\mathrm{RTZ}$ \\
\hline $3 \mathrm{H}$ & & & & & -1.5 & +1 & 18400 & RTZ \\
\hline $5 B$ & \multirow{2}{*}{ MA } & \multirow{2}{*}{0.4} & \multirow{2}{*}{0.15} & \multirow{2}{*}{ yes } & +20 & +8 & 1500 & SR \\
\hline $5 \mathrm{H}$ & & & & & -1.5 & 4 & 10600 & $\mathrm{RTZ}$ \\
\hline $6 \mathrm{~B}$ & \multirow{2}{*}{ MA } & \multirow{2}{*}{0.4} & \multirow{2}{*}{$\begin{array}{l}0.15 \\
0.30\end{array}$} & \multirow{2}{*}{ yes } & -1.5 & 0 & \multirow{2}{*}{1900} & \multirow{2}{*}{ SR } \\
\hline $6 \mathrm{H}$ & & & & & +20 & +23 & & \\
\hline 7B & \multirow{2}{*}{ TT } & \multirow{2}{*}{0.4} & \multirow{2}{*}{0.30} & \multirow{2}{*}{ yes } & +20 & +26 & 11100 & $\mathrm{OZ}$ \\
\hline $7 \mathrm{H}$ & & & & & -1.5 & +3 & 11000 & SR \\
\hline $8 B$ & \multirow{2}{*}{ MA } & \multirow{2}{*}{0.4} & \multirow{2}{*}{0.30} & \multirow{2}{*}{ no } & +20 & +23 & 11750 & $\mathrm{RTZ}$ \\
\hline $8 \mathrm{H}$ & & & & & -1.5 & +2 & 12850 & RTZ \\
\hline 10B & \multirow{2}{*}{$\mathrm{TT}$} & \multirow{2}{*}{0.4} & \multirow{2}{*}{0.30} & \multirow{2}{*}{ no } & +1.5 & - & \multirow{2}{*}{34000} & \multirow{2}{*}{ No leak } \\
\hline $10 \mathrm{H}$ & & & & & -1.5 & - & & \\
\hline 11B & \multirow{2}{*}{ TT } & 04 & 030 & n & +20 & +22 & 10750 & $\mathrm{RTZ}$ \\
\hline $11 \mathrm{H}$ & & 0.4 & 0.30 & no & +20 & & 10500 & $\mathrm{RTZ}$ \\
\hline $12 B$ & $M A$ & 04 & 030 & $\mathrm{mo}$ & +20 & +24 & 20000 & RTZ \\
\hline $12 \mathrm{H}$ & IVIA & 0.4 & 0.30 & no & +1.5 & - & 30000 & No leak \\
\hline 14B & MA & 095 & 015 & no & +1.5 & +1.5 & 1300 & $\mathrm{RTZ}$ \\
\hline $14 \mathrm{H}$ & & & & 110 & -1.5 & +2 & 800 & RTZ \\
\hline 15B & MA & 0.95 & 0.15 & no & +20 & +23 & 3800 & $\mathrm{RTZ}$ \\
\hline $15 \mathrm{H}$ & & & & & +20 & +23 & 4050 & $\mathrm{RTZ}$ \\
\hline 16B & & 095 & 015 & & +1.5 & +7 & 3500 & 7ח \\
\hline $16 \mathrm{H}$ & 11 & 0.95 & 0.75 & no & -1.5 & +2 & 3500 & $0 \angle$ \\
\hline 17B & TT & 095 & 015 & no & +20 & & 5400 & $\mathrm{RTZ}$ \\
\hline $17 \mathrm{H}$ & 11 & & & 110 & +20 & +23 & 5900 & RTZ \\
\hline $18 B$ & $\mathrm{MA}$ & 095 & 030 & 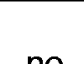 & +20 & +23 & 4000 & No leak \\
\hline $18 \mathrm{H}$ & VIA & 0.90 & 0.00 & 110 & +20 & +23 & 4000 & RTZ \\
\hline $19 B$ & $\mathrm{MA}$ & 095 & 030 & $m$ & -1.5 & +1 & 1600 & 7ח \\
\hline $19 \mathrm{H}$ & $\mathrm{NIA}$ & 0.50 & 0.00 & 110 & +1.5 & +6 & 1000 & $0<$ \\
\hline $20 \mathrm{~B}$ & TT & 095 & 030 & no & +1.5 & & 1800 & $\mathrm{RTZ}$ \\
\hline $20 \mathrm{H}$ & 11 & 0.90 & 0.30 & no & -1.5 & +2 & 1500 & RTZ \\
\hline 21B & MA & 095 & 030 & vec & +20 & +25 & 3800 & RTZ \\
\hline $21 \mathrm{H}$ & IVIA & 0.95 & 0.30 & yes & +1.5 & +2 & 3000 & No leak \\
\hline
\end{tabular}

RTZ : cracked in roll transition zone - SR : cracked in skip roll - OZ : cracked in overlap zone 
Table B-10 Results for all mock-ups fabricated from Alloy 600 heat NX3335

\begin{tabular}{|c|c|c|c|c|c|c|}
\hline $\begin{array}{c}\text { Mock- } \\
\text { up }\end{array}$ & $\begin{array}{c}\text { T/TS } \\
\text { Gap } \\
(\mathrm{mm})\end{array}$ & $\begin{array}{l}\text { Kiss } \\
\text { rolling } \\
(\mathrm{mm})\end{array}$ & $\begin{array}{l}\text { Skip } \\
\text { roll }\end{array}$ & $\begin{array}{c}\text { Intended } \\
\text { Over-roll } \\
(\mathrm{mm})\end{array}$ & $\begin{array}{l}\text { Duration } \\
\text { (h) }\end{array}$ & Result \\
\hline $4 B$ & \multirow[t]{2}{*}{0.4} & \multirow[t]{2}{*}{0.30} & \multirow[t]{2}{*}{ No } & +20 & 19600 & RTZ \\
\hline $4 \mathrm{H}$ & & & & +1.5 & 27000 & RTZ \\
\hline $9 B$ & \multirow[t]{2}{*}{0.95} & \multirow[t]{2}{*}{0.30} & \multirow[t]{2}{*}{ No } & +20 & 11300 & RTZ \\
\hline $9 \mathrm{H}$ & & & & +20 & 12150 & RTZ \\
\hline
\end{tabular}

RTZ : cracked in roll transition zone

\section{B.4.2 Mock-up examinations}

As previously explained, most of the leaking mock-ups were examined by ET or UT nondestructive techniques, and then by PT and optical microscopy in order to determine the cause of cracking (inevitably stress corrosion cracking initiated inside the tube). Several mock-ups that were not destructively examined were retained for use in another program.

The location and length of the cracks detected by non-destructive testing (NDT) were compared with the results of the destructive examinations and a very good correlation was obtained. All detected defects were correlated with actual cracks. However, several cracks were not detected by NDT when their length was shorter than $2 \mathrm{~mm}$.

As an example, Figure B-27 and Figure B-28 show the results obtained for mock-up 17H using the EC technique. The profile was determined with an axial probe and the cracks shape with a rotating probe. Figure B-29 shows photographs of the corresponding half-tubes after liquid dye penetrant testing of mock-up $17 \mathrm{H}$ while Figure B-30 shows macro-photographs of two of the detected cracks.

The main observations were:

All the cracks were axial

All the cracks were located in the roll transition zones, i.e., the roll transition zone at the edge of the tubesheet (RTZ), or the two transition zones of the skip rolls (SR), or the transition zone due to lack of overlap between two rolling steps (OZ).

The lengths of the through-wall cracks were between 1 and $9 \mathrm{~mm}$. The longest cracks were located within the tubesheet, (OZ or SR). 


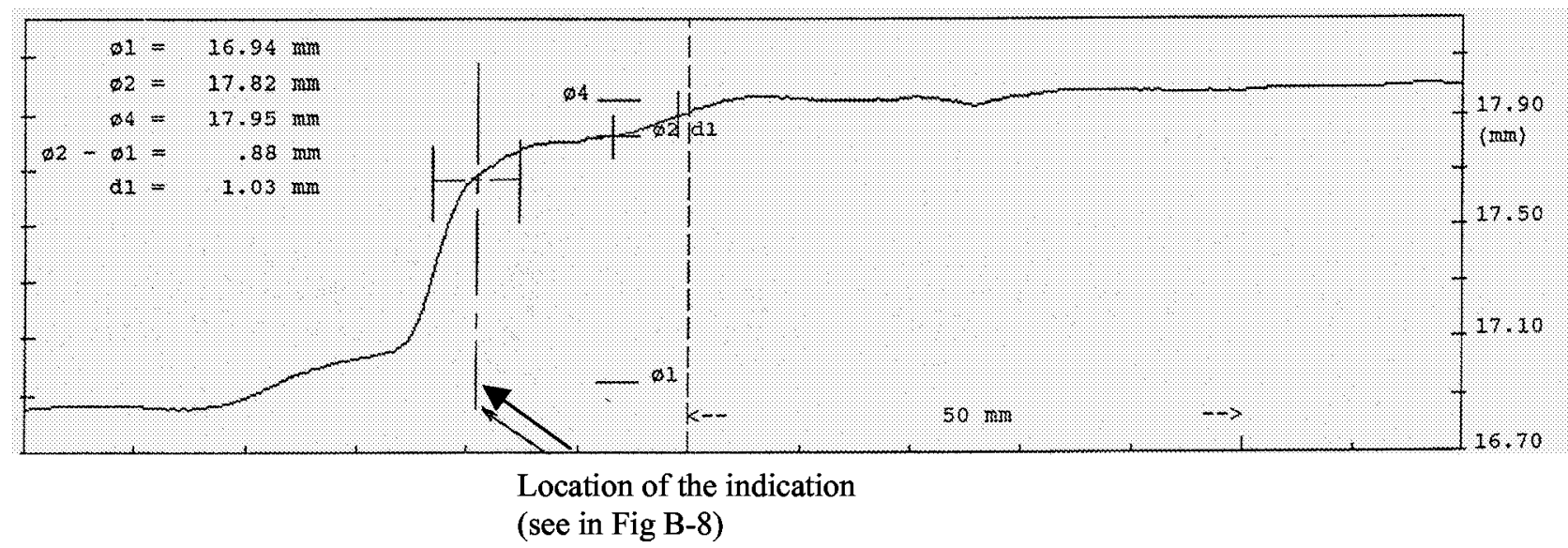

Figure B-27 Profilometry of mock-up 17-H showing the location of the cracks detected by the EC technique.

Tube sheet

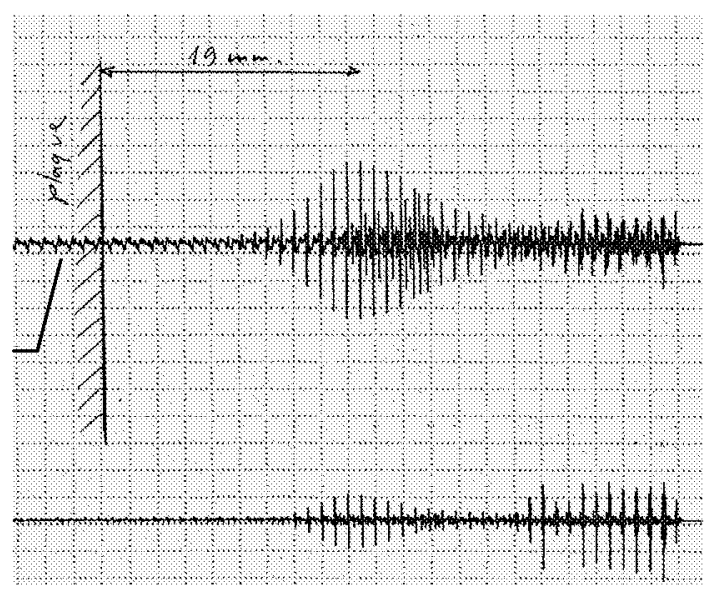

Figure B-28 Detection and location of cracks on mock-up 17H found at the limit of the kiss roll by an EC technique. 


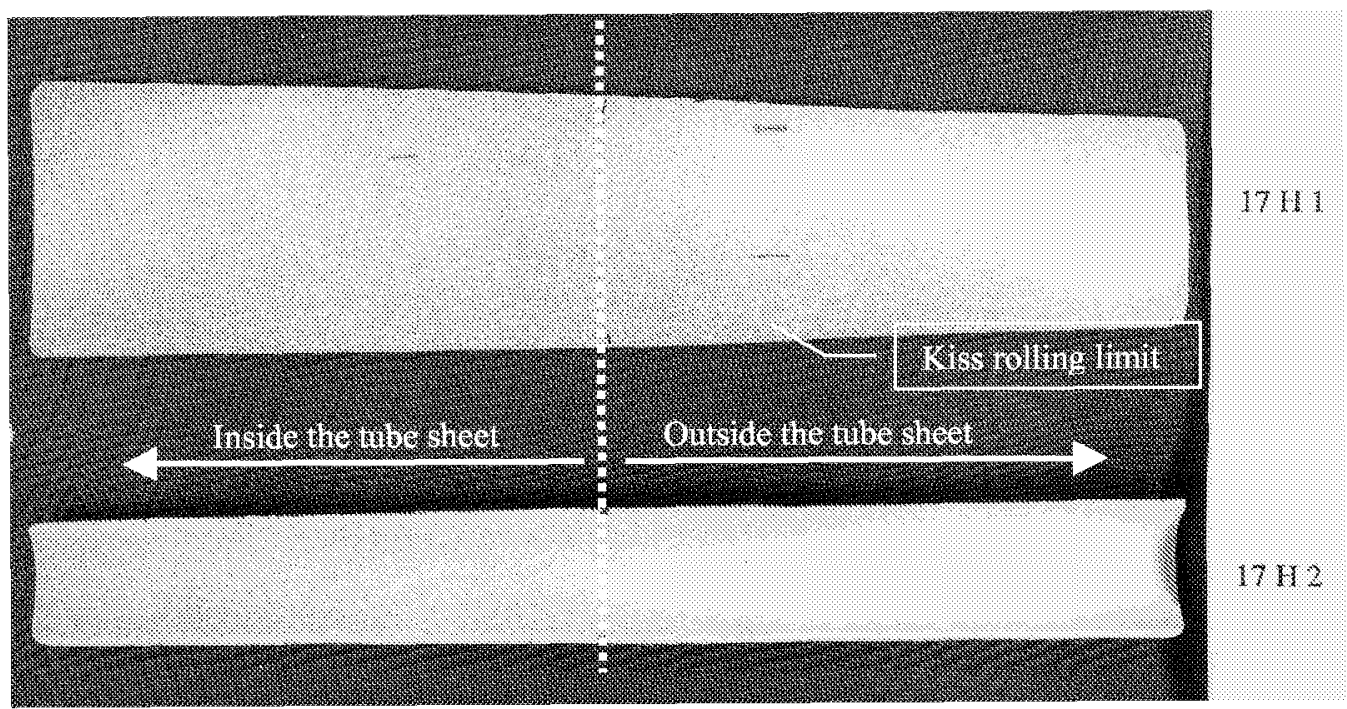

Figure B-29 Liquid dye penetrant test on mock-up 17H. View of the two half tubes after test showing the detected cracks.
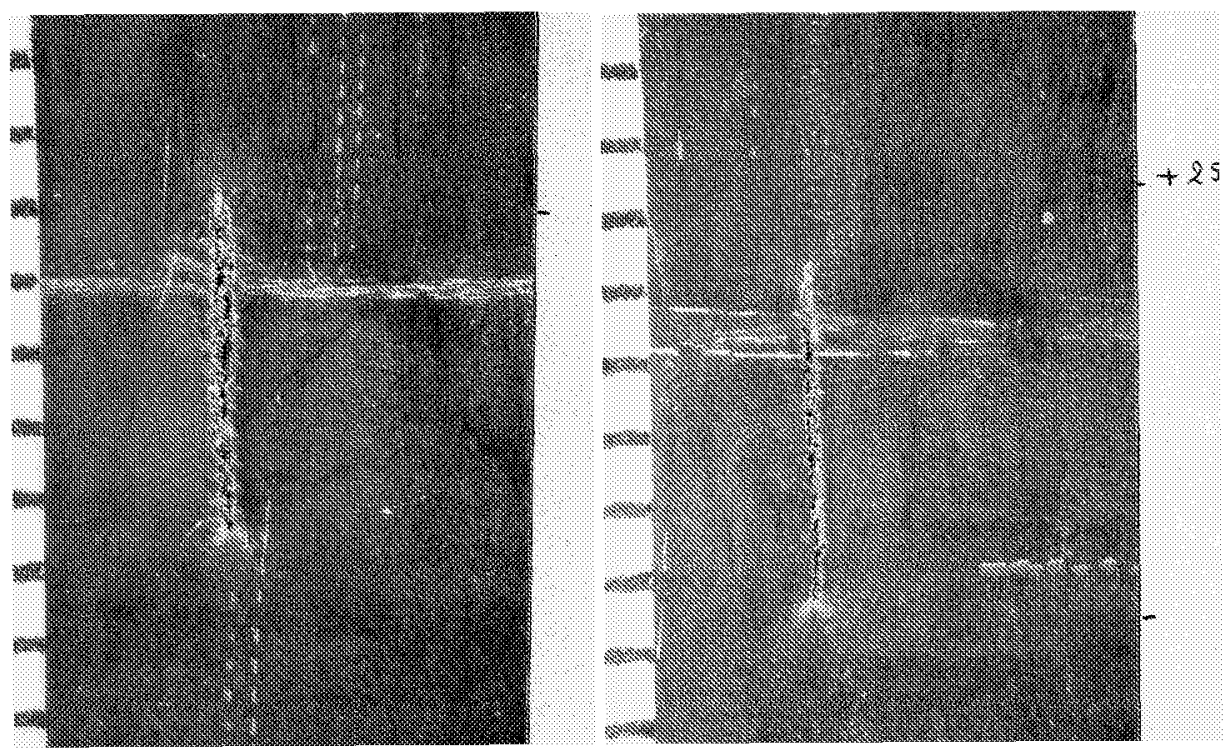

Figure B-30 Macrograph of two cracks after flattening the half tubes of mock-up $17 \mathrm{H}$.

Several metallographic examinations were performed to characterize the cracking. Figure B-31 gives a typical view of such cracks. They were intergranular, often with several branched secondary cracks. In the particular case shown in Figure B-31, the half tube was flattened before examination; thus the cracks were opened with considerable plastic strain located at the crack tip. No intergranular attack was detected on the internal surfaces of the tubes outside the rolling zones. 


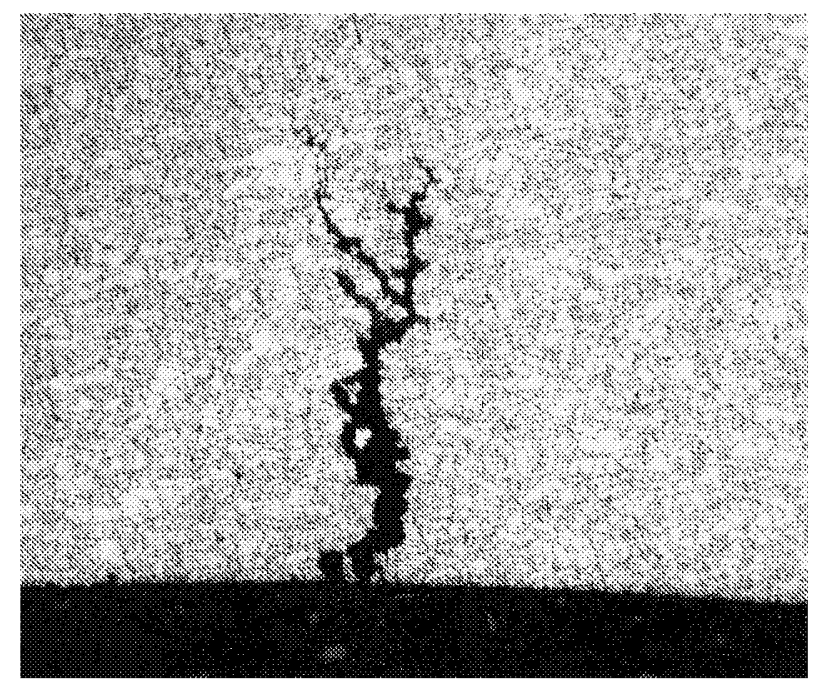

Figure B-31 Metallographic cross section of cracks in mock-up 17H.

Table B-11 summarizes the NDT and optical microscopy results for the cracked mock-ups.

Table B-11 Main results obtained by NDT and optical metallographic examination

\begin{tabular}{|c|c|c|c|c|c|}
\hline \multirow{2}{*}{ Mock-up } & \multirow{2}{*}{$\begin{array}{c}\text { Characteristics of } \\
\text { the mock-up }\end{array}$} & \multicolumn{2}{|c|}{ Through-wall crack } & \multicolumn{2}{c|}{$\begin{array}{c}\text { Detected cracks on } \\
\text { half tube }\end{array}$} \\
\cline { 3 - 6 } & & Location & $\begin{array}{c}\text { Inside length } \\
\text { (mm) }\end{array}$ & Number & Location \\
\hline 1H & Gap 0.4mm & RTZ & 3 & 4 & RTZ \\
\hline 1B & Gap 0.4mm & RTZ & 5 & 3 & RTZ \\
\hline 2H & Gap 0.4mm & RTZ & 5 & 5 & RTZ \\
\hline 3H & Gap 0.4mm & RTZ & 3 & 4 & RTZ \\
\hline 5H & $\begin{array}{c}\text { Gap 0.4mm - KR - } \\
\text { SR }\end{array}$ & RTZ & 6 & 2 & RTZ \\
\hline 5B & $\begin{array}{c}\text { Gap 0.4mm - KR - } \\
\text { SR }\end{array}$ & SR & 9 & 8,6 & SR, RTZ \\
\hline 6H & $\begin{array}{c}\text { Gap 0.4mm - KR - } \\
\text { SR }\end{array}$ & SR & 9 & 8 & SR \\
\hline 7H & $\begin{array}{c}\text { Gap 0.4mm - KR - } \\
\text { SR }\end{array}$ & SR & - & - & SR \\
\hline 7B & Gap 0.4mm - KR - & RTZ & 8 & 1 & RTZ \\
\hline
\end{tabular}




\begin{tabular}{|c|c|c|c|c|c|}
\hline & SR & & & & \\
\hline $8 \mathrm{H}$ & Gap $0.4 \mathrm{~mm}-\mathrm{KR}$ & RTZ & 6 & 2 & RTZ \\
\hline 8B & Gap $0.4 \mathrm{~mm}-\mathrm{KR}$ & $\mathrm{RTZ}$ & 7 & 5 & $\mathrm{RTZ}$ \\
\hline $9 \mathrm{H}$ & Gap 0.95mm - KR & $\mathrm{RTZ}$ & 6 & 3 & RTZ \\
\hline 9B & Gap 0.95mm - KR & RTZ & 1 & 3 & RTZ \\
\hline $11 \mathrm{H}$ & Gap $0.4 \mathrm{~mm}-\mathrm{KR}$ & RTZ & 7 & 5 & RTZ \\
\hline 11B & Gap $0.4 \mathrm{~mm}-\mathrm{KR}$ & RTZ & 6 & 4 & RTZ \\
\hline 12B & Gap $0.4 \mathrm{~mm}-\mathrm{KR}$ & RTZ & 6 & 2 & RTZ \\
\hline $14 \mathrm{H}$ & Gap $0.95 \mathrm{~mm}-\mathrm{KR}$ & RTZ & 6 & 2 & RTZ \\
\hline 14B & Gap $0.95 m m-K R$ & RTZ & 6 & 6 & RTZ, OZ \\
\hline $15 \mathrm{H}$ & Gap $0.95 \mathrm{~mm}-\mathrm{KR}$ & RTZ & 5 & 6 & OZ \\
\hline 15B & Gap $0.95 \mathrm{~mm}-\mathrm{KR}$ & RTZ & 5 & 4 & $\mathrm{RTZ}$ \\
\hline $16 \mathrm{H}$ & Gap $0.95 \mathrm{~mm}-\mathrm{KR}$ & RTZ & 3 & 1 & RTZ, OZ \\
\hline 16B & Gap $0.95 \mathrm{~mm}-\mathrm{KR}$ & RTZ & 3 & 4,4 & $\mathrm{RTZ}, \mathrm{OZ}$ \\
\hline $17 \mathrm{H}$ & Gap $0.95 \mathrm{~mm}-\mathrm{KR}$ & RTZ & 5 & 2,1 & $\mathrm{RTZ}, \mathrm{OZ}$ \\
\hline 17B & Gap $0.95 \mathrm{~mm}-\mathrm{KR}$ & RTZ & 8 & 6 & RTZ, OZ \\
\hline $18 \mathrm{H}$ & Gap 0.95mm - KR & RTZ & 4 & 1 & RTZ \\
\hline 19B & Gap $0.95 \mathrm{~mm}-\mathrm{KR}$ & OZ & 4 & 4,4 & RTZ, OZ \\
\hline $20 \mathrm{H}$ & Gap $0.95 m m-K R$ & RTZ & 5 & 3 & RTZ \\
\hline $20 B$ & Gap $0.95 \mathrm{~mm}-\mathrm{KR}$ & RTZ & 6 & 9 & RTZ \\
\hline 21B & $\begin{array}{c}\text { Gap } 0.95 \mathrm{~mm}-\mathrm{KR}- \\
\mathrm{SR}\end{array}$ & RTZ & 5 & 1 & RTZ, SR \\
\hline
\end{tabular}

KR: kiss roll transition zone - RTZ : cracked in roll transition zone - SR : cracked in skip roll $\mathrm{OZ}$ : cracked in overlap zone 


\section{B.4.3 Analysis of results}

Among the 40 roll transition zones tested in Alloy 600, six were stopped without any through wall crack (leak) occurring. Those mock-ups were:

$21 \mathrm{H}$ and $18 \mathrm{~B}$ that were stopped after about 4,000 hours because of cracking of the adjacent roll transition zone in the mock-up and could not be tested anymore. However, mock-ups $2 \mathrm{~B}, 12 \mathrm{H}$, $10 \mathrm{~B}$ and $10 \mathrm{H}$ survived more than 30,000 hours of testing without leaking.

\section{B.4.3.1 Tube / tubesheet gap and heat treatment influence}

A statistical analysis of the results was carried to evaluate the failure time as a function of the asmanufactured characteristics: initial tube / tubesheet gap size and material heat treatment (mill annealed or thermally treated). Table B-12 summarizes the results of this analysis using initially only results corresponding to cracks / leaks in the roll transition zone.

Table B-12 Results of statistical analysis of the influence of tube/tubesheet gap and heat treatment of Alloy 600 tubes on failure time

\begin{tabular}{|c|c|c|}
\hline Tube/tubesheet gap (mm) & MA & TT \\
\hline 0.95 & Mean $=3427 \mathrm{~h}$. & Mean $=3620 \mathrm{~h}$. \\
& $\sigma=1770 \mathrm{~h}$. & $\sigma=2072 \mathrm{~h}$. \\
\hline 0.4 & Mean $=16092 \mathrm{~h}$. & Mean $=12412 \mathrm{~h}$. \\
& $\sigma=4829 \mathrm{~h}$. & $\sigma=4004 \mathrm{~h}$. \\
\hline
\end{tabular}

The analysis of variance shows, within $95 \%$ confidence limits, that for a tube / tubesheet gap of 0.95 or $0.4 \mathrm{~mm}$ there is no noticeable influence of heat treatment on the time to failure. For either heat treatment condition, there was a larger influence of the tube / tubesheet gap size on the time to leakage.

The influence of tube heat treatment was analyzed more accurately by taking into account some results where cracks were not observed in the rolling transition zone due to cracking having previously occurred in the adjacent zone. These results are presented in the Table B-13 and Table B-14. 
Table B-13 Influence of the heat treatment for mock-ups with a large tube / tubesheet gap

\begin{tabular}{|c|c|c|c|c|cr|c|}
\hline Mock-up & $\begin{array}{c}\text { Gap } \\
\mathbf{( m m})\end{array}$ & $\begin{array}{c}\text { Kiss rolling } \\
\text { expansion } \\
(\mathbf{m m})\end{array}$ & Skip roll & $\begin{array}{c}\text { Over-roll } \\
\mathbf{( m m})\end{array}$ & \multicolumn{2}{|c|}{$\begin{array}{c}\text { Time to leak } \\
\mathbf{( h )}\end{array}$} & $\begin{array}{c}\text { Location of } \\
\text { the crack }\end{array}$ \\
\hline 14H & 0.95 & 0.15 & No & +2 & MA & 800 & RTZ \\
\hline 16H & 0.95 & 0.15 & No & & TT & 3500 & ROL \\
\hline 14B & 0.95 & 0.15 & No & +1.5 & MA & 1300 & RTZ \\
\hline 16B & 0.95 & 0.15 & No & +7 & TT & 3500 & ROL \\
\hline 15B & 0.95 & 0.15 & No & +23 & MA & 3800 & RTZ \\
\hline 15H & 0.95 & 0.15 & No & 23 & MA & 4050 & RTZ \\
\hline 17B & 0.95 & 0.15 & No & $?$ & TT & 5400 & RTZ \\
\hline 17H & 0.95 & 0.15 & No & +23 & TT & 5900 & RTZ \\
\hline 19H & 0.95 & 0.30 & No & +1 & MA & 1600 & ROL \\
\hline 20H & 0.95 & 0.30 & No & +2 & TT & 1500 & RTZ \\
\hline 19B & 0.95 & 0.30 & No & +6 & MA & 1600 & ROL \\
\hline 20B & 0.95 & 0.30 & No & $?$ & TT & 1800 & RTZ \\
\hline 18H & 0.95 & 0.30 & No & +23 & MA & 4000 & RTZ \\
\hline 21B & 0.95 & 0.30 & YES & +25 & MA & 3800 & RTZ \\
\hline
\end{tabular}


Table B-14 Influence of the heat treatment for mock-ups with the nominal specification tube/tubesheet gap.

\begin{tabular}{|c|c|c|c|c|c|c|c|}
\hline Mock-up & $\begin{array}{l}\text { Gap } \\
(\mathrm{mm})\end{array}$ & $\begin{array}{c}\text { Kiss rolling } \\
\text { expansion } \\
(\mathrm{mm})\end{array}$ & Skip roll & $\begin{array}{l}\text { Over-roll } \\
\text { (mm) }\end{array}$ & Tim & $\begin{array}{l}\text { to leak } \\
\text { h) }\end{array}$ & $\begin{array}{l}\text { Location of } \\
\text { the crack }\end{array}$ \\
\hline $5 \mathrm{H}$ & 0.4 & 0.15 & No & +4 & MA & 10600 & RTZ \\
\hline $8 \mathrm{H}$ & 0.4 & 0.15 & No & +2 & MA & 12850 & RTZ \\
\hline $3 \mathrm{H}$ & 0.4 & 0.15 & No & +1 & TT & 18400 & RTZ \\
\hline 3B & 0.4 & 0.15 & No & $(+20)$ & TT & 10000 & $\mathrm{RTZ}$ \\
\hline $5 B$ & 0.4 & 0.15 & YES & +8 & MA & 1500 & SR \\
\hline $6 \mathrm{H}$ & 0.4 & 0.15 & YES & 0 & MA & 1900 & SR \\
\hline $7 \mathrm{H}$ & 0.4 & 0.15 & YES & +3 & TT & 11000 & SR \\
\hline 8B & 0.4 & 0.30 & No & +23 & MA & 11750 & RTZ \\
\hline $12 B$ & 0.4 & 0.30 & No & +24 & MA & 20000 & RTZ \\
\hline $11 \mathrm{H}$ & 0.4 & 0.30 & No & $(+20)$ & TT & 10500 & RTZ \\
\hline $11 B$ & 0.4 & 0.30 & No & +22 & TT & 10750 & RTZ \\
\hline $7 B$ & 0.4 & 0.30 & No & +26 & TT & 11100 & ROL \\
\hline $6 \mathrm{~B}$ & 0.4 & 0.30 & YES & +23 & MA & 1900 & SR \\
\hline $7 B$ & 0.4 & 0.30 & YES & +26 & TT & 11000 & SR \\
\hline
\end{tabular}

In the case of the large tube / tubesheet gap, the thermally treated tubes showed statistically significant higher times to leakage compared to other configurations with large stresses (short times to leakage) such as roll transition zone cracks with high gaps, or SR cracks with small tube / tubesheet gap configuration. On the other hand, the times to leakage, for TT tube or MA tube belong statistically to the same population in the case of moderate stresses (long times to leakage) such as roll transition zone cracks with small tube / tubes sheet gaps and kiss rolling. Thus, thermally treated tubes seemed to have better resistance to PWSCC in the case of severe non conformities such as a large tube / tubesheet gaps but in case of roll transition parameters typical of the specification for steam generator manufacture, no effect of thermal treatment was observed. 


\section{B.4.3.2 Influence of skip roll}

Four mock-ups were manufactured with skip rolls: 5, 6, 7 and 21.

Table B-15 shows the data used to examine the influence of a skip roll on failure time.

Table B-15 Data used to examine the influence of skip roll

\begin{tabular}{|c|l|l|l|l|l|ll|}
\hline Mock-up & $\begin{array}{c}\text { Heat } \\
\text { treatment }\end{array}$ & $\begin{array}{c}\text { T/TS gap } \\
\mathbf{( m m})\end{array}$ & $\begin{array}{c}\text { Over-roll } \\
\mathbf{( m m})\end{array}$ & $\begin{array}{c}\text { Kiss roll } \\
\text { expansion } \\
\mathbf{( m m})\end{array}$ & Skip roll & \multicolumn{2}{|c|}{$\begin{array}{c}\text { Time to leak (h) } \\
\text { and location }\end{array}$} \\
\hline 5B & MA & 0.4 & +20 & 0.15 & YES & 1500 & SR \\
\hline 3B & MA & 0.4 & +20 & 0.15 & NO & 10000 & RTZ \\
\hline $\mathbf{6 H}$ & MA & 0.4 & -1.5 & 0.15 & YES & 1900 & SR \\
\hline $\mathbf{5 H}$ & MA & 0.4 & -1.5 & 0.15 & NO & 10600 & RTZ \\
\hline $\mathbf{8 H}$ & MA & 0.4 & -1.5 & 0.15 & NO & 12850 & RTZ \\
\hline $\mathbf{7 H}$ & TT & 0.4 & -1.5 & 0.15 & YES & 11000 & SR \\
\hline $\mathbf{3 H}$ & TT & 0.4 & -1.5 & 0.15 & NO & 18400 & RTZ \\
\hline $\mathbf{2 1 B}$ & MA & 0.95 & +20 & 0.30 & YES & 3800 & RTZ \\
\hline $\mathbf{1 8 H}$ & MA & 0.95 & +20 & 0.30 & NO & 4000 & RTZ \\
\hline
\end{tabular}

For a nominal tube / tubesheet gap of $0.4 \mathrm{~mm}$, a skip roll gave rise to very rapid cracking (between 1,500 and 1,900 hours) in comparison with the normal roll transition zone that survived $>10,000$ hours).

For a large tube / tubesheet gap of $0.95 \mathrm{~mm}$, the presence of a skip roll did not seem to induce cracking earlier than was typical of the roll transition. However, just one mock-up was tested in this configuration combining a large tube / tubesheet gap and a skip roll. 


\section{B.4.3.3 Influence of kiss rolling}

Table B-16 shows the results that were compared to examine the influence of kiss rolling.

Table B-16 Analysis of the influence of kiss rolling

\begin{tabular}{|c|c|c|c|c|c|}
\hline $\begin{array}{c}\text { Heat } \\
\text { treatment }\end{array}$ & $\begin{array}{c}\text { T/rS gap } \\
(\mathbf{m m})\end{array}$ & $\begin{array}{c}\text { Over-roll } \\
(\mathbf{m m})\end{array}$ & $\begin{array}{c}\text { Kiss roll } \\
\text { expansion } \\
(\mathbf{m m})\end{array}$ & Skip roll & $\begin{array}{c}\text { Time to leak } \\
\mathbf{( \mathbf { m } ) \text { and }} \\
\text { location }\end{array}$ \\
\hline MA & 0.4 & -1.5 & NO & 0.15 & $10600 \mathrm{RTZ}$ \\
\hline MA & 0.4 & -1.5 & NO & 0.15 & $12850 \mathrm{RTZ}$ \\
\hline MA & 0.4 & +20 & NO & 0.30 & $11750 \mathrm{RTZ}$ \\
\hline MA & 0.4 & +20 & NO & 0.30 & $20000 \mathrm{RTZ}$ \\
\hline MA & 0.4 & +3 & NO & 0 & $14400 \mathrm{RTZ}$ \\
\hline MA & 0.4 & -1.5 & NO & 0 & $20250 \mathrm{RTZ}$ \\
\hline MA & 0.4 & +6 & NO & 0 & $22800 \mathrm{RTZ}$ \\
\hline
\end{tabular}

By inspection, the time to leakage in the roll transition zone seemed to be longer without a kiss roll than with one in the case of a nominal tube / tubesheet gap. However, if the variance of these samples is analyzed, this hypothesis cannot be sustained with $95 \%$ confidence. Thus kiss rolling did not statistically improve or degrade significantly the resistance of the rolling zone to stress corrosion cracking on the primary side (internal surface of the tube). 


\section{B.4.3.4 Influence of Alloy 600 heat}

Table B-17 shows a comparison of mock-ups manufactured with similar characteristics from two heats of Alloy 600 including heat NX3335, which was known to have low susceptibility to PWSCC.

Table B-17 Influence of Alloy 600 heat

\begin{tabular}{|c|c|c|c|c|}
\hline Heat & Mock up & T/TS gap (mm) & Over-roll (mm) & Time to leak (h) \\
\hline \multirow{2}{*}{ NX3335 MA } & $4 \mathrm{H}$ & 0.4 & +1.5 & 19600 \\
\cline { 2 - 5 } & $4 \mathrm{~B}$ & 0.4 & +20 & 27000 \\
\hline \multirow{2}{*}{ WD281 MA } & $5 \mathrm{H}$ & 0.4 & +1.5 & 10600 \\
\cline { 2 - 5 } & $8 \mathrm{~B}$ & 0.4 & +20 & 11750 \\
\hline \multirow{2}{*}{ NX3335 MA } & $9 \mathrm{H}$ & 0.95 & +20 & 12150 \\
\cline { 2 - 5 } & $9 \mathrm{~B}$ & 0.95 & +20 & 11300 \\
\hline \multirow{2}{*}{ WD281 MA } & 15H & 0.95 & +20 & 4050 \\
\cline { 2 - 5 } & 15B & 0.95 & +20 & 3800 \\
\hline
\end{tabular}

The less susceptible heat clearly gives longer times to leakage under the same test conditions. However, this observation is difficult to support statistically since it depends on a one-to-one comparison of mock-ups. Nevertheless, it demonstrates the large influence of tube heat on the PWSCC phenomenon. 


\section{B.4.4 Conclusions}

The main results of this part of the study on Alloy 600 mock-ups were:

40 roll transitions zones were exposed to hydrogenated, pure water at $360^{\circ} \mathrm{C}$ of which 6 did not crack after the tests lasting up to 30,000 hours. All the others cracked after exposure times between 800 and 22,800 hours.

All the cracks were axial, intergranular and were always located in a transition zone characterized by a change in tube diameter due to rolling.

Cracking was ascribed to IGSCC in pure hydrogenated water, which is indistinguishable from that which occurs in PWR primary water except for a small increase in the kinetics of the degradation process.

The most detrimental parameters were: a skip-roll and an over-size tube /tubesheet gap.

The kiss-roll transition did not seem to have a statistically demonstrable beneficial or detrimental effect independent of the value of the tube expansion.

Thermally treated tubes seemed to have better resistance to PWSCC in the case of severe non conformities such as a large tube / tubesheet gaps but in case of roll transition parameters typical of the specification for steam generator manufacture, no effect was observed.

A marked heat-to-heat effect on PWSCC was observed, as is characteristic of field behavior, independent of roll transition fabrication characteristics. 


\section{B.5 Conclusions}

The aim of the present program was a comparative study of the resistance of Alloy 690 TT and Alloy 600MA and TT to PWSCC using mock-ups representative of the tube expansion zones in the tubesheet of recirculating PWR steam generators.

Several different types of manufacturing anomalies were reproduced in the mock-ups:

- Over-size tube / tubesheet gaps

- Over-rolling

- Skip rolls in the tubesheet

- Excessive kiss-rolling

The mock-ups were tested in the form of heated capsules containing deaerated, hydrogenated and demineralized water at $360^{\circ} \mathrm{C}$.

The first leaks due to through-wall cracking appeared on the Alloy 600 MA mock-ups after exposure times as short as 800 hours. Alloy 600TT tubes seemed to have better resistance to PWSCC in the case of severe nonconformities such as over-sized tube / tubesheet gaps. With normal roll transition parameters, no effect of the thermal treatment was observed. Nevertheless, there was a marked heat-to-heat effect on PWSCC (as is characteristic of field behavior) independent of roll transition fabrication characteristics.

Almost all the Alloy 600 mock-ups cracked. Of the 40 different roll transition zones that were tested, two were withdrawn without any leakage after short exposure times and four zones survived 30,000 hours (the maximum exposure time of the Alloy 600 mock-ups) without any leakage occurring. All the other roll transition zones cracked. The average time to leakage of the Alloy 600 mock-ups was 8,350 hours with a standard deviation equal to 6,600 hours. The most susceptible zones were roll transition zones with over-size tube / tubesheet gaps and / or with skip rolls inside the tubesheet (independent of the tube / tubesheet gap if skip rolls were present).

Eight mock-ups were manufactured with Alloy 690 TT tubing and tested in the same conditions as the Alloy 600 mock-ups. None of the Alloy 690 TT mock-ups cracked even after exposure times extending up to 100,000 hours. Non-destructive and destructive examinations showed that no stress corrosion crack initiation or propagation had occurred, despite the simulated manufacturing anomalies that had such severe detrimental effects on PWSCC resistance of similar Alloy 600 mock-ups.

Since leak events occurred in Alloy 600 mock-ups before 20,000 hours with 95\% confidence (average value plus two standard deviations) and given that no failure occurred in the comparable Alloy 690 TT mock-ups after 100,000 hours, the beneficial effect of using Alloy 690 TT instead of Alloy 600 was greater than a factor of 5 . 
Metallurgical examinations of the Alloy 690 TT mock-ups confirmed that even when some mechanically-induced intergranular cracks were initiated by severe straining of a hard perturbed internal surface layer, such cracks did not propagate in hydrogenated water at $360^{\circ} \mathrm{C}$ after exposure times up to 100,000 hours.

In conclusion, no initiation of stress corrosion cracks was observed and mechanically-induced intergranular cracks created by severe straining of a perturbed surface layer did not propagate in Alloy 690 TT material. These tests demonstrated that the change from Alloy 600 to Alloy 690 TT gives an improvement factor greater than 5 for PWSCC initiation. 



\section{C alloy 690 corrosion in secondary water}

The laboratory data and field experiences reviewed in the proceeding sections are related to corrosion degradations of Alloys 690, 152, and 52 in PWR primary water. In addition to corrosion concerns in primary water, an equally amount of research efforts have been directed toward Alloy 690 SG tubing corrosion degradations pertinent to PWR secondary water environment (the secondary side of steam generators). Even though the secondary water corrosion is not the focus of the present review, many studies of Alloy 690 conducted in environments pertinent to PWR secondary water have been reviewed in this section in order to provide a comprehensive comparison of Alloy 690 and Alloy 600 under various environmental conditions encountered in PWRs. By examining the secondary water conditions and the thermal mechanical processing parameters that promote stress corrosion cracking or intergranular attack in Alloy 690, some insights may be obtained as to Alloy 690 corrosion resistance in primary water. Furthermore, the types of corrosion specimens used in secondary water are the very same ones used in primary water. A couple of studies listed below are referenced in the proceeding sections to compare with similar observations made in a few primary water studies.

\section{C.1 AVT Water Environment}

Miglin et al. performed stress corrosion cracking tests of Alloys 600 and 690 in all-volatile treated (AVT) water. ${ }^{[88]}$ Five types of stress corrosion cracking test specimens were used including RUB (also called split-tube U-Bend), Single U-Bend, Double U-Bend, Ring-Tensile, and C-Ring. Identical specimens were fabricated from Alloy 600 and Alloy 690. The Alloy 600 specimens were fabricated from 23 heats of Alloy 600 in a variety of MA and TT conditions. The Alloy 690 specimens were fabricated from 4 heats of Alloy 690 in the MA, TT $\left(1150^{\circ} \mathrm{F}\right)$, and TT $\left(1300^{\circ} \mathrm{F}\right)$ conditions. The Alloy 690 heat chemical compositions are listed in Table C-1. The tests were conducted in four once-through (refreshed) high-pressure autoclaves with AVT water at $550,630,650$, and $680^{\circ} \mathrm{F}$. The autoclave pressure were kept above the water-steam equilibrium pressures at the respective test temperatures, so the test environment was water, not steam. The water chemistry and test duration are listed in Table C-2.

During the testing, 78 of the 520 Alloy 600 specimens developed cracking. Most of the cracked specimens were the RUB type and fabricated from Alloy 600 heat treated to produce a susceptible condition. Alloy 600 cracking occurred much more rapidly and frequently at $680^{\circ} \mathrm{F}$ and at $650^{\circ} \mathrm{F}$ than at the lower temperatures. Examination of some cracked Alloy $600 \mathrm{RUB}$ specimens indicated that the IGSCC cracks started as short longitudinal cracks at the apex, then became longer and wider, and eventually propagated through-wall with exposure time. Destructive metallographic examination revealed the presence of blunt and shallow (on the order of $0.02 \mathrm{~mm}$ ) crack indications on the I.D. surface of the RUB apex. These defects were not typical IGSCC. Further examination showed that some IGSCC initiated from the base of these defects. However, most IGSCC cracks did not initiate from these shallow defects. 
None of the 113 Alloy 690 specimens failed in a typical IGSCC manner. The Alloy 690 C-ring specimens were exposed up to 72,000 hours. The maximum exposure time for Alloy 690 RUB specimens was approximately 37,200 hours, significantly less than the maximum exposure time for Alloy 600 RUB specimens. However, longitudinal shallow and blunt defects were found on the I.D. surface of the Alloy 690 RUB apex. These defects were not typical of IGSCC. Metallographic examinations showed that some of these defects appeared to be like mechanical grooves while others appeared to be separation along the grain boundaries. No evidence of further IGSCC cracking emanating from the base of these defects were found. SEM examinations of archive Alloy 690 RUB specimens found similar longitudinal defects, but they were shorter in length than those detected after the AVT autoclave exposure $(0.1$ to $0.35 \mathrm{~mm}$ long in archive Alloy 690 RUB vs. $\sim 1.0 \mathrm{~mm}$ in Alloy 690 RUB after the AVT exposure).

Miglin et al. offered two explanations for the apparent longitudinal growth of the defects. The first explanation was the defect growth was a stress relaxation process. Once the defects grew to a sufficient length to relieve the stress at elevated temperature, no further growth would occur. The second explanation by Miglin et al. was that the defects did not grow at all during the AVT exposure. The growth in length observed was due to an opening process of closed or partially closed defects. During the high temperature exposure, the surface oxide growth (in the defects) would enhance an opening process by a wedging effect to give an appearance of longitudinal growth. The less strained leg portions of the RUB specimens were free from these defects. Similar SEM examinations of archive Alloy 600 RUB specimens also found the apex to be relatively free of these defects. It is noted that Framatome ANP, France noted similar longitudinal defects in the roll-transition areas of the Alloy 690 SG tube mock-ups (see Appendix B). The cause of these defects was attributed to mechanical strain from the roll expansion and a shallow cold worked layer of SG tubing surface. These defects also did not affect the PWSCC resistance Alloy $690 \mathrm{SG}$ mock-ups in the $680^{\circ} \mathrm{F}$ deaerated water for up to 100,000 hours. In the end, Miglin et al. concluded that these defects were due to mechanical strain rather than due to IGSCC.

\section{C.2 Deaerated Caustic Solution With or Without Contamination}

Intergranular attack (IGA) and IGSCC has been experienced on the secondary side of Alloy 600MA SG tubings within the drilled tube support plate and the tubesheet crevices in PWR steam generators. Table C-3 is a summary of past laboratory tests of Alloy 690 in a high temperature deaerated $\mathrm{NaOH}$ solution by Crum et al. ${ }^{[89]}$

\section{C.2.1 Sedricks et al.}

Sedricks et al. tested Alloy 690 in deaerated $10 \%$ and $50 \% \mathrm{NaOH}$ solutions. ${ }^{[9]}$ When the temperature of a layer of water at a heat transfer surface exceeds the temperature of the main body of slightly alkaline water by a temperature difference of $\Delta \mathrm{T}$, a high concentration of $\mathrm{NaOH}$ can develop in this layer. $\mathrm{A} 50 \% \mathrm{NaOH}$ solution used in some laboratory tests corresponds to a $\Delta \mathrm{T}$ of $80^{\circ} \mathrm{F}\left(27^{\circ} \mathrm{C}\right)$. The maximum $\Delta \mathrm{T}$ attainable on the secondary side the SG was not known. However, a $50 \% \mathrm{NaOH}$ solution was considered as representing a theoretical extreme. After 2 weeks exposure in $600^{\circ} \mathrm{F}$ deaerated $50 \% \mathrm{NaOH}$ solution, Alloy 690 had a slightly higher descaled weight loss than Alloy 600 and a slightly lower descaled weight loss than Alloy 800 . Results from the U-Bend specimens showed that, at $600^{\circ} \mathrm{F}$, Alloy 690 had a slightly lower SCC 
resistance than Alloy 600 in the deaerated $50 \% \mathrm{NaOH}$ solution while Alloy 690 had a slightly higher SCC resistance than Alloy 600 in $10 \% \mathrm{NaOH}$ solution.

Sedricks et al. also tested Alloy $690 \mathrm{U}$-bend specimens in non-deaerated $50 \% \mathrm{NaOH}$ solutions at $600^{\circ} \mathrm{F} .{ }^{[9]} \mathrm{After} 27$ days exposure, except for one cold rolled specimen, none of the Alloy 690 specimens developed cracks irrespective of the heat treatment, cold work, or the presence of welds. On the other hand, most of the Alloy 600 U-bend specimen developed cracks. Hence, it was concluded that in the non-deaerated caustic solution, Alloy 690 had a higher SCC resistance than Alloy 600 .

\section{C.2.2 A. Smith et al.}

A. Smith et al. reported stress corrosion tests on commercially produced Alloy 690 SG tubes. ${ }^{[32,}$

${ }^{33]} \mathrm{C}$-ring stress corrosion test specimens were fabricated per ASTM G $38^{[90]}$ from Alloy 690TT. The C-ring specimens were tested in a variety of environmental conditions at $340^{\circ} \mathrm{C}\left(644^{\circ} \mathrm{F}\right)$. No intergranular attack or stress corrosion cracking was noted after 1,500 hours of exposure in deaerated pure water (see Section 3.1). However, All C-ring specimens developed intergranular attack (IGA) when tested in deaerated caustic environments. These C-ring specimens were fabricated from Alloy 690 SG tubes " $\mathrm{A}$ " and " $\mathrm{E}$ " and " $\mathrm{F}$ " and were tested in $50 \% \mathrm{NaOH}$ solution and/or $30 \% \mathrm{NaOH}+10 \% \mathrm{Na}_{2} \mathrm{SO}_{4}$ solution at $340^{\circ} \mathrm{C}\left(644^{\circ} \mathrm{F}\right)$. The chemical composition of tubes "A", "E", and "F" and their mechanical properties are summarized in Table 3-15.

Results in deaerated $50 \% \mathrm{NaOH}$ solution are listed in Table C-3. Figure C-1 shows the IGA in the C-ring specimen $\mathrm{E} 3$ after 1,200 hours exposure in deaerated $50 \% \mathrm{NaOH}$. Results of $\mathrm{C}$-ring specimen from tubes " $\mathrm{\text {"and }}$ " $\mathrm{E}$ " in deaerated $50 \% \mathrm{NaOH}$ and $30 \% \mathrm{NaOH}+10 \% \mathrm{Na} 2 \mathrm{SO} 4$ are summarized in Table $\mathrm{C}-4$. The results showed that $50 \% \mathrm{NaOH}$ was a more aggressive environment than $30 \% \mathrm{NaOH}+10 \% \mathrm{Na}_{2} \mathrm{SO}_{4}$. Unexpectedly, tube " $\mathrm{E}$ " with a lower carbon content had a lower IGA resistance than tube " $\mathrm{A}$ ". This was attributed to the higher aluminum content in tube " $E$ " than in tube " $A$ " $(0.13 \%$ vs. $0.03 \%)$. It was suggested that aluminum increased the propensity for IGA in Alloy 690. However, IGA growth rate in Alloy 690 appeared to decrease rapidly with continued exposure. In deaerated $30 \% \mathrm{NaOH}+10 \% \mathrm{Na}_{2} \mathrm{SO}_{4}$, it appeared that the tip of the advancing IGA became blunted by corrosion products after a short distance. Further intergranular attack was in a direction parallel to the surface (or perpendicular to the original IGA direction), resulting in a general corrosion (or wastage) across the exposed surface. C-ring specimens from tube " $\mathrm{F}$ " were given different thermal treatment (at $650-750^{\circ} \mathrm{C}$ for $1-15$ hours). These specimens were tested in $30 \% \mathrm{NaOH}+10 \% \mathrm{Na}_{2} \mathrm{SO}_{4}$ at $350^{\circ} \mathrm{C}\left(662^{\circ} \mathrm{F}\right)$ for 1,500 hours. The specimens showed comparable IGA depth.

\section{C.2.3 K. Smith et al.}

K. Smith et al. tested the SCC resistance of Alloy 690TT and Alloy 600 in deaerated $\mathrm{NaOH}$ solutions at elevated temperatures. ${ }^{[1]}$ The Alloy 690 chemical composition and mechanical properties are listed in Table 3-3. Table C-5 summarizes the $\mathrm{K}_{\mathrm{ISCC}}$ obtained from wedgeopening-loading (WOL) specimens of Alloy 690 and Alloy 600 in deaerated $\mathrm{NaOH}$ solutions. Figure C-2 shows the crack propagation rates obtained from C-ring specimens of Alloy 690TT and Alloy 600 tested in deaerated $10 \% \mathrm{NaOH}$ solution at temperatures between 315 and $343^{\circ} \mathrm{C}$ 
Appendix C-Alloy 690 Corrosion in Secondary Water

$\left(600\right.$ and $\left.650^{\circ} \mathrm{F}\right)$. The C-rings were loaded to different percentages of the yield strength and Alloy 690TT had the lowest crack propagation rate regardless of the loading levels.

Table C-6 summarizes the results of C-ring specimens stressed to 50,75, 90, $150 \%$ of the yield strength and C-ring specimens strained until the legs touch (14\% strain, TLT) after 1,000 hours of exposure to $10 \% \mathrm{NaOH}$ deaerated solution at $315^{\circ} \mathrm{C}\left(600^{\circ} \mathrm{F}\right)$. The potential was maintained at the active-passive transition (140 mV vs. $\mathrm{Ni}$ ) to accelerate any SCC propensity during the 1,000 hours exposure. The Alloy 690TT C-ring specimens, except for the TLT specimens, did not develop cracking. Based on these results, K. Smith et al. concluded that Alloy 690TT was more SCC resistant than Alloy 600 in low concentration of deaerated $\mathrm{NaOH}$ solution at $600^{\circ} \mathrm{F}$ and in all concentrations of deaerated $\mathrm{NaOH}$ solution at $650^{\circ} \mathrm{F}$. The improvement of Alloy 690TT over Alloy 600 was attributable to a higher SCC threshold stress level and a lower crack propagation rate.

\section{C.2.4 Sarver et al.}

Sarver et al. investigated the effect of thermal treatment on the Alloy 690 SG tubing in $10 \%$ and $30 \% \mathrm{NaOH}$ solutions. ${ }^{[91]}$ The chemical compositions of the Alloy 690 and Alloy 600 used in these tests are listed in Table C-7. The Alloy 690 U-bend specimens were stressed well beyond the yield stress and tested in $10 \%$ and $30 \% \mathrm{NaOH}$ solution at $228^{\circ} \mathrm{C}\left(550^{\circ} \mathrm{F}\right)$ held at different potential levels. In the $10 \% \mathrm{NaOH}$ solution, only the Alloy $690 \mathrm{TT}\left(1 / 2\right.$ hour at $\left.1200^{\circ} \mathrm{F}\right)$ specimens held at $+170 \mathrm{mV}$ vs. Ni developed cracking approximately $15 \%$ through-wall. In the $30 \% \mathrm{NaOH}$ solution, the Alloy $690 \mathrm{MA}$ specimens held at $+170,+190$, and $+210 \mathrm{mV}$ experienced through-wall cracking. Compared to Alloy 600 , the Alloy 690 has a narrower range of potential which produces SCC in $10 \% \mathrm{NaOH}$. This is attributed to the greater stability of the oxide film formed on the Alloy 690 than on the Alloy 600 due to the higher Cr content.

At higher $\mathrm{NaOH}$ concentration levels, the stability of Cr-rich oxide films is reduced and the SCC potential range is expanded. In addition to U-bend specimens, Sarver et al. tested Alloy $690 \mathrm{C}$ ring specimens with varying thermal treatment conditions $228^{\circ} \mathrm{C}\left(550^{\circ} \mathrm{F}\right)$. The specimens were first put in the $10 \% \mathrm{NaOH}$ solution held at $+170 \mathrm{mV}$ potential for two months. Cracking was only observed in the Alloy 600MA C-ring specimens. Subsequently, the solution concentration was increased to $30 \% \mathrm{NaOH}$ and held at $+210 \mathrm{mV}$ for two additional months. The C-rings specimens were metallographically examined at the end of the test and the results are summarized in Table C-8. The cracking in the Alloy 690 C-ring specimens was less than anticipated based on the Alloy $690 \mathrm{U}$-bend results. This was attributed to the lower stress level in the C-ring specimens than the U-bend specimens. Sarver et al. concluded that continuous grain boundary carbides from thermal treatment is insufficient in itself to prevent caustic SCC in Alloy 690 material.

\section{C.2.5 Vaillant et al.}

Vaillant et al. tested Alloy 690 , Alloy 600 , and Alloy 800 SG tubing in a variety of deaerated caustic solutions. ${ }^{[2]}$ The Alloy 600 and Alloy 690 material properties used in the testing are summarized in Table C-9. The IGSCC test results in $350^{\circ} \mathrm{C}\left(662^{\circ} \mathrm{F}\right)$ deaerated $\mathrm{NaOH}$ solutions are listed in Table $\mathrm{C}-10$. The tests were stopped after a given duration (minimum time: 720 hours on C-rings; some tests of Alloy 690 were extended to 11,000 hours). However, the test duration 
for the test results listed in Table C-10 was not listed. Table C-10 shows that the Alloy 600 was susceptible to IGSCC in 4 to $500 \mathrm{~g} / \mathrm{L} \mathrm{NaOH}$ solutions, with a maximum at $100 \mathrm{~g} / \mathrm{L}$. The Alloy 690 was susceptible to IGSCC in 40 to $400 \mathrm{~g} / \mathrm{L} \mathrm{NaOH}$ solutions, with a maximum also at a concentration of $100 \mathrm{~g} / \mathrm{L}$.

The Alloy 690TT condition was found to have the highest resistant to IGSCC. Vaillant et al. observed that the SCC threshold stress for Alloy 600 increases with increasing yield strength at $350^{\circ} \mathrm{C}\left(644^{\circ} \mathrm{F}\right)$. The Alloy 600 heats with the lowest yield strength at $350^{\circ} \mathrm{C}$ were the most susceptible to caustic IGSCC. However, no correlation was found between caustic IGSCC in the Alloy 690 and the yield strength at $350^{\circ} \mathrm{C}$. The IG $\Lambda$ of Alloys 600 and 690 was investigated in a deaerated $100 \mathrm{~g} / \mathrm{L} \mathrm{NaOH}$ solution at $350^{\circ} \mathrm{C}\left(662^{\circ} \mathrm{F}\right)$ with or without the addition of magnetite. After 8,000 hours, the IGA depth was $150 \mu \mathrm{m}$ in the Alloy $600 \mathrm{MA}$ and $30 \mu \mathrm{m}$ in the Alloy 600TT. No IG $\Lambda$ was identified in the Alloy 690TT, which had an oxide layer $50 \mu \mathrm{m}$ thick. Adding magnetite significantly increased the IGA of the Alloy 600 while only slightly increasing the Alloy 690 oxide thickness without any IGA.

\section{C.2.6 Mertz et al.}

Mertz et al. performed SCC testing of Alloy 690 materials in high temperature caustic solutions. ${ }^{[93]}$ However, no Alloy 600 specimens were included in the testing program. The materials tested were two heats of Alloy 690 SG tubing and one heat of Alloy 690 plate. The chemical composition, heat treatment, and mechanical properties in the as-received state are listed Table C-11. The RUB specimens were fabricated from the Alloy 690 SG tubing with the $12.70 \mathrm{~mm}$ O.D. dia. bent around a $25.4 \mathrm{~mm}$ dia. mandrel and the $6.35 \mathrm{~mm}$ O.D. dia. bent around a $12.70 \mathrm{~mm}$ dia. mandrel. The U-bend specimens were fabricated from the Alloy 690 plate that had been reduced to $2.8 \mathrm{~mm}$ in thickness. The U-bend specimens were bent around a $25.4 \mathrm{~mm}$ dia. mandrel. The Alloy 690 materials were given different processing and heat treated to produce a variety of grain boundary carbide morphology as summarized in Table C-12 and Table C-13.

The RUB specimens were placed in a $25 \% \mathrm{NaOH}$ solution and the U-bend specimens were placed in a $10 \% \mathrm{NaOH}$ solution. Both caustic solutions contained $<100 \mathrm{ppb}$ oxygen and $<100$ ppb chloride and were held at $307+/-6^{\circ} \mathrm{C}\left(585+/-11^{\circ} \mathrm{F}\right)$. The crack depth in the Alloy $690 \mathrm{U}-$ bend specimens (from the plate) after 500 hours of exposure is listed in Table C-13. Cracking was generally intergranular, although transgranular cracking was also observed. The crack depth was clearly related to the grain boundary carbide morphology. Specimens with a continuous network of intergranular carbides (in the HRA+SA+WQ+TT condition) had the smallest depth while specimens without intergranular carbides (in the HRA+SA+WQ) had the maximum depth. Hence, it was concluded that thermal treatment improved caustic SCC resistance of the Alloy 690 plate as it did for the Alloy 690 SG tubing material. The cracking depth after an exposure of 200 to 2,100 hours in the Alloy 690 RUB specimens (from the SG tubing) is shown in Figure C-3. Cracking in the Alloy 690 RUB specimens was both intergranular and transgranular. Figure C-3 shows that the crack depth was very small (from 0 to $0.11 \mathrm{~mm}$ ) and had a specific correlation among the three types of grain boundary carbide morphology. Therefore, it was concluded that caustic SCC resistance of thermally treated Alloy 690 was independent of grain boundary carbide decoration. Mertz et al. suggested that the thermal treatment improves caustic SCC resistance by removing carbon from the grain interior, hence also reducing the yield 
Appendix C-Alloy 690 Corrosion in Secondary Water

strength. The reduction in yield strength was thought to shift the stress distribution to the grain interior from the grain boundaries.

\section{C.2.7 Kawamura et al.}

Kawamura et al. investigated caustic IGA and SCC of Alloy 690TT along with Alloy 800 (shot peened) and Alloy $600 .^{[94]} \mathrm{C}$-ring specimens were fabricated from SG tubing while double cantilever beam (DCB) specimens were fabricated from plate of these materials. Details of the heat chemical composition, heat treatment, and mechanical properties are listed Table C-14. The Alloy 690 and Alloy 600 C-ring specimens had a dimension of $22.23 \mathrm{~mm}$ O.D. dia. by $1.27 \mathrm{~mm}$ thick by $15 \mathrm{~mm}$ wide. All C-ring specimens were stressed to 1.63 times the yield strength at the apex. Each material condition had $30 \mathrm{C}$-ring specimens and was exposed to a deaerated $10 \%$ $\mathrm{NaOH}+2 \% \mathrm{Na}_{2} \mathrm{CO}_{3}$ solution at $350^{\circ} \mathrm{C}\left(662^{\circ} \mathrm{F}\right)$. The dissolved oxygen was kept to below $5 \mathrm{ppb}$. The Alloy 600MA specimens developed through-wall IGA/SCC after 1,000 hours of exposure. The Alloy 600FS specimens had an average IGA/SCC depth of $40 \mathrm{~mm}$ after 500 hours of exposure. In contrast, the Alloy 690TT specimens had neither developed IGA nor SCC after 10,000 hours of exposure. The IGA/SCC crack propagation rates were determined using DCB specimens. The DCB specimens had a dimension of $58 \mathrm{~mm}$ (length) by $20 \mathrm{~mm}$ (height) by $8 \mathrm{~mm}$ (thickness) and was given a fatigue pre-crack prior to the testing. The DCB tests were conducted in a deaerated $20 \% \mathrm{NaOH}+4 \% \mathrm{Na}_{2} \mathrm{CO}_{3}$ solution at $320^{\circ} \mathrm{C}\left(608^{\circ} \mathrm{F}\right)$.

The results of the DCB tests are shown in Figure C-4. The stress dependency of Alloy 690TT and Alloy 600MA are similar. The SCC crack growth rate dependence on stress intensity factor can be divided into two regions, Region I and Region II. In Region I, the crack growth rate increases rapidly with increasing stress intensity factor. In Region 2, the crack growth rate is mostly unaffected by increasing stress intensity factor. At the same stress intensity factor (up to $75 \mathrm{MPa} \sqrt{\mathrm{m}}$ ), the crack growth rate of Alloy 690TT is approximately $1 / 100$ th of Alloy $600 \mathrm{MA}$. Hence, the improvement in IGA/SCC resistance of the Alloy 690TT over the Alloy 600MA in a deaerated caustic solution was derived from a combination of a longer crack initiation time and a lower crack propagation rate.

\section{C.2.8 H.P. Kim et al.}

H.P. Kim et al. conducted caustic SCC testing of both Alloy 600 and Alloy 690 materials. ${ }^{[95]}$ Cring specimens were fabricated from archive heats of Alloy 600 and Alloy 690 SG tubing that were used in Korean nuclear power plants. The chemical composition and the mechanical properties are listed in Table C-15. The Alloy 600 and the Alloy $690 \mathrm{C}$-ring specimens were stressed to $565 \mathrm{MPa}$ at the apex and placed in a deaerated $10 \% \mathrm{NaOH}$ solution at $315^{\circ} \mathrm{C}\left(600^{\circ} \mathrm{F}\right)$. The corrosion potential was kept at $200 \mathrm{mV}$ vs. $\mathrm{Ag} / \mathrm{AgCl}$ reference. After 15 days of exposure, the Alloy 690TT showed no IGA/SCC while all four of the Alloy 600 heats showed varying degrees of cracking. The Alloy 600 with a low mill anneal temperature (LT600) had the deepest cracking. 


\section{C.3 Lead Contaminated Secondary Water}

\section{C.3.1 Castano-Marin et al - Acidic, Caustic, AVT Water + Lead}

Castano-Marin et al. performed C-ring tests of Alloy 690TT and Alloy 600MA SG tubing in a variety of $\mathrm{PbO}$-doped water environments. ${ }^{[96]}$ Table C-16 and Table C-17 list the chemical composition, mechanical properties, and size of these SG tubing materials. The environmental conditions and metallographic examination results are summarized in Table C-18. In caustic water un-doped by $\mathrm{PbO}$ at 350 and $320^{\circ} \mathrm{C}$, the Alloy 690TT was resistant to IGA/IGSCC while the Alloy $600 \mathrm{MA}$ was susceptible to IGSCC. In $\mathrm{PbO}$ doped caustic waters at $350^{\circ} \mathrm{C}\left(662^{\circ} \mathrm{F}\right)$, the Alloy 690TT developed TGSCC cracks (see Figure C-5) more quickly than the Alloy 600MA developed IGA/IGSCC cracks. In acidic water with or without PbO doping, the Alloy 600TT was resistant to SCC while the Alloy 600MA failed by IGSCC irrespective of PbO doping. In $\mathrm{PbO}$ doped caustic water and in AVT water with or without $\mathrm{PbO}$ doping at $320^{\circ} \mathrm{C}$, the Alloy 690TT was immune from IGA/SCC. Both the Alloy 600TT and the Alloy $600 \mathrm{MA}$ were susceptible to IGA/SCC under these conditions, although the Alloy 600TT was slightly more resistant than the Alloy 600MA.

\section{C.3.2 Vaillant et al. - Deaerated Caustic Water + Lead}

Vaillant et al. tested Alloys 690 and 600 in lead-contaminated deaerated solutions containing 100 $\mathrm{g} / \mathrm{L} \mathrm{NaOH}$ at $350^{\circ} \mathrm{C}\left(662^{\circ} \mathrm{F}\right) .{ }^{[92]}$ Lead in the form lead oxide $(\mathrm{PbO})$ was added to a concentration of $10 \mathrm{~g} \mathrm{PbO} / \mathrm{L}$. The test showed that lead significantly increased both IGA and SCC of the Alloy 600 and the Alloy 690 in caustic solutions at $300-350^{\circ} \mathrm{C}\left(572-662^{\circ} \mathrm{F}\right)$. The cracking was found to be both transgranular and intergranular SCC. The Alloy 600TT has the highest SCC resistance in the lead-contaminated caustic solution while the Alloy 600MA and the Alloy 690TT were similar. The Alloy 600TT lost the beneficial effect of intergranular carbides observed in pure $\mathrm{NaOH}$ solution after lead introduction. The IGA rate in PbO doped water was increased by 10 times for the Alloy 600MA and by 6 times for the Alloy 600TT. The growth rate of the Alloy 690TT oxide thickness was increased by 8-10 times.

\section{C.3.3 Helie - Non-deaerated Acidic Water + Lead}

Helie performed CERT and RUB tests of Alloy 600MA and Alloy 690TT in non-deaerated pure water doped either with $\mathrm{PbO}$ or $\mathrm{PbS}$ to a concentration of $10 \mathrm{~g} / \mathrm{L} .{ }^{[97]}$ The CERT and RUB specimens were cut from the SG tubing. The chemical composition and the heat treatment of the Alloy 600 and Alloy 690 materials are listed Table C-19. The Alloy 690TT CERT tests were performed at $360^{\circ} \mathrm{C}\left(680^{\circ} \mathrm{F}\right)$ and at a strain rate of $5 \times 10^{-8} \mathrm{~s}^{-1}$. The Alloy 600MA CERT tests were performed at $320^{\circ} \mathrm{C}\left(608^{\circ} \mathrm{F}\right)$ and at a strain rate of $2.7 \times 10^{-7} \mathrm{~s}^{-1}$.

The CERT test results showed that the Alloy 690TT did not develop SCC, except for some indentations less than $20 \mu \mathrm{m}$ deep. The Alloy 600MA specimens showed extensive cracking. Compared to the previous test results in the undoped water, the addition of $\mathrm{PbO}$ drastically increased the Alloy 600MA CERT cracking propensity and changed the SCC mode from IGSCC to predominantly TGSCC. The RUB tests were performed at $325^{\circ} \mathrm{C}\left(617^{\circ} \mathrm{F}\right)$ for 5000 hours in two autoclaves, respectively doped with $\mathrm{PbO}$ and $\mathrm{PbS}$. Testing in one of the two autoclaves was interrupted after 1,000 hours and then resumed. None of the Alloy 690TT RUB specimens in the 
Appendix C-Alloy 690 Corrosion in Secondary Water

two autoclaves showed any SCC. In contrast, the Alloy 600MA RUB specimens showed extensive SCC cracks in both autoclaves. The SCC was predominantly TGSCC in the PbO doped water and predominantly IGSCC in the PbS doped water.

\section{C.4 Chloride and Sulfate Containing Secondary Water}

\section{C.4.1 Berge et al. - Acidic Chloride Containing Solutions}

Berge et al. investigated SCC resistance of Alloy 600 and Alloy 690 materials in various chloride containing solutions. ${ }^{[98]}$ Table C-20 is a summary of past laboratory tests of both Alloys 600 and 690 in various chloride-containing solutions at low elevated temperatures ranging from room temperature to $180^{\circ} \mathrm{C}\left(356^{\circ} \mathrm{F}\right)$. These tests indicate that Alloys 600 and 690 are not susceptible to cracking in chloride-containing media at lower elevated temperatures. This is consistent with the fact that alloys with greater than $40 \%$ nickel are immune to cracking in standard boiling $\mathrm{MgCl}_{2}$ solution. At high elevated temperature, Alloy 600 material is known to develop SCC when both chloride and oxygen are present.

Table C-21 is a summary of past laboratory tests of Alloy 690 in various chloride-containing solutions at high elevated temperatures by Berge et al. These results showed that Alloy 690 is resistance to SCC in chloride containing solutions with or without dissolved oxygen. Berge et al. tested RUB specimens fabricated from Type 304L stainless steel, Alloy 600, and Alloy 690 in boiling $\mathrm{MgCl}_{2}$ solution, whose $\mathrm{pH}$ was adjusted with addition of $\mathrm{HCl}$ acid to 2.3, 1.6, and 1.0. The chemical composition and heat treatment of these materials are listed in Table C-22. The results of the boiling $\mathrm{MgCl} 2$ tests are listed in Table C-23. The Type 304L specimens cracked in less than 24 hours in all three $\mathrm{pH}$ solutions. Alloy 600MA developed intergranular crack after 1500 hours at $\mathrm{pH}$ of 1.6. Alloy 690MA developed intergranular crack after 288 hours in the strongest acidic $(\mathrm{pH}=1.0)$ boiling $\mathrm{MgCl}_{2}$ solution. Berge et al also perform SCC tests of Alloy 600 in many acidified chloride-containing solutions at temperatures ranging from 100 to $360^{\circ} \mathrm{C}$ $\left(212\right.$ to $680^{\circ} \mathrm{F}$ ). The results showed that Alloy 600 is susceptible to SCC in acidified chloridecontaining media. However, Alloy 690 was not among these tests.

\section{C.4.2 Cullen et al. - Acidic Sulfate and Chloride Containing Solutions}

Cullen et al. tested Alloys 600 and 690TT SG tubing materials for wastage, IGA, and IGSCC in acid chloride and sulfate environments at various $\mathrm{pH}$ levels, temperatures, and applied

potential. ${ }^{[99,100]} \mathrm{C}$-ring specimens were fabricated from Alloy 690TT and Alloy 600 materials in low and high temperature MA, TT, and sensitized conditions. The chemical composition and heat treatment are listed in Table C-24. The C-ring specimens were strained to $0.1 \%, 0.2 \%$, $0.5 \%$, and fully closed ( $4 \%$ to $5 \%$ strain). The autoclave water chemistry was adjusted to simulate the concentration of species in secondary water based on the computer program MULTEQ. The solutions for some of the tests are listed in Table C-25. The test results showed that the Alloy 690TT material wastage measured from weight loss in the C-ring specimens was as much or more than the Alloy 600 material in any heat treatment condition. However, the Alloy 690TT had the highest IGSCC resistance in these solutions and was considered to be relatively immune to IGSCC in the acidified sulfate and chloride environments. 


\section{C.4.3 Bouvier et al. - Neutral to Slightly Caustic Sulfate Solutions}

Bouvier et al. tested C-ring specimens fabricated from Alloy 690 and Alloy 600MA\&TT materials in neutral to slightly caustic sulfate solutions. ${ }^{[101]}$ The chemical composition, heat treatment, and mechanical properties of the Alloys 600 and 690 SG tubing tested are listed in Table C-26. In order to be representative of the creviced areas in the SG, a calculation was performed. The calculation showed the maximum soluble sulfate concentration obtained with a $\Delta \mathrm{T}$ of $50^{\circ} \mathrm{C}\left(90^{\circ} \mathrm{F}\right)$ between primary and secondary temperature was $0.6 \mathrm{M}(57000 \mathrm{ppm})$. Because the actual sulfate concentration value was considered to be less, the three deaerated solutions selected for the testing contained $0.6 \mathrm{M}, 0.05 \mathrm{M}$, and $0.001 \mathrm{M}$ sulfate, respectively. The C-ring specimens were stressed to 0.8 YS (only for the Alloy 600), YS, and until the C-ring was closed. The C-ring specimens were tested at $320^{\circ} \mathrm{C}\left(608^{\circ} \mathrm{F}\right)$ for 2000 to 3000 hours. The $\mathrm{pH}$ at elevated temperature was adjusted to between 5 and 9.5 with sulfuric acid and sodium hydroxide. The neutral $\mathrm{pH}$ at $320^{\circ} \mathrm{C}\left(608^{\circ} \mathrm{F}\right)$ is about 5.5 . Hence, the test solutions were neutral to slightly alkaline at these $\mathrm{pH}$ values.

The test results showed that the Alloy 600MA material had a maximum IGSCC susceptibility at $\mathrm{a} \mathrm{pH}$ of 5 and that the susceptibility decreased with increasing $\mathrm{pH}$ values. The crack growth rate increased by a factor of 10 when the sulfate concentration was increased from $0.001 \mathrm{M}$ to $0.05 \mathrm{M}$ and from $0.05 \mathrm{M}$ to $0.6 \mathrm{M}$. The stress level was not a factor in crack growth rate when the Alloy $600 \mathrm{MA}$ specimens were loaded above the yield stress. The Alloy 600TT responses paralleled those of the Alloy 600MA, except the Alloy 600TT crack growth rate decreased by a factor of two. The Alloy 690TT material was not affected in any of the solutions.

\section{C.4.4 Bouvier et al. - Neutral Sulfate Solution + Copper}

Bouvier et al. tested C-ring specimens fabricated from Alloy 690TT and Alloy 600MA\&TT materials in neutral to sulfate solutions containing copper. ${ }^{[102]}$ Among the large number of chemical elements present in the secondary side deposit, copper has been found on numerous pulled SG tubes. This copper may become oxidized during a lay-up and/or a shutdown in the presence of air and stagnant water. The copper oxide could have a detrimental effect on SG tubing IGSCC. The Alloy 690TT used was the same as listed in Table C-26, which was used in a previous study by Bouvier et al. The C-ring specimens were stressed to $0.8 \mathrm{YS}$ (only for the Alloy 600), YS, and until the C-ring was closed. The C-ring specimens were tested at $320^{\circ} \mathrm{C}$ $\left(608^{\circ} \mathrm{F}\right)$ for 2000 to 3000 hours. In order to study the copper influence, the following solutions were also used.

1. $\mathrm{R}$ - the reference solution, deaerated and containing $0.05 \mathrm{M}$ sulfate $\left(\mathrm{SO}_{4}\right)$;

2. $\mathrm{R}+$ mixed copper oxides $\left(\mathrm{CuO}+\mathrm{Cu}_{2} \mathrm{O}\right)$ both at $0.01 \%$ and $1 \%$;

3. $\mathrm{R}+$ metallic copper $(13 \mathrm{~g} / \mathrm{L})$

4. $\mathrm{R}+$ metallic copper deposit on C-ring samples (electrolytic deposit);

5. $\mathrm{R}$ without copper but with electrochemical polarization.

The test results showed that copper or copper oxides were in general not detrimental to IGSCC of Alloy 600 material. The copper or copper oxides were beneficial in some cases as the measured crack growth rate was sometimes lower than in the reference solution. High amounts of copper oxide were found to be detrimental to the Alloy 600 material, especially to sensitized 
Appendix C-Alloy 690 Corrosion in Secondary Water

Alloy 600 material. However, the Alloy 690 material was never affected by the addition of copper or copper oxides.

\section{C.5 Summary of Secondary Water Corrosion}

1. In an AVT water environment, the laboratory tests have demonstrated that Alloy 690 (MA or TT) is very highly resistant to IGSCC.

2. In deaerated caustic solutions, various laboratory tests consistently showed that Alloy 690TT material usually has significantly higher IGA/SCC resistance than Alloy 600MA and Alloy 600TT materials, although it may have a slightly lower SCC resistance in highly caustic water $(50 \% \mathrm{NaOH})$ at $600^{\circ} \mathrm{F}$. The observed improvement for Alloy 690 is derived from longer crack initiation times and lower crack propagation rates compared to the Alloy 600 materials. However, these tests also showed that Alloy 690TT material can undergo IGA/SCC in deaerated caustic environments.

3. In neutral or acidic water, or AVT water doped with lead, Alloy 690TT material is more resistant to IGA/SCC than Alloy 600TT material, which is more resistant than Alloy 600MA material. However, all of these materials are considered to be susceptible in neutral or acidic environments containing lead.

4. In caustic water doped with $\mathrm{PbO}$, Alloy $690 \mathrm{TT}$ material has a somewhat lower resistance than Alloy 600MA and Alloy 600TT, but all three materials are susceptible to IGA/SCC.

5. In chloride-containing solutions in the absence of oxygen, laboratory test data confirm that both Alloy 600 and Alloy 690 materials possess very high SCC resistance. However, they can be susceptible to SCC in highly acidified chloride solutions, or when both oxygen and chloride are present. Alloy 690 material has a higher SCC resistance than Alloy 600 material under such extreme conditions.

6. In acidic solutions containing sulfate and chloride, laboratory tests show that Alloy 690TT material has a much higher IGSCC resistance than Alloy 600TT\&MA materials.

7. In deaerated neutral, or slightly caustic, sulfate solutions, laboratory tests indicate that Alloy 690TT is highly resistant to IGA/IGSCC, even when copper or copper oxides are present.

In summary, even though it cannot be considered immune to IGA/SCC, Alloy 690TT material has nevertheless demonstrated far superior IGA/SCC resistance compared to Alloy $600 \mathrm{MA}$ or Alloy 600TT materials under most conditions pertinent to faulted secondary water. Lead-doped caustic water is an exception here. Furthermore, Alloy 690 appears to be just as resistant to IGSCC in AVT water as it is to PWSCC in primary water. 
Table C-1 Alloy 690 Heats Tested in AVT Water by Miglin et al. ${ }^{[8 B]}$

\begin{tabular}{|c|c|c|c|c|c|c|c|c|c|c|c|c|c|c|}
\hline Alloy & $\mathrm{Ni}$ & $\mathrm{Cr}$ & $\mathrm{Fe}$ & C & Mn & Si & $S$ & $\mathrm{Ti}$ & $\begin{array}{c}\mathrm{Nb}+ \\
\mathrm{Ta}\end{array}$ & $\mathrm{Cu}$ & $P$ & $\mathrm{Al}$ & Mo & Other \\
\hline $\mathrm{NX} 4457 \mathrm{H}$ & 62.44 & 28.01 & 8.81 & 0.01 & 0.19 & 0.14 & 0.007 & 0.23 & & & & 0.14 & & \\
\hline $\mathrm{NX} 4458 \mathrm{H}$ & 62.58 & 27.93 & 8.81 & 0.01 & 0.19 & 0.10 & 0.007 & 0.23 & & & & 0.12 & & \\
\hline $\mathrm{NX} 4459 \mathrm{H}$ & 62.01 & 28.25 & 8.86 & 0.06 & 0.20 & 0.10 & 0.007 & 0.32 & & & & 0.17 & & \\
\hline $\mathrm{NX} 4460 \mathrm{H}$ & 62.07 & 28.25 & 8.86 & 0.06 & 0.20 & 0.10 & 0.007 & 0.26 & & & & 0.17 & & \\
\hline
\end{tabular}

(a) All tubes are $12.7 \mathrm{~mm}$ O.D $\times 1.35 \mathrm{~mm}$ wall from Huntington Alloys.

Table C-2 Alloys 600 and 690 Corrosion Test in AVT Water by Miglin et al. ${ }^{[88]}$

\begin{tabular}{|l|l|c|c|c|}
\hline \multicolumn{3}{|c|}{ Test Duration } & \multicolumn{2}{c|}{ AVT Water } \\
\hline${ }^{\circ} \mathrm{C}$ & ${ }^{\circ} \mathrm{F}$ & Hour & $\mathrm{SiO}_{2}$ & $<0.002 \mathrm{ppm}$ \\
\hline 360 & 680 & 17,917 & $\mathrm{Cl}$ & $<0.05 \mathrm{ppm}$ \\
\hline 343 & 650 & 93,750 & $\mathrm{Fe}$ & $<0.01 \mathrm{ppm}$ \\
\hline 332 & 630 & 52,343 & $\mathrm{O}_{2}$ & O (excess hydrazine $)$ \\
\hline 288 & 550 & 95,960 & Conductivity & $4-10 \mu \Omega / \mathrm{cm}$ \\
\hline & & & $\mathrm{pH}$ & $9.3-9.5\left(\mathrm{NH}_{3}\right.$ at $\left.25^{\circ} \mathrm{C}\right)$ \\
\hline
\end{tabular}


Table C-3 Summary of Alloy 690 SCC Results in Deaerated $50 \%$ NaOH Solution ${ }^{[8]}$

\begin{tabular}{|c|c|c|c|c|c|c|c|c|}
\hline \multirow{2}{*}{ Test } & \multirow{2}{*}{$\begin{array}{c}\text { Strain } \\
\%\end{array}$} & \multirow{2}{*}{$\begin{array}{c}\mathrm{NaOH} \text { Conc. } \\
\%\end{array}$} & \multicolumn{2}{|c|}{ Temp } & \multirow{2}{*}{$\begin{array}{l}\text { Time, } \\
\text { Hour }\end{array}$} & \multicolumn{2}{|c|}{ SCC Results ${ }^{(a)}$} & \multirow{2}{*}{ TT Condition } \\
\hline & & & ${ }^{\circ} \mathrm{C}$ & ${ }^{\circ} \mathrm{F}$ & & MA & $\pi$ & \\
\hline U-Bend & & 10 & 307 & 585 & 500 & & NC & 10 -hour at $1325^{\circ} \mathrm{F}$ \\
\hline U-Bend & & 10 & 307 & 585 & 500 & & $\mathrm{C}$ & 7 -hour at $1125^{\circ} \mathrm{F}+7$-hour at $1050^{\circ} \mathrm{F}$ \\
\hline U-Bend & & 10 & 316 & 600 & 1176 & C & & \\
\hline U-Bend & & 10 & 316 & 600 & 1296 & $\mathrm{C}$ & NC & 10 -hour at $1200^{\circ} \mathrm{F}$ \\
\hline U-Bend & & 10 & 316 & 600 & 1008 & C & C & 2-hour at $1200-1250^{\circ} \mathrm{F}$ \\
\hline U-Bend & & 10 & 325 & 617 & 500 & $\mathrm{C}$ & NC & 15 -hour at $1292^{\circ} \mathrm{F}$ \\
\hline U-Bend & & 10 & 350 & 662 & 5976 & C & $\mathrm{NC}$ & $>0.2$-hour at $>1300^{\circ} \mathrm{F}$ \\
\hline U-Bend & & 50 & 284 & 543 & 336 & C & C & 2-hour at $1200-1250^{\circ} \mathrm{F}$ \\
\hline U-Bend & & 50 & 300 & 572 & 840 & $\mathrm{C}$ & $\mathrm{C}$ & 2-hour at $1200-1250^{\circ} \mathrm{F}$ \\
\hline U-Bend & & 50 & 315 & 599 & Unknown & $\mathrm{C}$ & & \\
\hline U-Bend & & 50 & 316 & 600 & 72 & C & & \\
\hline U-Bend & & 50 & 316 & 600 & 336 & $\mathrm{C}$ & & \\
\hline U-Bend & & 50 & 316 & 600 & 1680 & $\mathrm{C}$ & C & 2-hour at $1200-1250^{\circ} \mathrm{F}$ \\
\hline U-Bend & & 50 & 332 & 630 & 1680 & C & C & 2-hour at $1200-1250^{\circ} \mathrm{F}$ \\
\hline RUB & & 10 & 360 & 680 & 10000 & $\mathrm{C}$ & & \\
\hline C-Ring & 0.5 & 4 & 323 & 613 & 2000 & & $\mathrm{NC}$ & 5 -hour at $1300-1328^{\circ} \mathrm{F}$ \\
\hline C-Ring & $<0.4$ & 10 & 288 & 550 & 480 & NC & $\mathrm{NC}$ & 10 -hour at $1300^{\circ} \mathrm{F}$ \\
\hline C-Ring & $>0.2$ & 10 & 315 & 599 & 144 & $\mathrm{C}$ & & Unknown \\
\hline C-Ring & 0.3 & 10 & 316 & 600 & 4800 & NC & $\mathrm{NC}$ & 10 -hour at $1200^{\circ} \mathrm{F}$ \\
\hline C-Ring & 0.3 & 10 & 316 & 600 & 2000 & NC & NC & 16 -hour at $1292^{\circ} \mathrm{F}$ \\
\hline C-Ring & 2 & 10 & 316 & 600 & 1920 & $\mathrm{C}, \mathrm{NC}$ & NC & 4-hour or 15 -hour at $1300^{\circ} \mathrm{F}$ \\
\hline C-Ring & 0.2 & 10 & 320 & 600 & 2000 & & $\mathrm{NC}$ & Unknown \\
\hline C-Ring & 0.2 & 10 & 332 & 630 & 5592 & $\mathrm{NC}$ & NC & 10 -hour at $1200^{\circ} \mathrm{F}$ \\
\hline C-Ring & 0.3 & 10 & 343 & 650 & 2000 & $\mathrm{C}$ & $\mathrm{NC}$ & 16 -hour at $1292^{\circ} \mathrm{F}$ \\
\hline C-Ring & 0.3 & 10 & 343 & 650 & 1500 & NC & NC & 15 -hour at $1292^{\circ} \mathrm{F}$ \\
\hline C-Ring & 2 & 10 & 350 & 662 & 2000 & & NC & \\
\hline C-Ring & 0.2 & 50 & 316 & 600 & 336 & NC & & \\
\hline C-Ring TLT ${ }^{(b)}$ & 14 & 10 & 316 & 600 & 2000 & $\mathrm{C}$ & $\mathrm{NC}$ & 16 -hour at $1292^{\circ} \mathrm{F}$ \\
\hline C-Ring TLT ${ }^{\text {(b) }}$ & 14 & 10 & 343 & 650 & 2000 & $\mathrm{C}$ & NC & 16 -hour at $1292^{\circ} \mathrm{F}$ \\
\hline C-Ring TLT ${ }^{(b)}$ & & 30 & 288 & 550 & 2900 & NC & $\mathrm{NC}$ & $<10$-hour at $1200-1600^{\circ} \mathrm{F}$ \\
\hline C-Ring TLT $^{(\mathrm{b})}$ & & 50 & 340 & 644 & 8000 & C & C & 12 -hour at $1220^{\circ} \mathrm{F}$ \\
\hline
\end{tabular}

(a) NC - Not cracked; C - Cracked.

(b) C-Ring until the legs touched. 
Table C-4 IGA in Alloy $690 \mathrm{TT}$ C-Rings in Deaerated Caustic Solutions at $644^{\circ} \mathrm{F}$ by A. Smith et al. ${ }^{[32]}$

\begin{tabular}{|c|l|c|c|c|c|}
\hline Alloy & \multicolumn{1}{|c|}{ Environment } & $\begin{array}{c}\text { Mean IGA Depth } \\
(\mu \mathrm{m})\end{array}$ & $\begin{array}{c}\text { Standard } \\
\text { Dev. }\end{array}$ & $\begin{array}{c}\text { Maximum IGA Depth } \\
(\mu \mathrm{m})\end{array}$ & $\begin{array}{c}\text { Test Time } \\
(\text { hour })\end{array}$ \\
\hline E1 & $50 \% \mathrm{NaOH}$ & 38.4 & 17 & 157 & 8000 \\
\hline A1 & $50 \% \mathrm{NaOH}$ & 26.1 & 10 & 56 & 8000 \\
\hline E4 & $\begin{array}{l}30 \% \mathrm{NaOH}+10 \% \\
\mathrm{Na}_{2} \mathrm{SO}_{4}\end{array}$ & 29.4 & 9 & 75 & 8000 \\
\hline A5 & $\begin{array}{l}30 \% \mathrm{NaOH}+10 \% \\
\mathrm{Na}_{2} \mathrm{SO}_{4}\end{array}$ & 17.4 & 8 & 59.2 & 8000 \\
\hline A5 & $\begin{array}{l}30 \% \mathrm{NaOH}+10 \% \\
\mathrm{Na}_{2} \mathrm{SO}_{4}\end{array}$ & 10.9 & 5 & 41 & 1200 \\
\hline E3 & $\begin{array}{l}30 \% \mathrm{NaOH}^{2}+10 \% \\
\mathrm{Na}_{2} \mathrm{SO}_{4}\end{array}$ & 26.0 & 12 & 88 & 1200 \\
\hline
\end{tabular}

Table C-5 $\mathrm{K}_{\mathrm{Iscc}}$ of Alloys 600 and 690 in Deaerated $\mathrm{NaOH}$ Solution by K. Smith et al. ${ }^{[1]}$

\begin{tabular}{|c|c|c|}
\hline Alloy & $\begin{array}{c}\text { NaOH Concentration } \\
\text { (gram/liter) }\end{array}$ & K Iscc, MPa $\sqrt{m}$ \\
\hline $600 \mathrm{MA}$ & 100 & 9.2 \\
\hline $600 \mathrm{TT}$ & 100 & 12.8 \\
\hline $690 \mathrm{MA}$ & 100 & 16.4 \\
\hline $690 \mathrm{TT}$ & 100 & 23.2 \\
\hline $600 \mathrm{MA}$ & 4 & 20.4 \\
\hline $600 \mathrm{TT}$ & 4 & 21.6 \\
\hline $690 \mathrm{MA}$ & 4 & No SCC \\
\hline $690 \mathrm{TT}$ & 4 & No SCC \\
\hline
\end{tabular}

(a) $\mathrm{TT}$ - thermally treated, 15 -hour at $1292^{\circ} \mathrm{F}$. 
Table C-6 Alloys 600 and 690 C-Rings in Deaerated $10 \% \mathrm{NaOH}$ at $315^{\circ} \mathrm{C}$ by K. Smith et al. ${ }^{[1]}$

\begin{tabular}{|c|c|c|c|c|c|}
\hline \multirow{2}{*}{ Alloy } & \multicolumn{5}{|c|}{ Crack Depth, $\mu \mathrm{m}$} \\
\cline { 2 - 6 } & $50 \% \mathrm{YS}$ & $75 \% \mathrm{YS}$ & $90 \% \mathrm{YS}$ & $150 \% \mathrm{YS}$ & TLT (14\% Strain) \\
\hline $600 \mathrm{MA}$ & 0 & 25 & Thru-wall & Thru-wall & Thru-wall \\
\hline $600 \mathrm{TT}$ & 10 & 10 & 10 & Thru-wall & Thru-wall \\
\hline $690 \mathrm{MA}$ & 0 & 10 & 10 & 30 & Thru-wall \\
\hline $690 \mathrm{TT}$ & 0 & 0 & 0 & 0 & 5 \\
\hline
\end{tabular}

(a) Corrosion potential was kept in the active-passive transition, $140 \mathrm{mv}$ vs. Ni.

Table C-7 Alloys 690 and 600 Tested in Deaerated $10 \%$ and $30 \%$ NaOH Solutions by Sarver et al. ${ }^{[9]]}$

\begin{tabular}{|l|c|c|c|c|c|c|c|c|c|c|c|c|c|c|}
\hline \multicolumn{1}{|c|}{ Heat } & $\mathrm{Ni}$ & $\mathrm{Cr}$ & $\mathrm{Fe}$ & $\mathrm{C}$ & $\mathrm{Mn}$ & $\mathrm{Si}$ & $\mathrm{S}$ & $\mathrm{Ti}$ & $\begin{array}{c}\mathrm{Nb}+ \\
\mathrm{Ta}\end{array}$ & $\mathrm{Cu}$ & $\mathrm{P}$ & $\mathrm{Al}$ & $\mathrm{Mo}$ & $\mathrm{Co}$ \\
\hline $\begin{array}{l}753234 \\
\text { Alloy } 690\end{array}$ & 59.2 & 29.9 & 9.8 & 0.02 & & & & & & & & & & \\
\hline $\begin{array}{l}96834 \\
\text { Alloy } 600\end{array}$ & 75.0 & 15.8 & 8.0 & 0.04 & & & & & & & & & & \\
\hline
\end{tabular}


Table C-8 Results of C-Ring Specimens in Deaerated NaOH Solution by Sarver et al. ${ }^{[91]}$

\begin{tabular}{|c|c|c|c|}
\hline & Heat Treatment & $\begin{array}{c}\text { Depth of } \\
\text { Attack } \\
\text { (\% through- } \\
\text { wall) }\end{array}$ & Form of Attack \\
\hline Alloy 690MA & $5-\mathrm{min}$ at $2000^{\circ} \mathrm{F}$ & 3.6 & Pits, Heavy Oxide \\
\hline Alloy $690 \mathrm{TT}$ & 5 -min at $2000^{\circ} \mathrm{F}+30-\min$ at $1200^{\circ} \mathrm{F}$ & 6.4 & $\begin{array}{l}\text { Intergranular Penetration, Pits, Heavy } \\
\text { Oxide }\end{array}$ \\
\hline Alloy $690 \mathrm{TT}$ & 5 -min at $2000^{\circ} \mathrm{F}+10$-hour at $1218^{\circ} \mathrm{F}$ & 3.6 & Intergranular Penetration \\
\hline Alloy 690TT & 5 -min at $2000^{\circ} \mathrm{F}+1$-hour at $1300^{\circ} \mathrm{F}$ & 4.5 & Intergranular Penetration \\
\hline Alloy $690 \mathrm{TT}$ & 5 -min at $2000^{\circ} \mathrm{F}+5$-hour at $1300^{\circ} \mathrm{F}$ & 4.5 & Intergranular Penetration \\
\hline Alloy $690 T \mathrm{~T}$ & 5 -min at $2000^{\circ} \mathrm{F}+10$-hour at $1300^{\circ} \mathrm{F}$ & 2.7 & Intergranular Penetration \\
\hline Alloy $690 T \mathrm{~T}$ & 5 -min at $2000^{\circ} \mathrm{F}+1$-hour at $1400^{\circ} \mathrm{F}$ & 2.7 & Intergranular Penetration, Heavy Oxide \\
\hline Alloy $690 T T$ & 5 -min at $2000^{\circ} \mathrm{F}+1$-hour at $1500^{\circ} \mathrm{F}$ & 3.6 & Intergranular Penetration, Heavy Oxide \\
\hline Alloy $690 T T$ & $5-\min$ at $2000^{\circ} \mathrm{F}+10-\min$ at $1600^{\circ} \mathrm{F}$ & 3.6 & Intergranular Penetration \\
\hline Alloy 600MA & $5-\min$ at $1900^{\circ} \mathrm{F}$ & 100 & Intergranular Penetration \\
\hline Alloy $600 T T$ & 5 -min at $1900^{\circ} \mathrm{F}+15$-hour at $1300^{\circ} \mathrm{F}$ & 100 & Intergranular Penetration \\
\hline
\end{tabular}

(a) At $550^{\circ} \mathrm{F}$ for 2-month in $10 \% \mathrm{NaOH}$ solution with $170 \mathrm{mV}$ potential an 2 -month in $30 \% \mathrm{NaOH}$ solution with $210 \mathrm{mV}$ potential. 
Table C-9 Alloys 690 and 600 SG Used by Vaillant et al. ${ }^{[2]}$

\begin{tabular}{|c|c|c|c|c|c|c|c|c|}
\hline \multirow{2}{*}{ Heat ${ }^{\text {(a) }}$} & \multirow[t]{2}{*}{$\% \mathrm{C}$} & \multirow{2}{*}{ Heat Treatment } & $\begin{array}{l}Y S \\
20^{\circ} \mathrm{C} \\
\end{array}$ & $\begin{array}{c}\text { YS } \\
350^{\circ} \mathrm{C}\end{array}$ & $\begin{array}{c}\text { UTS } \\
350^{\circ} \mathrm{C}\end{array}$ & $\begin{array}{l}\text { Grain } \\
\text { Size }\end{array}$ & \multirow{2}{*}{$\begin{array}{l}\text { Inter- } \\
\text { granular } \\
\text { Carbides }\end{array}$} & \multirow{2}{*}{$\begin{array}{l}\text { Intra- } \\
\text { granular } \\
\text { Carbides }\end{array}$} \\
\hline & & & $\mathrm{MPa}$ & $\mathrm{MPa}$ & $\mathrm{MPa}$ & ASTM & & \\
\hline 6C, Ind, Alloy 600 & 0.025 & $1000-1020^{\circ} \mathrm{C}$ & 310 & 690 & 240 & $7-8$ & Low & Low \\
\hline 6D, Exp, Alloy 600 & 0.045 & $1070^{\circ} \mathrm{C}$ & $340-353$ & $700-710$ & $270-300$ & $8-9$ & Low & Heavy \\
\hline 611 , Exp, Alloy 600 & 0.021 & Not listed & 305 & 698 & 258 & 9 & Medium & Low \\
\hline $6 \mathrm{~J}$, Ind, Alloy 600 & 0.038 & $980^{\circ} \mathrm{C}$ & 396 & 752 & 369 & 10 & Medium & Low \\
\hline $6 \mathrm{M}$, Ind, Alloy 600 & 0.039 & $980^{\circ} \mathrm{C}$ & 380 & 720 & 340 & 10 & Heavy & Low \\
\hline \multirow{2}{*}{$6 \mathrm{P}$, Ind, Alloy 600} & \multirow{2}{*}{0.016} & $980^{\circ} \mathrm{C}$ & $320-340$ & $702-720$ & $275-300$ & 9 & Low & Low \\
\hline & & $980^{\circ} \mathrm{C}+700^{\circ} \mathrm{C}$ & 329 & 719 & 254 & 9 & Low & Heavy \\
\hline SL, Ind, Alloy 600 & 0.014 & $950-990^{\circ} \mathrm{C}$ & 286 & 691 & 227 & 6 & Low & Low \\
\hline 6V, Exp, Alloy 600 & 0.030 & $1150^{\circ} \mathrm{C}$ & 175 & 613 & 125 & 2 & Low & Medium \\
\hline \multirow{2}{*}{ 9E1, Exp, Alloy 690} & \multirow{2}{*}{0.028} & $1040^{\circ} \mathrm{C}$ & 370 & 760 & 280 & $8-9$ & Heavy & Low \\
\hline & & $1040^{\circ} \mathrm{C}+700^{\circ} \mathrm{C}$ & 350 & 750 & 270 & 9 & Heavy & $\begin{array}{l}\text { Low- } \\
\text { medium }\end{array}$ \\
\hline \multirow{2}{*}{ 9E2, Exp, Alloy 690} & \multirow{2}{*}{0.032} & $1010^{\circ} \mathrm{C}$ & 360 & 710 & 290 & $7-8$ & Heavy & Low \\
\hline & & $1010^{\circ} \mathrm{C}+700^{\circ} \mathrm{C}$ & 330 & 690 & 270 & $7-8$ & Heavy & $\begin{array}{l}\text { Low - } \\
\text { medium }\end{array}$ \\
\hline \multirow{2}{*}{ 9G3, Exp, Alloy 690} & \multirow{2}{*}{0.012} & $1045^{\circ} \mathrm{C}$ & 319 & 722 & 241 & $7-8$ & Medium & Low \\
\hline & & $1045^{\circ} \mathrm{C}+700^{\circ} \mathrm{C}$ & 314 & 730 & 244 & 7 & Medium & Heavy \\
\hline \multirow{2}{*}{ 9G4, Exp, Alloy 690} & \multirow{2}{*}{0.012} & $980^{\circ} \mathrm{C}$ & 409 & 806 & 331 & 10 & Medium & Low \\
\hline & & $980^{\circ} \mathrm{C}+700^{\circ} \mathrm{C}$ & 407 & 792 & 323 & 10 & Medium & Medium \\
\hline 9P1, Exp, Alloy 690 & 0.028 & $980^{\circ} \mathrm{C}+700^{\circ} \mathrm{C}$ & 497 & 848 & 423 & 11 & $\begin{array}{l}\text { Medium } \\
\text { - heavy }\end{array}$ & Medium \\
\hline 9P2, Exp, Alloy 690 & 0.028 & $1040^{\circ} \mathrm{C}+700^{\circ} \mathrm{C}$ & 419 & 825 & 358 & $9-10$ & Medium & $\begin{array}{l}\text { Low- } \\
\text { medium }\end{array}$ \\
\hline 911, Ind, Alloy 690 & 0.015 & $\begin{array}{l}1040-1080^{\circ} \mathrm{C}+ \\
700^{\circ} \mathrm{C}\end{array}$ & 304 & 727 & 244 & 7 & Low & $\begin{array}{l}\text { Medium } \\
- \text { heavy }\end{array}$ \\
\hline 912 , Ind, Alloy 690 & 0.021 & $\begin{array}{l}1040-1070^{\circ} \mathrm{C}+ \\
700^{\circ} \mathrm{C}\end{array}$ & 360 & 755 & 287 & $7-8$ & Low & $\begin{array}{l}\text { Low- } \\
\text { medium }\end{array}$ \\
\hline
\end{tabular}

(a) Ind - industrial heat SG tube; Exp - experimental heat of SG tubes. 
Table C-10 IGSCC in $350^{\circ} \mathrm{C}$ Deaerated $\mathrm{NaOH}$ Solution Used by Vaillant et al. ${ }^{[92]}$

Stress Level > Yield Strength (C-Ring at 2YS, U-Bend, RUB, WOL)

\begin{tabular}{|l|l|l|l|l|l|l|}
\hline \multirow{2}{*}{} & \multicolumn{6}{|c|}{ NaOH Concentration, } \\
\cline { 2 - 7 } & $1 \mathrm{~g} / \mathrm{L}$ & $4 \mathrm{~g} / \mathrm{L}$ & $10 \mathrm{~g} / \mathrm{L}$ & $40 \mathrm{~g} / \mathrm{L}$ & \multicolumn{1}{|c|}{$100 \mathrm{~g} / \mathrm{L}$} & \multicolumn{1}{|c|}{$500 \mathrm{~g} / \mathrm{L}$} \\
\hline \multirow{2}{*}{ Alloy 600MA } & & $\begin{array}{l}\text { Crack } \\
\text { (C-Ring) }\end{array}$ & $\begin{array}{l}\text { Crack } \\
\text { (C-Ring) }\end{array}$ & $\begin{array}{l}\text { Crack } \\
\text { (C-Ring) }\end{array}$ & $\begin{array}{l}\text { Crack } \\
\text { (C-Ring) }\end{array}$ & $\begin{array}{l}\text { Crack } \\
\text { (C-Ring) }\end{array}$ \\
\hline Alloy 600TT & & $\begin{array}{l}\text { Crack } \\
\text { (C-Ring) }\end{array}$ & $\begin{array}{l}\text { Crack } \\
\text { (C-Ring) }\end{array}$ & $\begin{array}{l}\text { Crack } \\
\text { (C-Ring) }\end{array}$ & \\
\hline $\begin{array}{l}\text { Alloy 690 } \\
\text { intergranular carbides }\end{array}$ & & & $\begin{array}{l}\text { No Crack } \\
\text { (RUB) }\end{array}$ & & $\begin{array}{l}\text { Crack } \\
\text { (WOL) }\end{array}$ & \\
\hline $\begin{array}{l}\text { Alloy 690 with } \\
\text { intragranular carbides }\end{array}$ & & $\begin{array}{l}\text { No Crack } \\
\text { (C-Ring) }\end{array}$ & $\begin{array}{l}\text { No Crack } \\
\text { (RUB) }\end{array}$ & $\begin{array}{l}\text { Crack } \\
\text { (WOL) }\end{array}$ & $\begin{array}{l}\text { Very Short } \\
\text { crack } \\
\text { (C-Ring) }\end{array}$ \\
\hline
\end{tabular}

Stress Level $<=$ Yield Strength (C-Ring)

\begin{tabular}{|l|c|l|l|l|l|l|}
\hline \multirow{2}{*}{} & \multicolumn{6}{|c|}{ NaOH Concentration, } \\
\cline { 2 - 7 } & $1 \mathrm{~g} / \mathrm{L}$ & $4 \mathrm{~g} / \mathrm{L}$ & $10 \mathrm{~g} / \mathrm{L}$ & $40 \mathrm{~g} / \mathrm{L}$ & $100 \mathrm{~g} / \mathrm{L}$ & \multicolumn{1}{|c|}{$500 \mathrm{~g} / \mathrm{L}$} \\
\hline Alloy 600MA & & $\begin{array}{l}\text { Crack } \\
\text { (C-Ring) }\end{array}$ & $\begin{array}{l}\text { Crack } \\
\text { (C-Ring) }\end{array}$ & $\begin{array}{l}\text { Crack } \\
\text { (C-Ring) }\end{array}$ & $\begin{array}{l}\text { Crack } \\
\text { (C-Ring) }\end{array}$ & $\begin{array}{l}\text { Crack } \\
\text { (C-Ring) }\end{array}$ \\
\hline Alloy 600TT & & $\begin{array}{l}\text { No Crack } \\
\text { (C-Ring) }\end{array}$ & $\begin{array}{l}\text { Crack } \\
\text { (C-Ring) }\end{array}$ & & $\begin{array}{l}\text { Crack } \\
\text { (C-Ring) }\end{array}$ & $\begin{array}{l}\text { No Crack } \\
\text { (C-Ring) }\end{array}$ \\
\hline $\begin{array}{l}\text { Alloy 690 } \\
\text { intergranular carbides }\end{array}$ & & & $\begin{array}{l}\text { No Crack } \\
\text { (C-Ring) }\end{array}$ & & $\begin{array}{l}\text { No Crack } \\
\text { (C-Ring) }\end{array}$ & \\
\hline $\begin{array}{l}\text { Alloy 690 with } \\
\text { intragranular carbides }\end{array}$ & & $\begin{array}{l}\text { No Crack } \\
\text { (C-Ring) }\end{array}$ & $\begin{array}{l}\text { No Crack } \\
\text { (C-Ring) }\end{array}$ & & $\begin{array}{l}\text { Crack } \\
\text { (C-Ring) }\end{array}$ & \\
\hline
\end{tabular}


Table C-11 Properties of Alloy 690 in the As-Received Condition ${ }^{[93]}$

\begin{tabular}{|c|c|c|c|c|c|c|c|c|c|c|c|c|c|c|}
\hline Matl. & $\mathrm{Ni}$ & $\mathrm{Cr}$ & $\mathrm{Fe}$ & $\mathrm{C}$ & $\mathrm{Mn}$ & $\mathrm{Si}$ & $\mathrm{S}$ & $\mathrm{Ti}$ & $\begin{array}{c}\mathrm{Nb}+ \\
\mathrm{Ta}\end{array}$ & $\mathrm{Cu}$ & $\mathrm{P}$ & $\mathrm{Al}$ & $\mathrm{Co}$ & $\mathrm{Mg}$ \\
\hline $\begin{array}{c}\text { SG Tubing } \\
\mathrm{A}\end{array}$ & 59.03 & 29.93 & 10.0 & 0.025 & 0.16 & 0.19 & 0.001 & 0.34 & & 0.03 & 0.006 & 0.25 & 0.005 & 0.004 \\
\hline $\begin{array}{c}\text { SG Tubing } \\
\mathrm{B}\end{array}$ & 59.12 & 30.05 & 10.11 & 0.029 & 0.07 & 0.14 & 0.001 & 0.33 & & 0.05 & 0.005 & 0.18 & 0.01 & \\
\hline Plate & 59.38 & 29.98 & 9.41 & 0.028 & 0.11 & 0.32 & 0.001 & 0.32 & & 0.03 & 0.015 & 0.38 & 0.03 & 0.02 \\
\hline
\end{tabular}

\begin{tabular}{|l|l|l|l|l|l|}
\hline Matl. & Size & Final Anneal & Thermal Treatment & $\begin{array}{l}\text { ASTM } \\
\text { Grain Size }\end{array}$ & Mechanical Properties \\
\hline SG Tubing A & $\begin{array}{l}6.30 \mathrm{~mm} \text { O.D. } \\
\times 0.46 \mathrm{~mm}\end{array}$ & $<4$-min at $>1093^{\circ} \mathrm{C}$ & 10-hour at $718^{\circ} \mathrm{C}$ & $6-7$ & $\begin{array}{l}\text { YS }=302 \mathrm{MPa} \\
\text { UTS }=680 \mathrm{MPa} \\
\text { Elong. }=46.8 \%\end{array}$ \\
\hline SG Tubing B & $\begin{array}{l}12.70 \mathrm{~mm} \text { O.D. } \\
\times 1.45 \mathrm{~mm}\end{array}$ & $<4$-min at $>1093^{\circ} \mathrm{C}$ & 10 -hour at $718^{\circ} \mathrm{C}$ & $5-7$ & \\
\hline Plate & $38.1 \mathrm{~mm}$ thick & 4 -hour at $1038^{\circ} \mathrm{C}$, air cool & None & 6 & $\begin{array}{l}\text { YS }=324 \mathrm{MPa} \\
\text { UTS }=691 \mathrm{MPa} \\
\text { Elong. }=46 \%\end{array}$ \\
\hline
\end{tabular}

Table C-12 Alloy 690 SG Tubing Heat Treatments Used by Mertz et al. ${ }^{\left[{ }^{[9]}\right.}$

\begin{tabular}{|l|c|c|c|}
\hline Final Grain Boundary Carbide & $\begin{array}{c}\text { Reference } \\
\text { (Continuous) }\end{array}$ & $\begin{array}{c}\text { Modified } \\
\text { (Semi-continuous) }\end{array}$ & $\begin{array}{c}\text { Local Grain Growth } \\
\text { (None to discontinuous) }\end{array}$ \\
\hline SG Tubing Heat & $\mathrm{A}, \mathrm{B}$ & $\mathrm{A}, \mathrm{B}$ & $\mathrm{X}$ \\
\hline $\begin{array}{l}\text { Mill Annealed (MA) } \\
1107^{\circ} \mathrm{C}\end{array}$ & $\mathrm{X}$ & $\mathrm{X}$ & $\mathrm{X}$ \\
\hline $\begin{array}{l}\text { Thermal Treatment (TT) } \\
10 \text {-hour at } 718^{\circ} \mathrm{C}\end{array}$ & & $\mathrm{X}$ & $\mathrm{X}$ \\
\hline $\begin{array}{l}\text { Thermal HIP } \\
\text { 6-hour at } 995^{\circ} \mathrm{C}\end{array}$ & & & $\mathrm{X}$ \\
\hline $\begin{array}{l}\text { Deformation HIP } \\
\text { 0.25-hour at } 995^{\circ} \mathrm{C}\end{array}$ & & & \\
\hline $\begin{array}{l}\text { Thermal HIP } \\
5.75 \text {-hour at } 995^{\circ} \mathrm{C}\end{array}$ & & & \\
\hline
\end{tabular}

(a) HIP - hot isostatic pressing performed $995^{\circ} \mathrm{C}$. The treatment was used to cause strain-induced grain boundary migration without dissolving the carbides. Hence the migrated grain boundary would be undecorated by carbides. 
Table C-13 Alloy 690 Plate Heat Treatments Used by Mertz et al. ${ }^{[93]}$

\begin{tabular}{|l|l|l|}
\hline Condition & Final Grain Boundary Carbide & $\begin{array}{l}\text { Maximum Crack Depth, after } 500 \\
\text { hours in } 10 \% \mathrm{NaOH} \text { at } 585+/-11^{\circ} \mathrm{F}\end{array}$ \\
\hline $\begin{array}{l}\text { HRA - as received hot rolled plate + 4-hour at } \\
1038^{\circ} \mathrm{C} \text {, air cool }\end{array}$ & Semi-continuous & 0.043 \\
\hline HRA + TT (10-hour at $\left.718^{\circ} \mathrm{C}\right)$ & Semi-continuous & 0.025 \\
\hline $\begin{array}{l}\text { HRA + SA (2-hour at } 1177^{\circ} \mathrm{C} \text { solution anneal) } \\
+ \text { WQ (water quench) }\end{array}$ & Un-decorated & 0.508 \\
\hline HRA + SA + WQ + TT & Continuous & 0.010 \\
\hline
\end{tabular}

Table C-14 Properties of Alloys 600 and 690 Used by Kawamura et al. ${ }^{[94]}$

\begin{tabular}{|c|c|c|c|c|c|c|c|c|c|c|c|c|c|c|}
\hline Matl. & $\mathrm{Ni}$ & $\mathrm{Cr}$ & $\mathrm{Fe}$ & $\mathrm{C}$ & $\mathrm{Mn}$ & $\mathrm{Si}$ & $\mathrm{S}$ & $\mathrm{Ti}$ & $\begin{array}{c}\mathrm{Nb}+ \\
\mathrm{Ta}\end{array}$ & $\mathrm{Cu}$ & $\mathrm{P}$ & $\mathrm{Al}$ & $\mathrm{Mo}$ & Other \\
\hline $\begin{array}{c}\text { Alloy 600 } \\
\text { SG Tube }\end{array}$ & 74.90 & 15.90 & 8.20 & 0.026 & 0.29 & 0.29 & 0.001 & & & 0.01 & 0.007 & & & \\
\hline $\begin{array}{c}\text { Alloy 690 } \\
\text { SG Tube }\end{array}$ & 59.85 & 30.50 & 8.60 & 0.02 & 0.28 & 0.31 & 0.001 & & & & 0.009 & & & \\
\hline $\begin{array}{c}\text { Alloy 600 } \\
\text { Plate }\end{array}$ & 76.66 & 15.40 & 7.24 & 0.021 & 0.34 & 0.33 & 0.002 & & & 0.002 & 0.004 & & & \\
\hline $\begin{array}{c}\text { Alloy 690 } \\
\text { Plate }\end{array}$ & 60.75 & 29.95 & 8.42 & 0.018 & 0.29 & 0.28 & 0.001 & & & 0.03 & 0.009 & & & \\
\hline
\end{tabular}

\begin{tabular}{|c|c|c|c|c|c|c|}
\hline Test & Matl. & Mill Anneal Treatment & Thermal Heat Treatment & $0.2 \% \mathrm{YS}, \mathrm{MPa}$ & UTS, MPa & Elong, \% \\
\hline \multirow{4}{*}{$\begin{array}{l}\text { C-Ring, } \\
\text { from SG } \\
\text { Tube }\end{array}$} & $600 \mathrm{MA}$ & 2-min at $1025^{\circ} \mathrm{C}, \mathrm{H}_{2} \mathrm{cool}$ & & 284 & 667 & 52 \\
\hline & $600 \mathrm{FS}$ & 2-min at $1025^{\circ} \mathrm{C}, \mathrm{H}_{2} \mathrm{cool}$ & 1-hour at $700^{\circ} \mathrm{C}$ & & & \\
\hline & $600 \mathrm{TT}$ & 2-min at $1025^{\circ} \mathrm{C}, \mathrm{H}_{2} \mathrm{cool}$ & 15 -hour at $700^{\circ} \mathrm{C}$ & & & \\
\hline & 690TT & 3 -min at $1075^{\circ} \mathrm{C}, \mathrm{H}_{2} \mathrm{cool}$ & 15 -hour at $700^{\circ} \mathrm{C}$ & 333 & 735 & 50 \\
\hline \multirow{2}{*}{$\begin{array}{l}\text { DCB, from } \\
\text { Plate }\end{array}$} & $600 \mathrm{MA}$ & 30 -min at $925^{\circ} \mathrm{C}$, air cool & & & & \\
\hline & 690TT & 5-hour at $1050^{\circ} \mathrm{C}, \mathrm{H}_{2} \mathrm{cool}$ & 15 -hour at $700^{\circ} \mathrm{C}$ & 263 & 637 & 41 \\
\hline
\end{tabular}


Table C-15 Properties of Alloys 600 and 690 Used by Kim et al. ${ }^{[95]}$

\begin{tabular}{|c|c|c|c|c|c|c|c|c|c|c|c|c|c|c|}
\hline Matl. & $\mathrm{Ni}$ & $\mathrm{Cr}$ & $\mathrm{Fe}$ & $\mathrm{C}$ & $\mathrm{Mn}$ & $\mathrm{Si}$ & $\mathrm{S}$ & $\mathrm{Ti}$ & $\begin{array}{c}\mathrm{Nb}+ \\
\mathrm{Ta}\end{array}$ & $\mathrm{Cu}$ & $\mathrm{P}$ & $\mathrm{Al}$ & $\mathrm{N}$ & $\mathrm{B}$ \\
\hline HT600A & 72.5 & 16.85 & 9.00 & 0.025 & & 0.31 & 0.003 & 0.28 & & 0.01 & 0.008 & 0.015 & 0.016 & 0.001 \\
\hline HT600B & 74.76 & 15.63 & 8.62 & 0.025 & & 0.14 & $<0.001$ & 0.34 & & 0.03 & 0.007 & 0.21 & 0.01 & 0.004 \\
\hline HT600C & 76.11 & 15.29 & 7.57 & 0.026 & & 0.15 & 0.001 & 0.32 & & 0.015 & 0.008 & 0.23 & 0.004 & 0.004 \\
\hline HT600D & 75.08 & 15.38 & 8.56 & 0.023 & & 0.20 & 0.001 & 0.26 & & $<0.01$ & 0.006 & 0.24 & 0.01 & 0.003 \\
\hline HT600 & 75.14 & 15.46 & 8.42 & 0.025 & & 0.16 & 0.001 & 0.29 & & 0.011 & 0.008 & 0.21 & 0.0042 & 0.0039 \\
\hline LT600 & 74.66 & 15.21 & 9.16 & 0.022 & & 0.2 & 0.001 & 0.29 & & 0.01 & 0.003 & 0.24 & & \\
\hline TT690E & 58.9 & 29.57 & 10.54 & 0.02 & & 0.22 & 0.001 & 0.26 & & 0.01 & 0.009 & 0.019 & 0.017 & 0.004 \\
\hline HT690 & 60.39 & 29.66 & 8.90 & 0.017 & & 0.14 & 0.001 & 0.26 & & 0.007 & 0.005 & 0.35 & 0.009 & 0.0007 \\
\hline
\end{tabular}

\begin{tabular}{|l|l|c|c|c|c|}
\hline \multicolumn{1}{|c|}{ Matl. } & \multicolumn{1}{c|}{ Mill Anneal Treatment } & YS, MPa & UTS, MPa & Elong, \% & ASTM Grain Size \\
\hline HT600A & High temperature mill anneal & 275 & 689 & 44 & 5.5 \\
\hline HT600B & High temperature mill anneal & 244 & 647 & 47 & 5.0 \\
\hline HT600C & High temperature mill anneal & 258 & 675 & 43 & 6 \\
\hline HT600D & High temperature mill anneal & 255 & 661 & 44 & 6 \\
\hline HT600 & High temperature mill anneal & 255 & 669 & 44 & \\
\hline LT600 & Low temperature mill anneal & 310 & 679 & 44 & \\
\hline TT690E & $\begin{array}{l}\text { High temperature mill anneal } \\
+10-h o u r ~ a t ~ 715^{\circ} \mathrm{C}\end{array}$ & 330 & 730 & 44 & \\
\hline HT690 & High temperature mill anneal & 293 & 698 & 52.2 & \\
\hline
\end{tabular}

Table C-16 Chemical Composition of Alloys 600 and 690 Used by Castano-Marin et al. ${ }^{[96]}$

\begin{tabular}{|c|c|c|c|c|c|c|c|c|c|c|c|c|c|c|}
\hline Matl. & $\mathrm{Ni}$ & $\mathrm{Cr}$ & $\mathrm{Fe}$ & $\mathrm{C}$ & $\mathrm{Mn}$ & $\mathrm{Si}$ & $\mathrm{S}$ & $\mathrm{Ti}$ & $\begin{array}{c}\mathrm{Nb}+ \\
\mathrm{Ta}\end{array}$ & $\mathrm{Cu}$ & $\mathrm{P}$ & $\mathrm{B}$ & $\mathrm{N}$ & $\mathrm{Co}$ \\
\hline 690TT, A & 59.42 & 29.05 & 10.49 & 0.022 & 0.33 & 0.29 & 0.001 & 0.24 & & 0.007 & 0.008 & 0.001 & 0.037 & 0.011 \\
\hline 690TT, B & 60.10 & 30.10 & 8.51 & 0.019 & 0.26 & 0.40 & 0.002 & 0.32 & & 0.010 & 0.012 & 0.001 & 0.027 & 0.010 \\
\hline 600MA, G & 73.84 & 16.16 & 9.34 & 0.045 & 0.18 & 0.18 & 0.007 & 0.21 & & 0.260 & 0.007 & 0.002 & & 0.050 \\
\hline 600TT, H & 74.64 & 14.81 & 9.80 & 0.044 & 0.21 & 0.24 & 0.009 & 0.21 & & 0.260 & 0.009 & 0.003 & & 0.050 \\
\hline
\end{tabular}


Table C-17 Mechanical Properties of Alloys 600 and 690 Used by Castano-Marin et al. ${ }^{[96]}$

\begin{tabular}{|c|c|c|c|c|}
\hline Matl. & YS, MPa & UTS, MPa & Elong., \% & Tube Size, mm \\
\hline $690 T$ T, A & 359 & 754 & 42.2 & $19.05 \times 1.09$ \\
\hline $690 T$ T, B & 332 & 731 & 45.0 & $17.45 \times 1.02$ \\
\hline 600MA, G & 386 & 793 & 36.5 & $19.05 \times 1.09$ \\
\hline $600 T$ T, H & 386 & 772 & 36.5 & $17.45 \times 1.02$ \\
\hline
\end{tabular}

Table C-18 C-Ring Test Condition and Results by Castano-Marin et al. ${ }^{[96]}$

Test Temperature $350^{\circ} \mathrm{C}\left(662^{\circ} \mathrm{F}\right)$

\begin{tabular}{|c|c|c|c|c|c|c|c|}
\hline \multicolumn{2}{|c|}{ Solution } & $10 \% \mathrm{NaOH}$ & $\begin{array}{c}10 \% \mathrm{NaOH}+ \\
0.1 \mathrm{M}(2 \%) \mathrm{PbO}\end{array}$ & $\begin{array}{c}10 \% \mathrm{NaOH}+ \\
0.01 \mathrm{M}(0.2 \%) \mathrm{PbO}\end{array}$ & $\begin{array}{c}4 \% \mathrm{NaOH}+ \\
0.002 \mathrm{M}(0.04 \%) \mathrm{PbO}\end{array}$ & $\begin{array}{r}0.75 \mathrm{M} \mathrm{Na}_{2} \mathrm{SO}_{4} \\
+0.25 \mathrm{M} \mathrm{FeSO}_{4}\end{array}$ & $\begin{array}{c}0.75 \mathrm{M} \mathrm{Na}_{2} \mathrm{SO}_{4}+ \\
0.25 \mathrm{M} \mathrm{FeSO} \\
+0.1 \mathrm{M}(2 \%) \mathrm{PbO}^{+}\end{array}$ \\
\hline Matl. & $\mathrm{pH}^{(a)}$ & 13.77 & 13.76 & 13.80 & 13.57 & 3.99 & 6.49 \\
\hline $690 \mathrm{TT}, \mathrm{A}$ & $\begin{array}{l}\text { 500-h } \\
750-h \\
1000-h \\
\text { Mode } \\
\end{array}$ & $\begin{array}{l}0 \% \\
0 \% \\
<2.0 \%\end{array}$ & $\begin{array}{l}100 \% \\
\text { TGSCC }\end{array}$ & $\begin{array}{l}100 \% \\
\text { TGSCC }\end{array}$ & $\begin{array}{l}50 \% \\
-- \\
88 \% \\
\text { TGSCC } \\
\end{array}$ & $\begin{array}{l}0 \% \\
0 \% \\
0 \%\end{array}$ & $0 \%$ \\
\hline 690TT, B & $\begin{array}{l}500-h \\
600-h \\
750-h \\
1000-h \\
\text { Mode } \\
\end{array}$ & $\begin{array}{l}0 \% \\
-- \\
0 \% \\
<1.4 \%\end{array}$ & $\begin{array}{l}100 \% \\
\text { TGSCC }\end{array}$ & $\begin{array}{l}0 \% \\
63 \% \\
\text { TGSCC }\end{array}$ & $\begin{array}{l}0 \% \\
- \\
- \\
0 \%\end{array}$ & $\begin{array}{l}0 \% \\
-- \\
0 \% \\
0 \%\end{array}$ & $0 \%$ \\
\hline $600 \mathrm{MA}, \mathrm{G}$ & $\begin{array}{l}500-h \\
600-h \\
750-h \\
1000-h \\
\text { Mode }\end{array}$ & $\begin{array}{l}45 \% \\
-70 \% \\
80 \% \\
\text { IGSCC }\end{array}$ & $\begin{array}{l}10 \% \\
\text { IGA+IGSCC }\end{array}$ & $\begin{array}{l}50 \% \\
53 \% \\
\text { IGA+IGSCC }\end{array}$ & $\begin{array}{l}12 \% \\
-- \\
\overline{7} \% \\
\text { IGA+IGSCC }\end{array}$ & IGSCC & $\begin{array}{l}100 \% \\
\text { IGSCC }\end{array}$ \\
\hline
\end{tabular}

Test Temperature $320^{\circ} \mathrm{C}\left(608^{\circ} \mathrm{F}\right)$

\begin{tabular}{|c|c|c|c|c|c|c|c|}
\hline \multicolumn{2}{|c|}{ Solution } & $4 \% \mathrm{NaOH}$ & $\begin{array}{c}4 \% \mathrm{NaOH}+ \\
0.01 \mathrm{M}(0.2 \%) \mathrm{PbO}\end{array}$ & $\begin{array}{c}4 \% \mathrm{NaOH}+ \\
0.002 \mathrm{M}(0.04 \%) \\
\mathrm{PbO}\end{array}$ & $\begin{array}{c}4 \% \mathrm{NaOH}+ \\
0.0004 \mathrm{M}(0.008 \%) \\
\mathrm{PbO}\end{array}$ & $\begin{array}{c}\mathrm{AVT}+ \\
0.01 \mathrm{M}(0.2 \%) \\
\mathrm{PbO}^{(\mathrm{b})}\end{array}$ & $\begin{array}{l}\text { AVT + 0.002M } \\
(0.04 \%) \mathrm{PbO}^{(b)}\end{array}$ \\
\hline Matl. & $\mathrm{pH}^{(a)}$ & 13.80 & 13.79 & 13.82 & 13.69 & 9.52 & 7.06 \\
\hline 690TT, B & $\begin{array}{l}500-h \\
1000-h \\
1500-h \\
2000-h \\
\text { Mode }\end{array}$ & $\overline{0} \%$ & $\begin{array}{l}-- \\
0 \% \\
-- \\
0 \%\end{array}$ & $\begin{array}{l}-- \\
0 \% \\
-- \\
0 \%\end{array}$ & $\begin{array}{l}-\overline{0} \\
0 \% \\
-\overline{0} \%\end{array}$ & $\begin{array}{l}-\overline{0} \\
0 \% \\
0 \%\end{array}$ & $\begin{array}{l}\overline{0} \\
\overline{0} \% \\
\overline{0} \%\end{array}$ \\
\hline 600MA, G & $\begin{array}{l}500-h \\
1000-h \\
1500-h \\
2000-h \\
\text { Mode }\end{array}$ & $\begin{array}{l}-- \\
20 \% \\
\text { IGSCC }\end{array}$ & $\begin{array}{l}-- \\
10 \% \\
- \\
17 \% \\
\text { IGA }\end{array}$ & $\begin{array}{l}-- \\
2 \% \\
4 \% \\
9 \% \\
\text { IGA }\end{array}$ & $\begin{array}{l}-- \\
5 \% \\
- \\
12 \% \\
\text { IGA }\end{array}$ & $\begin{array}{l}- \\
40 \% \\
43 \% \\
37 \% \\
\text { IGSCC }\end{array}$ & $\begin{array}{l}- \\
11 \% \\
23 \% \\
25 \% \\
\text { IGSCC }\end{array}$ \\
\hline $600 T \mathrm{~T}, \mathrm{H}$ & $\begin{array}{l}500-h \\
1000-h \\
1500-h \\
2000-h \\
\text { Mode }\end{array}$ & & $\begin{array}{l}-\overline{2 \%} \\
-- \\
2 \% \\
\text { IGA }\end{array}$ & $\begin{array}{l}- \\
1 \% \\
-- \\
6 \% \\
\text { IGA }\end{array}$ & $\begin{array}{l}- \\
2 \% \\
-- \\
3 \% \\
\text { IGA }\end{array}$ & $\begin{array}{l}- \\
26 \% \\
- \\
27 \% \\
\text { TG+IGSCC }\end{array}$ & $\begin{array}{l}- \\
13 \% \\
- \\
34 \% \\
\text { TG+IGSCC }\end{array}$ \\
\hline
\end{tabular}

(a) Room temperature $\mathrm{pH}$ value.

(b) AVT - Deionized and deaerated water $+500 \mathrm{ppb} \mathrm{N}_{2} \mathrm{H}_{4}$. 
Table C-19 Properties of Alloys 600 and 690 Used by Helie ${ }^{[97]}$

\begin{tabular}{|c|c|c|c|c|c|c|c|c|c|c|c|c|c|c|}
\hline Matl. & $\mathrm{Ni}$ & $\mathrm{Cr}$ & $\mathrm{Fe}$ & $\mathrm{C}$ & $\mathrm{Mn}$ & $\mathrm{Si}$ & $\mathrm{S}$ & $\mathrm{Ti}$ & $\begin{array}{c}\mathrm{Nb}+ \\
\mathrm{Ta}\end{array}$ & $\mathrm{Cu}$ & $\mathrm{P}$ & $\mathrm{Al}$ & $\mathrm{N}$ & $\mathrm{Co}$ \\
\hline $600^{(\mathrm{a})}$ & 73.74 & 15.83 & 8.69 & 0.036 & 0.82 & 0.27 & $<0.005$ & 0.31 & & 0.005 & 0.009 & 0.26 & & 0.021 \\
\hline $690 \mathrm{~b}^{(\mathrm{b})}$ & 58.93 & 29.25 & 10.58 & 0.016 & 0.32 & 0.29 & $<0.001$ & 0.21 & & 0.01 & 0.008 & 0.13 & 0.034 & 0.010 \\
\hline $690 \mathrm{c}^{(\mathrm{c})}$ & 59.65 & 28.92 & 10.36 & 0.020 & 0.31 & 0.31 & $<0.005$ & 0.24 & & 0.006 & $<0.005$ & 0.16 & 0.035 & 0.014 \\
\hline
\end{tabular}

(a) Alloy 600 was mill annealed at $965^{\circ} \mathrm{C}\left(1769^{\circ} \mathrm{F}\right)$.

(b) Alloy $690 \mathrm{~b}$ was thermally treated at $700^{\circ} \mathrm{C}\left(1292^{\circ} \mathrm{F}\right)$ for 5 hours. Alloy $690 \mathrm{~b}$ was only used for CERT specimens in $\mathrm{PbO}$ doped water.

(c) Alloy $690 \mathrm{c}$ was thermally treated at $700^{\circ} \mathrm{C}\left(1292^{\circ} \mathrm{F}\right)$ for 5 hours. Alloy $690 \mathrm{c}$ was only used for RUB specimens in $\mathrm{PbO}$ and $\mathrm{PbS}$ doped water.

Table C-20 Summary of Alloys 600 and 690 in Chloride Solutions at Low Temperatures ${ }^{[98]}$

\begin{tabular}{|c|l|c|c|c|}
\hline \multirow{5}{*}{ Material } & \multicolumn{1}{|c|}{ Chloride-containing Solution } & Temperature, ${ }^{\circ} \mathrm{C}$ & Duration & IGSCC/TGSCC \\
\hline \multirow{5}{*}{600} & $3.5 \% \mathrm{NaCl}+0.5 \% \mathrm{CH}_{3} \mathrm{CO}_{2} \mathrm{H}+\mathrm{H}_{2} \mathrm{~S}$ & 30 & 5040 & None \\
\cline { 2 - 5 } & $50 \% \mathrm{H}_{2} \mathrm{SO}_{4}+3 \% \mathrm{NaCl}$ & 30 & 5040 & None \\
\cline { 2 - 5 } & $\mathrm{NaCl}$ & 100 & 5040 & None \\
\cline { 2 - 5 } & $\mathrm{NaCl}$ saturated $(\mathrm{pH} 4)$ & 109 & 5040 & None \\
\cline { 2 - 5 } & $42 \% \mathrm{MgCl}_{2}$ & 154 & 1680 & None \\
\cline { 2 - 5 } & $85 \% \mathrm{ZnCl}_{2}$ & 180 & 1680 & None \\
\hline 690 & $\mathrm{MgCl}_{2} \mathrm{U}$-bend & 154 & 2325 & None \\
\hline
\end{tabular}


Table C-21 Summary of Alloy 690 in Chloride Solutions at High Temperatures ${ }^{[98]}$

\begin{tabular}{|c|c|c|c|c|c|}
\hline \multirow{2}{*}{ Solution } & \multicolumn{2}{|c|}{$\begin{array}{c}\text { Temperatur } \\
\mathbf{e}\end{array}$} & \multirow[t]{2}{*}{ Test Type } & \multirow{2}{*}{ Duration (hour) } & \multirow{2}{*}{ Results } \\
\hline & ${ }^{\circ} \mathrm{C}$ & ${ }^{0} \mathrm{~F}$ & & & \\
\hline 500 ppm Cl- & 260 & 500 & Double U-Bend & 3024 & Not cracked \\
\hline 875 ppm Cl- & 260 & 500 & Double U-Bend & 1344 & Not cracked \\
\hline 600 ppm Cl- + 150 ppm Na2HPO4, un-deaerated & 260 & 500 & Double U-Bend & 1344 & Not cracked \\
\hline 100 ppm Cl- (CuCl2 + NiCl2 + Seawater) & 288 & 550 & $\begin{array}{l}\text { Double U-Bend } \\
\text { Double C-Ring }\end{array}$ & 4000 & Not cracked \\
\hline 500 ppm Cl- & 300 & 572 & Double U-Bend & 1000 & Not cracked \\
\hline Deaerated water $+500 \mathrm{ppm} \mathrm{Cl}-$ & 316 & 600 & Double U-Bend & 16128 & Not cracked \\
\hline 100 ppm Cl- + 50 ppb O2 & 320 & 608 & Capsules & 14000 & Not cracked \\
\hline $\mathrm{AVT}+400 \mathrm{~g} \mathrm{NaCl}(\mathrm{pH} 3-9)$ & 333 & 631 & Not listed & 2000 & Not cracked \\
\hline $\mathrm{AVT}+200 \mathrm{~g} \mathrm{NaCl}+200 \mathrm{~g} \mathrm{FeCl} 2(\mathrm{pH} 3-5)$ & 333 & 631 & Not listed & 840 & Not cracked \\
\hline 100 ppm Cl- & 350 & 662 & Capsules & 21000 & Not cracked \\
\hline 100 ppm Cl- +300 ppb O2 & 350 & 662 & Capsules & 15000 & Not cracked \\
\hline
\end{tabular}

Table C-22 Materials Tested in Boiling $\mathrm{MgCl}_{2}$ by Berge et al. ${ }^{[98]}$

\begin{tabular}{|l|l|l|l|l|l|l|l|l|}
\hline Matl. & Identification & \multicolumn{1}{|c|}{ Heat Treatment } & SCC Specimens & C & Cr & Ni & Fe & Mo \\
\hline 600 & U572, tube & MA, Sensitized $\left(1-\mathrm{h}\right.$ at $\left.700^{\circ} \mathrm{C}\right)$ & RUB & 0.028 & 15.25 & 74.5 & 9.25 & - \\
\hline 690 & U455, tube & MA & RUB & 0.018 & 28.90 & 59.3 & 10.95 & $<0.01$ \\
\hline $304 \mathrm{~L}$ & U118, tube & MA $\left(1040^{\circ} \mathrm{C}\right)$ & RUB & 0.023 & 18.15 & 11.4 & 67.4 & 0.50 \\
\hline
\end{tabular}

Table C-23 RUB Test Results in Boiling $\mathrm{MgCl}_{2}$ by Berge et al. ${ }^{[98]}$

\begin{tabular}{|c|c|c|c|c|c|}
\hline Matl. & Identification & Heat Treatment & pH 1 & pH 1.6 & $\mathrm{pH} 2.3$ \\
\hline \multirow{2}{*}{600} & \multirow{2}{*}{ U572, tube } & MA & $\begin{array}{l}\text { Not cracked after } 1500- \\
\text { hour }\end{array}$ & $\begin{array}{l}\text { Intergranular crack } \\
\text { after } 1500 \text {-hour }\end{array}$ & $\begin{array}{l}\text { Not cracked after } \\
1500 \text {-hour }\end{array}$ \\
\hline & & Sensitized (1-h at $\left.700^{\circ} \mathrm{C}\right)$ & $\begin{array}{l}\text { Not cracked after } 1500- \\
\text { hour }\end{array}$ & $\begin{array}{l}\text { Not cracked after } \\
1500 \text {-hour }\end{array}$ & $\begin{array}{l}\text { Not cracked after } \\
1500 \text {-hour }\end{array}$ \\
\hline 690 & U455, tube & MA & $\begin{array}{l}\text { Intergranular crack depth } \\
60 \mu \mathrm{m} \text { after 288-hour }\end{array}$ & $\begin{array}{l}\text { Not cracked after } \\
1200 \text {-hour }\end{array}$ & Not cracked \\
\hline $304 \mathrm{~L}$ & U118, tube & $\operatorname{MA}\left(1040^{\circ} \mathrm{C}\right)$ & Fail $<24$-hour & Fail $<24$-hour & Fail $<24$-hour \\
\hline
\end{tabular}


Table C-24 Chemical Composition of Alloys 600 and 690 Used by Cullen et al. ${ }^{[99,100]}$

\begin{tabular}{|c|c|c|c|c|c|c|c|c|c|c|c|c|c|}
\hline Alloy & $\mathrm{Ni}$ & $\mathrm{Cr}$ & $\mathrm{Fe}$ & $\mathrm{C}$ & Mn & Si & $S$ & $\mathrm{Ti}$ & $\begin{array}{c}\mathrm{Nb}+ \\
\mathrm{Ta}\end{array}$ & $\mathrm{Cu}$ & $P$ & Al & Co \\
\hline $\begin{array}{l}\text { 600, LTMA \& } \\
\text { Sensitized }\end{array}$ & 74.26 & 14.46 & 9.47 & 0.024 & 0.39 & 0.17 & 0.004 & & & 0.40 & & & 0.074 \\
\hline 600, HTMA & 74.29 & 14.41 & 9.40 & 0.025 & 0.39 & 0.17 & 0.001 & & & 0.40 & & & 0.074 \\
\hline $600, \mathrm{TT}$ & Bal. & 16.00 & 9.00 & 0.046 & 0.24 & 0.100 & 0.004 & 0.26 & & & & 0.26 & \\
\hline 690, TT & 59.80 & 28.58 & 10.50 & 0.021 & 0.36 & 0.34 & 0.001 & 0.28 & & 0.005 & 0.008 & 0.13 & 0.013 \\
\hline
\end{tabular}

\begin{tabular}{|l|l|l|l|}
\hline \multicolumn{1}{|c|}{ Alloy } & Heat & Heat Treatment & Surface Finish \\
\hline 600, LTMA & NX3587 & Low-temperature MA, 3 to 5-min. at $927^{\circ} \mathrm{C}\left(1700^{\circ} \mathrm{F}\right)$ & As ground \\
\hline 600, HTMA & NX3587 & High-temperature MA, 3 to 5-min. at $1024^{\circ} \mathrm{C}\left(1875^{\circ} \mathrm{F}\right)$ & As ground \\
\hline 600, TT & NX1054 & MA +15 -hour at $705^{\circ} \mathrm{C}\left(1300^{\circ} \mathrm{F}\right)$, air cool & As Heat treated \\
\hline 690, TT & WF657 & MA $+5.75-$-hour at $700^{\circ} \mathrm{C}\left(1292^{\circ} \mathrm{F}\right)$, air cool & As Heat treated \\
\hline 600 Sensitized & NX3587 & 3 to 5 -min at $1024^{\circ} \mathrm{C}\left(1875^{\circ} \mathrm{F}\right), 11$-hour at $621^{\circ} \mathrm{C}\left(1150^{\circ} \mathrm{F}\right)$, air cool & As Heat treated \\
\hline
\end{tabular}

Table C-25 Autoclave Solutions Used for C-Ring Tests by Cullen et al. ${ }^{[100]}$

\begin{tabular}{|l|l|l|}
\hline \multicolumn{1}{|c|}{ Alloy } & \multicolumn{1}{|c|}{ Heat Treatment } & \multicolumn{1}{c|}{$\mathrm{pH}$ at $315^{\circ} \mathrm{C}$} \\
\hline Test 3.1 & $0.00946 \mathrm{~m} \mathrm{NH}_{4} \mathrm{HSO}_{4}, 0.0045 \mathrm{~m}_{\left(\mathrm{NH}_{4}\right)_{2} \mathrm{SO}_{4}}$ & 3.16 \\
\hline Test 3.2 & $0.0045 \mathrm{~m} \mathrm{NH}_{4} \mathrm{HSO}_{4}, 0.0046 \mathrm{~m}_{\left(\mathrm{NH}_{4}\right)_{2} \mathrm{SO}_{4}, 0.005 \mathrm{~m} \mathrm{NaCl}}$ & 3.34 \\
\hline Test 3.5 & $0.1{\mathrm{~m}\left(\mathrm{NH}_{4}\right)_{2} \mathrm{SO}_{4}}$ & 4.33 \\
\hline Test 3.6 & $1.0 \mathrm{~m}\left(\mathrm{NH}_{4}\right)_{2} \mathrm{SO}_{4}$ & 3.90 \\
\hline
\end{tabular}


Table C-26 Properties of Alloys 600 and 690 Used by Bouvier et al. ${ }^{[101]}$

\begin{tabular}{|c|c|c|c|c|c|c|c|c|c|c|c|c|c|c|}
\hline Alloy & $\mathrm{Ni}$ & $\mathrm{Cr}$ & $\mathrm{Fe}$ & $\mathrm{C}$ & $\mathrm{Mn}$ & $\mathrm{Si}$ & $\mathrm{S}$ & $\mathrm{Ti}$ & $\begin{array}{c}\mathrm{Nb}+ \\
\mathrm{Ta}\end{array}$ & $\mathrm{Cu}$ & $\mathrm{P}$ & $\mathrm{Al}$ & $\mathrm{N}$ & $\mathrm{B}$ \\
\hline 600 & Bal. & 16.01 & 6.59 & 0.044 & 0.25 & 0.40 & 0.007 & & & & 0.007 & & & \\
\hline 690 & Bal. & 28.9 & 10.9 & 0.018 & 0.34 & 0.32 & 0.002 & & & & 0.004 & & & \\
\hline
\end{tabular}

\begin{tabular}{|l|l|c|c|c|}
\hline \multicolumn{1}{|c|}{ Matl. } & \multicolumn{1}{|c|}{ Mill Anneal Treatment } & YS, MPa & UTS, MPa & Elong, \% \\
\hline $600 \mathrm{MA}$ & 2-min at $1070^{\circ} \mathrm{C}\left(1958^{\circ} \mathrm{F}\right)$ & 350 & 280 & 36 \\
\hline $600 T \mathrm{~T}$ & $\mathrm{MA}+16$-hour at $700^{\circ} \mathrm{C}\left(1292^{\circ} \mathrm{F}\right)$ & 330 & 280 & 33 \\
\hline $690 \mathrm{TT}$ & $\mathrm{MA}+5$-hour at $700^{\circ} \mathrm{C}\left(1292^{\circ} \mathrm{F}\right)$ & 306 & 245 & 50 \\
\hline
\end{tabular}




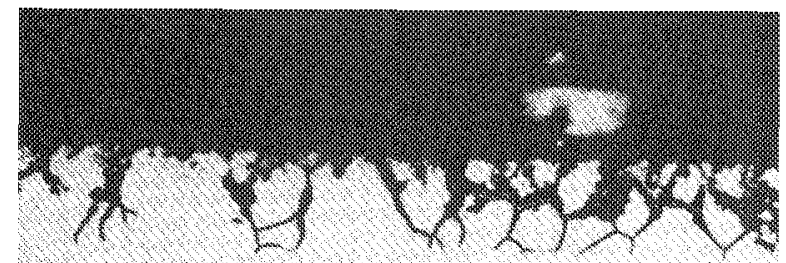

Figure C-1 Intergranular attack (IGA) in Alloy 690TT C-ring (specimen E3) after 1,200 hours in deaerated $50 \% \mathrm{NaOH}$ at $340^{\circ} \mathrm{C}\left(644^{\circ} \mathrm{F}\right)$. Magnification $500 \mathrm{X} .{ }^{[32]}$

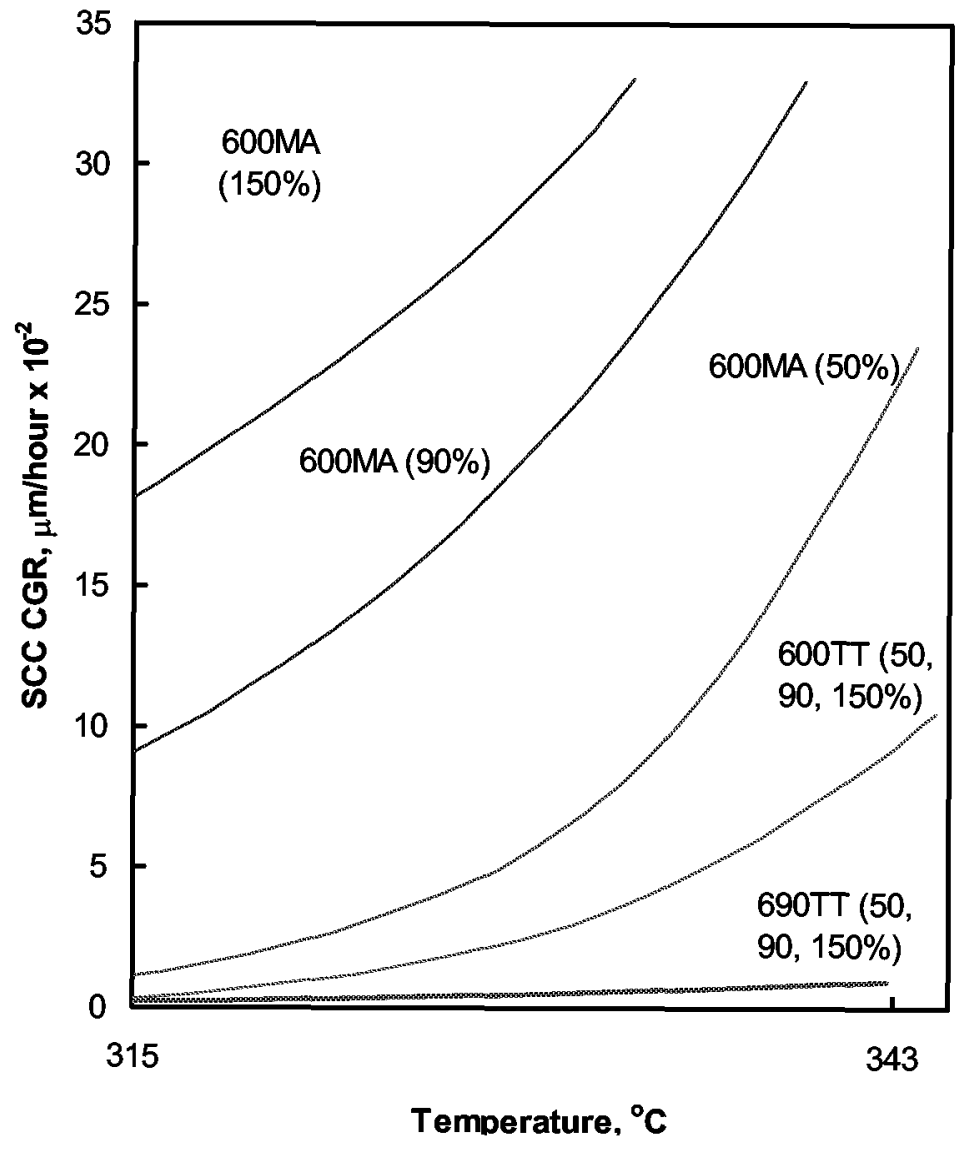

Figure C-2 Crack growth rate of Alloy 690TT and Alloy 600MA\&TT from C-Ring specimens in deaerated $10 \% \mathrm{NaOH}$ solution. $(\mathrm{x} \%$ ) indicate the loading stress to $\mathrm{x} \%$ of the yield strength. After Ref. 11. 


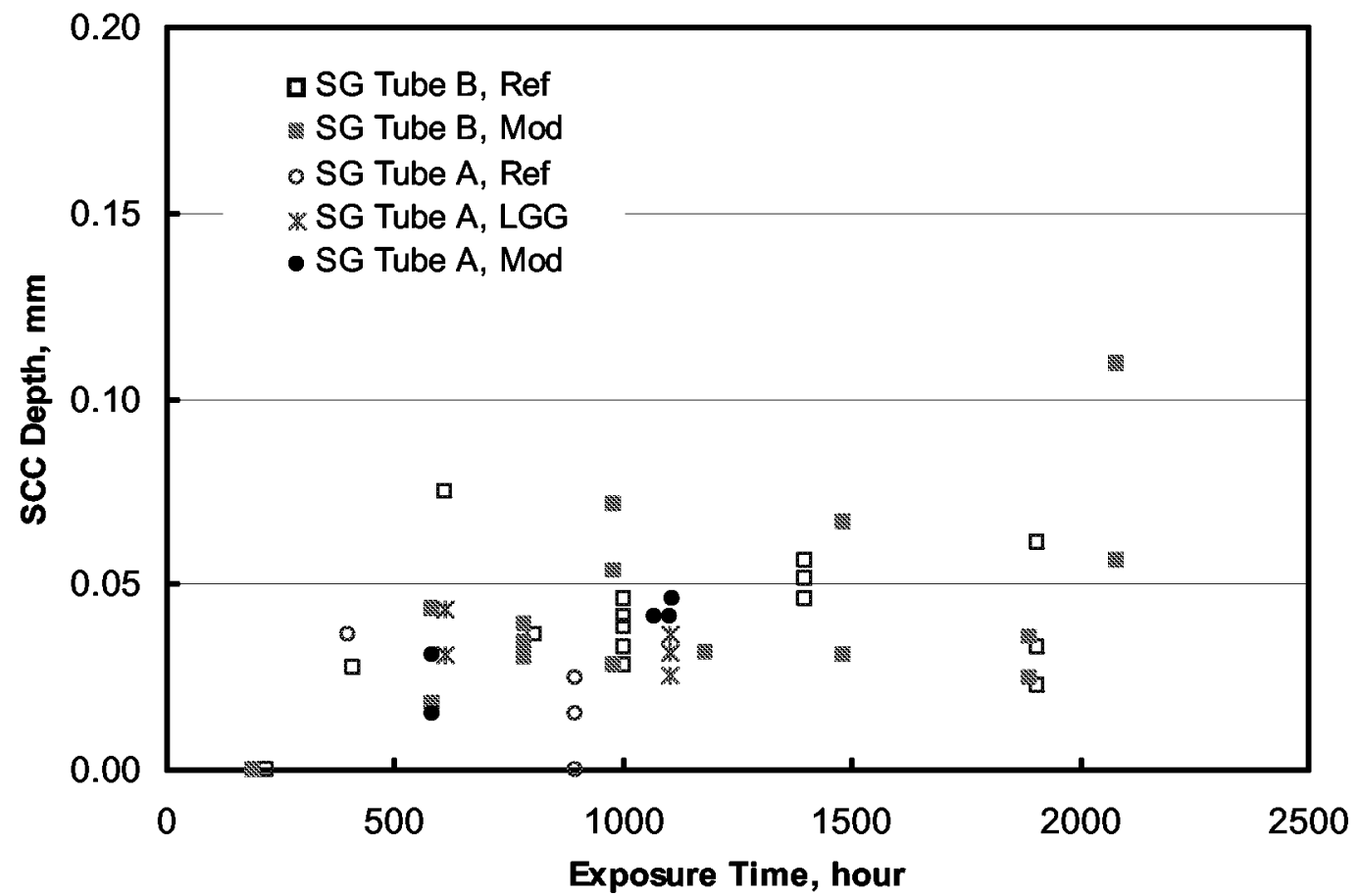

Figure C-3 Caustic SCC crack depth of Alloy 690 SG tubing thermally heat treated to produce different intergranular carbide morphology. The results indicate that there is little additional improvement in caustic SCC resistance from a continuous intergranular carbide coverage in thermally heat treated Alloy 690. After Ref. 93.

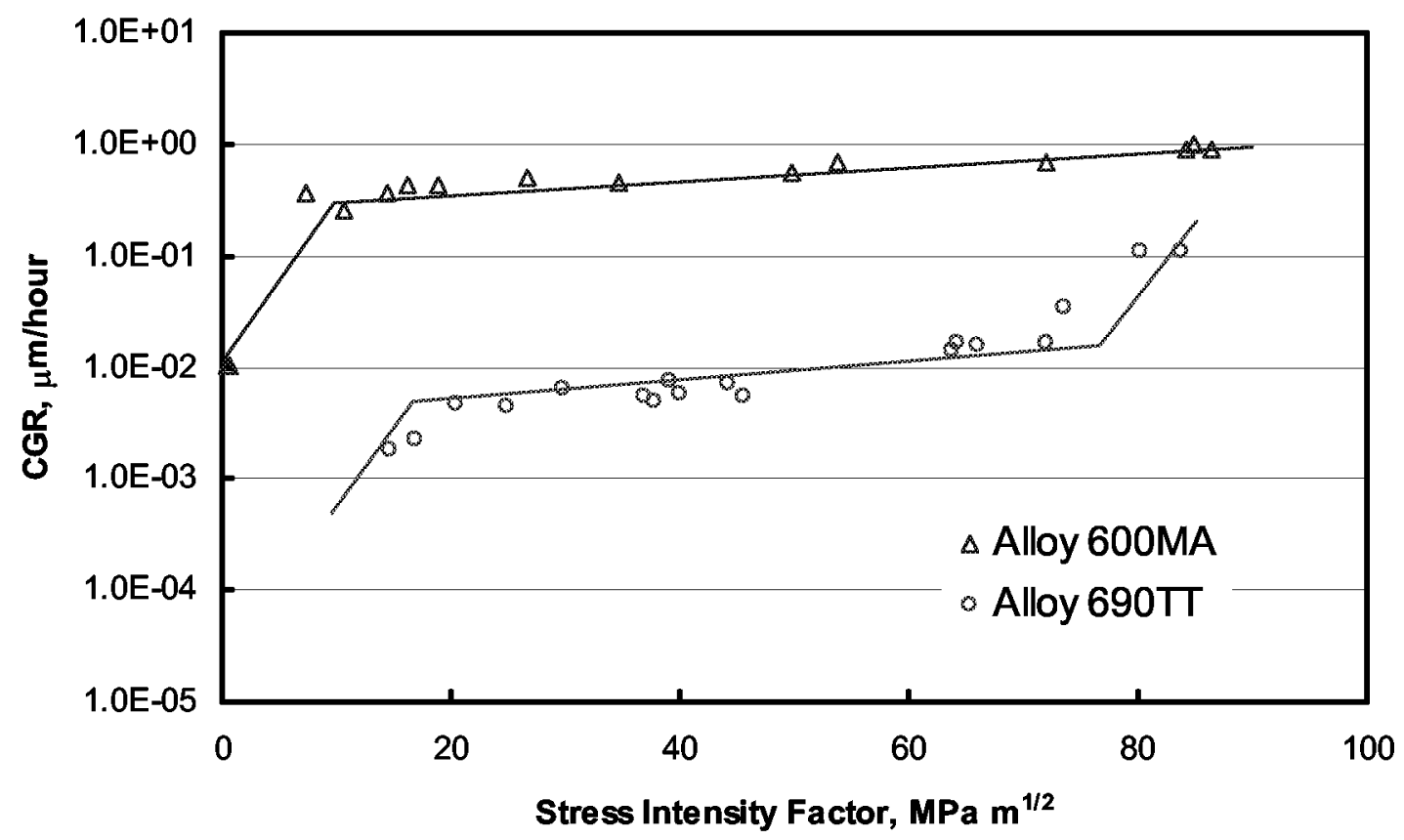

Figure C-4 Caustic SCC crack growth rate as a function of stress intensity factor by DCB tests in deaerated caustic solution. After Ref. 94. 


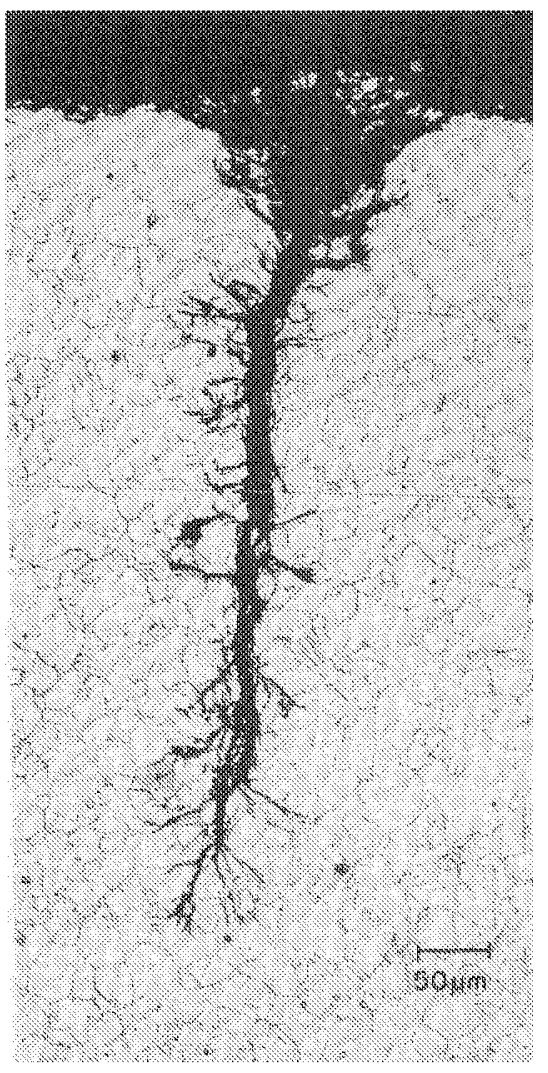

Figure C-5 TGSCC in Alloy $690 \mathrm{TT}$ after 500 hours in $10 \% \mathrm{NaOH}+0.1 \mathrm{M} \mathrm{PbO}$ at $350^{\circ} \mathrm{C}$ $\left(662^{\circ} \mathrm{F}\right) \cdot{ }^{[9]}$ 


\section{$D_{\text {REFERENCES }}$}

1. H. Coriou, et al., "High Temperature Stress Corrosion Cracking of Inconel in Water," Third Metallurgical Symposium on Corrosion (Aqueous and Gaseous), 1959, North Holland Publishing Co., Amsterdam, published in 1960, pp. 161-169.

2. F. Champigny, F. Chapelier, et al., "Maintenance Strategy of Inconel Components in PWR Primary System in France," paper presented NRC/ANL Conference on Vessel Head Penetration Inspection, Cracking, and Repair in Gaithersburg, MD from September 29 - October 2, 2003 (to be published).

3. B. Gronwall, L. Ljungberg, et al., "Intercrystalline Stress Corrosion Cracking of Inconel 600 Inspection Tubes in the Agesta Reactor," Atomenergi, (Rapp.) AE, AE-245, 1966.

4. C.A. Campbell and S. Fyfitch, "PWSCC Ranking Model for Alloy 600 Components," Proceedings of 6th International Conference on Environmental Degradation of Materials in Nuclear Power Systems-Water Reactors, TMS, 1993, p. 863.

5. INCONEL Alloy 600, Publication Number SMC-027, Special Metals Corporation, 2002 (Sept. 02).

6. INCONEL Alloy 690, Publication Number SMC-079, Special Metals Corporation, 2002 (Sept. 02).

7. Datasheet for "INCONEL Filler Metal 52M," Special Metals Corporation, 2003

8. EPRI Report TR-016743-V2R1 "Guidelines for PWR Steam Generator Tubing Specification and Repair," Vol. 2, Rev. 1: Guidelines for Procurement of Alloy 690 Steam Generator Tubing, Final Report, April 1999.

9. A.J. Sedricks, J.W. Schultz, and M.A. Cordovi, "Inconel Alloy 690 - A New Corrosion Resistant Material," Corrosion Engineering (Boshoku Gijutsu), vol. 28, pp. 82-95, 1979, Japan Society of Corrosion Engineering.

10. H. Xu and S. Fyfitch, "Aging Embrittlement Modeling of Type 17-4PH at LWR Temperatures," the 10th International Conference on Environmental Degradation of Materials in Nuclear Power Systems - Water Reactors, NACE International, Houston, Texas (2001). 
11. K. Smith, A. Klein, P. Saint-Paul, J. Blanchet, "Inconel 690, A Material with Improved Corrosion Resistance for PWR Steam Generator Tubes," Proceedings of 2nd International Symposium on Environmental Degradation of Materials in Nuclear Power Systems - Water Reactors, Monterey, CA, 1985 pp. 319-328.

12. T. Larsson, J. O. Nilsson, and J. Frodigh, "On the Possibility of Forming Ordered $\mathrm{Ni}_{2} \mathrm{Cr}$ in Alloy 690," Proceedings of 9th International Symposium on Environmental Degradation of Materials in Nuclear Power Systems - Water Reactors, Newport Beach, CA, 1999, pp. 143 to 147.

13. S.M. Bruemmer and C.H. Henager, "Microstructure, Microchemistry, and Microdeformation of Alloy 600 Tubing," Proceedings of 2nd International Symposium on Environmental Degradation of Materials in Nuclear Power Systems - Water Reactors, Monterey, CA, 1985 pp. 293-300.

14. K. Norring, K. Stiller, and J. Nilsson, "Grain Boundary Microstructure, Chemistry, and IGSCC in Alloy 600 and Alloy 690," Proceedings of 5th International Symposium on Environmental Degradation of Materials in Nuclear Power Systems - Water Reactors, Monterey, CA, 1991.

15. K. Stiller, J. Nilsson, and K. Norring, "Structure, Chemistry and Stress Corrosion Cracking of Grain Boundaries in Alloys 600 and 690," Metallurgical and Materials Transactions, Vol. 27A-No.2, February, 1996.

16. J.M. Sarver, J.R. Crum, and W.L. Mankins, "Carbide Precipitation and the Effect of Thermal Treatments on the SCC Behavior of Inconel Alloy 690," Proceedings of 3rd International Symposium on Environmental Degradation of Materials in Nuclear Power Systems - Water Reactors, Traverse City, MI, 1987. pp. 581-586.

17. T. Yonezawa, K. Onimura, N. Sasaguri, T. Kusakabe, H. Nagano, K. Yamanaka, T. Minami, M. Inoue, "Effect of Heat Treatment on Corrosion Resistance of Alloy 690," Proceedings of 2nd International Symposium on Environmental Degradation of Materials in Nuclear Power Systems - Water Reactors, Monterey, CA, 1985 pp. 593600 .

18. G.P. Airey, "Effect of Processing Variables on the Caustic Stress Corrosion Resistance of Inconel Alloy 600," Corrosion, vol. 36(1), 1980, pp. 9-17.

19. J.R. Crum, "Effect of Composition and Heat Treatment on Stress Corrosion Cracking of Alloy 600 Steam Generator Tubes in Sodium Hydroxide," Corrosion, vol. 36(1), 1982, pp. 40-45.

20. EPRI report NP-4665M-SR, "Proceedings: Workshop on Thermally Treated Alloy 690 Tubes for Nuclear Steam Generators," July 1986. 
21. ASTM Standard A 262, "Standard Practices for Detecting Susceptibility to Intergranular Attack in Austenitic Stainless Steels,".

22. O.K. Chopra and H.M. Chung, "Aging Degradation of Cast Stainless Steels: Effects on Mechanical Properties," Proceedings of the 3rd Environmental Degradation of Materials in Nuclear Power Systems - Water Reactors," pp. 737-748, September 1987, Traverse City, Michigan.

23. ASME SB-163, "Specification for Seamless Nickel and Nickel Alloy Condenser and Heat-Exchanger Tubes," ASME Boiler and Pressure Vessel Code, Section II Part B, Nonferrous Material Specifications, 2001.

24. ASME SB-166, "Specification for Nickel-Chromium-Iron Alloys (UNS N06600, N06601, N06603, N00690, N06025, and N06045) and Nickel-Chromium-CobaltMolybdenum Alloy (UNS N06617) Rod, Bar, and Wire," ASME Boiler \& Pressure Vessel Code, Section II Part B, Nonferrous Material Specifications, 2001.

25. ASME SB-167, "Specification for Nickel-Chromium-Iron Alloys (UNS N06600, N06601, N00690, N06025, and N06045) Seamless Pipe and Tube," ASME Boiler \& Pressure Vessel Code, Section II Material Specifications, Part B, 2001.

26. ASME SB-168, "Specification for Nickel-Chromium-Iron Alloys (UNS N06600, N06601, N06603, N00690, N06025, and N06045) and Nickel-Chromium-CobaltMolybdenum Alloy (UNS N06617) Plate, Sheet, and Strip," ASME Boiler \& Pressure Vessel Code, Section II Material Specifications, Part B, 2001.

27. ASME SFA-5.11, "Specification for Nickel and Nickel-Alloy Welding Electrodes for Shielded Metal Arc Welding," ASME Boiler \& Pressure Vessel Code, Section II, Part C, Specifications for Welding Rods, Electrodes, and Filer Metals, 2001.

28. ASME SFA-5.14, "Specification for Nickel and Nickel-Alloy Welding Bare Electrodes and Rods," ASME Boiler \& Pressure Vessel Code, Section II, Part C, Specifications for Welding Rods, Electrodes, and Filer Metals, 2001.

29. Data Sheet for Inconel Welding Electrode 152 and 182, Inconel Filler Metal 52 and 82, Special Metals Welding Products Company.

30. ASME Boiler \& Pressure Vessel Code, Section II Part D, Materials Properties, 2001.

31. J.N. Esposito, G. Economy, W.A. Byers, J.B. Esposito, F.W. Pement, R.J. Jacko, C.A. Bergmann, "The Addition of Zinc to Primary Reactor Coolant for Enhanced PWSCC Resistance," Proceedings of 5th International Symposium on Environmental Degradation of Materials in Nuclear Power Systems - Water Reactors, Monterey, CA, 1991. pp. 495-501. 
32. A. Smith and R. Stratton, "Relationship between Composition, Microstructure and Corrosion Behavior of Alloy 690 Steam Generator Tubing for PWR Systems," Proceedings of 4th International Symposium on Environmental Degradation of Materials in Nuclear Power Systems - Water Reactors, Jekyll Island, GA, 1989. pp.5-33 to 5-46.

33. A. Smith and R. Stratton, "Thermal Treatment, Grain Boundary Composition and Intergranular Attack Resistance of Alloy 690," Proceedings of 5th International Symposium on Environmental Degradation of Materials in Nuclear Power Systems Water Reactors, Monterey, CA, 1991. pp. 855-860.

34. ASTM Standard G 38 - 73 (Reapproved 1979), "Standard Practice for Making and Using C-Ring Stress-Corrosion Test Specimens," ASTM.

35. K. Norring, J. Engstrom, and P. Norberg, "Intergranular Stress Corrosion Cracking in Steam Generator Tubing, Testing of Alloy 690 and Alloy 600 Tubes," Proceedings of 3rd International Symposium on Environmental Degradation of Materials in Nuclear Power Systems - Water Reactors, Traverse City, MI, 1987. pp. 587-593.

36. K. Norring, J. Engstrom, and H. Tornblom, "Intergranular Stress Corrosion Cracking Steam Generator Tubing. 25,000 hours Testing of Alloy 690 and Alloy 600," Proceedings of 4th International Symposium on Environmental Degradation of Materials in Nuclear Power Systems - Water Reactors, Jekyll Island, GA, 1989. pp.12-1 to 12-10.

37. K. Norring, K. Stiller, and J. Nilsson, "Grain Boundary Microstructure, Chemistry, and IGSCC in Alloy 600 and Alloy 690," Proceedings of 5th International Symposium on Environmental Degradation of Materials in Nuclear Power Systems - Water Reactors, Monterey, CA, 1991. pp. 482-487.

38. T.M. Angeliu, J.K. Sung, and G.S. Was, "The Role of Carbon and Chromium on the Mechanical and Oxidation Behavior of Nickel-Based Alloys in High Temperature Water," Proceedings of 5th International Symposium on Environmental Degradation of Materials in Nuclear Power Systems - Water Reactors, Monterey, CA, 1991. pp. 475-481.

39. J.K. Sung and G.S. Was, "The role of Grain Boundary Chemistry in Pure Water Intergranular Stress Corrosion Cracking of Ni-16Cr-Fe Alloys," Proceedings of 4th International Symposium on Environmental Degradation of Materials in Nuclear Power Systems - Water Reactors, Jekyll Island, GA, 1989. pp.6-25 to 6-37.

40. Nakayama, H. Tomari, K. Fujiwara, K. Shimogori, H. Hamada, and K. Takaishi, "GC/IGSCC and General Corrosion Behavior of Alloy 800 As a PWR S/G Tube Material," Corrosion 87, Paper No. 82, NACE, March 1987.

41. M.J. Psaila-Dombrowski, J.M. Sarver, P.E. Doherty, W.G. Schneider, "Evaluation of Weld Metal 82 and Weld Metal 152 Stress Corrosion Cracking Susceptibility," Proceedings of 7 th International Symposium on Environmental Degradation of Materials 
in Nuclear Power Systems - Water Reactors, Breckenridge, Colorado, 1995, pp. 81 to 91.

42. M.J. Psaila-Dombrowski, C.S. Wade, J.M. Sarver, W.A. Van Der Sluys, and P.E. Doherty, "Evaluation of Weld Metals 82, 152, 52, and Alloy 690 Stress Corrosion Cracking and Corrosion Fatigue Susceptibility," Proceedings of 8th International Symposium on Environmental Degradation of Materials in Nuclear Power Systems Water Reactors, Amelia Island, FL, 1997. pp. 412 to 421.

43. N. Ogawa, T. Nakashiba, R. Umehara, S. Okamoto, and T. Tsuruta, "PWSCC Susceptibility Tests for Improving Primary Water Chemistry Control," Proceedings of 8th International Symposium on Environmental Degradation of Materials in Nuclear Power Systems - Water Reactors, Amelia Island, FL, 1997. pp. 395 to 401.

44. M.G. Angell, S.J. Allan, and G.P. Airey, "The Effect of Primary Coolant Zinc Addition on the SCC Behavior of Alloy 600 and 690," Proceedings of 9th International Symposium on Environmental Degradation of Materials in Nuclear Power Systems Water Reactors, Newport Beach, CA, 1999, pp. 97 to 102.

45. C. Raquet, C. Dufour, G. Watilliaux and D. Besnard, CEA Technical Report RTSCCME 618 Rev. A, 2002, "Résistance a la CSC en milieu primaire REP de matériaux tubulaires en alliage 690 soumis to une déformation globale constante", (English translation of the title, "Resistance of Alloy 690 Tubular Products to Stress Corrosion Cracking in PWR Primary Water at Constant Deformation").

46. F. Vaillant, EDF Report HT-44/95/013/A, 1996, "Résistance a la corrosion sous contrainte en milieu primaire des alliages 690 et 800 - Point des résultats en Décembre 1995", (English translation of the title, "Resistance of Alloys 690 and 800 to Stress Corrosion Cracking in PWR Primary Water - Status of Results Available to December 1995").

47. J-D. Mithieux and F. Vaillant, EDF Report HT-44/97/020/A, 1997, "Influence de la teneur en chrome et de la structure des alliages de nickel sur leur comportement en corrosion sous contrainte en milieu primaire de REP", (English translation of the title, " Influence of Chromium Content and Microstructure of Nickel Base Alloys on Their Stress Corrosion Behavior in PWR Primary Water").

48. J-P Saulay and J-M Boursier, EDF Report HT-29/02/001/A, 2002, "Influence des états de surface sur la propagation lente des fissures de corrosion sous contrainte: Comportement des alliages 600 et 690 en milieu primaire REP", (English translation of the title "Influence of Surface Condition on the Slow Propagation Stage of Stress Corrosion Cracking: Behavior of Alloys 600 And 690 in PWR Primary Water".

49. F. Vaillant, J.D. Mithieux O. de Bouvier, D. Vancon, G. Zacharie, Y. Brechet, and F. Louchet "Influence of Chromium Content and Microstructure on Creep and PWSCC 
Resistance of Nickel Base Alloys," Proceedings of 9th International Symposium on Environmental Degradation of Materials in Nuclear Power Systems - Water Reactors, Newport Beach, CA, 1999, pp. 251 to 260.

50. J.M. Boursier, F. Vaillant, , P. Saulay, Y. Brechet, and G. Zacharie, "Effect of the Strain Rate on the Stress Corrosion Cracking in High Temperature Primary Water: Comparison Between the Alloys 690 and 600," Proceedings of the 11th International Symposium on Environmental Degradation of Materials in Nuclear Power Systems Water Reactors, American Nuclear Society, 2003.

51. F. Vaillant, " EDF Report HT-44/98/016/A, 1998, "Métaux déposés base nickel contenant 15 to $30 \%$ de chrome: bilan des essais de corrosion en milieu primaire", (English translation of the title "Nickel Base Weld Deposits Containing 15 To 30\% Chromium: Status of Corrosion Tests In Primary Water").

52. G. Sui, G.B. Heys, and J. Congleton, "Stress Corrosion Cracking of Alloy 600 and Alloy 690 in Hydrogen/Steam and Primary Water Side Water," Proceedings of 8th International Symposium on Environmental Degradation of Materials in Nuclear Power Systems - Water Reactors, Amelia Island, FL, 1997. pp. 274 to 281.

53. G. Sui, J.M. Titchmarsh, G.B. Heys, and J. Congleton, "Stress Corrosion Cracking of Alloy 600 and Alloy 690 in Hydrogen/Steam at $380^{\circ} \mathrm{C}$," Corrosion Science, Vol. 39, No.3, pp. 565-587, 1997.

54. R.J. Jacko, R.E. Gold, and A. Kroes, "Accelerated Corrosion Testing of Alloy 52M and Alloy 182 Weldments," Proceedings of the 11th International Symposium on Environmental Degradation of Materials in Nuclear Power Systems - Water Reactors, American Nuclear Society, 2003.

55. G.V. Rao, R.J. Jacko, and A.R. Mcllree, "An Assessment of the CRDM Alloy 600 Reactor Vessel Head Penetration PWSCC Remedial Techniques", Proceedings, Contributions of Materials Investigation to the Resolution of Problems Encountered in Pressurized Water Reactors, Fontevraud V, pp. 93-105, SFEN, September 2002.

56. C.M. Brown and W.J. Mills, "Fracture Toughness, Tensile and Stress Corrosion Cracking Properties of Alloy 600, Alloy 690, and Their Welds in Water," paper 90, Corrosion 96, NACE, 1996.

57. C.M. Brown and W.J. Mills "Effect of Water on Mechanical Properties and Stress Corrosion Behavior of Alloy 600, Alloy 690, EN82H Welds, and EN52 Welds," Corrosion, v55(2), February 1999.

58. W.J. Mills and C.M. Brown, "Fracture Behavior of Nickel-based Alloys in Water," Ninth International Conference on Environmental Degradation of Materials in Nuclear Power Systems--Water Reactors, August 1-5, 1999, Newport Beach, CA, TMS/NACE. 
59. D.M. Symons, "The Effect of Carbide Precipitation on the Hydrogen-Enhanced Fracture Behavior of Alloy 690," Met. Trans. A, Vol. 29A, pp. 1265-1277, April 1998.

60. I. Lenartova, "Fragilisation par hydrogène et corrosion sous contrainte d'alliages de nickel et d'un acier inoxydable utilisés dans les générateurs de vapeur: influence de la composition chimique et de la microstructure" (English translation: "Hydrogen Embrittlement of Nickel Base Alloys And A Stainless Steel Used in Steam Generators: Influence of Chemical Composition and Microstructure"), $\mathrm{PhD}$ thesis, Ecole Centrale de Paris, 1996,

61. NUREG/CR-6335, "Fatigue Strain-Life Behavior of Carbon and Low-Alloy Steels, Austenitic Stainless Steels, and Alloy 600 in LWR Environments," by J. Keisler, O.K. Chopra, and W.J. Shack of Argonne National Laboratory (ANL-95/15), 1995.

62. EPRI Report TR-105714-V1R4, "PWR Primary Water Chemistry Guidelines, Volume 1 and 2", revision 4, March 1999.

63. G.P. Airey, "The Stress Corrosion Cracking (SCC) Performance of Inconel Alloy 600 in Pure and Primary Water Environments", Proceedings of the (1st) International Symposium on Environmental Degradation of Materials in Nuclear Power Systems Water Reactors, pp. 462-478, NACE, 1983.

64. EPRI Report 1006695, "Materials Reliability Program Crack Growth Rates for Evaluating Primary Water Stress Corrosion Cracking (PWSCC) of Thick-Wall Alloy 600 Materials (MPR-55) Revision 1," Final Report, November 2002.

65. EPRI Report TR-111993, "Crack Growth of Alloy 182 Weld Metal in PWR Environments," Final Report, January 1999.

66. "The New Weibull Handbook," 2nd Ed., Dr. Robert .B. Abernethy, Author and Publisher, July 1996.

67. "Steam Generator Reference Book," EPRI TR-103824s-V1R1, December 1994.

68. "Experience of U.S. and International Steam Generators with Alloy 600TT and Alloy 690TT Tubes and Sleeves," EPRI Document No. 1003589, 2002.

69. "NRC Bulletin No. 89-01: Failure of Westinghouse Steam Generator Tube Mechanical Plugs," U.S. Nuclear Regulatory Commission, Washington, D.C. May 15, 1989.

70. Turluer, G., et al., "The French Regulatory Experience and Views on Nickel-Base Alloy PWSCC Prevention and Treatment," Conference on Vessel Head Penetration Inspection, Cracking and Repairs Sponsored by U.S. Nuclear Regulatory Commission 
and Argonne National Laboratory, Sept. 29 to Oct. 2, 2003; Marriott Washingtonian Center, Gaithersburg, Maryland.

71. J.I. Bennetch, G.E. Modzelewski, L.L. Spain, and G.V. Rao, "Root Cause Evaluation and Repair of Alloy 82/182 J-Groove Weld Cracking of Reactor Vessel Head Penetrations at North Anna Unit2," PVP2002-1189, PVP-Vol. 437, Service Experience and Failure Assessment Applications, ASME 2002.

72. W.H. Bamford, et al., "The Embedded Flaw Process for Repair of Reactor Vessel Head Penetrations and Its Application at North Anna Unit 2," WCAP-15986, Westinghouse Electric Company LLC, 2003.

73. NRC Information Notice 2003-11, Supplement 1, "Leakage Found on BottomMounted Instrumentation Nozzles," US NRC, January 8, 2004.

74. G.A. Young, N. Lewis, and D.S. Martin, "The Stress Corrosion Crack Rate of Alloy 600 Heat Affected Zone Exposed to High Temperature Purity Water," Conference on Vessel Head Penetration Inspection, Cracking and Repairs Sponsored by U.S. Nuclear Regulatory Commission and Argonne National Laboratory, Sept. 29 to Oct. 2, 2003; Marriott Washingtonian Center, Gaithersburg, Maryland.

75. Coriou, H. et al.: Proc. Conf. Fundamental Aspects of SCC ; ed. By R.W. Staehle et al.; NACE Houston 1977; p. 352.

76. Coriou, H. et al.: Third Metallurgy Symposium on Corrosion; Amsterdam; 1960; pp. 161-166.

77. Coriou, H. et al.: Corrosion NACE 22; 1966; pp. 280-290.

78. Shah, V.N.; Lowenstein, D.B.; Turner, A.P.L.; Ward, S.R.; Gorman, J.A.; MacDonald, P.E.; Weidhammer, G.H.: Assessment of Primary Water Stress Corrosion Cracking of PWR SG Tubes; Nuclear Engineering and Design134; 1992; pp 199-215.

79. Bouecke R., Odar S., Stellwag B.: Operating Experience with SGs ; Service Report Power Plants, December 1989, p 4-10.

80. Latanison R.M., Staehle R.W.: Stress Corrosion Cracking of Iron-Nickel-Chromium Alloys, Proc. Symposium on Fundamental Aspects of Stress Corrosion Cracking, NACE, Houston 1969, pp 214-296.

81. Shen Y., Shewmon P.G.: A Mechanism for Hydrogen Induced Stress Corrosion Cracking In Alloy 600, Metal Trans A. 21A (1990), pp 2161 - 1271.

82. Szklarzka-Smialowska Z., Xia Z., Valbuena R.P.: Mechanism of Crack Growth in Alloy 600 In High Temperature Deaerated Water, Corrosion, 50 (1994), pp 676 - 681. 
83. Sung J., Was G.S.: The Role of Grain Boundary Chemistry in Pure Water Intergranular Stress Corrosion Cracking Of Ni-16Cr-9Fe Alloys, Proc Fourth International Symposium On Environmental Degradation Of Materials In Nuclear Power Systems - Water Reactors, NACE; Jekyll Island, Georgia 1989, Pp 625 - 636.

84. Scott P.M., Le Calvar M.: Some Possible Mechanisms of Intergranular Stress Corrosion Cracking of Alloy 600 in PWR Primary Water, Proc Sixth International Symposium on Environmental Degradation of Materials in Nuclear Power Systems Water Reactors, The Metallurgical Society, San Diego, CA, 1993, pp $657-665$.

85. G. Economy; R.J. Jacko; J.A. Begley; F.W.: Pement; Westinghouse Corporation EPRI Workshop, Mechanisms of Primary Eater IGSCC; Alexandria, VA; April 1987.

86. Gimond, C.: Recent Corrosion Results; from Proceedings1989 EPRI Alloy 690 Workshop, New Orleans, 12-14 April 1989; EPRI NP-6750M (1990).

87. Mcllree, A.; Ruud, C.O.; Pement, F.W.; Ed: Theus, G.J.; Weeks, J.R.: The Description of Residual and Applied Stresses and SCC of Row 1 Steam Generator UBends; Proc. of 3rd Int. Symposium on Environmental Degradation of Materials in Nuclear Power Systems - Water Reactors, The Metallurgical Society, Inc., Warrendale, PA, 1988, p. 555.

88. B.P. Miglin, and C.E. Shoemaker, "A Comparison of the Stress Corrosion Cracking Behavior of Alloys 600 and Alloy 690 in AVT Water," Corrosion 86, Paper Number 255, NACE, 1986.

89. J.R. Crum and T. Nagashima, "Review of Alloy 690 Steam Generator Studies," Proceedings of 8th International Symposium on Environmental Degradation of Materials in Nuclear Power Systems - Water Reactors, Amelia Island, FL, 1997. pp. 127 to 137.

90. ASTM Standard G 38 - 73 (Reapproved 1979), "Standard Practice for Making and Using C-Ring Stress-Corrosion Test Specimens," ASTM.

91. J.M. Sarver, J.V. Monter, B.P. Miglin, "The Effect of Thermal Treatment on the Microstructure and SCC Behavior of Alloy 600," Proceedings of 4th International Symposium on Environmental Degradation of Materials in Nuclear Power Systems Water Reactors, Jekyll Island, GA, 1989. pp.5-47 to 5-63.

92. F. Vaillant, D. Buisine, and B Prieux, "Comparative Behavior of Alloys 600, 690, and 800 in Caustic Environments," Proceedings of 7th International Symposium on Environmental Degradation of Materials in Nuclear Power Systems - Water Reactors, Breckenridge, Colorado, 1995, pp. 219 to 231.

93. D.A. Mertz, P.T. Duda, P.N. Pica, G.L. Spahr, "Role of Microstructure in Caustic 
Stress Corrosion Cracking of Alloy 690," Proceedings of 7th International Symposium on Environmental Degradation of Materials in Nuclear Power Systems - Water Reactors, Breckenridge, Colorado, 1995, pp. 477 to 494.

94. H. Kawamura, H. Hirano, S. Shirai, H. Takamatsu, T. Matsunaga, K. Yamaoka, K. Oshinden, and $\mathrm{H}$. Takiguchi, "Role of Grain Boundary Characteristics in Caustic IGA/SCC Resistance of Thermally-Treated Alloy 690 and Shot-Peened Alloy 800," Proceedings of 9th International Symposium on Environmental Degradation of Materials in Nuclear Power Systems - Water Reactors, Newport Beach, CA, 1999, pp. 601 to 610.

95. H.P. Kim, Y.S. Lim, and J.S. Kim, "Stress Corrosion Cracking of Alloy 600 in $0.1 \mathrm{M}$ $\mathrm{NaHSO}_{4}$ and $\mathrm{NaOH}$ Solution," Proceedings of 10th International Symposium on Environmental Degradation of Materials in Nuclear Power Systems - Water Reactors, Lake Tahoe, NV, 2001.

96. M.L. Castano-Marin, D. Gomez-Briceno, and F. Hernandez-Arroyo, "Influence of Lead Contamination on the Stress Corrosion Resistance of Nickel Alloys," Proceedings of 6th International Symposium on Environmental Degradation of Materials in Nuclear Power Systems - Water Reactors, San Diego, CA, 1993, pp. 189 to 196.

97. M. Helie, "Lead Assisted Stress Corrosion Cracking of Alloys 600, 690, and 800," Proceedings of 6th International Symposium on Environmental Degradation of Materials in Nuclear Power Systems - Water Reactors, San Diego, CA, 1993, pp. 179 to 188.

98. P. Berge, D. Noel, J-M Gras, and B. Prieux, "Chloride Stress Corrosion Cracking of Alloy 600 in Boric Acid Solution," Proceedings of 8th International Symposium on Environmental Degradation of Materials in Nuclear Power Systems - Water Reactors, Amelia Island, FL, 1997, pp. 189 to 199.

99. W.H. Cullen, M.J. Patridge, J.A. Gorman, and J.P.N. Paine "IGA/IGSCC of Alloy 600 in Acidic Sulfate and Chloride Solutions," Proceedings of 5th International Symposium on Environmental Degradation of Materials in Nuclear Power Systems - Water Reactors, Monterey, CA, 1991. pp. 780-788.

100. W.H. Cullen, M.J. Patridge, and J.P.N. Paine "Corrosion of Alloy 600 \& 690 in Acidified Sulfate and Chloride Solutions" Proceedings of 6th International Symposium on Environmental Degradation of Materials in Nuclear Power Systems - Water Reactors, San Diego, CA, 1993, pp. 197 to 203.

101. O.D. Bouvier, B. Prieux, and F. Vaillant, "Nickel Alloy Stress Corrosion Cracking in Neutral and Lightly Alkaline Sulfate Environments," Proceedings of 9th International Symposium on Environmental Degradation of Materials in Nuclear Power Systems Water Reactors, Newport Beach, CA, 1999, pp. 695 to 701. 
102. O.D. Bouvier, F. Vaillant, M. Bouchacourt, and P. Lemaire "Effect of Copper Species on IGA/SCC of Alloy 600 in Neutral Sulfate Environments," Proceedings of 10th International Symposium on Environmental Degradation of Materials in Nuclear Power Systems - Water Reactors, Lake Tahoe, NV, 2001. 




\section{About EPRI}

EPRI creates science and technology solutions for the global energy and energy services industry. U.S. electric utilities established the Electric Power Research Institute in 1973 as a nonprofit research consortium for the benefit of utility members, their customers, and society. Now known simply as EPRI, the company provides a wide range of innovative products and services to more than 1000 energy-related organizations in 40 countries. EPRI's multidisciplinary team of scientists and engineers draws on a worldwide network of technical and business expertise to help solve today's toughest energy and environmental problems.

EPRI. Electrify the World

\footnotetext{
(c) 2004 Electric Power Research Institute (EPRI), Inc. All rights reserved. Electric Power Research Institute and EPRI are registered service marks of the Electric Power Research Institute, Inc. EPRI. ELECTRIFY THE WORLD is a service mark of the Electric Power Research Institute, Inc.

1009801

$\$$ Printed on recycled paper in the United States of America
} 